


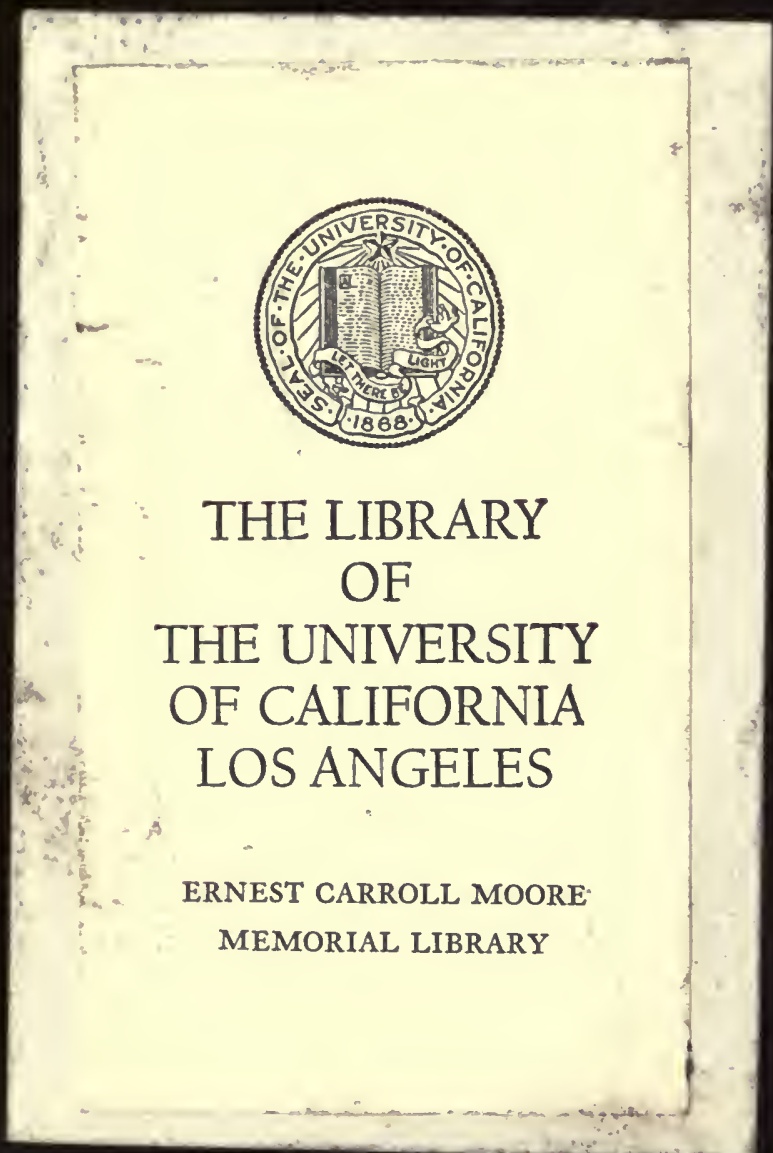


, . . . 


$$
400 x+3(1+4)
$$

$$
37^{\prime}
$$






\section{EUROPEAN THOUGHT IN THE NINETEENTH CENTURY}




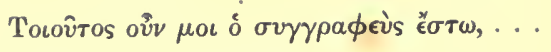

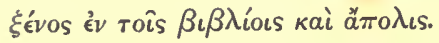

-Lucian. 


\section{A HISTORY}

OF

\section{E UROPEAN THOUGHT IN THE}

\section{NINETEENTH CENTURY}

BY

JOHN THEODORE MERZ

VOL. I.

INTRODCCTION-SCIENTIFIC THOUGHT, PART I.

WILLIAM BLACKWOOD AND SONS

EDINBURGH AND LONDON

- M DCC C V I 
Digitized by the Internet Archive in 2007 with funding from Microsoft Corporation 


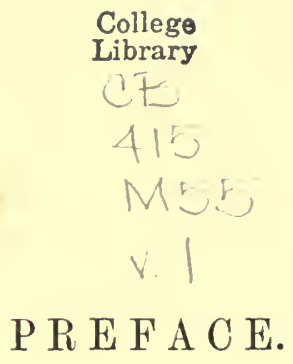

As the plan of this work is fully given in the Introduction, only a few points, chiefly of a personal character, remain to be touched on here.

The first refers to the motive which led me to a course of studies, extending over more than thirty years, of which this book is the outcome.

The object of the book is philosophical, in the sense now accepted by many and by divergent schools-i.e., it desires to contribute something towards a unification of thought. When in the beginning of my philosophical studies I became convinced that this is the task of philosophy, I felt the necessity of making myself acquainted, at first hand, with the many trains of reasoning by which, in the separate domains of science, of practical and of individual thought, such a unification has been partially and successfully attempted. Such a survey seemed to me indispensable. The possession of a map showing the many lines of thought which our age has cultivated seemed to me the first requisite, the basis from which a more complete 
unification would have to start. The following pages contain the result of this survey. Like every survey, it can claim to be merely an approximation. It gives outlines which closer scrutiny will have to correct and fill up.

My original intention was to complete this survey in three volumes, corresponding to the three divisions of the subject set out in the Introduction.

Some of my friends, who desired that the publication of the book should not be unduly delayed, considered that the Introduction and the earlier chapters of the work would give something intelligible in themselves, and urged the advantage of smaller volumes. I therefore decided to complete the first part of the history, which deals with scientific thought, in two volumes instead of in one.

For the information of my readers, I mention here that the two last chapters of this volume, which treat of the astronomical and of the atomic views of Nature, will be followed in the second volume by similar chapters on the mechanical, the physical, the biological, the statistical, and the psychophysical views of Nature, and that it is my intention to close the first part of my subject by an attempt to trace concisely the development of mathematical thought in this century.

My thanks are due to many friends who have supported me with assistance and encouragement.

I consider myself fortunate in having secured for the revision of the whole volume the invaluable aid of $\mathrm{Mr}$ Thomas Whittaker, B.A., whose profound erudition, know- 
ledge of ancient and modern literature, and great editorial experience, were well known to my late friend Professor Croom Robertson, during his successful editorship of the first series of 'Mind.'

Mr S. Oliver Roberts, M.A., of the Merchant Taylors' School, has kindly read over the fourth, and Professor Phillips Bedson, of the Durham College of Science of this city, the last, chapter of this volume. The Introduction has greatly benefited by a thorough revision by my brotherin-law, Dr Spence Watson, a master of the English language.

I must also thank him and Dr Thomas Hodgkin for having given me what I value as much as assistancenamely, encouragement.

One indeed to whom I an in this respect more indebted, perhaps, than to any one else-whom to have known has meant, for many, a revelation of the power of mind and the reality of spirit-is no more: Ernst Curtius. While I was writing the last pages of this volume, in which he took a warm interest, the tidings arrived that he had passed away. But she who was nearest and dearest to him is still with us-a true priestess of the higher life, who has kept burning in the soul of many a youthful friend the spiritual fire when it was in danger of being quenched by the growing materialism of our age.

J. THEO. MERZ.

The QUARRIES,

Newcastle-upon-Tyne, November 1896. 



\section{CONTENTS OF THE FIRST VOLUME.}

\section{INTRODUCTION.}

I. Thought, the hidden world, 1 ; The only moving principle, 2 ; History of Nature, how to be understood, 2 ; Not intelligible without intellect, 2 ; History of savage tribes, what is it? 3 ; Two ways in which thought enters into history, 4; Definition of thought impossible, 4; Relation of outer and inner worlds undefined, 5 ; Many meanings of thought, 5 ; Thought of the present age, 6 ; Contemporary history, to what extent possible and valuable, 6 ; Supposed objectivity of historians, 7 ; Value of contemporary records, 8 ; Mystery of the life of thought, 8 ; Latent thought the material for genius, 8 ; Contemporary record of thought more faithful, 10 ; Events of the immediate past, 10 ; Changes of language, 11 ; Coining of new words, 12 ; Object of this work, 13 ; Not a political history, nor a history of science, literature, and art, 13 ; Influences which have a result on our inner life, 14 ; Personal knowledge necessary, 14 ; American influence only touched upon, 14 ; Only French, German, and English thought treated, 15; Unity of thought, a product of this century, 16; Voltaire, 16 ; Adam Smith, 16 ; Coleridge and Wordsworth, 17 ; Mme. de Staël, 17 ; Paris the focus of science, 17 ; Babbage, Herschel, and Peacock, 18 ; Liebig's laboratory, 18 ; Comte's philosophy, 18; Constable's influence in France, 19 ; Science become international, 19) The light which etymology throws on the history of thought, 20 ; Goethe, 22 ; Peculiarity of the German language, 22 ; New thought has found new words, 23 ; De Bonald and Max Müller, 23; Thought, how expressed in French and German, 24 ; Philosophy of History, 25 ; Want of precise terms in German and French, 26; Carlyle, 26. 
II. The two factors of intellectual progress, 27 ; Object of the book, 28 ; Nineteenth century, what it has achieved: (a) Method of knowledge ; (b) Unity of knowledge, 29 ; Search after truth, 29; Method of science, practised by Galileo, \&c., defined by Bacon, \&c., 30 ; Disintegration of learning, 30 ; Apparent distance between science and poetry, 31 ; Closer connection between science and life, 31 ; What has nineteenth century done for the ideals? 32 ; Deeper conception of the unity of human interests, 33. Different terms for expressing this unity, 33 ; Definition of thought, 33 ; Agc of encyclopredic treatment of learning, 34; Unity of knowledge gradually lost sight of, 35 ; Lectures on "Encyclopædie" in Germany, 37 ; Encyclopredias did not fulfil their promise, 39 ; French were masters in scicnce in beginning of the century, 41; Reaction in Germany against metaphysics, 43; Reform in school literature, 44; Germany has taken the lead in studying the life of thought, 46 ; Transition from metaphysical to historical method, 47 ; Herbert Spencer, 48; Lotze, 48; Herder's 'Ideen,' 50 ; Humboldt's 'Kosmos,' 51 ; Lotze's 'Microcosmus,' 52 ; What the mental life of mankind consists of, 55 ; Methods have their day and cease to be, 56 .

III. Necessity of choosing a road, 57 ; No central event in our age, 58 ; Is history of thought history of philosophy? 60 ; Goethe's work involves the deepest thought of the century, 61; Philosophy retrospective, 62 ; Two questions, 63 ; Speculation, 64 ; Philosophy defined, 65 ; Division of the book, 65 ; Neither science nor philosophy exhaust "thought," 66 ; Thought also hidden in literature and art, 66; Goethe's and Word: worth's influence, 67 ; Unmethodical thought, 68; Summed up in term "religious thought," 69 ; Science is exact, 69 ; Subjective interests, 70 ; Philosophy intermediate between exact science and religion, 71 ; Threefold aspect of thought : scientific, philosophical, individual,72; Difficult to separate the three aspects, 74 ; French thought centred in science, 75 ; State of philosophy in England, 75); Goethe's 'Faust' representative of the thought of the century, 76; $\mathbf{A}$ period of ferment, 76; Caused by the Revolution, 77 ; Thought of century partly radical, partly reactionary, 77 ; Byronic school, 78; Revolutionary theories, 79 ; Thought to be considered as a constructive power, 80 ; Darwin, Spencer, and Lotze, 81 ; Romanticism, 82 ; Scientific thought to be dealt with first, 84 ; Hegel's doctrine, 85 . 


\section{PART I.-SCIENTIFIC THOUGHT.}

Three chapters on the growth and the diffusion of the scientific spirit in the first half of the nineteenth century.

\section{CHAPTER I. THE SCIENTIFIC SPIRIT IN FRANCE.}

Our century the scientific century, 89 ; Difference of English and Continental notions of science, 91 ; Relation of science and life, 92; Foreseen by Bacon, 93 ; Defect in Bacon's philosophy, 94 ; Corrected by Newton, 95 ; Bacon's and Newton's ideas taken up by French philosophers : Bacon and Newton compared, 96 ; Laplace's work, 97 ; French Academy of Sciences, 99 ; Continental methods in mathematics, 100; Modern analytical methods, 102; Older synthetical methods, 103; Influence of science on French literature, 104; Absence of this influence in England and Germany, 106 ; Schools of science in Paris, 106 ; Promoted by Governments of Revolution, 108 ; Condorcet, 110 ; Lakanal, 111 ; École normale, École polytechnique, 112 ; Monge's 'Descriptive Geometry,' 114; Science of Chemistry, 114; New mathematical sciences, 116 ; Crystallography, 116 ; Theory of probability, 118; Laplace gained his results by disregarding "individuality," 124 ; The centre of interest in the sciences of life, 125 ; Into this centre Cuvier carried exact research, 128 ; Cuvier's training, 133; Cuvier the greatest representative of the Academic system, 136 ; Science during the Revolution and First Empire, 138; Popularisation of science in France, 142 ; Literary and national popularisation, 142 ; Dangers of the former, 143; The Revolution added the practical popularisation, 145; Influence of the first Napoleon on science, 149; Napoleon favoured the mathematical sciences, 151; Discountenanced contemporary philosophy, 152 ; Used statistical methods, 153 ; Prominence given deservedly to French names by Cuvier, 155 .

\section{CHAPTER II.}

\section{THE SCIENTIFIC SPIRIT IN GERMANX.}

Foundation of German universities, 158 ; Development of the universities by the people, 159 ; Geographical distribution of the universities, 162 ; Full development of the German university system, 163; Philosophical faculty, 164; University of Göttingen, 164; Relation of universities and 
high schools, 166; The university a training-school for research, 167 ; The ideal of Wissensehaft, 168 ; Developed under the German university system, 170; Reception of exact science in Germany, 174; Science not yet domiciled during the eightecnth century, 178; Scientific periodicals, 180 ; Gauss's mathematical researches, 181 ; Scientific spirit enters the universities in second quarter of century, 183; Jacobi's mathematical scliool, 185; Chemical laboratories established in 1826 through Liebig, 188 ; Cosmopolitan character of German science, 189 ; Liebig's organic analysis, 191; Biology a German science, 193; Cellular theory of Schleiden, 194 ; and Schwann, 195 ; Ernst Hcinrich Weber, 196 ; and Joliannes Müller, 197 ; Psychoplyysics, 198 ; Spirit of exact research and Wissenschaft, 202; Encjclopxdic view necessary in philosophy and history, 203; Plilosophy of Nature, 204; Conflict between the scientific and the philosophical views, 205 ; A. von Humboldt, 206 ; Influence of Berzelius on German science, 208; Philosophy of Nature and medical science, 209 ; Science for its own sake, 211 ; Bequest of the classical and philosophical school, 211; Completeness and thoroughness of research, 213 ; Combination of research and teaching, 214 ; Combination of science and philosophy, 215 ; Biology grown out of science and philosophy combined, 216; Du Bois-Reymond on Müller, 217 ; "Vital force" abandoned, 218 ; Mechanical view in biology, 219 ; Criticism of principles of mathematics, 221 ; The exact, the historical, and the critical habits of thought, 222.

\section{CHAPTER III.}

\section{THE SCIENTIFIC SPIRIT IN ENGLAND.}

Scientific organisation abroad, 226 ; Similar institutions in Great Britain, 227 ; English science in the early part of the century, 229 ; Alleged decline of science in England, 230 ; Criticisms of Playfair, 231 ; Babbage's criticisms, 233 ; Foreign opinions on English science, 235 ; English replies to Babbage, 238 ; Foundation of the British Association, 238 ; Characteristics of higher mental work in England, 239 ; Academies and universities not always impartial, 240; Fourier, 241; Fresnel, 241; Plücker, 242 ; Grassmann, 243; Central organisation wanting in England, 243 ; Thomas Young, 244; Dalton, 245 ; Faraday, 246 ; Green, 246 ; Boole, 247 ; Babbage, 248 ; Characteristics of English thought, 249 ; Absence of schools of scientific thought, 250; Individual character and practical tendency of English science, 251 ; English peculiarities more pronounced during earlicr part of the century, 252; Unique character of English universities, 254 ; Ideal of "liberal education," 255 ; Union of education and instruction, 258; Educational organisations in England, 262; The 
Royal Institution, 264 ; Manchester Literary and Philosophical Society, 265 ; John Dawson of Sedbergh, 267 ; The Scotch Universities, 267 ; The Royal Society of Ediuburgh, 269 ; The 'Edinburgh Review,' 270; The Analytical Society of Cambridge, 271; University life in Scotland, 271; The Dublin Mathematical School, 274 ; Importance of British contributions to science, 276 ; Diffusion of scientific knowledge on the Continent, 276; Isolation of English men of science, 277; Individualism of the English character, 279 ; Changes during the last fifty years, 280 ; British contributions to biology, 282 ; Jenner, 284 ; English love of Nature, 284 ; Union of individualism and naturalism in England, 286; White of Selborne, 288; The Geological Society, 290; William Smith, 291 ; Charles Bell, 292 ; Historical geography, 294 ; Martin William Leake, 296 ; Work of the three nations compared, 298.

\section{CHAPTER IV.}

\section{THE ASTRONOMICAL VIEW OF NATURE.}

The scientific spirit in the first and second half of the century, 302 ; Science become interuational, 303; Disappearance of national differences, 305 ; Special scientific ideas, 306; Philosophy of science, 306; Whewell's 'History' and 'Philosophy,' 309 ; Philosophy and science, 311 ; Leading scientific ideas mostly very ancient, 312; Mathematical spirit, 314; When first introduced into science, 317 ; Newton's 'Principia,' 318 ; 'The gravitation formula, 319 ; Lines of thought emanating from it, 321 ; Element of error, 323 ; Laplace and Newton, 326 ; Several interests which promote science, 326 ; Insufficiency of observation, 328; Practical interest, 328 ; Focalising effect of mathematical formulæ, 332 ; Matter and force mathematically defined, 334 ; Weight and mass, 336 ; Gravitation not an ultimate property of matter, 338 ; Attraction and repulsion, 342 ; Electrical and magnetic action, 344; Law of emanations, 344 ; Molecular action, 346 ; The astronomical view : Cosmical, molar, and molecular phenomena, 348 ; Special interest attached to molar dimensions, 350 ; Geometrical axioms, 352 ; Difficulty of measuring gravitation directly, 353 ; Astronomical view of molecular phenomena, 354 ; Capillary attraction, 356 ; Boscovich's extension of the Newtonian formula, 357 ; Coulomb's measurements, 360 ; Extended by Gauss and Weber, 360 ; Davy and Faraday, 363 ; Ampere and Weber develop the astronomical view, 366 ; Weber's fundamental measurements, 368 ; Necessity of developing the infinitesimal methods, 373 ; Newtonian formula the basis of physical astronomy, 375; The Newtonian formula unique as to universality and accuracy, 377 ; Is it an ultimate law? 378 ; Laplace's opinion, 378 ; Opposition to the astronomical view of uature, 381. 


\section{CHAPTER V. \\ THE ATOMIC VIEW OF NATURE.}

Recapitulation, 382 ; Atomic theory, 385 ; Lavoisier, 386 ; Phlogistic theory, 388 ; Theory of combustion, 389 ; Rule of fixed proportions, 392 ; J. Benjamin Richter, 393 ; Dalton, 394; Berzelius, 396; Atomic theory and gravitation compared, 396; Wollaston's prophecy, 397 ; Rule of multiple proportions, 398 ; Equivalents, 399 ; "Simplex sigillum veri," 401 ; Prout's hypothesis, 402 ; Discovery of Isomerism, 405 ; Organic Chemistry, 407; Liebig's definition of same, 409 ; Type theory, 411 ; Uncertainty in chemical theory about middle of century, 413; Two aspects of the atomic theory, 415; A convenient symbolism, 417 ; Neglect of the study of affinity, 420; Kopp on chemical theory in 1873, 421 ; The periodic law, 422 ; Difference between chemical and physical reasoning, 424 ; The kinetic theory of gases, 425; Avogadro's hypothesis, 427 ; Neglect of same, 429; Development of the atomic view, 431 ; Pasteur's discovery of "Chirality," 431; Atom and molecule, 432 ; Joule's calculations, 434 ; Clausius's first memoir, 435 ; Internal energy of molecules, 436; The atomic theory accepted as a physical theory about 1860, 437 ; Clerk Maxwell : The statistical view of nature, 438; Doctrine of averages, 440 ; Geometrical arrangement of atoms, 441 ; Crystallography, 441; Analogy between crystallographic and atomic laws, 444; Isomorphism, 444; Polymorphism, 446; Structural and stereo-chemistry, 447 ; Valency, 447 ; Atomic linkage, 449 ; The carbon tetrahedron, 450; Defects and insufficiency of the atomic view, 451 ; Theories of chemical affinity, 452 ; Practical influences, 453; Change in definition of organic chemistry, 454; Criticisms of the atomic view, 455 . 


\section{A HISTORY OF EUROPEAN THOUGHT}

\section{IN THE NINETEENTH CENTURY.}

\section{INTRODUCTION.}

I.

BEHIND the panorama of external events and changes which history unfolds before our view there lies the $\begin{gathered}\text { Thought, } \\ \text { worldden }\end{gathered}$ hidden world of desires and motives, of passions and energies, which produced or accompanied them; behind the busy scenes of Life lie the inner regions of Thought. Only when facts and events cease to be unconnected, when they appear to us linked together according to some design and purpose, leading us back to some originating cause or forward to some defined end, can we speak of History in the sense which the word has acquired in modern language; and similarly do the hidden motives, desires, and energies which underlie or accompany the external events require to be somehow connected, to present themselves in some order and continuity, before we are able to grasp and record them. That which has made

VOL. I. 
facts and events capable of being chronicled and reviewed, that which underlies and connects them, that which must be reproduced by the historian who unfolds them to us,

Thouglit, the only moving principle.

History of Nature, how to be understood. Not intellisible without intellect. is the hidden element of Thought. Thought, and thought alone, be it as a principle of action or as the medium of after-contemplation, is capable of arranging and connecting, of combining what is isolated, of moving that which is stagnant, of propelling that which is stationary. Take away thought, and monotony becomes the order.

This assertion may seem bold to many, who would look rather to the grand phenomena of Nature than to the narrow limits of man's activity. A few remarks will, however, suffice to show that my proposition is not opposed to the view which they take. It may be urged that, independent of human life altogether, the earth has a history, the planetary system has a development, and that, according to modern theories, evolution is the principle which governs inanimate as well as animated nature; that rest and sameness are nowhere to be found, everywhere change and unrest. But change and unrest do not necessarily constitute history. Motion and change would be as monotonous as absolute rest, were they merely to repeat themselves endlessly, did the whole movement not produce something more, and were this something more not greater or better than the beginning. But greater and better are terms which imply comparison by a thinking beholder, who attaches to one thing a greater value than to another, judging by certain ideal standards, which are not in the objects or process of nature themselves, but are contained only in his own thinking mind. It may be that a mechanical and mindless series 
of changes can produce numbers without end, or forms of countless variety: but this process would deserve the name of history only if either the transition from unity to multiplicity, or the production of formal variety, were capable of being understood by a thinking mind, - if the result of the process were a matter of some concern, if an interest were attached to it, if a gain or loss could be recorded. The pendulum which swings backwards and forwards in endless monotony, the planet which moves round the sun in unceasing repetition, the atom of matter which vibrates in the same path, have for us no interest beyond the mathematical formulæ which govern their motions, and which permit us mentally to reproduce, i.e., to think them. A combination of an infinite number of these elementary movements would have as little interest, were it not that out of such a combination there resulted something novel and unforeseen: something that was beautiful to behold or useful to possess, something that was valuable to a thinking mind in a higher or lower meaning of the word.

But if, even in inanimate nature, the processes of change acquire an interest, possess a history, only if referred to a thinking mind which can record, understand, and appreciate them, how much more is this the case when we deal with human affairs, where man is not only the thinking beholder but the principal agent? Here the historic interest would cease, were the succeeding years and ages to produce no valuable change, were the rule of existence and the order of life to repeat themselves in unceasing monotony. The savage tribes of Africa have a $\underset{\text { Hastory of }}{\substack{s_{2} \\ \text { savage }}}$ history: but this lisstory is all known when the order of tribes, what 
the day, the year, at most of a generation, is known. Even the highly complicated but stagnant life of China would have a short historical record-many thousands of years taking up no more space than as many days of modern European history:

"Better fifty years of Europe than a cycle of Cathay."

6.

Two ways in which Thought enters into History.

Definition of Thought impossible.

Thus it is that Thought becomes in two ways a subject of great interest and importance to the historian. Of every change in nature or human life we can ask: What has been its result in the world of thought? What gain or loss, what progress, has it worked in the minds of men, of us the beholders? Has it increased our knowledge, enriched our stock of ideas, deepened our insight, broadened our views and sympathies-in one word, has it added to our interests? has it made larger and fuller our inner life?

And of every change in human affairs we can ask this further question: What part has thought, the inner life, played in this change? These two questions mark the task of the historian of Thought.

i. I do not think it necessary or practicable at this stage to explain minutely the terms with which we have so far been dealing. Many a one might be tempted to ask for a definition of Thought, or for a preciser statement of the actual relation between Nature, Life, and Thought. ${ }^{\text {? }}$

1 In refusing to define what I mean by Thought, I take up the opposite position to that occupied by Prof. Max Müller in his latest work, 'The Science of Thought,' London, 1887, p. 1, where he says: "I mean by Thought the act of thinking, and by thinking I mean no more than combining. I do not pretend that others have not the right of using Thought in any sense which they prefer, provided only that they will clearly define it." So far as definition is at all a part of the work of the historian, I maintain that it is the result and 
Such definitions must be left to the reader himself, if in course of the perusal of these volumes he finds it necessary to form abstract theories on these points. Any definition given now would inevitably involve us in controversies, which would be embarrassing and confusing. I rely upon the general and undefined sense of the word Thought, assuming that every one will connect some intelligible meaning with it, some meaning which will enable him to understand the very general proposition with which we started, the existence of an inner or hidden world behind the world of external Relation of outer and inner world events and facts, the continually changing nature of undefined. this inner world, and the connection and reaction between the two worlds. Whether in time and in importance the outer or the inner world is the first, whether within the latter equal value attaches to the clearer province of Reason, i.e., defined Thought, to the obscurer regions of Feeling and Imagination, and to the unconscious world of Impulse, these are questions which it is not necessary to answer at present. As it was enough to point to the existence of the two worlds of Life and Thought, so it will be enough to notice that thought does not mean merely defined, clear, methodical thought, but likewise the great region of desire, ings of mean impulse, feeling, and imagination, all of which play, we must admit, a great part in the inner life of the soul as well as in that of the outer world.

outcome of his narrative, the impression which he leaves on the mind of the reader when he has perused the work. History is not mainly a science which proceeds by analysis; it is the attempt to collect and arrange in a living picture an enormous mass of detail. Too rigid definitions, like lines which are too hard and marked, spoil the total effect. 
In this sense of the word we have in the following treatise to deal with the History of Thought: not, however, with the history of thought in general, but with that of

Thought of the present age.
11. Contempor. ary history, to what extent possible able. a defined period, with that of the present age and the age immediately preceding it,- - the age, in fact, to which the writer and his readers belong, of which they have a personal knowledge and recollection more or less wide and intimate. It is the latter circumstance which has made me select this special portion of the history of thought; for it is that portion of which, it seems to me, I and my contemporaries should - if we go about it in the right way - know most. As every person is his own best biographer, so it seems to me every age is, in a certain sense, its own best historian.

We know that this has been frequently denied so far as external events (that which many persons call history par excellence) are concerned. Contemporary writers do not, it is stated, get beyond mere records of events, records at once one-sided, incomplete, and confusing. It is indeed necessary to have the records in great number and variety: because the true and real record can only be given by him who combines all these many records into one, who avoids the errors arising from special points of view, from narrowness of outlook, from individual ignorance, blindness, or prejudice. Still, in spite of such defects, the contemporary records will always remain the most valuable sources for the future historian who may succeed in sifting their various testimonies, combining and utilising them to produce a fuller and more consistent picture of the bygone age. But while his work may be only temporarily valuable, theirs is lasting. It is 
hardly doubtful that, after hundreds or thousands of years have passed, the simple, detailed, and perhaps contradictory, narratives of contemporary witnesses will outlive those more elaborate and artistic efforts of the historian which are so largely inspired and coloured by the convictions of another-viz., his own-age. For as Goethe has remarked: "History must from time to time be rewritten, not because many new facts have been discovered, but because new aspects come into view, because the participant in the progress of an age is led to standpoints from which the past can be regarded and judged in a novel manner." 1

Most of the great historians whom our age has produced will, centuries hence, probably be more interesting as exhibiting special methods of research, special views on political, social, and literary progress, than as faithful and reliable chroniclers of events; and the objectivity on which some of them pride themselves will be looked $\begin{aligned} & \text { Supposed } \\ & \text { ob hivitivity }\end{aligned}$ upon not as freedom from but as unconsciousness on their ians. part of the preconceived notions which have governed them. But where the facts recorded and the mind which records them both belong to the same age, we have a double testimony regarding that age. The events, and the contemplating mind, supplement each other to form a more complete picture, inasmuch as the matter and the medium through which it is viewed belong to the same time. And so it comes to pass that historians like Thucydides, Tacitus, and Machiavelli are looked upon as

1 'Materialien zur Geschichte der Farbenlehre,' Werke, 2te Abtheilung, Band 3, p. 239. I quote from the new edition, brought out by the German Goethe Society. 
perfect models in the art of writing history, and the memoirs of many modern statesmen are more lastingly valuable than the more elaborate and connected narratives of remote and secluded scholars.

13.

Value of contemporboth of Facts and Thought. Thought.

But if the contemporary record of facts will always have a peculiar value, however incomplete it may be, still more must this be the case with the contemporary record of thought; especially if thought means the whole of the inner life of an age, not merely that portion which in the form of defined thought has been incorporated in the written literature of the age. For a large portion of this hidden life is known only to those who have taken part in it. The vague yearnings of thousands who never succeed either in satisfying or expressing them, the hundreds of failures which never become known, the numberless desires which live only in the hearts of men or are painted only in their living features, the uncounted strivings after solutions of practical problems dictated by ambition or by want, the many hours spent by labourers of science in unsuccessful attempts to solve the riddles of nature, - all these hidden and forgotten efforts form indeed the bulk of a nation's thought, of which only a small fraction comes to the surface, or shows itself in the literature, science, poetry, art, and prac-

15. tical achievements of the age. Equally important, though Thought not equally prominent, this large body of forgotten the material for genius.

thought has nevertheless been that which made the measure full, which heaped the fuel ready for the match to kindle; it constitutes the great propelling force which, stored up, awaits the time and aid of individual talent or genius to set it free. Philosophers tell us of 
the wastefulness of organic life, of the thousands of germs which perish, of the huge volume of seed scattered uselessly. A similar fate seems to fall on the larger portion of intellectual and moral effort; but here a deeper conviction tells us that it is not the sacrifice but the cooperation of the many which makes the few succeed, that excellence is the prize of united effort, that many must run so that one may reach a higher goal. What other feeling could console those legions of honest workers who spend their lives in trying to deal with the seemingly unconquerable host of social evils, the apparently growing vice and misery of large towns, who raise a cry for oppressed nationalities, or preach against the curses of war and militarism? Or what higher and unselfish satisfaction could an author derive from spending half a lifetime in producing a work which in the end may fall dead-born from the press, if it were not the conviction that in the cause in which he has failed another after him may succeed, and that his failure may be a portion of the silent and hidden efforts that co-operate towards a useful end ? ${ }^{1}$ But who in afterages can write the history of this forgotten and hidden work of a nation? Whose historical sense is delicate enough to feel where the pressure was greatest and the effort longest ere the new life appeared, whose eye penetrating and discerning enough to follow up the dim streaks

1 "Sehen wir nun wälirend unseres Lebensganges dasjenige von anderen geleistet, wozu wir selbst frïher einen Beruf fühlten, ihn aber, mit manchem andern, aufgeben mussten, dann tritt das schöne Gefiihl ein, dass die Menschheit zu- sammen erst der wahre Mensch ist, und dass der Einzelne nur froh und glücklich sein kann, wenn er clen Muth hat, sich im Ganzen zu fiihlen."-Goethe, "Wahrheit und Dichtung,' 9th Book; Werke, 27, 277. 
of twilight, dazzled as he must be by the blaze of the 16. risen sun? We who live in the expectation of the light Contempor. of Thought more taitlfill.

which is to come, surrounded by the shadows, difficulties, and obstacles; we who belong to the army, and are not leaders, who live in, not after, the fight,-we claim to be better able to tell the tale of endless hopes and endeavours, of efforts common to many, of the hidden intellectual and moral work of our age. ${ }^{1}$

How far back we who have lived during the second half of the present century may extend the period of which we claim to have a personal knowledge, is a point of further interest. Certain it is that in our parents and immediate forefathers we have known the representatives of a generation which witnessed and laboured in the interests of the great Anti-Slavery, the Reform, and the AntiCorn-Law movements, who experienced the revolutions worked by the introduction of steam-power and gas, who took part in the great work of national and popular education abroad and in the reform of school-life in England. They themselves went through the enthusiasm of the anti-Napoleonic Revolution in Germany, came under the influence of Goethe's mature manhood, were fascinated by the stories from the pen of the Wizard of the North, par-

1 Compare what A. de Tocqueville says, 'CEuv. comp.,' vol. riii. p. 170: "Nous sommes encore trop près des évènements pour en connaître les détails. Cela paraît singulier, mais est vrai. Les détails ne s'appren. nent que par les révélations posthumes, contenues dans les Mémoires, et sont souvent ignorés des contemporains. Ce qu'ils sarent mieux que la posterité, e'est le mourement des esprits, les passions générales du temps, dont ils sentent encore les derniers frémissements dans leur esprit ou dans leur cœur; c'est le rapport vrai des principaux personnages et des principaux faits entre eux. Voila ce que les roisins des temps racontés aperçoivent mieux que ne fait la postérité." 
took of the spirit of the Romantic School, felt the electrical touch of Lord Byron's verse, listened to the great orators of the third French Revolution, and could tell us of the now forgotten spell which Napoleon I. exercised over millions of reluctant admirers. Most of these fascinations and interests live only in the narratives of contemporaries and surviving witnesses, few of whom have succeeded in perpetuating them with pen or brush, making them intelligible to a future age; most of them die with the generation itself. Not only have we listened to their words and seen in their features the traces of the anxieties they lived through, in their eyes the reflected enthusiasms and aspirations, in their glances and in the trembling of their voices the last quiverings of bygone passion and joy,-we have received from them a still more eloquent testimonial, a more living inheritance. But this we cannnot hand down to our children in the form in which it was given to us: it has not passed through our hands unaltered. This inheritance is the language which our parents have taught us. Unknowingly they have themselves altered the tongue, the words and sentences, which they received, depositing in these altered words and modes of speech the spirit, the ideas, the thought of their lifetime. These words and modes of speech they handed to us in our infancy, as the mould wherein to shape our minds, as the shell wherein to envelop our slowly growing thoughts, as the instrument with which to convey our ideas. In their language, in the phrases and catchwords peculiar to them, we learnt to distinguish what was important and interesting from what was trivial or indifferent, the subjects which

15. which Language undergoes from parent to child, a proof of the changing life of Thought. 
should occupy our thoughts, the aims we should follow, the principles and methods which we should make use of. The bulk and substance of this they indeed inherited themselves; but the finer distinctions of their reasoning, the delicate shading of their feelings and aspirations, they added and modified for themselves, modelling for their own special use the pliable and elastic medium of the mother tongue. With this finer moulding we have inherited the spirit of the former generation: predisposing us to certain phases of thought and placing in our path a difficulty in acquiring otherwise than by gradual and almost imperceptible degrees the faculty of assimilating new and unexpected opinions, tastes, and feelings. Many of us adhere to the special character and phase of thought acquired in our youth. Some by learning foreign languages, and living in other countries, gain a facility for understanding quite different phases of thought: very few among us

Inadequacy of conven. tional speech for original thought. Coining of new words. develop so much original thought that they burst the shell of conventional speech, coining new words and expressions for themselves, embodying in them the fleeting ideas of their time, the indefinable spirit of their age. Once expressed, these new terms are rapidly circulated, and if we look back on the period of a generation, we note easily the progress and development of opinion and tastes in the altered terms and style of our language.

Thus it is that the writer, and those of his readers whose memory carries them back to the middle of the century, and whose schooling and education embodied the ideas of a generation before that time, can claim to have some personal knowledge of the greater portion of the nineteenth century, of the interests which it created and 
the thoughts which stirred it. ${ }^{1}$ It is the object of these volumes to fix, if possible, this possession; to rescue from oblivion that which appears to me to be our secret property; in the last and dying hour of a remarkable age to throw the light upon the fading outlines of its mental life; to try to trace them, and with the aid of all possible information, gained from the written testimonies or the records of others, to work them into a coherent picture, which may give those who follow some idea of the peculiar manner in which our age looked upon the world and life, how it intellectualised and spiritualised them. This attempt is therefore not a history of outward political changes or of industrial achievements: the former will probably be better known to our children than they have been to us; the latter will soon be forgotten as such, or incorporated in the still greater results of the future, for which they will be the preparation. Nor is it a history Not a politi. cal history, nor a history of Science, Literature, of Knowledge and Science, of Literature and Art, which I purpose to write; though as these are the outcome of the inner life, and contain it, so to say, in a crystallised form, they will always have to be appealed to for the purpose of verifying the conclusions which we may arrive

${ }^{1}$ On the division of History into centuries see what Du Bois-Reymond says ('Reden,' Leipzig, 1886, vol. i. p. 519), and the fuller discussion of the subject by Prof. O. Lorenz, 'Die Geschichts - wissenscliaft' (Berlin, 1886, p. 279 sqq.) The latter refers to what the first historian says (Herodotus, ii. 142:

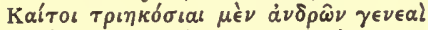

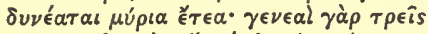

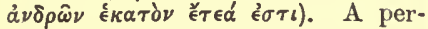
son born in 1840 can claim to have a personal knowledge of the last half, and through his parents and teachers a knowledge of the first half, of the century. In this way it may be said that his personaldirect or indirect-knowledge extends over nearly a century. Lorenz says correctly: "Für jeden einzelnen bildet der Vater und der Sohn eine greifbare Kette von Lebensereignissen und Erfahrungen." And that this applies even more to ideas and opinions, to Thought, than to events and facts, is evident.
20.

Object of this work to retrace Thought through the dying cen. tury. 
52.

Where the interest of the book will lie:

in all the

influences

which have

a result on

our inner

life.

23.

The personal knowledge and experience necessary for a true portrayal forms a limitation of the extent of ground to be
traversed.

24. American influence only touched upon. at. What will interest us most will be the conscious aims and ends, if such existed, of any political or social movement, and, where they did not exist, at least the results to our inner life which have necessarily followed, the methods by which knowledge was extended or science applied, the principles which underlay literary composition and criticism, and the hidden spiritual treasure which poetry, art, and religious movements aimed at revealing or communicating; in fact the question: What part has the inner world of Thought played in the history of our century,- - what development, what progress, what gain has been the result of the external events and changes?

But if personal knowledge and experience are-as it seems to me-of the greatest importance in an attempt like this; if, without having lived the inner life, a record of it would be either a mere string of names or a criticism of opinions, not a living picture,-so it is also the factor which necessarily limits the extent of the ground which I propose to traverse. Thus I feel obliged in the first place to limit myself to European Thought. Such a limitation would hardly have been called for a century ago, because it would have been a matter of course: but the steady growth and peculiar civilisation of a new and vigorous people on the other side of the Atlantic force from me the twofold confession, that there is a large world of growing importance of which I have no personal knowledge, and to estimate which I therefore feel unqualified and unprepared; and further, that I am equally unable to picture to myself the aspect which the whole of our European culture in its present state may assume to an outside and far-removed observer who is placed in the 
New World. As this New World grows not only in numbers and national wealth, but also in mental depth, as it becomes more and more intellectualised and spiritualised, so it will no doubt experience the desire of recording its own inner life and culture, emphasising the peculiarities which distinguish it as a whole from our civilisation. But the tendencies of this new culture are to me vague and enigmatical, and I frankly admit that I am unable to say anything definite on this subject. Convinced as I am that in human affairs all outer life is the vessel which contains an inner substance, the shell which envelops a growing kernel, I am, nevertheless, unable in this case to penetrate to either, and must therefore content myself with taking notice of this vast new element of nineteenth-century culture only where it comes into immediate contact with European thought, which has indeed been powerfully influenced by it. And of European thought itself I am forced to select likewise only the central portion, the thought embodied in French, Only French, and English thought the subject of German, and English Literature. I have to admit that the present Italian, Scandinavian, and Russian influences are all around this centre, sometimes penetrating far into it; but here again languages unknown and interests foreign to me have made it impossible to identify myself ever so superficially with the new life that is contained in them. I must therefore here also confine myself to very imperfect and casual notices, which make no attempt to do justice to the subject.

The subject before us, then, is European Thought-i.e., the thought of France, Germany, and England-during the greater part of the nineteenth century. Circumscribed as 
Unity of Thought a product of this century.

this subject is by the limits of time and space which I have mentioned, it is, nevertheless, still vast, intricate, and bewildering. And yet it is my intention, throughout the inquiries which $I$ have to institute and in the various outlines and sketches which I have to draw, never to lose sight of the unity of the whole. This unity, I maintain, the progress of our age has more and more forced upon us. It is itself a result of the work of the century. A hundred years-even fifty years-ago, it would have been impossible to speak of European Thought in the manner in which I do now. For the seventeenth and eighteenth centuries mark the period in which, owing to the use of the several vernacular languages of Europe in the place of the medirval Latin, thought became nationalised, in which there grew up first the separate literatures and then the separate thought of the different civilised countries of Western Europe. Thus it was that in the last century, and at the beginning of this, people could make journeys of exploration in the region of thought from one country to another, bringing home with them new and fresh ideas. Such journeys of discovery, followed by importation of new

27. ideas, were those of Voltaire ${ }^{1}$ to England in 1726, where he found the philosophy of Newton and Locke, at that time not known and therefore not popularly appreciated

28. in France; the journey of Adam Smith in 1765 to France, Smith. where he became acquainted with the economic system of Quesnay and the opinions of the so-called "physiocrats," which formed the starting-point of his own great work,

1 For a most complete collection of data referring to this subject see Du Bois-Reymond's address in the Berlin Academy, 30th January 1868 , reprinted in the collection of his 'Reden,' Leipzig, 1886, vol. i. 
'The Wealth of Nations.' During the last quarter of the eighteenth century A. G. Werner raised the Mining Academy at Freiberg, which had been founded in 1766, from a mere provincial institution to be one of the great centres of scientific light in Europe, to which students from all parts of the world flocked to listen to his eloquent teaching. Towards the end of the century Wordsworth and Coleridge went on a trip to Germany, whence the latter brought to England the new philosophy of Kant and Schelling. Madame de Staël, in an age when tidings of a new literary life in Germany had reached French Society through some of the emigrants of the Revolution, set herself reluctantly to learn German, ${ }^{1}$ convinced that a new phase of thought had appeared there; and then with 30. German Benjamin Constant visited the country itself at the end imported of 1803 , and again in 1807. The result of these journeys by France de Staël. of exploration was her work 'De L'Allemagne.' Whilst Coleridge and Madame de Staël drew inspiration from the new life which centred in the Weimar of Goethe and Schiller, the scientific students of the whole Continent directed their gaze to Paris, where alone for many decades the modern methods could be learnt, where the new scientific ideas were, so to speak, collected in a focus. For more than half a century Paris remained the centre Paris the of scientific thought, ${ }^{2}$ and even English philosophers, who ideas.

1 See Lady Blennerhasset's interesting work on Madame de Staël, German ed., vol. ii. p. 461 sqq.; especially the remarkable passage quoted there, p. 465 , in her letter to the Baron de Gérando, October 1802: "Ich glaube wie Sie, dass der menschliche Geist, der zu wan- dern scheint, jetzt bei Deutschland angelangt ist."

${ }_{2}^{2}$ See Bruhns, 'Life of A. v. Humboldt,' translated by Lassell, vol. i. p. 232: "Notwithstanding the sardonic expression of the frantic judge, 'Nous n'avons pas besoin de savans,' Paris was yet at the close

VOL. I. 
since Bacon and Newton had followed their own independent line of research, had to discover in the second decade of the century that Newton's great name was not a guarantee for the efficiency of his methods, which had been greatly developed and improved in the hands of 32. Continental mathematicians. These improved methods Continental mathematical methods introduced into England by Babbage, Herschel, and Pea-' cock.

were imported into England by three Cambridge graduates, Herschel, Babbage, and Peacock, who translated Lacroix's Treatise, and by doing so gave a great impetus to mathematical research in this country. Fifteen years later, students from all parts of the world flocked to the small University town of Giessen in Germany, thence to take home with them a knowledge of the new science and 33. methods of Chemistry, taught in the laboratory of LiebigLiebig's
Laboratory. methods previously used only in the private and inaccessible laboratories of learned investigators. ${ }^{1}$ It will be in 34. the memory of many how the philosophy of Auguste philosophy
shown to his Comte, published between the years 1830 and 1840,

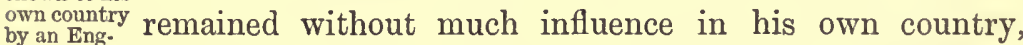
lishman. whereas, mainly through the writings of J. S. Mill and

of the eighteenth century the metropolis of the exact sciences. Lalande, in writing to von Zach on January 26, 1798, remarks : 'The love of mathematics is daily on the increase, not only with us but in the army. The result of this was unmistakably apparent in our last campaigns. Bonaparte himself has a mathematical head, and though all who study this science may not become geometricians like Laplace and Lagrange, or heroes like Bonaparte, there is yet left an influence upon the mind which enables them to accomplish more than they could possibly have achieved without this training. Our mathematical schools are good, and successfully accomplish their main object in the diffusion of mathematical knowledge." Compare also vol. i. p. 342 , referring to 1804 . Also vol. ii. p. 92 , referring to the period 1820 to 1830. "Humboldt continued to regard Paris as the true metropolis of Science" (p. 70), and many other passages. See also Steffens, "Was ich erlebte," vol. x. p. 233, and what Goethe said to Eckermann on the contrast of Germany and Paris in the year 1827.

1 See A. W. Hoffmann, "The Life - Work of Liebig,' Faraday Lecture for $1875, \mathrm{p} .8$. 
his school, it became, as it were, a centre of thought, an embodiment of a circle of modern ideas in this country, whence it was reimported into France nearly a generation after its first appearance. Something similar happened to a once neglected but now renowned English landscapepainter, Constable, whose pictures when exhibited in France in 1824 created a profound sensation, and had such an influence on the artists of that country that they are said to mark an era in landscape-painting there. ${ }^{1}$

Such journeys of discovery in the realm of thought and ideas have now become almost impossible. In the course of our century Science at least has become international: isolated and secluded centres of thought have become more and more rare. Intercourse, periodicals, and learned societies with their meetings and reports, proclaim to the whole world the minutest discoveries and the most recent developments. National peculiarities still exist, but are mainly to be sought in those remoter and more hidden recesses of thought, where the finer shades, the untranslatable idioms, of language suggest, rather than clearly express, a struggling but undefined idea. Thought has its dawn and twilight, its chiaroscuro as well as its open day; but the daylight has grown wider and clearer and more dif-

1 See Walter Armstrong in the 'Nineteenth Century' for April 1887 ; Julius Meyer, 'Geschichte der modernen französischen Malerei,' Leipzig, 1867, Book 7, chap. 2 ; A. Rosenberg, 'Geschichte der modernen Kunst,' vol. i. p. 63. Rosenberg thinks the influence of Constable on French Art is exaggerated, and mentions Paul Huet, whose early pictures date from 1822. But an Englishman Bonington, who, however, is claimed as of the French School, was even before Huet and Constable. See also what Delacroix wrote to Th. Sylvestre in 1858: "Constable est une des gloires anglaises. C'est un véritable réformateur, sorti de l'ornière des paysagistes anciens. Notre école a grandement profité de ses examples et Géricault était revenu tout étourdi de l'un des grands paysages qu'il nous avait envoyés" (quoted by Emile Michel in 'Grande Encyclopédie,' art. "Constable").
35. Constable's influence in France.
36. Science become international. 
fused in the course of our century, and so far as the greater volume of ideas is concerned, we can speak now of European thought, when at one time we should have had to distinguish between French, German, and English thought. Reserving, therefore, in the meantime the task of investigating what still, within the bounds of this larger international life, remains peculiar to the thought of each nation, it is the great body of common European thought with which I propose at first to deal. How has it grown to be what it is now, what special contributions have the several nations made to the general stock, what is at present our inventory of it, how has it been changed in course of the century? But how, it may be asked, are we to take stock? how is this inventory to be drawn up? There is indeed one very obvious method which presents itself, though it is not the one which I propose to use exclusively, or even largely. And yet it seems to me well worthy of special attention.

Already I have remarked how the changes of thought are deposited in the altered language and style of the age. A closer study of the changes which, in the course of this century, have taken place in the vocabularies as well as in the styles of the three principal European languages, would no doubt reveal to a great extent when and how new ideas have presented themselves, how they have become fixed and defined in special words or terms. It would allow us to trace to a very large extent not only the growth of the general stock of European thought, but also the migration of single ideas from one nation to an-

38. and on the migration of ideas. other. And, lastly, it would exhibit to a great extent in what peculiar phrases, in what secluded corners, the indi- 
vidual thought of each of the three nations has found refuge. ${ }^{1}$ Any one who has attempted to translate from one of these languages into another, be it prose or be it lyrical, philosophical, or descriptive poetry, will have experienced the necessity of studying minutely the meaning or hidden thought which a word or a phrase may signify: he will have been led to notice what is common and what is peculiar to different languages,

1 The only books which treat of words in the sense mentioned above, and which have come under my notice, are Horne Tooke's 'Diversions of Purley' and Archbishop Trench's little volumes on 'The Study of Words' and 'English Past and Present.' So far as the use of merely philosophical terms is concerned, I may refer to $R$. Eucken, 'Geschichte der philosophischen Terminologie,' Leipzig, 1879. A great deal of material for a research of this kind may be found in the large Dictionaries of Grimm, Littré, and Murray, though I do not feel sure that the great change which has come over language, through the expansion, deepening, and differentiation of ideas and of thought in our age, has been specially taken note of. The plan of Grimm's Dictionary, which aims at embracing the German language in its development during three centuries, beginning with Luther and ending with Goethe (see Wilh. Grimm's 'Kleinere Schriften,' vol. i. p. 508), almost excludes the period which I am reviewing.

It is interesting to remember that Diderot, the first writer who attempted to collect the great body of modern Thought and Learning into an encyclopædic whole, referred to Language very much in the same manner as we do now, a hundred and fifty years later.
See the article "Encyclopédie," where Diderot says that a Dictionary is only an exact collection of titles, to be filled in by the Encyclopædia; and further on, p. 639 : "Si l'on compte les hommes de génie, et qu'on les répande sur toute la durée des siècles écoulés, il est évident qu'ils seront en petit nombre dans chaque nation et pour chaque siècle, et qu'on n'en trouvera presqu'aucun qui n'ait perfectionné la langue. Les hommes créateurs portent ce caractère particulier. Comme ce n'est pas seulement en feuilletant les productions de leur contemporains qu'ils rencontrent les idées qu'ils ont à employer dans leurs écrits, mais que c'est tantôt en descendant profondément en euxmêmes, tantôt en s'élançant au dehors, et portant des regards plus attentifs et plus pénétrans sur les natures qu'ils environnent, ils sont obligés, surtout à l'origine des langues, d'inventer des signes pour rendre avec exactitude et avec force ce qu'ils y decouvrent les premiers. C'est la chaleur de l'imagination et la méditation profonde qui enrichissent une langue d'expressions nouvelles : c'est la justesse de l'esprit et la sévérité de la dialectique qui en perfectionnent la syntaxe; c'est la commodité des organes de la parole qui l'adoucit; c'est la sensibilité de l'oreille qui la rend harmonieuse." 
39. and the thought which they express. Of Goethe it Goethe. may be said that he created to a large extent the language and style of that which is best in the modern literature of his country. No such supreme influence belonging to a single individual can probably be found in any other German, French, or English writer in our century, for reasons which are obvious: but the great French novelists, the German metaphysicians, and the original poetical minds of modern England have enlarged and enriched the vocabulary of their respective languages, and have added a number of useful and novel modes of expression (tournures, Wendungen). Carlyle's influence has been great in introducing novel epithets, borrowed or imported frequently from the German. Matthew Arnold has laboured in a similar direction, his models being, besides Goethe and Heine, mostly French authors, such as Sainte-Beuve and the 40. introspective school. Germany has been less fortunate of the German Language. in extending her vernacular vocabulary: the facility which her language possesses of assimilating foreign words and using them almost without any alteration has done much to complicate German style, destroying its simplicity, its graces, the poetical element. It will, however, probably be found that by far the greatest accession to the vocabularies - though not to the finer modelling - of the modern languages has come from the influence

41. Growth in the mean. ings of words. of the sciences on general culture and literature. Wellknown words, long in use, have at the same time through this influence acquired altered or more specific meanings.

The vaguer" word "development" has been supplanted by "evolution." "Differentiation" has a definite philo- 
sophic-not only a mathematical-neaning. The word "positive" has, besides the logical signification, acquired at least two meanings which are very specific, and which it did not possess formerly. "Energy" has, besides the general meaning, and the philosophical one which Aristotle assigned to it, acquired a special meaning, having first in England and then abroad taken the place of "force" as a more correct and definable term. In connection with it, "correlation" and "conservation" are terms of very specific value. The word "fittest" and the phrase "struggle for existence" mean something different from what they meant fifty years ago. Then there are the terms "exact" and "science" themselves, which mean something different now from what they meant formerly. has found And coming out of the more recent doctrines of the limits of human and conscious individual knowledge, there are the words "unconscious," "unknowable," and "agnostic," which indicate whole trains of novel thought. It would indeed be an interesting and useful investigation to follow up to their origin the many new words and phrases, or the altered meanings of well-known and familiar words, in which the three principal European languages abound. It would be a methodical study of the changes which thought has undergone.

Nor need such an undertaking be based upon any particular or one-sided theory as to the connection of Civilisation, Thought, and Language. This century has not been wanting in such, from the extreme theory of De Bonald, ${ }^{1}$ who saw in Language an immediate Divine revelation, to the most recent and more scientific view

43. De Bonald's theory of Language and Max Miuller's Science of Language.

1 De Bonald (1754-1840), 'Législation primitive,' Paris, 1802. 
of Max Müller, who would absorb philosophy in the science of Language ${ }^{1}$ in the same way as Astronomy has to many become merely "une question d'analyse." In a certain sense we can agree with both of these thinkers. Without discussing the vexed question of the origin of Language and Thought, to us as individuals, born in a civilised and intellectual age, words certainly came earlier than clear and conscious thought. The easy manner also in which, through the use of our parents' tongue, we became introduced into a complex and bewildering labyrinth of highly abstract reasoning is little short of a miraculous revelation. But, as I mentioned above, it is not my intention to study the development of European thought during this century by means of a close analysis of the changes and growth of the three principal languages. Such an enterprise would demand an amount of lexicographical knowledge possessed only by the authors of dictionaries like those of Grimm, Littré, and Murray. But though I am not qualified for such a task, there is one special point on which I cannot avoid being drawn into a grammatical discussion. It refers to the word Thought

itself. How is the meaning which $I$ and my readers connect with this word to be expressed in French and German? How are we to translate the word? The subject we deal with does not belong to England alone, but as much to France and to Germany : it must thus have a name in each of their languages. Now I believe that the word pensée expresses in French very nearly the same thing which we mean in English by thought. It is some550 .

1 See his 'Science of Thought,' London, 1887, especially pp. 292 and 
what more difficult to find a corresponding word in German. I have for some time hesitated whether to use the word Geist or Weltanschauning, two terms frequently used to express the aggregate of the inner life of an age: but have finally resolved to use the word Denken, as this word lends itself to the same contrasts of Life and Action (Leben und Handeln), denoting the inner world, whereas the opposite of Geist is Stoff (matter), and Weltanschaunng, though an expressive and untranslatable word, denotes rather the outcome, the result, of thought than thought itself. Passing from the word to the subject itself, I find that the greater definiteness of the term in the English language is accompanied also by a more abundant literature of the subject. The larger idea of a Philosophy of History is indeed due mainly to Continental thinkers, 45.
Philosophy of History especially to Herder, Hegel, Comte, and Guizot, and due to ConVoltaire's 'Siècle de Louis XIV.' will always be the model of the historical picture of a period. Still it isin my opinion-mainly the writings of Carlyle, Buckle, Draper, Lecky, Leslie Stephen, and, considering its size, perhaps more than all, Mark Pattison's 'Essay,' ${ }^{1}$ which have fixed in our minds the meaning of the word Thought as the most suitable and comprehensive term to denote the whole of the inner or hidden Life and Activity of a period or a nation. I therefore put in a claim to start with the use of the English word, as sufficiently familiar to most of my readers, and request those who may object to the vagueness of the French

1 See 'Essays and Reviews,' 'Tendencies of Religious 'Thought in England, 1688-1750,' by Mark Pattison; also Leslie Stephen's re- marks on it in the Preface to his 'History of English Thought in the Eighteenth Century.' 
and German equivalents to look for a definition of $\mathrm{my}$ intention in the English word "Thought." I am not aware that French literature possesses any "histoire de la pensée," either of a longer or shorter period; I know of innumerable works in German which cover a similar field, but they have mostly used the word Weltanschaung, or expanded the meaning of Thought into the wider sense of a history of Civilisation (Kulturgeschichte) or narrowed it to that of Literature, proving-as it seems to me-

Want of precise tern in German and French.

$4 \%$ Conception of Thought nevertheless not specifically English.

45.

Carlyle the first to give a special meaning to the word Thought. the real want of a concise term such as the English language now supplies. And yet, I think I am right in saying that the conception of Thought, in the sense in which I am using it, is truly an outcome of international, not of specifically English progress, and belongs mainly to the period of which I am treating,--a period characterised, as I have already remarked, by the great interchange of ideas, by the breaking down of intellectual barriers, between the principal European nationalities. It was above all in the mind of Thomas Carlyle, who first among Englishmen made a profound study of the intellectual agencies which brought about the great change in modern Europe, that the conception formed itself of an intellectual and spiritual organism, underlying and moving external events. He first gave the peculiar sense to the word Thought, in which we here employ it, and made it an object of special study for those who came after him; an object, indeed, definable in various ways and to be contemplated from differing points of view, but yet a something, a power recognised by every one, and for which no better word could be invented. No other language has a word so comprehensive, denoting at once the process and 
the result, the parts and the ideal whole, of what is felt and meant: it commits us to no preconceived theory, can be used equally by thinkers of the most opposite views, and lends itself to any specialisation which may become necessary.

\section{II.}

Two processes have helped to determine the intellectual progress of mankind. These two processes have often been apparently opposed to each other in their intellectual operations; but in reality neither of them can proceed very far without calling the other into existence. They are the extension and the condensation of knowledge. Curiosity, the demands of practical life, the experiences of every day, all tend to an enlargement, to an accumulation of knowledge. Such growing knowledge is, however, of little avail if it be not readily grasped: the command of knowledge is as important as its accumulation. The more extensive the country which we wish to explore, the more we look out for elevated and commanding points of view, which permit us at a glance to overlook a wide landscape measuring the distance behind or the prospect before us. But, however enticing, these elevated views are frequently seductive and misleading. They permit us not only to look backward on the land which we have explored, giving us a clearer picture of its many features, of its winding paths, of the position of its separate objects - these elevated views present to us likewise the regions which we have not yet explored, and suggest the attempt to supersede the laborious process of further exploration 
by the more delightful venture of filling up the dim outlines which we see before us, with analogies of past experience or creations of our imagination. And even if we do descend into the plains and continue the minuter and more laborious search, we cannot rid ourselves of certain preconceived but frequently misleading ideas which the superficial glance has impressed on our minds.

The condensation may become an idealisation of knowledge. History affords numerous examples of these different stages of progress; centuries of dull accumulation, of unmethodical and ill-arranged learning, have been followed by short periods of enlightenment, by the triumphant shout of sudden discovery or the confident hope of invention. Patient work and real progress have for a long time been repressed by the allurements of seductive phantoms, which have had to be abandoned after an immense waste of labour. New prospects have suddenly opened the view into vast unexplored regions, heights have been gained from which the whole of human knowledge appeared for the moment condensed into a single truth or idealised into a vision, and again these delightful achievements have for a time appeared lost in an all-pervading discouragement and dismay.

2.

Object of the book.

3. Nineteenth century un. equalled in accumulation of
knowledge.

Whether our century has been characterised by any one or by a succession of several of these varying moods, is a question which I hope to answer in the sequel. For the present it is sufficient to note that in both directionsin that of accumulating and in that of condensing and idealising knowledge-the efforts of the nineteenth century have been many and conspicuous. In the former it is altogether unparalleled, whereas in the latter it has 
probably not equalled the ideal greatness of Greece in the Periclean age, the brilliancy of the Renaissance in Italy, or the great discoveries of the sixteenth and seventeenth centuries in France and England. But what our century has done is this; it has worked out and deposited in special terms of language a clearer view of the correct methods for extending knowledge, and a peculiar conception of its possible unity. At one time-and that not of know- $_{\text {ledge; }}^{a}$. un. very long ago-the word truth seemed to indicate to the ledge. seeker not only the right method and road for attaining knowledge, but also the end, the crown of knowledge. "Truth, and nothing but truth," seems still to the popular mind the right maxim for seeking knowledge-the whole truth stands before it as the unity of all knowledge, were it found. I think it is now sufficiently clear to the scientific inquirer, as well as to the philosopher, that love of truth, while it does indeed denote the moral attitude of the inquiring mind, is insufficient to define either the path or the end of knowledge. "What is truth?" is still the unsolved question. The criteria of truth are still unsettled. It would, indeed, be a sorrowful experience, a calamity of unparalleled magnitude, if ever the moral ideas of truth and faith should disappear out of the soul of either the active worker or the inquiring thinker; but it is with these as with other treasures of our moral nature, such as goodness and holiness, beauty and poetry_our knowledge of them does not begin, nor does it increase, by definition; and though in the unthinking years of our childhood we acquire and appropriate these moral possessions through the words of our mother-tongue, they rarely gain in depth or meaning by logical distinctions which we may learn, 
or to which we have to submit, in later life. These do not touch the essence, though very frequently they may succeed in destroying the depth, of our convictions.

In the place, then, of the high-sounding but indefinable search after truth, modern science has put an elaborate

Method of scientific inquiry. Practised first by Galileo, Newton, \&c., defined by Bacon, Comte, IIill, \&.c. method of inquiry: this method has to be learnt by patient practice, and not by listening to a description of it. It is laid down in the works of those modern heroes of science, from Galileo and Newton onward, who have practised it successfully, and from whose writings philosophers from Bacon to Comte and Mill have-not without misunderstanding and error-tried to extract the rationale. These methods will take up a large portion of our attention. For the moment it is important to note that the result or aim of scientific inquiry does not dictate the methods,- - the purely scientific inquirer does not know where the path will lead him: it is sufficient that it be clearly marked. Modern science defines the method, not the aim, of its work. It is based upon numbering and calculating-in short, upon mathematical processes; and the progress of science depends as much upon introducing mathematical notions into subjects which are apparently not mathematical, as upon the extension of mathematical methods and conceptions themselves. The terms "exact" and "positive" are current in the Continental and English languages to denote these methods and their application. Now to any one who does not stand in the midst of the scientific work of the age, it might appear as if by merely following Disintegra tion of learning only apa defined method which is capable of numerous modifications,- - by treading a clear path which in its course leads us to endless equally defined ramifications,- the scientific 
inquirer is losing daily more and more those elevated views, those points of condensation, those unifying and idealising aspects on which, as it seems to us, the command and grasp of knowledge depends. This is indeed almost inevitable so far as the older ideas are concerned. Unity of knowledge, order and harmony, even completeness and symmetry, truth and beauty, are indeed no longer of direct use as canons for the scientific inquirer, any more than the mysteries once supposed to be inherent in certain numbers. Though we still live under the charm of such entities, however much we may try to get rid of them, it must nevertheless be admitted that the poetical, philosophical, and religious aspects of things seem to recede into an increasing distance from the scientific; they do not guide scientific search; it does not receive from them much support. Have both sides been losers by this change? So far as science is concerned, it can claim to have attained by it not only a greater formal completeness and certainty of progress, but also another very important advantage which was unknown to ancient and mediæval research.

This advantage consists in the closer connection between science and practical life. The same mathematical spirit which governs scientific methods rules also in trade, Closer con. nection between science and commerce, and industry, and is gradually penetrating into the professions, such as medicine, law, and administration. For all these pursuits have either directly to do with numbers, measures, and weights, with distances of space and time, or they have found it necessary to introduce an elaborate system of statistics and averages through which the irregularity and captiousness of subjective and individual influences are practically eliminated. The 
problems of scientific research have thus enormously increased; each advance in science increases our command of certain measurable phenomena in practical life; each new development in the latter prepares a new field for scientific inquiry. The contact between science and life has become more intimate in the course of our century. This to a great extent has counterbalanced the tendency of modern scientific method, which, operating alone, would have led to endless specialisation; for it is the peculiarity 10. Solidarity of
all pratcical the same way as scientific experiments-that they, in fact,
problems. force upon us the necessity of looking at a large number of surrounding and extraneous circumstances, at the totality of life and its interests. ${ }^{1}$

If our century can claim to have firmly established exact or positive methods in science and life, and to have furthered in this way the interests of both, the question 11. remains, Has nothing been done to uphold those older, What has the
nineteentl those time-hallowed ideals of truth, beauty, and wisdom century done for the ideals of life? which to former ages seemed to denote the unifying and harmonising principles of science and life? What has become of philosophy, art, and religion, which were once intrusted with the special care of those ideals, charged with preventing the falling asunder of the many branches of knowledge and practice, and expected to save us from a loss of the belief in the integrity, interdependence, and co-operation of all human interests?

${ }^{1}$ Science deals with things in the abstract, in their isolation, in vacuo. Practical life deals with the same things in their position in the real world, surrounded by other things.
In this distinction lies the value of Lotze's definition of the reality of a thing as "a standing in relation," viz., to other things, to all things. See 'Microcosmus,' book ix. 
Unless I believed that our age was elaborating a deeper and more significant conception of this unity of all human interests, of the inner mental life of man and mankind, I Deeper conception of the unity of human do not think I should have deemed it worth while to write the following volumes: for it is really their main end and principal object to trace the co-operation of many agencies in the higher work of our century; the growing conviction that all mental efforts combine together to produce and uphold the ideal possessions of our race; that it is not in one special direction nor under one specific term that this treasure can be cultivated, but that individuals and peoples in their combined international life exhibit and perpetuate it.

A number of words have during this century been introduced by various systems of philosophy to denote this Different terms for expressing unity of the inner life of mankind: Hegel's Geist, Comte's this unity. Humanity, Lotze's Microcosm, Spencer's Social Organism, all refer to special sides and aspects of the same subject. And it is interesting to note how the great schools of Idealism in Germany, of Positivism in France, of Evolution-physical and mental-in England, and-in spite of their apparently disintegrating tendencies-how the social changes of the Revolution and the specialisations of science have all combined to emphasise this unity of human life and interests. To show this in detail is the object I have in view. So far we have not committed ourselves to any of the many existing theories: the word Thought seems to me to be capable of the widest application, and to denote Detinition in the most catholic spirit whatever of truth and value may be contained in the combined aim and endeavour of VOL. I. 
all these modern aspirations. A history of this thought will be a definition of Thought itself.

Much has been done in the course of this century to prepare for an undertaking such as the one before me. It will be well to review shortly this special side of modern literature. We have indeed passed out of what may be

15. 1750 to 1550 . The age of encyclopre. dic treatment of learning.

called the age of encyclopædic treatment of learning-the hundred years from the middle of the last to the middle of the present century. ${ }^{1}$ The plan of such an arrangement of knowledge belongs to an earlier period, the period immediately succeeding the birth of modern science. Lord Bacon was the father of it, but neither he nor the most encyclopædic intellect of modern times, Leibniz, did much to realise the idea, and it was reserved for the genius and the labours of Diderot and d'Alembert ${ }^{2}$ in France, in the

1 " Encyclopædiæ nomen hodie frequentius auditur quam alias." Gessner in Göttinger Lections-Kata$\log$ for 1756 .

"Diderot's "Prospectus" to the 'Encyclopédie' appeared 1750 ; the first volume appeared 1751 with the celebrated "Discours préliminaire" of d'Alembert and a reprint of the "Prospectus." The complete title was 'Encjclopédie ou dictionnaire raisonné des sciences, des arts et métiers, par une société de gens de lettres, mis en ordre et publié par Diderot et d'Alembert.' The principles which guided the editors, and the object of the work, are explained, with repeated references to Lord Bacon, in this introduction, as well as in the article "Encyclopédie," in the fifth volume (1755), which was written by Diderot, and occupied 28 pages. See also Diderot's 'Pensées sur l'interprétation de la Nature,' published anonymously in 1754 .
Copious details about the history, the reception, and the influence of the 'Encyclopédie' are to be found in the correspondence and memoirs of Grimm, d'Alembert, and Voltaire, Madame d'Épinay, the Abbé Morellet, and many others. They are combined into a concise narrative, giving all the important facts, in Rosenkranz's 'Leben und Werke Diderots,' 2 vols., Leipzig, 1866, and in John Morley's 'Diderot.'

It is interesting to note how the idea of the unifying and life-giving influence of thought was as familiar to Diderot as it is to us: "Si l'on bannit l'homme ou l'être pensant et contemplateur de dessus la surface de la terre; ce spectacle pathétique et sublime de la nature n'est plus qu'une scène triste et muette. L'univers se tait; le silence et la nuit s'en emparent. Tout se change en une vaste solitude, où les phénomènes inobservés se passent d'une manière obscure et sourde. . . . 
middle of the eighteenth century, to carry out the plan, foreshadowed in the 'Novum Organum,' of collecting all knowledge, which had been accumulated ever since science had been liberated from the fetters of theology, into one comprehensive whole. It must, however, be admitted that whilst the practical end of these laborious undertakings, the diffusion of knowledge, has certainly been greatly furthered, the original idea, that the sum of human knowledge is an organic whole, has in the execution been by degrees entirely lost sight of. The unity works. of thought and knowledge was indeed referred to in Diderot's "Prospectus" and d'Alembert's “Discours préliminaire," and in the introduction to Ersch and Gruber's great Encyclopædia, ${ }^{1}$ as also in Coleridge's celebrated essay

Voilà ce qui nous a déterminé à chercher dans les facultés principales de l'homme la division générale ì laquelle nous avons subordonné notre travail."-Article "Encyclopédie," p. 641.

${ }^{1}$ Ersch und Gruber's 'Allgemeine Encyclopädie der Wissenschaften und Künste,' Leipzig, 1818 to 1875 , unfinished, 151 vols. It was founded by Professor Johann Samuel Ersch, librarian at Halle in 1813, assisted by Hufeland, Gruber, Meier, and Brockhaus, and contained contributions by the most learned and eminent Germans of the century. It is interesting to compare the plan and principles which guided the editors, as expounded in the in. troductions to the first and second volumes, with the corresponding dissertations prefixed to the 'Encyclopédie' in France and the 'Encyclopæedia Metropolitana' in England. The unity aimed at by Bacon was either purely formal, securing only uniformity and completeness of treatment, or it was that of prac- tical usefulness-the philosophy of fruit and progress. The plan adopted by Diderot and d'Alembert could hardly attain anything more than this. Coleridge, nursed in German philosophy, and deeply impressed with the fact that there is a higher view than that of Lord Bacon, and that such is to be found rather in writers like Plato and Shakespeare, uses the word method in a mucl wider sepse. He was deeply affected by the spirit of the idealistic philosophy, which was foreign to Bacon and unduly despised by him.

In the idealistic systems of the Continent, beginning with Kant, the opinion was current that the methods and treatment of science alone were insufficient to close the circle of knowledge. The truly encyclopædic view was only possible in a scientific investigation specially carried on for that purpose, and this was considered to be one of the main objects of philosophy. Thus Kant in many passages of his works, notably vol. ii. pp. 377,378 ,
16. knowledge gradually lost sight of in encyclo- 
on the science of method prefixed to the 'Encyclopædia Metropolitana'; but the result has shown, what was not evident to Lord Bacon, that neither a systematic division of learning according to some logical principle, nor the historical identity of the beginnings of all branches of knowledge, can in the end preserve the real unity and integrity of thought. The work of the advancement of learning, if it be once handed over to different sciences and intrusted to separate labourers, does not proceed in a cycle which runs back into itself, but rather in the rings of an ever-increasing spiral, receding more and more from the common origin. Such is the impression we get if we contemplate the unfinished ${ }^{1}$ rows of Ersch and Gruber's

613 ; vol. iii. pp. 188,212 ; vol. v. p. 312 (Rosenkranz's edition), especially the two following: "Philosophy is the only science which can procure for us inner satisfaction, for she closes the scientific cycle, and through her only do the sciences receive order and connection." And: "Mere ' $\pi 0 \lambda v \iota \sigma \tau o \rho i \alpha$ ' is a cyclopean learning which wants one eye-the eye of Philosophy-and a cyclops among mathematicians, historians, naturalists, philologists, and linguists, is a scholar who is great in all these lines, but having these considers all philosophy as superfluous." Still, with Kant Philosophy is not an "instrument for the extension," but merely a study of "the limits of knowledge" ; she does not "discover truth," but only "prevents error." This modest definition was given up in the systems of Fichte, Schelling, and Hegel, who maintained that a certain kind of-and this the highest - knowledge could be attained by starting from one highest principle deductively : the all-embracing, encyclopadic character of philoso- phical, speculative knowledge was increasingly emphasised, and this not only in special lectures on the subject, as in Fichte's lectures on "The Nature of the Scholar," in Schelling's on "The Method of Academic Study," in Hegel's 'Encyclopædia of Philosophy,' but also in the regeneration and reform of many older and in the foundation of new unirersities and academies throughout Germany. The great 'Encyclopædia' of Ersch and Gruber was planned in a similar spirit, as the reform of university teaching and of academic learning. This reform has been of the greatest importance to the German nation and to the interests of science and knowledge. The Encyclopædia, on the other hand, has remained incomplete, a huge but abortive attempt to combine not only the principles of knowledge, but also the colossal and growing volume of it, into a systematic whole.

1 The promoters of it were evidently not sufficiently impressed with the two very essential conditions which make a work of this 
volumes, or if we recognise the fact that the more useful and popular publications of our day have abandoned the philosophical introductions and preliminary discourses ${ }^{1}$ by which the earlier works preserved a semblance of unity and method, and are contented to be merely useful dictionaries of reference. The encyclopædic treatment of knowledge, the execution of Lord Bacon's scheme, has shown that the extension and application of learning leads to the disintegration, not to the unification, of knowledge and thought. A conviction of this sort is no doubt the reason why in German universities lectures on "Encyclopädie" have been abandoned." They were very general and popular in the earlier years of the century, when, under the influence of Kant, Fichte, and

kind useful-viz., that it must be finished, however imperfect it may be, and that it must be completed within a limited time, on account of the revolutions and smaller changes in thought and knowledge. These essential conditions were always before the mind of Diderot. See his article "Encyclopédie," pp. 636-644.

1 The object of the philosophical introductions has in course of this century been much more completely attained by such works as Mill's 'Logic' and Jevons's 'Principles of Science'; whilst the "preliminary dissertations," such as were contained in the older editions of the 'Encyclopædia Britannica,' have been partially superseded by works like Whewell's 'History' and his 'Philosophy of the Inductive Sciences,' in which the common origin, the genesis, the continuous development and interdependence of the different sciences, are traced. The value in this respect of an undertaking like that of the Royal Ba- varian Academy ("Geschichte der Wissenschaften in Deutschland,' vol. i., 1864 : it has now reached 22 rols., the science of War significantly filling three large volumes, that of Mathematics one small one) is much diminished by the title suggesting that science is a national, not a cosmopolitan or international concern. Fortunately many of the contributors to this important and highly useful publication lave not limited their narratives to purely German science, but have largely taken notice of non-German research. Special reports on the state of any science or branch of science in a nation have, of course, quite a different meaning and value.

2 The term is still in use for courses of lectures giving a general and comprehensive view of special sciences : thus, "Encyclopädie des Rechts, der Medicin, der Philologie, der Philosophie, der Theologie."
17. Lectures on "Encyclopädie" abandoned in German universities. 
Schleiermacher, university teaching and learning entered on a new era, in which the idea prevailed that completeness, universality, and unity of knowledge could be secured by one and the same arrangement of study. ${ }^{1}$ It was the age when philosophy for the last time had got a firm hold of all departments of knowledge, and permeated all scientific pursuits $;{ }^{2}$ when, favoured by political events,

${ }^{1}$ On this subject the literature connected with the foundation of the University of Berlin in the year 1809 is of special interest. It was essentially the creation of Wilhelm von Humboldt, though prepared by Wolf and Beyme in 1807. See Seeley, 'Life of Stein,' vol. ii. p. 430 sqq.; Haym, 'Leben W. v. Humboldts,' p. 270 sqq. The foundation of this university in the year of Prussia's greatest misery, when the first gleams of liberty in the rising of Spain and the success of Aspern had been extinguished by the defeat of Wagram, the voting of $£ 22,500$ per annum for the purposes of the new University and the Academy of Science and Arts, when a crushing war-tax hung over the country, when land was depreciated, the necessaries of life at famine prices, the currency of the country at a large discount, when every one, from the king to the lowest subject, was forced into sacrifices and economies of every kind, was an act as heroic as the great deeds on the battle-field, and as farseeing as the measures of Stein and Scharnhorst. Interesting from our point of view are the ideas of Fichte on university teaching and academic learning, laid down in his 'Deducirter Plan einer zu Berlin zu errichtenden höheren Lehranstalt,' written at the request of the minister Beyme in 1807. In it a great deal is said about encyclopredic treatment. The question of the position of philosophy in the encjclopredic or academic treatment of knowledge was easily solved in the Kantian school, to which most of the abovementioned writers belonged. Later on in the school of Schelling it became more difficult. It was frequently discussed by Schelling him. self, who was one of those that initiated the new era in the Academy of Munich, which was remodelled in the year 1807. See, inter alia, Schelling's essay, "Suggestions concerning the Occupation of the Philologico-Philosophical Class" of the Academy, and especially the following remarkable passage (Werke, rol. viii. p. 464) : "If, indeed, Philosophy were denied living contact with real things, if she were obliged to soar in transcendent regions without end and measure, and to rise a hungry guest from the well-appointed table of Nature and Art, of History and Life; then it would be incomprehensible how she could still find so much support as to be received in an academy, and it would be much better if we also followed the path of other nations, who hare lately said good-bye to all philosophy, and have thrown themselves, with the most glowing ardour, upon the exploration of Nature and Reality in every direction."

2 The principal representatives of the encyclopredic teaching at the German unirersities were Eschenburg, Krug, and Gruber. The latter, in his introduction to the 
ideal aims, a generous spirit of self-sacrifice, and a feeling of one common duty pervaded the German nation, and foremost in it the teachers and students of the German universities. ${ }^{1}$ This spirit, as it produced co-operation and unity of action, also favoured unity of thought, and contributed much to the popularity of several philosophical systems which promised more than they could give. Encyclopædic surveys were then supposed to be more Encyclo pædias did not fulfil than the empty shell, the mere skeleton of learning appeared which they have since proved to be; they were looked upon as being able to grasp and convey the living spirit of knowledge. This phase of thought, which in the sequel will largely command our attention, has dis-

second volume of Ersch and Gruber's 'Encyclopïdie,' gives a definition and history of encyclopredic study, which, according to him, was introduced into the modern (German) universities together with the philosophical faculty. In the beginning this was subservient to the three ligher faculties (theology, law, and medicine), but gradually took the lead. He argues that only since university studies have become encyclopxdic can they be considered as furthering true humanity. $\mathrm{He}$ refers to the great crisis through which in the beginning of the century literature, science, and arts were passing (p. li), and mentions the conflicting principles in the treatment of mathematics, physics, history, philosophy, and philology. Vid. also the 'Vorbericht,' vol. i. p. vii.

1 Among the mass of literature dealing with this subject, the 'Memoirs of Frederick Perthes,' by his son (English translation, vol. i. chap. xi. sqq.), and Steffens's 'Autobiography ' ('W as ich erlebte,'
Breslau, 1840-44, 10 vols.), give the most vivid and exhaustive accounts. Neither Stein, the great statesman, nor Goethe, the great poet and thinker of the age, took part in this alliance of the patriotic and intellectual interests of the German nation. Stein's attitude to the idealism of the age is defined by Seeley, 'Life of Stein' (vol. i. p. 30, "It is desirable to mark that between him and the literature and philosophy of his time and country there was no connection at all "), and is expressed in a remarkable conversation which he had with Steffens, March 1813, at Breslau (quoted by Seeley, vol. iii. p. 119 ; Steffens, vol. vii. p. 120 sqq.) Goethe's position is defined by his reply to the invitation to contribute to the 'Deutsches Museum,' a periodical planned by the bookseller Perthes. It was to be a scientific alliance of all the intellect of Germany, and was in time "to be transformed into a political one possessing the strength and union necessary for vigorous action " (Perthes' Memoirs, vol. i. p. 167). 
appeared; the second half of our century does not expect to find the essence of knowledge condensed in any philosophical formula, any more than it expects to find the real unity and integrity of thought preserved in the fragmentary articles of an alphabetical dictionary. The purpose of the latter is purely practical; it is a popular and handy instrument for the diffusion of knowledge, whilst philosophical divisions are merely formal, and at best are applicable only to a narrow and limited sphere of research. ${ }^{1}$

The age of encyclopædic representation of learning and the short period of philosophical formalism seem both to belong to the past; but the desire of bringing together what is scattered, of focussing knowledge and learning, and of realising the organic continuity and unity of thought and progress, is as great as, perhaps greater than ever. Neither the shapelessness of a huge dictionary nor the barrenness of a concise formula will satisfy the deeper

1 It is interesting to observe the development and spread of encyclopredic learning in the three countries. Encyclopxdias in the modern sense hare their origin, like so many other modern institutions and ideas, in England. They were there compiled mainly for practical purposes. France took up the scheme in a philosophical spirit, and carried it as far as it is capable of being carried under this aspect. Attempts to improve and amplify the plan proved impracticable; and when subjected to the vast erudition of Germany, it became evident that unity, depth, and breadth of view could not be maintained. In course of this century the country which produced the classical era of encyclopædism has done least for encyclopædic learning. This has now its home in Germany, where encyclopædic labours have been specialised, and where every science is represented by some compilation or annual register aiming at collecting and systematically arranging the scattered contributions of the whole world. But it would be ungrateful not to mention the Royal Society's catalogue of scientific papers, and the services which America has rendered in summarising the literary productions of the English-speaking nations in such works as Poole's 'Index to Periodical Literature.' Without the aid of such laborious compilations the present work could not have been undertaken. 
conviction that all mental work is living, individual, and of endless variety. To stimulate individual thought, to bring about life and change, is nowadays felt to be quite as necessary as to insist on method, system, and order. Prompted by this conviction, the last fifty years have done much to facilitate intellectual interchange, and to record the historical development of all branches of science.

This object has been promoted in three different ways. The French, who in the beginning of the period were the masters in science, led the way by founding a series of periodicals devoted to the development of separate sciences. Germany followed, and still later England. ${ }^{1}$ A living in-

19. French were the masters in science at the beginning of the century.
1 The oldest scientific periodical is the 'Journal des Savants,' which was started in 1665 in Paris; next to it comes probably Rozier's ' $\mathrm{Ob}$ servations sur la Physique' (1771), continued under the title 'Journal de Physique' (1778, continued with interruptions from $1794-95$ till 1823). In opposition to this journal, which defended the older phlogistic theories in chemistry, the 'Annales de Chimie' were started in 1789 by Berthollet, Guyton de Morveau, and Fourcroy, as an organ of Lavoisier's ideas. In 1788 the Société Philomatique started its 'Bulletin,' and in 1795 the 'Journal de l'École Poly. technique' started its influential career. No such periodicals existed for special sciences at that time in any other country, if we perhaps except the "Transactions of the Royal Linnaan Society, which started in 1791. 'Nicholson's Journal' started in 1797; the 'London, Edinburgh, and Dublin Philosophical Magazine and Journal of Sciences' had its origin in Tilloch's 'Philosophical Magazine'; but the first journal devoted specially to mathematical sciences in England was probably the 'Cambridge $\mathrm{Ma}$ thematical Journal,' started in 1839. In the meantime the number of scientific journals in France had grown enormously. In Germany we have Crell's 'Chemische Annalen' (1778), Gehlen's 'Allgemeines Journal für Chemie' (1803), Gren's 'Journal der Physik' (1790), Gilbert's 'Annalen der Physik' (1799), Zach's 'Monatliche Correspondenz' (1800), Crelle's 'Journal für die reine und angewandte Mathematik ' (1826), and many others, all periodicals of the first importance. The 'Transactions of the Royal Society,' which of course contain many of the valuable scientific contributions of this country, can nevertheless hardly be looked upon as a repository of the work of English mathematicians and physicists of the period in question,--not even as much as the Memoirs of the Paris Academy in France. In Great Britain a new centre of scientific and literary work existed during the latter part of the last century 
tercourse between men of science was greatly promoted by the British Association for the Advancement of Science, which held its first meeting at York in 1831. Associations and meetings of this kind had their origin ten years earlier in Germany through Oken ; ${ }^{1}$ but the line in which Germany has done most is the establishing of and continuing annual Reports ${ }^{2}$ of the progress of the different

in Edinburgh ("Transactions of the Royal Society of Edinburgh,' started in 1788), and somewhat later likewise in Dublin ("Transactions of the Royal Society of Dublin,' started 1799), and Manchester ('Memoirs of the Manchester Philosophical Society,' started in 1789). Many of the first scientific writers of the age published in these provincial papers or in separate pampliletsthe want of a common collecting centre being very obvious.

1 Alexander v. Humboldt supported them, and was instrumental in giving to the Assembly at Berlin in 1828 - which he called "The inrasion of philosophers"-a special importance. It was, as he says, "a noble manifestation of scientific union in Germany ; it presents the spectacle of a nation divided in politics and religion, rerealing its nationality in the realm of intellectual progress."-Bruhns, "Life of A. v. Humboldt,' vol. ii. p. 130. The British Association for the Advancement of Science was (as Prof. Owen informs us) at the outset avowedly organised after the Okenian model.- "Encyclopadia Britannica,' art. " Oken."

2 The first reports aiming at giring a statement of the position of Science were those drawn up by Delambre and Cuvier at the request of the Emperor Napoleon I., and presented in the year 1808 under the title 'Discours sur les Progrès des Sciences, Lettres, et Arts depuis
1789 jusqu'à ce jour' (1808). They were imitated on a larger scale by the Emperor Napoleon III., on the occasion of the great Paris Exhibition 1867 , and have been continued under the Republic. Of the report of 1808 Cuvier says, "Ce tableau historique nous servira désormais de point de départ et nos rapports annuels en seront autant de continuations." $\mathrm{He}$ also adds significantly, "Dans les relations actives où nous nous trourons arec la plupart de ceux qui cultivent les sciences, il est bien difficile qu'ils se fassent en Europe quelques découvertes importantes sans que le bruit en retentisse promptement dans cette enceinte, et nous excite a des traraux qui s'y rapportent plus ou moins directement."

By far the most important work of reporting and summarising the results of scientific labour has been done by Germany. The first publication of this kind, however, originated with Berzelius, who from the year 1821 reported regularly to the Academy of Stockholm on the progress of the physical sciences. Of Berzelius's periodical Kopp says ('Geschichte der Chemie,' vol. i. p. 403), that it "summarises with the greatest completeness all that had been done in chemistry since 1820." This work, which regularly appeared in German translation, was continued in Liebig's 'Jahresbericht der Chemie' (1847). In Berlin the 'Physikalische Gesellschaft' has 
sciences, in which all scientific researches are-without regard to nationality - reviewed, classified, and arranged in the most complete manner, according to the place which they occupy in the general development. Invaluable service has also been done in England by special Reports or Addresses, prepared by men of the greatest eminence-frequently at the request of the British Association-in which the position of special branches of science is explained, the work of the past summed up, the leading principles clearly brought out, and the unsolved problems placed prominently before the minds of young and aspiring workers.

In Germany during the first half of the century a reaction set in against the metaphysical treatment of scientific subjects, which had been exaggerated in the schools of Schelling and Hegel Experimental research of scientific following mainly the great French and English models, was next favoured, and through the establishment of laboratories and observatories, through voyages of discovery and the application of science to the industries, an enormous amount of detailed and minute knowledge was accumulated. ${ }^{1}$ For a time-even within the limits

continued to issue regularly since 1845 annual Reports under the title 'Fortschritte der Physik.' But it was only in 1868 that a similar annual was started in Berlin having reference to mathematics, under the title 'Fortschritte der Mathematik.' A 'Jahresbericht' on Zoology has appeared ever since 1879 , and one on Botany since 1873.

1 It was the age which compiled the great repositories of chemical knowledge. Such were Gmelin's 'Handbuch der Chemie' (1st ed., 1817. Translated into English by the Cavendish Society, 1848), and the 'Handwörterbuch der reinen und angewandten Chemie' (edited by Liebig jointly with Poggendorf and Wöhler, 1837). The same age also set going and filled the rolumes of Liebig's 'Annalen' (started by Hänle in 1823 under the title 'Magazin der Pharmacie,' it finally assumed the title of 'Annalen der Chemie und Pharmacie' under Liebig's editorship), of Poggendorf's 'Annalen der Physik und Chemie' (1824), and the 'Annales de Chimie et de Physique.' 
of exact reasoning - attempts to condense and unify knowledge were discredited. The result-especially in Germany - was that in many sciences information became buried in periodicals and in the memoirs of learned societies: text-books were chiefly written by men of secondary importance, translated from the French and English, and frequently on somewhat antiquated lines. ${ }^{1}$ The new spirit which began to leaven scientific research in the middle of the century was confined to a few master minds, who-frequently almost unknown-marched in advance of their age. In the course of the last thirty years this has been entirely changed. The means of intercourse and communication, referred to above, make scientific isolation almost impossible; the necessity has

21. been felt of remodelling the whole of the popular school literature on more modern lines: some of the first inature.

1 The greater part of the higher German school literature in mathematics and physics was supplied by the French or modelled on French ideas-Legendre and Monge in elementary and descriptive geometry, Lacroix in the higher branches. Francœur's course of mathematics was introduced in England as well as Germauy ; Poisson, and later Lagrange and Duhamel, became the models in mechanics, Biot and Pouillet in experimental physics, Regnault in chemistry. The only great popular authorities which clid not belong to France were Berzelius and Graham in chem. istry, and Euler in mathematics. As late as 1860 hardly any textbook existed in Germany on the theoretical and mathematical portions of physics. The second volume of 'Baumgartner' was a miserable compilation. Beer's 'Höhere Optik' was the first im- portant work of this kind. Germany had indeed not been wanting in original research, but the new ideas of Möbius, Steiner, Staudt, Pliicker, and Grassmann in geometry found no adherents till, mainly through the translation of Sal. mon's text-books by Fiedler, a new spirit came over geometrical teaching. In the meantime Lejeune Dirichlet, and Neumann the elder, cultiratel in their academical lectures the higher branches of mathematical physics, and educated a whole generation of mathematicians and physicists., Through them the original researches of Gauss and Jacobi became better known, and an independent school of Germau mathematical thought was established. In England the influence of French science was much more limited, and to the present day Euclid is preferred to Legendre's more elegant methods. 
tellects in science have condescended to write text-books of their subjects, by which a great reform has been brought about in the higher scientific literature. ${ }^{1}$ At the same time - after fifty years of experimental research and accumulation of material-it has become necessary to review the fundamental principles on which scientific reasoning rests: a more philosophical, not to say metaphysical, spirit is manifesting itself within the limits of science. ${ }^{2}$ In the Scientific reasoning more philoabstract, and especially the mathematical, sciences, real progress depends now mainly upon the discovery of methods of simplification, on conciseness and elegance of treatment, and on the discovery of unifying principles and generalising aspects. ${ }^{3}$

1 This remark refers mainly to England and Germany. In France, as a result of giving lectures at the École Polytechnique, the Bureau des Longitudes, the Faculté des Sciences, \&c., the great mathematicians and physicists of the century have frequently worked up their researches in connected treatises. For such we are indebted to Lamé, Cauchy, Poncelet, and many others. But the two works which in Eng. land and Germany created probably the greatest reform in the teaching of the principles of natural philosophy were Thomson and Tait's 'Natural Philosophy' (first sketch, 1863, 1st ed., 1867) and Kirchloff's 'Vorlesungen über Mechanik' (Leipzig, 1877).

II refer principally to the various writings of Helmholtz, following those of Riemann, and the many hints thrown out in Gauss's published papers, and in his correspondence with Schumacher. Helmholtz has-of all purely scientific writers - paid most attention to the metaphysical foundations of geometry and dynamics, and has critically examined the earlier theories of Kant, published a century ago. It is interesting in this respect to note what Kant is reported to have said to Stägemann in 1797: "I have come with my writings a century too soon; after a hundred years people will begin to understand me rightly, and will then study my books anew and appreciate them." (Vid. 'Tagebücher,' von Varnhagen von Ense, Leipzig, 1861, vol. i. 队. 46.) Next to Helmholtz we are most indebted to Emil du BoisReymond and his brother Paul. See Emil's 'Reden' (Leipzig, 188687,2 vols.), and the posthumous work of his brother: "Ueber die Grundlagen der Erkenntniss in den exacten Wissenschaften ' (Tübingen, 1890).

${ }^{3}$ An authority on this subject says: "Generality of aspects and methods, precision and elegance of exposition, have, since the time of Lagrange, become the common property of those who claim to be scientific mathematicians. This 
All these are merely external signs of the new life, indications of progress and change: the inner reason and result, the altered ways of thinking which underlie or are produced by these external changes, will be the object of closer study hereafter; they constitute the real substance of this work. What I draw attention to here, by way of introduction, are merely fingers on the dialplate of a complicated clock-work : their motion and position are patent to every one. Later on I shall invite the reader to remove the outer case, and try with me to understand the delicate working parts and the principle of the mechanism, the prime mover and the mode of transmission of motion within. The general curiosity that exists to follow the internal and hidden workings of thought is manifested especially in that country which in modern history has frequently taken the lead in philosophical reasoning.

23. Germany has taken the lead in studying the life of thought.

It is manifested by the huge and increasing historical literature of Germany, which is devoted to tracing out the growth and development of modern science and thought. In that country history seems for the moment to have taken the place of metaphysical speculation. A similar transition from the logical to the historical view can be traced in English literature in the last century, the

generality is sometimes exaggerated at the expense of simplicity and usefulness, and then leads to $a b$ struseness and to the enunciation of theorems which have no special application; precision may degenerate into an affected brevity which renders a dissertation more difficult to read than to write; elegance of form has in our days almost become the test of the value of a theorem. Yet in spite of all draw. backs these conditions of efficient progress are of the greatest importance, inasmuch as they keep the scientific matter within those limits which are intrinsically necessary if mathematical research is not to lose itself in minutiæ or be drowned in over-abundance." - Hankel, 'Die Entwickelung der Mathematik in den letzten Jahrhunderten' (Tiibingen, 1869). 
typical representative of that change being David Hume, who, starting with the metaphysical problems involved in Locke's and Berkeley's writings, was from them led on to the study of moral, political, and economic questions, and ended by devoting himself to the study of history. ${ }^{1}$ At the end of his career political and historical writings were as frequent in English literature as metaphysical and theological writings had been at the beginning. The causes which have effected the same transition from the metaphysical to the historical mode of treatment in Germany during the present century are similar to those existing in England in the last century; but the whole movement has taken place on a larger scale, penetrates deeper into the mental life and work of the nation, and cannot be so easily studied in the writings of any great representative.

Whilst in Germany historical studies are now foremost,

I I am quite aware that generalisations of this kind must be made and used with great caution. I therefore refer my readers to Leslie Stephen's 'History of English Thought in the Eighteenth Century,' especially to the Introduction, where the typical position of Hume is fully discussed, and also to the last chapter of the second volume, where he says of Hume (vol.ii. p. 381, Ist ed.): "Hume was, in one sense, far in advance of his time, and indeed of the average opinion of the present time. But the change may in many respects be described as a revolt from Hume's opinions, much more than a development of them. . . . The history of philosophical and of theological opinion in England is a history of gradual decay down to the revolutionary era." And p. 444 : "The last half of the century was pre-eminently historical. As civilisation progresses, as records are better preseryed, and a greater permanence in social organisation makes men more disposed to look beyond their immediate surroundings, a tendency to historical inquiry is naturally awakened. This cause alone, without the more philosophical considerations which might lead a Hume or a Gibbon to turn from abstract investigations to historical inquiries, may account for the growth of antiquarianism in the latter years." But the mere statistics of English literature in the eighteenth century suffice to prove the decline of argumentative and the growth of realistic literature.
24. Causes of transition from meta. physical to historical method. 
and have almost dislodged systematic philosophy, England has for the first time in her history produced a system 25. of philosophy - that of Mr Herbert Spencer; and this with Spencert the the distinct understanding that the object of philosophy first Eng. lishman who is the unification of knowledge. ${ }^{1}$ It is a remarkable fact, duced a system of philosophy. which will occupy our close attention hereafter, that the unifying principle in this system is historical,- - a process of development now specially known under the term Evolution. This system forms in a certain way a contrast to the last great system in German philosophy, that of Hermann Lotze. Whereas in all systems of evolution the unity of things is historical, and has to be sought in

26. Definition of Lotze's system. their common origin, Lotze emphasises the truth that unity must be a living presence, a principle which exists in individual things, not merely a link which connects them by proximity in time or space. His object is to answer the question, How can the human mind represent to itself such a living unity, in what ideas

${ }^{1}$ Vid.G. H. Lewes ('Problems of Life and Mind,' 1st ed., vol. i. p. 84), who says: "The absence of a philosophy in England during the last two hundred years has been a serious defect in her culture. Science she has had, and poetry and literature, rivalling when not surpassing those of other nations. But a philosophy she has not had, in spite of philosophic thinkers of epoch - making power. Hobbes, Locke, Berkeley, Hume, have produced essays, not systems. There has been no noteworthy attempt to give a conception of the world, of man, and of society, wrought out with systematic harmonising of principles. There has not been an effort to systematise the scattered labours of isolated thinkers. Mr Herbert Spencer is now for the first time deliberately making the attempt to found a philosophy." And in his "History of Philosophy' (3d ed., vol. ii. p. 653) the same author says: " $\mathrm{Mr}$ Spencer alone of British thinkers has organised a system of philosophy." Croom Robertson would take exception to this in favour of Hobbes, "who attempted a task which no other adherent of the 'mechanical philosophy' conceived -nothing less than such a universal construction of human knowledge as would bring Society and Man within the same principles of scientific explanation as were found applicable to the world of Nature" (Ency. Brit., 9th ed., vol. xii. p. 39). 
belonging to human thought can this unity be grasped, by what words of human speech can it be expressed?

Both Mr Herbert Spencer's 'System ' and Lotze's 'Microcosmus' are written with the object of establishing the unity of thought, of preserving the conviction that things exist and that events happen in some intelligible connection, and especially that the religious and the scientific views of the world and life are reconcilable. But whereas $\mathrm{Mr}$ Spencer is content to point to the underlying unity as the Unknowable, and then betakes himself to the study and exposition of the manner in which events follow and things develop, Lotze considers the whole of this part of philosophy as merely an introduction to the solution of the real problem. To him a process of development is merely the outer form in which some real substance presents itself, a mechanical method by which something of higher value is accomplished. He admits the all-pervading rule of such a mechanism, but he urges the necessity of finding the substance itself, and of gaining a view of the end and aim which is to be attained by this array of processes, by this parade of mechanical means, of the interest that attaches to them, and the result which is to be secured. ${ }^{1}$ Knowing the mechanism by which a certain object is accomplished, we may be able to calculate phenomena and events, but to understand ${ }^{2}$ them requires a

1 The earliest passage in which Lotze gives us a pretty complete idea of his philosophical methods and aims is to be found in his polemical pamphlet against Fichte the younger ('Streitschriften,' Leipzig, 1857 , p. 52 sqq.) He there also reviews his attitude to the idealistic school of German Philosophy and to Herbart, whose follower he refuses to be called (ibid., p. 5 sq.) It is evident that at that time his system was not yet definitely settled in his mind (p. 58).

2 The difference between calculating and understanding phenomena is probably to be traced to Leibniz. Lotze emphasises this difference.

VOI. I. 
further knowledge of the worth of the object which is accomplished, of the result which is gained by the calculation. It is one thing to be able to trace the mechanical conditions upon which the accuracy of a clock depends; it is another to mark the hour which the clock strikes, and to note the time which it measures out to us for our work. Curiosity will lead a child to pry into the former; but the latter depends on our appreciation of the objects of life and the seriousness of our duties.

27. Lotze's relation to Herder's 'Ideen.'

When Lotze undertook to write the 'Microcosmus,' he referred to two great works of a kindred tendency. Both attempted, yet in very different ways, to give a comprehensive view of a large field of scattered phenomena, to take in at a glance the entire scheme of a great world of facts. The earlier of the two belonged to the last century and was concerned with history, with the uniting bond of all human development. For this Herder, in his 'Ideen zur Philosophie der Geschichte der Menschheit,' had, if not invented, yet endowed the term Humanity with a specific pregnancy, meaning by it the unity of all human interests in their social and historical development-an idea which since Leibniz has goverued German literature. ${ }^{1}$ The other

See, inter alia, the closing paragraph of the first volume of the 'System der Philosophie' (1st ed., Leipzig, 1874). I cannot omit to notice here the extraordinary and misleading misprint in Erdmann's quotation of this passage: see his valuable 'Geschichte der Philosophie' (3d ed., Berlin, 1878, vol. ii. p. 861), where instead of berechnen, to calculate, we read bezeichnen, to designate!

1 The history of this idea has been written by Hettner in the last two volumes of his 'Literaturgeschichte des 18ten Jahrhunderts.' I quote from the $2 \mathrm{~d}$ edition, Braunschweig, 1872. Herder had inherited the spirit of Leibniz (see, inter alia, the concluding chapter of my essay on Leibniz, in Blackwood's Philosophical Classics, Edinburgh, 1884). Herder formed a kind of centre of thought, inasmuch as he gathered up in his own mind and writings the influences of Leibniz, Rousseau, and the English writers of the eighteenth cen- 
of a long career, peculiarly favoure of a long career, peculiarly favoured by opportunities for A.v. Hum. studying Nature on an extensive scale, and for appreciating ' $\mathrm{b}$ bosmos. the detail of modern research, of which he was an illustrious representative, had never lost sight of the all-pervading unity. ${ }^{1}$ In an elevated style, in which poetry and science

tury, together with classical influences and new inspirations drawn from the popular song-literature of all nations. Hettner says (see last volume but one, p. 7): "Herder applied Rousseau's gospel of Nature to the demands of poetical sense and creation. Thus he has become essentially the forerunner of the new school of poets : the last fetters of the moralising style by which even Lessing was still hampered fell, and through the scientific study of the beginnings and development of human culture he became the founder of a new science of Language, Religion, and History, in the lires of which we are still advancing." And p. 101: "Herder does not belong to the classics of the style of Winckelmann, Lessing, Kant, Goethe, and Schiller; he is everywhere only suggestive, hardly anywlere conclusive and final. For this reason his writings are to some extent antiquated. Nevertheless Herder is one of our most important and influential spiritual heroes. Herder made so deep an impression on lis age that the great poetry of Goethe and Schiller, the so-called Romantic School, the philosophies of Schelling and Hegel, cannot be imagined without Herder as the precursor." The fourth volume of Gervinus, 'Geschichte der deutschen Dichtung,' contains likewise a very important chapter on Herder. But the great authority on Herder is R. Haym, 'Herder nach seinem Leben und seinen Werken' (Berlin, 2 vols., 1880 and 1885).
From the unpublished literary notes, correspondences, and diaries of Herder, which Haym inspected, it is evident that the great idea of writing a History of Humanity originated in Herder's mind as far back as the year 1769 , on a voyage from Riga to Nantes (on the way to Paris). His diary closes thus: "History of the progress and of the powers of the human mind in the concurrence of whole ages and nations-a spirit, a good demon, has exhorted me to do this. Be that my life's work, History, work !"

The first attempt to carry out his great idea was published by Herder in the year 1774, with the title: 'Auch eine Philosophie der Geschichte zur Bildung der Mensch. heit.' Herder was then in his thirtieth year. His chief work appeared ten years later (1784), with the title 'Ideen zur Geschichte der Menschheit.' Herder died in 1803. Goethe's 'Faust,' which is an attempt to deal with the highest problems of human interest, the problems of knowledge, evil, sin, and redemption, as they appear in the history of a great individual, not of the race, had its first beginnings about the same time as Herder's 'History of Mankind.' But the work was not finisled till a year before Goethe's death in 1831 .

1 Alex. v. Humboldt, 'Kosmos. Entwurf einer physischen Weltbeschreibung,' 1845. Like Herder's great work on the 'History of Humanity' and Goethe's 'Faust,' Humboldt's 'Kosmos' occupied a 
are happily blended, he essayed in the evening of life to unroll before the gaze of his readers a picture of the grand features of nature as his mind had viewed them from the elevated regions of scientific study, and his eyes from the heights of Chimborazo.

In the great picture of the world, in the vast changes of the universe, where is man with his life and his interests? In the huge Kosmos where is the Microcosmus?

Lotze's ' $\mathrm{Mi}$. erocosmus.

This question naturally presented itself to the mind of Lotze. "It is not," he tells us, "the all-embracing "kosinos' of the universe which we wish to describe again on the model which has been given to our nation. As the features of that great world-portrait sink deeper into general consciousness, so much more vividly will they lead us back to our own selves, suggesting anew the question, What significance belongs to man and human life with its lasting characteristics and the changing

long perior in the life of its author. Goethe's 'Faust' deals with the individual problem, Herder's 'Ideen' with the problem of the race or mankind, Humboldt's 'Kosmos' with the same problem as referring to the world, the universe. In the preface $\mathrm{Humboldt}$ confesses "that the image of his work had stood before his mind's eye in undefined outlines for nearly lialf a century ": cf. what Goethe says in the dedication to 'Faust' (written probably after 1797):-

"Again se come, ye hovering forms; I find ye

As early to my clouded sight ye shone," \&c.

-Transl. B. Taylor.

The view of the universe which was given in Humboldt's 'Kosmos' was prepared by his own publication,
'Die Ansichten der Natur' (1808); also by Georg Forster (1754-1794), who wrote an account of the second voyage of Captain Cook round the world, whom he accompanied with his father. "He conceived of nature as a living whole; his account is almost the first example of the glowing yet faithful description of natural phenomena, which has since made the knowledge of them the common property of the educated world " (R. Garnett in 'Ency. Brit.,' art. "Forster"). Humboldt confesses to have received from him "die lebhafteste Anregung zu weiten Unternehmungen " ('Kosmos,' vol. i. p. 345, also vol. ii. p. 65 , and especially vol. ii. p. 72, where incidentally also Darwin's narrative of the "Adventure" and "Beagle" is mentioned). 
course of its history in the great totality of nature?"1 And in collecting the answers to this question which suggest themselves both in and outside of the study, Lotze professes only to renew the enterprise brilliantly begun by Herder in his 'Ideen zur Geschichte der Menschheit.' Both Herder's 'Ideen' and Humboldt's 'Kosmos' belong to the age in which philosophy and poetry largely influenced science and history. Many may now think it premature or altogether impossible to try to combine the detailed studies of modern science and modern history with the comprehensive view demanded by philosophers and poets, or to grope through the labyrinth of external phenomena and events to their underlying significance and unity. They may, whilst fully maintaining the existence of an all-pervading power, nevertheless relegate it with Mr Spencer to the region of the Unknowable. ${ }^{2}$ Without desiring at present to

1 Microcosmus, 1st ed., Leipzig, 1856, Preface. Hermann Lotze was born in 1817, and died in 1881 . His first philosophical essay of importance was the 'Metaphysik' (Leipzig, 1841).

2 Herbert Spencer's philosopliy of the "Unknowable" is laid down in his Introduction to 'First Principles.' I believe the first appearance of the first part of this book was in 1860, and the first collected publication in the year 1867. In defining the region of the Knowable an opposite course has been adopted by Emil du Bois-Reymond, who in a series of addresses and articles, now collected in two volumes with the title 'Reden' (Berlin, 1886 and 1887), tried to lead up to the limits which are fixed around scientific knowledge. The purport of his teaching on the highest "World - problem" is contained in the four words, ignoramus, ignorabimus, dubitemus, laboremus. The first of these addresses, which are full of brilliant suggestions and vivid illustrations, furnishing in the notes especially an invaluable store of historical references on the subject of the philosophy of the sciences, was delivered at the fortyfifth meeting of the German "Naturforscher und Aertze," and published at Leipzig, August 1872, with the title "Die Grenzen des Naturerkennens.' It made a great sensation, and was translated into several languages. It was followed some years later by an address delivered in the Berlin Academy, 1880, and published with the title 'Die sieben WVelträthsel.' If H. Spencer's philosophy is termed the philosophy of the Unknowable, Du Bois-Rey- 
criticise the weighty considerations which have led them to a view so modest and resigned, I propose in the sequel to test within narrower limits, and by what seems to me a novel method, the validity of the conviction that a true understanding of phenomena and events can be attained only by viewing them in their interdependence and collective effect. If anything in the wide expanse of physical and mental life deserves to be considered as one and indivisible, it is surely human thought in its various branches and manifestations. The attempt to trace its origin in the early ages of civilisation, or to foreshadow the end which it is slowly approaching, may indeed be impossible; but of the age to which we belong, and the literature of which we have witnessed the growth, we may claim to possess a deeper knowledge. Astronomers have succeeded in gaining a view of immense and distant orbits by minutely observing and tracing merely an insignificant portion ${ }^{1}$ which came within their view. Comparative anatomy teaches how from a few surviving links to construct the whole framework of an organism. I propose to apply a similar method to the small portion

mond's may be termed the philosophy of the Limits of the Knowable. Both views form a contrast to Lotze's philosophy.

1 The most brilliant example of this is the discovery of the planet Ceres by Piazzi at Palermo in the New Year's night of 1801 ; the inrention of special methods for calculating the orbit of this planet, which had been lost, by Gauss in the course of 1801; and the rediscovery of it by Olbers, aided by Gauss's ephemeris, in the New Year's night of 1802. After the discovery of this first of the small planets, but before it was known in Germany, Hegel published his 'Dissertatio philosophica de orbitis planetarum,' in which he ridiculed the search for new planets, but which the Duke Ernest of Gotha sent to the astronomer Zach with the superscription, "Monumentum insaniæe sæculi decimi noni." Vid. R. Wolf, Geschichte der Astronomie, München, 1877, p. 684 sqq. 
of mental progress of which I have been able to take personal notice and of which I have felt the immediate personal influence. A tracing as concisely as possible of this comparatively small portion of the course of European thought may be the first approximation to more accurate delineations, which themselves will be the means of gradually gaining a truer idea of the purport and significance that belong to the larger dimensions of the mental life of mankind.

This life does not consist in the accumulated knowledge of our century, not in the results of scientific inquiry deposited in libraries and museums, not in the many schools for learning and study, not in educational and social reforms, least of all in political and economic institutions. These are all external objects, which are capable of being described or photographed like the external objects of nature. The mental life of mankind consists in the inner processes of reflection, by which these external objects have been produced, by which man has been able to add to the What the mental life of mankind physical creation of nature a new creation of his own, by which he has been able to change the face of the earth, and endow the objects of nature with an ideal meaning. To this end he is always inventing and using methods which change, suggesting and applying principles which turn out to be half true or totally fallacious, guessing at results and aims which have to be abandoned, inventing theories which are short-lived-in fact, erecting scaffoldings with the help of which he raises the structures of Society, Art, and Science: these remain as the historical testimonies of his activity; the scaffoldings are removed as of merely transient and temporary value; and yet they 
alone constitute the mental life which interests us. Only so far as we have taken part in building the scaffolding, only in so far as we have witnessed the many contrivances which have been used, only in so far as we have seen the growth of any structure from small beginnings, from the first sketch of the architect, can we say that we know something of the mental life which lies hidden in and behind those external signs and documents. A closer study of what we ourselves have witnessed is thus the only way of attaining some insight into the workings of the mind-the spiritual life of mankind. We shall presently find that in science as well as in philosophy every period starts from certain assumptions and proceeds ac-

31. the most approved, have their day, and cease to be. cording to certain methods, that certain habits of thought become general, and certain views become accepted; but in the course of one or two generations we find those assumptions questioned, those methods criticised, a new habit of thought introduced, and those general views which seemed so natural and convenient giving way to new and altered ones. The whole fabric of society, the whole structure of science and knowledge, all the applications of art, have to be remodelled on new principles, and to meet our changed 32. demands. Few indeed, very few, of the old creations does not
inherit all remain. One or two so-called laws of science that surof the past; much. vive, a few dozen books that are re-edited, half-a-dozen works of art and one or two great poems,- - this is about all that our century will at its close have preserved as the living inheritance of its early years: all the others will be relegated to the growing bulk of historical records. Possessed of merely monumental interest as documents of a bygone life, these creations had to be left aside as incap- 
able of marking or guiding any longer our onward career. A few centuries lapse, and posterity will look upon them as we do on the huge monuments of early Eastern civilisation, on the Sphinx in the desert or the Pyramids of Egypt, wondering by what ingenious contrivances they were raised, what amount of human work and suffering they represent, or what idea lived in the minds of those who planned and placed them where they still remain.

\section{III.}

It is the privilege of art to represent at a glance the whole of its object, and thus to produce at once a total Necessity of effect on the mind of the beholder. Closer scrutiny may follow and may show how the various parts support the whole, how the uniting idea is revealed in all the manifold detail of the component elements: still the impression of the whole remains and supplies the key for the comprehension of every part. Literature, science, and history are denied this privilege of presenting their objects in their entirety, and thus giving from the outset a commanding view, a leading and abiding impression of the whole. We have to ask the student to follow us patiently by an isolated path to the summit: many ways lead to it, and we may err in the choice of the right and convenient one. Even if we succeed in reaching the central position, we may have fatigued the reader on the road or produced sensations which prevent the unbiassed contemplation of the whole view when it is presented. With us the whole is only the sum of its many parts, whereas with the artist the parts are merely fractions of a united whole. In 
treating of the thought of the century, even within the narrow limits which have been prescribed, I am met with similar difficulties. In the large circumference of the domain of thought I have to choose a starting-point and to construct a road which may lead to the central position, hoping there to gain a comprehensive view of the whole.

2. Some periods of his. tory take their name from some great event or move. ment.
3. No central event in our age.

Sone periods of history are characterised by one great and central movement which absorbs all active forces and all intellectual and imaginative power, making them either subservient to one end and purpose, and helpful in the elaboration of one idea; or else forcing them into opposition, where they testify equally to the importance of this central movement. Such periods were, for instance, the long centuries of Jewish history, the early age of the Christian Church, the period of the culmination of Papal power, the Reformation, the French Revolution. In studying the thought of such ages, we are not at a loss where to find the leading idea,-we easily fix the centre of the vortex which draws into its motion all the existing forces, all genius and all talent. In an age like that of the Reformation we can speak of the Politics of the Reformation, the Religion of the Reformation, the Philosophy, Literature, and Art of the Reformation, and we are pretty sure to embrace under these various heads an account of all the mental progress and to trace all the thought of that age, be it friendly or antagonistic. It is evident that no such central event, no such all-absorbing vortex of motion, exists in the period which we have lived through. The uniting bond, if it exists, lies much deeper; the problem we have been engaged in solving, the prize we are fighting for, does not present itself on 
the surface; it is not explicitly stated, it must be implied rather than defined. The great object of our life and labour has not been clear to us, as it seemed clear to those who lived during the Reformation or the Revolution, otherwise we should not have philosophies of the Unconscious and of the Unknowable, and the century would not end in asking, Is life worth living?

Then, again, we find in history long periods of quiet development, where men's minds seemingly run very nuch in the same direction, exhibiting a general tendency of ideas, the spreading of a defined habit of thought and of simple methods, the application of a few principles: such a period was that preceding the French Revolution, the greater part of the eighteenth century. It has therefore been easy to characterise that century: it has been termed the philosophical century, the century of the Aufklärung, the century of Voltaire. ${ }^{1}$ No such one

1 The first who reviewed the literature of the eighteenth century from an international point of view was Villemain, who as early as 1820 was engaged in lecturing at the Sorbonne before the élite of the rising literary generation of France on the literature of the eighteenth century, taking France as the centre, and showing the influence of foreign literature, especially English, as likewise the reaction of French ideas abroad. He was too early to recognise the true meaning of the new spirit which had tlien already gone forth from Germany. In this respect his 'Cours de Littérature française,' published in 1828 and republished in 1864, remains incomplete. Schlosser next attempted to present in his 'Geschichte des achtzehnten Jahrhunderts,' after the manner of Gibbon, a picture of the combined political and literary work of the last century. The first draft of it appeared in 1824, after Schlosser had passed two years in Paris, where no doubt he must have come under the influence of Villemain. The work itself began to appear in 1826 , and was finished in 1848. It is considered to be Schlosser's greatest work, and had a large circulation. The connection of political and literary history was studied by Gervinus, who with Häusser is usually counted as a pupil of Schlosser. But the great work which Villemain had begun and Schlosser taken up was adequately carried out by Hettner, who in his 'Literaturgeschichte des achtzehnten Jahrhunderts' conceived the whole inteliectual movement of that age as a battle for enlightenment (Kampf der A ufllärung). The 
term can be applied to our age, no one name can be found which carries with it the recognition of all the many interests which surround us.

4.

Is history of thought history of philosophy?

It has been suggested by some that the history of thought is equivalent to the history of philosophy; that the different philosophical systems and theories exhibit in the abstract the course which ideas have taken in an age. ${ }^{1}$ A history of thought in the nineteenth century would thus mean a history of nineteenth century philosophy. There have indeed been plenty of philosophies and systems during our period, but in spite of their great number and variety - ranging from the extreme idealism of Fichte to the equally extreme materialism of Biichner2 - we feel that they do not cover the whole area of thought. The period in our century which in England was most barren in philosophy, the first forty years, produced an entirely new literature and a novel conception of art, both containing new sources of mental life, though they have hardly yet found expression in any philosophical system. Equally barren in speculation was France during the Restoration; yet there, too, was a bril-

latter part of his work deals with the reaction against Aufklärung and "Rationalism" as it began in England, and was represented on the Continent by Rousseau and the earlier ideals of the French Revolution. Through Rousseau and the Revolution the growing influence of the new spirit of English literature was overpowered and lost for the Continent. And, as we have to regret in Villemain his neglect of the new life of Germany, so we liave to deplore that Hettner followed the developments of Rationalism and Aufklarung only in the form they assumed in Germany, neglecting to notice the contemporary growth of the new life in English Literature and Art, to which, in fact, no German historian has as yet done justice.

' See especially Hegel's Lectures on the History of Philosophy in his collected works, vol. xiii. p. 68 sqq. (Complete edition, Berlin, 1832.)

2 The principal publications of this school are Vogt, 'Physiologische Briefe,' 1845-47 ; Moleschott, 'Der Kreislauf des Lebens,' 1852 ; Buichner, 'Kraft und Stoff,' 1855. 
liant era of literature, and the whole of Europe was illuminated by the light of science which emanated from Paris during the first third of this century. History of philosophy has little to say about Goethe, though his Goethe's work in: work embodies for us probably the deepest thought of modern times. Again, the only great and novel system volves the deepest thought of of philosophy which France has produced during this century is that of Comte, but it has had only smal! influence in its own country; and who would say that it reflects French thought of the period as Voltaire and Montesquieu reflected the thought of the last century? Hegel himself, who was intent upon tracing the working of the human mind in the systems of philosophy, declared that philosophy is the latest fruit of civilisation,- that the special idea which governs any period is already dying out when it appears in a system. ${ }^{1}$

1 The principal passage expounding this idea of Hegel's is to be found in the introduction to the course of lectures which he delivered at Berlin repeatedlyduring the years 1816 to 1830 . Vid. his collected works, vol. xiii. p. 66 : "Philosophy makes its appearance at the time when the mind of a nation has worked itself out of the indifferent dulness of the early life of nature, as well as out of the period of passionate interest; inasmuch as the direction towards detail has spent itself, the mind transcends its natural form-it passes on from practical morals, from the force of real life to reflection and comprehension. The consequence is, that it attacks this actual form of existence, these morals, this faith, and disturbs them ; and with this comes the period of decay. The further stage is, that thought tries to collect itself. One may say, that where a people has come out of its concrete forms of life, where distinction and separation of classes has set in, where the nation approaches its fall, where a rupture has taken place between the inner desires and the external reality, where the ruling form of religion, \&c., \&c., does not satisfy, where the mind shows indifference towards its living existence or lingers discontentedly in it, where moral life is in dissolutionthen only does one philosophise. The soul takes refuge in the realms of thought, and in opposition to the real world it creates a world of ideas. Philosophy is then the reparation of the mischief which thought has begun. Philosophy begins with the decline of a real world: when she appears with her abstractions, paint. ing grey in grey, then the freshness of youth and life is already gone; and her reconciliation is not one in reality, but in an ideal world." 
6. This means that philosophy is retrospective: it sums up, Philosopliy tive.

it criticises, it does not prefigure the future. The correctness of this proposition may be doubted. We shall have to deal with it in another place. At present it reminds us that thought, in the sense in which we take it, cannot be identified with philosophy, and hence a history of philosophy in the nineteenth century is not identical with a history of its thought. There is indeed a sense in which the word philosophy is sometimes used, when it approaches more nearly to the meaning of the word thought, as we intend to use it. Whewell has in this sense written the philosophy of the inductive sciences, meaning to trace in that work the processes of thought which are consciously or unconsciously employed in scientific research and reasoning, and which lead to progress in science. Something similar might be attempted in regard to art, commerce, politics, government, religion, and literature generally. In every case philosophy would simply mean the peculiar way of thinking and reasoning which is adopted in these various branches of practical or intellectual life. This is, however, not the sense in which the word philosophy is generally used. It generally denotes something more than a statement of method or a rationale of ideas and reflections; it denotes a definite theory, an explanation of a larger or smaller circle of phenomena. As such it certainly forms a part of the thought of the century, probably the most interesting and fascinating part; but it is also that which is most liable to change, most subject to discussion; whereas the other more hidden thoughts and reasonings form, as it were, the ground upon which all the 
intellectual, artistic, and practical achievements of the age rest.

It would thus appear as if an account of the thought of the century might naturally divide itself into two separate investigations. In the first place, we should regard thought merely as a means to an end, as the method adopted to attain a certain purpose, be it practical or theoretical. It would mean the peculiar kind of reasoning which has been employed in the search for knowledge or in its useful application. As all reasoning starts from certain assumptions, called premisses, or principles, or axioms, and progresses from these by certain methods, this portion of our task would divide itself again into a statement of the principles which underlie, and an account of the methods which have guided, theoretical and practical reasoning. But thought does not exist merely for the sake of increasing our knowledge of things and of applying this to practical purposes. Occupied in this way merely, it remains fragmentary, incomplete, and not infrequently it reveals contradictions. Even those who devote themselves purely to detailed research or to practical work are again and again compelled to take a wider and deeper view of things than their special occupation affords. One may find that the methods which he is using daily become useless for certain practical purposes he has in view, and may thus be forced to question the principles which during half his lifetime he has applied with unquestioning faith in their validity and usefulness. Another may have met with such success in the use of a special method of research, that he wishes to apply it to subjects which were previously handled in a different manner, or elevate it to 
the dignity of a general rule of thought. A third may, accidentally, be interested in two or more pursuits which are seemingly unconnected, but which-being brought side by side in his mind-he feels the wish to unite and harmonise. A fourth may, at a certain time of life, grow tired of the drudgery of petty pursuits which never carry him beyond a very limited sphere of interests: he is tempted to look beyond this narrow range, and gain some wider view of other pursuits and interests. Allowing that ignorance or indifference prevents even the majority of those whose powers are not exhausted in the struggle for mere existence from looking much beyond their narrow circle, allowing also that many of us live-like children-in a blessed trust that the great and important interests of mankind are under higher and better guidance than we can understand or control, there still remain a considerable number of persons who are always on the look-out for something higher, wider, and better, who are driven by an undying thirst after real wisdom, or by an 9. inherent restlessness of disposition to inquire into the deepest foundations and the ultimate ends of the world and life. Language has coined a word which denotes the whole of these occupations and endeavours, how various so ever they may be, and for whatsoever purpose they may be undertaken. It calls them speculations. The word also indicates the venturesome and risky nature of these undertakings. They have existed in all ages and countries and languages wherever literature has existed, and have been carried on by the powers of reason or imagination, in prose, verse, or symbol, sometimes in defined and clear terms, more often in mystic allegory. Philosophy may be 
said to have grown out of these vague and scattered beginnings by the attempt to conduct them according to some method, and to unite them into a complete and consistent whole. Philosophy may thus be defined as speculation carried on according to some clear method, and aiming defined. at systematic unity. ${ }^{1}$ Both science and philosophy may be called methodical thought, but the word system is applicable only to the higher and more advanced forms of philosophic thought which aim at unity and completeness.

We have thus arrived at a second division of our subject. In the first we have to consider thought merely as a means to an end; in the second we have to consider it as its own object, as a reflection on itself, carried on with the object of knowing its own origin, its laws, its validity, of testing its powers, and with the end and aim of gaining certainty, completeness, and unity. The whole of this great division of thought I shall comprise under the the book.

1 This view of the nature and object of Philosophy agrees with Lotze's definition (vid. 'Grundzüge der Logik,' Leipzig, 1883, § 88): 'The common culture of life and the separate scicnces contain a number of suppositions the origin of which is obscure to us, because they have been very gradually formed within us through the comparison of many experiences, or because they have first become conscious by means of such experiences, have then received definite names and become habitual without having been subjected by us to any examination as to the reason, the sense, and the extent of their validity. In this way science and life make use of the notions of cause and effect, of matter and force, of means and end, of freedom and necessity, of matter and

VOL. 1 . mind, and they frequently entangle themselves, owing to the above-mentioned defect, in contradictions, inasmuch as they are unable to fix the limits of validity of these to some extent contradictory assumptions.

"Now we may formally define the task of Philosophy as follows: that it is an endeavour to import unity and connectedness into the scattered directions of cultured thought, to follow each of these directions into its assumptions and into its consequences, to combine them all together, to remove their contradictions, and to form out of them a comprehensive view of the world ; mainly, however, to subject those ideas which science and life regard as principles to a special scrutiny, in order to determine the limits of their validity." 
term Philosophy; and as the first part. will deal with the scientific, so will the second deal with the philosophical thought of our century.

Science has gradually risen out of the mass of accumulated but inaccurate and disorderly knowledge by the desire of making it accurate, orderly, and useful. Philosophy has similarly emerged from the great world of speculative thought by the desire of carrying it on methodically and for a defined end and purpose. Nevertheless neither the one nor the other, nor both together, really exhaust the whole meaning of the word "Thought"; neither science nor philosophy covers the whole region of thought. Both are comprised under the term methodical thought; but there remains the great

Neither science nor philosophy comprises the whole meaning of the word thought.

13. Thought also hidden in the literature and art of the age. body of immethodical, undefined thought. This is buried in gelleral literature, in poetry, fiction, and art; it shows its practical influence in the artistic, moral, and religious life of our age. It is a reflection of the knowledge of science or the light of philosophy, but, like all reflected light, it not only follows, it also precedes the real and full light: it is not only the dusk that comes after, it is also the dawn that comes before the day, it is the twilight of thought. In it lie hidden the germs of future thought, the undeveloped beginnings of art, philosophy, and science yet unknown and undreamt of ; it encloses and surrounds the innermost recesses of the mind, where all thought had its origin, and whence it ever and again draws fresh life and inspiration. ${ }^{1}$

I This is originally a Leibuizian idea. It is laid down in the doctrine of the pctitcs perceptions, as given in the introduction to the 'Nouveaux Essais,' and referred to in many passages of Leibniz's various 
No account of the thought of our century would be complete or satisfactory which took no notice of this great volune of immethodical and unsystematic thought which lies buried in the general literature and in the art of the age. Both have shown a vitality, originality, and versatility which exceed that of any except the few favoured periods-those of Athens under Pericles, Italy during the Renaissance, and England under Elizabeth. In one of the arts, in music, our age has, according to the opinion of many competent judges, exceeded in originality and certainly in productiveness all former ages. In poetry Goethe and Wordsworth have raised our tastes and demands to a higher level, in fiction France and 14. Goethe and Wordsworth raised our England liave almost created a new branch of literature, tastes. whilst the peculiar features of modern English landscapepainting were unknown to previous centuries. All this, though produced under no scientific or philosophical rule

writings. Vid. 'Nouv. Ess.,' Preface, Leibniz, Philosophische Werke, ed. Gerhardt, vol. v. p. 48 :-

"Ces petites perceptions sont donc de plus grande efficace par leur suites qu'on ne pense. Ce sont elles qui forment ce je ne sçay quoy, ces gouts, ces images des qualités des sens, claires dans l'assemblage, mais confuses dans les parties, ces impressions que des corps environnans font sur nous, qui enveloppent l'infini, cette liaison que chaque estre a avec tout le reste de l'univers. On peut même dire qu'en consequence de ces petites perceptions le present est gros de l'avenir et chargé du passé, que tout est

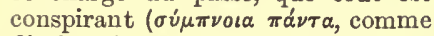
disoit Hippocrate) et que dans la moindre des substances, des yeux aussi perçans que ceux de Dieu pourraient lire toute la suite des choses de l'univers.

"Quæ sint, quæ fuerint, quæ mox futura trahantur. ... C'est aussi par les perceptions insensibles que s'explique cette admirable harmonie préestablie de l'âme et du corps, et même de toutes les Monades ou substances simples, qui supplée à l'influence insoûtenable des uns sur les autres, et qui au jugement de l'auteur du plus beau des Dictionnaires exalte la grandeur des perfections divines au delà de ce qu'on eu jamais conçu."

The importance of this idea of Leibniz has been dwelt on at length by Kuno Fischer in his 'Geschichte der neueren Philosophie,' where he also traces its influence in the development of philosophy and literature in Germany after Leibniz. 
and very frequently outside of any school, points to novel modes of mental conception, to a fund of ideas yet undeveloped or only partially developed into clear thought. The whole of this productiveness indicates a vast amount of mental work which, though not yet absorbed by science or philosophy, belongs nevertheless, according to our original conception, to the world of thought. The meaning of it may be enigmatical, and the clear expression which it will some day produce in philosophical and scientific reasoning may be far distant and unintelligible

15. cal thought.

to us now. Still there it is, this great body of undefined thought, this volume of diffused light, the focus and centre of which is still hidden from us. We feel that in discussing the thought of the century we cannot pass it by or neglect it.

It is difficult to find any one term under which we could comprise this great body of unmethodical, scattered, and fragmentary thought,- any one word, similar to science and philosophy, in which we could sum up and characterise its general meaning and tendency. So far we have only stated what it is not, what to a large extent it perhaps never will be-viz., methodical. And yet we feel that it contains that kind and portion of thought which touches our deepest interests, our most intimate concerns, our noblest aspirations. Science becomes more and more a mere calculation, une question d'analyse, an occupation for the laboratory, the workshop, the manufactory, and the market; philosophy savours at its best too much of the school and lecture-room, runs too much into systems and categories, it fatigues us with definitions 
and abstractions. But neither calculation and measurement, nor definition and abstraction, suffice to exhaust what is to us, in the quiet and serious moments of life, of the deepest concern-viz., our religion. I use the word here in its original sense, and I propose to sum up in the term religious thought the whole of the thought contained in that large volume of literature which does not submit to scientific and philosophical treatment, but which nevertheless forms so important an outcome of the mental life of the century.

There are other words more or less current in modern literature that may serve to throw some light on the distinction that I am here drawing for the purpose of affording a preliminary view of the course to be pursued in the following treatise.

Science is said to be exact, positive, and objective, and it is opposed to such other thought as is inexact, vague, and subjective. Science is said to convey its results or 17. science is exact, posiobjective. ideas in defined, direct, and general terms, whereas there is a large department of literature and thought which moves in undefined, symbolical, and indirect expressions. Science professes to rest on clear and precise knowledge, and is thus opposed to such other realms of thought as rest on opinion, belief, and faith. It may be well to note here that these different terms refer either to the method of treatment or to the matter which is under treatment. Science alone professes to have a rigid and undisputed method. Other branches of thought either borrow their methods from science, or they have fluctuating, not generally recognised methods, or they refuse to submit to method 
altogether. But so far as the matter under treatment is concerned, a clearer division is possible. Science deals with all such things or objects of thought as are common to a great many persons and-under certain circumstances -are accessible to everybody: it thus claims that its observations and reasonings can be checked and submitted to repeated examination and verification; so that a large portion of them can always be regarded as settled and agreed upon, and can be taken for granted and used as a secure foundation by those persons who are themselves unable or unwilling to go through the process of verification. But

Some in terests or objects of thought are personal or subjective.

19. Agreement on these matters impossible. there are a great many things and interests which centre in the individual mind of each person-which are, in fact, personal, individual, or subjective. They are to all of us just as important as the others. They form the real subject-matter of all that thought which is separated from science, and in its very nature and aspect opposed to it. In this great province of thought one person cannot do the work for many in the same way as is possible in science. Proof is almost impossible, and agreement refers always only to a certain number of persons. Doctrines or theories in this region of thought cannot be accepted and taken for granted as they are in science, but every person must go over the same ground for himself before he has any right to accept or make use of what is given to him. The real and true character of all this thought is that it is individual and personal, whereas all scientific thought - whatever its origin may be-must be general and impersonal. At the extreme end of thought in one direction are placed the mathematical sciences, at the extreme end in the other lies religion. Disagreement in the former is 
almost as unknown ${ }^{1}$ as agreement in the latter. There we have an almost universal unity of thought; here unity of thought probably never existed; it is unknown. Popularly we can say that at the one extreme lie knowledge and certainty, at the other faith and belief. There is, however, a very large extent of ground between these two extremes. This is covered by all such intermediate thought as rests partly on knowledge, partly on faith, where certainty is largely mingled with belief. This large intermediate region, where changes and fluctuations are frequent Philosophy intermediate between and rapid, is the proper home of philosophy, which occupies mathematical science itself with the grounds of certainty and belief, the origin of and religion. knowledge and faith, and the relations in which both stand to each other. Were all our thoughts either purely mathematical-i.e., referring to number, measurement, and calculation, or purely religious-i.e., referring to our individual concerns and personal convictions,- - the need of a continued compromise or mediation would be unnecessary, the question as to the grounds of certainty or belief would never arise. But no sooner do we wish either to apply our strict mathematical notions and processes, or to bring our personal convictions into practical use, than the two kinds of thought come into contact, not to say into conflict, and there is need of some theory according to which this contact may be regulated, this conflict settled. And as the occasions for such contact change with the demands of practical life, or the progress of applied science, these theories must them-

${ }^{1}$ It may be doubted whether this is quite correct, looking at the controversies which have been connected with many mathematical theories-such as the theory of parallel lines, the meaning of infinitesimals, the correct measure of force. These controversies, however, referred really to applied, not to pure mathematics, and were settled by introducing correcter and more stringent definitions. 
selves change and develop. Now it may be generally stated that it is the task of philosophy to take note of these different ways by which the strict methods of science are applied and made useful, or by which personal and individual convictions are brought to bear upon practical questions which are not only of personal but of general interest and importance. It does not follow that philosophy must necessarily construct a complete system; but it is a natural and frequent occurrence that the occupation with a great number of detached theories or aspects of thought generates the desire to bring them into harmony and to unite them in a connected whole. Thus the enterprise which was originally purely critical and preparatory, and undertaken merely as a means to an end, may lead to the formation of a general and all-embracing view of things -i.e., to a philosophical system.

From whichever side we approach the matter, we are

21.

Threefold considera. tion of thought: scientific, - philosophi. cal, indi. vidual.

thus always led to a threefold consideration of thought, as scientific, as individual, and as philosophical. An attempt in which any of these three aspects were neglected could have no value in an account of the thought of our age. There have indeed been schools of thought which identified science with philosophy, or which maintained that no independence belonged to religious, personal, or individual thought, inasmuch as this was merely of a derived character. Though such theories may have exerted considerable influence, they have as a whole failed, ${ }^{1}$

1 This can be said of Hegelianism as well as of Comtism. In the former it was a favourite doctrine that philosophy was the higher wisdom compared with religion and art. Vid. Hegel, 'Geschichte der'
Philosophie' (Werke, vol. xv. p. 684): "The highest aim and interest of philosophy is to reconcile thought, the idea, with reality. Philosophy is the veritable theodicy, compared with art and religion 
and we find ourselves at the end of a long and critical period unable to say that any one of the three realms of thought has gained an undisputed victory over the others. Science is more than ever that kind of thought which gives knowledge and certainty. Religion is still the generally recognised abode for those convictions which refer to our deepest personal interests. And more than ever do we feel the need of a reconciliation of both in some theory of life which is neither purely scientific nor the mediapurely individualistic; and this means that philosophy is $\begin{gathered}\text { science and } \\ \text { religion. }\end{gathered}$ as much needed as ever. Our century has witnessed a great development of scientific thought, a great revival in religious interest, religious feeling, and religious activity, and it is probably richer than any preceding age in philosophical theories and systems.

I must repeat here what I said above, that it is a misfortune that in dealing with a complicated subject we are obliged to divide it,-that we are forced to give preference to some one aspect, and to choose a special

and their sentiments-this reconciliation of the mind, indeed of that mind which has grasped itself in the freedom and wealth of its reality. It is easy otherwise to find satisfaction in subordinate regions of intuition and feeling," \&c., \&c. Although it is an exaggeration to say that Hegel desired to absorb or evaporate religious belief in philosophical knowledge, as his lengthy explanation (Introduction to the 'History of Philosophy,' Works, vol. xiii. p. 77 sqq.) sufficiently proves, there is no doubt that the sentiment expressed in the above passage indicates that philosophy was coming to the rescue of true religious belief, which threatened to be lost in the rationalistic and mystical schools of the day. And this had the further consequence that a scientific occupation with or interest in religious subjects - be it metaphysical or historical - took the place of a purely religious interest, and that many eminent German theologians became either pure metaphysicians or merely critics, the practical side being lost sight of.

It is probably just as incorrect to accuse Comte of an intention to destroy true religion because he preached the well-known doctrine of the three stages of human thought-the theological, the metaphysical, and the scientific or positive. 
point from which to set out. In dealing with the thought of our age, I have been obliged to divide what is in reality connected and coherent; and I am further forced, in examining more closely its different aspects, to select one as the most prominent with which to make a beginning. In reality such a preference does not exist in my plan. I recognise all the aspects of thought as equally important, and I feel that I might begin with any one of the three, and that I should in due course be 23. led on to a consideration of the other two. They are in Dimaits separate tlie three as
pects of thought. their actual historical appearance in the course of our period so interwoven that they cannot practically be separated. And it is indeed not difficult to assume various positions in contemplating the whole subject from which either one or the other of the three forms of nineteenth century thought assumes as it were the ascendancy. Thus it would be undeniable that from a German point of view the great movement of ideas centred in the first third of the century in what I have called philosophy. The number of systems which succeeded each other was astonishing, the influence they had on literature, science, and practical life was without precedent, the enthusiasm with which students from all parts gathered in the lecture-rooms of the great metaphysicians was quite extraordinary, and probably equalled only in the schools of Athens in antiquity, or in the lecture-room of Abelard in the middle ages. From this point of view an account of this great movement-how it grew, flourished, and died away - would no doubt afford a suitable introduction to the history of thought in our century. If after this we were to turn to France and try to fix upon the 
most striking intellectual feature of the century, it would be the equally great and remarkable array of scientific names of the first magnitude. In France during the early part of the century the foundation of nearly all the part of the modern sciences was laid; many of them were brought under the rule of a strict mathematical treatment. It was there that scientific subjects were made so popular, and clothed with a garment of such elegant diction, that they have since that time greatly entered into general consciousness, and have promoted in literature and art an independent school - the naturalistic. Compared with this mathematical and naturalistic spirit, philosophy proper has found but a meagre development and culture in France: the constructive tendency of idealism has found nourishment for the most part only in leanings to the older systems of Descartes, Plato, and Aristotle, or to the foreign ones of Hegel and other German metaphysicians. Compared witn Germany in philosophy, and with France in science, England during the early part of the century appears remarkably unproductive. English science and English philosophy had flourished in the seventeenth and eighteenth centuries, and leavened the whole of European thought, but in the beginning of our period we find neither represented by any great schools. The great discoveries in science belonged to individual names, who frequently stood isolated; the organisation and protection which science could boast of in France was then unknown in England; into popular thought it hardly entered as an element at all. philosophy Metaphysics had not recovered from the blow which in part of the David Hume had struck, and speculation was confined century in 
almost entirely to the novel field of social and economic problems. But against this there was a young growth of ideas springing up in the poetic literature of the nation. It is the freshness of individual thought as clothed in the poetic language of Shelley and Wordsworth, maturing and deepening in the works of Tennyson and Browning, which strikes us as the most original phase of English thought in this century, whether we compare it with Continental thought of the same period, or with English thought of the previous age.

Goethe'

'Faust're. presenta. tive of the thought of the century.

And lastly, we might be tempted to make the great work of the greatest mind of the early part of our period, Goethe's 'Faust,' the centre and beginning of our survey, singling it out as a comprehensive embodiment, as the classical expression of nineteenth-century doubts and aspirations, leading us - if we try to understand it now into the bewildering labyrinth of philosophy, now into the cheerful expanse of natural science, and again into the hidden depths of individual life, of religious faith with its mysteries of sin and redemption.

But from whatsoever point we may start on our journey, from whatsoever easily reached eminence we may cast a first eager glance across the wide country which we wish to explore, there is one feature which impresses itself $27 . \quad$ alike upon our minds from the very beginning. It is not a country of repose and restfulness, of healthy industry and quiet work, of gradual development, of ripening crops, of sowing or ingathering; it does not present the aspect of a happy division of labour, of successful cooperation, of peaceful regulation of employment. It looks more like a land which has lately been disturbed by 
great elemental forces, heaved up by an earthquake or visited by a destructive storm. We see some persons employed in filling up great breaches and recently made rents, others trying to lay new foundations; others again are fighting for their possession or trying to divide a disputed territory; even the peaceful workers are called out to help in the battle, or disturbed by the complaints of their neighbours, on whose ground they are trespassing inawares, whose foundations they are unconsciously undermining. If we inquire into the cause of this unrest and anxiety, which seems to be a feature common to nearly all the phases of nineteenth - century thought, we must Cause of it seen in the century of look back to the age which inmediately preceded it. It is the storm of the revolution which passed over Europe, and shook to the foundation all political and social institutions, that has likewise affected our ideas and thoughts in every direction. The period we refer to has thus not incorrectly been termed a century of revolution. If in spite of this I decline to consider nineteenth-century Nineteenth spite of this I decline to consider nineteenth-century century thought as essentially revolutionary, it is because the thot revoluwork of destruction belongs in its earlier and more drastic episodes to the preceding age. The beginning of our period witnesses everywhere the desire to reconstruct, either by laying new foundations or by reverting to older forms of thought and life which it tries to support by new arguments or to enliven by a fresh interest and meaning. We may say that the thought of 7 so. the century in its practical bearings is partly radical, this century partly reactionary, - meaning by the former all those cal, partly
reactionconstructive attempts which try to go to the root of ary. things and to build up on newly prepared ground; by 
the latter all those endeavours which, clinging to historical institutions and beliefs, aim at finding the truth and value which are in them, and the peculiar importance which they may have for the present day. The work of destruction is indeed still going on; in the midst of this constructive or reconstructive work we still witness the 31. workings of the revolutionary spirit. The healthy new

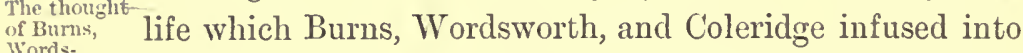
Wordsworth, and Coleridge thisturbed by the Byronic school.

English poetry at the beginning of our period was disturbed in its quiet growth by the revolutionary spirit of the Byronic school. The new thought, which grew up in Kant's philosophy and the idealistic school, degenerated in its further development into a shallow materialism and a hopeless scepticism. But none of these destructive inHuences, however passingly interesting they may have been, seem to have struck out any new line of thought.

32. Destructive spirit in writings of eighteenth century.

Whoever wishes to study the arguments by which social order was subverted and cherished beliefs destroyed will find them brilliantly and consistently expounded in the writers of the eighteenth century, from which many nihilists of our age have drawn their inspiration. This is not the task which I have in view. It has been performed in our time by many writers of great eminence. Nor do I intend to describe the courses which governments and politicians have taken in dealing with the legitimate demands of the people, such as a hundred years ago found a memorable expression in the American declaration of independence, and an exaggerated one in the cry of the French Revolution. Only to a small extent has the ideal of that great movement, as it lives in the mind of many a democratic leader, been realised in our century. In 
most European countries the work of national unification and consolidation, and the struggle for political independence, have retarded internal reforms; nor have theorists been able to agree in what form of social organisation liberty and equality could consistently live side by side. Their teaching must indeed command special attention as one of the many forms of the philosophic thought of Revolutionary theories the age; but a wide gap separates theory from practical not practi. politics, which have been largely occupied with wars and diplomatic feats, or, when they really dealt with social problems, have had to be content with awkward compromises between prejudices and institutions of bygone ages on the one side, and legitimate demands for freedom on the other.

Though much practical thought and much labour have been spent in achieving even these moderate results, I feel that they really fall outside of my programme. Wherever either science or philosophy steps out of the quiet regions of the study, the lecture-room, and the laboratory, or wherever religious faith leaves the secret recesses of the believing soul to solve the problems of life or to perform the work of the day, the line is crossed which I have felt obliged to draw around the following sketch. Not that I do not recognise this borderland, where the spirit subdues matter, where thought becomes useful, where the idea attains reality, this field of strife and endeavour, of patient toil and slow victory, as by far the most important subject of history, and as that in which our age has probably excelled every earlier period. But an account of this side of nineteenth-century life could ill afford to limit its view to the three principal countries of the Old World. For where are discovery and invention at this moment more at home 
than in America; where have political theories, the original rights of man, the ideas of liberty, equality, and brotherhood, been more widely put to the test; where have religious beliefs entered into closer contact with the work of the day; or where in our age has the simple rule of early Christianity been more successfully put into practice? An account of the application of thought taken merely from our European experience, where half our endeavour must always be spent in clearing away obstacles, in removing the debris of antiquated institutions, in overcoming prejudice, or battling with evils which have grown to uncontrollable magnitude, would give us but a poor notion of the influence of thought over material circumstances, and a very exaggerated one of the inertia of the

34.

'This is not a history of invention or of practi. cal politic:.

35.

Thouglit to be consirlered in its construc. tive, not in its lestmetive attitude. mechanism of older societies. With the work of the inventor, the practical statesman, or the lawgiver, I have thus nothing to do at present; only in cases where practical problenss have immediately reacted upon scientific research, or where social questions have given rise to special theories, shall we be compelled to cast a glance outside of the inner world of thought into which I invite my readers to retire.

This inner world has, indeed, not been all rest and peace and quiet development. No age has been so rich in rival theories, so subversive of old ideas, so destructive of principles which stood firm for many ages, as ours. It is not my intention to emphasise this critical or radical tendency more than is necessary. True to the original view which I have already expressed, I intend to look upon thought as a constructive, not a destructive agency; on the world of ideas as a positive acquisition, not as a mere counterpart 
or shadow of material existence. Though demanding for its growth an outer stimulus, and unable to proceed very far without external correctives, I nevertheless maintain that the human mind in its individual and collective life encloses an independent source of reality which contact with outer things and thought in all its various forms has to reveal, to preserve, and to develop. To what extent this has been done in our century is the question I propose to answer. With this object in view I shall try to gather my observations and my narrative around the prominent and novel constructive ideas which have sprung up in the course of the century, not omitting the great development which the purely formal side of thought, the method of research, has undergone. Such constructive ideas are those of energy, its conservation and dissipation; the doctrine of averages, statistics, and probabilities; Darwin's and Spencer's ideas of evolution in science and philosophy; the doctrines of individualism and personality, and Lotze's peculiar view of the world Darwin's, Spencer's, and Lotze's constructive of "values" or "worths." Around these centres of thought cluster the many critical oppositions, the great controversies of radical or conservative opponents. As regards these, I shall welcome all radicalism which lays bare the roots of our ideas, which delves deep into the ground of our opinions and principles, or which points out new methods by which we may test the correctness and consistency of our axioms. As such I consider the spirit infused by Kant into all modern thought. That other radicalism, which merely roots up, which destroys without building, which fails to find any ground of certainty, simply because human thought and observation may after TOL. I. 
all be a delusion,-this kind of radicalism I shall try to pass over as meaningless. And equally meaningless appear to me those opposite conservative tendencies which merely annul progress, which shut out the daylight, and preach the doctrine of inertia. But this, again, will not prevent me from recognising the real gain and $3 s$.
stionary interest which belong to some 'reactionary movements, Reactionary
moovement
of Romanticism. of the past, its artistic idealisation of the childhood of mankind, of aspects of life in their infancy and primitiveness, with its study of mediævalism and its more sober historical tastes. I shall endeavour always to ask what addition to the great stock of human ideas has resulted; what gain we have to register; convinced that everything that lives must grow, increase, and multiply: and what can be more living than Thought?

But although the school of Critical Thought in Kant, and the Romantic school as centred in Walter Scott and the German Romanticists, are in time almost the first intellectual phases of the century, they will not in the beginning command my special attention. ${ }^{1}$

1 In order to give some idea of the complexity of the different currents of thought in the first years of the century, I place here a carefully selected list of dates. They refer to events or publications which mark epochs or important stages in the history of thought. Of specifically scientific importance are-

1796 Laplace's 'Exposition du Système du Monde.'

1799. (2 vols.) - 1825. Laplace's 'Mécanique céleste.'

1799. Legendre's 'Théorie des Nombres.'

1801. Gauss's 'Disquisitiones Arithmeticæ.'

1801. Piazzi discovers and

1802 Olbers rediscovers the first of the minor planets, "Ceres," being assisted by Gauss's new methods of calculation, which were published in extenso in

1809. Gauss's 'Theoria motus corporum colestium.'

1798. Cuvier's 'Tableau élémentaire d'Histoire naturelle.'

1800-5. Cuvier's 'Leçons d'Anatomie comparée.' 
Though somewhat later in point of time than they, the school of exact research seems to have become the more generally recognised agent in nineteenth-century progress.

1809. Lamarck's 'Philosophie zoologique.'

1799. Volta constructs his first electric pile, and announces this in

1800 to Sir Joseph Banks.

In chemistry the early years of the century brought many of GayLussac's important Memoirs, in

1801 Humphry Davy publishes the first of his electro-chemical discoveries, and

1802-3 Berzelius publishes his own.

1803. Berthollet's 'Essai de Statique chimique.'

1810. John Dalton's 'New System of Chemical Philosophy.'

1801. Thomas Young announces to the Royal Society his belief in the undulatory theory of light, which during

1802,3 , and 4 he substantiates further in his papers, and fully expounds during

1802 and following years in his lectures to the Royal Institution.

1808. Malus announces his discovery of the polarisation of light through reflection.

1802. Chladni's 'Akustik.'

Count Rumford's papers, which laid the foundation of the mechanical explanation of heat, belong to the end of the last century, and in

1799 H. Davy publishes his equally important 'Essay on Heat, Light, \&c.'

1800. Bichat's 'Recherches physiologiques.'

1801. Bichat's 'Anatomie générale.'

1799-1804. Alexander von Humboldt travels in America, and lays by his observations the foundation of the sciences of physical geography and meteorology.

For the listory of the philosophical movement of thought the years

1793-1806 witnessed in Germany the great development, expansion, and criticism of Kant's ideas in the writings of

1793 Schiller, 'Briefe iiber ästhetische Erziehung.'

1796. Schiller, 'Über naive und sentimentalische Dichtung.'

1797. Fichte, 'Wissenschaftslehre.'

1797. Schelling, 'Naturphilosophie.'

1803. Schelling, 'Transcendentaler Idealismus.'

1799. Schleiermacher, 'Reden iiber die Religion.'

1800. Schleiermacher, 'Monologen.'

1799. Herder, 'Metakritik.'

1799. Jacobi, 'Offener Brief an Fichte.'

1806. Hegel, 'Phänomenologie des Geistes.'

In France-

1804. Destutt de Tracy's 'Idéologie' represents the reigning philosophy, and

1803 Maine de Biran's 'Mémoire sur l'Habitude' the beginning of the later reaction against it.

In England-

1792-1827. Dugald Stewart's 'Elements of the Human Mind' and his 
To it are due the great changes in every department of science, of life, and probably also of literature and art, the great inventions and the great conflicts of our age. Science has not only very largely influenced our ideas, it has also by its applications altered the external face of the world we live in. It is therefore simply a tribute to the popular view, and a desire to start from some striking and generally conceded position, if I select the

39.

Scientific progress to be consid. ered first.

scientific movement of ideas as the first with which I have to deal. How has it spread in the course of the century? From what begimnings and through what influences? What are its principles and methods? How have they themselves changed and developed? What has it led to? These are some of the questions which

1803 'Life and Writings of Thomas Reid' represent the predominant Scottish philosophy, and

1804 Thomas Brown, 'Inquiry into the Relation of Cause and Effect,' the beginnings of the later associationalist school. At the same period Jeremy Bentham's influence, which cannot be reduced to special dates, had already acquired European if not world-wide importance. His long life (1748-1832) was contemporary with Goethe's (1749-1832), whose 'Faust' was given to the world in successive stages between the years 1790 and 1832 .

1794. Thomas Paine's "Age of Reason."

1798. Malthus's 'Principles of Population.'

Literary criticism started on a new era and extended its influence in

1802 through the 'Edinburgh Review,' and

1808 the 'Quarterly Review'; in Germany somewhat earlier in

1794 Schiller's 'Horen.'

1797. Schiller and Goethe's "Xenien" in the 'Musenalmanach.'

1798. Schlegel's 'Athenreum.'

1802. A. W. v. Schlegel's Berlin lectures.

The Romantic school of fiction dates in Germany from 1798, when Frederick Schlegel uses the term for the first time as characteristic of a new departure in his review of Goethe's 'Wilhelm-Meister' ('Athenæum,' vol. i.) A literary movement with frequently similar aims and characteristics is represented in this country by Walter Scott ("Lay of the Last Minstrel," 1805), Southey ("Thalaba," 1802), and Coleridge ("Christabel," 1806), and spreads later into France. As the great source of the new and original poctic inspiration of nineteenth-century poetry we have the "Lyrical Ballads," 1798, and besides 'Faust,' the other principal works of Goethe and Schiller (died 1805). 
I shall try to answer as concisely as possible. This selection does not commit me to any theory on the value of the scientific view as compared with other aspects. Such theories will have to be dealt with in a later portion of the work. They have sprung up in the course of the last hundred years, partly as the inevitable outcome of scientific progress itself, partly in the educational world, where a reaction has set in against the undue importance which former generations attached to classical learning and training. I need not at present do more than note these opinions, nor need I define my position with regard to Comte's celebrated positivist theory on the advancing stages of the human intellect. Curiosity and the consensus of popular opinion suffice for the moment to make me take up the scientific side of the thought of the age. As we proceed, other directions and movements will present themselves, and the interdependence of all human interests will reveal and explain what truth attaches to Hegel's celebrated doctrine of the inherent dialectic of ideas, the spontaneous development of thought.

40.

Hegel's doctrine of the spontaneous developthought. 



\title{
A HISTORY OF EUROPEAN THOUGHT IN THE NINETEENTH CENTURY
}

\author{
PART I.
}

SCIENTIFIC THOUGHT 



\section{CHAPTER I.}

THE SCIENTIFIC SPIRIT IN FRANCE.

IT will be generally admitted that the scientific spirit is a prominent feature of the thought of our century as the seientific compared with other ages. Some may indeed be inclined to look upon science as the main characteristic of this age. The century may thus be called with some propriety the scientific century, as the last was called the philosophical century, or as the sixteenth was termed the century of the Reformation and the fifteenth the century of the Renaissance. It is therefore natural that we should begin our study of the thought of the age with an examination of this side of modern culture.

It is not necessary to define what I mean by science. ${ }^{1}$

1 The use of the word science and its adjective scientific has varied considerably in the English language. We must wait for $\mathrm{Dr}$ Murray's great work to give us a history of the word. I venture to assert that it acquired its present definite meaning about the time of the formation of the British Association for the Advancement of Science (1831). The two other great organisations which profes- sedly started for the culture of what we now call science-viz., the Royal Society for the Improvement of Natural Knowledge, and the Royal Institution-did not use the word officially in their charter or title, although it is used frequently in the documents and correspondence connected with the foundation of the younger, and occasionally in those referring to the older Society. The Royal So- 
Schools and colleges of science, triposes, examinations, and degrees in science, have established a popular meaning which did not exist a hundred years ago, but which is now well understood. For my purpose it is of some interest to note that the meaning of the word in French is somewhat different, and that the word Wissenschaft, ${ }^{1}$

ciety, and sometimes the Royal Institution, use the word "philosophy" in formal and official statements of their object. This is in accordance with older English usage. What we now universally call science was not infrequently termed in the seventeenth century natural knowledge, and Bacon himself translates scientice by "knowledge," by "learning," and sometimes by "sciences." In France, on the other hand, the word "science" seems to have acquired its present meaning as far back as the middle of the seventeenth century. At the time of the foundation of the "Académie des Sciences," in 1666 , the word was used almost in the same sense - embracing the same separate departments of knowledge-as tlie word "science" is now used in this country when we speak of a college of science. In France, so far as I am aware, a cultivator of science has never been called a philosopher. Science and philosophy have there never been synonymous. But science in France has been made to cover a larger field of knowledge by such adjectives as "moral," "social," "political," and has been narrowed by sucli other adjectives as "exact" and "natural," in the same way as the word philosophy has been more strictly defined in the English language by the adjectives "natural," "experimental," "moral," "mental," \&c. At the head of the sciences in France stood "mathematics," at the base of the new philosophy in England stood "experiment" and "observation."

1 The word Wissenschaft has a much wider meaning than science in the modern sense, and is the literal translation of the Latin scientia. It means knowledge in a systematic form and connected by some method. What the French call science, the Germans call exacte Wissenschaft. This includes mathematies and Naturwissenschaft, which covers the ground covered by the word "sciences" in English. The word Wissenschaft plays an important part in German culture, as we shall see later on. The modern term "scientist" is about synonymous with the word Naturforscher in German. The word savant in French has no synonym in English, but is about equivalent to the term Gelehrter in German; and this, again, is partially translated by "scholar" in English. I suppose "man of science" and "scholar" together would be about covered by either savant or Gelchrter. Those who desire to study the older and modern, the English and foreign, uses of the word science and other kindred terms, should read Bacon's English writings; Weld's 'History of the Royal Society' (1848, vol. i.); Bence Jones's 'The Royal Institution ' (1871); J,éon Aucoc's 'L'Institut de France' (Paris, 1889); Alfred Maury, 'Les Académies d'autrefois' (vol. i., Paris, 1864) ; and the correspondence in connection with the foundation of the British Associa. 
by which science is translated into German, requires a qualification in order to cover approximately the same ground. These verbal differences point to differences of thought. Only since Continental ideas and influences Difference of English and Contineutal have gained ground in this country has the word science science. gradually taken the place of that which used to be termed natural philosophy or simply philosophy. One reason why science forms such a prominent feature in the culture of this age is the fact that only within the last hundred years has scientific research approached the more intricate phenomena and the more hidden forces and conditions which make up and govern our everyday life. The great inventions of the sixteenth, seventeenth, and eighteenth centuries were made without special scientific knowledge, and frequently by persons who possessed skill rather than learning. They greatly influenced science and promoted knowledge, but they were brought about more by accident or by the practical requirements of the age than by the power of an unusual insight acquired by study. ${ }^{1}$ But in the course of the last

tion in Dr Whewell's 'Writings and Correspondence' by Todhunter (2 vols., London, 1876). I believe the word philosophy has lost the specific meaning which it acquired in the Baconian school, as much through the influence of French science on the one side as through that of metaphysics on the other. The latter emanated from Scotland and from Germany through Coleridge. It reinstated the word philosophy in its original sense.

${ }^{1}$ Examples are plentiful. Not to speak of gunpowder and printing, which came earlier, we have later nearly all the great improvements connected with the manufacture of textiles, the $\mathrm{fly}^{\mathrm{y}}$-shuttle, the selfacting mule, the power-loom, the spinning - roller, invented by men of little or no scientific education. The same is the case with the older metallurgical processes, the refining of copper and the introduction of cast-iron. Watt was one of the first who brought a trained intellect to his mechanical work. The Royal Society was started with the distinct purpose of cultirating such knowledge as has "a tendency to use"; the Royal Institution still more so. It is, however, still doubtful, view- 
hundred years the scientific investigation of chemical and clectric phenomena has taught us to disentangle the intricate web of the elementary forces of nature, to lay bare the many interwoven threads, to break up the equilibrium of actual existence, and to bring within our power and under our control forces of undreamed-of magnitude.

3.

Relation of science and practical life.

The great inventions of former ages were made in countries where practical life, industry, and commerce were most advanced; but the great inventions of the last fifty years in chemistry and electricity and the science of heat have been made in the scientific laboratory: the former were stimulated by practical wants; the latter themselves produced new practical requirements, and created new spheres of labour, industry, and commerce. Science and knowledge have in the course of this century overtaken the march of practical life in many directions. ${ }^{1}$ A confused

ing the history of the learned societies as well as the rare cases in which highest scientific genius is allied with practical skill in the same person, whether the cultivation of research for its own sake should not preferably be kept distinct from its hasty application. This is the view held by many great thinkers abroad. In England the opposite view has frequently impeded the progress of pure science.

${ }^{1}$ A few examples may suffice. The discovery by Oersted and Ampère of Electromagnetism (1819, 1820) led at once to the idea of electrical telegraphy : the first telegraph over considerable distances was constructed by Gauss and Weber (vid. 'Wilhelm Weber,' Breslau, 1893, p. 26, \&c.) The artificial preparation of an organic substance by Wöhler in 1828 led at once to many attempts at preparing expensive organic compounds - especially medical substances-by chemical synthesis. The occupation with this problem under A. W. Hofmann's instructions led Perkin in 1856 to the discovery of the first anilin colour (Mauvein, vid. 'Berichte der deutschen chemischen Gesellschaft,' No. 17, p. 3391). Leblanc's discovery how to make carbonate of soda from salt, for which a prize had been offered by the Paris Academy under Napoleon, led to the enormous development of the sulphuric acid industry in England and on the Continent. Liebig foretold in 1840 the recovery of sulphur from the waste of chemi. cal works and the effect on the sulphur mines of Sicily, fifty years before this process was satisfactorily carried out (vid. Liebig's familiar 'Letters on Chemistry,' list ed.,1843, pp. 22, 31, \&c.) But the greatest of all industries created in the laboratory was probably that of 
picture of this latest stage of culture lived in the pro1. Foreseen by phetic but essentially unscientific rnind of Lord Bacon. Lorl Bacon. But he did not sufficiently allow for the amount of patient scientific toil that was needed, nor for the time which the preparation of the instruments of research would require, nor for the necessity of destroying existing superstition and accumulated errors. All that has since been done by Newton and the great Continental mathematicians in the former, and by Bayle and Voltaire in the latter sense, Bacon had hoped to achieve at once by the new philosophy of fruit and progress. Such expectations were inevitably doomed to disappointment, though posterity has made amends by all but universally referring to him as the pioneer of modern thought,- -as the herald of a new era of human civilisation. ${ }^{1}$

making artificially the fertilising compounds required in common agriculture which followed on the publication of Liebig's famous work on 'Chemistry in its applications to Agriculture and Physiology' in 1840 (vid. Hofmann's Faraday Lecture of 1875 , "The Lifework of Liebig,' p. 15, \&c.) Liebig also discovered and described in 1832 the properties of chloroform and chloral, fifteen years before Simpson introduced the first as an anæsthetic and twenty years before Oscar Liebreich discovered the physiological action of chloral (ibid., p. 101, \&c.) Sir Lowthian Bell calculated, many years before the invention of the so-called basic process of making steel, the fertilising value of the phosphorus which was contained in the ironstone of Cleveland, and which then made it useless for the manufacture of highclass iron and steel. The great revolution in the theory of the steam-engine embodied in the work of Macquorn Rankine is to be traced back to the patient measurements by Joule of the mechanical equiva. lent of heat.

1 A great controversy arose on this subject through the publication of Liebig's pamphlet in 1862, entitled, 'Francis Bacon von Verulam und die Methode der Naturforschung.' It was directed mostly against the exaggerated view taken by Macaulay in his celebrated essay. The fact is that Bacon, like Voltaire after him, was much more of an essayist and a man of the world than a patient labourer in any special field of research; he was more of a plilosopher in a worldly sense (what the Germans call "ein Weltweiser") than a profound thinker. $\mathrm{He}$ misunderstood many of the great discoveries of his age, though he prophetically foresaw the great change in the spirit of inquiry. He did not appreciate 
5. Our age has in many ways inherited the spirit of

Defect in Bacon's philosophy.

Bacon's philosophy; but it would be a mistake to attribute its great scientific achievements to the exclusive working of this spirit. Bacon was neither a retired and patient nor an accurate thinker-the desire to apply and make his learning useful led him away from the "sapientum templa serena" into the forum of life: in his own experience, as well as in his writings, he anticipated many of the dangers which beset modern culture-the love of premature application, and the haste for practical results and achievements. Science, which in the hands of patient and diligent observers ${ }^{1}$ had just been rescued from the sway of empty metaphysical and theological reasoning,

the enormous part which mathematics would play in the development of science. In this respect Descartes was a genius of much greater originality-his actual contributions to scientific progress, as well as those of Pascal, being far beyond those of Bacon; but they both retained the metaphysical habit of thought which has characterised many, if not all, among the greatest mathematicians. In modern culture the popularisation of novel views and ideas has become so important a factor that writers like Bacon and Voltaire, who combine the scientific and literary taste, are of the greatest importance in the diffusion of new ideas, though none of their works need be looked upon as great repositories of research and knowledge. Before Liebig wrote his pamphlet, a very impartial and temperate estimate of Bacon's philosophy and its relations to actual science was published by Robert Leslie Ellis in his introduction to the philosophical works of Lord Bacon (London, 1857). As the literature of the subject is so large, I cannot but recommend this essay as containing one of the best discussions of it.

${ }^{1}$ A very good and concise account of the achievements of these contemporaries and forerunners of $\mathrm{Ba}$ con-of Tycho (1546-1601), Kepler (1571 - 1630), Galileo (1564 - 1642), Gilbert (1540-1603), Harriot (15601621), Napier (1550-1617), Harvey $(1578-1656)$ - is given by John Nichol in the second volume of his 'Francis Bacon, his Life and Philosophy' (Edinb., 1889), pp. 86, 254. In the same volume (p. 193) there is also a useful summary of Bacon's real claims to a place among physicists, of his ignorances (p. 196), and of the reception which his works met with in England and abroad (p. 233 to end). Not quite so readable, but more complete, is the little volume of Hans Heussler, 'F. Bacon und seine geschichtliche Stellung' (Breslau, 1889), with its flood of references-which exhaust the subject. See especially p. 160, \&c., on Bacon's anticipations. 
was in danger of falling a prey to hasty generalisation for the purpose of practical ends. Practical demands threatened then, as they frequently still do, to stifle or to force into premature growth the patient thought which had just begun to germinate in the new light and freedom of reason. The narrow view had indeed been widened, and the breadth of the land had been surveyed, but there was little inclination to deepen the view, or to do more than search on the surface. The spirit of Bacon's philosophy required a corrective. For a long time to come the hope of practical application had to be postponed; the thinker and student had to retire into solitude, and there to lay the more permanent foundations of the new research. This was done by Newton for all time. His by Newton. reputation spread more slowly than that of the great High Chancellor; but it rests on a surer foundation, which baffles every attempt to shake it, and will outlast all coming changes of thought.

The beginnings of modern scientific thought are thus to be found in this country. Lord Bacon foretold prophetically the great change which the new philosophy was destined to work. Newton more patiently drew up the first simple rules and gave the first brilliant application. More than the unfinished and wearisome pages of Bacon's 'Novum Organum' does the 'Principia' deserve to be placed on a line with Aristotle and Euclid as a model work of scientific inquiry.

For a real recognition of the greatness of Newton, as well as for a partial realisation of Bacon's plans, we are, however, mainly indebted to the French philosophers of the second half of the eighteenth century. Bacon's plan of promoting

7. Bacon's and Newton's ideas taken up by French phil. usophers. 
knowledge and research by the co-operation of many was more thoroughly realised in the old French Academy than in the Royal Society of London: his desire to unite all knowledge in a collective work underlies the great productions of Bayle, and still more those of the Encyclopædists. The many problems contained in Newton's 'Principia' were first treated singly by Clairault and Maupertuis; a general knowledge of his view of the universe was introduced into popular literature by Voltaire, ${ }^{1}$ who made use of it as a powerful weapon wherewith to combat error and superstition, or, as he termed it, "pour écraser l'infâme"; but for a full announcement of its scientific value and its hidden resources we are indebted to Laplace, whose 'Mécanique céleste' was the first comprehensive elaboration of Newton's ideas, and whose 'Système du Monde' became the scientific gospel of a whole generation of Continental thinkers.

Bacon and Newton compared.

We may look upon Lord Bacon as one who inspects a large and newly discovered land, ${ }^{2}$ laying plans for the

${ }^{1}$ I believe Voltaire was the author of the term Newtonianisme. The modesty and truly scientific spirit of Newton would not have allowed him to apply such a term to his work, and it is doubtful whether Voltaire did not extract from Newton's 'Philosophia Naturalis' a general philosophy which was not conceived in his spirit.

${ }^{2}$ Cowley in his Ode to the Royal Society :-

"Bacon at last, a mighty man, arose,.... And boldly undertook the injur'd pupil's canse.

... led us forth at last,

The barren wilderness he past;

Did on the very border stand

(of the blest promis'd land;

And, from the mountain's top of his exalted wit,

Saw it limself, and shew'd us it."
On this Mr Ellis remarks (Bacon's Works, vol. i. p. 63): "Bacon has been likened to the prophet who, from Mount Pisgah, surveyed the Promised Land, but left it for others to take possession of. Of this happy image, perhaps part of the felicity was not perceived by its author. For though Pisgah was a place of large prospect, yet still the Promised Land was a land of definite extent and known boundaries, and, moreover, it was certain that after no long time the chosen people would be in possession of it all. And this agrees with what Bacon promised to himself and to mankind from the instauration of the sciences. ... In this respect, as in others, the liopes of Francis Bacon 
development of its resources and the gathering of its riches. But the wealth lies deep down, and is only indicated by the first labours of the early pioneers. Newton, following these, unites their beginnings into a systematic exploration, and sinks the main shaft which reaches the lode of rich ore. $\mathrm{He}$ opens out the wealth of the mine and marks out the work for his followers. But many difficulties had to be overcome, much united effort and a vast organisation of labour were required, in order to develop to the full Newton's scheme, and to raise the great treasure which he had reached. This was not done until the end of the last century, when Laplace collected, arranged, and condensed the work of French and English mathematicians and observers into a picture of the universe. A variety of circumstances had combined to make the French capital the place above all others where the means and materials for the development of the great work could be most easily procured. Let us glance for a moment at the different factors in operation during the eighteenth century which contributed to the great achievement.

Whilst Newton was labouring privately and almost unassisted ${ }^{1}$ at the greatest scientific work produced in

were not destined to be fulfilled. It is neither to the technical part of his method, nor to the details of his view of the nature and progress of science, that his great fame is justly owing. His merits are of another kind. They belong to the spirit rather than to the positive precepts of his philosophy."

1 It has been stated that Newton, not knowing of Norwood's approximately correct determination of the

VOI. I. length of a degree in 1635 (and published in his 'Seaman's Practice' in 1637), but relying on the old figure of sixty miles for a degree of latitude (confirmed by Ed. Wright, Cambridge, 1610), was led away from the right supposition, which he entertained as far back as 1665 , regarding the moon's orbit, and had to wait for Picard's figures (ascertained about 1669, published in France about 1672, and in the 
modern times by any single mind, ${ }^{1}$ the penetrating and far-seeing genius of Colbert had already recognised the important part which science would one day play in the government of the world, and had secured the approval of his royal master to the constitution of an Aca-

Philos. Transactions in 1675), by applying which he determined that "the moon appeared to be kept in her orbit purely by the power of gravity." See Brewster's 'Life of Newton,' vol. i. p. 290, \&c.; Todhunter's 'History of the Theories of Attraction,' vol. i. p. 38, \&c. This account is, however, now discredited (see infra, chap. iv.) For the part which Dr Hooke and Halley took in the discovery of the "reciprocal duplicate" ratio, see also Brewster, loc. cit., vol. i. p. 291, \&c. During the writing of the 'Principia' Newton carried on a useful correspondence with Flamsteed, who was then Astronomer-Royal. How this happy co-operation ceased ten years later can be read at length in Brewster (loc. cit., vol. i. p. 312 ; vol. ii. p. 164, \&c.) The greatest material assistance which Newton received was from Halley, who defrayed the expenses of publishing the 'Principia,' after the Royal Society, to which it was dedicated, had reversed its resolution to defray them (Brewster, vol. i. p. 305, \&c.) Nevertheless Weld, in his 'History of the Royal Society,' says: "Fortunate indeed was it for science that such a body as the Royal snciety existed, to whom Newton could make his scientific communications; otherwise it is very possible that the 'Principia' would never have seen the light." Though one must lament the differences between Flamsteed and Newton, which prevented the latter from bringing his investigations of the lunar and planetary theories to a close (Brewster, vol. i. p. 312), a word of deep gratitude is due to Flamsteed's own exertions in the cause of astronomy. After Charles II. had built the Observatory in order to have the places of the fixed stars "anew observed, examined, and corrected for the use of his seamen " (Flam. steed, History of his own Life), and after he had appointed Flamsteed Astronomer-Royal at a salary of $£ 100$ per annum, the Observatory, "hurriedly established, was left for a period of nearly fifteen years without a single instrument being furnished by the Government" (Weld, vol. i. p. 255). The instruments were mostly supplied by Flamsteed himself or lent by others, and besides, "the king had ordered that Flamsteed should instruct monthly two boys from Christ Church Hospital, which was a great annoyance to him, and interfered with his proper avocations" (Baily, Account of the Rev. J. Flamsteed). "Any other man would probably have succumbed under the amount of drudgery appertaining to the office (earning his salary by labour harder than thrashing), if indeed, in the absence of encouragement, he would have continued in it at all, and particularly when the reward was so insignificant" (Weld, vol. i. p. 256).

1 "And it may be justly said, that so many and so valuable Philosophical Truths, as are herein discovered and put past dispute, were never yet owing to the Capacity, and Industry of any one Man" (Words of Halley, Philos. Transactions, vol. xvi., 1687). 
demy, which was based upon the endowment of research, and which prompted the co-operation of its members in organised $^{1}$ scientific work. Whilst the Royal Society of London only received a charter, and existed by the entrance payments and contributions of its own members, augmented by private donations, the Paris Academy had, $\underset{\text { Frencli }}{10 .}$ as far back as 1671, received the funds with which to Academy commence its labours in connection with the survey of the kingdom and its extensive dependencies. It was these labours which led to the measurements of the length of the seconds pendulum, and of the variation of gravity in different latitudes; to the explanation of this variation by Huygens; to the controversy regarding the figure of the earth; to the direct measurements of the arcs of the meridian in Peru and Lapland; and, finally, to Clairault's celebrated work on this subject. ${ }^{2}$ It was almost exclusively by these observations that the data were found with which to substantiate Newton's mathematical reasonings: in his own country that fruitful co-operation which

I " Le roi assurait l'existence des Académiciens par des pensions et mettait libéralement à leur disposition un fonds destiné à pourvoir aux frais de leurs expériences et de leurs instruments" (Maury, "Les Académies d'autrefois,' vol. i. p. 13). Organisation and co-operation are difficult to obtain in societies founded on private and voluntary contributions. In England they scarcely existed before the foundation of the British Association, with perhaps one illustrious exception pointed out by Struve ('Description de l'Observatoire de Pulkowa,' 4to, Pétersbourg, p. 5) : "Il y a, dans l'histoire de l'observatoire de Greenwich, un point très remarquable, savoir que les astronomes ont travaillé sur un même plan, depuis l'origine de l'établissement jusqu'à l'époque actuelle." Organisation and cooperation were the order in the Paris Academy from the beginning. "On y travaillait de concert"; and, "Dès les premiers mois de 1667 , Perrault proposa un plan de travail pour la physique, c'est à dire pour l'ensemble de l'histoire naturelle" (Maury, loc. cit., p. 15).

${ }_{2} \mathrm{~A}$ full account of these is given in Todhunter ('Hist. of Theories of Attraction, \&c.,' vol. i.) Clairault's book was published in 1743, and had the title, "Théorie de la Figure de la Terre, tirée des Principes de l'Hydrostatique, par Clairault.’ 
can only be secured by an academic organisation and by endowment of research was wanting. No one since the time of Bacon had been more impressed with this necessary condition of modern progress than Newton's great rival, Leibniz, ${ }^{1}$ much of whose time was spent in promoting academies all over Europe-in Berlin, St Petersburg, Dresden, and Vienna-and who had himself been early attracted to Paris and London by the scientific fame of their learned societies, though he significantly pointed out the want of activity and efficiency in the early history of the Royal Society.

11.

Continental methods in mathematics.

There was, moreover, another and independent line of scientific thought which had centred in France, the development of which came greatly to the aid of the students of Newton's work. This was the purely mathematical elaboration of the various infinitesimal methods of the French and English mathematicians, by which they were all brought together, simplified, and united into a calculus with strict rules, a practical notation, and an easy algorithm. Newton himself had for the purposes of his great work invented a new and powerful

1 A collection of Leibniz's mrit. ings on this subject will be found in the 7 th volume of M. Foucher de Careil's edition of Leibniz's Works, Paris, 1875. Of the projects of Leibniz, only the Academy of Berlin came into existence during his lifetime (1700 and 1701); the otlers were discussed at great length with the Elector of Saxony, with the Emyeror, and with Peter the Great. The Academy of St Petersburg was founded in 1724, eight years after the death of Leibniz. The Academy of Vienna did not come into life till
1846 , and in the same year that of Saxony was founded, which has its seat at Leipsic. Leibniz had the largest views on academic life and work: they were to embrace the historical and philosophical studies as well as the purely scientific, and were to stand in relation with the higher and lower educational institutions. His ideas are best realised at Berlin. See Jacob Grimm's interesting discourse, entitled 'Ueber Schule Universität Akademie' (Kleine Schriften, vol. i. p. 211, \&c.) 
instrument, afterwards called "the method of fluxions"; but he had not made it generally known before the invention of Leibniz was published. ${ }^{1}$ This, though much later in time, had been perfected and applied by his friends and followers in a most extensive manner, and had, in fact, become the recognised mathematical language of the Continent. No learned body did more than the Paris Academicians to perfect (with purely scientific

${ }^{1}$ Leibniz seems to have been in possession of his method as early as 1675, and communicated it to Collins in 1677. It was, however, not published before 1684 in the 'Acta Eruditorum,' and then probably only on account of some writings of Tschirnhausen trenching on the same subject. Newton seems to have been in possession of his methods as early as 1665 , fully ten years before Leibniz made use of his. Immediately after the publication of Leibniz's paper in 1684, the differential calculus was taken up by the Continental mathematicians, especially by James Bernoulli (1654-1705) and John Bernoulli (1667-1748), and the Marquis de l'Hopital, who published the first treatise on the new calculus in 1696. Newton did not publish any account of his method, though he must have used it extensively in arriving at the results contained in the 'Principia.' Different views have been expressed on the reasons which induced Newton to withhold from publication his new methods, and the question to what extent Leibniz owed the first suggestions of his method to Newton remains also undecided. Those who take an interest in the personal question should refer to the original documents, the 'Commercium Epistolicum,' published by the Royal Society in 1715 ; the pamphlet of Gerhardt,
'Die Erfindung der Differentialrechnung' (Halle, 1848). An extreme view, unfavourable to Leibniz's originality, is taken by Sloman, 'Leibnitzens Anspruch auf die Erfindung der Differentialrechnung' (Leipzig, 1857); but it has not been generally adopted by those who have examined into the subject. As to the superiority of the Continental notation for practical purposes, this seems to have been generally admitted at the beginning of this century, when it was introduced into English mathematical works. In the school of W. R. Hamilton of Dublin the notation used by Newton acquired a peculiar importance, and it is still occasionally used in some important works like Tait and Steele's 'Dynamics of a Particle,' and Thomson and Tait's 'Natural Philosophy.' See on this Tait's article on Hamilton in the 'North British Review' (Sept. 1866). The importance of the labours of the Continental school, headed by Leibniz, for the diffusion of the new methods, is well described by Remont de Montmort in a letter to Brook Taylor, dated 18th December 1718, and given in the appendix to Brewster's 'Life of Newton' (vol. ii. p. 511, \&c.) Those who take more interest in the fate of ideas and the progress of thought than in personal matters will do well to read this letter. 
interest) this new calculus, which in the course of the eighteenth century had in the hands of Lagrange been adapted to all the purposes and problems contained or suggested in Newton's 'Principia.'

This leads me to a third and yet more important element of scientific thought, which was peculiar to the Continental, and especially to the French mathematicians, counting among them Leibniz, who, though a German, was wholly trained in the French school. This factor is the establishment of pure mathematics on an independent foundation, and the cultivation of research into the abstract relations of quantity, without reference either to geometrical or mechanical problems and applications. It is the modern analytical spirit introduced by the great French algebraists of the seventeenth century, which looks upon geometry, mechanics, and astronomy merely as "questions d'analyse," and makes their solutions depend upon the perfecting of an abstract calculus rather than on the study of these individual problems themselves. Opposed to this spirit of analysis, which in general seeks the solution of any given question by looking upon it as a special case of a wider and more abstract problem, is the method known to the ancients, which never loses sight of the actual application, be it a figure in geometry or a special arrangement of physical forces, and is more interested in the peculiarities of the individual case than in the abstract formula of which it may be considered an application. This opposite view regards the calculus and mathematics in general merely as an instrument, the value of which lies solely in its application to real physical problems. It is usually 
termed the synthetical method, and has in modern times survived principally in England, where inductive reasonOlder synthetical ing, based upon observation of detail, has since the age method. of Lord Bacon been most successfully cultivated. ${ }^{1}$ These different ways of approaching the same subject will frequently engage my attention in the course of this survey: the greatest mathematicians of modern times have recognised the importance of both aspects, and the enormous progress of the science itself has depended, no doubt, on an alternating employment of them. Leibniz clearly foresaw this when, in his correspondence with Huygens and others, he urged the necessity of not abandoning the purely geometrical view, or entirely sacrificing the older for the modern methods. ${ }^{2}$ There can, however, be no doubt that

1 See on this point the opinion of an authority, Hermann Hankel, in his highly interesting and suggestive lecture, 'Die Entwickelung der Nathematik in den letzten Jahrhunderten ' (Tübingen, 1869, republished by $\mathrm{P}$. du Bois - Reymond, 1884). Speaking of the age of Leibniz he says: "Though on the Continent mathematicians were not so conservative as in England, where a purely geometrical exposition was considered to be the only one worthy of mathematics, yet the whole spirit of that age was directed to the solution of problems in geometrical clothing, and the result of the calculus had mostly to be retranslated into geometrical forms. It is the inestimable merit of the great mathematician of Basel, Leonhard Euler, to have freed the analytical calculus from all geometrical fetters, and thus to have established analysis as an independent science. Analysis places at its entrance the conception of a function, in order to express the mutual dependence of two variable quantities. . . The abstract theory of functions is the higher analysis. . . The conception of a function has been slowly and hesitatingly evolved out of special and suburdinate conceptions. It was Euler who first established it, making it the foundation of the entire analysis, and hereby he inaugurated a new period in mathematics" (p. 12, \&c.)

2 To Huygens, 16th September 1679 : "Je ne suis pas encor content de l'Algèbre, en ce qu'elle ne donne ny les plus courtes royes, ny les plus belles constructions de Géométrie. . . Je croy qu'il nous faut encor une autre analyse proprement géométrique ou linéaire, qui nous exprime directement situm, comme l'Algèbre exprime magnitudinem. Et je croy d'en avoir le moyen, et qu'on pourroit représenter des figures et mesures des machines et mouvements en caractères, comme l'Algèbre représente les nombres ou grandeurs" (Leibniz, Mathem. Werke, ed. Gerhardt, vol. ii. p. 19). 
the great success which attended Laplace's work, the elaboration of a system of the universe out of the principles of Newton, was largely due to the perfection which the analytical methods had gained in the hands of his predecessors, and to the skill with which he himself reduced the several problems to purely analytical questions.

But however much exact methods, learned societies, and regal endowments, may do to promote the growth of the scientific spirit, experience has shown that popular favour and interest furnish a still more effective stimulus. Even the most abstract reasonings of the mathematician require to be brought into some connection with the general concerns of mankind, before they can attract talent from outside, or enter into that healthy action and reaction which are the soul of all mental progress. In this respect, also, France during the second half of the eighteenth cen14. tury was far in advance of other countries. No other literature of that age can be compared with that of France, when we look at the influence or the expression which modern scientific views and interests had already attained in it; and no other country could at the end of the eighteenth century boast of such splendid means of scientific instruction as then existed in Paris. In two important departments - the popularisation and the teaching of scienceFrance for a long period led the way. ${ }^{1}$ A general inter-

To Bodenhausen (about 1690): "I am of opinion that in the problems of ordinary Geometry the methodus Veterum has certain advantages over Analysin Algebraicam, and I think I have remarked to you that there remains an Analysis geometrice propria, toto codo ab Algcbra diversa it in multis longe Algebra compendio- sior utiliorque" (ibid., vol. vii. p. 359). "It is certain that algebra, by reducing everything a situ ad solam magnitudinem, hereby very frequently complicates things very much" (p. 362).

1 Perhaps it would be more correct to say that science was fashionable than that it was popular in the 
est was thus created in the proceedings and debates of the Academy, and the discoveries of its illustrious members found their way into the lectures and text-books of the professors. Whatever eminence German science may have gained in this century, from a purely literary point of view, through the works of A. von Humboldt, or English science through those of Darwin, the history of both literatures during the eighteenth century can be written almost without any reference to science at all-so small was the direct influence of such giants as Newton and Leibniz on the popular mind. But who could exclude from a history of the elegant literature of France the names of Voltaire, of Buffon, of D'Alembert, or of Condorcet? These form a connecting link between science and general literature. ${ }^{1}$ A study either of English or

eighteenth century in France. But it became popular through the in. fluence of the great schools of Paris. Before becoming popular with the - masses it became so in cultivated and literary circles. The result has been that science in France alone has attained to a perfect form of expression. Whereas in other countries the great models of original research and thought were written in the severe style handed down by the ancients (Newton's 'Principia' and Gauss's 'Disquisitiones Arithmeticæ '), the great work of Lagrange (the 'Mécanique analytique') is a model of literary style in the modern sense. Science in our age has become popular through its applications. It is the utilitarian spirit that has popularised science in Germany and England. In France alone science, before com. ing under the influence of the utilitarian, came under that of the literary spirit. It was the influence of the academies that brought this about. See Maury, 'Les Académies d'autrefois,' vol. i. p. 178, \&c. More than with Richelieu, the interest in science nowadays is unfortunately only too often purely "metallic" (quoted from Lord Chesterfield's Letters). See also on the literary as compared with the modern practical character of science, Maury, ibid., p. 161.

1 " On érigeait même en principe la nécessité pour un philosophe de ne rester étranger à aucune science. 'L'esprit philosophique fait tant de progrès en France depuis quarante ans,' écrivait Voltaire à madame Du Châtelet, en lui dédiant sa tragédie d'Alzire, 'que si Boileau vivait encore, lui qui osait se moquer d'une femme de condition, parce qu'elle voyait en secret Roberval et Sauveur, il serait obligé de respecter et d'imiter celles qui profitent publiquement des lumières des Maupertuis, des Réaumur, des 
of German eighteenth-century literature does not intro-

15. duce one to the great controversies of science, but a

Absence of this influ. ence in Eng. land and Germany.

16.

Scliools of science in Paris. study of Voltaire leads one into the midst of the profound problems of the Newtonian and Cartesian philosophy, the disputes on the correct measure of force. ${ }^{1}$ Buffon's influence, also, by spreading a taste for the study of nature and by making objects of natural history attractive, was probably much more important than his actual contributions to the natural sciences themselves. ${ }^{2}$

For the growth and diffusion of the scientific spirit itself, the great schools in Paris were even of greater value than the popular writings of Voltaire and Buffon. Most of the Academicians were trained in these schools,

Mairan, des Du Fay et des Clairault; de tous ces véritables savants qui n'ont pour objet qu'une science utile, et qui, en la rendant agréable, la rendent insensiblement nécessaire ì notre nation. Nous sommes au temps, j'ose le dire, où il faut qu'un poëte soit philosophe et où une femme peut l'être hardiment.' En parlant ainsi, Voltaire ne faisait qu'exprimer l'opinion de son siècle, et ambitieux lui-même de réunir le titre de géomètre à celui de poëte et d'historien, il s'était fait expliquer par madame Du Châtelet laphysique de Newton" (Maury, 'Les Acad. d'autrefois,' vol. i. p. 156).

1 Vid. Maury, vol. i. p. 157, \&c.; and Du Bois-Reymond, "Voltaire als Naturforscher" in "Gesammelte Reden,'vol. i. p. 1.

2 "Sans l'éloquence de Buffon, Ia zoologie serait demeurée encore longtemps le privilége d'un petit nombre ; elle eut laissé indifférents ceux que la nature émeut moins que le charme de la parole. La vieille éducation classique avait le tort de nous laisser très-ignorants des choses du monde créé. Buffon com. muniqua aux sciences le charme des lettres. La curiosité s'éveilla, et en 1760, Valmont de Bomare put ouvrir à Paris le premier cours d'histoire naturelle; il fut assidûment suivi" (Maury, vol. i. p. 283). A. von Humboldt had a similar influence in Berlin seventy years later. Vid. Du Bois-Reymond, loc. cit., vol. i. p. 510. Guardia, 'Histoire de la Médecine' (Paris, 1884), says of Buffon, "Fontenelle avait rendu la science aimable et accessible. Buffon l'associa à la philosophie et aux lettres et l'introduisit définitivement dans la société" (p. 384). What a contrast, when we read in the 'Life of Sir W. R. Hamilton' (by R. P. Graves, vol. ii. p. 196) that Dr Buckland's communication at the Bristol meeting of the British Association (1836) "was apparently the first occasion of bringing before the public mind in England the geological doctrine of the great antiquity of the earth; for out of the expressly scientific circles, very little-you [viz., Count Adare] are aware - is known of what scientific men are about" ! 


\section{and many of them taught there for many years. ${ }^{1}$ It was with a true insight into the higher intellectual needs of the nation that the successive Governments of the Revo-}

1 Before the age of the Rerolution, which did so much to promote higher scientific education, Paris possessed already many great schools. First in importance was the Collége de France, founded in 1530 by Francis I. Gassendi and Roberval taught there in the seventeenth century, and about the middle of the eighteenth century science began to be more extensively represented, Lalande and Daubenton occupying chairs. The Collége et École de Chirurgie was an ancient establishment. There was the Jardin des Plantes, with Buffon, Lemonnier, ,Daubenton, and Fourcroy ; the Ecole royale des Mines, founded in 1783, where Duhamel taught metallurgy; the École des Ponts et Chaussées, founded by Turgot in 1775. Daubenton, Fourcroy, and Vicq d'Azyr taught in the École vétérinaire d'Alfort, founcled in 1766 . Besides the Académie des Sciences, the Académie royale de Chirurgie, founded by Lapeyronie under Louis $\mathrm{XV}$. in 1731 , had a great influence on the development of anatomy and surgery during the eighteenth century. Tenon and Petit, as well as Quesnay the economist, were amongst its members, and it kept up a lively intercourse with anatomists all over Europe. The Paris academies had also their representatives and connections in the provinces. Independent academies of science were affiliated with the Académie des Sciences-1716 at Bordeaux, 1706 at Montpellier, 1746 at Toulouse, 1766 at Béziers. Before having received their lettres patentes, which gave their members certain privileges, most of these academies had existed as independent societies. Other provincial academies, such as Arles (1668), Nîmes (1684), Soissons (1674), Marseilles (1726), were affliated with the Académie française. Others, such as Caen (1705), Lyons (1724), Dijon (1740), Rouen (1744), Amiens and Nancy (1750), Besancon (1757), Metz (1760), Clermont (1780), Orléans (1786), were not specially affiliated. These dates show how very much earlier a literary and scientific organisation existed in France than in other countries. The Protestant universities in Germany formed an organisation of a different kind, with which I shall deal later on. The academic system, so early dereloped in France, was of great use to the culture of the sciences. French science is usually considered to be almost entirely located in Paris. M. Bouillier ('L'Institut et les Académies de Province,' Paris, 1879) has drawn attention to the great services of this network of academies. Many of the most eminent writers belonged to these provincial centres, and worked for them even after becoming members of the more celebrated academies. Montesquieu is connected with Bordeaux, Cassini and many eminent doctors with Montpellier, Dijon has the honour of bringing out Rousseau, and Toulouse gave prizes to Bossut and Clairault. Robespierre's name is connected with the Academy of Arras, Marat discourses at Rouen and Lyons on electricity and optics, and Danton and Bonaparte compete for the prix Raynal at Lyons. "Mais," says M. Bouillier, "ce qui nous semble le plus digne de remarque et d'éloge, ce sont les écoles gratuites de dessin, les cours gratuits de physique, de chimie 
lution, in the midst of the more pressing problems of national safety and welfare, betook themselves to the solution of the great problem of national education and the instruction of all grades of society. "The Convention," says the historian of public instruction," "affords us the strange and grand spectacle of an assembly, which on the one side seems to have no other mission than to crush in the name of public welfare everything that stands in the

17.

Promoted by Governments of Revolution. way of the triumph of the Republican State, and which can see no other way of attaining this than the most terrible and cruel of tyrannies; and which on the other side devotes itself, with a stoical calm and serenity, forming a surprising contrast to its acts, to the study, the examination, and the discussion of all the problems involved in public instruction, of all the measures conducive to the progress of science. It had the glory of creating institutions, some of which were carried away by the blast of the Revolution, but among which the most important still exist for the great honour of France, and bear proof of the loftiness of her ideas." 2

d'histoire naturelle, d'anatomie, d'antiquités, fondés par un certain nombre d'académies et, entre autres, par Dijon, par Rouen, par Bordeaux, par Toulouse, par Montpellier, et dont les professeurs étaient des membres, non rétribués de ces académies. . . A combien de jeunes talents les académies provinciales n'ont-elles pas donné l'essor, par leurs récompenses solennelles et leurs encouragements? Combien de leurs lauréats ne sont pas devenus des hommes célèbres?" (p. 81, \&c.) Besides Bouillier, consult on these matters the several articles, "Académie," "Collége," "École," in the 'Grande Encyclopédie.'
1 C. Hippeau, 'L'Instruction publique en France pendant la Révolu. tion,' $1^{\mathrm{e}}$ série, préface, p. xix.

2 It appears nowadays a kind of paradox that, as M. Hippeau remarks, in the very year 1793 , when "the Convention was labouring with a feverish ardour at the creation of schools of all degrees," this same Convention, on a report of the Committee of Public Instruction, voted on the 8 th of August the suppression of all the academies of Paris and the provinces. On this M. Bouillier ('L'Institut et les Académies'’ p. 95) remarks : "Bientôt il est vrai, les académies devaient renaître après la chute de la 
It was of immense importance to the cause of science that in many of the discussions of that assembly a marked preference was shown for the scientific side of instruction. In this matter, as in many others, the successful constructive efforts of the Revolutionary Governments came from the side of those brought up in the

Montagne et du Comité de salut public. Nous n'ignorons pas que c'est encore la Convention qui, prise d'un tardif remords, la veille seulement du jour où elle devait faire place à un autre gouvernement moins despotique et moins cruel, décréta l'organisation de l'Institut. Mais la Convention du 3 brumaire an iv. n'était plus celle de 1793 ; c'était en réalité une autre Convention, épurée, décimée, renouvelée, animée d'un tout autre esprit," \&c., \&c. The idea of a national Institute for the advancement of letters, science, and arts was a very early one (vid. 'Rapport de Talleyrand Périgord,' September 1791, Hippeau, p. 102). The explanation how the same Government which was labouring at the problem of a national instruction, crowned by the higher teaching and research of an Institute, could begin by closing the existing academies and universities, lies in this, that the aim was to make education general and learning popular, not merely fashionable, as it had been. See, for instance, what Ducos said un the 18th December 1892: "Les mœurs d'un peuple corrompu ne se régénérent point par de légers adoucissements, mais par de vigoureuses et brusques institutions. Il faut opter ouvertement entre l'éducation domestique et la liberté ; car citoyens, tant que par une instruction commune vous n'aurez pas rapproché le pauvre du riche, le faible du puissant; tant que, pour me servir des expressions de Plutarque, vous n'aurez pas acheminé ì une même trace, et moulé sur une même forme de vertu tous les enfants de la patrie, c'est en vain que vos lois proclameront la sainte égalité, la République sera toujours divisée en deux classes: les citoyens et les messieurs" (Hippeau, 2 série, p. 21). It was because the academies and colleges supported "les messieurs" that they were suppressed. In the end education must always begin from above, and before the people can be taught you must form their teachers. See Lakanal's Report on the Écoles normales, Hippeau, vol. i. p. 408. The academies and colleges of the eighteenth century were closed in order to make room for that uniform system of public instruction described by Talleyrand and Condorcet; but not without a frequently expressed admiration for the work which they had done. See the defence of the academies by Condorcet (Hippeau, loc. cit., vol. i. p. 272), and the tribute to the "College de France," by Gilbert Romme (ibid., vol. i. p. 308). The arguments for radical change are summed up by that speaker as follows: "L'existence de ces corps privilégiés blesse tous nos principes républicains, attaque l'égalité et la liberté de penser et nuit aux progrès des arts. Mais si leur organisation est vicieuse, les éléments en sont bons, et nous serviront utilement dans l'organisation nouvelle de l'instruction publique que vous allez décréter" ( $p$. 309). 
school of Voltaire and the Encyclopædists, whilst the work of destruction had been performed by the followers of Rousseau. No one has expressed himself on the value of scientific study and knowledge in a clearer or more 1s. far-seeing manner than Condorcet. In his 'Report and Project of a Decree on the General Organisation of Public Instruction,' which he presented to the National Assembly in the name of the Committee of Public Instruction, he says:" "Many motives have brought about the kind of preference which is accorded to the mathematical and physical sciences. Firstly, for men who do not devote themselves to long meditations, who do not fathom any kind of knowledge-even the elementary study of these sciences is the surest means of developing their intellectual faculties, of teaching them to reason rightly and to analyse their ideas. ${ }^{2}$. . It is because in the natural sciences the ideas are more simple, more rigorously circumscribed, it is because their language is more perfect, \&c., \&c. . . . These sciences offer a remedy for prejudice, for smallness of mind-a remedy, if not more certain, at least more universal, than philosophy itself. ${ }^{3}$. . . Those

1 It was presented on the 20th and 21st April 1792. See Hippeau, $1^{\circ}$ série, pp. 185-288. It was printed by order of the Convention, Paris, Imprimerie nationale, 1793.

2 Ibid., p. 203.

3 Ibid., p. 204. It is interesting to see how in all these reports the exact sciences are placed in the foreground. See, for instance, what Gilbcrt Romme says of the teaching of the proposed instituts: "Les sciences mathématiques et phys. iques, morales et politiques, l'agriculture et les arts mécaniques, la littérature et les beaux-arts, com- poseront l'enseignement des instituts où l'on pourra suivre, dans leurs éléments, l'échelle entière des connaissances humaines" (vol. i. p. 322). "Les lycées seront l'école des gens instruits ; ils embrasseront les sciences, les arts et les lettres dans toute leur étendue." One is forcibly reminded that the most perfect realisation of this arrangement of studies is to be found a century later in the provincial science colleges of this country. The preference, however, is now given to science mainly for utilitarian reasons: the difference is shown by 
who follow their course, see the coming of an epoch when the practical usefulness of their application will reach greater dimensions than were ever hoped for, when the progress of the physical sciences must produce a fortunate revolution in the arts. And lastly, we have yielded to the general tendency of men's minds, which in Europe seem to incline towards these sciences with an ever-increasing ardour. . . Literature has its limits, the sciences of observation and calculation have none. Below a certain degree of talent, the taste for literary occupations produces either ridiculous pride or a mean jealousy towards such talents as one cannot attain. In the sciences, on the contrary, it is not with the opinion of men but with nature that we have to engage in a contest, the triumph of which is nearly always certain, where every victory predicts a new one." 1

"It is," says Lakanal, in his report on the "Écoles centrales," 16th December 1794, "of great importance for Lakanal. the nation to assure itself that the mathematical sciences are cultivated and deepened, for they give the habit of accuracy: without them astronomy and navigation have no guide; architecture, both civil and naval, has no rule; the sciences of artillery and of fortification have no foundation."2 Gradually, under the pressure of exter-

the importance then attached to mathematics as a training of the intellect in precise thinking; nowadays it is the mechanical side that is favoured, and this is only too often destructive of the truly scientific and exact spirit.

1 Hippeau, loc. cit., p. 258. Cf. p. 261: "Hâtons-nous... de porter dans les sciences morales la philosophie et la méthode des sciences physiques" (Condorcet).

2 Hippeau, vol. i. p. 432. It is interesting to see how the study and teaching of the sciences in course of the second half of the last century in France undergo a development. The literary interest predominates in Fontenelle. Buffon and Voltaire add to it the philosophical and 
nal events, the exigencies of war and the defence of the country gain the upper hand, and a central establishment is founded to cultivate and teach the sciences and arts, " upon which depend the defence of the Republic by land and sea." 1 Few of the higher and philanthropic aims of the great educational leaders of the early years of the Revolution-of Mirabeau, of Talleyrand, of Condorcetwere realised; little was done for primary education; but science can boast of having been worthily represented and supported in the two great schools which still bear their original designation, and which can show a record of celebrated names and magnificent work superior probably to that of any other similar institution in Europe. École nor. - They are the "École normale supérieure" and the

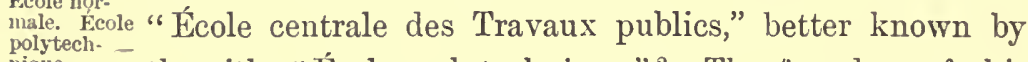
nique. the title "École polytechnique." 2 The founders of this

philanthropic, the Encyclopædists and Condorcet the educational ; the events of the Rerolution and the discussions in the Assemblies bring out more and more the instructive, the utilitarian, and the economical aspects. The only creations which resulted were those in which the latter aims were predominant.

1 Lakanal, vid. Hippeau, vol. i. p. 447.

2 To these two great schools must be added as a third the "Muséum d'Histoire naturelle," "le plus magnifique établissement que les sciences aient possédé" (Cuvier, "Éloge de Fourcroy," part ii. of the "Éloges historiques,' p. 44, Strasbourg, 1819). The foundation of the "Ecole centrale des Travaux publics" was proposed by Barère on the 11th March 1794, and definitely organised on the report of Fourcroy (Hippeau, vol. i. p. 446) by a decree of 7 th vendémiaire, an iv. (name changed to
École polytechnique, 15 th fructidor). The opening of the courses was announced for the 10th frimaire following (Hippeau, vol. ii. pp. 139, 174, 175). The foundation of the "Ecoles normales" was proposed by Barère (13th prairial, an ii.), and decreed on a report of Lakanal (Hippeau, vol. i. p. 423) on the 9 th brumaire, an iii. (30th October 1794) (ibid., vol. ii. p. 179). The courses opened on the lst pluviose. The work of the school was distributed as follows : Mathematics, Lagrange and Laplace; physics, Hauiy ; descriptive geometry, Monge ; natural history, Daubenton; chemistry, Berthollet; agriculture, Thouin; geography, Buache and Mentelle; history, Volney; morals, Bernardin de St Pierre. (Hippeau, vol. ii. p. 180, where also will be found extracts from the 'Moniteur' of the 9th pluviose on the opening addresses.) The oldest pupil was Bougainville, the great 
magnificent institution recognised "that, in spite of the diversity of applications, mathematics and physics are the indispensable basis of the studies in view." 1 Though the first period of the life of the École normale only counted four months, ${ }^{2}$ we are indebted to it for the

traveller. The École polytechnique received an allocation of $£ 12,000$, and had 400 pupils to start with. On the 20th frimaire, an iii., the Convention, on a report of Thibaudeau, voted the necessary expenses for the enlargement of the Muséum d'Histoire naturelle (Hippeau, vol. ii. p. 196), - viz., nearly $£ 8000$ for expenses, and $£ 200$ for each of the professors. The Museum had been originally destined for the culture of medicinal plants. Tournefort had given a great impetus to botanical, and Buffon, with Daubenton, to zoological studies. The Convention added several to the courses regularly held there on natural history, botany, mineralogy, and general chemistry. "Ces cours," says Thibaudeau, "fournissent 500 leçons par an, offrent l'ensemble le plus vaste et le plus complet d'enseignement sur toutes les branches d'histoire naturelle dont le plus grand nombre manquaient totalement à la France et dont quelques-unes manquent encore à l'Europe, l'application immédiate de toutes les sciences naturelles au commerce et aux arts."

Of other scientific and teaching institutions I must mention the "Bureau des Longitudes." This was organised by the Convention on a discourse by Grégoire, 7th messidor, an iii. (24th June 1795), in which he refers to the British Board of Longitude and the superiority of the British navy (Hippeau, vol.ii. p. 219). The appointments to this bureau were the géomètres Lagrange and Laplace, the astronomes Lalande, Cassini, Méchain, De- lambre, one of whom bad to deliver a course of astronomy, the travellers Borda, Bougainville, the géographe Buache, and the artist Carocher. It had charge of the observatory, which liad already been reorganised by a decree promoted by Lakanal on the 31st August 1793 (Hippeau, vol. ii. p. 76), and published in the 'Connaissance des Temps.' There were, besides, several military schools and the medical schools, not to mention other foundations less connected with our subject but equally important, such as the School of Oriental Languages, established in the Bibliothèque nationale (germinal, an iii., Hippeau, vol. ii.p. 215); the Écoles de Santé, established 14 th frimaire, ar iii., on a report of Fourcroy, in Paris, Strasbourg, and Montpellier (Hippeau, vol. ii. p. 194).

1 Ibid., vol. i. p. 450.

2 The Ecole normale was closed on the 30th floréal, an iii., on a decree of the Convention dated the 7 th of that month. Danton explained that the school had not taken the line which the Convention had marked out-the courses in general having offered a direct teaching of the sciences rather than an exposition of the methods which are to be adopted in teaching (Hippeau, vol. ii. p. 215). It also seems that the eminent teachers of this institution had few pupils sufficiently, prepared to follow them. The Ecole normale was reopened in the year 1808 under the Empire, by the same decree of 17th March which organised the Unirersity of France.

VOL. I. 
21. foundation of a new branch of science-the 'Descriptive 'Descriptive Geometry' of Monge, which was given to the world through shorthand notes ${ }^{1}$ from his lectures delivered in that institution. They form the beginning of the new science, since developed by Poncelet, Steiner, and others, and known under the name of "projective geometry." 2

Next to mathematics with its analytical and graphical application to physics and the arts, the subject most cultivated in these higher educational establishments of Paris

22.

Science of Chemistry. at the end of the last century was the new science of chemistry. With some justice this science has been termed a French science, ${ }^{3}$ not so much because even at that time

1 See the account of the origin of this branch of mathematics in Brisson's edition of the 'Géométrie descriptive,' Paris, 1847. In the programme prefixed to the treatise the three aspects of the new schoolthe national, the practical, and the educational - are well set forth : "Pour tirer la nation francaise de la dépendance où elle a été jusqu'ì présent de l'industrie étrangère, il faut premièrement diriger l'éducation nationale vers la connaissance des objets qui exigent de l'exactitude. . . Il faut, en second lieu, rendre populaire la connaissanced'un grand nombre de phénomènes naturels. . . . La géométrie descriptive est un moyen de rechercher la vérité; elle offre des exemples perpétuels du passage du connu à l'inconnu ; et parcequ'elle est toujours appliquée à des objets susceptibles de la plus grande évidence, il est nécessaire de la faire entrer dans le plan d'une éducation nationale." Monge generalised and placed on a scientific basis the methods used previously by carpenters and stonecutters, and partially dealt with geometrically by Courcier, Derand, Mathurin, Jousse, and Frezier. Vid.
Montucla, 'Histoire des Mathéma. tiques,' vol. iii. p. 15.

2 Monge taught also at the École polytechnique from the beginning. See the remarks of Chasles ('Rapport sur les Progrés de la Géométrie,' Paris, 1870, p. 2) : “L'enseignement théorique et profond qui a été la base de la première et judicieuse organisation de ce grand établissement était éminemment favorable aux progrès de la science, en même temps qu'il préparait sérieusement les élèves à l'entrée dans les écoles d'application." The author then refers with regret to the less scientific tone which had crept into the studies of that great school in the course of this century. See also p. 379 .

${ }^{3}$ A. Wurtz ('Histoire des Doctrines chimiques,' Paris, 1868, p. 1): "La chimie est une science française ; elle fut constituée par Lavoisier." Cf. Dumas ("Leçons sur la Philosophie chimique,' Paris, 1837, p. 137). Buckle ('History of Civilisation,'\&c., 3 vols., vol. ii. p. 366 , London, 1866) says: "That we owe to France the existence of chemistry as a science will be admitted by every one who uses the word science in the sense 
chemistry was not indebted to illustrious foreigners ${ }^{1}$ for some of its most important discoveries, as because the modern scientific spirit of accurate measurement first took hold of chemical phenomena on a large scale in the many important investigations which bear the name of Lavoisier and his followers, through whom the great reform of modern chemical knowledge and research was permanently established. It has been significantly pointed out ${ }^{2}$ that it was the union of mathematical with empirical knowledge which, through men like Laplace, Meusnier, Monge, first

in which alone it ought to be understood, \&c. ... Until Lavoisier entered the field there were no generalisations wide enough to entitle chemistry to be called a science." The correctness of this view is fully and impartially examined by Hermaun Kopp ('Die Entwickelung der Chemie in der neueren Zeit,' München, 1873, p. $89, \&$ c.) He fully upholds the claims of Lavoisier to be called the father of modern chemistry (p. 145). See also what Liebig says.

1 These were mainly, Black (discovered carbonic acid, called fixed air, in 1754), Cavendish (discovered hydrogen or inflammable air in 1767), and Priestley, who between 1771 and 1774 discovered oxygen (dephlogisticated air), nitrogen (phlogisticated air), and several of its compounds, among them ammonia (alkaline air). Of Priestley it is said by Cuvier that he may well be considered as one of the fathers of modern chemistry, "mais c'est un père qui ne voulut jamais reconnaître sa fille" ('Éloges,'vol. i. p. 208). Elsewhere ('Rapport his. torique sur les Progrès des Sciences naturelles,' Paris, 1810 , p. 90) Cuvier dates the revolution in chemistry from the introduction of the mathematical spirit: "Il en est une cause encore plus essentielle ì laquelle même on doit à proprement parler, et cette théorie nouvelle, et les découvertes qui l'ont fait naître. . . C'est l'esprit mathématique qui s'est introduit dans la science et la rigoureuse précision qu'on a portée dans l'examen de toutes ses opérations. . . . C'est dans le Traité élémentaire de Lavoisier que l'Europe vit pour la première fois avec étonnement le système entier de la nouvelle chimie," \&c.

"Kopp, loc. cit., p. 202 : "Indeed, if we look at those who first worked together with Lavoisier or in his spirit, we shall find such as had devoted themselves principally to mathematics or mathematical physics, men like Laplace, Meusnier, Monge. Among chemists Lavoisier stood for a long time almost alone in his opinions." This view is also taken by Cuvier ('Rapport,' p. 91): "Les nouveaux chimistes français . . ont eu à se louer du concours de quelques-uns de nos géomètres les plus distingués," \&c. ; and he attributes the next great step in chemical science to a similar introduction of a "rigueur toute mathématique" ("Rapport sur la Chimie lu ì la Séance des 4 Acad.,' 23d April 1826). 
brought about the general recognition of Lavoisier's ideas ; whereas the more exclusive representatives of chemistry, such as Berthollet and Guyton, held aloof for some considerable time. In the earlier syllabus of the École polytechnique, chemistry was brought into a similar proximity with the mathematical branches. And Berthollet's 'Statique chimique' denotes by its title alone the mathematical spirit in which the work was conceived.

New mathematical sciences.

24.
Crystallo. graphy.
About that time also two new sciences were, if not invented, at least set on a firm basis, by which the use of mathematics was very largely extended, and by which great realms of interesting facts were made accessible to accurate measurements and exact reasoning. Both these sciences can be claimed by France as almost exclusively her own creations. They are the science of crystallo24. graphy and the great theory of probabilities. The former was the work of the Abbé Haiiy; the latter formed, next to the mechanics of the heavens, the main original contribution by which Laplace has perpetuated his name in the history of science. The theory of the Abbé Haüy, who first taught how crystals are built up from small particles of definite and regular geometrical forms, such as cubes, pyramids, \&c., came to the aid of the mineralogists, who before him had vainly groped in the dark, searching for some method by which order and system could be introduced into the lifeless forms of nature as by the methods of Linnæus and Jussieu it had been introduced into the world of animals and plants. Before Haiuy, the doctrines of mineralogy had been either attached to geology-especially in the celebrated school of Werner, or latterly, after the great developments in chemistry had 
set in, to chemistry - especially by Bergmann. ${ }^{1}$ Haüy established the science of minerals on an independent foundation by studying and systematising the forms of their crystallisation; and he brought the science of mineralogy from Sweden and Germany into France, and gave it an independent position. Thus it came to form a connecting-link between the mathematical-i.e., the measuring and calculating-and the purely descriptive sciences. "Mineralogy, though it is that part of natural science which deals with the least complicated objects, is nevertheless also that which lends itself least to a rational classification. The first observers named the minerals vaguely according to their external appearances and their use. It was not until the middle of the eighteenth century that it was attempted to subject them to those methods which had done service to geology and botany: the hope existed of establishing among them genera and

1 See an account of the work of the chemical school, to which Cronsted (the inventor of the blowpipe), Bergmann, Kirwan, and Klaproth belonged, in Cuvier's 'Rapport' (p. 163). Also his "Éloge de Haüy" ('Éloges histor.', vol. iii. p. 143, \&e.) The beginnings of geometrical crystallography seem to go back to Linnæus; but his view was discouraged in France by Buffon, who disliked Linnæus's writings. Whewell, who was himself an authority on crystallography, thinks Romé de l'Isle, who was not an Academician, had only scant justice done to him by Haüy and his friends ('Hist. of the Induct. Sciences,' $3 d$ ed., vol. iii. p. 176). More recent writers, such as Kobell ('Geschichte der Mineralogie,' München, 1864, p. 73, \&c.) and Nicol (article "Crystal- lography," 'Ency. Brit.'), have done him justice. The 'Grande Encyclopédie' thus summarises the work of Romé de l'Isle: "Il mesura mécaniquement [viz., with Carangeot's goniometer] les angles et établit que ces angles ont toujours une valeur constante dans une même espèce minéralogique." That of Haüy is summarised in the two laws: " $1^{\circ}$, Tous les éléments semblables d'un cristal sont toujours semblablement et simultanément modifiés (loi de symétrie); $2_{0}$, toute facette modifiante intercepte sur les arêtes de la figure primitive des longueurs proportionelles à des multiples simples de la longueur de ces arêtes (loi de dérivation)" (Berthelot in 'Grande Encyclop.,' vol. xiii. p. 397). 
species, as among organised beings, and it was forgotten that in mineralogy the principle is absent which had given birth to the idea of species - viz., that of generation. The principle of individuality, such as it is conceived in the organic world-viz., the unity of action of different organs which co-operate in the preservation of the same life-can scarcely be admitted in mineralogy." 1

The Abbe Hauiy, by founding the science of minerals on their regular forms of crystallisation, made mineralogy "as precise and methodical as astronomy; in fact, we can say in one word that he was to Werner ${ }^{2}$ and Romé de l'Isle, his predecessors, what Newton had been to Kepler and Copernicus." 3

25.

Theory of Probability.

From that well-defined province of science which deals in a precise and strict manner with the simple numerical relations which seem to underlie all forms of movement in nature, be they on a stupendous or on a minute scale

I Cuvier, "Éloge de Haüy" in 'Éloges historiques,' vol. iii. p. 155.

2 'The character of Werner (17501815 ) is nowhere better, painted than by Cuvier in his "Eloge de Werner" (loc. cit., vol, ii. p. 303, \&c.) "Il commence l'époque la plus remarquable de la science de la terre, et même l'on peut dire qu'র̀ lui seul il la remplit. . . . Il s'est formé des académies entières, qui ont pris son nom" (for instance, the Edinburgh Wernerian Society, founded by Jameson, 1808-1859), "comme si elles eussent voulu invoquer son génie et s'en faire un patron d'une espèce auparavant in. connue. Qui ne croirait, à entendre parler de succès si peu ordinaires, que ce fut quelqu'un de ces hommes ardens à propager leur doctrine, qui par des ouvrages nombreux et éloquens, ont subjugué leurs contemporains, ou qui se sont procuré des partisans par l'ascendant d'une grande richesse ou d'une position élevée dans l'ordre social? Rien de tout cela: confiné dans une petite ville de Saxe, sans autorité dans son pays, il n'avait aucune influence sur la fortune de ses disciples; il n'entretenait point de liaisons avec des personnes en place: d'un naturel singulièrement timide, hésitant toujours à écrire, à peine subsistet-il de lui quelques feuilles d'impression. . . C'est ainsi qu'en peu d'années la petite école de Freyberg, destinée seulement, dans le principe, à former quelques mineurs pour la Saxe, renouvela le spectacle des premières universités du moyen âge," \&c., \&c.

3 Cuvier, ibid., l. 163. 
-i.e., from the province of mechanics and astronomytwo different roads lead into those extensive domains in which, not simplicity and regularity, but endless variety and complication, seem to be the order and the rule of Life. Even a century ago the contrast must have been striking between the 'Principia' of Newton and the 'Exposition du Système du Monde' of Laplace on the one side, and the great array of volumes of Linnæus, Buffon, Jussieu, Cuvier, and Lacépède on the other; though these after all embraced only a small portion of the living forms of nature which they attempted to classify or to describe. ${ }^{1}$ I have pointed out how the new and especially the French methods of chemistry and crystallography conquered a large portion of intermediate ground, subjected many tangled phenomena to exact treatment, and pushed the mathematical method far into the dominion of natural history. It is that other history, not natural, but human and often unnatural, which presents the opposite extreme of the great panorama of world-life. It is significant that almost at the same time that mathematical reasoning found its way into natural history, conquering an extensive province of its vast territory, an entirely different method was invented with the aim of dealing in a still more vigorous manner with the phenomena of human life and society. This was the science of statistics, and

1 Cuvier gives some figures as to the increase of the known species during his own lifetime. Lacépède had described about 1200 or 1300 distinct species of fishes; but when Cuvier pronounced his Éloge in 1826, the Cabinet du Roi contained already more than 5000 species ('Éloges historiques,' rol. iii. p. 317).
Linnaus had counted in 1778 about 8000 species of plants. Cuvier in 1824 estimates the, number as 50,000 or more (see 'Éloges,' rol. iii. p. 469 , \&c., where he also gires some idea of the numbers of known species in the different classes of animals). 


\section{connected with it the doctrine of averages and the mathe- matical theory of probabilities. ${ }^{1}$ The same great mind}

1 The beginnings of the science and theory of probabilities are not subject to controversy, as were those of the infinitesimal calculus. Pascal and Fermat about the middle of the seventeenth century entered into a correspondence relative to a question in a game of chance, propounded by the Chevalier de Méré, a noted gambler. They agreed in their answer, but could not convince their friend, who moreover made this the occasion of denouncing the results of science and arithmetic. But this comparatively insignificant problem - so different from the great cosmical problems which led to the invention of the infinitesimal calculus about the same time - was the origin of a series of investigations and discussions in which the greatest mathematicians, such as Huygens, James and Daniel Bernoulli, De Moivre, D'Alembert, and Condorcet joined. Most of them did not escape the errors and misstatements which creep in an insidious manner into the discussion and vitiate the conclu. sions. In fact, the science advanced through the influence of those who depreciated it like D'Alembert, and those who exaggerated its importance like Condorcet. At length, under the hands of Laplace, who defined it as common-sense put into figures and attributed to it a high educational value, it assumed a state wellnigh approaching to that perfection which Euclid gave to geometry and Aristotle to logic. Since the publication of Laplace's celebrated 'Théorie analytique des Probabilitćs' (Paris, 1812) writers on the subject have found ample occupation in commenting on the theorems or recasting the proofs given in that work, which holds a similar position to that occupied in another department of mathematics by the 'Disquisitiones Arithmetice' of Gauss (1801). Up to the present day there exist differences of opinion as to the value of the science, the two opposite views being represented in this country by Mill ('Logic,' 5th ed., vol. ii. p. 62) and Jevons ("Principles of Science,' vol. i.), the latter summing up his opinion as follows: "In spite of its immense difficulties of application, and the aspersions which have been mistakenly cast upon it, the theory of probabilities is the noblest, as it will in course of time prove perliaps the most fruitful, branch of mathematical science. It is the very guide of life, and hardly can we take a step or make a decision of any kind without correctly or incorrectly making an estimation of probability" (1st ed., p. 248). A similar opinion seems to have been held by James Clerk Maxwell (see Life by Campbell and Garnett, p. 143), who called the calculus of probabilities "Mathematics for practical men." In this country A. de Morgan and Todhunter, the former in a popular essay in the 'Cabinet Cyclopredia' and in a profound treatise in the 'Encyclopædia Metropolitana,' the latter in his well-known History (London and Cambridge, 1865), have done a great deal to make this subject better understood. The applications of the theory have gradually increased through numerous mortality and insurance calculations; as also in the estimations of error in astronomical and physical observations, where the well-known method of least squares (first employed by Gauss in 1795, see Gauss, Werke, vol. vii. p. 242 ; first published by Legendre in 1806, and then proved by Laplace in his 'Théorie,' 
which elaborated the principles of Newton into a system of the universe, and attacked the intricate mathematical problem which this system presented, gave to the world likewise the first complete treatise on that calculus which comes into play if we eliminate from the apparently most arbitrary region of phenomena, that of human life and history, all regard for final or efficient causes, for providential design and freewill, for human error, human malice and benevolence-in fact, all notice of that element which from another and equally important point of view forms the subject of greatest interest-the inner life of the individual. It was proposed, and it has since been carried out, to look upon human beings and human events not as things possessed of an inner world of thought and freewill, but as lifeless units, more uniform and regular than the balls thrown into the urn at an election, or the counters in a game of chance. By overstepping with one bound the great field of human activity, full os so much confusion and so much interest, it was proposed to investigate what knowledge would result from a purely mathematical inspection, in which human beings figured merely as units and symbols. ${ }^{1}$ This attempt, which has since

\&c., 1812) is now extensively employed. Of this branch of mathematics Bertrand says: "Les plus grands géomètres ont écrit sur le calcul des probabilités; presque tous ont commis des erreurs: la cause en est, le plus souvent, au désir d'appliquer des principes à des problèmes qui par leur nature échappent à la science." In the hands of Clerk Maxwell the calculus has acquired an additional interest and importance through the distinction which he made between what he termed the "histori- cal" and the "statistical method" of treating phenomena, and the application of the latter to the kinetic theory of gases (see Life, pp. 438, 562). This subject will occupy our attention in a special chapter.

1 The beginnings of the science of statistics belong likewise to the age that produced the higher mathematics. More extensive "countings" seem to have been contemporaneous with more refined calculations. Hermann Conring, professor at Helm. städt, a friend of Leibniz (see Leib. 
led to such interesting results, and which has furnished almost all the knowledge upon which a judicious regulation and government of society depends, was the work of Laplace, and was produced in an age and in a nation which seemed to have set at naught all ideas of order and method in human affairs, which defied all authority and all tradition, and trusted its fate to the most radical revolution which civilised society ever witnessed. ${ }^{1}$

It is curious to read the criticism which the first Napoleon, that wayward child of the Revolution, passed on the author of the mechanics of the heavens and the theory of probability. Laplace, like so many other men of science, had been called by the Emperor to assist in the labours of administration, but, according to his judgment, proved himself a poor administrator, being unable

niz's 'Philosophische Schriften,' ed. Gerhardt, vol. i. p. 155), lectured about 1660 on subjects now comprised under the term "Statistics," and about the sametime John Graunt of London published 'Natural and Political Annotations made upon the Bills of Mortality' (1666). Sir William Petty, one of the founders of the Royal Society, published in 1683 'Five Essays in Political Arithmetick.' The newly discovered calculus of probabilities induced mathematicians to take an interest in the subject, and to urge the desirability of gaining data for their calculations. Many of these turned upon questions of mortality and the ravages of diseases, such as the smallpox. But though undoubtcaly the fact that during the French Revolution mathematicians for the first time had a great influence in administrative and governmental matters contributed enormously to the introduction of statistical methods, the great epoch in this science is allied with the name of the Belgian Quetelet (1796-1874), of whom more later on.

I Cantor ('Historische Notizen über die Wahrscheinlichkeitsrechnung,' Halle, 1874, p. 6) say's : "The tendency of thought which prepared the Revolution, and which is marked by an unsparing and destructive criticism of the conditions of society in state and family, could not dispense with an instrument which, more than any other, enables one to subject to general viers the most different factors of civilisation. It belonged to the favourite ideas of that age, that the calculus of probabilities should be among the most important subjects of public instruction; for it was said to be the calculus of common-sense, through which alone the influence of hope, fear, and emotion on our judgment could be destroyed, and prejudice and superstition remored from the decisions of social life." 
to grasp practical issues, and always descending into infinitesimals. It is hardly to be doubted now, after the lapse of a century, that the infinitesimals of Laplace play a more important part in problems of administration and government than the ideas of Napoleon. Laplace, unlike some other great scientific thinkers, attached great value to a popular exposition of the principles of his discoveries. Descartes required a Fontenelle and Newton a Voltaire to make their ideas accessible and useful to the mass of students. Laplace was his own Fontenelle and Voltaire. "Few works," says Sir John Herschel, "have been more extensively read, or more generally appreciated, than Laplace's 'Essai philosophique sur les Probabilités,' and that on the 'Systeme du Monde' by the same author. It is not, perhaps, too much to say that were all the literature of Europe to perish, these two essays excepted, they would suffice to convey to the latest posterity an impression of the intellectual greatness of the age which could produce them, surpassing that afforded by all the monuments antiquity has left us. Previous to the publication of the 'Essai philosophique,' few, except professed mathematicians or persons conversant with assurances and similar commercial risks, possessed any knowledge of the principles of this calculus, or troubled themselves about its conclusions, regarding them as merely curious and perhaps not altogether harmless speculations. Thenceforward, however, apathy was speedily exchanged for a lively and increasing desire to know something of a system of reasoning which for the first time seemed to afford a handle for some kind of exact inquiry into matters no one had ever expected to see reduced to calculation, and bear- 
ing on the most important concerns of life. Men began to hear with surprise, not unmingled with some vague hope of ultimate benefit, that not only births, deaths, and marriages, but the decisions of tribunals, the results of popular elections, the influence of punishments in checking crime, the comparative value of medical remedies and different modes of treatment of diseases, the probable limits of error in numerical results in every department of physical inquiry, the detection of causes, physical, social, and moral-nay, even the weight of evidence and the validity of logical argument-might come to be surveyed with that lynx-eyed scrutiny of a dispassionate analysis, which, if not at once leading to the discovery of positive truth, would at least secure the detection and proscription of many mischievous and besetting fallacies."

Both ways of approaching the intricate phenomena of nature and history, that of mechanics dealing with the general laws of motion and of lifeless masses, and that of statistics dealing with the arithmetical properties of large numbers of units, leave out of consideration that hidden and mysterious phenomenon to which alone is attached, if not order and method, yet certainly all that commands interest in the created world: the factor

Laplace gained his results by lisresarding the principle of individuality. of life-the existence of individuality. The view which Laplace took of the universe or of human affairs is an attempt to see how far science and reasoning can go while disregarding the principle of individuality. ${ }^{1}$ The

1 See Clerk Maxwell on 'Science and Freewill' (Life by Campbell and Garnett, p. 438): "Two kinds of knowledge, which we may call for convenience dynamical and statistical. The statistical method of investigating social questions has Laplace for its most scientific and Buckle for its most popular expounder. Persons are grouped according to some characteristic, and the number of persons forming 
method has been most fruitful, and, far from being exhausted, promises undreamt of results in the future. It was probably more from the desire to keep his view clear and his method simple, than with any necessarily sceptical tendency, that when Laplace was questioned by Napoleon how it was that in the great volumes of the 'Mécanique céleste' the name of God did not appear, he replied, "Sire, je n'ai pas besoin de cette hypothèse."

But French science did not leave that great field of research uncultivated, which is the very playground of Individu. individual life. Its cultivation was the work of that other great representative of French science-the conality the interest in the sciences temporary of Laplace-Georges Cuvier.' Linnæus had

the group is set down under that characteristic. This is the raw material from which the statist endeavours to deduce general theorems in sociology. Other students of human nature proceed on a different plan. They observe individual men, ascertain their history, analyse their motives, and compare their expectation of what they will do with their actual conduct. This may be called the dynamical method of study as applied to man. However imperfect the dynamical study of man may be in practice, it evidently is the only perfect method in principle, and its shortcomings arise from the limitation of our powers rather than from a faulty method of procedure. If we betake ourselves to the statistical method, we do so confessing that we are unable to follow the details of each individual case, and expecting that the effects of "widespread causes, though very different in each individual, will produce an average result on the whole nation, from a study of which we may estimate the character and propensities of an imaginary being called the Mean Man."

1 It is not necessary here to explain the reasons which have induced me to confine myself mainly to the two great names of Laplace and Cuvier as the great representatives of the exact scientific spirit, as it first asserted its supremacy in France, and from there gradually fought its way all over Europe. To me it seems that nowhere has this modern scientific spirit been represented in greater completeness and greater purity. This is so much the more remarkable, as other influences and temptations were not wanting in that age and country which might have in. terfered with the application of the purely scientific method. The scientific spirit is in danger of being contaminated by two interests which are essentially foreign to it: the one is the practical, the other the philosophical. Frequently they are united ; and when united their influence on the progress of science has frequently been disastrous. In no department of knowledge has this 
begun the work of natural history by inventing a system of classification and a technical language or nomenclature. Buffon in his brilliant and elegant portraits had cast around it the charms of poetry and romance. Jussieu had imported botany from Sweden into France, and in the garden of Trianon had given a living model of the arrangement of plants; botanising had become popular through the

union of the practical and philosophical spirit been more marked than in the medical sciences. Essentially interested as it is in the immediate application of scientific discoveries to the needs of suffering mankind, we witness in the course of the seventeenth and eighteenth centuries a one-sided alliance of the art of healing with chemistry (Sylvius, 1614-1672), with physics (Borelli, 1608-1679), and with mechanics (Pitcairn, 1652-1713), and the reaction of the animists (Stahl, 1660-1734, and Hoffmann, 1660-1742), and the vitalists (Bordeu, 1722-1776, and Barthez, 1734-1806). A large portion of the history of medicine (see Haeser, 'Geschichte dor Medicin,' Jena, 1881, vol. ii., and Guardia, 'Histoire de la Médecine,' Paris, 1884) consists in the account of the opposition to premature generalisations, adopted from other sciences, or still more dangerously from metaphysics. As examples of the metaphysical tendency we have the Scotch systems of Cullen and Brown, and the German "Philosoplyy of Nature." The reasons why philosophy has so frequently allied itself with medicine, thus preventing the purely scientific spirit from gaining admission, are twofold. "Young mcll," says Cuvier, "adopt these theorics with enthusiasm, because they seem to abridge their studies and to give a thread in an almost inextricable labyrinth" ("Rapport,' p. 333). The other reason is that the art of healing has as mucl a psychological as a physical 'side, and a philanthropic as much as a scientific interest. In respect of this it is well to note that the age and country which gave to Europe the great models of purely scientific research in Laplace and Cuvier was rich also in great thinkers who applied themselves in a philosophical spirit to the advancement of scientific and practical medicine, to the reform of hospitals, to the care of the insane, to the education of the deaf and dumb. The whole school of the ideologues, headed by Condorcet, Cabanis, and Destutt de Tracy, was closely allied with the medical profession. But however important this side of French thought may have been, its influence on the rest of Europe at that time cannot be compared with that of the purely scientific writings belonging to mathematics and natural science. Such names as Cabanis and Bichat belong to a different current of European thought, which I purposely separate from the exact or purely scientific. And this separation is justified historically by the fact that in the Académie des Sciences for a considerable time medical science was only meagrely represented, whilst philosophy during the period of the suppression of the Académie des Sciences morales et politiques, from 1803-1832, had no academic representation at all. The great name of Bichat is not among the Academicians, and Cuvier himself 
writings of Rousseau; gardening and the study of plantlife had become a royal pastime, and a favourite recreation for those oppressed with the troubles of the State or the sorrows of private life. Cuvier, while asking the reason why other portions of natural history had not shared the same attention, breaks out into the following eloquent words: "The study of animals presents diffi-

explains the exclusive attitude of the Academy to the medical profession in his Éloges of Hallé, Corvisart, and Pinel ('Éloges,' vol. iii. p. 339, \&c.) See also Maury (p. 304) : "Les sciences physiques, chimiques et naturelles avaient pris une telle extension dans les travaux de l'Académie, qu'à la fin du dixhuitième siècle, la médecine, qui n'y avait jamais été au reste bien largement représentée, fut de plus en plus reléguée à l'arrière plan; ce n'était plus que de loin en loin que les médecins, les chirurgiens de la Compagnie, ... y présentaient des observations sur des points médicaux. . . L La médecine, qui, selon la juste observation de Cabanis, tend aux hypothc̀ses par la nature même du sujet auquel elle s'applique, n'offrait point assez de constance dans ses principes et d'évidence dans ses démonstrations pour satisfaire des esprits qui se détachaient tous les jours davantage des vieilles spéculations de l'école. C'est ce qui explique le peu de faveur qu'elle rencontrait à l'Acadénie." To what extent this rigid demarcation, according to which "observations relatives aux dispositions morales et intellectuelles des individus n'entrent assurément dans les attributions d'aucune académie des sciences " ('Mémoires de l'Institut,' vol. ix. p. 110), was beneficial to medical science is an important question. In the organisation of the Institute of the 3d brumaire, an iv. (25th October 1795), there are awarded out of 60 members only 6 to medicine and surgery combined, and in the "nouvelle organisation" of $3 d$ pluviose, an xi. (23d January 1803), there are 6 members out of 63. This section is given as the last, even after "économie rurale et art vétérinaire" (see Aucoc, 'L'Institut,' p. $3, \&$ c.). It is interesting to note how in contrast to this the medical profession occupied for a long period a foremost place in the Royal Society of London, so much so that frequently opposition was made to the admission of new members belonging to it (see Weld, 'History of the Royal Society,' vol. i. chap. 4 ; vol. ii. p.153). Of 5336 papers contained in the 'Philosophical Transactions ' from 1665 to 1848,1020 , the largest number in any department, belonged to anatomy, physiology, and medi. cine (ibid., vol. ii. p. 565). Babbage complained of the influence of the Colleges of Physicians and Surgeons in the Royal Society, as occasionally filling the pages of the "Transac. tions' with medical papers of very moderate merit; and also because the preponderance of the medical interest introduces into the Society some of the jealousies of that profession ('Decline of Science in England,' 1830, p. 188). In the foundation of the British Association this union with the medical interest was dropped; though the older "Versammlung deutscher Naturforscher und Ärzte," after which it was modelled, established and maintained that union. 
culties which only great zeal can surmount; we have to subject them to torments in order to appreciate their physical powers; their innermost energies only reveal themselves to the dissecting-knife-only by living among corpses can we discover them. Among them we find the same spectacle as in the world, whatever moralists may say: they are hardly less wicked or less unhappy than we are; the arrogance of the strong, the meanness of the weak, vile rapacity, short pleasures bought by great efforts-death brought on by long suffering-that is the rule among animals as much as among men. With plants existence is not surrounded by pain - no sad image tarnishes their splendour before our eyes, nothing reminds us of our passions, our cares, our misfortuneslove is there without jealousy, beauty without vanity, force without tyranny, death without anguish - nothing resembles human nature." 1

$2 s$. Into this centre Cuviel car. ried exact research.

Into the centre of individual and organised life-the life of the animal and luman creation-Cuvier carried exact research, grounding it on the science of comparative anatomy. ${ }^{2}$ At the same time, he marked out as the principal problem, around which all investigations must turn, and upon which all classification must depend,

1 'Éloges listoriques,' vol. i. p. 91.

2 Cuvier, in the Introduction to

'Le Règne animal, distribué d'aprìs son organisation, pour servir de base it l'histoire naturelle des animaux et d'introduction à l'anatomie comparée' (Paris, 181\%), says that for thirty years he had deroted to comparative anatomy all his time ( $p$. $v)$, that the first results had appeared in 1795, his 'Leçons d'Anatomie comparée' in 1800 (p. vii), that he has made anatomy and zool- ogy march side by side (p. vi). He compares natural history as a science with other sciences, stating that dynamics is become a science almost entirely of calculation, that chemistry is still a science altogether of experiments, that natural history will for a long time to come remain in most of its parts a science of observation (p. 5) ; he maintains that geometry is a study of syllogisms, natural history a study of method (p. xviii). 
the phenomenon of individual life, that great vortex into which agencies, processes, and the elements of inorganic nature are continually drawn, from which they are continually ejected, preserving not the unity of substance but, among changing events, the unity of form. ${ }^{1}$

"It is not," he says, "in the substance that in plants and animals the identity of the species is manifested, it is in the form. There are probably not two men, two oaks, two rose-trees, which have the compound elements of their bodies in the same proportion - and even these elements change without end, they circulate rather than reside in that abstract and figured space which we call the form; in a few years probably there is not left one atom of that which constitues our body to-day-only the form is persistent; the form alone perpetuates in multiplying itself; transmitted by the mysterious operation which we call generation to an endless series of individuals, it will attract successively to itself numberless molecules of different matter, all of them merely transient." 2

1 "La vie est donc un tourbillon plus ou moins rapide, plus ou moins compliqué, dont la direction est constante, et qui entraine toujours des molécules de mêmes sortes, mais où les molécules individuelles entrent et d'où elles sortent continuellement, de manière que la forme du corps vivant lui est plus essentielle que la matière" ("Règne animal,' p. 13, \&c.) " Il vient sans cesse des éléments du dehors en dedans: il s'en échappe du dedans au dehors: toutes les parties sont dans un tourbillon continuel, qui est une condition essentielle du phénomène, et que nous ne pouvons suspendre longtemps sans l'arrêter pour jamais. Les branches les plus simples de l'histoire naturelle par- ticipent déjà à cette complication et à ce mouvement perpétuel, qui rendent si difficile l'application des sciences générales" ('Rapport,'p. 150, \&c.) "Dans les corps vivans chaque partie a sa composition propre et distincte; aucune de leurs molécules ne reste en place; toutes entrent et sortent successivement : la vie est un tourbillon continuel, dont la direction, toute compliquée qu'elle est, demeure constante, ainsi que l'espèce des molécules qui $y$ sont entraînées, mais non les molécules individuelles elles-mêmes. . . . Ainsi la forme de ces corps leur est plus essentielle que leur matière," \&c. (ibid., p. 200).

2 'Eloges historiques,' rol. iii. p. 156.

VOL. I. 
Keeping this unity of form, this absorbing vortex of life, the totality of organisation, always before him, Cuvier, in surveying the whole region of animated nature, ${ }^{1}$ fixes finally for the purposes of classification and division on that system of organs which expresses most truly the peculiarity of each of the great branches into which he divides the animal world-namely, the nervous system. ${ }^{2}$ But rather than follow him at present into the

1 "La partie anatomique du problème général de la vie est résolue depuis longtemps pour les animaux, au moins pour ceux d'entre eux qui nous intéressent le plus. Les voies que les substances y parcourent, sont connues; . . . il aperçoit aussi comment ces routes, si compliquées dans l'homme, se simplifient par degrés dans les animaux inférieurs, et finissent par se réduire à une spongiosité uniforme. Les recherches de M. Cuvier-dans les leçons d'anatomie comparée - ont achevé d'assigner à chaque animal sa place dans la grande échelle des complications de structure" ("Rapport,' p. 202, \&c.)

2 It is not my object here to give an account of the views of Cuvier, still less of his contributions to llatural history, which-in spite of the special theories and laws which he and his followers established (see especially Flourens, 'Histoire des Travaux de Georges Cuvier,' 3' éd., 1858)-remained in his hands to the last pre-eminently a science of obserration. It has been pointed out that Cuvier only gradually (probably about 1812) arrived at the final principle of division-viz., the nervous system-and that he adopted it from others (notably Virey and De Blainville), that before 1812 he had successively used the organs of generation (1795), of nutrition, and of circulation as principles of classification. In his Report of 1808, in mentioning his own labours, he says: "M. Cuvier, en étudiant la physiologie des animaux vertébrés, a trouvé dans la quantité respective de leur respiration, la raison de leur quantité de mouvemens, et par conséquent de l'espèce de ces mouremens. . . En effet, M. Cuvier, ayant examiné les modifications $q u$ ' éprouvent dans les animaux sans rertébres les organes de la circulation, de la respiration, et des sensations, et ayant calculé les résultats nécessaires de ces modifications, en a déduit une division nouvelle où ces animaux sont rangés suirant leurs réritables rapports" ("Rapport,' p. 311, \&c.) Compare also Carus, 'Geschichte der Zoologie,' München, 1872, p. 602 ; Flourens, "Éloge de Cuvier," in his "Éloges historiques,' $3^{\text {me }}$ série, Paris, 1862, p. 122, \&c.; Hahn in the 'Grande Encyclopédie,'article "Cuvier." See also the Introduction to the "Règne animal,' which proposes to arrange living beings according to their "organisation," by investigating their "structure," their "internal as well as external conformation." Cuvier here states that no one before had tried to arrange the classes and orders according to the "ensemble de la structure" (p. vi). He is thus led to the law of the "subordination des caractères, . . . ayant soin d'établir toujours la correspondance des formes extérieures et intérieures qui, les unes comme les 
details of his natural history, his comparative anatomy, or his palæontology, of which latter sciences he is the creator, it serves our present purpose better to learn how he viewed the object of natural science in general-how he defined its task. As the first step in civilisation was the creation of a language possessing definite rules, so the first step in the growth of a science is that taken by Linnæus, who was not terrified by this enormous work, that of giving names, of framing a nomenclature. ${ }^{1}$ "But," says Cuvier, "to name well, you must know well. These

autres, font partie intégrante de l'essence de chaque animal" (p. xiv). He opposes former artificial classifications, such as the principle that living beings can be arranged "de manière à former des êtres une seule ligne" ( $\mathrm{p} . \mathrm{xx}$ ). "Un être organisé est un tout unique, un ensemble de parties qui réagissent les unes sur les autres pour produire un effet commun. Nulle de ses parties ne peut donc être modifiée essentiellement sans que toutes les autres ne s'en ressentent " ('Éloges,' vol. ii. p. 279).

1 The formation of a nomenclature or a terminology is one of the most important steps in the beginning and the progress of science. Cuvier refers frequently to this: "Nos livres saints, à leur début, nous représentent le Créateur faisant passer ses ouvrages sous les yeux du premier homme, et lui ordonnant de leur imposer des noms. . . . Ces noms, qu'il est prescrit à l'homme d'imposer, ne sont pas des signes incohérens appliqués au hasard à quelques objets isolés. Pour qu'ils deviennent réguliers et significatifs, ils exigent, comme il est dit, que les êtres aient passé devant le nomenclateur" ('Éloges,' vol. uii. pp. 450, 452). Nowhere is terminology more import- ant than in chemistry. "L'un des moyens qui ont le plus puissamment contribué à faciliter l'enseignement de la science en général, et à préparer l'adoption universelle de la théorie nouvelle, c'est la nomenclature créée par cette société de chimistes français. . . . Donner aux élémens des noms simples; en dériver, pour les combinaisons, des noms, qui exprimassent l'espèce et la proportion ćes élémens qui les constituent, c'était offrir d'avance ì l'esprit le tableau abrégé des résultats de la science, c'était fournir à la mémoire le moyen de rappeler par les noms la nature même des objets. C'est ce que M. Guyton de Morveau proposa le premier dès 1781 , et ce qui fut complétement exécuté par lui et par ses collègues en 1787 " ("Rapport,' p. 88, \&c.) Cf. 'Eloges,' vol. iii. pp. 194, 482, 496. Cuvier ('Éloges,' vol. iii. p. 302) mentions "cette antipathie pour les méthodes et pour une nomenclature précise à laquelle Buffon s'est laissé aller en tant d'endroits" ; he speaks of Pinel "qui avait cherché d'abord à former pour les descriptions des maladies un langage précis, modelé sur celui que Linnæus avait introduit en botanique" (ibid., vol. iii. p. 386). 
beings and their parts which are to be known are to be counted by the million; it is not enough to know them singly, for they are submitted to an order, to mutual relations, which must likewise be appreciated, for it is according to this order that each has its part to play, that each disappears at its time, that they reappear similarly made, always in the same proportions, and armed with the necessary forces and faculties for the maintenance of these proportions, and of the whole of this perpetual vortex. Not only is each being an organism, the whole universe is one, but many million times more complicated; and that which the anatomist does for a single animal-for the microcosm-the naturalist is to do for the macrocosm, for the universal animal, for the play of this alarming aggregation of partial organisms." 1

It was this sustained regard for the value of detailed research and minute observation, coupled with an equal appreciation of the unity of all regions of existence, and all branches of learning, that elevated Cuvier to the height of the science of his age and his country, and made him a true exponent of the modern scientific spirit. The works of Newton and Laplace may contain more formulæ of lasting value, more instruments of permanent scientific use-they may, for all time, have traced a few lines of the enwoven cipher of the all-pervading mechanism of nature; it is, however, well to note that he only who keeps in steadfast view the life rather than the mechanism of existence, approaches the great secret of nature, and gauges rightly the value of each component

1 Cuvier 'Éloges historiques,' rol. iii. p. 453. 
part, or the worth of each human effort. ${ }^{1}$ In this respect the nineteenth century knows no greater figure than Cuvier; not even Humboldt, great and comprehensive as was his scientific view. The advantages also of Cuvier's position as permanent Secretary of the French Academy of Sciences were exceptional, and well fitted to bring out his extraordinary talents. We can say that in him science has become fully conscious of its true methods, its usefulness, its most becoming style, its inherent dignity, its past errors, its present triumphs, the endless career which lies before it, and the limits which it cannot transgress.

Educated in Germany, at the same school as Schiller and Dannecker, ${ }^{2}$ imbued by early experience and by training.

1 "C'est la continuation de ce commandement de voir et de nommer, par où s'ouvre la vie de notre espèce, c'est la voie qui devait nous conduire soit ì des contemplations plus hautes, soit seulement à des inventions utiles. En effet l'histoire naturelle ne fait aucun pas sans que la physiologie et la philosophie générale marchent d'un pas égal, et sans que la société reçoive leur tribut commun " ('Éloges,' vol. iii. p. 474).

2 Cuvier has himself written an account of his early life and studies. It is given by Flourens, 'Éloges,' vol. i. pp. 167-193. He was born in 1769, of a Protestant stock, at Montbéliard, the capital of a small principality, situated in the Jura, and then belonging to Wiirtemberg. The autocratic Duke Charles (1737. 1793) had founded a military academy in Stuttgart, his capital, where 400 youths were at his expense housed and educated according to a strict rule, but under the guidance of enlightened masters, and in a thoroughly modern spirit. The institution was a kind of oppo- sition to the Protestant Church rule, which had very early spread a system of popular and compulsory education throughout the country. It is a chapter of history wcll worth reading. The great problems of popular education as against higher instruction, Protestant discipline in the lower as against military discipline in the higher schools, the democratic as against the aristocratic spirit, the independence as against the State-regulation of University teaching, were fought out by the dukes and the Estates of Würtemberg in a prolonged warfare, a sample of similar movements all over Germany, and well told by Perthes in liis 'Politische Zustände und Personen in Deutschland zur Zeit der französischen Herrschaft, (Gotha, 1862, pp. 501-548). Cuvier evidently saw the better side of the system, for he entered after the imperious character of the duke had been subdued by the victorious estates. Forced to change his ways, which he conscientiously did, the duke laid by for his country, as a local historian says, "a fund of in- 
personal contact with that spirit of general education and universal training which then animated the Germanspeaking nations of the Continent, thoroughly grounded in classics and mathematics, with a cosmopolitan knowledge of languages and literature, which fitted him to understand the merits of different nations, he became the great exponent of that peculiar system of higher culture which since the time of Colbert the French had elaborated-the academic system. ${ }^{1}$ The centre of this

telligence and acquisitions by which we have benefited up to modern times" (Perthes, p. 510). We know the other and older side of the picture from the 'Life of Schiller' (vid., inter alia, Carlyle, 'Life of Schiller,' collected works, library edition, vol. v. p. 258). Cuvier gives a long description of the "Karlschule": "C'était un établissement vraiment magnifique. Environ quatre cents boursiers et pensionnaires, logés dans un édifice tel qu'il n'y en a aucun d'approchant en Europe (parmi ceux qui sont consacrés à l'instruction de la jeunesse), vêtus d'un bel uniforme, conduits par des officiers et des sousofficiers tirés des régiments du duc, reçevaient des leçons de tout genre de plus de quatre-vingts maitres ou professeurs. On a beaucoup parlé de l'esprit de despotisme avec lequel le duc disposait de leurs personnes et choississait pour chacun d'eux l'état qu'il devait embrasser, et je crois en effet qu'il en était ainsi dans l'origine de l'établissement; mais de mon temps, je n'ai rien vu de semblable, et ce qui est certain, c'est que personne ne prétendit même me donner de conseil à cet égard. Il y avait cinq facultés supérieures, droit, médecine, administration, militaire et commerce" (Flourens, loc. cit., p. 171).

1 The first great representative of this academic spirit and culture was Fontenelle, who, living during a hundred years, from 1657 to 1757 , was Secretary of the Académie des Sciences during forty-two years, from 1699 (the year of the reconstitution of the Academy) to 1741. Among his successors were men like Condorcet, Delambre, Cuvier, and Arago. Fontenelle gave to scientific subjects a dignified popularity, separated the departments of science and metaphysics, kept the scientific interest free from the commercial, and through his connection with the Académie française did probably more than any other writer to establish that superiority of style and diction for which the great French men of science are so remarkable and so superior to those of other countries. Bertrand, himself a successor of Fontenelle, says of him: "Prêtant aux travaux de ses confrères la finesse de ses aperçus et la vivacité ingénieuse de son style, il a su dans leurs portraits, qui sont des chefsd'œuvre, plus encore que dans l'analyse de leurs découvertes, donner aux plus humbles et aux plus modestes une célébrité imprévue et durable, et le juste et sérieux hommage qu'il rend au vrai mérite fait aimer et respecter tout à la fois les savants et la science" ('L'Académie des Sciences et les Académiciens,' p. 113). See also Voltaire's 
system was the old Academy of Sciences, which, with a short interruption during the storm of the Revolution, survived, ${ }^{1}$ and formed the principal feature in the Institute. Allied with this institution, and directly inspired by its spirit, were the great schools of natural science, the great collections of natural objects, latterly also the great medical institutions of Paris. It professed to protect scientific studies in a royal and generous manner, attracted talent from outside, rewarded foreign as well as French research, ${ }^{2}$ and tried to keep the scientific spirit of inquiry, as well as the form in which it found expression, pure and undefiled. ${ }^{3}$ It favoured the co-

'Siècle de Louis XIV.'; Cabanis, 'Révolutions de la Médecine' (Euvres, Paris, 1823, vol. i. p. 200); Flourens, 'Eloges historiques,' vol. iii. p. 31, \&c.; Maury, 'Les Académies d'autrefois,' vol. i. p., 153, 163 et passim; Bouillier, 'Éloges de Fontenelle,' Introduction.

1 "Tandis que tout a été renouvelé dans la politique et les mours publiques . . la vie scientifique et littéraire a sensiblement gardé sa constitution. . . Le Collége de France, l'Académie française, l'Académie des Inscriptions et Belleslettres, l'Académie des Sciences, la Bibliothèque impériale, l'Observatoire, le Muséum d'Histoire naturelle, subsistent encore, comme au siècle dernier, et dans nos provinces, une foule d'académies sont d'une création antérieure à 1789" (Maury, loc. cit., p. 1).

2 "Euler fut quatre fois couronné pour des questions de physique et de mathématiques. . . Daniel Bernoulli obtint le prix dix fois" (Maury, p. 171). Among the celebrated Eloges by Fontenelle there are those of Leibniz, of Peter the Great, of Newton, of Marsigli, of Boerhaave; among those by Con. dorcet there are those of Haller, Linnæus, Hunter, and Euler; among Cuvier's there are those of Gilbert, Priestley, De Saussure, Cavendish, Pallas, Rumford, Werner, Banks, and Davy.

3 "Jusqu’à présent," says Fontenelle in 1699, "l'Académie des Sciences ne piend la nature que par petites parcelles. Nul système général, de peur de tomber dans l'inconvénient des systèmes précipités dont l'impatience de l'esprit humain ne s'accommode que trop bien, et qui, étant une fois établis, s'opposent aux vérités qui surviennent" (quoted by Flourens, 'Éloges,' vol. iii. p. 19). "L'esprit de l'Académie des Sciences a donc toujours été l'esprit d'expérience, d'étude directe, d'observation précise, l'amour de la certitude. D'abord cartésienne, elle devint ensuite Newtonienne," \&c. (ibid., p. 21). Fontenelle contrasts the "philosophie des mots et celle des choses, de l'École et de l'Académie" ('Éloge de Du Hamel' in Bouillier, p. 10). "Fontenelle se plait à multiplier les exemples de cette incapacité chez les savants de faire fortune et de ce noble désintéressement." "Il aimait mieux 
operation of many minds in rearing the great edifice of science, and found a place for the minutest research, as well as a field for the development and sway of great and

30.

Cuvier the greatest representative of the Academic system. governing ideas. Of the best form of this spirit and system-the Académie-Cuvier was the greatest representative. Through several dozen Éloges which he pronounced on the decease of a number of the most illustrious scientific men of Europe, as well as through several Reports, in which he summed up the labours and progress of his age, and the peculiar features of his period, he affords to the student of history an insight into that distinctive phase which scientific thought had entered in France at the end of the eighteenth century. This he allows us to contrast with other phases of thought, such as the philosophical or individual, which obtained in other ages or countries, and suggests as well as gives the means of answering the question, to what extent the scientific ideal

étudier que subsister," he said of one of the Academicians (Bouillier, pp. ix, xii). Cuvier was very watchful over the Academy in keeping out the speculative spirit. See what lie says in the joint Report on geology with Haiiy and Lelièvre ('Mém. de l'Institut,' vol. viii. 1607, p. 136). "Que doirent donc faire les corps savans pour procurer à une science aussi intéressante et aussi utile, les accroissemens dont elle est susceptible? . . . Ils doivent tenir la conduite, qu'ils ont tenue depuis leur établissement, à l'égard de toutes les autres sciences: encourager de leurs éloges ceux qui constatent des faits positifs et garder un silence absolu sur les systemes qui se succèdent." Compare with this what he says about the use of the principle of "vital force," always referring to Newton's method
('Mém. de l'Inst.,' vol. vii. p. 77, \&c.), further in his analysis of Gall and Spurzheim's Mémoire ("Mém. de l'Inst.,' vol. ix. p. 65): "Les commissaires de la classe . . . ont donné leur assentiment à presque toutes les propositions de MM. G. \& S., qui ne dépendent que de l'inspection anatomique, \&c. . . . les commissaires ont cru également de leur devoir de prévenir le public, qu'il n'y a aucun rapport direct, aucune liaison necessaire entre ces découvertes et le doctrine enseignée par MM. G. \& S., \&c. . . . Toutes ces matières sont encore trop étrangères aux attributions de la classe, elles tiennent aux faits sensibles d'une manière trop lâche, elles prêtent ì trop de discussions vagues, pour qu'un corps tel que le nôtre doive s'en occuper" (p. 159). 
of the end of this century agrees with or differs from that of its beginning. Upholding the Newtonian rather than the Baconian and Leibnizian standard in the mathematical and physical sciences, ${ }^{1}$ he has marked that line which our whole century has contributed to trace out more distinctly; whilst, as regards the purely natural sciences, his continued emphasising of the great problem of organisation, and his later controversy with Geoffroy de Saint-Hilaire, mark that point in which this century has most distinctly departed from the prevailing ideas of its early years. ${ }^{2}$ He also recognised earlier than any other mind of similar eminence what our century increasingly realises, how, without a system of condensation, contained in reports, statistics, and figures, aided by classifications and systems, the growing bulk of accumulated knowledge becomes chaotic and unmanageable. ${ }^{3}$

1 Cuvier was not brought up in the school of the Encyclopædists, and I cannot find that he attached the great importance to the writings of Bacon which that school commonly did. As to Newton and Leibniz, he contrasts their methods, considering them "comme les chefs et les représentans des deux méthodes opposées qui se sont disputé l'empire de la science" ("Histoire des Sciences naturelles,' publiée par Magdeleine de SaintAgy, Paris, 1841, vol. iii. p. 19, \&c.) See also in his joint Report with Haüy and Lelièvre on the Science of Geology ('Mém. de l'Institut,' 1807, p. 133): “On vit renaître dans cette partie de l'histoire naturelle la méthode systématique de Descartes, que Newton semblait avoir bannie pour jamais de toutes les sciences physiques, . . . et lorsqu'on songe que Leibniz et Buffon sont au nombre des philosophes dont je parle ici," \&c.

${ }^{2}$ A future chapter will deal specially with this subject. Cuvier, as is well known, maintained the fixity of species, and opposed the theories of St Hilaire and Lamarck, in which a later generation recognises the beginnings of the Darwinian doctrine of the transmutation of species. "On est obligé d'admettre certaines formes, qui se sont perpétuées depuis l'origine des choses, sans excéder ces limites; et tous les êtres appartenans à l'une de ces formes constituent ce que l'on appelle une espèce" ("Règne animal,' vol. i. p. 20).

${ }^{3}$ Cuvier was the first great scientific writer who undertook to give a historical survey of the position of the different natural sciences, with a view of ascertaining what had been achieved and what remained to be done. $\mathrm{He}$ did what 
Cuvier had also a true historical sense, which enabled him to trace the connection of science with political history, with literature, with the fine and useful arts.

On the

fortunes of science during the Revolution and the First Empire. And he helps to answer a question which to us is of paramount interest, How did science fare during the great cataclysm of the Revolution? how under the reactionary despotism of the First Empire? Before attempting to reply to these questions in the light of subsequent and general European history, I will select a few passages from Cuvier which throw light upon these points : ${ }^{1}$

"There is always a revolution required in order to change habits which have become general, and the most necessary revolutions do not take place without some circumstance, which is sometimes long delayed. We have been able to see how in such a case everything furthers the sciences, even the delays and contrarieties which they seem to suffer under.

"The events which disturbed the world, and which for natural science temporarily dried up the sources of its riches, ${ }^{2}$ obliged it to return to itself, and to make a new study of what it possessed, more fruitful than the most

a generation later the British Association undertook to do, and what in Germany the many "Jahresberichte" do nowadays. See his "Analyse des Travaux," \&c., "Mfém. de l'Institut,' vol. ix. p. 53, and his celebrated 'Rapport historique sur le Progrès des Sciences naturelles depuis 1789,' Paris, 1810.

1 'Éloges historiques,' vol. iii. p. $456,1824$.

2 This refers to the isolation of France during the war and the Continental blockade, which deprived it of foreign imports and the scientific collections of foreign specimens; see also 'Eloges,' vol. i. p. 9 ; vol. iii. p. 202: "Quand la jalousie des peuples nous privait des produits étrangers, la chimie les faisait éclore de notre sol." "Le conseil des mines établi en 1793, lorsque l'in. terruption de tout rapport avec l'étranger fit sentir le besoin de tirer parti de notre territoire a donné à ces sortes de recherches une impulsion toute nourelle" ('Rapport,' p. 178). 
fortunate departures could have been. During this apparent rest, all the different parts of method were deepened; the interior of natural objects was studied; even minerals were dissected and reduced to their mechanical elements; a still more intimate analysis was made by a perfected chemistry; the earth itself was, during this interval, if the expression is allowable, dissected by the geologists; its depths were sounded; the order and layers of rock which form its shell were recognised. ${ }^{1}$ In the absence of foreign contributions the interior of the soil on which we walk became tributary to science. The beings of which it contains the remains came to light, and revealed a natural history anterior to that of today, different in its forms, and nevertheless subject to similar laws, thus giving to these laws a sanction which no one expected. The botanists did not gather so many plants in their collections, but with the lens in hand they demonstrated more and more the intimate structure of the fruit, the seed, the various relations which connect the parts of the flower, and the indications which these relations furnish for a natural division. The most delicate forms of organic tissues were exhibited; medicine

${ }^{1}$ Cuvier refers here to the inves. tigation of the fossils in the Paris basin, which he undertook during the years 1804 to 1808 : "La singularité des animaux dont je découv. rais les ossements à Montmartre me fit désirer de connaître plus en détail la composition géologique des environs de Paris. Mon ami Brongniart s'associa à moi pour ce travail ; nous fîmes ensemble et séparément beaucoup de courses. . . . Ces recherches ont donné une face toute nouvelle à la géologie, et ont occa- sionné toutes celles qu'ont faites ensuite en Angleterre MM. Webster, Buckland, I abêche et autres" (Cuvier, "Mrém. sur sa Vie" in Flourens, 'Éloges,' vol. iii. p. 188). This was the beginning of the Science of Palrontology, a term which Cuvier did not use himself (Flourens, 'Travaux de Cuvier,' p. 147). See also Cuvier, 'Recherches sur les Ossemens fossils de Quadrupèdes,' \&c., Ist ed., 1812, 3d ed., 1825 , in the Introduction. 
and chemistry united their efforts to appreciate in the minutest detail the action of external elements on the living organism. ${ }^{1}$ The different combinations of organs, or what we call the different classes, the different genera, were not less studied than general theories. There were no animals, ever so small, the inner parts of which, unveiled by anatomy, did not become known as well as our own. Every organic system was likewise submitted to a special examination. The brain, marking the degree of intellectual power; the teeth, signs of the nature and energy of the digestive forces; the bony system, above all, which is the support of all others, and which determines the connected forms of animals, -all these were followed into the smallest species and into the minutest parts. We see how, after such studies, there could be no more talk of superficial or artificial methods. The old natural history had ceased to rule. It was not that old natural history any more, but a science full of life and youth, armed with quite novel ways and means, which beheld the world reopened by the Peace." 2

In an earlier passage, ${ }^{3}$ speaking of the reopening of academies and schools by the Government of the Revolu-

${ }^{1}$ Compare with this the 'Rapport' of the year 1808, p. 201, \&c. The above remarks refer mainly to Bichat. "Bichat a donné à l'anatomie un grand intérêt, par l'opposition de structure et de forme qu'il a développée, entre les organes de la vie animale, c'est-à-dire, du sentiment et du mouvement, et ceux de la vie purement végétative. . . L'attention particulière donnée par Bichat au tissu et aux fonctions des direrses membranes, et l'analogie qu'il a établie entre celles de parties très éloignées, ont jeté aussi des lumières nouvelles sur l'anatomie, principalement dans ses rapports avec la médecine" ("Rapport,' p. 218).

2 This refers to the peace which concluded the Napoleonic wars, and re-established the free intercourse of France with the rest of the world.

3 In the "Eloge of Fourcroy," of the year 1811 ('Éloges,' vol. ii. p. $40, \&$ c.) 
tion, Cuvier remarks: "It was not merely a question of isolated discoveries, but of institutions, which, in assuring the conservation of the sciences, would multiply their progress indefinitely. What was needed was no longer a simple experimenter, master of his subject and his instruments, it was a man obliged to battle against all kinds of obstacles, and to benefit his fellow-citizens, mostly in spite of themselves. The Convention had destroyed academies, colleges, universities; nobody would have dared to ask boldly for their restitution; but soon the effects of their suppression showed themselves in the most susceptible point; the armies were without doctors and surgeons, and these could not be created without schools. ${ }^{1}$ But who would believe that time was required to give courage enough to call them schools of medicine. Doctor and surgeon were titles too contrary to equality, apparently because there is no authority over the patient more necessary than that of the doctor; therefore the odd term "schools of health" was used, and there was no question of either examination or diploma for the students. In spite of this, a penetrating glance reveals, in the regulations which were carried, the intentions of him (Fourcroy) who drew them up. The three great schools founded at

1 See 'Éloges,' vol. i. p. 353. "Cependant les gens qui avaient fait toutes ces suppressions eurent promptement lieu de s'apercevoir que, s'il était à la rigueur superflu d'apprendre toute autre chose, on ne pouvait guère se dispenser d'apprendre la médecine. Toute la France se précipitait aux frontières, et, après des prodiges inouis de dévouement et de valeur, les défenseurs de la patrie ne trouvaient aucun secours pour leurs blessures et pour leurs maladies. On com. mença donc par l'érection des écoles de médecine cette longue suite de restaurations, que l'établissement de l'université vient de couronner et de lier en un ensemble aussi imposant par l'étendue de son plan que par la vigeur de son organisation." See also 'Rapport,' \&c., p. 360 . 
this epoch, ${ }^{1}$ received an abundance of means, of which up to that time there was no idea in France, and which still form the finest ornament of the University."

Similar passages might be collected in which Cuvier enlarges on the influence of war and revolutions, of the Contineutal blockade and the isolation of the country; on the reconstruction of hospitals and the admission of medical science into the Academy; on the creation of new industries; on the development of the mining and mineral wealth of the country; on the scientific value of colonies and travels, and many other interesting topics. In confining myself more closely to the history of thought and the growth of the modern scientific spirit, I will make some reflections which his remarks force upon us.

32.

France has than other countries to popularise science.

33. Difference between the literary and the national popularisation.

I have noted above how France more than any other country worked for the popularisation of science, how her polite literature alone during the eighteenth century bears the strong impress of modern scientific ideas; no other country has a Fontenelle, a Voltaire, a Buffon. This peculiarity must be recognised as a very powerful and valuable stimulus to the growth of the scientific spirit. It emanates largely, if not exclusively, from the peculiar position of the old Academy of Science. It must, however, not be forgotten that it was not a popularisation of the kind we witness nowadays.

The class of literature which in our age spreads broadcast the discoveries or ideas of science; the endless number of magazines, reviews, and daily papers; the small treatises, the cheap primers, the compact text-books, did

1 They were the three "Écoles de $\mid$ struction publique en France,' vol. Santé" at Paris, Strasbourg, and Montpellier (see Hippeau, 'L'Inii. p. 194). 
not then exist. ${ }^{1}$ Science was not a subject of general, still less of popular, instruction. It was an occupation of the few, who, privileged by fortune or talent, or gifted with inordinate perseverance, forced their way into the salons of society ${ }^{2}$ or the rooms of the Academy. The first public course of natural history was opened in Paris by Valmont de Bomare in 1760.3 Science still stood far out of the reach of the practical man or the poor man; it had not yet become an element of education or an instrument for industry. It was a fashionable pursuit, a luxury of the great, a key that occasionally opened the door of the palace; but it was not a thing of immediate use, except in adding glory and renown to its royal protectors, or to the rare genius which could make new discoveries. Almost the only application made of it was in navigation, and in the construction of instruments connected therewith. This essentially literary - not national popularisation of science had also its great dangers. No ideas lend themselves to such easy, but likewise to such shallow, generalisations as those of science. Once let out of the hand which uses them, in the strict and cautious manner by which alone they lead to valuable results, they are apt to work mischief. Because the tool is so sharp, the object to which it is applied seems to be

1 Cuvier, in his 'Rapport,' \&c., p. 361 , mentions the elementary works published by some of the medical professors at the beginning of the century, but says also that ' En Allemagne, surtout, où l'usage des livres élémentaires est plus commun que chez nous, il n'est presque aucune université, dont les professeurs n'en aient publié d'excellens."
${ }^{2}$ See Maury, p. 182, \&c. Also Cuvier, 'Rapport,' vol. ii. p. 427 : "En France la réputation des ouvrages dépend, pour l'ordinaire, des femmes et de quelques gens de lettres, qui croient pouvoir juger des sciences positives, parcequ'ils ont combiné quelques idces générales de métaphysique."

3 See Maury, L'ancienne Académie des Sciences,' p. 283.
34.

Dangers of the merely literary popularisation. 
so easily handled. The correct use of scientific ideas is only learnt by patient training, and should be governed by the not easily acquired habit of self-restraint. It is well known how the fundamental notions of a mechanical science, let loose into literature by Fontenelle, by D'Alembert, by Condorcet, or absorbed by Voltaire and Diderot, were expanded into a system of materialistic philosophy in 'L'Homme Machine,' the 'Système de la Nature,' and other works, the extreme views of which the great scientific thinkers could hardly approve of. ${ }^{1} \quad$ These hasty but

${ }^{1}$ As a great deal of confusion existed for a long time in European literature as to the exact succession in time of the different works which assisted to spread mechanical views of the world and of life, I put down the main dates :-

Fontenelle (1657-1757) published his Éloges of the great Academicians, in which the principles of the philosophy of Descartes, Leibniz, and Newton were popularly expounded and discussed, from 1700 onward. His 'Pluralité des Mondes' had appeared already in 1686 ; it had popularised Cartesian ideas.

Voltaire (1694-1778) published his 'Élémens de la Philosophie de Newton' in 1738 .

La Mettrie (1709-51) published his 'Histoire naturelle de l'Âme' in 1745 , and his 'L'Homme Machine' in 1748 .

D'Alembert and Diderot published the first volume of the 'En. cyclopédie ' in 1751.

Buffon (1707-88) published, 1749, his 'Théorie de la 'Terre,' being the first portion of the 'Histoire natur. elle.'

Holbach (1723-89) published under the name of Mirabaud, 1770 , the 'Système de la Nature.'

Of these works, the three whicl created the greatest popular sensation - viz., Voltaire's 'Elémens,' La Mettrie's 'L'Homme Machine,' and Holbach's 'Système ' - were all published in Holland. Voltaire, D'Alembert, and Diderot appear to have approached philosophical problems mainly from the position of Newton's natural philosophy, La Mettrie from the teachings of the great Boerhaare, Holbach principally from a study of chemistry. It is unnecessary to say that none of them had the sanction of their great masters for the applications they made of principles which had been established and used for special scientific purposes. And the same may be said with reference to the influence of Locke, which in almost all the instances mentioned was combined with that of the great naturalists. But this does not belong to the line of thought in which we are interested at present. For the sake of completeness only I mention that Locke's teachings as well as Newton's were made popularly known in France by Voltaire's 'Lettres sur les Anglais' (burnt by order of the Parliament of Paris in 1734), whereas Condillac's (1714-80) more systematic treatise, entitled 'Essai surl' Originedes Connaissances humaines,' appeared in 1746. It is 
brilliant generalisations, expressed frequently in the most perfect language, did no good to the truly scientific cause; they did not spread the genuine scientific spirit. Much of the good done by Fontenelle, by Voltaire, by Buffon, was spoiled or neutralised by premature and ill-founded theories. How much, or how little, they contributed (either directly or by a kind of reaction which set in against them, of which Rousseau may be regarded as the centre) to bring about the Revolution is a matter of much controversy; certain it is that the Revolution broke their sway, and destroyed their immediate influence. ${ }^{1}$ To the purely literary the Revolution added

important, in dealing with the extreme materialistic writings which French literature produced between 1745 and 1770 , to keep distinct the different origins from which they started, and the different influences which combined to produce them: the mathematical and mechanical principles borrowed from Newton, the physiological and medical emanating from Linnæus and Boerhaave, and the psychological coming from Locke and Shaftesbury. Lange, in his 'History of Materialism' (transl. by Thomas, London, 1880, 3 vols.), was the first to point out clearly the correct chronology and succession of these writings (see especially vol. ii. pp. 49-123), and to dispel the misconceptions which, since the appearance of Hegel's 'Geschichte der Philosophie ' in 1833-36, had passed through nearly all historical works published in Germany. From his exhaustive references, it is evident that the extreme views of $\mathrm{La}$ Mettrie, Diderot, and Holbach cannot be fathered on any of the great scientists or philosophers, but were an attempt to apply scientific prin. ciples to the solution of philosophical, ethical, or religious questions, frequently for practical and politi- science. cal purposes.

${ }^{1}$ It would probably be more correct to say that these daring attempts to deal with the general problems of knowing and being, with the nature of the soul and the conduct of life, were discarded as premature, and 'hat the followers of Condillac and Locke betook themselves to a more patient study of the facts of the inner life, as the followers of Buffon forsook his brilliant generalisations for the more patient and fruitful study of all the forms of physical nature. And in this respect the Government of the Revolution took a memorable step when it founded on the $3 d$ brumaire, an iv. (25th October 1795), on a Report of Dannon, based mainly on ideas expounded by Condorcet, the "Académie des Sciences morales et politiques." It was the intention to abandon metaphysical generalisations, and to com. bine the scientific and historical spirit in the study of mental, moral, and social phenomena, draw: ing extensively on the assistance of the medical sciences, or a knowledge of human nature in its nor-
35. The Revolu. tion added the modern practical popularisation of

VOL. I. 
something different-viz., the modern practical popularisation of science: it established its educational and its technical importance. Science was to be not an elegant amusement, or a refined luxury, nor even exclusively the serious occupation of the rare genius: it was to be the basis of a national instruction, and the foundation of the greatness and wealth of the nation. The Memoirs of the Academy were cleansed of all dangerous generalisations which might have brought them into touch with political controversy; the language was confined to the measured and concise statement of facts, or to theories capable of mathematical verification and treatment; conjectural matter was carefully excluded, and a standard of scientific excellence, both in matter and form, was raised, to which we still look up with admiration. ${ }^{1}$ At the same time, this lofty and dignified spirit enlivened the courses

mal and diseased conditions. This organisation produced, during its short existence of only seven years, some memorable works; but its position was for various reasons secondary only : it was eclipsed by the European renown which the "Académie des Sciences" possessed, owing to its historical antecedents and its brilliant discoreries and the practical usefulness of its labours. But the idea of including ethical and political studies under the term "Science," due probably to Condorcet, was fixed by this organisation, and has in the course of the century acquired increasing influence. From these beginnings we shall have to study its career in another portion of the present work.

1 According to Curier, "la langue naturelle de l'Académie des Sciences" is "la langue des chiffres" ('Éloges,' vol. i. p. 24); "l'Académie a toujours eu pour principe de ne se rendre qu'à des calculs ou à des expériences positives" (vol, iii. p. 12). Compare also 'Mém. de l'Institut,' rol. vii. p. 77, where he speaks of the method of Newton, showing how little the employment of a principle like that of "vital force" in physiology can be compared with that of gravitation, employed by Newton to explain the movement of the heavenly bodies; again, rol. viii. p. 139, where he refers to the great service rendered by the Academy, "s'il parvenait à diriger les esprits vers des recherches positives, mais longues et pénibles." And vol. ix. p. 61: "On aime toujours à voir se multiplier dans les sciences expérimentales les moyens simples d'arriver à la précision et de se rapprocher des sciences mathématiques," and other passages quoted above, p. 115 and p. 128 . See also his remarks on the Philosophy of Nature, 'Rapport,' p. 335. 
of lectures delivered in the great schools by the first men of the nation, and became, through them, the habit of a large number of ardent pupils, who were to carry it further into more popular teaching, or into the applications of art and industry. ${ }^{1}$ The results of both are well known. We.still live, at the end of the century, under their immediate influence. If now we continually appeal to scientific authorities for aid in the solution of practical problems, it is well to remember that nothing helped more to raise science to the eminence of a great social power than the action of the Revolutionary Government in 1793 . Whilst it guillotined Lavoisier, Bailly, and Cousin ; drove Condorcet to suicide, and others like Vicq-d'Azyr and Dionis du Séjour into premature death $;^{2}$ it had to ap-

${ }^{1}$ See Cuvier, "Réflexions sur les Sciences," 1816, in 'Eloges,' \&c., vol. i. p. 24, \&c. : "Que l'on recherche, ce qu'ont valu à la France depuis vingt ans les inventions pratiques dérivées des découvertes de MM. Berthollet, Chaptal, Vauquelin, Thénard, \&c., dans la seule chimie minérale, dans cette branche assez bornée des sciences physiques; l'extraction de la soude, la fabrication de l'alun, du sel ammoniac, des oxydes de plomb, des acides minéraux, toutes substances que nous tirions de l'étranger; l'épuration des fers, la cémentation de l'acier et enfin le développement des arts qui emploient ces matières premières: il est clair que c'est par centaines de millions qu'il faudra calculer." Also, vol. iii. p. 202: "Les applications de la science ì la pratique avaient fait de M. Berthollet, lorsque la guerrc de la révolution éclata, le chimiste le plus connu du public, après Lavoisier; et il était presque impossible que l'on ne recourât pas à lui au moment où la chimie devint pour la guerre un auxiliaire de première necessité, et lorsqu'il fallut demander à notre sol le salpêtre, la potasse et jusqu'aux matières colorantes; qu'il fallut apprendre à faire en quelques jours toutes les opérations des arts. Chacun se souvient de cette prodigieuse et subite activité qui étonna l'Europe, et arracha des éloges même aux ennemis qu'elle arrêta. M. Berthollet et son ami M. Monge en furent l'âme."

${ }^{2}$ Vicq-d'Azyr (1748-94), the great forerunner of Cuvier in the new science of comparative anatomy, "au sortir d'une de ces parodies sinistres décorées du nom de fête nationale, était saisi d'un mal qui l'enlevait en quelques instants dans le délire de la peur. Dionis du Séjour (1734-94), après deux années d'effroi et de misère, ne trouvait plus assez de force pour goûter les temps moins malheureux amenés par la chute de Robespierre" (MIaury, 'Les Académies d'autrefois,' vol. i. p. 332). 
peal for its most necessary requirements to the society of scientific authorities, which it professed not to need. "Everything," says the historian of the Academy," "was wanting for the defence of the country-powder, cannons, provisions. The arsenals were empty, steel was no longer imported from abroad, saltpetre came not from India. It was exactly those men whose labours had been proscribed who could give to France what she wanted. Fourcroy, assisted by researches begun by Lavoisier, taught the methods of extracting and refining saltpetre; Guyton de Morveau and Berthollet made known a new method of manufacturing gunpowder, and studied the making of iron and steel; Monge explained the art of casting and boring cannons of brass for land use, and cast-iron cannons for the navy. On the 6th of August 1793 the Convention had again to appeal to the Academy in order to know what advantage it would be to refine as much as possible the coins of the Republic?" In the space of a few years science had become a necessity to society at large. ${ }^{2}$ In the Constitution of the regenerated Academies it was placed at the head, as the most important department of knowledge.

1 Maury, loc. cit., vol. i. p. 329. See also Biot's 'Essai sur l'Histoire générale des Sciences pendant la Révolution française.' Paris, 1803.

2 The last entry in the record of the "procès-verbaux de l'Académie" before the suspension was a Report by Borda, Laplace, and Lagrange, in answer to a demand of the Convention, dated 19th January 1793, for advice on the new system of weights and measures which the Republic should adopt. And so necessary had the assistance of men of science become to the Government, that even during the suspen- sion, which lasted from the 8 th August 1793 till the 22d August 1795, Lakanal had succeeded in procuring the following decree from the Government of the Convention : "La Convention nationale décrète que les membres de la ci-devant Académie des Sciences continueront de s'assembler dans le lieu ordinaire de leurs séances, pour s'occuper spécialement des objets qui leur auront été ou pourront leur être renvoyés par la Convention nationale" (Maury, loc. cit., p. 331; Aucoc, 'L'Institut de France,' p. ecvii, \&c.) 
The influence of the first Napoleon on science is naturally a matter of as much controversy as his merit in

36. Influence of the first Napoleon almost every branch of administration. The reports 1 on science.
1 According to a decree of the Government, dated 13 th ventose, an x (4th March 1802), the Institute, then consisting of three classesthe "Académie des Sciences physiques et mathématiques," the "Académie des Sciences morales et politiques," and the "Académie de Littérature et Beaux - arts"was ordered to furnish "un tableau de l'état et des progrès des sciences, des lettres et des arts, depuis 1789 jusqu'au $1^{\text {re }}$ vendémiaire an $x . "$ This "tableau" was to be divided into three parts according to the three classes of the Institute. These Reports were to be repeated every five years. The first (and only) Reports were not presented before February and March 1808. The Republican Government had then been superseded by the Empire, and by a decree of the $3 d$ pluviose, an xi (23d January 1803), the Institute had been reorganised. There were now four classes: 1. Des Sciences physiques et mathématiques (corresponding to the old Académie des Sciences). 2. De la langue et de la littérature françaises (corresponding to the old Académie française). 3. D'histoire et de littérature ancienne (corresponding to the "Académie d'Inscriptions et de Belleslettres"). 4. Des beaux-arts. "On supprima la classe des sciences morales et politiques qui existait dans l'organisation du 3 brumaire, an iv. Ce fut un trait caractéristique de la répugnance du premier Consul pour la discussion des matières politiques et leur enseignement"'(Thibaudeau, 'Le Consulat et l'Empire,' Paris, 1835-37, vol. iii. p. 396). Accordingly there were prepared four, or rather five, Reports, the first in two parts by Delambre and Cuvier on the progress of the Mathematical and Physical Sciences; the second by Marie-Joseph Chénier on the progress of Literature; the third by Dacier on the progress of History and Classical Literature; the fourth by Le Breton on Fine Arts. Of these the two Reports of Delambre and Cuvier gave great satisfaction, that of Dacier gave less satisfaction; Chénier, who himself admired the eighteenth - century philosophy, had an embarrassing task to perform, of which, however, he acquitted himself worthily (Thibaudeau, loc. cit., vol. vi. p. 557). The Report of Chénier has been several times reprinted. The new science which was founded by Condillac, Turgot, Condorcet, and others, and which aimed at introducing the truly scientific spirit into psychology, psycho-physical researches, and questions of society and legislation, received no recognition, as it had also lost its representation in the sus. pended "Acarlémie des Sciences morales et politiques." After the re-establishment of this section of the Institute in 1832, a royal decree of $22 \mathrm{~d}$ March 1840 ordered a Report on the progress of the Moral and Political Sciences from 1789 to 1832. The task was so great that it could not be accomplished before the Revolution of 1848 , and was therefore abandoned (Aucoc, 'L'Institut de France,' pp. 62 note, 300). Some reference to the subject is contained in the introduction to Chénier's Report, and in the last chapter of Dacier's, which was written by De Gérando. The true history of the new science has been recently written by F. Picavet, 'Les Idéologues,' Paris, 1891. 
which Delambre and Cuvier drew up at his request, touching the progress of science during the twenty years which followed the outbreak of the Revolution, have become classical as monuments of the achievements of a great age, ${ }^{1}$ and as examples of the best style in which to treat such a subject. Written immediately under his eye, they cannot be considered quite impartial, so far as the tone is concerned in which they refer to his personal favours and protection. ${ }^{2}$ There can, however, be no doubt that he recognised scientific merit, and drew many eminent men of science into the service of the Government. The institutions on which he prided himself so much,-the École Normale, the École Polytechnique, and the unfinished scheme of a great centralised Institution of Learning and Education, descending from the heights of the Institute, through the various branches of the higher and secondary into a multitude of primary schools, bearing the name of the "University," - had either existed, or been planned before him. ${ }^{3}$

1 Napoleon in discussing at the council meeting the decree which ordered the several reports, said to Regnaud: "Soignez bien cette rédaction, car elle sera examinée par les pédagogues de toute l'Europe " (Thibaudeau, loc. cit., vol. ii. p. 496).

${ }^{2}$ See what Cuvier himself says on this subject (Mémoires, \&c., in Flourens, 'Eloges,' vol. iii. p. 187): "Un rapport sur le progrès des sciences devait être présenté aux consuls en fructidor an $x i$.

Ou ne fut prêt qu'à la fin de 1807 : ce n'était plus aux consuls mais à l'empereur que l'on avait à présenter le travail. Il le reçut avec un grand appareil dans la séance du conseil d'État. M. Delambre et moi présentâmes le nôtre les pre- miers; le 3 févr. 1808, accompagnés de Bougainville, président, et des doyens de toutes les sections. La cérémonie fut solennelle; l'em. pereur fit une belle réponse,".qui est imprimée à la fin du rapport. Je sus le lendemain, par M. de Ségur et d'autres conseillers d'État, qu'il avait exprimé une grande satisfaction de mon rapport en particulier: 'Il m'a loué comme j'aime à l'être, dit-il.' Cependant je m'é. tais borné à l'inviter à imiter Alexandre et à faire tourner sa puissance au profit de l'histoire naturelle."

${ }^{3}$ Regarding the University, see ' Code Universitaire ou Lois, Statuts et Règlemens de l'Université Royale de France, mis en ordre par MI. Ambroise Rendu,' Paris, 1835. In 
It will therefore always remain a matter of doubt to what extent he originated ideas, or merely adopted those of others before and around him. He favoured the mathematical sciences, and created great prizes for physical, notably electrical, discoveries, partly because these pursuits mathenati. promised to surround his Government with glory, partly because he recognised their practical importance for the purposes of the state and nation; partly also, because he himself had had a mathematical training. ${ }^{1}$ During his

the Introduction we read as follows: "Bonaparte passait à Turin. Un jour qu'il parcourait le palais de l'Université fondée en 1771 par Charles Emmanuel III., il se fit représenter les statuts qui régissaient cette institution. Il $\mathrm{y}$ vit quelque chose de grand et de fort qui le frappa. . . Tout ce plan d'éducation établi sur la base antique et impérissable de la foi chrétienue, tout cela lui plut, et il en garda la mémoire jusqu'au sein de ses triomphes en Italie et en Allemagne. Rassasié enfin de gloire militaire, et songeant aux générations futures, après avoir solidement établi l'administration civile, après avoir relevé les autels et promulgué le Code Napoléon, après avoir par différentes lois, substitué les Lycées aux Écoles Centrales, régénéré les Écoles de Médecine, et créé les Ecoles de Droit, il voulut fonder aussi pour la France un système entier d'instruction et d'éducation publique. Il se souvenait de l'université de Turin et l'agrandissant comme tout ce qu'il touchait, dans la double proportion de son empire et de son génie, il fit l'Université impériale."

1 Among many references relat. ing to this subject, I select one from Villemain, 'Souvenirs contemporains d'Histoire et de Littérature,' which in the first volume $\left(9^{\mathrm{me}}\right.$ éd.,
Paris, 1874, p. 137) contains, the description of a visit to the Ecole Normale in 1812, and a discussion with Narbonne, to whom the Emperor had fully expressed his aims regarding education and learning. "L'Empereur n'est inquiet que d'une chose dans le monde, les gens qui parlent, et à leur défaut les gens qui pensent. . . . Il veut, et il me l'a dit vingt fois, que son règne soit signalé par de grands travaux d'esprit, de grands ouvrages littéraires. Etre loué comme inspirateur de la science et des arts, être le chef éclatant d'une époque glorieuse pour l'esprit humain, c'est l'idée qui le flatte le plus; c'est ce qu'il a cherché par des Prix Décennaux. . . . Il veut (à l'École Normale) des études fortement classiques, l'antiquité et le siècle de Louis XIV.; puis quelques éléments de sciences mathématiqucs et plus tard la haute géométrie, qui est, dit-il, le sublime abstrait, comme la grande poésie, la grande éloquence est le sublime sensible." Napoleon said to Narbonne: "J'aime les sciences mathématiques et physiques; chacune d'elles, l'algèbre, la chimie, la botanique, est une belle application partielle de l'esprit humain; les lettres, c'est l'esprit liumain lui-même. . . . Aussi, j'ai deux ambitions : élever la France au plus haut degré de la puissance 
campaigns in Italy and Germany, and on his expeditions to Egypt and the East, he surrounded himself with some of the greatest scientific authorities, such as Berthollet and Monge. From political as well as personal motives, he discountenanced the once fashionable sensualistic philosophy. This philosophy had now fallen to the second 38. rank, though still represented by eminent thinkers, such He discountenanced the as Cabanis, Destutt de Tracy, Daunon and Garat. It contemporary repre. sentation of philosophy.

was these thinkers of whom Napoleon sneeringly spoke under the designation of "Idéologues." 1

After all that has been said by admirers to magnify, and by opponents to minimise, Napoleon's merits in promoting the cause of science, and in spreading the modern scientific spirit, I cannot but recognise that he was, amongst the great heroes and statesmen of his age, the first and foremost, if not the only one, who seemed thoroughly to realise the part which science was destined to play in

guerrière et de la conquête affermie, puis y développer, y exciter tous les travaux de la pensée sur une échelle qu'on n'a pas vue depuis Louis XIV. C'était le but de mes Prix Déceunaux qu'ou m'a gâtés par de petites intrigues d'idéologues et de couronnements ridicules, comme celui du catéchisme de SaintLambert."

${ }^{1}$ A full account of these authors, their influence and their aims, will be found in F. Picavet, 'Les Idéologues, Essai sur l'histoire des idées et des théories scientifiques, philosophiqucs, religieuses, \&c., en France depuis 1789,' Paris, 1891.

Thibaudeau, 'Le Consulat et l'Empire,' gives many details regarding Napoleon's connection with science, with literature, and with the growing industries of France. Among the latter see especially the great efforts made to supersede colonial and foreign goods by home productions. Prizes and encouragements of all sorts were given; technical schools and colleges were established; exhibitions were promoted. Sheep were imported from Spain, sugar was made from raisins and beetroot, saltpetre and soda by chemical processes, the garance or madder root and the kermès were to take the place of cochenille; the pas$t e l$ the place of the imported indigo. That an enormous impetus was thus given to chemistry cannot be denied. (See Thibaudeau, passim, and especially vol. v. p. $248, \&$ c.) See also Cuvier's 'Rapport,' \&c., for an account of applications of science, especially chemistry, $\mathrm{pp}$. 376-386, and Delambre, 'Rapport,' \&c., pp. 326.362. 
the immediate future. This part, as we know, it has played both by entirely changing the external face of things, and by running out into endless applications; and we have seen the importance of that statistical spirit of numbering, measuring, and registering, by which alone a survey of complicated phenomena is possible. Of the statistical method Napoleon himself made use on an extensive scale: perhaps he was the first among rulers to He himself made extensive use of do so. ${ }^{1}$ That the great leader of men has to recognise not only the inductive philosophy of statistics and averages, but likewise governing ideas of a different class, Napoleon was well aware, and his ultimate failure may be traced to the fact that, however great as a general and as a calculator, his soul had no room for those high, religious, and unselfish motives of which he himself said to Fontanes, that they in the end always decide the fate of nations. ${ }^{2}$ Yet he belongs to the small company of great military figures in history - a company which includes Alexander the Great, Crsar, and Peter the Great

1 See Delambre, 'Rapport,' \&c., p. 222. "Depuis le peu de temps qu'on s'en [i.e., with statistics] occupe en France, elle y a fait les plus grands progrès, au moyen de l'attention particulière et des secours que le Gouvernement francois donne à tous les travaux utiles. Les préfets des départemens ont été invités à recueillir et à transmettre au Ministre de l'intérieur les renseignemens les plus précis sur toutes les questions qui sont du ressort de la statistique."

2 See 'Euvres littéraires de Napoléon Bonaparte,' vol. iii. p. 5 ; Conversation avec Fontanes, Saint Cloud, 19 Sept. 1808: "Fontanes, savez vous ce que j'admire le plus dans le monde? C'est l'impuis. sance de la force pour organiser quelque chose. Il n'y a que deux puissances dans le monde: le sabre et l'esprit. J'entends par l'esprit les institutions civiles et religieuses. À la longue, le sabre est toujours battu par l'esprit." Also vol. iv. p. 423 : "Les vraies conquètes, les seules qui ne donnent aucun regret, sont ceux que l'on fait sur l'ignorance. L'oceupation la plus honorable comme la plus utile pour les nations, c'est de contribuer à l'extension des idées humaines. La vraie puissance de la République française doit consister désormais à ne pas permettre qu'il existe une seule idée nouvelle, qui ne lui appartienne." 
-who have succeeded in permanently inscribing their names in the annals of science beside those of its true and great representatives. Some of the glory of Laplace 40. and Cuvier falls upon him. Except for this Napoleon has His scientific glory is
mainly derivative. scarcely a place in the history of thought. In it those who were Napoleon's servants are rulers and lawgivers; it is they who enlighten our century. They were the first great exponents of the scientific spirit, nursed under the influence of the academic system. This was peculiarly a product of the French mind and culture. It is well to recall in the words of Cuvier what the scientific spirit is. At the end of the report which he presented in the year 1808 he says: ${ }^{1}$ "These are the principal physical discoveries which have lighted up our period, and which open the century of Napoleon. What hopes do they not raise! how much does not the general spirit signify, which has brought them about, and which promises so much more for the future! All those hypotheses, all those suppositions, more or less ingenious, which had still so much sway in the first half of the last century, are now discarded by true men of science: they do not even procure for their authors a passing renown. Experiments alone, experiments that are precise, made with weights, measures, and calculation, by comparison of all substances employed and all substances obtained: this to-day is the only legitimate way of reasoning and demonstration. Thus, though the natural sciences escape the application of the calculus, they glory in being subject to the mathematical spirit, and by the wise course which they have invariably adopted, they do not expose them- 
selves to the risk of taking a backward step; all their propositions are established with certainty, and become so many solid foundations for that which remains to be built." 1

Nor can we look upon the great prominence which Cuvier gives to French names in the course of his survey as unjust or partial. He was well aware of the contributions of other nations: no one has spoken in more generDeserved prominence given to French names by ous and correct terms of Priestley and Cavendish, of Banks and Rumford, of Pallas, Werner, and Humboldt. We must admit the correctness of the remark, "that even in those departments where chance has willed that Frenchmen should not make the principal discoveries, the manner in which they have received, examined, and developed them, and followed them out into all their consequences, places their names next to those of the real inventors, and gives them in many ways the right to share in the honour." 2

In the first decades of this century the home of the scientific spirit was France: for though not born there, it was nevertheless there nursed into full growth and vigour. But it soon set out on its wanderings through

1 Compare also the "Réflexions sur la marche actuelle des Sciences," being the introduction to the 'Eloges historiques,' vol. i. p. 1, \&c.

2 'Rapport,' p. 391. It is also remarkable how clearly Cuvier here announces the defects which the teaching of science was still labouring under. Whilst he rightly praises the great Paris institutions, the medical schools, the mathematical, physical, and polytechnic establishments, the new schools of technology and agriculture, as unequalled organisations for higher instruction, he draws attention to the absence of equally efficient elementary schools and to the neglect of those provincial institutions which before that age had already done so much to disseminate knowledge and learning. At the end of our century both France and Great Britain have still only very partially supplied the wants which Cuvier so clearly defines in the beginning. 
other lands and nations. At the end of our centurynay, even during the whole of the second half-we find this spirit naturalised in Italy, in Germany, in England, in the north and east of Europe. There is now no science which can be named pre-eminently after one nation. All nations have contributed their share to the cosmopolitan power and influence which science possesses. They have enlarged and deepened the scientific spirit and widened its career. Thus far it has been the growth of the scientific spirit which has occupied us; we must now proceed to study its diffusion, and learn to recognise the peculiar features which Germany and England have on their part contributed. In doing so, we must turn away for a moment from the academic system with which we have been specially occupied. 


\title{
CHAPTER II.
}

\section{THE SCIENTIFIC SPIRIT IN GERMANY.}

\author{
"No Augustan epoch flowered, \\ No Lorenzo favours showered \\ Ever German Art upon; \\ She was not by glory nourished \\ And her blossom never flourished \\ In the rays of Royal sun." 1
}

Perhaps with more correctness Schiller might, early in the century, have applied these lines to German science than to German art. If art and poetry were only slightly indebted to princely protection, German science was still less so. ${ }^{2}$ Leibniz's scientific labours languished while he

1 Schiller, "Die deutsche Muse."

${ }^{2}$ Astronomy was the only science that enjoyed some little princely favour. William IV., surnamed "the Wise," son of Philip the Magnanimous of Hesse and himself Elector, was an astronomer of some note, and stood in intimate relations with Mercator, Tycho, and other astronomers. In 1561 he built himself an observatory at Cassel and appointed Rothmann to be his "Mathematicus." Frederick II. of Denmark gave Tycho a magnificent observatory, called "Uranienburg," where he laboured from 1576 to 1597 , but which was subsequently destroyed. Tycho was then employed by the Emperor Rudolf II., and inaugurated the observatory in Prague (1599-1601); he made Kepler his assistant, and enabled the latter by the use of his observations to find and prove his three celebrated laws ("Astronomia nova," Prague, 1609 ; "Harmonices mundi," Linz, 1619 ; "Tabulæ Rudolphinæ," 1627). Full details will be found in Rudolf Wolf, 'Geschichte der Astronomie,' München, 1877, p. 266, \&c. 
occupied the position of historiographer and diplomatist at the Court of Brunswick, ${ }^{1}$ and Tobias Mayer's valuable observations were only published with the aid of English

1.

Foundation of German universities. money. ${ }^{2} \quad$ But if the German princes did little or nothing directly for the development of science, they indirectly

1 Leibniz (1616-1716) entered, 1676 , the scrvice of John Frederick, Duke of Hanover, as librarian and councillor. The Duke died 1679, and Ernest Augustus, who in 1692 was made Elcctor of Hanover, succeeded him. Leibniz's time was taken up with diplomatic and legal researches and negotiations referring to the position of the House of Hanover, and the reunion of the Protestant and Roman Catholic Churches; latterly with genealogi. cal and antiquarian studies referring to the history of the House of Brunswick. He wrote the 'Annales imperii occidentis Brunsvicenses,' beginning with the year 768 , the date of the accession of Charles the Great, from whom Leibniz proved that the House of Brunswick descended through the Italian House of Este. $\mathrm{He}$ carried the history down to the year 1005 , closing a few days before his death with the words "quos ex tenebris er'uendos aliorum diligentix relinquo." The work was not printed till 1843, when G. H. Pertz, the first editor of the celebrated "Monumenta Germanixe' founded by the great Stein, published it with an elaborate preface. Of the annoyances to which Leibniz was subjected in the course of his studies, see an account in the correspondence with the Minister ron Bernstorff (1705-16), published by Docbner, Hanover, 1882, introduction. See also Guhrauer, 'Leibnitz, eine Biographie,' 2 vols., $2 d$ ed., Breslau, 1846. Considering the greatness of Leibniz in so many different directions, his motto is note- worthy: "Didici in mathematicis ingenio, in natura experimentis, in legibus divinis humanisque auctoritate, in historia testimoniis nitendum esse."

2 Tobias Mayer (1723-62), born at Marbach, the birthplace of Schiller, from 1751 Professor of Economics and Mathematics at Göttingen. To use the words of Karsten Niebuhr, "Though he had never seen a big ship, he taught the English how to determine the longitude on the open sea." He competed for the great prize of $£ 20,000$ offered in 1713 by the Board of Longitude for a method of determining the longitude at sea within $\frac{1}{2}^{\circ}$ accurately; smaller prizes being offered for an accuracy of $3^{\circ}$ and $1^{\circ}$. The prize of $£ 5000$, and subsequently of $£ 10,000$, was awarded to Harrison in 1758 and 1764 for his chronometers. Euler and Mayer laboured in a different direction at the same subject, by publishing lunar tables and per. fecting the lunar theory. After repeated revisions, Mayer sent his tables, 1755, to London, where they were submitted to Bradley, who reported favourably on them. After further corrections, and after also submitting his theory, Mayer's widow received, in $1765, £ 5000$, Euler $£ 3000$, and the work was published, 1770, by order of the Board of Longitude, under the title, "Tabulæ motuum solis et lunæ novæ et correctæ, auctore Tob. Mayer: Quibus accedit methodus longitudinum promota eodem auctore.' 


\section{furthered her cause most powerfully by founding that} great institution of culture, which more than anything else is characteristic of the German mind, in which it has found its most perfect expression, and where it can be most exhaustively studied-the system of the German universities.

"There is no people," says Mr James Bryce, "which has given so much thought and pains to the development of its university system as the Germans have done-none which has profited so much by the services universities render-none where they play so large a part in the national life." 1 If it is correct to say that this system owed its foundation to the German princes, it is equally true that its development is the work of the German people. ${ }^{2}$ It may be doubtful whether, without the

${ }^{1}$ See James Bryce's preface to the English translation of Conrad's valuable book, 'The German Universities for the last Fifty Years,' Glasgow, 1885, p. xiii.

2 A great deal has been written about the German universities. For the purposes of a History of Thought, I confine myself to a reference to the valuable writings of F. Paulsen, 'Geschichte des gelehrten Unterrichts auf den deutschen Schulen und Universitäten,' Leipzig, 1885, and two essays in the 45 th volume of Von Sybel's 'Historische Zeitschrift,' 1881. The succeeding phases of mediaval and modern, of Roman Catholic and Protestant, of the thought of the Church, the Renaissance, the classical and the modern ideals, are all reflected in the foundation and reform of the universities and high schools of Germany and the surrounding countries. The first foundations, in imitation of the universities of
Paris and of Italy, were Prague 1348, Vienna 1365, Heidelberg 1386, Cologne 1388, Erfurt 1392, Würzburg 1402, Leipsic 1409, Rostock 1419. 'A second epochunder the influence of the humanistic studies-begins in the middle of the fifteenth century and adds eight new foundations-Greifswald 1456, Freiburg 1457, Trier 1457, Basel 1459, Ingolstadt 1472, Tübingen 1477, Mainz 1477, Wittenberg 1502, Frankfort on the Oder 1506 (Paulsen, 'Geschichte,' p. 14). A third epoch begins with the Reformation. The first Protestant university is Marburg, founded by Philip of Hesse, 1524. Melanchthon's influence is everywhere decisive. Tübingen is reconstituted by Duke Ulrich 1535 ; Leipsic by Duke George 1539. Basel, after three years' suspension, is reopened 1532 . Frankfort on the Oder is reopened by Joachim of Brandenburg 1537, who also founds the new University of Königsberg 1541. Greifswald is
2. Development of the universities by the people. 
individual influence of the former, without the divided interests of the dismembered empire, without the conflicting religious views, the political and personal rivalry of the many states and sovereigns, ${ }^{1}$ so many scattered centres of culture and learning would have sprung so early into existence; but it is not doubtful that it is owing to the common interests of the nation, to the uniting tie of the same language, the same thought, and the same aspirations, that these scattered centres have been in course of time united into a great network, ${ }^{2}$ a vast organisation for the higher intellectual work of the nation and of mankind. The German nation may pride itself on possessing at the present moment the most

reconstituted on a Protestant foundation 1539; Rostock in 1540-50; Heidelberg by the Elector Frederick II. in 1544. Jena is founded 1558 by John Frederick, Helmstädt by Julius of Brunswick in 1568 ; Giessen followed in 1607 ; Rinteln in 1621; Altdorf in 1622. Of the greatest influence on German culture were the Dutch Protestant universities - Leyden 1575, Franeker 1585, Utrecht 1634, Harderwyk 1648 ; they were for a long time-as formerly the Italian universitiesthe goal of the young scholar's wanderings (Paulsen, p. 179). They-as well as Geneva-held a similar position to the Scotch universities (see Sir A. Grant, 'Story of the University of Edinburgh,' vol. i. pp. $21,126,188,213,229,233,263$, $274,283,297$, \&c., vol. ii. p. 263). A fourth epoch begins with the foundation of Halle 1694, the first really modern university (Paulsen, p. 353). The spirit of Bacon and Leibniz, represented by Thomasius, is the leading power; it is not by any means irreligious, since Francke (the so-called "pietist") is as im. portant a factor as Thomasius. German is substituted for Latin. Other universities follow the reform, thus Königsberg 1735, Leipsic, Wittenberg, Helmstïdt, Kiel, Tübingen, \&c. A fifth epoch -the evolution of the ideal of science in the German sense, Wissenschaft-begins with the foundation of Göttingen in 1737. Of this more in the text.

${ }^{1}$ Conrad, loc. cit., p. 2: "There is scarcely a stronger bond of connection between the various parts of Germany than that supplied by the universities, and in no other respect have the barriers that separated State from State been so long broken down. . . . The historical development cannot be accurately traced unless the growing extent in which the south German universities are attended by students from the north be kept in view."

2 See especially Paulsen's remarks referring to the foundation of Göttingen under George II. ('Geschichte des gelehrten Unterrichts,' p. 425). 
powerful and best equipped army. But this is only the creation of the present age. With greater pride it may boast of having trained in the course of centuries the largest and most efficient intellectual army, ready at any moment to take up and carry to a successful issue great scientific undertakings demanding the intense thought and labour of a few secluded students, or the combined efforts of a large number of ready workers. This army is scattered through the length and breadth of the land, and even beyond its frontiers in neighbouring countries, wherever universities and high schools are situated. ${ }^{1}$ It is not a stationary power, but is continually on the move from south to north, from west to east, to and fro, exchanging and recruiting its forces, bringing heterogeneous elements into close contact, spreading everywhere the seed of new ideas and discoveries, and preparing new land for still more extended cultivation.

I The extent of the German university system cannot be estimated by the twenty universities marked on the map attached to the trans. lation of Conrad's book, as these represent only the existing universities of the present German empire ; nor yet by the forty-three universities given in the appendix, p. 290 , as they contain only some of the Austrian, but none of the Swiss universities ; nor even by taking up Ascherson's valuable 'Deutscher Universitäts-Kalender,' which contains the German-speaking universities - thirty-four in number in 1887 -but of course does not contain the names of those which have been suppressed. There are also the universities of Denmark, Norway, and Sweden, which have exchanged many important professors with Germany, and those of Holland in older, of Belgium in modern times, which have done the same thing. The Russian universities also were largely organised on German models, though since the reforms of 1863 they aim at a more national character. Brandis founded the University of Athens on German lines in 1837. The Russiall University at Kasan, that "ultima musarum Thule," was founded in 1804, and Göttingen supplied its first professors. From there and from the hardly less remote Transylvanian town, Maros Vásárhely, there issued the revolution of our fundamental notions in geometry, and there is reason to believe that both Lobachérsky's and Bolyai's theories are ultimately connected with the speculations of Gauss. See Prof. A. Vasilier's Address on Lobachérsky, translated by Halsted, p. 5 sqq.

VOL. I. 
It is not my intention to dwell on the history of the German universities, on the gradual growth of the university system; though every stage in that history is interesting and important if we wish to understand the inner working and usefulness of this great organisation. Neither do I wish to do more than just mention, as an equally impor3. tant subject, the geography of the German universities; Geographical distribuGerman universities. how through nearly fifty larger or smaller towns, in the course of six centuries, learning and higher education have been spread over the German-speaking countries of Europe. These figures alone suggest the intricacy of the subject, the many springs, the continual ebb and flow of the rising tides of ideas, the many courses of thought, the many schools of learning, the internal conflicts, the unavoidable friction, the healthy competition and rivalry, the republican spirit, the impossibility of any creeping stagnation of life, the absence of any lengthened tyranny of doctrine, of an oppressive hierarchy, or of idols of opinion and belief. I leave it to my readers to indulge in comparisons easily suggested by these different aspects, to fasten upon the strong and upon the weak points of this great system of the German universities. ${ }^{1}$ What I wish to emphasise

1 The migration of students as well as of eminent professors from one university to another is one of the most important features of German academic life. Thus we find the imaginative tendencies of the southern intellect represented by Hegel and Schelling in philo. sophy transplanted into the midst of the encyclopredic and logical sciences of the North, or into the centre of industrial Switzerland in the person of Vischer; the theological criticism of the Tübingen school wandering northward to
Marburg and Berlin in Zeller; and the philological criticism of Gottfried Herrmann locating itself in Zürich in his celebrated pupil and biographer Köchly, and in Bavaria through Thiersch. Jacobi came from the lower Rhine to Munich, where also Liebig formed a centre of modern scientific celebrities. Savigny in Berlin and Thibaud in Heidelberg represent the historical and philosophical schools of German jurisprudence. Vienna for a long time was the most celebrated German training-school of practical 
very strongly here is the existence in the midst of European life, all through our century, of this vast organisation for intellectual work, this great engine of thought; and to assign to it one of the foremost places among the great agencies with which we shall have to deal.

The beginning of the present century found this great institution of university education in full swing among all the German-speaking nations. ${ }^{1}$ The eighteenth century university brought it to that state of perfection in which we have been accustomed to see it. In the course of that century it outgrew its earlier and more limited phases of existence, its period of more restricted usefulness; it emancipated itself from Court and personal favouritism, from ecclesias-

medicine and surgery, whereas Berlin concentrated the great representatives of the more recent scientific developments. In the course of the last hundred years no one university has been allowed to retain for any length of time the supremacy in any single branch. The light has quickly been diffused all over the country, when once kindled at one point. How will the future compare in this respect?

1 This is not quite the case as regards Switzerland. The city of Basel, which before the Reformation was the seat of much learning, the names of Sebastian Brandt, Reuchlin, and Erasmus being intimately connected with it, had a university from 1459. The antagonism to classical and polite literature which characterised a large section of the Reformers (see Paulsen, p. 128 sqq.) destroyed many flourishing centres of culture ; amongst them the University of Basel, which was suspended in 1529 , when the city accepted the Reformation, but reopened three years later in 1532.
Geneva, though this is outside of the German-speaking area and presents a culture quite peculiar to itself, had an academy from 1559 , with many celebrated professors and numerous students of theology from all countries of Europe. Lausanne, Bern, and Züirich had colleges or high schools in the seventeenth century. But down to the nineteenth century Basel remained the only university in the Continental sense. The reasons why Switzerland developed her university system so late are discussed in Tholuck, 'Das akademische Leben des $17^{\text {ten }}$ Jahrhunderts,' vol. ii. p. 314 , \&c., where also minute information is given on the several high schools of Switzerland. The question is interesting, seeing that the greatest in many branches of science-such as Bernoulli, Euler, Haller, Cuvier, Steiner-have come from Switzerland, and that by reason of the names of Rousseau and Pestalozzi it has become the centre of modern ideas on education. 
tical protection and influence; it acquired through the statutes of governments or special foundations larger and better secured means of subsistence; it substituted the vernacular for the Latin tongue. The circle of studies, though from early times professedly all-embracing, did not become worthily filled up and cultivated with equal and The philosophical impartial care till the fourth faculty, the philosophical faculty, was properly developed. Theology, law, and medicine conduct their studies for practical ends and purposes; the two former especially were frequently liable to be used merely for the ends of the Church or the State; but the philosophical faculty embraces all those studies which aim at establishing truth, be this defined as merely formal or as real, as belonging to method or to knowledge. We can assign a definite date to the firm establishment of the "libertas philosophandi," and the professed introduction of the "libertas docendi" in the university progranıme ${ }^{1}$ - namely, the opening (in 6. 1734) of the University of Göttingen (inaugurated in sity of Göttingen.

1737). "The foundation stone," says Professor Paulsen, "of the academic constitution is the 'libertas docendi.' On this point Von Münchhausen, whom we may call the real founder of the university, and his two advisers, Mosheim, the theologian of Helmstädt, and Böhmer, the jurist of Halle, were agreed. All 'inquisitiones,' so writes the former, choke the powers 'ingeniorum,' and spoil the beginnings of a learned society. He advises above all that the greatest care should be used in the equipment of the theological faculty. Accordingly Münchhausen laid his eye upon men whose teaching led neither to. ${ }^{1}$ Paulsen, 'Geschichte des gelehrten Unterrichts,' p. 424, \&c. 
'Atheismo' nor 'Naturalismo,' who neither attack the 'articulos fundamentales religionis evangelicæ,' nor introduce enthusiasm, nor yet evangelical popedom. Likewise the jurists received full freedom for teaching and for the expression of legal opinions, whereas at Halle, following the common rule, the Prussian interest, at least in matters of public law, was the measure of things. At Göttingen the chief stress was laid on the culture of the essentially modern sciences. In the foremost rank stood the administrative and historicopolitical branches where Pütter, Achenbach, Schlözer, Gatterer, Heeren, gave to the university her worldwide fame; the mathematical and scientific branches are marked by the brilliant names of Haller, Lichtenberg, Blumenbach, Kästner; the philological branches by Gesner, Heyne, Michaelis. The university met the demand for encyclopædic discourses. Münchhausen arranged in 1756 that a member of each faculty should deliver a public course on the whole field of the sciences taught there; in the philosophical faculty Gesner treated philologico-historical, Kästner physico-mathematical subjects. An 'Index Lectionum' of the year 1737 shows nine professorships: 1. Politics and Morals. 2. History of Literature. 3. History. 4. Elocution and Poetry. 5. Logic and Metaphysics. 6. Oriental Languages. 7. Mathematics and Physics. 8. Administrative Sciences; to which is added, lastly, a professorship of Philosophy, without special definition." 1

It is evident that, owing to their constitution, as well

1 The original endowment of Göttingen was fixed at 16,000 thalers, equal to $£ 2400$. This was more than double the endowment of Halle. (Paulsen, p. 425.) 
as to their number, the German universities were destined to become the most powerful organisation for the diffusion 7 . of knowledge. Further, they have been in the course of Relation of universities and higll schools. the present century more closely linked with many hundreds of high schools, and with the growing number of technical schools. ${ }^{1}$ For both of these they had to train the teaching staff, and from the ranks of these they again largely filled their own chairs. Thus they not only combined in themselves the spirit of research and the profession of teaching, but they infused into the widely scattered teaching staff of many hundreds of

1 The technical schools in Ger. many and Switzerland are a creation of modern times. We can distinguish three classes. (1) The "Realschule." This stands in a kind of opposition to the "Latin school." The name (according to Paulsen, p. 483) occurs first in Halle, where the archdeacon Semler es. tablished in 1706 a mathematical and mechanical "Realschule." J. J. Hecker established at Berlin in 1739 an "economico-mathematical Realschule." The object of these schools was to teach "Realia," to introduce practical rather than learned information. A special development was the "philanthropinism" of Basedow, well known even to English readers from Lewes's Life of Goethe (see rol. i. p. 276, \&c.) (2) A second class embraces the "Gewerbeschulen," which may be rendered "schools of industry." Karl Schmidt ("Geschichte der Pädagogik,' vol. iv. p. 163) calls Beuth the founder of them in Prussia, 1817, and gives the school of Aachen as the first. They form a kind of bifurcation with the ligher classes of the Gymnasia (or learned schools). They may be more specially commercial, agricul- tural, or military. (3) Out of these a third class - answering to the growing demand for the practical application of the higher mathematical sciences-has grown up, named polytechnic schools. The celebrated Ecole Polytechnique of Paris has been the model. The first of this class in Germany was established at Vienna in 1816. Then followed Munich, Hanover, Karlsruhe, Stuttgart, Nürnberg, Augs. burg, Darmstadt, Zürich, Aachen, latterly also Berlin (Reichsanstalt) and Brunswick (Carolinum). In many ways they equal the universities in the scientific spirit of their teaching. What is wanting is the philosophical, the historical, the encyclopredic treatment. In this respect they form in their best examples a contrast to the Göttingen programme. To many seriousthinking minds they indicate the gradual dissipation of the German ideal of Wissenschaft, the narrowing down of Hissenschaft to science in the English and French meaning of the word. Their danger lies in the direction of being contented with practical usefulness, as the danger of the German type of university lay in being contented with erudition. 
schools the same habit-almost absent in other countries -of looking upon private study and research as a necessary qualification of the lecturer and teacher. The educational organisation of the combined universities and higher schools has thus become an equally powerful organisation for research, and for increasing knowledge. Wherever the progress of learning and science requires a large amount of detailed study inspired by a few leading ideas, or subservient to some common design and plan, the German universities and higher schools supply a welltrained army of workers, standing under the intellectual generalship of a few great leading minds. Thus it is that no nation in modern times has so many schools of The university a train. thought and learning as Germany, and none can boast of research. having started and carried through such a large number of gigantic enterprises, requiring the co-operation and collective application of a numerous and well-trained staff. ${ }^{1}$ The university system, in one word, not only teaches knowledge, but above all it teaches research. This is its pride and the foundation of its fame.

1 The editions of the ancient classics brought out by Tauchnitz, Weidmann, and Teubner are well known. The collections of the Histories of all countries, begun by Heeren and Ukert and continued in this century by the publishing firm of Salomon Hirzel of Leipsic; the 'Jahresberichte,' started by Berzelius for chemistry, and now separately conducted for all the different sciences; contain summaries of the labours of the whole world systematically arranged. There is the geographical establishment of Petermann at Gotha; not to speak of publications specifically national, such as the 'Monumenta Germaniæ,' as other countries possess similar undertakings. Von Zach was the first to establish a regular international organ for astronomical observations. It was started in 1798 , and soon became the "living organ of astronomy," equally appreciated by Lalande and Gauss. This "monthly" was soon succeeded by Schumacher's "weekly," the 'Astronomische Nachrichten.' See Wolf, 'Geschichte der Astronomie,' p. 764, \&c. Humboldt's and Gauss's scheme for a network of magnetic observations all over the world was taken up by English men of science. 
It is a useful and interesting task to trace intellectual developments and habits to their external causes. The centralisation of the powers and resources of a whole nation into one capital, as was the case in Rome and in Paris, may explain the brilliancy of their literatures; the more scattered and diffused culture of Greece and of Germany is likewise reflected in their many schools of thought and learning; the insular position of England has impressed its advantages and disadvantages upon her history, and has influenced her mental life. These influences have frequently been pointed out and examined. The historian of thought has another and more difficult task to perform. Habits of thought and intellectual qualities never become the property of a large number of persons unless they assume a definite form; through this they become a marketable article which can be communicated and transmitted, and in which those also can participate from whom the deeper motives and higher aims remain hidden. Every school has its watchword, in which its leading thought, its ideal, is embodied. The widely scattered and yet closely connected community of intellectual workers represented by the German university system, which covers with its network of universities and high schools the German-speaking countries of Europe, has during the period of its greatest influence developed its own special ideal, and it has expressed this in a special word-namely, the word Wissensehaft. Neither the French nor the English application of the word science ${ }^{1}$ corresponds to the use or gives the meaning of the word Wissenschaft. This meaning cannot be defined by any

${ }^{1}$ Compare the notes at the beginning of the last chapter, p. 89, \&c. 
single word in the English language. Expressions such as "student of science" or "science tripos" have a meaning in English, but they would have none if translated into German. In each case the word Wissenschaft would require a qualification. An "Académie des Sciences" could not according to German usage exist separately beside an "Académie française" or an "Académie des Inscriptions," for it would include them. ${ }^{1}$ Scientific treatment in England means the exact experimental or mathematical treatment of a subject: no one ever calls Bentley $^{2}$ or Gibbon ${ }^{3}$ a great scientific writer, though in

1 The two older academies in Paris, the "Académie des Sciences" and the "Académie des Inscriptions et Belles Lettres," covered very nearly the same ground as the modern Berlin "Academie der Wissenschaften und Kiinste," which is divided into two classes, the " nuathematisch - naturwissenschaftliche" and the "philosophisch-historische Classe," the two sides being equally comprised under the term Wissenschaften. A similar division exists in the learned societies of Vienna, Leipsic, Munich, and Göttingen.

$2 *$ Richard Bentley (1662-1742), popularly known in England mainly through his Boyle Lectures, his controversy about the Epistles of Phalaris, and his thirty years' feud as Master of Trinity College, Cambridge, with the dons of his col. lege, but hardly known "as the first, perhaps the only, Englishman who can be ranked with the great heroes of classical learning " (Mark Pattison, 'Ency. Brit.'), was from the first recognised as a consummate genius by the scholars of Germany, by Gravius and Spanheim, who welcomed him as "novum et lucidum Britannia sidus," as "splendidissimum Britanniæ lu- men." The many beginnings which he had laid for subsequent critical research among the ancient classical authors were taken up abroad by men like Heyne, Reiz, F. A. Wolf, Gottfried Hermann, and Friedrich Ritschl, in whose hands they have developed into a special school of philology, counting probably over a hundred representatives, many of whom have openly avowed their indebtedness to Bentley. (SeeKöchly, 'Gottfried Hermann,' Heidelberg, 1874, pp. 115 sqq., 142, 189 . Rib. beck, 'Friedr. Wilh. Ritschl,' 2 vols., Leipzig, 1879 and 1881, vol. i. p. 229 ; vol. ii. pp. $111,176, \&$ c., 418, 429.)

3 Gibbon (1737-94) gave a new impetus to the study of the history of Roman law through the celebrated 44 th chapter of his 'Decline and Fall of the Roman Empire.' It was translated by Professor Hugo of Göttingen and Professor Warnkönig of Liège, and has been used as the text-book on Civil Law in some of the foreign universities. See Smith's edition of Gibbon's History with the Notes of Milman and Guizot, chap. xliv., note. Herder, Savigny, and Niebuhr stand all under the immediate influence of Gibbon, and Lessing saw 
Germany each stands at the head, and forms the beginning, of a definite scientific movement. The distinction between scientific and philosophical thought which I have explained in the Introduction would be unintelligible if science were translated simply by Wissenschaft; the word Wissenschaft is not opposed to, but embraces, the word philosophy: Fichte, whose whole doctrine was, according to French and English ideas, almost the reverse of scientific, uses the word Wissenschaftslehre to denote and characterise his system. ${ }^{1}$ In fact the German word for science has a much wider meaning than scienee has in French or English; it applies alike to all the studies which are

10.

Has been developed under the German university system. cultivated under the roof of "alma mater"; it is an idea specially evolved out of the German university system, where theology, jurisprudence, medicine, and the special philosophical studies are all held to be treated "scientifically," and to form together the universal, all-embracing edifice of human knowledge. ${ }^{2}$ Such an

in him kindred tendencies, though in a different direction (see Wattenbach, 'Zum Andenken Lessing's,' p. 23).

1 Fichte (1762-1814) begins his first philosophical work, published in 1794 , with the words, "Philosophy is a science," and he then proceeds to give to his philosophy the term Wissenschaftslehre, or general doctrine or theory of science. A further definition which he gives is as follows: "A science has a' systematic form; all propositions in it hang together in one single fundamental proposition, and are united by it into a whole." It is evident that whoever approached Fichte's writings with the ideal of science, as it was established by the labours of Lavoisier and the great French academicians, would not accept these first sentences of Fichte's book. He would admit that the sciences as cultivated by the great Frenchmen had a unity of method, the exact method, the method of observation, measurement, and calculation, but not necessarily a unity of system, or a highest all-embracing proposition. It is evident that science means to Fichte something more than it meant to the Académie des Sciences: it meant Wissenschaft, not merely methodical, but systematic, unified knowledge.

2 It would be an interesting task to trace in German literature from the time of Leibniz the gradual evolution of the idea of Wissenschaft, to see how the word has grown in pregnancy and signifcance till it became firmly estab- 
idea, the use of such a term, could only be born and developed where the different faculties, the various branches of knowledge, lived habitually, for many ages, under the same roof, coming into continual contact, and learning to regard each other as members of one family, as integral parts of one whole. The German university

lished as denoting a moral as mucl as an intellectual ideal, which it was the duty of the German university to uploold and to realise. Such an investigation would have to show low the encyclopedic view is represented by Leibniz, low Winckelmann applied the term to the studies of antiquity, how Lessing taught method and clearuess, how Herder widened and deepened the view, extending it to the elemental forces as well as to the finished forms of human culture, how it was finally raised as the standard of German university teaching by F. A. Wolf and W. von Humboldt, finding an eloquent exposition in Fichte's lectures on the "Nature of the Scholar" ("Vorlesungen iiber das Wesen des Gelehrten,' Erlangen, 1805 ), and a practical realisation in the foundation of the University of Berlin in 1809, during the period of Germany's greatest degradation. The following words of Fichte liave reverberated in the soul of many a German scholar to whom Fichte's philosophy was unknown or distasteful, and this same spirit has leavened and united studies which stand apparently in no connection with each other. "The scholar" (and specifically the teacher of scholars) "shows his respect for science [Wissenschaft] as such and because it is science, for science generally as one and the same divine Idea in all the various branches and forms in which it appears." Of one who may be seduced into overestimat- ing his own branch, Fichte says: "It becomes evident that he has never conceived science as One, that he has not comprehended his own branch as coming out of this One, that he thus does not himself love his branch as science but only as a trade; this love of a trade may otherwise be quite laudable, but in science it excludes at once from the name of a scholar. ... In the aca. demic teacher science is to speak, not the teacher himself," he is to speak to "his hearers not as his hearers but as future servants of science," he is to represent the dignity of science to coming generatious (Fichte, Werke, vol. vi. p. 436 , \&c.) I have myself heard expressions similar to these from the mouth of one who represented what we should now consider the very opposite phase of nineteenthcentury thought, from one of the earliest representatives in Germany of exact research, Wilhelm Weber of Göttingen. Driven into a corner by the questioniugs of devoted friends as to his own discoveries and contributions, which he was modestly fond of tracing to Gauss, and unable to deny his own part, - he would warmly exclaim, "But is it not possible that science could do something herself ?" Professor Adamson lias pointed out ('Fichte,' in "Philos. Classics," p. 79) how the fundamental idea in these writings of Fichte has been made familiar to English readers through the teaching of England's greatest modern moralist, Carlyle. 
system has the merit of having elaborated the widest conception of science, of having fixed the highest and most general scientific standards. Opposed to science is that which is unscientific, dilettante, popular; that which is not a vocation, but a handicraft; that which grows and lives outside of the great university system, including in this the innumerable learned schools which form its base, and the academy which forms its summit.

11.

In France and England Science, is called in Germany Exact Science; but it is "Science"

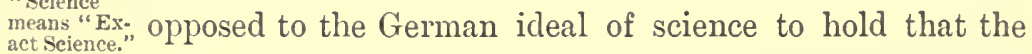
act science. called scientific. ${ }^{1}$

1 This is perhaps not quite correct. No loubt the term "exact Sciences" is used frequently during the last half-century to denote the mathematical and experimental sciences; very much in the same sense as we see them defined by Cuvier in the beginning of the century, and described as the ground covered by the labours of the "Académie des Sciences." There exists, however, in Germany another school of thought, very influential throughout this century, and one that has exerted a very wide and wholesome influence, which stands in no connection whatever with the mathematical sciences, though it applies the word "exact" to its methods and researches. This is the school which maintains that the real introduction to the study of antiquity lies in a knowledge of the ancient, preeminently the classical, languages, as exact and precise as any mathematical knowledge could be, and sees in an acquisition of such precise knowledge the training necessary for success in philological and his- torical research, just as familiarity with mathematical formulæ and measuring instruments has long been considered quite indispensable training to success in the natural sciences. Of this view Gottfried Hermann may be considered as a somewhat one-sided, Friedrich Ritschl as a more profound and far-seeing, but equally energetic representative. It is Ritschl who was the most influential. Without at present entering into the controversies which existed between what were termed the "Sprachphilologen" and the "Sach-philologen," I desire here to refer to the fact that such very different representatives of thought as Fichte, Weber, and Ritschl, than whom no men could be more dissimilar in cast of mind, all find their ideal expressed in the word Wissenschaft. I have quoted Fichte, the speculative generaliser, and Weber, the exact mathematical physicist. I will add what Ritschl, the critical philologist, says. He trusted, as his biographer reports, "in the indestructible magnetic force of 
Before the methods of exact science were introduced into Germany under English and French influences, the Germans possessed many scientific methods. There was the science of philosophical criticism, established by Kant; the science of historical criticism, of Biblical criticism; the science of philology: all these professed to have methods as definite, aims as lofty, and a style as pure, as the exact sciences brought with them.

At present a tendency of thought may exist in Germany, akin to the positive philosophy in France and England, which aims at introducing the methods of the natural sciences so as to cover the whole ground of research, and to allow of no other methods. Should it succeed, it will destroy the essential features of the German university system, and with it the ideal of Wissenschaft as it has existed in all the leading minds of Germany during the last hundred years.

I intend to conie back to this subject later on, and to define more clearly what the German ideal of science - what Wissenschaft-is. That which we are occupied with at present is the diffusion of the scientific spirit, in the narrower sense, as it was firmly established in France through the great mathematicians and scientists at the

the studies of classical antiquity" ; he maintained that philology, as science, not the barren training of a pedagogic seminary, is the only right thing for future masters. "The good teacher must, even for teaching purposes, have and know, both in quantity and quality, more than he requires for immediate progress; the portion he requires for immediate communication, for practical teaching purposes, must be delivered out of the fulness and the depth of knowledge; it must, even in its circumscribed nature, contain the germs of further mental development. Such depth, such fructifying power, comes only from science" (Wissenschaft). See Rib. beck, 'Leben Ritschl's,' vol. ii. p. 277 . And as every mode of thought, if clearly felt and active, finds its expression in language, so Ritschl was fond of characterising his scientific method by the word a $k \rho$ i $\beta \in \iota$. 
beginning of this century, as it is summed up in their works and in the Memoirs of the Institute. What reception did it find in Germany? How has it thriven under the German university system? These are the questions which interest us at present.

12.

Reception of Exact Science in Germany.

The general recognition of the purely scientific studies conducted on a large scale by the French Academy of Science, as an integral portion of the German university syllabus, belongs to the beginning of the present century. During the first forty years of the century complaints were continually heard that some of the most important sciences were not worthily represented. ${ }^{1}$ The eighteenth

1 One of the latest instances of such complaint is to be found in J. Liebig's paper "On the state of Chemistry in Austria" ("Annalen der Pharmacie,' 1838, vol. xxv. p. 339). This was followed by the highly interesting pamphlet 'On the state of Chemistry in Prussia' (Braunschweig, 1840). According to the eminent author, chemistry was the science which was the latest to attain a worthy domicile and an independent footing in the great universities of Germany. Mathematical physics had a centre at Königsberg, physiology had been established as an independent science at Berlin through the appointment of Johannes Miüller in 1833, chemistry was still only taught in Prussia in connection with other branches of science, with medicine, with technology, with mineralogy. There were no chemical laboratories to be found in Prussia. Men like Rose, Rammelsberg, Mitscherlich, received none or only the scantiest support in their practical courses of chemistry. It is interesting to note how Liebig, whilst pointing to the enormous importance which chemistry possesses from an economic and political point of view by reason of its working great changes and revolutions, industrial and other, insists on the necessity of teaching chemistry scientifically, and not with an immediate practical bias. In? this respect he is as much a representative of the scientific spirit in the wider sense as the great men mentioned in the note to $\mathrm{p} .171$. The following passage (p. 39) may still be read with in. terest and profit: "I have found among all who frequent this laboratory [Giessen] for technical purposes a prominent inclination to occupy themselves with applied chemistry. They usually follow hesitatingly and with some suspicion my advice to leare alone all this time-absorbing drudgery, and simply to become acquainted with the necessary ways and means of solving purely scientific questions. By following this advice their minds learn easily and quickly how to find the best means; they themselves adapt them to circumstances and morify them; all operations, all analyses, which serre to ascertain a certain state, which must be made in order to find the conditions 
century produced in Germany men of great scientific importance; but their position was irregular and uncertain, and they undoubtedly do not wholly or exclusively belong to the history of the university system. Leibniz, Euler, Haller, Werner, Markgraf, Tobias Mayer, Lambert, and Humboldt are all intimately connected with the growth of modern science: their position and sphere of action were in each case different. ${ }^{1}$ Leibniz was a courtier, Euler an

for the solution of the problem, have a definite sense ; each of them possesses a certain charm which dispels fatigue, and if the question is really answered, then they know the ways and means of attaining similar ends. I know many who are now at the head of soda-, vitriol-, sugar-factories, of colour-works and other establishments. Without ever having had anything to do with them beforehand, they were in the first half-hour acquainted with the processes, the second already brought a number of appropriate improvements, \&c., \&c." Similarly Helmholtz in 1862 ('Reden,' vol. i. p. $142)$ : "He who in the cultivation of the sciences aims at immediate practical usefulness, may be pretty sure that he will miss his aim. Science [Wissenschaft] can aspire only to a perfect knowledge and a complete understanding of the sway of physical and mental forces. The individual worker must find his reward in the joy over new discoveries, as new victories of mind over matter, in the rsthetical beauty which an orderly display of knowledge affords, \&c., \&c." How little do our modern colleges of science correspond with this view of Wissenschaft!

1 On Leibniz (1646-1716), see p. 158; Werner (1750-1817), p. 118 ; and Tobias Mayer $(1723-62)$, p. 158. A. von Humboldt (1769-1859) is well known to English readers.
Leonhard Euler (1707-83), a native of Basel, passed the greater part of his life at St Petersburg as a mem. ber of the Academy, a portion of it $(1741-66)$ as an Academician at Berlin. $\mathrm{He}$ has been termed the father of pure mathematics, inasmuch as he freed mathematical analysis from geometrical conceptions, established the notion of function or mathematical dependence, and did much to make the theory of numbers an independent branch of science. His memoirs are said to number nearly a thousand; his works, if all printed, would fill 60 to 80 quartos (see Hankel, 'Die Entwicklung der Mathematik,' Tübingen, 1884, p. 12). Andreas Sigismund Markgraf (1709-82) was born and lived at Berlin, a member of the Academy. On his various chemical researches see Kopp, 'Geschichte der Chemie,' vol. i. p. 208. Albrecht von Haller $(1708-77)$ was a native of Bern. He was, next to Leibniz, perhaps the most encyclopredic mind of modern times, equally celebrated as botanist, physiologist, and poet. $\mathrm{He}$ has been termed the father of physiology. Brought up under the celebrated Boerhaave, he accepted a chair at the newly founded University of Göttingen in 1736, and taught there for seventeen years anatomy, botany, medicine, and surgery. 
academician, Werner the head of a great mining school, Humboldt a traveller, Markgraf a private gentleman. Haller, indeed, shone as a great light in the University of Göttingen, where he did more than any other to place scientific studies on a level with classical ones, and to create for them a permanent abode within the pale of "alma mater." He founded in 1751, in close connection with the university, the Göttingen Society, which from 1753 published the celebrated 'Göttinger Gelehrte Anzeigen.' 1 Tobias Mayer and Lambert ${ }^{2}$ can hardly be said to have got much help either from the university, to which the former belonged, or from the Academy, of which the latter was a member; their celebrity rests on works produced by private and unaided effort. Humboldt also depended upon his personal means and upon his comnection with the Paris Academy, and only attained late in life, and in the course of the present century, his eminent position as the head and patron of German science. Von Zach and Olbers, who together with Tobias Mayer and Lambert raised German astronomy during the eighteenth century to the level of English and French science, stood outside the university systern. Von Zach was indebted to personal connections, and ultimately to Duke Ernest II. of Gotha, for the position which

1 The 'Göttinger Gelehrte Anzeigen' had existed since 1739 .

2 Joh. Heinrich Iambert (1728$7 j)$, a very extraordinary man, was a native of Mühlhausen, Alsace, which then belonged to Switzerland. He was received as a member of the Berlin Academy, and associated there with Euler and Lagrange. He is celebrated through his 'Photometry' (1760) and 'Pyrometry' $(1779)$, his equation referring to the orbits of comets, employed by Olbers in his method for calculating them (Weimar, 1797, republished by Encke, 1847), and his prophetic prediction of the proper motion of the sun (in his Cosmolo. gical Letters, 1761). This motion was actually calculated by Sir William Herschel in his paper "On the proper Motion of the Sun and Solar System " ('Philos. Trans.,' 1783). 
he held as a kind of corresponding centre of European astronomy, and as the leader of a large school of German astronomers of this century. ${ }^{1}$ Olbers was a practising physician at Bremen, ${ }^{2}$ where he followed astronomical studies as a recreation, making himself eminent by great services to science, among them by his method of calculating the orbit of a comet: as the greatest of his services he counted the fact of having discovered, trained, and appreciated the rising genius of Bessel. ${ }^{3}$

1 Franz Xaver von Zach (17541832) was a native of Pesth. After having served in the Austrian artillery, and taken to astronomy as a favourite study, he spent some time in Paris and London, and became acquainted with Lalande, Laplace, Herschel, Maskelyne, Ramsden, and others. He was engaged by Duke Ernest II. of Gotha in 1786 to erect an observatory on the Seeberg near Gotha. This was completed in 1791. Here he trained a number of younger astronomers, and was the first to establish and maintain a periodical specially devoted to astronomy. It was first (1798) published under the title 'Geographische Ephemeriden,' then (1800-13) as 'Monatliche Correspondenz zur Beförderung der Erdund Himmelskunde.' Lalande and Gauss both testified to the usefulness of this international publication, without which Piazzi's discovery (see p. 182, note 1) would probably have been lost. See Wolf, 'Gesch. d. Astronomie,' p. 764.

${ }^{2}$ Heinr. Wilh. Mat. Olbers (17581810) was born near Bremen. He followed astronomy as a private study. $\mathrm{He}$ is mainly known by his rediscovery of the first of the smaller planets (see p. 182, note 1), by his theory, once generally accepted, of the origin of the smaller planets through the disruption of a primitive large planet, and by his 'Abhandlung über die leichteste und bequemste Methode die Bahn eines Cometen aus einigen Beobachtungen zu berechnen' (1797). In this work, by using Lambert's equation, he succeeded in perfecting the methods of Newton and his successors so as actually to calculate the elements of several comets. This method is still in general use (see Wolf, loc. cit., p. 519).

${ }^{3}$ Friedr. Wilh. Bessel (1784-1846) attracted the attention of Olbers by his mathematical abilities whilst employed as clerk in a shipping office at Bremen. If Tobias Mayer's lunar tables were remunerated and published with English money, Germany repaid the debt by the industry of Bessel, who calculated and reduced the observations made by Bradley (1692.1762, Astronomer Royal from 1742) at Greenwich during the years 1750 to 1761 . They had been neglected and remained unpublished till 1798, when Olbers induced Bessel to make them useful to science. This he did by calculating from them some of the most important and fundamental data of astronomy. After many years of labour he brought out his 'Fundamenta Astronomix pro A. 1755 deducta ex observationibus viri incomparabilis James

VOL. I. 
13. Science not yet domiciled at the German universities during the eighteenth century.

The general impression we receive from a perusal of the histories of science and learning in Germany at the close of the eighteenth century is, that the university system had, so far as philosophical and classical studies were concerned, attained almost to the eminence which it has held during this century, but that it had not-with the exception perhaps of Göttingen-received into its pale the modern spirit of exact research, such as it had been developed by the great French Academicians. Eminent students of science lived outside of the universities, belonging wholly or largely to the international Republic which had its centre in Paris, exerting little influence on higher German education through the universities, and hardly any on German literature, which had meanwhile ripened into the age of Classicism. This scattered condition of German science gave it on the one side a character which was foreign to the general tendencies of German thought, since this had come under the excessive influence of the speculative spirit without that wholesome check which exact research has always exerted. ${ }^{1}$

Bradley in specula astronomica Grenoviænsi per A. 1750-62 institutis' (1818). By his determination (1838-40) of the parallax of the star 61 Cygni he made the first accurate calculation of the distance of a fixed star, which he computed at 12 billion astronomical miles.

${ }^{1}$ It was the age of the Naturphilosophie, which, through the in. fluence of Schelling in the south and Hegel in the north of Germany, filled the chairs in the universities, and penetrated into the learned societies. This philosophy of nature had the effect of frequently replacing induction by speculation, the patient work of the calculator, the observer, the experimenter, and the dissector by general theories, such as, applied to literary, historical, and poetical subjects, had acquired a certain importance, and a semblance of veracity and usefulness. In France the whole spirit of the Academy of Sciences opposed this form of learning. Cuvier denounced it or regarded it with suspicion, in England it remained unknown, and in Germany itself individual great minds opposed it, or did their work outside of its influence. Such were notably A. von Hum. boldt and Gauss. Younger men, such as Liebig and Joh. Müller, 


\section{On the other side, we find in the wide domain of gen- eral literature valuable beginnings and foreshadowings of later scientific thought, as in Georg Forster ${ }^{1}$ and in}

came temporarily under its influence. As regards its harmful effect on the natural and medical sciences, the popular addresses of Helmlioltz and Du Bois-Reymond may be consulted. Its philosophical value will frequently occupy us in later chapters of this work. Its period can be approximately fixed by the publication in 1797 of Schelling's 'Ideen zu einer Philosophie der Natur.' 'The death of Hegel in 1831, and Humboldt's Berlin lectures during the years 1827 and 1828 , may be considered as marking approximately the end of the generation which came under the one-sided influence of the Naturphilosophie. We shall have ample occasion later on to notice how many valuable leading ideas connected with this phase of thought were temporarily abandoned and have since come prominently before the scientific world. The year 1830 marked the victory of Cuvier's ideas over those of his great contemporary Geoffrey StHilaire in the French Academy, and with it the temporary defeat of the valuable suggestions contained in the writings of Lamarck and Goethe.

1 Georg Forster (1753-94) was one of those unique men in the history of literature and science who combine the artistic with the scientific spirit, promoting equally the interests of poetry and of exact know. ledge by a loving study of Nature, leading to new views of art as well as to deeper conceptions in science. He may be classed with White of Selborne and other naturalists of England among the small number of those who quietly and unostentatiously prepared the healthier forms of Naturalism which permeate the poetical and scientific thought of our century, culminating in the great names of Wordsworth and Goethe, of Humboldt and Darwin, of Wallace and Häckel. His life presented many interesting and some unhappy episodes; it introduces us into the political aspirations of the early French Revolution, to which he sacrificed himself. It has been written by Moleschott, the naturalist, by Heinrich König, the novelist (' G. Forster in Haus und Welt,' Leipzig, 1858, 2 vols.), by Klein ('Georg Forster in Mainz'). Fr. Schlegel ('Charakteristiken und Kritiken,' vol. i.), Gervinus (Introduction to the 7 th vol. of 'Georg Forster's Werke'), and Hettner ('Literatur des $18^{\text {ten }}$ Jahrhunderts,' vol. iii.) have written appreciative essays on him. A, von Humboldt calls him his master ('Kosmos,' vol. i. p. 345), and Herder (Preface to Georg Forster's translation of 'Sakuntala') prophesies his lasting fame against the opinion of his less appreciative contemporaries. He has a place in the classical literature both of England and Germany through his beautiful description of Captain Cook's second voyage round the world - his father, Joh. Reinhold Forster, having been selected as the naturalist on that voyage (London, 1777, 2 vols. 4to), German edition, 1779. Richar'd Garnett has said of him: "His account of Cook's voyage is almost the first example of the glowing yet faithful description of natural phenomena which has since made a knowledge of them the common property of the educated world. . . . As an author he stands very high; he is almost the first 
Goethe $;^{1}$ but they could hardly be encouraged and developed sufficiently without that strict training which is acquired through the routine of the class-room, or under the eye of a recognised authority.

14. Scientific periodicals.

The want of academic union and organisation, and the scattered situation of the many small centres of learning and culture in Germany, led, however, to the early development of those scientific periodicals which form such a characteristic feature in German literature. They were the medium for the exchange of ideas, and the collectingground for researches, in an age when exact science was not systematically taught at the Universities, and when such researches otherwise would have run the risk of being lost in obscurity or oblivion.

At the end of the eighteenth century Germany,

and almost the best of that valuable class of writers who have made science and art familiar by representing them in their essential spirit, unencumbered with technical details" ('Ency. Brit.,' vol. ix. p. 419). Forster lived in the period of transition from the thought of the eighteenth century to that of the nineteenth, and a study of his Life, Works, and Correspondence is a very good introduction to nearly all the great problems which then, especially on the Continent, troubled the minds of the greatest men. If he may be accused of want of patriotism, he is certainly to be admired for his freedom from national narrow-mindedness.

1 It has taken nearly a century before the real value of Goethe's scientific ideas has been correctly gauged. His non-academic surroundings, his unscientific style, his antagonisu to Newton, his mission as a poet-supposed in those days to be less realistic than we have since become accustomed to consider it - all these circumstances contributed to the result that Goethe's scientific writings were not taken au sérieux by the naturalists of his age. Then came a period when men of science began to sift the wheat from the chaff ; but even they have only tardily recognised that, more than in special discoveries or suggestions, his greatness lies in that general conception of Nature which was so foreign to his age, and which nevertheless is becoming more and more familiar and necessary to ours. See especially Helmholtz's valuable essays on Goethe as naturalist from the years 1853 and 1892 ('Vorträge,' vol. i., and address delivered at the meeting of the Goethe Society at Weimar, 1892), and the remarkable progress of his own views on this subject contained therein. We shall have ample opportunity of reverting to this subject. 
though not by its universities, was already an important power in the Republic of exact Science which then had its centre in Paris. Just at the beginning of the nineteenth century two events happened which foreboded for the highest branches of the mathematical sciences a revival of the glory which in this department Kepler and Leibniz had already given to their country. These two events are both coupled with the name of Carl Friedrich Gauss. They added greatly to the reputation of the University of Göttingen, with which this remarkable man was connected for half a century.' The first was the publication of the 'Disquisitiones Arithmeticæ' in Latin in 1801-a work by which Gauss placed himself on a level with the great mathematicians, Euler, Lagrange, and Legendre. ${ }^{2}$ The

1 Carl Friedrich Gauss (17771855 ), a native of Brunswick, called by Laplace the first mathematician of Europe, may be considered as the first and foremost representative of the modern mathematical school, of which we shall have to treat later on. Unlike most of the great mathematicians of the Continent, he was self-taught, and followed in his earliest works quite independent lines of thought; resembling in this the great isolated thinkers of Britain whose ideas take a generation or more to penetrate into the text-books of the school. Gauss had the highest opinion of the dignity of pure science, and it almost appears as if, among the moderns, only Newton had come up to his ideal. For him alone he reserves the adjective "summus," and he adopts his synthetic and classical methods of exposition, removing, as has been said, the scaffoldings by the aid of which he had erected his monumental works.
Gauss trained few mathematicians; but among the few who penetrated the secret of his ideas are such original thinkers as the Hungarian Bolyai (1775-1856), the geometers Möbius (1790-1868) and Von Staudt (1798-1867), who all mark quite independent lines of research. On Gauss see Sartorius, 'Gauss zum Gedïchtniss,' Leipzig, 1856 ; Hänselmann, 'K. F. Gauss,' Leipzig, 1878 ; E. Schering, 'C. F. Gauss,' Göttingen, 1887.

${ }^{2}$ It appears that Gauss, to whom the arithmetical discoveries of Fermat and the proofs of Euler, La. grange, and Legendre remained for a long time unknown (see his Works, edited by Schering, vol. i. p. 6; vol. ii. p. 444), had independently, in his eighteenth year, as a student at Göttingen, already arrived at a great number of propositions referring to the properties of numbers, and had then also found methods of geometrically constructing the regular polygon of seventeen sides. 


\section{second was the invention of a new and shorter method of calculating the orbit of a planet from a limited number of contiguous observations. ${ }^{1}$ This method was communi-}

The latter was the first addition made after 2000 years to the knowledge of this matter possessed by the ancients. (See 'Disquis. Arithm.,' sec. 365: "Magnopere sane est mirandum, quod, quum jam Euclidis temporibus circuli divisibilitas geometrica in tres et quinque partes nota fuerit, nilhil his inventis intervallo 2000 annorum adjectum sit," \&c. ; and his manuscript note to this passage, given by Schering, vol. i. p. 176: "Circulum in 17 partes divisibilem esse geometrice, deteximus 1796 , Mart. 30.") It is probably owing to the independent manner in which Gauss approached the subject that he early found the necessity of treating subjects of higher arithmetic (i.e., of the theory of numbers or "discrete magnitudes" as distinguished from algebra, which is the theory of "continuous magnitudes") by an independent method, for which he invented a language and an algorithm. $\mathrm{He}$ thus raised this part of mathematics into an independent science, on which the 'Disquisitiones Arithmetices' is the first elaborate and systematic treatise. Legendre's 'Traité des Nombres' (1799) is a complete thesaurus of all that was at that time known and of what was added by him, but it does not attempt to establish the science on a new basis.

1 On the 1st January 1801 Piazzi at Palermo had found a movable star of 8 th magnitude, RA. $57^{\circ} 47^{\prime}$, ND. $16^{\circ} 8^{\prime}$, which he announced to Bode at Berlin as a comet on the 24th January; but a few days later he concluded it must be a planet, and named it "Ceres Ferdinandea." No one be- sides Piazzi could find the star, but several astronomers, Piazzi himself, Olbers at Bremen, and Burckhardt at Paris, tried to calculate the orbit from the observations of the discoverer, which were contained within only 9 degrees. The attempt to do so under the supposition of either a circular or a parabolic or an elliptic orbit failed, and Olbers expressed the fear that with the circular or elliptic elements which had been published in Zach's periodical, it might prove impossible to find the star when it should again become visible. Very near the expected time, as late as the beginning of December, Gauss communicated his elements to Von Zach, who published them at once, recommending astronomers to follow Dr Gauss's figures and look $6^{\circ}$ to $7^{\circ}$ more eastward than the positions of Burckhardt, Piazzi, and Olbers indicated. And actually on the 7 th December 1801 Zach himself, and on the 1st January 1802 Olbers, succeeded in finding the star, "like a grain of sand on the sea-shore," very near the positions calculated by Gauss. These results, followed soon by the discovery of other planets by Olbers and Harding, gave a great impetus to the study of astronomy. Gauss's methods were published in cxtenso in the now celebrated 'Theoria motus corporum cœlestium' in 1809. Two problems are herein treated in a novel and complete manner. The first was to calculate by a simple and accurate method from the necessary number of observations the orbit of a planet or comet on the assumption of Newton's law of gravitation, but with. out any other special conditions. 
cated to Von Zach in the course of the year 1801, and enabled him and Olbers to rediscover the first of the small planets, Ceres, which Piazzi had observed on the 1st of January 1801 at Palermo, and afterwards lost as it approached the region of the sun's light. Through this Gauss placed himself on a level with the great French astronomers Laplace, Lalande, and others. The new professor of mathematics and director of the observatory of Göttingen was admitted into the august company of the Paris academicians, who then ruled, and since the death of Euler had almost monopolised, the mathematical studies of the world. Although Gauss thus introduced the higher and abstract branches of exact science into the programme of a German university, and established a link between Paris and Germany in mathematics, as Humboldt had done shortly before in the natural sciences, fully a quarter of a century was to elapse before the spirit of exact research, and of the higher mathematics, really began to leaven the German universities. It then at length entered the field as a third and equally important agent by the side of the

16. Scientific spirit enters the universities in the second quarter of the
This was achieved to perfection, a proof of the usefulness of the method being the fact that Gauss succeeded in finishing in one hour a calculation which had taken Euler three days, and had resulted in his blindness. The second problem arises from the fact that the number of observations is always in excess of the number mathematically necessary, and that, owing to the unavoidable inaccuracies, different sets of observations give slightly different orbits. How are these to be used so as to give the most correct average result? This involves a question in probabilities. As early as 1795 Gauss was in pos. session of the so-called method of least squares, which occurred to him so naturally that he suspected that Tobias Mayer must have already known about it. It also occurred independently to Legendre, who was the first to publish it, in 1806, in his 'Nouvelles méthodes pour la détermination des orbites des comètes.' See Sartorius, 'Gauss zum Gedächtniss,' p. 41 sqq. 
philosophical and classical spirit. During these twentyfive years Gauss lived and soared in solitary height-a name only to the German student, as Euler had been before him. Probably he was better known to the younger astronomers whom he trained, and the elder ones with whom he corresponded. But astronomy was not then within the pale of the universities. To what extent the character of Gauss's own genius was the cause of this it is difficult to say. ${ }^{1}$ He himself had not come under the influence of any great teachers such as Paris then possessed; he was self-taught, and had early imbibed a great admiration for the methods of Euclid, Archimedes, and Newton; he wrote in the classical style fitted for all times, but not for uninitiated beginners. ${ }^{2}$ It is certain,

1 Bjerknes, in his most interesting memoir on Abel, refers frequently to the awe in which Gauss was held by younger mathematicians.

2 In this Gauss resembled Newton. He was therefore, like Newton, frequently forestalled by others, who published his new methods and ideas in an unfinished and fragmentary form; whereby it is not suggested that these simultaneous discoveries or inventions were not quite independent. Two examples of this may be added to those given above. IThen Gauss published the 'Disquis. Arith.' in 1801, he left out the last or eighth section, which was to treat of the residues of the higher orders. He had already nearly completed the theory of biquadratic residues. In dealing with this subject he had found it necessary to extend the conception of number beyond the limits then in use. If we confine ourselves to integers, the only extension which then existed of the notion of number was in the use of negative numbers.
These were counted on a straight line backward, as positive (or ordinary) numbers were counted forward. Gauss conceived the idea of counting numbers laterally from the straight line which represented the ordinary-positive and negativenumbers. He called numbers which were thus located in the plane "complex numbers," as they had to be counted by the use of two units, the ordinary unit 1 and a new unit i. He also showed that this new unit i stood in such relations to the ordinary unit 1 as were algebraically defined by the mysterious imaginary symbol $\sqrt{-1}$. The complete exposition of this new or complex system of counting was not explained by Gauss till the year 1831, when he published the 'Theoria residuorum biquadraticorum.' In the meantime the geometrical representation of imaginary quantities had been devised and published by Argand (1806), but not being employed for such important researches, it had re- 
however, that the spirit of exact and specially mathematical research owed its right of domicile within the universities to others who came after him, and to circumstances with which he was hardly connected.

The man to whom Germany owes its first great school of mathematicians was Jacobi. He was self-taught like Gauss; but whilst Gauss followed in the footsteps of Newton and the ancients, Jacobi followed in those of Euler, Lagrange, and Laplace. The style and methods of these mathematicians, being more suited for didactic purposes than the classical style of Euclid, Newton, and Gauss, was probably more congenial to the mind of Jacobi, who from his twenty-first year (1825) developed a great activity as an academic teacher. ${ }^{1} \mathrm{He}$ was first

mained unknown and unnoticed. See on the history of the subject, Hankel, "Theorie der complexen Zahlensysteme,' 1867, pp. 71, 82. Gauss, through hiding his researches on this subject so long, lost the claim to the priority of the invention, though not of the effectual use of it. In another instance he allowed others to appropriate the merit of cultivating a large new field which had been familiar to him many years before. It was known all through the first half of the century that Gauss was in possession of valuable discoveries in what he termed the "new transcendent functions." References in the 'Disquisitiones,' § 335 , in his corres. pondence with Schumacher, Bessel, Olbers, and Crelle, had made his friends curious to see the "amplum opus " which he had promised. It appears, however, that, independently of him, Jacobi and Abel (1802-29) following the investigations of Legendre (whose labours began in 1786 and culminated in his great work 'Traité des fonctions elliptiques, \&c.,' 1825-28, 2 vols. and 3 supplements), succeeded in developing the theory very much on the same lines as Gauss had taken nearly a generation earlier. Eminent mathematicians who, since the publication of Gauss's posthumous papers, have fully investigated the subject, assign to Jacobi and Abel the undisputed priority of publishing, but to Gauss that of discovering, the fundamental properties of the "doubly periodical" functions. Full details will be found in the historical introduction to Enneper's 'Elliptische Functionen,' 2d ed., Halle, 1890. See also Gauss's Werke, vol. iii. p. 491496 ; Dirichlet's Discourse on Jacobi in Jacobi's Werke, vol. i. p. II ; C. A. Bjerknes, 'N. H. Abel,' Paris, 1885; Koenigsberger, 'Zur Geschichte der Theorie der elliptischen Transcendenten,' Leipzig, 1879.

1 Carl Gustav Jacob Jacobi (born at Potsdam 1804, died at Berlin 1851) was the first great mathe-
17. Jacobi's cal school. 
at Berlin, then at Königsberg; these two universities having become through him and Bessel the German teaching centres of the higher mathematics, both pure and applied. They have up to the present day fully maintained this pre-eminent position. They were teaching centres in the sense defined above - not only as regards mathematical knowledge and method, but likewise as regards mathematical research. For this purpose-as in the philological sciences - the lecture-room was not sufficient; there was also wanted a repository for the independent and original contributions of the school. Like the École polytechnique thirty years before in Paris, the Berlin school of mathematicians started with an important periodical. This was known as Crelle's Journal. Together with the Memoirs of the Paris Academy and the Journal de l'École polytechnique, it forms the principal repository for the higher mathematical work of the first half of the century. ${ }^{1}$ It was also through

matical teacher of Germany. Of him Lejeune Dirichlet says: "It was not his business to communicate what was finished and what had been communicated before; his lectures all treated of subjects which lay outside of the field of the text-books, and covered only those parts of science in which he had himself been creative. With him this meant that they exhibited the greatest variety. His lectures were not remarkable for that kind of clearness which is characteristic of intellectual poverty, but for a clearness of a higher kind. He tried primarily to show the leading ideas which underlay any theory, and whilst he removed everything that had an artificial appearance, the solution of problems presented itself so easily to his hearers that they could hope to do something similar. . . The success of this unusual method was truly remarkable. If in Germany the knowledge of the methods of analysis is now spread to a degree unknown to former times, if numerous mathematicians extend the science in every direction, this gratifying result is principally owing to Jacobi. Nearly all have been his pupils," \&c. (Dirichlet's Discourse in the Academy of Berlin, 1852, Jacobi's Werke, vol. i. p. 21.)

1 The two mathematicians on whom A. L. Crelle (1780-1855) relied mainly for contributions when he started the 'Journal für die reine und angewandte Mathematik' in 1826 were Abel and Steiner. For originality of thought they stand quite alone. Both extended 


\section{Jacobi, and still more through his contemporary Lejeune Dirichlet (born 1804 at Düren, of French extraction, and trained in Paris under Laplace, Legendre, Fourier,}

the field of research which they cultivated by fundamentally new ideas of such breadth that fully half a century was required before they were thoroughly appreciated by mathematicians. Abel (a Norwegian by birth) died in 1829 when only twenty - seven years old, having during the four years which embrace his published memoirs extended the limits of algebra and laid the foundations for a more comprehensive treatment of the higher or transcendent functions, or forms of mathematical dependence. Mathematicians before him had tried to solve algebraically equations beyond the fourth degree, but had failed. Abel proved that the problem as then conceived could not be generally solved. Legendre had through his unaided labours, extending over thirty years, established the theory of elliptic integrals as far as was possible on the lines then adopted. Abel-and simultaneously Jacobitreated the subject from an entirely novel point of view, and by doing so opened out quite a new field of research, the extent and importance of which Abel fully recognised when he presented to the French Academy his memoir of 1826, in which he dealt with functions of which those studied by Legendre and Jacobi were only special cases. This memoir, containing Abel's celebrated theorem, which he had already discovered in 1825, and which was published in a brief article in Crelle's Journal in 1829, remained unnoticed, being, as Legendre explained to Jacobi, almost unreadable. See Enneper, 'Elliptische Eunctionen,' 2d ed., p. 192; Jacobi's Werke, vol. i. p. 439 , \&c. Abel has been called the greatest mathematical genius that has yet existed (Oltramare in 'La grande Encyclopédie," art. "Abel"); his fellowworker, Jacob Steiner (1796-1863, a Swiss by birth), has been termed the greatest geometrician of modern times. The progress of analysis had thrown into the background purely geometrical researches, although a revival of these had commenced in France with Monge and his followers, and had been further promoted by Poncelet, as well as simultaneously by Möbius and Plücker in Germany. The labours of the two latter remained for a long time unknown and unrecognised. Steiner, who was selftaught, who disliked the calculus, and considered it a disgrace that geometry could not solve her problems by purely geometrical methods, undertook to find the common root and leading principle which connected all the theorems and porisms bequeathed to us by ancient and modern geometry; he brings order into the chaos, and shows how nature with a few elements and the greatest economy succeeds in giving to figures in space their numberless properties. $\mathrm{He}$ not only completed that part of geometry which had been treated by the ancients-the geometry of the line, the conic sections or curves of the second order, and the surfaces in space corresponding to them-but he also attacked problems which before him had been solved only by the calculus, and even succeeded in carrying his methods beyond the reach of the calculus of variations, specially invented to deal with geometrical questions. Like Fermat in the theory of numbers, 
Poisson, Cauchy), that the great work of Gauss on the theory of numbers, which for twenty years had remained sealed with seven seals, was drawn into current mathematical literature, and became, as Newton's 'Principia' had become a century earlier, an inexhaustible mine of wealth for succeeding generations.

18.

Chemical laboratories established in 1526 through Liebig.

About the same time the experimental side of exact researcl一-the use of the chemical balance, through which Lavoisier and his followers had done so much to establish chemistry on a firm and independent basis-received a great impetus by the establishment of the first chemical laboratories within the pale of the universities. ${ }^{1}$ In this direction the greatest influence probably belongs to the small town of Giessen, where Liebig opened his celebrated laboratory in the year 1826 . It became the

Steiner in geometry left to his followers a large number of theorems and problems without proofs which he had solved by his methods; and it was only in quite recent times that the Italian Cremona succeeded in definitely clearing up the whole of this original and valuable bequest. See Hankel, 'Die Elemente der projectivischen Geometrie,' chapter i. ; Jacob Steiner, Werke, vol. ii. p. 495.

1 On Liebig's laboratory see Hofmann's Faraday Lecture, p. 8. Chemical laboratories existed for teaching purposes before Liebig's at Giessen. Kopp ('Geschichte der Chemie,' vol. ii. p. 19) mentions one at Altorf, which was founded, 1683 , by the council of the city of Nïrnberg for academic teaching purposes. For the training of the modern school of chemists no man did more than Berzelius, in whose laboratory there were trained $\mathrm{Chr}$. Gmelin, Mitscherlich, $\mathbf{H}$. and G.
Rose, Wöhler, Magnus, Arfvedson, Nordenskiöld, Mosander, and others. Sir William Thomson (Lord Kelvin) in 'Nature,' vol. xxxi. p. 409 , mentions the beginnings of laboratoryteaching at Glasgow by Prof. Thomas Thomson in 1828. But what was probably peculiar to Liebig's laboratory was the systematic and methodical training, on a specially devised plan, in qualitative, quantitative, and organic analysis, by which young persons were introduced to a thorough knowledge of chemical properties and manipulations. The guides, text-books, and tables for analytic work of Will, Fresenius, and others were elaborated to meet the requirements of such methodical teaching. Almost simultaneously with Liebig at Giessen, Purkinje at Breslau laid the foundation for the first physiological laboratory. See Du Bois-Reymond, 'Reden,' vol, ii. p. 367 . 
training school for the greater part of the eminent chemists outside of Paris, and the model for similar establishments, and extended its influence over the world - into England, Scotland, and America. It also did more than any other institution of that kind for the development of ready and accurate methods of analysis, such as are now used in the remotest regions. But it was significant for German chemistry, and for the cosmopolitan character of German science generally, that this brilliant development of experimental research was ter of Gerstimulated from two independent centres; that German chemists as little as German mathematicians attached themselves in a one-sided manner to the Paris school.

In mathematical science the classical style of Gauss, transmitted from the ancients through Newton, combined with the analytical or modern French style of Jacobi and Dirichlet to give to German research its character of universality. In a similar manner, when chemistry again found a domicile in Germany and became an integral portion of the university programme, it had been trained in two different schools. For there lived at that time in Sweden the eminent authority Berzelius, ${ }^{1}$ who divides with Gay-Lussac the glory of being

1 J. Jacob Berzelius (a Swede, 1779-1848), one of the most eminent and industrious of chemists, had a great influence on the development of modern chemistry by the number as well as by the accuracy of his experimental determinations, by his invention of methods and apparatus for analysis, and by his extensive proofs of several of the most im. portant theories. The latter directed the labours and governed the opinions of many - especially Ger- man-investigators. It was through him mainly that Richter's chemical equivalents and Dalton's atomic theory were extensirely verified and applied to all parts of the science, to organic and mineralogical chemistry. He also elaborated, in close connection with Davy's electrical discoveries, his celebrated electrochemical theory, which up to the year 1840 was very generally accepted by chemists; and he assisted through his repeated expositions 


\section{the master of the great German chemists of the middle} of the century. Mitscherlich at Berlin and Wöhler at Göttingen belonged to the school of the former, whereas Liebig had the good fortune to be introduced through Humboldt into Gay-Lussac's laboratory at Paris as the first pupil. ${ }^{1}$

and criticisms in breaking down the older oxygen theory of acids in favour of Davy's more general views, based upon his recognition of chlorine and iodine as elementary bodies. His handbook of Chemistry, as well as lis 'Jahresbericht' (from 1820), probably did more than any other publications for the diffusion of accurate chemical information.

${ }^{1}$ Liebig has himself, in an autobiographical memoir published posthumously, so fully described the merits of the two schools, and at the same time given such a rivid picture of the truly scientific spirit which animated German universities at that time, that I am tempted to give here some extracts. Of his studies in Paris he says : "What influenced me most in the French lectures was their inner truthfulness and the careful omission of all mere semblance of explanations: it was a complete contrast to the German lectures, in which, through a preponderance of the deductive process, the scientific doctrine had quite lost its rigid coherence. . . . I returned to Germany (1824), where, through the school of Berzelius, - . a great reform had already begun in inorganic chemistry. . . . I always remember with pleasure the twenty-eight years which I passed at Giessen: it was, as it were, a higher providence which led me to the small university. At a large university, or in a larger town, my powers would have been broken up and frittered away, and the attainment of the aim which I had in view would have been much more difficult, if not impossible; but at Giessen all were concentrated in the work, and this was a passionate enjoyment." "The necessity of an institute where the pupil could instruct himself in the chemical art, by which I understand familiarity with chemical operations of analysis and adroitness in the use of apparatus, was then in the air, and so it came about that on the opening of my laboratory . . pupils came to me from all sides. . . . The greatest difficulty presented itself, as the numbers increased, in the practical teaching itself. In order to teach many at once, an ordered plan was required and a progressive way of working, which had to be thought out and tried. ... A very short time had sufficed for the celebrated pupils of the Swedish master to give to mineral analysis . . an admirable degree of perfection. . . Physical chemistry . . had through the discoveries of Gay-Lussac and Humboldt, ... and of Mitscherlich, ... gained a solid foundation, and in the chemical proportions the edifice appeared to have received its coping-stone. ... No organic chemistry ... then existed ; Thénard and Gay - Lussac, Berzelius, Prout, Döbereiner, had indeed laid the foundation of organic analysis; but even the great investigations of Chevreul on the fatty bodies received for many years only scant attention. Inorganic chemistry still absorbed too many, and indeed the best, forces. 
Twenty years after Gauss's great mathematical achievements, two new discoveries announced to the scientific world that Germany had again taken a foremost position in chemistry. These were Mitscherlich's discovery of isomorphism in $1819,{ }^{1}$ and Wöhler's preparation of an organic compound from inorganic materials in $1828 .^{2}$

In 1830 Liebig succeeded in finally establishing that simple and accurate method of organic analysis known Liebig's organic analysis. by his name. Organic chemistry, in its modern sense,

The direction I had received in Paris was a different one. ... I saw very soon that all progress in organic chemistry depended on its simplification... The first years of my residence at Giessen were almost exclusively devoted to the improvement of organic analysis, and with the first successes there began at the small university an activity such as the world had not yet seen. . . . A kindly fate had brought together in Giessen the most talented youths from all countries of Europe. . . . Every one was obliged to find his own way for himself. ... We worked from dawn to the fall of night: there were no recreations and pleasures at Giessen. The only complaints were those of the attendant, who in the evenings, when he had to clean, could not get the workers to leave the laboratory." See 'Deutsche Rundschau,' vol. Ixvi. pp. 30-39.

1 Eilhard Mitscherlich (17941863), a pupil of Berzelius, discovered in 1819 that in compound bodies which crystallise in definite forms certain elements can be replaced by others in the proportion of their chemical equivalence without changing the form of crystallisation. Such elements are termed "isomorphous." Berzelius declared this to be the most important discovery that had been made since the theory of chemical proportions had been established.

2 This synthesis was the preparation of urea, a highly organic substance, out of the compounds of cyanogen, with the examination of which he and Liebig were then occupied. "It was the first example of the fact that an organic substance could, by chemical methods alone, be produced out of inorganic materials; this discovery destroyed the difference which was then considered to exist between organic and inorganic bodies-viz., that the former could only be formed under the influence of vege. table or animal vital forces, whereas the latter could be artificially produced" (Kopp, "Geschichte der Chemie,' vol. i. p. 442). It must here be remarked that this state. ment is only correct if the substances, cyanic acid and ammonia, out of which Wöhler produced urea, are considered to be inorganic; in. asmuch as neither of them had then been produced otherwise than out of organic substances, the popular notion on Wöhler's important discovery requires this correction. See Kopp, 'Gesch. der Wissenschaften in Deutschland,' vol. x. p. 546 . 
may be said to date from these and other simultaneous labours of Liebig and Wöhler. ${ }^{1}$ But although the pure sciences, mathematics, physics, and chemistry, advanced on new lines in the hands of German students, and although theoretical investigations have always been favourite pursuits of theirs, as we shall have ample opportunity to note in the course of our further survey, the greatest contribution to the progress of science, and the most brilliant performances of the exact spirit of research which emanated from Germany during the first half of this century, lay in a different direction. And it is hard to believe that the conditions favourable to this peculiar growth could have been found anywhere else than in the German universities. The many elements of thought which meet on that ground, the equal dignity

1 The joint labours of Liebig (1802-75) and Wohler (1800-82), which have become of such im. portance to science, form one of the most interesting instances of scientific co-operation between two men pursuing different lines of thought and trained in different schools. See the preface to Hofmann's edition of Liebig and Wöhler's Correspondence. In Liebig's autobiographical sketch, quoted above, he thus enlarges on his relations to Wöhler: "It was my good fortune that, from the beginning of my career at Giessen, similar inclinations and endeavours secured me a friend, with whom, after so many years, I am still (between 1860 and 1870) connected by ties of the warmest affection. Whereas in me the tendency predominated to look for the likenesses of substances and their combinations, he possessed an incomparable talent for seeing their differences; acuteness of observation was joined in him to an artistic aptitude and to a genius for finding new ways and means of analysis such as few men possess. The perfection of our joint researches into uric acid and the oil of bitter almonds has been frequently praised; this is his work. I cannot sufficiently estimate the advantage which both my own and our joint aims derived from my union with Wöhler; for in them were combined the peculiarities of two schools, and the good which each had, attained its value through co-operation. Without grudge or jealousy we pursued our way hand in hand; if one required help, the other was ready. An idea can be formed of this mutual relation when I mention that many of the smaller productions which bear our names belong to one alone; they were charming little presents which one gave the other" (p. 39). 
which there belongs to pure and to applied science, the continual contest which exists there between metaphysical and exact reasoning, and the general ebb and flow of rival currents of ideas, all seem to have been necessary to raise to the rank of an exact science those researches which deal with the phenomena of life and consciousness in their normal and abnormal forms of existence. In the hands of German students ${ }^{1}$ chemistry and physics, botany and zoology, comparative anatomy and morphology, pathology, psychology, and metaphysics, have laboured from different and unconnected beginnings to produce that central science which attacks the great problem of organic life, of individuation, and which studies the immediate conditions of consciousness. Physiology, or to use its more comprehensive name, Biology, ${ }^{2}$ may be

1 The two greatest discoveries in physiology belong to England. These are Harvey's discovery of the circulation of the blood in the seventeenth century, and Charles Bell's discovery of the difference of sensory and motor nerves in the early part of this century. The two men, however, who have done most to establish physiology as an independent science, whose systematic works have done most for the student of physiology, are probably Haller (see supra, p. 176), whose 'Elementa' cast into the shade all older handbooks, and Johannes Miiller (1801-58), whose 'Handbuch' (1833-40) was translated into French and English. See Du Bois-Reymond, 'Reden,' \&c., vol. ii. pp. 143, \&c., 195, 360, who also points out low in other sciences, like mathematics, physics, chemistry, Germans made use almost exclusively of translations of French and English textbooks and handbooks, whereas in physiology they furnished for a long period the systematic treatises for the whole world (vol. ii. p. 196). Physiology has therefore with some right been termed a German science (see Helmholtz, 'Vorträge,' \&c., vol. i. pp. 339, 362 ; Du Bois-Reymond, 'Reden,' vol. ii. p. 265). Compare also what Huxley says, 'Critiques and Addresses,' pp. 221, 303. On the connection of physiology with all other sciences see likewise Helmholtz, loc. cit.; Du Bois-Reymond, vol. ii. p. 341 ; Huxley, 'Lay Sermons,' \&c., p. 75 ; 'Science and Culture,' p. 52 : "A thorough study of human physiology is, in itself, an education broader and more comprehensive than much that passes under that name. There is no side of the intellect which it does not call into play, no region of human knowledge into which either its roots or its branches do not extend," \&c.

2 The word "biology" seems to have been first used by G. R.

VOL. I. 
said to be a German science as chemistry has been named a French science. I have already referred to the great Haller in the last century, who may be called the father of physiology; to Blumenbach, the comparative anatomist; and to Liebig and Wöhler, who first among chemists succeeded in producing an organic compound by the processes of inorganic chemistry. I have now to add two names, which together mark a great revolution in our ideas of the structure of organisms, and link together the two sciences which had treated separately of the

22.

Cellular theory of Schleiden animal and vegetable worlds. About the year 1838 Mathias Schleiden ${ }^{1}$ propounded his cellular theory con-

Treviranus (1776-1837), a learned physician of Bremen, who began to write his 'Biologie oder Philosophie der lebenden Natur' in 1796 and to publish it in 180.2 (6 vols., 1802 22). Lamarck used the word in his 'Hydrogéologie,' 1801. They, as well as Bichat about the same time, independently "conceived the notion of uniting the sciences which deal with living matter into one whole, and of dealing with them as one discipline" (Huxley, on the study of Biology, 1876, in 'American Addresses,' p. 136, \&c). The term, though of German origin, has not found favour in that country, and after having been used officially in France and England, makes its appearance in German only since the great works of the modern English school, headed by Darwin, lave gained so much influence in Germany. In the meantime the biological sciences had been extensively represented at the German universities by chairs of physiology, zoology, botany, \&c. According to Huxley, biology has been "substituted for the old confusing name of natural history," and "denotes the whole of the sciences which deal with living things, whether they be animals or whether they be plants" (loc. cit., p. 138). It can be divided into three branches -(1) Morphology, which comprises the sciences of anatomy, development, and classification; (2) the science of the distribution of living beings, present and past; and (3) physiology, which deals with the functions and actions of living beings, and tries to "deduce the facts of morphology and of distribu. tion from the laws of the molecular forces of matter" (Huxley, "Lay Sermons,' \&c., p. 83, 1864). To these three Huxley adds ("Ency. Brit.,' art. "Biology") the infant science of "xtiology," which "has for its object the ascertainment of the causes of the facts of biology and the explanation of biological phenomena, by showing that they constitute particular cases of general physical laws" (p. 688).

1 Mathias Jacob Schleiden (180481), for some time Professor of Botany at Jena, was a man of peculiar ability and disposition, combining a philosophical mind with exact knowledge and a general literary taste, not frequently 
cerning the structure and growth of plants. About the and same time Theodor Schwann ${ }^{1}$ extended this theory to Schwann. animal organisms. A variety of circumstances combined to make the announcement of the cellular theory, which will always be associated with those two names, an epoch in the history of scientific, indeed of general, thought.

The historian of botany, Julius Sachs, describes the publication of Schleiden's great work as a burst of daylight, ${ }^{2}$ and Du Bois-Reymond says : "In order to measure the magical progress which it marks, one must have witnessed the rise of the cellular theory, when it suddenly spread daylight in the darkness of the hidden structure

to be found among men of pure science in Germany. Opposed to the idealistic philosophy as a follower of Fries, and on the other side to the dry systematisation of the Linnoan school, he was the man at once to broaden the scientific view and to create a popular interest in the "life of the plant"-world. The titles of his two best known works are characteristic, 'Die Botanik als inductive Wissenschaft' (1842-45), and his short-lived periodical (filled with the labours of his equally im. portant co-editor, Nägeli), 'Zeitschrift für wissenschaftliche Botanik.'

1 Through the friendship of Sclileiden and Schwann (1810-82, a pupil of Johannes Miiller and professor at Louvain), two independent courses of research and scientific thought were brought together. Schleiden placed the "cell" - a term used before him by Hooke, Malpighi, Grew, Wolff, Brown, and Mirbel-in the forefront of his description as the element of form and as the origin of life, or-as we now express it -as the morphological and embryological unit, in the plant. A similar series of great names, beginning with Bichat and leading up to Johannes Müller, marks the studies of animal tissues. Schwann, struck with the analogy of Schleiden's nucleated cells and similar structures which he had observed in the notochord, conceived and verified on a large scale the idea "that a common principle of development exists for the most different elemental parts of the organism, and that the formation of cells is this principle." This is the beginning of the cellular theory, which produced at once a reconstruction of the whole of "general anatomy" by Jacob Henle (1809. $85)$, and subsequently the "cellular pathology" of Rudolph Virchow. As the latter has himself said, he aims at the establishment of a general biological principle, and thus the discovery of Schleiden and Schwann is characterised as the transition from the "historical" to the " biological" study of animated nature.

2 See Julius Sachs, 'Geschichte der Botanik vom 16 Jahrh. bis 1860 , p. 203, and in many other passages. 
of animals and plants, where the rays of comparative anatomy and embryology could not reach." 1 This bold generalisation, which had been prepared by a long series of botanical and morphological researches in and out of Germany, met alternately with applause and criticism; it gave rise to a long controversy, and was the starting-point of a whole line of important discoveries. ${ }^{2}$ It secured for Germany a long period of supremacy in physiological science. This supremacy was more than maintained by a great 23. volume of minute investigations, which emanated from Ernst Hein rich Weber the schools, and centred in the names, of $\mathrm{E} . \mathrm{H}$. Weber ${ }^{3}$

${ }^{1} \mathrm{Du}$ Bois-Reymond, 'Reden,' vol. ii. p. 541, \&c.

2"Whatever cavillers may say, it is certain that histology before 1838 , and histology since then, are two different sciences-in scope, in purpose, and in dignity-and the eminent men to whom we allude may safely answer all detraction by a proud Circumspice."-Huxley in his valuable paper on "The Cell Theory" in the "British and Foreign Medical Chirurgical Review,' 1853, vol. xii. p. 290.

3 The three brothers Weber (Ernst Heinrich, 1795 - 1878; Wilhelm, 1804-91; and Eduard, 1806-71) may be looked upon as early representatives of the best form of German research on the lines now recognised as the true and fruitful ones in natural science. Born in an age when other great and more widely known reformers-such as Liebig, Schönlein, and Joh. Müller - freed themselves with difficulty from the prevailing metaphysical systems, they seem to have at once seized the true spirit of exact research without relinquishing the broader philosophical and encyclopsedic view of the sciences which they cultivated. Living far into an age when the utilitarian spirit became equally seductive in an opposite direction, they preserved pure and undefiled within themselves the German ideal of Wissenschaft as a pursuit carried on for its own intrinsic value, not for any immediate practical object. Their position, especially that of the two elder brothers, is in this respect unique, and may be studied independently of the scientific ideas which they represented, and which will occupy us later on as a chapter in the history of thought characteristic of the German mind and the best type of the university studies. In three works of classical value'Die Wellenlehre auf Experimenten begriindet' (E. H. and W. Weber), 1825; 'Die Mechanik der menschlichen Gehwerkzeuge' (W. and E. Weber), 1836 ; 'Elektrodynamische Maasbestimmungen' (W. Weber), 1846 onward-and in a great number of special investigations, the method of exact measurement was applied to physical, physiological, and even mental phenomena, and the foundation laid for a mechanical description and mathematical calculation. The later generalisations, known as Wilhelm Weber's law of electro-dynamics and E. H. Weber's law of psycho-physics, have given rise to 
and Johannes Miiller. The school of the latter especially and Johan. has the merit of having introduced over the whole field nes Miiller. of physiological phenomena exact methods of inquiry, of having established physiological laboratories all over Germany similar to Liebig's chemical laboratory at Giessen, and of having effectually chased away the vague notions of the older metaphysical school, and diffused the true scientific spirit. It boasts of having filled the chairs of medicine, physiology, and anatomy at the German universities with a long list of eminent teachers who have spread this true scientific spirit in every branch of the medical sciences, ${ }^{1}$ which it has in consequence drawn into

long controversies and fruitful theories. Their joint labours cover fully half a century. See for a sympathetic picture of the position whicl the three brothers Weber held in the learned world the biography of Fechner by Kuntze, 1892, p. 243: "They were among the first to raise the study of Nature among Germans to the eminence occupied by the philosophers and discoveries of the Latin races."

1 The medical sciences, represented by the medical faculty, but also by those biological sciences which, like botany, zoology, anthropology, \&c., belong to the philosophical faculty, now furnish the largest number of students to the German universities. In the beginning of the century the theological faculty, which then included the greater part of those who prepared themselves for higher teaching, stood at the head as regards numbers. Under the influence of the philologico-historical movement, which grew and culminated in the course of this century, and the rising tide of the exact sciences, the plilosophical faculty for a time gained and maintained the upper hand. Biological — including medical studies now command the greatest attention. In his statistical report (contained in Lexis, 'Die deutschen Universitäten,' Berlin, 1893) Prof. Conrad gives an interesting table of the changing numerical proportion in the different faculties (vol. i. p. 125, \&c.) Prof. Billroth in his admirable treatise, 'Ueber das Lehren und Lernen der medicinischen Wissenschaften,' Vienna, 1876 , deals with this subject at all the German universities, including the Austrian. As Vienna is such an important centre of medical studies, the proportion of those students who cultivate biological studies would probably be still greater if we were to include the Austrian universities. I suppose the figure would be about 40 per cent of the whole. To Billroth's treatise I may also refer as confirming in relation to these more modern branches what I said above of the culture of Wissenschaft. See p. 279 and the whole section on the relation of the biological sciences to the university, pp. 411.446 . It is 
the circle of the exact or mechanical sciences. But not only in its far-reaching applications to medical knowledge and practice has the movement which centred in Weber and Mïller shown its strength and importance; it has also, from the commencement, extended its influence

24.

Psychopliysics. in another direction. To it belongs pre-eminently the cultivation of that borderland which connects the natural and the mental sciences. Muiller ${ }^{1}$ himself began his career by a study of the mechanism of the perceptions of the senses. He affirmed the law of specific energies,

interesting to note that Prof. Billroth does not employ the word biological, but uses the untranslatable compound naturwisscnschaftlich-medicinisch.

1 Johannes Miuller (1801-58) has been termed the Haller of the nineteenth century, the Cuvier of Germany. A very good account of his work, which forms an important chapter in the history of German biology, is contained in $\mathrm{Du}$ Bois-Reymond's 'Gedächtnissrede auf Joh. Müller' (1858), reprinted with extensive notes in his 'Reden,' vol. ii. pp. 143-334. Muiller is there considered as the last representative of a dynasty of philosophers who embraced the whole domain of "biology," which since has become divided into various sciences, notably the morphological and the physiological branches. He thus stands out as the master of some of the greatest modern representatives of natural and medical science, such as Schwann and Henle in anatomy, Brücke, Du Bois-Reymond, and Helmholtz in physiology, Virchow in pathological anatomy. He together with Lucas Schönlein (1793-1864) may be considered as the founder of the modern Berlin school of medicine, contemporaneous witl whicl is the modern
Austrian school, with the names of Purkinje, Skoda, Oppolzer, and Rokitansky. An excellent characterisation of the different positions and influences, of the cross-currents of thought, of the original homes and of the wanderings of the scientific spirit through the many German-speaking countries and the extensive network of German universities, will be found in Billroth, loc. cit., pp. 307-366. If we imagine a similar life as existing all through the century in other domains of thought-in philosophy, theology, philology, mathematics, chemistry, law, and the science of history-we get a faint idea of the work of the German universities. In Lexis, 'Die deutschen Universitäten,' an attempt has been made to give such a picture. The picture, however, suffers by the exclusion of the Austrian universities, and thesenotably in the medical world-hold such a very high position that the record of the united work is somewhat incomplete. The sciences are also in this record cut up into many branches, whereas in the earlier part of the century many of these were united and represented by one great name. Such a name was Johannes Müller in biology. 
which declares that the differences of the sensations of light and colour, of sound, of touch, \&c., do not depend upon the mode of irritation, nor even upon the different structure of the specific nerves, but upon the nature of the central sense organ. In the school of Müller the phenomena of voltaic electricity, which had been so seductive and misleading to an earlier school of physiologists not experienced in the methods of exact research, were again subjected to scientific investigation, and led to the brilliant researches with which the name of $\mathrm{Du}$ BoisReymond is so intimately connected. $\mathrm{He}$ is as ready as Helmholtz, who in his two great works on physiological optics and musical acoustics has founded new branches of science, ${ }^{1}$ to acknowledge the leadership of Johannes

${ }^{1}$ Helmholtz (1821 - 95), equally celebrated as physiologist and mathematical philosopher, was educated under the influence of Johannes Miuller on the one side, of Jacobi and the Königsberg school of mathematicians (Bessel and Neumann) on the other. If we add to this that he also made a profound study of those far-reaching speculations which originated in the philosophy of Kant, we realise how rare is the combination of ability and knowledge which he has brought to bear on the discussion of the most advanced problems in physics, biology, and psychology. In the sequel I shall have to refer so frequently to his writings that I confine myself here to giving the date of his principal, his epoch-making publications : 1847. 'Ueber die Erlialtung der Kraft'; 1858. 'Ueber die Integrale der hydrodynamischen Gleichungen, welche der Wirbelbewegung entsprechen :- both reprinted in "Wissenschaftliche $\mathrm{Ab}$ handlungen,' Leipzig, 1882 and
1883, 2 vols. These two Memoirs may be considered as corner-stones of two of the most important modern theories in physical science, the "conservation of energy" and the "tlieory of vortex motion." In both, the name of Helmholtz is intimatelyallied with that of William Thomson (Lord Kelvin). Equally important and more comprehensive have been his researches in the physiology and psychology of senseperceptions in his 'Physiologische Optik,' Leipzig, 1867 ; 'Lehre von den Tonempfindungen,' Braunschweig, 1863.

Helmholtz has also contributed largely to the discussion of two very important branches of modern speculation-first, the theoretical views on the nature of electrical phenomena expressed by the opposite conceptions of Wilhelm Weber in Germany and Faraday in England ; second, the origin of geometrical axioms, especially the axiom referring to parallel lines. A great interest in this subject had been 
Miiller. And out of the circle of which E. H. Weber was the centre, has emanated that work of Fechner, 'Elements of Psycho-physics,' which marks an epoch in psychology: it is indeed mainly occupied with the exposition and application of what is termed Weber's law of sensation. ${ }^{1}$ In the course of the second quarter of the century, the names of Gauss and Jacobi in mathematics, of Liebig and Wöhler in chemistry, of Schleiden and Schwann in the science of life, of Müller and Weber in physiology, raised German science to the level previously reached by the French Academicians, by Laplace and Lagrange, by Lavoisier and Berthollet, by Cuvier and St-Hilaire, by Vicq-d'Azyr and Bichat. During

created by the posthumous publication of Riemann's celebrated Memoir, 'Ueber die Hypothesen welche der Geometrie zu Grunde liegen,' Göttingen, 1865. Helmholtz's invention of the ophthalmoscope in 1851 marks an epoch in ophthalmo$\log y$.

${ }^{1}$ Gustav Theodor Fechner (180687), professor at the University of Leipsic, was an extraordinary man. The wide range of his interests and his great personal influence are well described in his biography by Dr Kuntze, 'G. T. Fechner, Ein deutsches Gelehrtenleben,' Leipzig, 1892. Together with Lotze he may be said to have brought about the reform of German speculative philosophy, and in relation to this he will occupy our attention largely in a later portion of this book. He belonged to the circle of which $\mathrm{E}$. $\mathrm{H}$. Weber was the centre, and has taken an important place in the history of philosophy and science by his now celebrated work, 'Elemente der Psychophysik,' 2 vols., Leipzig, 1860; $2 d$ ed., 1890. The object of this work is to establish "an exact doctrine of the relations of body and mind," the principal task being "to fix the measure of psychical quantities." He says in the preface: "The empirical law which forms the principal foundation, was laid down long ago by different students in different branches, and was expressed with comparative generality mainly by E. H. Weber, whom I would call the father of psycho-physics" (Preface, p. v). In early life Fechner did much, by his translations of Biot's 'Physics' and Thénard's 'Chemistry,' as well as by his own experimental works, to introduce the French scientific spirit into German research. His psycho-physical labuurs have been continued by Prof. Wundt; his importance as marking a turning-point in German philosophy is brought out in Paulsen's 'Einleitung in die Philosophie,' Berlin, 1890. See especially Preface, p. viii, and p. 318 , where Fechner is placed before Lotze. 
the second half of the century, the influence of French thought on German science has been less marked, partly owing to the independent course which the latter, since the age of Johannes Müller, has struck out for herself in the biological sciences, partly through the more intimate intercourse which has set in between English and German thought. The three great scientific ideas which the second half of the century has been establishing-the law of the conservation of energy, Darwin's theory of descent, and Faraday's novel conception of electrical phenomena - have been elaborated mainly by the cooperation of English and German research, though it must be admitted that at least one of these developments dates back to the beginnings laid by French science, ${ }^{1}$ whilst the views of Faraday are subversive of some of the fundamental notions to which the works of the great French mathematicians had given very general currency. Before we can enter more fully on a review of these more modern ideas, I must, however, give a picture of the state of scientific thought in England during the first half of the century. This will be our subject in the last portion of the present section.

${ }^{1}$ Darwin's theory of descent has its forerunners in Lamarck and StHilaire, whose merits in this respect are supposed to have been overlooked owing to the overwhelming authority of Cuvier. See Huxley, "Origin of Species" in "Lay Sermons,' 1891, p. 252 ; “Evolution in Biology" in "Science and Culture,' 1888, pp. 296, 313. But whilst it is true that Lamarck and St-Hilaire entertained doubts as to the fixity of species, the explanation of the particular manner in which the change of species takes

place is entirely due to Darwin, and without this further step speculations as to the origin of species would have remained for a long time in the vague. Lamarck's speculations were of no real use to Darwin, and had besides been anticipated by Erasmus Darwin. On the other hand, the researches of Sadi Carnot were of great value in the hands of Joule, Thomson, and Helmholtz, who may be regarded as the founders of the doctrine of the conservation of energy. 
25.

Spirit of ex. act research and $W$ issen. schaft.

But it is my object at present not so much to dwell upon specific ideas or doctrines as on the growth, the diffusion, and the general character of scientific thought, as this has been established by the separate contributions of the three nations in the course of the first half of our century. I therefore cannot leave the subject of German science without still more precisely noting the peculiar character which scientific thought has assumed under the influence of the German university system. As we saw before, when the spirit of exact research, mainly through the influence of the great French mathematicians and physicists, became diffused in Germany, and entered the pale of the German universities, it was met there by that peculiar ideal of learning which the German language terms Wissenschaft. This encounter did not everywhere produce a favourable reception for the new school; but in the end it led, like every controversy, to a firmer establishment of the true principles of research. The life of the German universities had in the earlier centuries begun with classical studies; it had been reformed under the influence of the theological and juridical requirements of the Protestant Governments; and ultimately it had been entirely renewed under the influence of the classical and philo- sophical studies centred in the fourth or philosophical faculty. These classical and philosophical studies combined to create the ideal of Wissenschaft, or science, in the broadest sense of the word. This ideal formed the central conception in the new scheme of a higher and general education of the nation; it accompanied the great revival in art, poetry, and literature. In the 
philosophy of Kant and Fichte, the republican notions which led the political movements in America and France had been reduced to a system and theoretically proved; the discipline of a classical education was the school in which leaders and youths were trained who marched into the war against the great oppressor. This ideal of Wissenschaft had thus acquired a practical meaning, an ethical-not to say a religious-significance; it was allied to the religious revival preached by Schleiermacher and a section of the Romantic school. Of its value as a principle for guiding research and learning it had given proof in that great circle of studies which, since the time of F. A. Wolf and Wilhelm von Humboldt, was comprised under the name of Philology. Under its influence new universities were being founded and academies remodelled.

Now, it is the peculiarity of all philosophical and historical studies that they deal with one great subject, which cannot easily be divided into a number of independent parts capable of separate treatment; since their interest attaches mainly to the fact that they explore the workings and manifestations of the human mind in the past and in the present. These studies are therefore forced to keep always in the foreground the idea of a great unity of action and purpose, to aim at completeness of view, and to refer all special researches to general principles and standards. The encyclopredic view, in fact, is forced upon all philosophical and historical sciences. Almost without exception the great masters Encyclo. pædic view necessary in and teachers who lived in the beginning of this century philosophy
and history. adhered to this view, and however great in special and 
detailed research, measured the importance of their results according to the light which they were able to throw upon the questions referring to the whole subject and its combined life and unity.

It was also natural, seeing that this comprehensive or philosophical treatment led to such great results in the historical sciences, that an attempt should have been made to deal with the phenomena of Nature by a similar conception. It was not a new or a far-fetched suggestion to regard Nature as the play-ground of a hidden intelligence, of an unconscious mind, just as history, language, and thought were viewed as the manifestations of the conscious human mind. After this the further conception was not remote that both the mind of Nature and the mind of Man are only two different sides of the universal or absolute Mind. The philosophy of Schelling was the first attempt to put this idea into an applicable form, the system of Hegel the first confident elaboration of it in its various ramifications and applications. At the time when the mathematical and physical sciences were leading the way in France, and gradually forcing their way into Germany, most of the universities in the latter country had one or more representatives of that new and apparently promising school which termed itself the "Philosophy of Nature." The trammels of this school had to be shaken off by those who, as they became gradually convinced of its barrenness in actual results, took up the cause of the exact or mathematical sciences now that they had been cultivated by many isolated labourers in Germany and in England, and had been 
for the first time connected into a great organisation by the French Academy of Sciences.

The opposition in which the new school of exact and detailed research stood to the representatives of the broad philosophical view gave rise to a great many currents of thought; for neither the former nor the latter presented a united front. Among those who advocated the exact methods of research there was a section which clung more exclusively to the empirical side, and cultivated the descriptive and experimental sciences; whereas others, whom we may call the French school of science, developed the mathematical methods, not without a certain ill-disguised contempt for pure empiricism. ${ }^{1}$ On the side of classical and philosophical studies there was a section which cultivated the historical ${ }^{2}$ in contradis-

1 On the relations of mathematical and experimental physics, and the different opinions which existed during the first half of the century, see Helmholtz's popular addresses in many places, but especially the discourse on Gustav Magnus (1802. $70)$, who may be regarded as a representative of the experimental school in Germany. In the opinion of this school, which cultivated the borderland of physics and chemistry, of organic and inorganic phenomena, or investigated the less known phenomena of frictional electricity (Riess) or the complicated phenomena of meteorology (Dove), a danger existed that mathematical theories and elaborate calculations might lead to an estrangement from nature and observation, similar to that which speculative philosophy had created before. Helmholtz himself was met by this sentiment when he published his great memoir,
25. Conflict between the scientific and the philosophi. cal views.
'Ueber die Erhaltung der Kraft,' in 1847 ; Poggendorf's physical periodical would not receive it, and Jacobi, the mathematician, was the only one who showed any interest in it. See Helmholtz, 'Wissenschaftliche Abhandlungen,' vol. i. p. 73 ; 'Reden,' vol. ii. p. 46.

2 As the philosophy of Schelling promoted a study of nature, and in doing so prepared its own downfall, so the philosophy of Hegel led to a study of history, and thus to the proof of the insufficiency of its own generalisations. Many valuable beginnings of historical research emanated also from the Romantic school of literature. In all these instances philosophical interests led beyond the abstract logical and metaphysical treatment into the broad and fertile plains of actual life, be it that of nature or of art or of history. But the true methods of research in 
tinction to the philosophical view, and another which elaborated what it termed exclusively the critical methods, ${ }^{1}$ not without a certain suspicion regarding those who showed a desire to roam into outlying fields which did not permit of equally strict discipline and treatment. So far as this refers to the purely historical sciences, I shall revert to the subject when I come to treat of the principles which underlie and guide this line of studies. At present I an concerned with the growth and diffusion of the exact scientific spirit and its methods.

No one did more to spread the ideas and methods of

29.

Alexander von $\mathrm{Hum}$ boldt. French science in Germany than Alexander von Humboldt. He himself had done original scientific work ${ }^{2}$ be-

these extensive fields were afterwards found not so much in philosophical canons as in a love of detail and observation, and in the exercise of an unbiassed criticism of facts and records. For the relations of philosophy to history in respect of this, see Wegele, 'Gesclichte der deutschen Historiographie,' München, 1885, 5th book, p. 975, \&c. Equally important are-Gervinus, 'Grundzïge der Historik,' Leipzig, 1837 ; the 'Nekrolog auf Schlosser,' Leipzig, 1862, including the whole literature which it provoked; and O. Lorenz, 'Die Geschichtswissenschaft,' Berlin, 1886, especially the first chapter.

1 On the Critical school of philology, and the wider and narrower sense in which the aims and methods of the science of antiquity were defined, see Bursian, 'Geschichte der classischen Philologie in Deutschland,' München und Leipzig, 1883, p. 665 , \&c. ; also O. Ribbeck, 'Friedrich Ritschl,' Leipzig, 1879 and 1880. Further, the essays on Böckh, K. O. Müller, and Georg Curtius in the third volume of Einst Curtius,
'Alterthum und Gegenwart,' Berlin, 1889 ; and, finally, the chapter on "Klassische Philologie" by Willamowitz-Möllendorf in Lexis, 'Die deutschen Universitäten,' vol. i. p. 457 , \&c.

2 Alexander von Humboldt (17691859) published in 1797, shortly after Galvani's great discovery, his 'Versuche iiber die gereizte Muskel- und Nervenfaser.' In the history of science his name will live as that of the man who organised that "scientific conspiracy of nations" which is peculiar to our century, and witlout which the study of geography, meteorology, astronomy, the phenomena of tides and magnetic disturbances-called by him magnetic storms - could not effectually be carried on. The fact also that on his return from his great travels he became next to Napoleon Bonaparte the most famous man in Europe, did more than anything else to raise the natural sciences in the popular mind to that eminence which earlier belonged to polite literature. 
fore he left Germany for the extensive travels by which he became celebrated, and through which he founded a new science-the science that deals with the geographical distribution of plant-life. Moreover, his absence from his native country fell within that period during which the philosophical school, headed by Schelling and Hegel, attained to its greatest power. He was never drawn into its vortex; on the contrary, he maintained a lifelong protest against the spirit of its doctrine at a time when the circle which surrounded him at Berlin came- under its powerful influence. ${ }^{1}$ He led a long line of ardent young workers both to the right sources of scientific knowledge and to an ultimate victory over the opposed school of thought. Though not a profound mathematician himself, he appreciated the part which mathematics were destined to play in science. Among other things, he protected and encouraged younger mathematical talents, and tried to draw Gauss from the solitary heights which he inhabited into the midst of the scientific circles of the day. ${ }^{2}$ Then there was the great influence which

${ }^{1}$ Cf. p. 178, note 1 . It has latterly become the fashion to say so much against the mistaken methods of the Naturphilosophie that it is well to remember how many men of foremost rank in the natural sciences belonged at one time to this school or were influenced by it. Foremost of all stands Oken (1779-1851), the founder of the German Association of Science, and editor of the periodical 'Isis.' Further, the comparative anatomist Carus (1789-1869); Oersted (1777-1851), the discoverer of electro-magnetism ; Kielmeyer, the friend of Cuvier (1765-1844); Ignaz Döllinger (1770-1841), one of the earliest evolutionists ; D. G. Kieser (1779-1862), a medical teacher of great influence. More or less influenced by the teachings of this school were Goethe (1749. 1832) ; Karl Ernst von Baer (1792. 1876), whose impartial opinion on the Naturphilosophie as early as 1821 is important. Further, Liebig (1803-73); Johannes Müller (1801-58) ; Röschlaub (1768-1835); Schönlein (1793-1864), the founder of what is called the "naturalhistory" school of medicine.

2 See A. von Humboldt's Life by Brulıns, translated by Lassell, 1873, vol. ii. p. $145 s q q$. 
30. Berzelius exerted on German science through his teachBerzelius on German science. ing and his writings. From him emanated that great perfection of the purely experimental methods which in his own hands, as well as in those of Wöhler, Mitscherlich, Magnus, and others, led to an accumulation of detailed knowledge in chemistry of unforeseen importance and magnitude. His own annual reports, as well as Gmelin's celebrated handbook of chemistry, are monuments of this unparalleled industry.

Others, like Liebig, Johannes Müller, Lucas Schönlein, freed themselves under the influence of French science, ${ }^{1}$ or by their own deeper insight, from the sway of the false and misleading philosophy to which they had at one time listened. A third section started from philosophical premisses, but from premisses opposed to the doctrines of Schelling and Hegel.

The school of Fries, ${ }^{2}$ in which Schleiden was the most

1 English science had an important but less marked influence on the development of naturalistic and medical studies in Germany. So far as the latter especially are concerned, see Billroth, 'Ueber das Lehren und Lernen der medicinischen Wissenschaften an den Universitäten der deutschen Nation,' Wien, 1876, p. 33 . He roughly divides the medical schools of Germany into two groups, both descending from Boerhaave: the one, the modern Berlin school of Muiller, Schönlein, Romberg, and Virchow, through Haller, Reil, Hufeland, and Röschlaub; the other, the modern Vienna school of Oppolzer, Rokitansky, and Billroth, through Gerhard von Swiet. en, De Haen, Stoll, Frank, Purkinje, and Skoda. Of French names which had great influence he gives Broussais, Corvisart, Bayle, Cruveilhier, and Laënnec; of English, John Hunter, Matthew Bailie, and Astley Cooper. He gives also the name of Immanuel Kant as an important influence in the development of the German schools of medicine.

2 Jacob Fries (1773-1843) professor at Heidelberg and Jena, led the critical philosophy of Kant into the channels of psychology and anthropology. During the heyday of transcendental philosophy, the philosophy of Fries, like that of the Scotch school, was regarded with contempt by Hegel, and even by Herbart, the opponent of Hegel. It succeeded, however, in the end in influencing a considerable number of philosophical minds, who carried philosophical thought into the in. ductive sciences. Besides the psy. 
illustrious name, carried on within the pale of the philosophical school of science itself a successful opposition to the philosophy of Nature. ${ }^{1}$ But whilst much good and sound work was done by many who were content to remain outside of the favoured studies which set the tone of university culture during the classical and philosophical period of German thought, the great attack upon the mistaken canons of the philosophy of Nature came from that science which had probably suffered of of ature 31. Philosophy more than any other under the baneful influence of seience. hollow theories and empty phraseology.

Helmholtz describes the despair which had taken hold of thinking minds in the medical profession ${ }^{2}$ : "My education fell within a period of the development of medicine when among thinking and conscientious minds there reigned perfect despair. It was not difficult to understand that the older and mostly theorising methods of treating medical subjects had become absolutely useless. But with the theories the facts which underlay them were so indissolubly entangled that these too were mostly cast overboard. How the science must be newly built up the example of the other natural sciences had made clear, but yet the new task stood of giant-height before us. A beginning was hardly made, and the first beginnings were

chologist Beneke and the theologian De Wette, these were principally members of the Jena school, Apelt, Schlömilch, and others, who edited 'Abhandlungen der Fries'schen Schule,'Jena, 1847 ; and foremost among them Schleiden, the reformer of botany in Germany. Schleiden's great work appeared with the title 'Botany as an Inductive Science.' It opened with a philosophical in- troduction of 131 pages, in which inductive reasoning is recommended in opposition at once to the transcendental Naturphilosophie, and to dry empiricism. See Sachs, 'Geschichte der Botanik, p. 203, \&c.

1 See Schleiden, 'Schelling's und Hegel's Verhältniss zur Naturwissenschaft,' Leipzig, 1844.

2 See Helmholtz, 'Vortrïge und Reden,' vol. i. p. 361.

VOL. I. 
often very crude. We cannot wonder if many honest, serious, thinking men then turned away in dissatisfaction from medicine, or if they from principle embraced an extreme empiricism." 1 "But the right kind of work brought forth its fruits much sooner than many had hoped. The introduction of mechanical notions into the theories of circulation and respiration, a better insight into the phenomena of heat, the more minutely elaborated physiology of the nerves, speedily produced practical results of the greatest importance; the microscopical examination of parasitic tissues, the stupendous development of pathological anatomy, led irresistibly from nebulous theories to real facts." And again ${ }^{2}$ : "Whilst in the investigation of inorganic nature the different nations of Europe progressed pretty evenly, the recent development of physiology and medicine belongs pre-eminently to Germany. The questions regarding the principle of life

1 Cf. Helmholtz, ibid., vol. ii. p. 178 , in his discourse "Ueber das Denken in der Medicin": "At that time there were many among the younger doctors who, in despair about their science, gave up all therapeutics, and took to empiricism, such as was then taught by Rademacher. This on principle regarded as vain all hope of scientific insight." Not only the extreme empiricism of Rademacher (1772-1850), but still more the wild theories of Halinemann (1755-1843) found during this age of general unsettlement many followers. See on the origin, the principles, and the spread of homocopathy, Häser, 'Geschichte der Medicin,' vol. ii. p. $793, \&$ c. Häser gives the year 1816 as the date at which Hahnemann's doctrines began to be accepted in wider circles. "It must not be forgotten that the heyday of homoopathy fell in that age when medicine, especially in Germany, was in a very deficient state, so that the accusations raised by Hahnemann and his adherents did not appear quite unfounded. It is even to be admitted that homocopathy has contributed to the reaction through which in our times the regeneration of the art of healing has been brought about, though this would have taken place without Hahnemann" (p. 803). Homœopathy has no scientific representative at any of the German universities, and yet it is admitted that it "still enjoys a great reputation in some influential circles among the general public" (Hirsch, 'Gesch. d. medicinischen Wissenschaften,' p. 570).

${ }^{2}$ Helmholtz, loc. cit., vol. i. p. 362. 
are closely allied to psychological and ethical questions. To start with, here also that untiring industry is required which applies itself to pure science for purely ideal purposes, without immediate prospect of practical usefulness. And indeed we may glory in the fact that in this German scholars have always distinguished themselves by their enthusiastic and self-renouncing diligence, which labours for inner satisfaction and not for outer success."

This habit of self-renouncing labour, of singleness of purpose-in short, the ideal of pure science and its pursuit itsown sake. - had been elaborated in many a secluded workshop of a retired German university mainly under the influence of the classical and philosophical studies of the end of the last and the beginning of the present century. It was held up high and conspicuous by the priests of humanity, beginning with Lessing, Herder, and Kant, and ending in Schleiermacher, Hermann, and Böckh, at the head of a great army of devoted followers, travelling through the wilderness of national depression, barbarism, and despair into the promised land of freedom, culture, and hope. Such an ideal is of priceless worth, and it is this ideal which the philosophical and classical school of thought bequeathed during the first half of the century to that new school of thinkers which was destined to study, in an equally patient and unselfish spirit, the seemingly less elevated, but not less mysterious and fascinating, problems of Nature. Truly Gauss, Weber, and Johannes Mïller worthily headed the new army of labourers.

But though the elevated spirit in which scientific work is carried on may be the most valuable bequest of the classical and philosophical to the exact and empirical and philosophical school. 
school, there were certain more tangible characteristics of German research, which were carried over from the older to the modern type of thought. It will be useful to define these more clearly.

In the course of the second half of the eighteenth century German literature and German philosophy had started from the beginnings laid by other nations, and after mastering and appropriating their achievements, had set out for a new course and a higher flight. Milton and Shakespeare ${ }^{1}$ in epic and dramatic poetry; Ossian, the Percy Ballads, and Burns in song and lyric; Gibbon in history; Joseph Scaliger and Bentley in philology; Locke, Hume, and Spinoza in philosophy; Rousseau in prose,-all these great names of a later or earlier past had become familiar watchwords to German poets or students-to Lessing, Herder, and Goethe, to Schlegel, F. A. Wolf, and Wilhelm von Humboldt, to Böckh, Hermann, and Niebuhr, to Kant, Fichte, and Jacobi, before they cane forward with their own creations. The same cosmopolitan spirit of looking elsewhere and everywhere for beginnings, and for co-operation in the united work of learning; the same historical taste, the same desire to glean from all quarters,-characterised the early decades of the revival of German science. Hence the many periodicals and annual reports; hence the fact that the

1 These names are not given as they follow in time, but as they followed in their influence on German thought and literature. Thus the early representatives of the German revival were influenced by Milton and Pope more than by the greater Shakespeare: epic and didactic preceded dramatic poetry: Shakespeare was made familiar to
German readers only through Goethe and Schlegel. Similarly the reaction against the school of Leibniz and Wolff in philosophy began with Kant's reply to Hume's sceptical philosophy, whereas the study of Spinoza influenced Kant's followers and opponents, Jacobi, Fichte, and Schelling. 
nation which requires them least ${ }^{1}$ possesses the most 34 . and the best translations of foreign authors. But the nessand and the best translations of foreign authors. But the thorough. quality of greatest value for science which springs from ness of rethe cosmopolitan and historical spirit is that of completeness and thoroughness of research.

Secondly, the German man of science was not only thorough, but was as little as the German philosopher or classicist had been, an isolated thinker. He was neither the member of an academy only, nor a solitary genius reduced to the resources of his own study. $\mathrm{He}$ lived mostly at a university, surrounded by others, whose labours came in contact with his own, or who treated the same subject from a different point of view. He had thus to define the limits of his science, and to see that no part of the common field was left uncultivated and unexplored. His object could not be to produce simply a work of individual greatness or of finished artistic merit; his work was an integral portion of the one great science; his

1 This must not be misunderstood. A knowledge of the masterpieces of foreign literature was as necessary to the development of the German mind as it is to that of any other nation; it was and is more complete there than in any other country: what I mean is, that as a knowledge of French and English has been for a long time so common among the educated classes in Germany, translations are more easily dispensed with there than in other countries. In spite of that, German literature abounds in excellent translations of the classics of France and England both in general literature and in science. It is also interesting to note that no modern language lias succeeded so well in imitating foreign and classical metres as the
German, hexameter's having become domiciled in Germany through Voss and Goethe, the Alcaic and Sapphic metres through Klopstock and Herder, the more complicated stanzas through Platen, and above all through Donner's excellent renderings of the Greek dramatists. Ruickert excelled in the imitation and reproduction of Persian, Indian, and Arabic poetry, and through him and Friedrich Bodenstedt German literature has been enriched by many lines of which it would be difficult to say whether their home was in Germany or in the far East, so perfectly is the spirit and diction reproduced. The well-known 'Weisheit des Brahmanen' of Rückert, and Bodenstedt's 'Mirza Schaffy' are examples. 
labours had to fit in with the general plan, to find a place in the one great edifice.

Combina. tion of re. search and teaching.
Thirdly, the German man of science was a teacher; he had to communicate his ideas to younger minds, to make the principles and methods of research clear, to guarantee, in his course of lectures, something like completeness, to give a comprehensive survey; not to teach " une science faite," but to draw out original talent in others, to encourage co-operation in research, to portion out the common work to the talents which surrounded him, or it might be to direct the flight of the aspiring genius. ${ }^{1}$

1 Here the two main objects of academic teaching are to impart a knowledge of the right method in the special science, and to give a survey of the whole domain of the science. The two principal institutions by which these objects are attained were first set going in the classical branches of study, and may be defined by two terms-the "seminary" and the lecture on "encyclopædia." Both terms are taken from earlier institutions. The seminary was originally a training-school for priests or teachers. Under such masters of methodical research as F. A. Wolf and Gottfried Hermann, the institution acquired a different character. "The seminaries are the real nurseries of scientific research. They were founded, indeed, with a different object; the first seminaries, the philological seminaries, which were started during the last century at Halle and Göttingen, were or should have been pedagogic seminaries for the future masters in the learned schools. In reality they wereespecially that of F. A. Wolfin the first place institutions in whicl the art of philological researcl was taught. This is even more the case in the philological seminaries and societies which during the nineteenth century have been conducted by G. Hermann, Fr. Thiersch, Fr. Ritschl, and others: they were nurseries of philologists, not of teachers. And the same may be said of the numerous seminaries which in modern times have grown up in the other sciences within the philosophical faculty, and also in the faculties of theology and law: they set up as their aim-with few exceptions -the training for scientific work and research, not the utilisation of knowledge for a practical purpose" (Paulsen in Lexis, 'Die deutschen Universitäten,' vol. i. p. 74, \&c.) The same idea was in the mind of Liebig when he started the first chemical laboratory at Giessen (see supra, p. 188, note). The encycloprdic treatment of every large subject in a special course of lectures arranged for this purpose had the object of preventing the different studies from falling asunder or ultimately failing to unite in the realisation of one great aim. This great aim of all philological studies, for instance, was always held up by men like Wolf, Hermann, Böckh, and Ritschl, among 
Lastly, the German man of science was a philosopher. Whaterer his aversion might be to combina Whatever his aversion might be to special philosophical science and doctrines, he had generally come under the influence of philosophy. some philosophical school, the teaching of which he desired either to uphold or to combat. Sooner or later, consciously or unconsciously, he had to make clear to himself and to his disciples the underlying principles which he thought the right ones, to defend them against attacks from others, or to modify them, as progressing research made it necessary. If the historical sciences had benefited most by the philosophy of Schelling and Hegel, which attempted to give new and constructive views on the intellectual and ethical manifestations of the human or the general soul, the mathematical and phy-

whose favourite lectures were those on "encyclopredia" of philology. Something similar existed, and exists still, in theology, law, and what are called "Staatswissenschaften." All these terms are supposed to embrace a variety of studies which are organically combined in one whole, forming a cycle. In plilosophy proper Hegel, and later Lotze, delivered well-known and largely attended lectures under the title of Encyclopedia. This is a remnant of the encyclopædic or organic treatment of knowledge sketched out by Bacon, and proposed as a basis for their celebrated work by Diderot and D'Alembert (see ante, p. 35 and note). The encyclopredia, as a learned dictionary, we have seen, has since become merely a synopsis. How different from this was the truly encyclopredic treatment given by men like Böckh can be seen from his correspondence with $K$. O. Müller, where he scolds his younger friend for undertaking to write the article
"Topography of Athens" for "such a cursed publication as an encyclopxdia," whereas he himself was regularly lecturing on "encyclopædia of philology," in which he took in earnest the idea of classical philology as "the historical science of the life of the ancient peoples" (see Curtius, "Alterthum und Gegenwart,' vol. iii. p. 138, \&c.) Now although the exact sciences when they became domiciled in the German universities did not in general copy this institution, yet the historical and philosophical survey, giving method and unity to a large circle of studies, has been upheld by many among the foremost men of science, especially in the medical faculty. Of these I only mention Joh. Müller (see Du Bois-Reymond, 'Reden,' vol. ii. pp. 195, 279) and his pupil and follower Jacob Henle, who in his lectures on anthropology took a philosophical survey of the whole subject of the medical studies (see 'Jacob Henle' by Merkel, p. 271, \&c.) 
sical sciences have been most affected by the spirit of Kant's philosophy, which has ineradicably engrained in the German mind the necessity of a criticism of the principles of knowledge. Ever and anon some of the most brilliant intellects in mathematics and science have reverted to the same problems, and, on the whole, they have confirmed the position taken up by Kant a century ago.

It was thus under the influence of the exact methods of experiment and calculation taught by the great French school in the beginning of the century, and at the same time through the philosophical spirit peculiar to German science, that in the middle of the century the different sciences which deal with the phenomena of life and con-

Biology grown out of science and philosophy com. bined. sciousness were remodelled. The great science of biology, based upon mechanical principles, was thus created, and the results gained in it brilliantly applied to the reorganisation of the medical profession. But this great reform does not belong exclusively to one great name; it is the work of a long line of thinkers : nor can I conceive that the exclusive employment of the methods of exact research would have so effectually brought it about, unaided by the philosophical, historical, and critical spirit which formed the peculiar characteristic of German thought before the exact methods had been generally introduced. And just because this reform required to be effected from so many different beginnings, and gradually elaborated and defended before it became firmly established, do the modern sciences of physiology and pathology deserve to be termed pre-eminently German sciences; for no other 
country possessed the necessary conditions and extensive organisations, the habits of combined study and patient co-operation, the large views and the high aims, which had been acquired at the German universities under the guidance of the German ideal of Wissenschaft, and under the sway of the philosophical and classical spirit.

A great authority, ${ }^{1}$ who as much as any one represents the modern as distinguished fron the earlier views in biological science, reviewing the different agencies which have brought about the great change, speaks thus. $\mathrm{He}$ is referring to Johannes Müller, the father of modern physiology. "The modern physiological school," he says, Reynond "with Schwann at its head, has drawn the conclusions for which Müller had furnished the premisses. It has herein been essentially aided by three achievements which Müller witnessed at an age when deeply seated convictions are not easily abandoned. I mean, first of all, Schleiden and Schwann's discovery, that bodies of both animals and plants are composed of structures which develop independently, though according to a common principle. This conception dispelled from the region of plant-life the idea of a governing entelechy, as Muiller conceived it, and pointed from afar to the possibility of an explanation of these processes by means of the general properties of matter. I refer, secondly, to the more intimate knowledge of the action of nerves and muscles, which began with Schwann's researches, in which he showed how the force of the muscle changes with its contraction. Investigations which were carried on with all the resources

${ }^{3}$ See Du Bois-Reymond, 'Reden,' vol. ii. p. 219, \&c. 
of modern physics regarding the phenomena of animal movements, gradually substituted for the miracles of the 'vital forces' a molecular mechanism, complicated, indeed, and likely to baffle our efforts for a long time to come, but intelligible, nevertheless, as a mechanism. The third achievement to which I refer is the revival among us by Helmholtz and Mayer of the doctrine of the conservation of force. This cleared up the conception of force in general, and in particular supplied the key to a knowledge of the change of matter in plants and animals. By this an insight was gained into the truth that the power with which we move our own limbs (as George Stephenson did those of his locomotive) is nothing more than sunlight transformed in the organism of the plant: that the highly oxygenated excrements of the animal organism produce this force during their combustion, and along with it the animal warmth, the $\pi \nu \epsilon \hat{v} \mu a$ of the "39. ancients. In the daylight which through such knowforce" aban- ledge penetrated into the chemical mechanism of plants
doned. and animals, the pale spectre of a vital force could no more be seen. Liebig, indeed, who himself stood up so firmly for the chemical origin of animal heat and motive power, still retains an accompanying vital force. But this contradiction is probably to be traced to the circumstance that the celebrated chemist came late, and as it were from outside, to the study of the phenomena of life. And even Wöhler still believes in a vital force, he who in his time did more than any one to disturb the vitalistic hypothesis through his artificial production of urea." 
It was a process of critical sifting similar to that which Kant ${ }^{1}$ applied to our general metaphysical ideas, which in the middle of the century, through the writings of Berzelius and Liebig, of Schwann and Schleiden, of Henle, Lotze, and Du Bois-Reymond, gradually dispelled the older confused notions, and firmly established the mechanical view in the study of the phenomena of life. But Mechanical as we are forced to recognise the substance of much of Kant's philosophical criticism in the lucid expositions of Locke and Hume before him, so it has been pointed out that the words of the eminent French physiologist, Vicq-d'Azyr, contain the substance of the more modern ideas on life. ${ }^{2}$ It required the co-operation of the exact

1 The great influence which belongs to Kant in the development of modern German science has been frequently dwelt on. In more recent times some of the first representatives of the medical and biological sciences have dealt with the subject, and the opposition which fifty years ago originated in the extravagances of some of Kant's successors, has given way to a renewed recognition of the just claims of Kant. We may refer to Du Bois. Reymond, who, forgetting Lotze, calls Kant the last philosopher who took a part in the work of the naturalist ('Reden,' vol. i. p. 33) ; to Helmholtz, who in many passages of his popular addresses refers to the merits of Kant ("Vortrïge und Reden,' 1884, vol. i. pp. 44, 368 ; ii. $58,227,234,248, \& c$.$) ; to$ Haeser ('Geschichte der Medizin,' vol. ii. p. 811). I will add to these the opinion of so great an authority as Prof. Billroth of Vienna, who, speak ing of the two modern schools of medicine in Germany, says ('Lehren und Lernen der medicinischen Wis. senschaften,' \&c., p. 334) : "However great the degree of independence may be which the two parallel schools have attained, they would hardly have developed so rapidly without the powerful influence which came from France and in a lesser degree from England ; nor yet without that of Immanuel Kant, who in his 'Autophysiology of Reason' enlightened German minds regarding their own selves, and who with his lively imagination fervently embraced natural science."

2 The remarkable passage referred to is quoted by Du BoisReymond ('Reden,' vol. ii. p. 27): “Quelqu' étonnantes qu'elles nous paraissent, ces fonctions (viz., dans les corps organisés) ne sont-elles pas des effets physiques plus ou moins composés, dont nous devons examiner la nature par tous les moyens que nous fournissent l'observation et l'expérience, et non leur supposer des principes sur lesquels l'esprit se repose, et croit 
spirit of research with the critical methods acquired in the school of philosophy, and the exhaustive survey of a large array of facts acquired through historical and classical studies, before the significance of this brilliant aperçu became evident; before the underlying ideas could become useful guides of research and progress. "Tantæ molis erat Romanam condere gentem."

Though the reform of the biological ${ }^{1}$ sciences, and their application to pathological inquiries, are probably the greatest achievement which the methods of exact research, in conjunction with the philosophical spirit, can boast of in Germany in the century, the same habit

avoir tout fait lorsqu'il lui reste tout i faire." This was said at the end of the last century, and fifty years later Du Bois-Reymond (loc. cit.) could complain that the truth contained in these words was not yet generally admitted, in spite of the labours of Berzelius, Schwann, Schleiden, and Iotze. Compare also A. von. Humboldt's own confessions on this point in his 'Ansichten der Natur,' vol. ii. p. 309, \&c., edition of 1849 .

1 I must remind the reader here that though I use the word biological as denoting the more recent point of view from which all phenomena of the living world are being grouped and comprehended, and though the word seems to have been first used by a German, nevertheless the arrangement of studies at the German universities has hardly yet recognised the essential unity of all biological sciences. They are unfortunately still divided between the philosophical and the medical faculties. It is indeed an anomaly, hardly consistent with the philosophical and encyclopædic character of German research, that palæontology, botany, zoology, and anthropology should belong to the philosophical, whereas anatomy, physiology, and pathology are placed in the medical faculty. Eminent biologists and anthropologists, such as Schleiden, Lotze, Helmholtz, and Wundt, have accordingly belonged to both faculties. To place biological studies on the right footing would require a mind similar to that of F. A. Wolf, who evolved out of the vaguer idea of humaniora the clearer notion of a "science of antiquity," and who accordingly was able to convert the training school of teachers, the seminary, into a nursery of students of antiquity. Whether a similar reform in the purely scientific interests of the "science of life," which is now mostly cultivated for the benefit of the medical practitioner, can be effected in this age, when practical aims are gradually taking the place of scientific ideas, is another ques. tion. 
of thought has shown itself in other fields of research, and led to similar innovations. I will here only mention one other line of inquiry, where neither exact nor metaphysical reasoning alone suffices, but where a combination of both is essential. I mean the gradual change which, mainly through the writings of German mathematicians, principipes has come over our fundamental conceptions in the region matics. of geometry, algebra, and the theory of numbers. This subject belongs so essentially to the domain of pure thought that a history of thought seems specially called upon to take notice of it. Accordingly I intend to devote a special chapter to it. At present it interests us mainly because it is an outcome of that peculiar modification which the exact or scientific spirit of thought underwent when, introduced by French and English models, it came in contact with the philosophical and classical ideal of learning in Germany. I will repeat more clearly and concisely what I mean. The exact methods of thought, mainly elaborated in France, and there largely applied, give to science its accuracy and definiteness. In spite of this accuracy and definiteness, it is not immediately clear whether they will lead to completeness of knowledge, or whether they nay not be misapplied. To guarantee completeness, to make sure that in the whole great field no portion has remained untouched and unexplored, that love of detail, that searching and exploring spirit, is required which is nursed pre-eminently by historical and classical studies. And to avoid the abuse of existing methods, there is further required that critical spirit which inquires into the value of principles 
and the limit of their usefulness. These three directions of thought mark three tolerably distinct attitudes of the human mind. Skill in inventing and in applying new

The 42. the historical, and the critical habits of thought.

and precise methods - the exact habit or attitude of thought; love of detail, and the desire for complete and exhaustive knowledge - the historical habit or attitude of thought; lastly, the desire to become fully alive to the value of existing methods or principles, which implies a consciousness of the limited nature of one and every principle-the critical habit or attitude of thought. The progress of mathematics and natural science depends primarily on the first; classical studies depend on the second ; philosophical reasoning mainly on the last. Each of the three nations which have led human progress and thought during the past centuries has probably been possessed of these three cardinal virtues in equal proportions. For though Newton stands pre-eminent in the first, we have Laplace and Gauss and their numerous followers in other countries; though the great volume of classical learning and criticism has emanated from the schools of Wolf, Hermann, and Böckh, they themselves point back to Bentley and Joseph Scaliger; and even Kant's unrivalled enterprise was prepared by Hume, and dates back to Descartes. There need, therefore, be no angry rivalry or carping jealousy. We may point to the remarkably equal contributions of the three nations to the general progress of thought. But a very different and truly legitimate interest prompts us to note how in the great performances of each nation, in the literature of each of the three languages, different factors have been at work-different 
agencies have combined to produce the effect. In this regard the spectacles presented by French, German, and English thought differ. And there seems to me little doubt that during a considerable portion of this century the German universities, grown out of theological, legal, and medical studies, and widening gradually till they embraced and deepened all three by the philosophical, the classical, and the exact spirit of research, present that organisation in which the different elements of thought are most equally balanced, through which modern knowledge and the scientific spirit have been most widely and successfully diffused, and that the German ideal of Wissensehaft embraces at once the highest aims of the exact, the historical, and the philosophical lines of senschaft. thought.

Nor would it be right to pass from the consideration of this peculiar feature of nineteenth-century thought, which is an outcome of the German university system, without noticing the moral significance which this ideal of Wissenschaft acquired, and which marks it as a factor in progress and in culture of much more importance even than the lasting discoveries in science which it has made, or the monuments of learning which it has reared. It is not the political side of this movement which I refer to, not even pre-eminently the educational, though these are interesting and important enough to demand special historical treatment. What I should like to point to as the greatest in this movement is, that it belongs to the few and rare instances in the history of mankind when we see a large number of the most highly gifted members of a 
nation following a purely ideal cause, apart from the inducements which gain or glory may furnish. The pursuit of truth and the acquisition of knowledge for its own sake, as an ennobling and worthy occupation, has during a large portion of our century been the life-work of professors and students alike in the German universities. In the biographies of many of them we meet with that selfdenial and elevation of spirit which is the true characteristic of every unselfish human effort. In perusing these records of high aspirations, arising frequently amid disheartening surroundings, these stories of privations cheerfully endured, of devotion to an ideal cause, glowing with all the fervour of a religious duty, we gain a similar impression to that which the contemplation of the Classical period of Greek art or the early Renaissance produces on our mind.

Once at least has science, the pursuit of pure truth and knowledge, been able to raise a large portion of mankind out of the lower region of earthly existence into an ideal atmosphere, and to furnish an additional proof of the belief that there, and not here below, lies our true home. We may perhaps have to admit with regret that this phase is passing away under the influence of the utilitarian demands of the present day; we may be forced to think that another-and, we trust, not a lower-ideal is held up before our eyes for this and the coming age. But no really unselfish effort can perish, and whatever the duty of the future may be, it will have to count among the greatest bequests of the immediate past that high and broad ideal of science which the life of the Ger- 
man universities has traced in clear and indestructible outlines. ${ }^{1}$

The testimonies by illustrious foreigners to the great work of the German universities are frequent and well known, from the time when Mme, de Staël visited Gel. many, and her friend Villers wrote his 'Coup-d'œil sur les Universités d'Allemagne' in 1808, through the writings of Cousin, the verdict of Renan, of Cournot, of DreyfusBrisac, and of the American, J. M. Hart. To these often-repeated expressions I will add that of the great apostle of higher culture of our age, of Matthew Arnold, who sums up his interesting report on the German system of higher education in these characteristic words : "What I admire in Germany is, that while there, too, Industrialism, that great moderm power, is making at Berlin and Leipzig and Elberfeld most successful and rapid pro. gress, the idea of Culture, Culture of the only true sort, is in Germany a living power also. Petty towns have a university whose teaching is famous through Europe; and the King of Prussia and Count Bismarck resist the loss of a great savant from Prussia as they would resist a political check. If true culture ever becomes at last a civilising power in the world, and is not overlaid by fanaticism, by industrialism, or by frivolous pleasure-seeking, it will be to the faith and zeal of this homely and muchridiculed German people that the great result will be mainly owing " ("Schools and Universities on the Continent,' 1868, p. 256). 


\title{
CHAPTER III.
}

\author{
THE SCIENTIFIC SPIRIT IN ENGLAND.
}

1. THE history of science in France and Germany during organisation the first half of the present century is identical with the
abroad. history of two great organisations, the Paris Institute and the German Universities. It is to them that we owe nearly all the great scientific work in the two countries: to the former we owe the foundation of the modern methods of scientific work during the last period of the eighteenth and the early years of the nineteenth century; to the latter we owe pre-eminently the diffusion and widespread application of those methods. ${ }^{1}$ We now turn to the country which, in advance of France and Ger-

I In respect of this I cannot suffi. ciently recommend M. Maury's volume on 'L'ancienne Académie des Sciences,' which is as eloquent a testimonial to the scientific labours of eminent Frenchmen during the eighteenth century as the companion volume on ' $L$ 'an. cienne Académie des Inscriptions et Belles Lettres' is a proof of the absence of philological studies during that period. The recent publication of Lexis' work, 'Die deutschen Universitäten,' is just as eloquent a testimonial to the labours of the German universities during this century. The first impression we get from the perusal of these two works is that for a long period France almost monopolised the exact sciences, just as later, for a similar period, Germany almost monopolised classical research, the science of antiquity. And yet the former was probably as much indebted to the English. man Newton as the latter was to the Frenchman Joseph Scaliger for the character each acquired during the two periods I refer to. 
many, had produced the greatest scientific model of modern times, a work which has probably done more than any other purely scientific work to revolutionise our scientific notions-the 'Principia' of Newton. In the subsequent history of the thought of this century, the next chapter will deal with the part that the Newtonian ideas have played throughout the whole period. We have now to turn our attention to the state of science in Great Britain during the period when Paris academicians and German professors combined to define and carry the spirit of modern scientific thought into the several mathematical, physical, and biological branches of research.

Considering that the great scientific institutions of the Continent-the Paris Institute, the scientific and medical schools in Paris, and the German universities-have done so much for the furtherance of science and the diffusion of the scientific spirit, it is natural that we should ask, What have similar institutions done in this country? These institutions are, indeed, mostly older than the 7 similar in. academies and modern universities of the Continent. Britain. The Royal Society, if not older than the French Academy, is certainly older than the Paris Academy of Sciences. ${ }^{1}$

1 The actual dates are as follows: The first Academy devoted to the pursuit of science seems to have been the "Academia Secretorum Naturie," founded at Naples 1560. Several societies devoted to the culture of literature and art existed in Italy, such as the Academy "della Crusca" (founded at Florence in 1582). The great French Academy, devoted exclusively to the study of the French language, dates from 1629 , and received its charter in 1635. The Royal Society, though not the first scheme of its kind which was started in this country - for the establishment of a Royal Academy was discussed as far back as 1616 -actually started (1645) in the private meetings described in ' $\mathrm{Dr}$ Wallis's Account of Some Passages of his own Life' (quoted by Weld, 'Hist. of the Royal Society,' vol. i. p. 30). These meetings, according to him, were suggested by a German, Theodore Hank, then resident in London. The members were "persons inquisitive into natural philo- 
The universities of Oxford, Cambridge, Edinburgh, Dublin, and Glasgow ${ }^{1}$ are older than most of the German universities which have done the great scientific work of this century. So far as wealth is concerned, no institution on the Continent could compare with the two older English universities, and the Royal Society had in the beginning of this century long emerged from the poverty which characterised her early history during the lifetime of Newton. ${ }^{2}$ Let us look at the subject from a

sophy, ... and particularly of what hath been called the New Philosophy or Experimental Philosophy." It formed a branch at Oxford in 1649, and received a royal charter in 1662 , four years before the "Académie des Sciences" atParis-which had also previously existed as a private gathering of sarants at the houses of Marsenne, Montmort, and Thévenot-was formally installed in the Bibliothèque du Roi. The "Accademia del Cimento" at Florence was established in 1657 ; but it only lasted ten years. Very irregular were also the life and labours of the "Academia naturæ Curiosorum" (later called A. Cæsarea Leopoldina), founded at Vienna in 1652. The Accademia del Cimento printed an important rolume of Transactions in 1666. The Royal Society published its first volume in 1665. The first volume of the 'Journal des Savants' is of the same year. Very complete information will be found on all foreign Academies in the 'Grande Encyclopédie,' art. "Académie."

1 Although the dates of the foundation of Oxford and Cambridge are uncertain, they were certainly more than a century-probably two centuries-older than Prague, the first German university, founded by the Emperor Charles IV. in 1347. The older Scotch universities were founded in the course of the fifteenth century, about the same time that Leipsic appears to have had its origin through a secession from Prague. The German universities - Halle, Göttingen - which were the seat of modern erudition, hare a much later date, as giren in chap. ii. p. 159 , above. Edinburgh was founded at the end of the sixteenth century, and Trinity College, Dublin, about the same time. Leyden, which exerted a great influence both on Scotch and German higher education during the seventeenth century, was somewhat older than Edinburgh.

2 It appears from Weld ('History,' \&c., rol. i. pp. 231, 241, 246, 316, 462, 473) that the financial position of the Royal Society was precarious, and frequently engaged the serious attention of the Council, during the whole first hundred years of its existence; that as late as 1740 the whole revenue of the Society was only $£ 232$ per annum. An effort was then made to get in the large arrears of subscriptions and other contributions. In the following year the income seems to have exceeded the expenditure by $£ 297$. Weld adds, "It is a painful task to record these periodical risitations of porerty, which threatened the very existence of the Royal Society; 
different point of view. England has during the early part

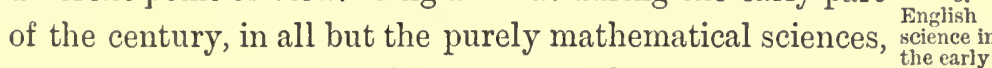
a greater array of scientific names of the first order than Germany, and nearly as great an array as France. Black, part of the century. Herschel, Priestley, Cavendish, Davy, Young, Dalton, Faraday, Rowan Hamilton, Brewster, Lyell, Charles Bell, are all identified with one or more novel ideas or definite branches of research. ${ }^{1}$ Great Britain had thus no lack

there is, however, a proportionate amount of pleasure in witnessing the triumphant manner in which the small band of philosophers extricated their institution from seri- ous difficulties, unassisted by Royal bounty and labouring alone on account of their love for science" (vol. i. p. 474).

1 The following are the principal dates referring to the great discoveries made in this country during the half-century ending 1825 :-

1774. Priestley (1733-1804) discovers oxygen and a variety of other gases.

1775. Black (1728-99), Memoirs on latent heat.

1775. Maskelyne (1732-1811) measures the Attraction of Mount Shehallien.

1775. Landen (1719-90) expresses the arc of an liyperbola in terms of two elliptic ares.

1778. Benjamin Thompson (Count Rumford, 1753-1814) first experiments on heat by friction.

1781, 13th March, Sir William Herschel (1738-1822) discovers Uranus.

1784. Cavendish (1731-1810) discovers the composition of water.

1786-97. Caroline Herschel (1750-1848) discovers her eight comets.

1798. Cavendish determines the density of the earth.

1799. Davy (1768-1829), essay on heat, light, \&c.

1800. Nicholson and Carlisle decompose water with the voltaic pile.

1801. Dalton (1766-1844), theory of evaporation.

1801. Young (1773-1829), first essay on the theory of light and colour.

1802. Dalton, law of expansion of gaseous fluids.

1802. Playfair (1748-1819), 'Illustrations of the Huttonian Theory.'

1802. Wollaston (1766-1829), on Iceland spar, and undulatory theory.

1802-3. William Herschel, observations on nebulæ and double stars.

1802-3. Young expounds the principle of "Interference."

1803-4. Dalton proposes the atomic theory.

1804. Leslie (1766-1832), experiments on heat.

1804. Wollaston discovers palladium and other kindred metals.

1806. Davy isolates the alkaline metals.

1807. Young introduces the word Energy (lect. i. p. 75).

1809. Ivory (1765-1842), on the attraction of ellipsoids.

1810. Young (in 'Quarterly Review') explains the different refractions in crystals.

1810. Davy discovers chlorine to be a simple body. 
either of great men of science or of great institutions, and yet-in spite of these-we read in the course of 4. the first third of the century about the decline of Alleged de cline of science in England. science in England. That such could be seriously said of a country which within fifty years had in astronomy discovered a new planet (the first addition to the number known to the ancients), had discovered oxygen, latent heat, and the decomposition of water, applied the galvanic current for isolating the most refractory metals, laid the groundwork for the undulatory theory of light, established the atomic theory, put forth in statics and dynamics two of the most important modern generalisations, ${ }^{1}$ and introduced in the treatment of electric and

1810. Brown (1773-1858) publishes his 'Prodromus Floræ Novæ Hollandire,' \&c.

1811. Charles Bell (1774-1842) asserts the difference of sensory and motor nerves.

1813. Brewster $(1781-1868)$ begins his experiments on refraction and dispersion.

1813. Davy discovers iodine.

1813. Wollaston publishes his synoptical scale of equivalents.

1814. Wells (1757-1817), essay on dew.

1815. William Smith (1769-1839) publishes his work on 'Strata.'

1815. Brewster gives his law for determining the polarising angle.

1815. Leslie (1766-1832) experiments on radiant heat and temperature of the earth.

1816. Prout (1785-1850), Memoir on the position of hydrogen.

1817. Young (in a letter to Arago) suggests transverse vibrations of light.

1819. Kater (1777-1835) measures the length of the seconds-pendulum.

1821. Faraday (1781-1867) discovers the rotation of a coil round a fixed magnet.

1821. Brown, monographs on botanical subjects.

1821. Sabine (1788-1883) experiments on the dip of the magnetic needle.

1823. Rowan Hamilton (1805-65) presents his paper on Caustics to the Irish Academy.

1823. Faraday condenses chlorine and other gases.

1824. Sir J. Herschel (1792-1871), observations of double stars.

1825. Sir J. Herschel, on the parallax of fixed stars.

1 The two important generalisations I refer to are contained in :

1. George Green, 'An Essay on

the Application of Mathematical Analysis to the Theories of Electricity and Magnetism,' published 
magnetic phenomena novel conceptions, the value of which other fifty years have hardly sufficed to realise -is, indeed, an extraordinary fact well worthy of careful examination. Certainly the language in which Cuvier with truth congratulates the French nation on the preeminence which it has attained in all branches of science contrasts strangely with the repeated attacks made in periodical literature, and in special pamphlets, on the state of science in England. And these not by persons ignorant of the great names and signal achievements just mentioned, but by men of note, occupying all but the very first places among the scientific men of this country.

It will suffice to give only two out of many examples of this criticism.

One of the earliest complaints regarding the culture of higher mathematics in this country will be found in an of Playfair.

at Nottingham by private subscription in 1828. The term "potential function," to denote the sum ( $V$ ) obtained by adding together the masses of all the particles of a system, each divided by its distance from a given point, or in mathematical language $V=\int \frac{d m}{r}$, occurs there for the first time. See Green's mathematical papers, ed. Ferrers, 1871, p. 22. The function had before that time been used by Legendre and Laplace, but Green was the first to give a general mathematical theory of it. His essay remained unknown to the mathematical world, and the principal theorems were independently published by Gauss in his celebrated essay' Allgemeine Lehrsätze uiber die im verkehrten Verhältnisse des Quadrats der Entfernung wirkenden Anziehungs- und AbstossungsKräfte,' 1839.
2. W. Rowan Hamilton's memoirs in the 'Philosophical Transactions' of 1834 and 1835 , preceded by his theory of systems of rass in the 'Transactions of the Royal Irish Academy,' 1828. In these papers is contained his celebrated principle of varying action, which is a development of Maupertuis's principle of least-or stationary-action. A great deal has been written on this principle, which is now considered to be the most general principle of dynamics, as well for its mathematical usefulness in calculations (see Kirchhoff, 'Vorlesungen iiber mathematische Physik,' vol. i. pp. 28,29 ), as from a phy. sical point of view (Helmholtz, in 'Journal für Mathematik,' vol. 100). It has gained this importance since the conception of energy, or power to do work, has been placed at the base of the theory of all physical processes. 
excellent review of Laplace's 'Mécanique céleste' by Playfair in the 'Edinburgh Review' of 1808.1 "In the list of the mathematicians and philosophers to whom the science of astronomy for the last sixty or seventy years has been indebted for its improvements, hardly a name from Great Britain falls to be mentioned. ${ }^{2}$. . . Nothing prevented the mathematicians of England from engaging in the question of the lunar theory, in which the interests of navigation were deeply involved, but the consciousness that in the knowledge of the higher geometry they were not on a footing with their brethren on the Continent. This is the conclusion which unavoidably forces itself upon us. . . We will venture to say that the number of those in this island who can read the 'Mécanique céleste' with any tolerable facility is small indeed. If we reckon two or three in London and the military

1 'Edinburgh Review,' vol. ii. p. 279, \&c. John Playfair (1748-1819) was a native of Forfarsliire, and Professur of Mathematics, and later of Natural Philosophy, at the University of Edinburgh. "Playfair was struck with the backwardness of the English mathematicians in adopting the results of the Continental analysts. While they boasted of Newton, they were unable to follow him, and the mantle of Newton liad indeed passed over to France, where it rested ultimately on the shoulders of Laplace. Play. fair accordingly set himself to diffuse among his countrymen a knowledge of the progress which science had been making abroad. This he did in a variety of ways, - by his articles in the 'Encyclopedia Britannica,' by his papers in the Transactions of learned societies, by his articles in the 'Edinburgh Review,' and by his class-teaching. As David
Gregory introduced the Newtonian philosophy, so Playfair introduced the Continental methods into the studies of the University of Edinburgh" (Sir A. Grant, "The Story of the University of Edinburgh,' vol. ii. p. 302).

- Playfair here exceptshis countryman, Colin Maclaurin (1698-1746), " in whose time the teaching of mathematics at Edinburgh reached a point which it cannot be said to have yet surpassed" (ibid., vol. ii. p. 299 ; cf. also vol. i. p. 271 , where a programme published in 1741 is given of the mathematical and physical lectures at Edinburgh, which surpassed probably at that time the teaching of any other English or Continental university). Playfair might have excepted also Ivory and the Englishman Landen, both of whom were well known among Continental mathematicians. 
schools in its vicinity, the same number at each of the two English universities, and perhaps four in Scotland, we shall hardly exceed a dozen, and yet we are fully persuaded that our reckoning is beyond the truth."

The other opinion I am going to quote dates from more than twenty years later, and is contained in a pamphlet by criticisms. Charles Babbage, ${ }^{1}$ who with Herschel and Peacock had done much to introduce at the University of Cambridge that knowledge of Continental mathematics which, according to the Edinburgh Reviewer, was so much needed. His 'Decline of the State of Science in England' (1830) was directed mainly against the Royal Society, as the review

${ }^{1}$ Charles Babbage (1792-1871), a native of Devonslire, well known all over Europe through his calculating machine, was a very remarkable and original man. $\mathrm{He}$ lived during the age when the application of machinery to manufactures, trades, and arts produced the great reform in the industrial system of this country, and his talents, which might well have been employed in promoting pure science, were largely spent in solving problems of practical interest. An account of these several pursuits and schemes is given in his 'Passages from the Life of a Philosopher,' London, 1864. Of his analytical machine we shall have occasion to speak hereafter (see p. $24 \mathrm{~S}$ ). Of the beginnings of the new school of mathematics at Cambridge he gives the following account (p. 27). Having purchased for seven guineas a copy of Lacroix's 'Differential and Integral Calculus,' he went to his public tutor to ask the explanation of one of his difficulties. "He listened to my question, said it would not be asked in the Senate House, and was of no sort of consequence, and advised me to get up the earlier subjects of the university studies." Repeated experience of this kind had the effect that he acquired a distaste for the routine studies of the place, and devoured the "papers of Euler and other mathematicians scattered through innumerable volumes of the Academies of Petersburg, Berlin, and Paris." $\mathrm{He}$ then perceived "the superior power of the notation of Leibniz." It being an age for forming societies for printing and circulating the Bible at Cambridge, Babbage conceived the plan of a society for promoting mathematical analysis, and to parody one of the many advertisements he proposed to call it a society for promoting "the Principles of pure $d$ 'ism ( $d$ being Leibuiz's symbol) in opposition to the dot-age (dots being Newton's notation) of the university." The most important result of this movement was the publication in 1816 of a translation of Lacroix's treatise, and of two volumes of examples in 1820 . 
of Playfair was against the English universities. " That science has long been neglected and declining in England is not an opinion originating with me, but is shared by many, and has been expressed by higher authority than mine." 2 The author then proceeds to give extracts from the writings of Davy, Herschel, and others on this subject. "It cannot," he says, "have escaped the attention of those who have had opportunities of examining the state of science in other countries, that

1 Some of the causes of the decline as given by Babbage are in. teresting, the more so if we remember that they were written at the period which marked the culmination of Wissenschaft in another country (p. 10): "The pursuit of science does not in England constitute a distinct profession, as it does in many other countries. ... Even men of sound sense and discernment can scarcely find means to distinguish between the possessors of knowledge merely elementary and those whose acquirements are of the highest order. This remark applies with peculiar force to all the more difficult applications of mathematics; and the fact is calculated to check the energies of those who only look to reputation in England." In 1794 Professor Waring of Cambridge wrote: "I have myself written on most subjects in pure mathematics, and in these books inserted nearly all the inventions of the moderns with which I was acquainted; ... but I never could hear of any reader in England, out of Cambridge, who took the pains to read and under. stand what I have written;" and "he then proceeds to console him. self under this neglect in England by the honour conferred on him by D'Alembert, Euler, and Lagrange " (see Todhunter, "History of the Theory of Probability,' p. 453). Babbage remarks (p. 13) that "in England the profession of the law is that which seems to hold out the strongest attraction to talent," that science is pursued as a favourite pastime, and that mathematics "require such overwhelming attention that they can only be pursued by those whose leisure is undisturbed by other claims." "By a destructive misapplication of talent we exchange a profound philosopher for but a tolerable lawyer" (p. 37).

2 One of the causes given by the Edinburgh Reviewer of 1822 (vol. xxxvii. p. 222) is the following: "In Cambridge there must always be a great number of men devoted to scientific pursuits; but from the want both of the facilities and the excitements furnished by such an association, apt to lose the spirit of original investigation, $-\mathrm{a}$ remark peculiarly applicable to those young men who yearly distinguish them. selves in the favourite studies of the University, and who, after the laborious course of discipline by which they have attained the first object of their ambition, are prone, if left alone, to become the mere instruments for enabling others to pursue tlie same course." 
in England, particularly with respect to the more difficult and abstract sciences, we are much below other nations, not merely of equal rank, but below several even of inferior power."

"It is," says the Edinburgh Reviewer of 1816,1 "certainly a curious problem with respect to national genius, whence it arises that the country in Europe most generally acknowledged to abound in men of strong intellect and sound judgment should for the last seventy or eighty years have been inferior to so many of its neighbours in the cultivation of that science which requires the most steady and greatest exertions of understanding, and that this relaxation should immediately follow the period when the greatest of all mathematical discoveries had been made in that same country."

It must be said that these opinions, expressed as they were by men of the highest attainments, did not remain Foreign opinions on unchallenged at home or unnoticed abroad. It will be science. interesting to see how they have been met. Let us first hear what Cuvier says in his Éloge of Sir Joseph Banks in $1821^{2}$ regarding the work of the Royal Society during the period of forty-one years of his presidency: "During this period, so memorable in the history of the human mind, English philosophers have taken a part as glorious as that of any other nation in those labours of the intellect which are common to all civilised peoples: they have faced the icy regions of both poles; they have left no corner unvisited in the two oceans; they have increased tenfold the catalogue of the kingdoms of nature; the

1 'Edinburgh Review,' 1816, vol. xxvii. p. 98.
2 See Curier, 'Éloges historiques,' rol. iii. p. 79. 
heavens have been peopled by them with planets, with satellites, with unheard-of phenomena; they have counted, so to speak, the stars of the Milky Way: if chemistry has assumed a new aspect, the facts which they have furnished have mainly contributed to this change: inflammable air, pure air, phlogisticated air, are due to them; they have discovered how to decompose water; new metals in great number are the outcome of their analyses; the nature of the fixed alkalis has been demonstrated by none but them; mechanics at their call have worked miracles, and have placed their country above others in nearly every line of manufacture." Another foreigner, Professor Moll of Utrecht, remarked in his reply to Mr Babbage's pamphlet" : If Mr Herschel and some of his friends

1 The pamphlet was entitled 'On the alleged Decline of Science in England.' By a Foreigner. London, 1831. It was by Dr Moll of Utrecht, and was introduced by a few lines from Faraday, who, without taking any side in the question, remarked that "all must allow that it is an extraordinary circumstance for English character to be attacked by natives and defended by foreigners." In the discussion on the subject by this writer, as also by Babbage, Herschel, Playfair, Whewell - pro and con. - a good many points of importance are brought out: some of them are still interesting, others refer to defects which have since been remedied. I will mention a few of them. Playfair, in the 'Edinburgh Review' (vol. xxxi. p. 393, 1819 ), thinks that the "very extensive dissemination of general knowledge, which is so much the case over the whole of this kingdom," is against the advancement of the higher branches of mathe- matics. This refers probably to the absence of periodicals devoted to special sciences, such as the 'Aunales de Chimie et de Physique,' published by Arago and Gay-Lussac in France. In the absence of these special organs, memoirs of original value, which marked an era in special researches, were scattered in general literary reviews, as Young's on Light and Hieroglyphics in the 'Quarterly,' Herschel's and Airy's in the 'Encyclopredia Metro. politana '; and much good mathematics were buried in the 'Ladies' Diary' among poetry of the "worst taste" and "childish scraps of literature and philosophy " ('Edin. Rev.,' vol. ii. p. 282, 1808). Another point is that "the researches of English men of science have been too much insulated from each other and from what is doing in other countries" (Whewell to Vernon Harcourt, 1831 ; see Life by Tod. hunter, vol. ii. p. 126). The British Association, which was founded very much as a result of this agitation, 
have such a poor opinion of the English scientific journals, a different judgment is entertained abroad, as is well proved by the eagerness with which the German journalists seize upon every article issuing from the presses of their British colleagues. The value which is set in Germany upon the scientific pursuits of the English, the rapidity with which translations are made in Germany of whatever English philosophers of some reputation publish, shows abundantly that in that country at least, in docta Germania, a far greater value is set upon the productions of English science than is done by Mr Herschel and his friends." 1

las remedied this defect; and special periodicals exist now in multitudes ; but who could say that a third point has been sufficiently attended to-viz., "the ignorance of foreign languages, which prevails both in England and in France: in England the number of those who acquire a smattering of French is very small, and still smaller is the number of those who know enough of German to read a book in that language without considerable trouble" (Dr Moll, loc. cit., pp. 7, 8). A fourth defect existing at that time is worth mentioning, as we have long left the age of such drawbacks; it "is the high price in England of foreign books, in consequence of an importation duty." The paper duties were repealed in 1861 .

${ }^{1}$ Moll, loc. cit., p. 7. Another passage is of interest, as bearing upon the difference between the culture of science in England and in France : "At the time of the French Revolution it so happened, by the exertions of d'Alembert, Clairault, Condorcet, and others, that of all sciences mathematics were the most fashionable. . . With this view the École Normale was founded, which, though of short duration, was perhaps of more utility towards the extension of mathematical knowledge than all the universities of Europe together. It was there that Laplace, Lagrange, and Monge were lecturers, and men like Lacroix among the hearers. The study of classics having been in a great measure abolished by the French Revolution, mathematics were studied in its stead; and it thus happened that a number of mathematicians, unusually great, were scattered over the soil of France, and every one thought himself capable de faire les $x$, as they themselves called it, upon any given subject. But most of these investigations were all theoretical, and practical applications were foregone in almost every instance" (p. 11). "Mechanics in particular do not seem accessible, according to the tenets of the French school, to any man not well versed in sublime analysis. . . . Hence it arises that many have acquired a profound knowledge of the higher branclies of mathematics, whilst the more elementary part of mathematics, which leads to the 
8. English replies to Babbage, \&c. Edinburgh Reviewer given by English writers themselves cannot on the whole be said to be very reassuring. One of them counts the scientific periodicals in England and in France, but omits to weigh the merit of their respective contributions. Another points to the 'Ladies' Diary', in which many curious mathematical problems, far beyond the mere elements of science, are often to be met with. A third, whilst in general admitting the correctness of Babbage's strictures, draws attention to the 'Penny Magazine' and the 'Cabinet Cyclopædia' as counterparts in England of the Reports of Cuvier and 9. Berzelius abroad. The true position was probably recogFoundation of the Brit. ish Associ. ation. nised by the founders of the British Association for the Advancement of Science about $1830,{ }^{1}$ who saw that, be-

most useful applications, is far less diffused in France than in England" (p. 12). "The principle of the division of labour [in science] is more acted upon in France than in England" (p. 14).

1 The movement, which originated in the circle to which Bab. bage belonged, was - as stated above, p. 42 - to some extent copied from the German Association founded by Oken in 1822. The latter acquired a kind of European renown through the exertions of Humboldt in 1828 , who succeeded in attracting a considerable number of celebrities-such as Gauss, Berzelius, Oerstedt, - who for themselves preferred a solitary to a "gregarious" mode of science. Babbage was a guest at this meeting at Berlin, and gave an account of it in an appendix to the 'Decline of Science.' A good account of the character and gradually declining influence of these German meetings will be found in Bruhns' 'Life of Hum. boldt' (rol. ii. p. 127, \&c., translation). They "degenerated after the usual German fashion into the unintellectual form of feasting." The British Association for the Advance. ment of Science, founded shortly afterwards on the 27th September 1831 at York, was the immediate outcome of a suggestion thrown out by Brewster at the end of a review in the 'Quarterly' of Bab. bage's 'Decline of Science.' $\mathrm{He}$ fully endorsed the latter's opinion, and was even more severe upon the universities, maintaining "that the great inventions and discoveries which have been made in England during the last century have been made without the precincts of our universities. In proof of this we have only to recall the labours of Bradley, Dollond, Priestley, Cavendish, Maskelyne, Rumford, Watt, Wollaston, Young, Davy, and Chevellix; and among the living to mention the names of Dalton, Ivory, Brown, Hatchett, Pond, Herschel, 
sides a number of separate societies, "concentration was needed in one association in order to give more systematic direction to scientific inquiry, and that the first thing needed would be to procure reports on the state and the desiderata of the several branches of science." Babbage, at the Oxford meeting in 1832, "expressed the general feeling that meetings should be held in places likely to bring science into contact with that practical knowledge on which the wealth of the country depends." There is also no doubt that in the course of half a century the British Association has done a very extensive service to science in the direction of supplying the wants which its early founders clearly defined, and in bringing about that concerted action and scientific co-operation which so highly distinguishes the great academies and universities of France and Germany. ${ }^{1}$ It has done so without altogether destroying that peculiar feature which characterises not only the scientific but all the forms of the higher mental work of this country. In no country has the voice of public criticism been so free to unveil the shortcomings which attach to all-even the highest-human effort. In England there has existed for a long time the habit of promoting advance in every department by the cultiva-

Babbage, Henry, Barlow, South, Faraday, Murdoch, and Christie; nor need we have any hesitation in adding that within the last fifteen years not a single discovery or invention of prominent interest has been made in our colleges, and that there is not one man in all the eight universities of Great Britain who is at present known to be engaged in any train of original research" ('Quarterly Review,' vol. sliii. p. 327,1830 ). He then suggests "an association of our nobility, clergy, gentry, and philosophers" (p. 342).

1 The British Association has from the beginning had two features which did not exist in the German society - first, the Reports on the position of various branches of science, delivered by specialists of the highest ability ; and, secondly, the Committees, which undertake to do special work requiring concerted action.
10. Characteristies of higher mental work in England. 
tion of party spirit, party criticism, and party shibboleths, as the easiest method of enlisting popular favour ${ }^{1}$ and individual interest; for here there exists no central authority which can create powerful organisations or disburse public means without the distinctly and repeatedly expressed support of a large section of the people. But all this must not induce us, in our historical survey, to dwell on the defects rather than on the excellence of the British contributions to the growth and the diffusion of science. Brilliant is undoubtedly the array of British names which have during the first half of this century become immortal by scientific labours, and it would be narrow-minded simply to emphasise the fact that they have not done so by the same means and through the same organisations as the Continental nations have established and perfected. For we must not forget that these even, with all their rightly extolled universality and breadth of spirit, have sometimes failed to recognise merit or to

11. Academies and univer. sities not always im. partial.

encourage genius. In spite of the impartial dealings of the Institute, on which Cuvier congratulates the French people, there are several instances in which contributions of the first order lay unnoticed for many years.

1 Referring to the British Association itself, Charles Lyell wrote in 1838, after the Newcastle meeting, to Charles Darwin : "Do not let any papers, whether of saints or sinners, induce you to join in running down the British Association. I do not mean to insinuate that you ever did so, but I have myself often seen its faults in a strong light, and am aware of what may be urged against philosophers turning public orators, \&c. But I am convinced, although it is not the way I love to spend my own time, that in this country no importance is attached to any body of men who do not make occasional demonstrations of their strength in public meetings. It is a country where, as Tom Moore justly complained, a most exaggerated im. portance is attached to the faculty of thinking on your legs, and where, as Dan O'Connell well knows, nothing is to be got in the way of hom. age or influence, or even a fair share of power, without agitation" ("Life, Letters, and Journals of Sir C. Lyell,' London, 1881, vol. ii. p. 45, \&c.) 
Fourier's great work on the theory of heat, which for the first time propounded a universal method applicable to Fourier. the mathematical treatment of almost every physical problem, inasmuch as it, so to speak, follows nature into the marvellous composition of the many movements out of which all her phenomena are compounded, lay buried for fourteen years in the archives of the Institute. That great authority had failed to recognise its paramount importance. ${ }^{1}$ Fresnel's first memoir, which established on a firm mathematical basis the undulatory theory of Fresnel. light, was for years left unpublished, whilst the whole scientific world was anxiously expecting the results of his inquiries. ${ }^{2}$ In Germany we have examples of similar

1 Jean Bapt. Jos. Fourier (17681830 ), of liumble origin, in his celebrated "Théorie analytique de la Chaleur' (Paris, 1822), and in previous memoirs, carried further the mathematical treatment of physical phenomena and introduced wider conceptions of mathematical quantities and their dependencei.e., of a mathematical "function." $\mathrm{His}$ investigations have led to farreaching applications in physical science (Ohm and Lord Kelvin), and to profound mathematical theories (Dirichlet, Riemann, \&c.) The so-called "Fourier" series has thus a great applied as well as theoretical interest. Fourier's first memoir was presented to the Institute in 1807 ; an extract was published in 1808 ; a second memoir was presented in 1811 and crowned, but was not printed till 1824, two years after the great work itself had appeared. On the physical importance of Fourier's analysis see Helmholtz, 'Vorträge und Reden,' rol. i. p. 101, \&c. ; Sir W. Thomson, Mathematical and Physical Papers, passim, but especially vol. ii. p. 41 , \&c. On the purely mathematical interest that attaches to the Fourier series see especially Riemann, 'Mathematische Werke,' p. 218, \&c. A very concise summary of the history of the series is also given by George A. Gibson in the 'Proceedings of the Edinburgh Mathematical Society,' rols. xi. and xii. We shall revert to this subject in a subsequent chapter.

${ }^{2}$ Augustin Fresnel (1788-1827) divides with Thomas Young the merit of having established the undulatory theory of light on a firm basis. His first memoir on Diffraction of Light was presented to the Academy in 1815 , a more extensive paper in 1818 ; this was crowned 1819 , but not printed till 1826. Other papers of his were mislaid or lost. The delay in bringing before the world these important discoveries has been attributed to the opposition of Laplace and his party in the Institute, which even the influence of Arago could not overcome. See what Sir John Herschel says in 1827 , referring to Fresnel's memoir of 1821 on

VOL. I. 


\section{discouragement and neglect being thrown in the way of} 1. 1 the growth of new ideas. Pliicker of Bonn laboured for Pliicker. many years on the union of the geometrical and analytical methods in the treatment of geometry; but he found so little appreciation that he abandoned his investigations, and only resumed them when in after-years a similar line of thought was independently developed in England. ${ }^{1}$

Transverse Vibrations, which the Academy had recommended to be printed: "We are sorry to observe that this recommendation has not yet been acted upon, and that this important memoir, to the regret and disappointment of men of science throughout Europe, remains yet unpublished" ('Ency. Metrop.,' article "Light"). A full account of the opposition and difficulties which both Young and Fresnel had to encounter will be found in Whewell's 'History of the Inductive Sciences,' vol. ii. In earlier times Réaumur seems to have exercised a similar tyranny in the Academy of Sciences; see Maury, 'Les Académies d'autrefois,' vol. i. pp. 280,123 ; also Huxley, 'Critiques and Addresses,' 1890 , p. 112, \&c.

I Julius Plücker (1801-68), professor at Bonn, equally known in England by his scientific co-operation with Faraday and by that with Cayley and Salmon, worked both in physics and geometry on independent lines. In the latter especially he brought about that union of purely geometrical and algebraic methods which has become so fruitful in the development of modern geometry and modern algebra. He had two periods of original geometrical work. The first began in 1826 (the year of the revival of mathematics in Germany), and closed in 1846. His mathematical researches were little noticed in his own country, whereas in France, and still more in
England, his name was well known. After having published in 1846 a 'System of Geometry,' which contained his former results in a more methodical form, he dropped his mathematical researches for twenty years, during which time he devoted himself to physical investigations of great originality. By these, if he had not been a personal friend, he might almost have been called a rival of Faraday (G. Chrystal in 'Ency. Brit.') During a visit to England in 1864 he was agreeably surprised to meet with appreciative interest from English geometricians, who had independently worked on the same lines as he had done twenty years earlier. He was thus induced to resume his favourite studies, and to develop an idea which had already been expressed in his last-named work of 1846 . This led to a new fundamental conception of geometrical forms, in which not the point but the line is the element of space. He was not spared to complete this linegeometry, but after his death his pupils found sufficient material to put his researches into a systematic form under the title, 'Neue Geometrie des Raumes, gegründet auf die Betrachtung der geraden Linie als Raumelement' (Leipzig, 1868 and 1869). See Clebsch on Julius Pliicker, Göttingen, 1872. A very appreciative notice of Pliicker, by George Chrystal, will be found in the 9th edition of the "Encyclopadia Britannica.' 
Grassmann, in his 'Ausdehnungslehre,' published in 1844, is now generally admitted to have originated quite a novel way of considering geometrical relations. ${ }^{1}$ It took twenty years, however, before he succeeded in attracting any attention, and his great work, of which the first edition had been sold as waste-paper, was later on reprinted in its original form-mathematicians having now begun to study and recognise its intrinsic value. Such cases of neglect have undoubtedly been much more frequent in England, where even at the present day no central organisation exists which annually collects and arranges the scattered labours of individual workmen, and where that historical

16. Central organisation wanting in England. and encyclopredic spirit is wanting which does its utmost to guarantee completeness and thoroughness of search and of research. Men of the greatest eminence, pioneers

${ }^{1}$ Hermann Grassmann (1809-77) was born, lived, and died at Stettin. $\mathrm{He}$ did not succeed till late in life, and fully thirty years after he had published his original investigations in geometry, in gaining for these the recognition and appreciation which they deserved. Neither he nor even Jacob Steiner at Berlin attained to positions worthy of their ability; the latter, in spite of his connection with other great mathematicians, never filled the chair of an ordinary professorship, whilst the former never entered the sphere of university teaching at all. The 'Ausdehnungslehre,' as a new branch of mathematics, appeared in 1844. It is a science of pure extension, the application of which to empirical space is geometry. Similar investigations, in which space of three dimensions is considered to be merely a particular case of pure extension of any number of dimensions, which are not neces. sarily determined by the same pro- perties as our empirical space, have become familiar since the publication of Riemann's celebrated dissertation of 1854 (published in 1867), and since Helmholtz was led to similar investigations by considering the different dimensions or manifoldnesses of our sense perceptions (see his 'Vorträge und Reden,' in many passages). Grassmann, who at the end of his life witnessed the growing appreciation of his ideas, had filled up the interval with entirely different studies, the translation of the 'Rig-Veda' (Leipzig, 1876-77), and the composition of a dictionary to the same $(1872-75)$. He seems to have been the only mathematician, besides Thomas Young, who combined the ability for exact mathematicophysical and for philological studies. Both can complain of having been very insufficiently appreciated by their contemporaries. See Victor Schlegel, 'Hermann Grassmann,' Leipzig, 1878.
15. Grassmann. 
in their line of thought and discovery, have to the present day remained popularly unknown to their countrymen, who have not only neglected but reviled them, allowing their great discoveries to be taken up as their own by 17. foreigners. Such was Dr Thomas Young, whom many

educated persons at the present day cannot distinguish from the author of 'Night Thoughts.' 1 The great founder

1 Thomas Young (1773-1829), a native of Somersetshire, attainer equal eminence by his discoveries in connection with the undulatory theory of light, in which he was the first to assert the principle of interference and that of transverse vibrations, and by his discovery of the key to the system of hieroglyphics. Of his discoveries and suggestions some were published in anonymous review articles (so especially his hieroglyphical papers); some in his Lectures on Natural Philosophy, delivered early in the century at the Royal Institution, and published 1807 ; some in the 'Transactions of the Royal Society' (from 1800 onwards); and some in various collective works, especially the 'Encyclopredia Britannica.' The remarkable fact that Young, of whom Helmholtz says ("Vortrïge und Reden,' vol. i. p. 279) that he came a generation too soon, remained scientifically unrecognised and popularly almost unknown to his countrymen, has been explained by his unfortunate manner of expression and the peculiar channels through which his labours were an. nounced to the world. His frequently unintelligible style, his obscure and inelegant mathematics, the habitual incognito which he preserved, his modesty in replying to attacks, and his general want of method in enunciating his ideas, contrast very markedly with the writings of some of his rivals, especially in France, where the qualities of style, method, and elegance were highly developed, and where recognised organs existed for the publication of works of genius. The historian of thought, however, must not omit to state that several great names contributed, by the authority they commanded, to oppose Young's claims to originality and renown. Lord Brougham, shielded by the powerful anonymity of the 'Edinburgh Review,' and osten. tatiously parading the authority of Newton, submitted the views of Young to a ruthless and unfair criticism, the popular influence of which Young probably never overcame. The great authority on optics, Brewster, who has enriched that science by such a number of experiments and observations of the first importance, never really adopted the theories of Young and Fresnel. In the other great branch of research with which Young's name is now indissolubly connected, in the science of hieroglyphics, the authority of Bunsen decided against Young and for the Frenchman Champollion. But this decision, which did so much to obscure the merits of Young, was founded on an insufficient knowledge of the dates of Young's pub. lications. Since these were collect. ed by Leitch in the third volume of the 'Miscellaneous Works' of Dr Young (London, 1855), the chrono$\log y$ of his discoveries, which begin 
of modern chemistry, who next to Lavoisier did more than any one else to introduce into this science mathematical ideas, John Dalton, grew old and infirm before his countrymen sufficiently recognised and honoured him. Deprived of all but the very meanest apparatus for the proofs of his theories, and yet able to do what he did, what might not such a genius have accomplished if he had possessed the means of a Gay-Lussac or a Regnault ? ${ }^{1}$

in 1814, has been well established. See Benfey, 'Geschichte der Sprachwissenschaft' (Mïnchen, 1869, p. 729). Bunsen pronounced his verdict in his well-known work, 'Egypt's Place in Universal History,' published in 1845-57. On the whole, the words of Peacock, 'Life of Dr Young' (London, 1855), p. 472 , are still correct: "His scientific works were rarely read and never appreciated by his contem. poraries, and even now are neither sufficiently known nor adequately valued; whilst if justice was award. ed more promptly and in more liberal measure by his own countrymen to his hieroglyphical labours, these also were singularly unfortunate, as far as concerned the general diffusion of his fame, by coming into collision with adverse claims, which were most unfairly and unscrupulously urged in his own age, and not much less so by some distin. guished writers in very recent times."

1 John Dalton (1766-1844), a native of Cumberland, spent the greater part of his life in teaching elementary mathematics at Manchester, first at a college and then privately. In 1801 he propounded the law known under the joint name of Dalton and Gay-Lussac (who stated it six months later). In the years immediately following he elaborated his atomic theory, which was to account for the existence of those definite quantitative relations between the chemical constituents of bodies known already to Richter. It was published in 1805 . But the man who did most to make known to chemists the ideas of Dalton was Thomas Thomson (1773-1852), Professor of Chemistry at Glasgow, who in 1807, in the 3d edition of his 'System of Chemistry,' gave an account of the atomic theory based upon communications of Dalton. Two memoirs published in the 'Philosophical 'Transactions' of 1808-one by Thomson on "Oxalic Acid," and one by Wollaston on "Super-Acid and Sub-Acid Salts" - pointed to the great importance of the atomic theory, which (Wollaston prophetically added) would not stop short with the determination of the relative weights of elementary atoms, but would have to be completed by a geometrical conception of the arrangement of the elementary particles in all the three dimensions of solid extension. The real merit of having experimentally proved the theory of Dalton belongs to Berzelius, whereas Sir Humphry Davy opposed it for many years after it had been accepted abroad. Dalton himself by no means followed the development which his ideas underwent at the hands of others. For example, he opposed Gay-Lussac's law of volumes. He was on the whole more successful in working out his own 
19.

Faraday.

Faraday, instead of being backed by a wealthy Academy and ample assistance, had during all the years when his great discoveries were being made, to keep alive, with an income scarcely exceeding a hundred pounds a-year, an institution which but for him the memory even of such names as Rumford, Young, and Davy would not have sufficed to preserve from utter ruin and collapse. ${ }^{1}$ The author of one of the most suggestive treatises in the application of mathematics to physical phenomena, 20. George Green, published it in 1828 at Nottingham by Green. private subscription. Seventeen years later, William Thomson (Lord Kelvin) tried in vain to procure a copy

ideas than in comprehending those of others who, like Berzelius, Mitscherlich, Laplace, Liebig, and many later, contributed to the confirmation of the atomic theory. A good account of this is given in Henry's 'Life of Dalton' (1854) and in Kopp's 'Entwickelung der Chemie in der neueren Zeit' (München, 1873).

1 Michael Faraday (1791-1867), though not a mathematician, introduced into the science of electricity those ideas which have since been developed into a mathematical theory approaching in completeness the mathematics of the undulatory theory of light. What the atomic theory has done for chemistry, Faraday's lines of force are now doing for electrical and magnetic phenomena. Dalton, though unacquainted with the higher mathematics of the French school, had essentially a mathematical or arithmetical mind. Faraday's peculiar ideas on the nature of electrical and magnetic action, though supported by an experimental knowledge many times surpassing in volume and accuracy that of Dalton, did not find much appreciation among his contem- poraries. They were much more interested in his experimental researches than in his theories. In France and Italy Faraday's eminence was recognised early. Already in 1823 he was elected member of the Academies of Paris and Florence, almost before any society at home had received him. "The circumstances under which Faraday's work was done were those of penury. During a great part of the twentysix years the Royal Institution was kept alive by the lectures which Faraday gave for it. "We were living,' as he once said to the managers, "on the parings of our own skin.' $\mathrm{He}$ noted even the expenditure of the farthings in research and apparatus. $\mathrm{He}$ had no grant from the Royal Society, and throughout almost the whole of his time the fixed income which the Institution could afford to give him was $£ 100$ a-year, to which the Fullerian professorship added nearly $£ 100$ more"' (Bence Jones, 'Life and Letters of Faraday,' London, 1870 , vol. ii. p. 344). See also Bence Jones, 'The Royal Institution,' p. 311. 
of this document, of which he knew by a reference in another work. At last he got possession of a copy which had probably during all this time been buried in the library of a prominent mathematical tutor at Cambridge, with whom he had been in frequent intercourse. Thomson then took it with him to Paris, where Sturm and Liouville at once recognised its merits. He then published it in 'Crelle's Journal,' where it has ever' since been referred to as a fundamental essay on the so-called potential theory. ${ }^{1}$ One of the most original thinkers on mathematics, who introduced a novel principle into algebraical science, George Boole, never attained to a higher position than that of teacher at a remote Irish provincial College. ${ }^{2}$ But perhaps the most signal example of the want of support which the

1 See note 1 to p. 231 ; also Sir William Thomson, reprint of papers on "Electrostatics and Magnetism," 2d ed., London, 1884, p. 2, note ; p. 126, note.

2 George Boole (1815-64), a native of Lincolnshire, was one of the few great and original mathematicians who, like Leibniz and Grassmann, and to some extent Gauss, looked at the logical as well as the purely arithmetical side of the language of symbols. Though his treatises on 'Differential Equations' (1859) and on 'Finite Differences' (1860) have become well-known text-books, and his 'Laws of Thought' (1854), in which he examined the foundations of the mathematical theories of logic and probabilities, remains a unique work, his principal services to science lie in the direction of the "calculus of operations." In this branch of mathematics, which is peculiar to England, the symbols indicating an arithmetical op. eration are separated from those denoting quantity and treated as distinct objects of calculation. In connection with these investigations, many of which have now penetrated into ordinary textbooks, Boole was led to examine the conditions under which and the forms in which algebraical expressions, whilst undergoing changes and transformations, remain, nevertheless, unaltered (invariant) (1841). By introducing this point of view he has, so to speak, created modern algebra; founding the extensive and fruitful science of "Invariants." Of this we shall treat later on. I now only refer to the further development of this subject in the hands of Cayley and Sylvester, and to the raluable sketch of the history of this branch of mathematics by Dr F. Mayer in the first volume of the 'Jahresbericht der deutschen Mathematiker-Vereinigung,' Berlin, 1892. 
wealthiest of nations has shown to scientific genius is 22. to be found in the history of Babbage's calculating engine. Yet this machine was approved by all experts -English and foreign-during the inventor's lifetime; and the Report of a Commission of the British Association appointed specially to examine into the matter, concluded by stating that the scheme was perfectly feasible, and might, if carried out, mark an invention as great probably as that of logarithms. ${ }^{1}$ Who among us who has been interested in the promotion of institutions for higher education has not a story to tell of pecuniary troubles, continued through many a long year, whilst the wealth of the country seemed to exert its influence only in the direction of making the demands on a struggling establishment more formidable, the expenses more difficult to defray. ${ }^{2}$

1 On Babbage see p. 233, note 1. The history of the "difference engines" and the "analytical engine" is given by Babbage himself in his 'Passages from the Life of a Philosopher.' See also Weld, 'History of the Royal Society,' rol. ii. p. $369, \& c$.

${ }^{2}$ Like the Royal Society, which for a century had to struggle with poverty, the Royal Institu. tion has a story to tell of want of funds through a long period of its early existence. See Bence Jones, 'The Royal Institution,' London, 1871, pp. 202, 281. The Royal Institution was founded by Benjamin Thompson, Count Rum. ford (1753-1814), and had originally not a scientific, hardly even a higher educational object. The scheme arose in the mind of its founder after he had successfully exerted himself at Munich under the patronage of the Elector of
Bavaria in founding industrial work houses, improving the state of the army, and putting down beggary and immorality in the capital and country. His principle was to make "vicious and abandoned people first happy and then virtuous" (p. 31). After leaving Munich in 1793 and spending two years in Italy, similarly occupied, he visited London in 1795 in order to publish his Essays, which appeared separately between 1796 and 1802 . The first essay contained "a proposal for forming in London by private subscription an establishment for feeding the poor and giving them useful employment, . . . connected with an institution for introducing and bringing forward into general use new inventions and improvements," \&c., \&c. (p. 44). The first outcome of this was the formation of a society for encouraging industry and promoting 
But it is hardly the duty of the historian of thought to record that which belongs more to the impediments of mental progress than to its promotion, were it not that in and through these peculiar circumstances the genius of the nation has developed its main features, its strong character. These are manifest as much in the department of science as they are in general literature and in the institutions of practical life. British science through English all the centuries, since the time of Roger Bacon, and in spite of the efforts of his illustrious namesake, has

the welfare of the poor. William Wilberforce was one of the original promoters; Thomas Bernard, the founder of many other charitable institutions, one of its most active members. To a committee of this Society Count Rumford submitted, in 1799 , his proposals for forming the Royal Institution, and it was accordingly founded in February of that year on private subscriptions of fifty guineas each. It was described as a "public Institution for diffusing the knowledge and facilitating the general introduction of useful mechanical inventions and improvements, and for teaching by courses of philosophical lectures and experiments the application of science to the common purposes of life." In the course of a very few years the original character of the Institution entirely changed, the aim of influencing directly the condition of the poor was lost sight of, and little remained besides the result of " bring. ing science into some degree of fashion" and "affording a new em. ployment and amusement to the higher classes of life." The interest of the Institution for the history of thought is the fact that in its laboratory Davy and Faraday conducted their researches, and that they, as well as Young, Coleridge, and Sydney Smith, there delivered their lectures. And the history of the Royal Institution is also typical of the history of other establishments for higher culture in this country: it has been in its main features repeated on a larger or smaller scale in many provincial societies, and notably in the colleges of Manchester, Birmingham, Liverpool, Newcastle, Leeds, Bristol, Nottingham, \&c. Started by persons with large but nevertheless insufficient means, or by subscriptions and endowments of moderate extent, obliged to gain popularity and fashionable support in order to meet their growing expenses, these institutions have depended mostly on individual energy for their first successes, and have all had to pass through periods of great difficulty, till in course of years they have acquired a special character of usefulness and defined their peculiar sphere of action. The absence of a definite programme and a great waste of energy and funds over special departures are not uncommon features of these developments. 
refused to congregate in distinct schools and institutions or to be localised in definite centres. The Royal Society, the Royal Institution, the British Association, and many other smaller societies, have all more or less started with the programme of Lord Bacon, and have failed to realise it: everywhere the schemes of co-operation or organised scientific research have encountered the opposition of individual pursuits or of local interests.

Newton could not secure the use of Flamsteed's observations, which on their part remained uncompleted and unpublished through the want of appreciation of others. Great schemes in practical life have been carried out by the unnided efforts of eminent persons, and great ideas have been put forward with all the power and

24. Absence of schools of scientific thought.

all the resources of individual genius, ${ }^{1}$ but no great master in scientific research in this country can point to a compact following of pupils-to a school which undertakes to finish what the master has begun, to carry his ideas into far regions and outlying fields of research, or to draw their remoter consequences. Newtonianism was a creation of Voltaire; the school of Locke is to be found in France; the best realisation of Bacon's schemes are the Encyclopédie, the French Institute, and the foreign Academies. ${ }^{2}$ Dr Young's discoveries in optics

1 See Huxley, 'Lay Sermons, \&c.,' edition of 1891, p. 43 : " England can show now, as she has been able to show in every generation since civilisation spread over the West, individual men who hold their own against the world, and keep alive the old tradition of her intellectual eminence. But in the majority of cases these men are what they are in virtue of their native intellectual force, and of a strength of character which will not recognise impediments. They are not trained in the courts of the Temple of Science, but storm the walls of that edifice in all sorts of irregular ways, and with much loss of time and power, in order to obtain their legitimate positions."

2 See above, pp. 34, 95. 
and hieroglyphics were made known to the learned world through his French contemporaries. Dalton, ${ }^{1}$ Charles Bell, ${ }^{2}$ Faraday, Darwin, and Maxwell, no less than Bentley and Gibbon, ${ }^{3}$ have furnished the text for lecturecourses in German universities, and created a whole literature of pamphlets and scientific memoirs. ${ }^{4}$ English societies may sometimes honour and admire, but they do not support, their great representatives, and these themselves often refuse to be tied by exclusive academic duties, still more by official restrictions. Two characteristics have marked most of them: they have, at all expense and sacrifice, guarded their individual freedom of thought, and they have almost always shown a great desire to combine some application with their abstract Individual character and practiresearches, to take part in the great practical work of cal tendency
of English researches, to take part in the great practical work of science. the nation. Continental thinkers, whose lives are devoted to the realisation of some great ideal, complain of the want of method, of the erratic absence of discipline, which is peculiar to English genius. The fascination which practical interests exert in this country appears to them an absence of full devotedness to purely ideal pursuits. ${ }^{5}$

1 See above, p. 245, note.

2 See above, p. 193, note.

3 See above, p. 169 , note.

${ }^{4}$ Germany may be said to have produced Darvinismus in this century as France created Newtonianisme in the last. Huxley writes ('Life of Darwin,' vol. ii. p. 186) : "None of us dreamed (in 1860) that in the course of a few years the strength (and perhaps I may add the weakness) of Darwinismus would have its most extensive and most brilliant illustrations in the land of learning." Quite recently Prof. Boltzmann at Munich, and M. Poincaré, have published courses of lectures on Maxwell's electric theories.

5 What appears irksome to an English genius--the red tape of academic restrictions, the barriers of officialism, and the duties of the teacher-melted away in the glow of enthusiasm and love of truth which animated the great leaders and founders of university culture abroad; as Goethe has told us that the rigid form of the sonnet melts in the fervour of the love-song:

"Das Allerstarrste freudig aufzuschmelzen

Muss Liebesfeuer allgewaltig gluhen." 
The English man of science would reply that it is unsafe to trust exclusively to the guidance of a pure idea, that the ideality of German research has frequently been identical with unreality, and that in no country has so much time and power been frittered away in following phantoms, and in systematising empty notions, as in the Land of the Idea; but he would as readily admit that his own country is greatly deficient in such organisations for combined scientific labour as exist abroad, and that England possesses no well-trained army of intellectual workers.

26.

English peculiarities more pronounced during early part of the century.

These differences between English and Continental science were most pronounced in the first half of the present century, when Germany developed her university system, when France clearly defined the exact scientific methods, and when the encyclopædic view-peculiar to the historical and philosophical pursuits of the earlier years-gradually became dominant in the exact sciences also. Since then the intercourse of the different nations has done much to destroy these national peculiarities. The reform of the universities, in which Germany was engaged in the early years of the century, did not touch the English universities before the middle of the century. In the meantime quite different demands had sprung up all through the civilised world; and as nothing repeats itself in history, it will be impossible to reach in this country the same broad organisation for purely intellectual work as Germany can rightly boast of during the period we are dealing with. Some persons doubt whether it will be maintained in Germany. It appears still more doubtful whether such an organisation could now be 
created in the face of the industrial spirit of our age. Ever since the latter half of the eighteenth century schemes for a general education of the masses have attracted the thought and the attention of philanthropists and statesmen in many countries of Europe. But the directions taken by these educational efforts have been characteristically different in the different countries, and their success, so far as the great masses of the people are concerned, has been very partial indeed. It is true that during the first thirty years no country possessed such distinguished schools of science as did France in the great scientific and medical institutions of her capital. It is also true that no country equalled Germany in her system of universities and higher schools, which had come under the influence of classical learning and philosophical ideals. England, which at that time took no part in the educational movements of the Continent, ${ }^{1}$ possessed, neverthe-

1 This statement requires two qualifications. Firstly, both Milton and Locke have had great influence in spreading enlightened views regarding the principles and the object of education in general especially in the direction of enlarging the idea of education, so as to make it comprise something more than merely instruction and pedan. tic teaching. I cannot find, however, that in England, either in the direction of higher university education or of a general system of popular education, their influence has been very marked. Locke's influence abroad, through his psychological analysis of the mind, has been very considerable. Secondly, in the direction 'of practical education, of the endeavour to reach large numbers of the people by educational institutions, we must look with admiration to the early work done in Scotland, which in this respect somewhat resembles Switzerland. The Scotch system of parochial schools, and their influence on the education of the people, has been too little studied abroad, though rightly extolled at home. It is true that, with the exception of Calvin, none of the great Continental educationalists-such as Fénelon, Rousseau, Pestalozzi, or WV. von Humboldt-have had any direct influence on Scotland; nor has the educational work of Scotland produced any great educational literature like that which Switzerland can boast of, and which has brought the theory of education so prominently before the world. But nevertheless there it stands, this creation of John Knox and the early Reformers. "Civilised 
27. less, something peculiar in her two great universities. Unique
character of It was neither the scientific, nor the classical, nor the
English universities. philosophical spirit exclusively which reigned there; if any or all of them had ruled, we should not meet with those repeated complaints that higher mathematics were absent in Cambridge, that no philological studies were cultivated in either of the universities, and that philosophy was represented merely by Aristotle, Butler, Locke, and Paley. ${ }^{1}$ According to the representatives of the university

Europe has never witnessed a nobler spectacle than the first Protestants of Scotland in the assembly of the nation demanding that from the funds before abused by a licentious superstition one-third should be devoted, not to increase the rerenue of the Reformed Church, but to the education, the universal education, of the youth in all departments of instruction, from the highest to the lowest" ("North Brit. Rev.''12, p. 483).

1 As to the deficient mathematical teaching at Cambridge, see p. 233 , note, \&c. The complaints regarding the teaching of other subjects are frequent, but belong to a later date, the middle of the century, when the Royal Commission of Inquiry, which was appointed under the Government of Lord John Russell on the 31st August 1850 and expired with the presentation of its report on the 30th August 1852, attracted the attention of the public to university reform, and gave rise to a very full discussion of the whole subject in the various literary papers and reviews. The two older universities are called "citadels of political prejudice and sectarian exclusiveness, instead of being the temples of liberal arts and the repositories of science" ("Brit. Quart. Review,' 1860, July, p. 205). Theology is stated to be "the last thing taught at Cambridge" (ibid., p. 221) ; there was no professor of Latin, none of English literature, of logic and metaphysics, of modern languages ( $p .225$ ). In 1849 Cambridge had no laboratory ; the unirersities took no part in the legal training of lawyers ('Edinb. Rer.,' April 1849, p. 511); Oxford afforded no training in natural science (ibid.) Cambridge "sacrificed to the monopoly of a severe geometry every other exercise and attainment of the human mind. There was no theological study, no study of history, none of moral science, none of chemistry, none eren of experimental philosophy" (ibid., p. 514). These criticisms were fully justified by the Reports of the Commissions published in 1852. See on the teach. ing of Theology at Cambridge, Report, pp. 89, 102 ; Eridence, pp. 88, $168,190,216$ : on the teaching of Latin, Rep., pp. 98, 102 ; Evid., pp. $165,176,289:$ on the teaching of English, Evid., pp. 124, 136 : of modern Languages, Rep., pp. 26, 101 ; Evid., pp. 165, 216, 300: of Law, Rep., pp. 35, 182 ; Erid., pp. 123, 190: of Natural Sciences, Evid., p. 115 , \&c. In 1874 the 'Edinburgh Review' could point out that during twenty years, whilst the examination for the Indian Civil Service had been thrown open, the English unirersities had practically contributed no 
system, what England did possess was the ideal of a liberal $2{ }_{\text {Ideal of }}^{28}$ cducation. But none of these three forms of intellectual ciberal Edutraining-neither the scientific in Paris, nor the classical in Germany, still less the liberal in England - touched the great masses of the people. They all did good work in their respective lines; but they left, or would by themselves have left, the country in darkness. The beginnings of general popular education are to be traced independently in Switzerland, in Scotland, and in many of the small States of Germany. ${ }^{1}$ The great scientific

candidates to the competition (April $1874, \mathrm{p}, 342)$. "Nothing about university life was more striking" to the Edinburgh Reviewer "than the contrast between the efforts and the high aims of the few, the culture and solid result achieved by them-and the utter uselessness of it to the many" (p. 354). The 'Quarterly Review' of June 1826, notes "a growing taste for the cultivation of physical science as characteristic of the state of the public mind in England" (p. 159), and refers to the "measures which have been carried into effect throughout the country with great harmony of design, although chiefly by the unassisted exertions of private individuals, .. . the recent establishment of numerous literary and philosophical institutions in our metropolis and many of our provinces" (ibid., p. 154).

1 The great Reformers-Luther, Melanchthon, Zwingli, and Calvinalike took a great interest in education, which they intended to be universal and popular. But their success, so far as the education of the people was concerned, remained every where very partial. A real organisation of primary schools was not attained. They prepared for it by introducing the vernacular languages, the reading of the Bible, the popular hymns. Their main efforts lay in the training of good teachers for church and schools in the reorganisation of what were called the Latin schools. In the course of the sixteenth and seventeenth centuries the smaller Protestant States of Germany-especially Saxony, Wïrtemberg, Brunswick, the northern cities Hamburg and Liibeck - received under various forms what was called "Eine Kir. chen- und Schulordnung." Luther's tract of the year 1524, addressed to the "burgomasters and councillors of all towns of the German land, that they should found and maintain Christian schools," was the beginning of this movement. In Scotland burgh schools, also grammar (or Latin) schools and lecture schools, " in which the children were instructed to read the vernacular language," existed long before the Reformation. But to John Knox is due the scheme for popular education contained in the 'First Book of Discipline.' The parochial schools were started in many instances by voluntary or ecclesiastical assessment through the efforts of the Reformed clergy. The foundation of the subsequent system of parochial schools was laid 


\section{schools of France trained the civil and military engin- eers in that country, and produced text-books for the}

in the statute of 1696 . It must not be forgotten, howerer, that the "Order of Jesus" (founded 1540), whose higher educational work lias found so much appreciation from men like Sturm - the Protestant educationalist - Lord Bacon, and Descartes (see the quotations in Schmidt's 'Geschichte der Püdagogik,'4th ed., vol. ii. p. 248), was also active in the direction of popular and primary education. In emulation of the Protestant movement, it had introduced "school regulations" in many Catholic countries, and even founded a special order -the "Patres piarum scholarum" (1600) - for the education of the poorer classes (ibid., p. 253). Whether the statute of 1696 is the earliest official document referring to popular education and providing the means of maintaining an adequate number of schools (one in 1000 of population) to teach the lower classes, I cannot say. It appears that Duke Ernest of Gotha, in the course of the seventeenth century, establisherl a general system of primary education in his territory which was "quite unique, at first an object of ridicule, but then very soon of emulation" (ibid., p. 333). The regulations were certainly most wise and liberal, and attendance was made compulsory. The question of popular education was taken up on a much larger scale by Frederick the Great in the middle of the eighteenth century. The year 1763, which marks the end of the Seven Years' War, is also the year of an edict which forms the basis of the regulation of popular education for the whole monarchy : it establishes village schools with compulsory attendance. It met with much opposition, and its ends were only slowly realiserl, and only as training-schools, where a sufficient number of teachers were educated, sprang up, and as popular school and story-books were provided. Campe, with his edition of 'Robinson Crusoe,' marks an epoch in this direction. In fact, the cause of universal popular education remained in the hands of private persons, frequently of men of great insight and organising ability - such as A. H. Francke (1663-1727), the indefatigable friend of the poor and of orphans; Basedow (1723-90), the founder of the Philanthropin and populariser of Rousseau's ideas; Von Rochow (1734-1805), the friend of the coun. try - folk and founder of rillage schools; Von Felbiger (1724-88), the adviser of Maria Theresa and Joseph II., the organiser of the popular educational system in Austria $(1770-80)$ : or else it was dependent on the casual favour of enlightened princes and sovereigns. At length, in the middle of the eighteenth century, training-schools for teachers, so-called "seminaries," were founded all over Germany. A beginning had been made by Duke Ernest of Gotha (1601-75), but had been neglected like many other beginnings. But in the second half of the eighteenth century no less than thirty-three seminaries were founded all over Germany, including Austria. For details on this important and interesting subject, see the third volume of Schmidt's 'Geschichte der Päda. gogik.' Freytag's 'Bilder aus der deutschen Vergangenheit' also contains many interesting details; but above all I would recommend for the countries of the west and south of Germany the valuable researches of C. T. Perthes contained in his 'Politische Zustände und Personen 
higher scientific training of the whole of Europe $;^{1}$ but no serious effort was made, during the brilliant days of the First Empire, to secure for the nation the blessing of a popular education. This state of things continued under the Restoration; the real beginnings of an organised primary system are to be found in Guizot's celebrated law of 1833. In Germany the influence of Pestalozzi and Zschokke in the south ; of Basedow, Franke, and the school of Kant and Herder, and, later, of Herbart in the north,-stimulated many Governments to establish a system of popular schools for the education of the masses, and a system of seminaries for the training of a popular teaching staff. This movement was chiefly carried on independently of the reform of the universities and higher schools, over which the ideal of Wissenschaft exercised a powerful spell. Under the latter were trained the leaders and higher teachers of the nation, as well as the members of the learned professions. The educational influence of this ideal on the more gifted among the student class was the very highest and best; but it hardly

in Deutschland zur Zeit der französischen Herrschaft,' 2 vols., Gotha, 1862 and 1869. As unfortunately this work, with its collection of interesting and not easily accessible facts referring to the inner history of the German people, has no index, I give the following references: Compulsory education in Kur Trier in 1712, vol.i. p. 225 ; in Kurmainz, 1750 , vol. i. p. 19 ; popular education in Baden, vol. i. p. 411 ; in Bavaria, vol. i. pp. 436,467 ; in Wuirtemberg, vol. i. p. 537 ; and the chapter on Joseph II.'s school reform, vol. i. pp. 153-170. The seminary or training-school being thus the centre and beginning of national education in Germany, as it has also, with a different constitution, become the centre of scientific work (see p. 214, note), it is interesting to note that Scotland, so far advanced in educational work, had no real training-school for teachers before Stow started his Normal School in Glasgow (see "Chambers's Encyclopædia,' art. "Education"), and that the "seminary" for higher scientific work has to this day not yet been introduced into this country.

1 See above, p. 44, note.

VOL. I. 
reached the multitude of less gifted minds, who always gave themselves to bread-studies; and it must necessarily fail yet more when not only the future teachers and leaders, but the masses of the nation, flock into the halls of the universities. Imperceptibly a differentiation has taken place in Germany between the educational work which was meant to reach the people at large and the intellectual

29.

Union of education and instruc. tion. instruction of a select few. But it is exactly this differentiation of education and higher instruction which the champions of a liberal education in England have desired to avoid. I In France, very soon after Rousseau's time, dis-

1 The two developments in Germany start from different centres. The purely educational movement began in Switzerland with Pestalozzi (1746-1827). His forerunuer was Martin Planta (1727-1772), his successors were legion, all over Europe, including sovereigns, statesmen, and philosophers. He created an enthusiasm for education, which was to begin at home, not in the school ; to depend on the influence of the mother; to be founded on a religious spirit; to direct itself to the development of the body as much as of the mind ; to rest primarily on observation and experience, not mainly on memory and learning ; and then to absorb the whole mind and the entire man, not exclusively the intellect. It was to begin from below, not from above, with the people, the poor, the unfortunate and deserted; on the part of the teacher it was to be a sacrifice, an end in itself, not a profession. The greatest followers of Pestalozzi were Von Fellenberg (1771-1844), the founder of Hofwyl and other industrial schools for poor and deserted children among the peasant population of Switzerland; Johannes Falk (1760-1826), the founder of a great number of houses for the poor and the fallen, of the "Society of Friends in Need"; J. H. Wichern (1808-1881), the founder of the "Rauhe Haus" near Hamburg ; lastly, the celebrated Fröbel (1782-1852, a native of Thüringen), the founder of the Kindergarten. The other-not to say oppositedevelopment was centred in F. A. Wolf, in whose school the ideal of Wissenschaft with its enormous influence on universities and high schools was elaborated. In the history of this development, with which our second chapter dealt, the name of Pestalozzi does not occur. The term "popular" was for a time banished as identical with the Bavavoia of the ancient Greeks. The two movements find a connecting-link in the extra-academical, the classical literature of Germany, notably of Herder and Goethe, to whom we must add Fichte and Schleiermacher. The present age is working towards a fusion of both interests, of the educational and higher scientific, the bridging over of the gap which had been left; it is trying to remove the estrangement which existed in the middle of the century. 


\section{cussions on educational matters confine themselves to the ends and means of general or higher instruction; ${ }^{1}$ in}

We may say that no educational scheme can be permanently satisfactory that does not regard with equal favour, and does not find equal room for, the two ideals of Pestalozzi and Wolf. It is interesting, however, to note that neither in Switzerland nor in Scotland, the two countries in which popular education has been longest at home, do we find a really great development of the higher institutions and centres of learning; the universities in these two countries have always stood somewhat in the relation of higher schools to the rest of the educational establishments; but both countries have produced and reared some of the greatest geniuses of all time-geniuses who have given to German and English literature and science a fame over the whole world and for all ages; they would have sufficed, had they stayed at home, to form academies and universities of the first order.

${ }^{1}$ Compare chapter i. pp. 112,142 , \&c. We are indebted to France for three great educational influences which have left indelible traces over the whole domain of European thought. These proceed from the Paris University, the model of higher education ; the great school of Port Royal, that model of secondary education; and the 'Émile' of Rousseau, which gave to the educational aspirations of Basedow, of Kant, and of Pestalozzi a definite direction. It has, however, frequently been stated that the valuable side of Rousseau's ideas was developed outside of France. "C'est une chose remarquable," says M. Compayré, "que l'influence du philosophe de Genève se soit surtout exercée à l'étranger, en Allemagne et en Suisse" ('His- toire critique des Doctrines de l'Education en France,' 5me. ed., 1885, vol. ii. p. 101). "Il y avait, chez Rousseau," says M. Bréal, "un côté généreux et vivifiant: l'amourdel'humanitéet particulièrement de l'enfant, la confiance dans ses facultés et le respect de son activité intellectuelle. Cette partie lit, qui était le germe de vie déposé dans les ceuvres de Rousseau, nous l'avons laissée aux étrangers." In French writers a great deal of discussion is to be found on the difference between education and instruction. Duclos (1704-72) in his celebrated 'Considérations sur les mœurs de ce siècle' (1751), in the second chapter, which treats of Education and Prejudice, says: "On trouve parmi nous beaucoup d'instruction et peu d'éducation. On y forme des savants, des artistes de toute espèce; chaque partie des lettres, des sciences et des arts $y$ est cultivée avec succès, par des ınéthodes plus ou moins convenables. Mais on ne s'est pas encore avisé de former des hommes, c'est à dire, de les élever respectivement les uns pour les autres, de faire porter sur une base d'éducation générale toutes les instructions particulières," \&c. When the successive Governments of the Revolution took up the question of a national education, the formula of Condorcet quite inevitably became more and more the leading principle. Condorcet distinguished "instruction" -i.c., knowledge positive and certain, truths of fact and calculation -from "education "-i.e., "political and religious beliefs." He gives the State the power to extend the former, whilst he denies it the right to direct and dispense the latter (see Hippeau, 'L'Instruction publique en France pendant la Révolution,' 
Germany, education and higher instruction present independent developments; in England alone the genius and language of the nation have refused to admit of any curtailment of the original sense of the word. This continued to imply a discipline of the character as well as of the mind, practical as well as intellectual training. So much has been said in this country and abroad regarding the shortcomings of the English universities and higher schools, that I feel it a duty to point to the positive gain which this ideal of a liberal education ${ }^{1}$ has

1881, vol. i. p. xrii ; also Compayré, loc. cit., vol. ii. p. 280, \&c.) Every Government which has attempted to systematise, to centralise education, has been forced also to secularise it, to reduce it to instruction, leaving out what many consider the central problem of education, the training of the character and the discipline of the feelings and the heart. Considering the large organisations which have been developed in England by the unaided efforts of working men, such as the tradeunions and the co-opera tive societies, and looking at the amount of selfgovernment, self-control, and selfdenial which they demand from their members, one might be tempted to say that England is the best educated, though it may be the worst taught and the least informed, of the three nations now under review.

1 The term "liberal education" has acquired a peculiar significance in the history of English culture and thought. It cannot be translated into Frencl or German with any certainty that the real significance of the term and the subject which it denotes is conveyed. It is interesting to note how each of the three nations has given to special words of the once common Latin language a peculiar pregnancy, denoting a peculiar form of thought or culture which they have especially elaborated. Thus "science" in the modern sense is a product of French thought, Wissenschaft a product of German thought. England has reserved to itself the elaboration of a "liberal education." I am at a loss how to translate it into French, unless I am permitted to use simply the word education in its contrast to instruction and $e n$. seignement, not as this was defined by Condorcet, but as it is understood in the writings of modern French educationalists, such as Gréard, Bréal, Compayré, and others. To convey the meaning of "liberal education" to a Ger. man, I would revert to the Greek

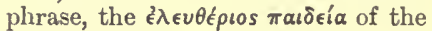
post-classical age. The fact is that down to the middle of the century the Germans in discussions on the work of universities and high schools always talk of Wissenschaft, English writers always talk of "liberal education." To a German scholar's heart Wissenschaft is dear beyond anything; to an English university man it is "liberal edu. cation." The former will sacrifice eversthing to Wissenschaft; the latter will not part with "liberal 


\section{been. For it is the principal object of this work to attempt to portray the actual progress of thought, the valuable contributions of each of the three nations to the}

education." In Germany, the real home of the educationalist or $\boldsymbol{E r}$ zicher has not been the university; the home of the man of science has not been and is not the university in England. The German educationalist can point to a special creation of his own, the Volksschule. The English man of science has no organisation to point to except it be the select society of a dozen great names of world-wide fame, corresponding to the solitary and unconnected heights of Homer, Sophocles, Dante, Shakespeare, and Goethe in literature. To descend, however, from generalities to the real thing, I give here some extracts referring to English university life, chosen from among hun. dreds, all variations on the same theme. Dr Thomas Young, who knew both German and English universities, having studicd at Göttingen and taken his degree at Cambridge, was not indebted to any university for his position or his knowledge ; yet he significantly defends the English universities against the criticism of the Edinburgh Reviewer: "We do not intend to imply a censure of the system adopted by our universities; . f for it must be remembered that the advancement of learning is by no means the principal object of an academical institution : the diffusion of a respectable share of instruction in literature and in the sciences among those classes which hold the highest situations and have the most extensive influence in the State is an object of more importance to the public than the discovery of new truths. . . We think that we have observed numerous instances, both in public life and in the pursuit of natural know. ledge, in which great scholars and great mathematicians have reasoned less soundly, although more ingeniously, than others, who, being somewhat more completely in the pos. session of common-sense, ... were still far inferior to them in the refinements of learning or of science" ('Quarterly Review,' May 1810, reprinted in Miscellaneous Works, vol. i. p. 235 , \&c.) I shall now give a quotation from an entirely different source, from one who in his department was equally well acquainted with German and English thought and life. In $1830 \mathrm{E}$. B. Pusey attempted to give his friend, Prof. Tholuck of Halle, a sketcli of what had been "recently done in English theology." He begins by referring to the "practical character of the nation " and " the different condition of the universities," and then continues as follows: "Few, if any, of our writings have originated in an abstract love of investigation: our greatest and some immortal works have arisen in some exigencies of the times. . . A German writes because he has something to say; an Englishman only because it is, or he thinks it is, needed" ("Life of Pusey,' vol. i. p. 238). The man who did most for the widening of the circle of university studies in England during the first half of the century was William Whewell (17941866), whose influence at Cambridge extended over more than a generation. In the beginning he assisted the movement begun by Babbage, Herschel, and Peacock, and published several text-books on mechanics and dynamics, in which the influence of Continental, especially 
general stock of ideal possessions, not merely to criticise the shortcomings and failures of separate schools of thought, or separate sources of mental development. Only in the aggregate of these different ideals is to be found the inventory of the intellectual possessions, the outcome of the higher work of the century.

30.

Educational organisations in England. When the modern scientific methods and their impelling force, the mathematical spirit, made their way from France to Germany during the first quarter of the century,

French models, can be clearly traced. Between 1830 and 1850 his influence exerted itself in two directions, firstly by the publication of his 'History of the Inductive Sciences' (3 vols., 1837 ; a second edition appeared in 1847 , a third in 1857 ), and, secondly, by a series of papers and pamphlets referring to unirersity education. As the ideal and definition of this Whewell adopts the term "liberal education." The first of these papers appeared in the "British Critic" (No. 17, 1831, "Science of the English Universities"). Then followed in 1836 "Thoughts on the Study of Mathematics"; "Additional Thoughts," 1836; "On the Principles of English University Education," 1837 ; "Of a Liberal Education in General " (Part 1, 1845 ; Part 2, 1850 ; Part 3, 1852). The second part of the little work on Liberal Education gires a history of the various changes previous to 1850 through which the University of Cambridge tried to meet the growing demands of the times for a wider and more liberal programme of higher scientific work. In these various writings the work of education and "original research" (a term introduced by Whewell-see Todhunter, 'Life of Dr Whewell,' vol. i. p. 50), the nature of "permanent" and "progressive" studies at the university, of "university" and
" college" education, of "tutorial" and "professorial" teaching, are fully discussed. In the course of thirty years the university of Cambridge added to the examinations for mathematical honours the "Classical" Tripos (1822), the "Moral Sciences" Tripos and the "Natural Sciences" Tripos (1848); also a "Board of Mathematical Studies" (1848). Dr Whewell's great influence declined when in 1850 Royal Commissions were appointed to "inquire into the state, discipline, studies, and revenues of the universities of $\mathrm{Ox}$ ford and Cambridge." $\mathrm{He}$ "regarded the Commission as an unwarranted and undesirable intrusion into the affairs of the university." The results of this inquiry belong to the second half of the century. Although this movement, which was brought about by many influences, lias somewhat changed the issues, the central idea which in England tries to assimilate the higher work and thought of the nation is that of education. The term liberal education, which for twenty years, from 1830 to 1850 , formed the banner of university reform, has since somewhat yielded to "scientific," and more recently to "technical," education; the influence of the universities has gone out in the work of university extension in the provincial towns; still 
they there met with a powerful intellectual organisation, the German university system, in which classical and philosophical studies had elaborated the ideal of Wissenschaft - of science in the larger sense of the word. Gradually, and not without opposition, the exact or mathematical spirit was received into this system, and has since become an integral portion of it. In England the older traditions which clung to the two great universities, and the higher

the whole movement can be defined as an educational movement. Whereas in Germany about a generation earlier the term Wissenschaft gained the upper hand and governed the intellectual life of the nation, purely educational movements being separated from it, in England the purely scientific interest has never gained the upper hand, and can still complain of having nowhere a full and complete representation. Around the writings of Whewell as a centre may be grouped those of A. Sedgwick ("A Discourse on the Studies of the University of Cambridge,' 1833, 5th ed., 1850); Sir Wm. Hamilton (articles in the 'Edinburgh Review,' reprinted in 'Discussions on Philosophy, \&c.,' 1853) ; Sir John Herschel ('A Preliminary Discourse on the Study of Natural Philosophy,' 1831); the criticisms of Lyell ("Travels in North America,' 1845), and of the 'Edinburgh,' 'British Quarterly,' and 'Westminster' Reviews ('Edin. Rev.', Ap. 1849, Jan. 1874, 'Brit. Quart.,' Nov. 1850, 'West. Rev.,' Jan. 1855). Whoever desires to gain an insight in to the different, frequently diametrically opposite, considerations which moulded and governed the reconstruction of the German university system on the one side, and on the other side widened in England the older ideas of university education, should com. pare the documents relating to the foundation of the University at Berlin in the beginning of this century (collected by Rudolf Köpke, 'Die Grïndung der Königlichen Friedrich - Wilhelms - Universitit zu Berlin,' Berlin, 1860) with the writings referred to in this note, and centering in Whewell's pamphlets and essays. The personification of the German scheme was IVilhelm von Humboldt, of whom Böckh said in his 'Logos epitaphios' : " $\mathrm{He}$ was a veritable statesman, penetrated and led by ideas-a statesman of a Periclean greatness of spirit. Philosophy and poetry, eloquence, historical, philological, linguistic erudition, were fused in him into undisturbed harmony and wonderful symmetry." The reforming and revolutionary ideas of Fichte, the classical ideals of Wolf, the historical interests of J. Miiller the historian, the literary interests of Schlegel, the philosophical interests of Schleiermacher, were combined by Humboldt into a realisable scheme. Stein said of him in 1810: "Prussia has intrusted the management of her educational and scientific in. stitutions to a man possessed of a remarkable intellect and of great firmness of character, and who utilises these qualities in his sphere of action with glorious loyalty" (ibid., pp. 61, 62). 
practical interests of a select class which upheld those traditions, prevented any of the Continental ideals, be it the philological of F. A. Wolf, or the philosophical of Fichte, or the scientific of Laplace and Cuvier, from establishing themselves in the older seats of learning. And they were, after all, the only organisations for higher culture which possessed a historical character and continuity. Around these centres, partly in a friendly, more. frequently in a hostile spirit, other institutions, other centres of culture and learning, had grown up. Let us rapidly survey these more recent institutions. It is hardly necessary again to mention the Royal Society, which was an early offspring of the older universities, a kind of overflow of the scientific interests from them into

31. the capital. More recent was the Royal Institution, the creation of that extraordinary man, Benjamin Thompson, Count Rumford. Like the Royal Society, it was dependent upon private subscriptions and on the popular interest created by its lectures. These were very promiscuous, exhibiting no plan or unity. In the early years Dr Young and Davy lectured there, as well as Coleridge and Sydney Smith. Later it became the home of Faraday, and through him, and many other illustrious lecturers, has done much to spread a taste for natural, especially experimental, science, in the higher and cultivated classes. It has been a means of diffusing the scientific taste, more perhaps than the exact scientific spirit, in the stricter sense of the word. Whilst its lectures may have kindled in many a young listener the love of scientific work, the Institution did not fulfil the early intention of its founder, nor did its laboratory play 
the part of some of the great laboratories of Paris or of Germany, in turning out a large number of well-trained experimentalists. Davy may be said to have educated Faraday, though he was suspected of having become jealous of him, and Faraday declared he received only one valuable suggestion from any member of his audience during the whole course of his lecturing. It is the strongly marked individuality of all these great men, expressed in their persons, their lives, and their works, rather than the character of the institution itself, which has given celebrity and historical importance to the Royal Institution. John Dalton's ${ }^{1}$ position in the Literary and Philosophical Society of Manchester was similar to that of Davy and Faraday in the Royal Institution; and as Literary and PhilosophiFaraday can in some sense be called a pupil of Davy, so can Prescott Joule 2 be termed a pupil of Dalton, whom cal Society.

1 See note, p. 245.

2 James Prescott Joule (1818. 89 ), a native of Salford, "received from Dalton his first inducement to undertake the work of an original scientific investigator." $\mathrm{He}$ was one of the first who tried to measure electrical action in terms of the units of well-known mechanical or chemical changes. His publications began in 1840 . Weber's 'Electrodynamische Maasbestimmungen,' that great monument of exact measurement, was published in 1846 . Mayer's first publication, containing a calculation of the mechanical equivalent of heat, bears the date 1842. But the great publication of Gauss, in which he measures magnetic action in ordinary mechanical (or absolute) units, dates from 1832 : 'Intensitas vis magneticæ terrestris ad mensuram absolutam revocata' (Comm. Societ., Götting., 1832, \&c.) Joule in 1843 published the first of his accurate determinations of what is termed in physical science " $J$ " or "Joule's equivalent of heat." He read successively papers on this subject before the meetings of the British Association, first at Cork (1843), giving the constant " $\mathrm{J}$ " as 838 , then as 770 , then as 890 in 1845 (Brit. Assoc. at Cambridge), lastly at Oxford (1847) as 781:5. From this meeting dates the acquaintance and scientific co-operation of Joule and Thomson (Lord Kelvin) and the gradual recognition of the importance of the subject by other men of science (see Thomson's address on Joule, 1893, in 'Popular Lectures and Addresses,' vol. ii. p. 558 sqq.) Helmholtz's memoir, "Ueber die Erhaltung der Kraft," which was tbeoretical-as Joule's were experimental-dates also from 1847. 
he succeeded as president of the Society. These names are identified with some of the greatest work in experimental science. Some of them may be said to be identified with quite original theoretical ideas which have governed the development of great departments of research ever since. Dalton's atomic theory in chemistry, however, received a tardy recognition in England, and was firmly established only by foreign research, while Faraday's "lines of force" remained a mystery to electricians, ${ }^{1}$ till William Thomson and Clerk Maxwell made them the groundwork of our most recent conceptions. It is well to note that neither Young, nor Davy, nor Faraday, nor Dalton, nor Joule belonged to the circle of Cambridge men, and that probably none of them received any inspiration from that official school of English mathematics. ${ }^{2}$ In the early years of the century that

1 See Helmholtz on Faraday's ideas in 'Vorträge und Reden,' vol. ii. p. 277. "Since the mathematical interpretation of Faraday's theorems has been given by Clerk Maxwell in methodically elaborated scientific formulæ, we see, indeed, how much definiteness of conception and accurate thought were contained in Faraday's words, which seemed to his contemporaries so indefinite and obscure. And it is indeed remarkable in the highest degree to observe how, by a kind of intuition, without using a single formula, he found out a number of comprehensive theorems, which can only be strictly proved by the highest powers of mathematical analysis. I would not depreciate Faraday's contemporaries because they did not recognise this; I know how often I found myself despairingly staring at his descriptions of lines of force, their number and tension, or looking for the meaning of sentences in which the galvanic current is defined as an axis of force, and similar things. A single remarkable discovery can indeed be brought about by a happy chance, . . . but it would be against all rules of probability that a numerous series of the most important discoveries, such as Faraday produced, could have had their origin in conceptions which did not really contain a correct, though perhaps deeply hidden, ground of truth."

2 Young resided at Cambridge to take his medical degree on his return from Göttingen; but though his biographer has inserted a chapter on Cambridge in the 'Life of Young, and though Young's first great discovery, that of the interferences of waves of sound and light, fell within that period, there is no eridence that his scientific studies were promoted by Cambridge influ- 
centre had, indeed, to receive aid from a still more secluded and unacademic quarter. Undergraduates of Cambridge used to migrate from the seat of teaching which has been immortalised by Newton to the remote Yorkshire village of Sedbergh, where John Dawson, ${ }^{1}$ one of the few British analysts who held their own against the great foreign authorities, taught the higher mathematics for five shillings a-week.

During the latter part of the eighteenth century a formidable rival to the learning of Oxford and Cambridge had sprung up in the Scotch universities. These were teaching centres, more after the manner of the foreign 34. The Scotch Universities. universities. They had been started on the model of the University of Paris or of the older Italian universities; some had their origin in the educational movement which, especially in those countries where the doctrines of Calvin prevailed, accompanied the Reformation. ${ }^{2}$ All through the

ences; in fact he makes a disparaging remark regarding British as compared with Continental mathematics. See Peacock's 'Life of Dr Young,' p. 127.

1 John Dawson (1734-1820), the son of a poor "statesman" of Gars. dale, tended his father's sheep till he was twenty. He studied mathematics with innate love and ability, inventing a system of conic sections out of his own brain. By teaching he gained a little money. In 1756 he instructed three young men-of whom Adam Sedgwick's father was one-before they went up for their Cambridge studies. He then became assistant to a surgeon at Lancaster. Haring sared $\$ 100$ lie walked to Edinburgh and studied medicine there. His funds spent he returned to Sedbergh, where he practised as a surgeon. When he had saved a larger sum he proceeded witl this to London. After taking his degree in 1767 , he settled in his native county to practise his profession and teach the higher mathematics to Cambridge undergraduates. They flocked to him in the summer, and between 1781 and 1794 he numbered eight senior wranglers among his pupils. In 1797 and subsequent years he counted four more. In 1812 he ceased teaching. He wrote papers on the "precession" and the lunar theory, and followed the development of higher mathematics on the Continent. See 'Life and Letters of Adam Sedgwick,' by J. W. Clark and T. M'K. Hughes, 1890, vol. i. p. 61 , \&c.

3 Details referring to the foundation of the Scotch universities are given by Sir $A$. Grant in the first rolume of his 'Story of the Univer.
33. John Daw. son of Sedbergh. versities. 
seventeenth and eighteenth centuries they stood in intimate relations with such Continental centres of study as Paris, Geneva, and the Dutch universities. Adam Smith and David Hume were in direct and very intimate intercourse with French thought, the former having obtained in France a knowledge of the novel views of the great political economists of the pre-revolutionary period. Edinburgh became in the first half of the last century, under the influence of John Monro and his son Alexander (16971767), who was a pupil of Boerhaave, a medical school of great importance, rivalling London in its foreign re-

sity of Edinburgh,' 2 vols., 1884. Three of them-St Andrews, Glas. gow, and Aberdeen-were founded in the century preceding the Reformation; St Andrews about 1411 by Bishop Wardlaw, because Scotch students had been unpopular and "molested" at Oxford. The University of Glasgow was founded in 1450, reference being made to the University of Bologna in the Bull of Pope Nicholas V.; but it has also been observed that "the customs and technical phraseology showed an imitation of the institutes of Louvain, then and for all the following century the model university of Northern Europe, of which a Scotchman, John Lichton, had been Rector" (p. 21). Aberdeen was started by Bishop Elphinstone, who had studied in Glasgow and Paris, and been professor, both there and at Orleans, of canon and civil law. In the preamble to the Bull of Pope Alexander VI. the Universities of Paris and Bologna are referred to (p. 29). But the universities seem not to have flourished previous to the Reformation, when they were "purged" and a new spirit and order infused in to them. St Andrews was to have four faculties, named as in foreign
universities-Philosophy, Medicine, Law, and Divinity (p. 63). Glasgow and Aberdeen were to have two faculties, of which the first was to be Philosophy (or Arts), the second to comprise Law and Divinity. The 'Book of Discipline' contained a very complete scheme of higher graded education; but this was only gradually and partially realised; secondary schools being wanting, the "colleges" had to descend to elementary teaching (p. 67). A jealousy also existed on the part of those in power regarding the older universities, these being-as the King of France declared when refusing to grant to the Academy of Geneva the rights of a university-hotbeds of heresy (p. 125). Accordingly the latest academic creation in Scotland was the foundation by the "Town Council and ministers of the city" of the College of Edinburgh (pp. $99,121,127$ ) between the years 1561 and 1578, King James's charter dating from 14th April 1582. "But it did not, like the older universities, commence with a blaze of success and then collapse. It started from a humble beginning and steadily expanded into greater things" (p. 158). 
putation. ${ }^{1}$ Edinburgh had also one of the earliest chairs of chemistry. It grew into an independent centre of original scientific work when in 1783 the Royal Society $\begin{gathered}\text { The Recty of } \\ \text { Eitlinburgh. }\end{gathered}$ of Edinburgh was incorporated. Ever since the foundation of the Scotch universities, mathematics had been studied independently in Scotland, where John Napier of Merchiston had at the end of the sixteenth century invented logarithms. "Whether we consider the great originality of the idea, the difficulty of carrying it into effect in the state in which algebraical analysis then was, or the immense practical and theoretical value of the invention, we shall have little difficulty in claiming for Napier the honour of a discovery unsurpassed in brilliancy in the whole history of mathematics." 2 From that time the

I "In 1738 the foundation-stone of that building which was till recently the Royal Infirmary of Edinburgh was laid, and a great public enthusiasm on the subject was manifested. Drummond, the greatest Edile that has ever governed the city of Edinburgh, and Monro, were appointed the Building Committee, and they paid the workmen with their own hands. All classes contributed: landowners gave stone; merchants gave timber; farmers lent their carts for carriage of materials; even the masons and other labourers gave one day's work out of the month gratis, as it was a building for the benefit of the poor" (Sir A. Grant, loc. cit., vol. i. p. 306).

$\because$ Quoted by Sir A. Grant (loc. cit., vol. ii. p. 293) from Chrystal's unpublished Inaugural Address, 'John Napier, Baron of Merchiston' (1550-1617). The 'Mirifici Logarithmorum Canonis Descriptio 'appeared 1614. The 'Logarithmorum Chilias prima' of Henry Briggs
(1556-1630), professor at Oxford, contains the first table of common or decimal logarithms. Kepler $(1571-1630)$ received the invention with great enthusiasm as of immense importance to astronomy. "The more one considers the condition of science at the time, and the state of the country in which the discovery touk place, the more wonderful does the invention of logarithms appear. . . . It is one of the surprises in the history of science that logarithms were invented as an arithmetical improvement years before their connection with exponents was known. It is to be noticed also that the invention was not the result of any happy accident. Everything tends to show that it was the result of many years of labour and thought undertaken with this special object; Napier succeeded in devising, by the help of arithmetic and geometry alone, the one great simplification of which they were susceptible - a simplification to 
science was cultivated at the different Scotch universities, which supplied Oxford with a Professor of Astronomy (preferred to Halley), in the person of David Gregory. "David Gregory not only introduced the 'Principia' to Edinburgh students, but he also brought them to the notice of Englishmen." 1 The Philosophical (afterwards called the Royal) Society of Edinburgh was much indebted to Colin Maclaurin, ${ }^{2}$ who almost alone with Landen and Ivory maintained the reputation of British mathematicians during seventy years, whilst the Continental school was revolutionising that science. A successor to Maclaurin in the mathematical chair at Edinburgh, John Playfair,, introduced the Continental methods into the studies of the Scotch universities about the end of the 3i. last century. He was one of the early contributors to the 'Edinburgh Review,' which in politics, literature, and science inaugurated a new kind of criticism, and led a powerful attack upon all those traditional forms of government, taste, and learning which prevented the free expansion of ideas and the progress of science and practical interests. Though not always judiciously used, the

which the following two hundred and eighty years have added no. thing "(Glaisher in 'Ency. Brit.,' 9 th ed., article "Napier").

1 David Gregory (1661-1708) has "the honour of having been the first to give public lectures on the Newtonian philosophy. This he did in Edinburgh five-and-thirty years before these doctrines were accepted as part of the public instruction in the university of their inventor" (Sir A. Grant and Chrystal, loc. cit., vol. ii. p. 296). Cambridge writers, headed by Whewell, are loath to admit any reluctance on the part of their university in accepting the Newtonian philosoplyy, in spite of Whiston's testimony to the contrary. See on this Whewell's 'History of the Inductive Sciences,' $3 d$ ed., vol. ii. p. 149, \&c.

2 Colin Maclaurin (1698-1746) published, 1742, a 'Treatise on Fluxions,' 2 vols. 4to. In 1740 he shared with Daniel Bernoulli and Euler the prize of the French Academy for his 'Essay on the Tides.'

3 John Playfair (1748-1819) was Professor of Mathematics and then (from 1805) of Natural Philosophy. 
influence of that review must have been very powerful in rousing the older English universities out of a state of stagnation, and especially in stimulating younger minds in the direction of the long-delayed reform of studies. An important step in this direction was taken by three undergraduates of Cambridge-Herschel, Babbage, and The AnalyPeacock-who in 1812 formed the Analytical Society, tical Society of Camwith the distinct object of introducing the more modern and powerful analytical methods developed mainly by Euler and Lagrange, and deposited in their numerous Memoirs in the publications of the foreign academies. ${ }^{1}$ In harmony with them worked Whewell, Airy, and Sedgwick, who did much to enlarge the programme of mathematical and scientific studies, though they very staunchly upheld that the real object of university education could not be identified with any special method or school of thought, but was expressed in the specific ideal peculiar to England, that of a liberal education. $^{2}$

The universities of Scotland, unlike those of England, instead of nursing an exclusive spirit, and encouraging University only scanty intercourse between teachers and students of different centres, lived in constant exchange of professors and ideas-much in the same way as has always been the custom on a larger scale among German and other Continental universities. Though this is destructive of that individual character of the university or the college which

1 See note 1 to p. 233 ; also for many details Rouse Ball's ' History of the Study of Mathematics at Cambridge,' 1889 , p. 120 , \&c.

2 On Whewell and his writings on university education see note to p. 261. Sir George Biddell Airy (1801-1891) published in 1826, 'Mathematical Tracts' (2d ed., 1831 ) on the lunar and planetary theories, \&c., for the use of students in the university. 
is so highly prized by many English fellows, it is certainly more conducive to the progress of studies and of research, and it is the cause why in the early history of recent science the universities of Scotland have played so much more important a part than those of England. Whilst in England modern science was cultivated outside the pale of the universities by Priestley, Davy, Wollaston, Young, Dalton, Faraday, and Joule, to whom we may even add Green and Boole, all eminent Scotch men of science, such as Gregory, Simson, Maclaurin, Playfair, Black, Thomson, Leslie, Brewster, and Forbes, were university professors, many of whom did not confine their labours to one centre, but spread the light of their ideas and researches all over the country. ${ }^{1}$ Whilst England has been great in single names, Scotland has certainly in proportion done more

1 Napier of Merchiston remained outside the pale of the universities. At that time the College of Edinburgh had no mathematical professor ; but Glasgow had, and so had Aberdeen. James Gregory was educated at Aberdeen, was then professor at St Andrews, and subsequently at Edinburgh. Colin Maclaurin was educated at Glasgow, then professor at Aberdeen and at Edinburgh. Playfair was educated at St Andrews, and lectured there before coming to Edinburgh. Leslie was trained at St Andrews, and was then professor first of mathematics and afterwards of natural philosophy at Edinburgh. Black was educated at Glasgow and Edinburgh, and was professor at both universities. Brewster studied at Edinburgh, and was subsequently principal of $\mathrm{St}$ Andrews and then of Edinburgh. Forbes, as student and professor, belongs exclusively to Edinburgh, and so did in earlier times Robert Sim. son, the great mathematical professor. Adam Smith belongs exclu. sively to Glasgow, though he had lectured in Edinburgh before he was appointed professor at Glasgow. But the contrast between England and Scotland becomes still more prominent if we look at the medical sciences and note the great array of celebrated professors at Edinburgh, Cullen, Brown, Gregory, Alison, Hamilton, Syme, Simpson, Christison, and Charles Bell, whereas the equally great names of John and William Hunter, of Jenner, of Astley Cooper and Bright, have no connection with the English universities; Sydenham was only slightly connected with Oxford and Cam. bridge, and even Harvey never occupied a prominent position at Oxford. Through situation or constitution the English universities were unable to open a field of activity for these celebrated men. 
to diffuse modern scientific knowledge. The great publishing firms of Edinburgh have also for more than a century done much through Cyclopædias, Reviews, and Magazines to spread general information of all kinds $;^{1}$ whilst Hume, Adam Smith, and the subsequent Scotch school of metaphysicians have exerted their influence during the whole of this century; not only in Great Britain, but over the whole of Europe. ${ }^{2}$ In the more circumscribed domain of scientific thought a powerful influence has again been exerted from Scotland as a centre, and through the larger instrumentality of the University of Cambridge, on the study of mathematical and experimental physics, and what we may term the spirit and method of these sciences. This influence be-

1 The most popular Cyclopædia, that of Chambers, had its origin in Edinburgh in 1860. It was founded on the tenth edition of Brockhaus's 'Conversations-Lexicon.' The more important 'Encyclopædia Britannica' was published there also in 1771,3 vols. ; $2 d$ ed., 1777 . The 'Edinburgh Review' was established in 1802 by Jeffrey, Scott, Horner, Brougham, and Sydney Smith; it was the first successful "Quarterly," carried on independently of the booksellers, after several unsuccessful attempts had been made in a similar direction by Adam Smith and Hugh Blair in 1755, and after Gilbert Stuart and William Smellie had issued from 1773 to 1775 the 'Edinburgh Magazine and Review.' No such periodical ever attained to the circulation of the 'Edinburgh Review,' of which at one time 20,000 copies were sold. The first high - class monthly Magazine was also printed in Edinburgh by Blackwood in 1817, with Scott, Lockhart, Hogg,
Maginn, Syme, and John Wilson as contributors. 'Tait's Edinburgh Magazine' was the first shilling magazine. The brothers William and Robert Chambers, in 1832, started the Journal named after them. They also brought out many popular works of sterling merit, mostly written by Robert Chambers, than whom none did more to introduce a knowledge of nature into popular reading, and to give a healthy tone and moral influence to the cheap literature which has become such an important factor in modern culture.

2 Whilst Locke exercised the greatest influence on French philosophy, Kant starts more directly from Hume. The literature of the Restoration in France again attaches itself to the Scotch metaphysicians, notably Reid. It is interesting that both Kant and the greatest representative of the French "Ideology," De Tracy, were of Scotch descent. 
longs to the second half of the century, and is centred in the two names of William Thomson (Lord Kelvin) and James Clerk Maxwell, who may be said to have jointly revolutionised natural philosophy. It began with the appearance of George Stokes's and William Thomson's important contributions to mathematical physics, and with the publication of that suggestive and stimulating-but unfortunately unfinished-work by Thomson and Tait on Natural Philosophy. It was represented to the fullest extent in Clerk Maxwell's activity in the Cavendish Laboratory at Cambridge. But the consideration of this subject belongs to a later chapter of the present work, and is only mentioned here in connection with the intellectual intercourse and exchange which has existed all through this century between the invigorating spirit of the north and the more conservative spirit of the southern

39.

The Dublin Mathemati. cal School. portion of the island. Besides Scotland another centre - the Dublin School-has gained European renown through a series of mathematical labours of the highest importance, some of them of an originality hardly yet sufficiently recognised. This school is represented by the names of Rowan Hamilton, ${ }^{1}$ MacCullagh, Sal-

1 Of Rowan Hamilton's dynamical "principle of varying action" I have spoken in a note to p. 231. William Rowan Hamilton (1805-65) cannot with the same certainty as Kant and De Tracy be claimed as of Scotch descent. Indeed he seems to belong distinctly to Ireland. See Tait's article in the 'North British Review,' September 1866, and Perceval Graves's reply in 'Life of W. R. Hamilton' (3 vols., $1882-89$, vol. i. p. 5). He was one of the few quite original mathe- maticians who, like Gauss, led the way into new channels of thought and succeeded in breaking through the traditional forms of this science, which more than any other is hampered in its development by transmitted customs and habits of representation. Thus, after ten years of research and thought in connection with the representation of extend. ed algebraical forms by means of the different directions in space, he succeeded in establishing the fundamental principle of his theory of 
mon; ${ }^{1}$ nor should we forget the suggestive writings of George Boole. ${ }^{2}$ The influence of these men originated outside of Cambridge, and a history of mathematics at that university does not contain their names, ${ }^{3}$ though the ideas of which they have been the bearers have largely entered into the text-books and the teaching of the Cambridge school.

So far I have mainly dealt with one side only on which the progress of science depends, namely, the methodical use of experiment, measurement, and calculation: this

quaternions - complex quantities which are compounded of a purely algebraical or quantitative element and three distinct elements corresponding to the three directions or dimcnsions of space. He was the first to work out this calculus, and the labour occupied twenty years of his life. In Hamilton's calculus of quaternions, distance (or length) and direction are introduced as they naturally present themselves when we deal with geometrical or physical problems, instead of all quantities being reduced to lengths, as was the case in the Cartesian geometry. Hamilton thus broke through the conventionalism of the latter and showed how the consideration of directions in space forces us to extend the original operations of arithmetic. It is interesting to note how simultaneously Grassmann (see p. 243, note 1) in his 'Ausdehnungslehre' (1844) and Von Staudt in his 'Geometrie der Lage ' (1847), quite independently worked at similar extensions of our arithmetical and geometrical conceptions, and how subsequently quaternions, in which Hamilton had seen a powerful method for solving geometrical and physical problems, present themselves as a special form of the extended algebra and geometry elabor- ated from these different beginnings. Whilst the practical usefulness of the calculus has been demonstrated by some extensive, applications, as, for example, to spherical trigonometry, the ideas contained in itfrequently without Hamilton's notation-are gradually finding their way into text-books, and the strangeness which for half a century prevented the labours of Hamilton, Grassmann, and Von Staudt from being generally appreciated, is disappearing. A popular exposition of the relation of quaternions to general arithmetic is given in 0 . Stolz, 'Grössen und Zahlen,' Leipzig, Teubner, 1891.

1 The excellent treatises of Salmon on 'Higher Algebra/' Higher Plane Curves,' 'Geometry of Three Dimensions,' and 'Conic Sections' have in their German translations by Fiedler done a great work in systematising and popularising modern conceptions in algebra and geometry. See Gino Loria's treatise on the "Principal Theories of Geometry" in the German translation by Schütte, Leipzig, 1888 , p. 25 , \&ic.

2 See p. 247, note 2 .

${ }^{3}$ See Rouse Ball, 'A History of the Study of Mathematics at Cambridge,' 1889. 
side had been very largely developed by the great French naturalists and mathematicians in the beginning of our period. The change in the higher branches of science which took place during the first half of the century is greatly owing to them, and to the later German school, 40. 5 which was much influenced by them. If we compare Importanc contribu. tions to science. the contributions of British science in these branches they are indeed inferior in bulk, and still more so in methodical arrangement; but among them is a small number of works of the first order which are embodiments of scientific ideas of the very highest importance. Introduced into the great edifice of scientific research which was being planned and erected on the Continent, they mark the very corner-stones of the building, standing out in bold and conspicuous prominence. But it is a fact that no Academy existed in this country which was zealous in collecting and arranging all the best labours of scattered philosophers, no university which was anxious to attract and train promising intellects, no comprehensive text-books and hand-books, ensuring right guidance, correctness of knowledge, and completeness of study, no historical and philosophical traditions guaranteeing that novel contributions should make their appearance under favourable conditions, or supplying the most appropriate mise en scene for new ideas.

41.

Diffusion of scientific knowledge on the Continent.
- It is the French Institute, in the earlier years of the century, and the German university system, with its many local ramifications and literary organs, during the whole of the century, which have done the great work of systematising and diffusing scientific knowledge, and of introducing the exact spirit of research. There is 
something casual and accidental about the great ideas which British men of science contributed during the first half of the century. Each of them chooses an isolated

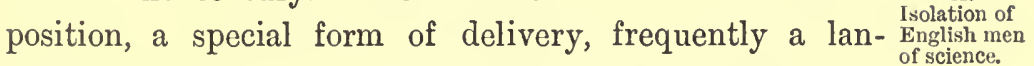
guage and style of his own. They attach little or no importance to the labours of others, with which they are frequently unacquainted. ${ }^{1}$ Important papers are lost or buried, as in the case of Cavendish and Green. Novel ideas are communicated in unintelligible language and symbols, and accordingly neglected. This was the case with Dr Young's writings, and to a certain extent with Faraday's. The greatest discoveries were unduly postponed through the absence of assistance, as seems to have been the case with Adams's discovery of Neptune, ${ }^{2}$ perhaps with Stokes's anticipation of spectrum analysis. ${ }^{3}$

1 This is correct of most of the great men referred to in the course of this chapter. Among them, how. ever, Rowan Hamilton forms an exception. Though working on quite original lines, he took a great interest in the labours and suggestions contained in the writings of lis forerunners and contemporaries, as the historical notices in the preface to his 'Lectures on Quaternions' (1853) prove; likewise his correspondence with De Morgan (see 'Life of Sir W. R. H.,' vol. iii.)

2 The story of the discovery of Neptune has been frequently told. The first publication of the elements of the suspected planet, which enabled a search to be made, came from Leverrier to the Paris Academy of Sciences on the 1st July and the 31st August 1846. In consequence of this publication, Galle at Berlin, requested by Leverrier to search in the neiglibourhood of $\delta$ Capricorni, and comparing lis observations made on the same night on which he received the request, $23 \mathrm{~d}$ September 1846 , with Bremiker's map, actually found the planet. Subsequently it became known that Adams of Cambridge had already communicated his elements in September and October 1845 to Challis and Airy, and that the former had actually seen the planet on the 4 tll and 12th of August 1846, but-for want of equally detailed maps - had not compared the observation and established the discovery. See Whewell's 'History of the Inductive Sciences,' third ed., 1857, vol. ii. p. 460, \&c.; also Wolf, 'Geschichte der Astronomie,' p. 537, \&c.

3 It appears from a communication of Sir William Thomson (Lord Kelvin) to Kirchhoff immediately after the latter had published in 1859 his explanation of the identity of the dark lines in the solar spectrum with the bright lines in the spectra of coloured flames, that Stokes, soon after the publication 
What might not these great minds have accomplished had they attached the same importance to style and form as most of the great French men of science, or had they been called upon to teach a number of eager pupils, anxious, not to take honours and degrees, but to understand and further elaborate the suggestions of their master, as has been the custom and tradition in Germany? The history of English science during the first half of the century consists of a series of biographies, or of monographs on single ideas and points of view. We are struck by the individual greatness of the minds which produced them, their originality or the suddenness of their appearance. - An éloge by the permanent secretary of the Academy has usually been considered sufficient to satisfy the historian of science in France; the life of every great philosopher in Germany is identical with the history of a phase of thought or with a school of research; in England alone the person of the thinker has nearly always claimed the

by Miller in 1845 and by Foucault in 1849 of observations relating to this subject, had suggested in the course of conversation that there is a correspondence between emission and absorption of the same kind of light by the vibrating molecules of the same body, according as it is used as a source or a screen for light. Had this idea of Stokes's, which suggested the presence of sodium in the atmosplere of the sun, been followed out at the time, the discovery of spectrum analysis would have taken place ten years earlier. Actually, the various publications, beginning with Fraunhofer's description of the dark lines in the solar spectrum in 1814 and proceeding through the observations of Herschel, Talbot, Drum. mond, Miller, Angström, Plücker, Swan, and Balfour Stewart on the absorption and radiation of heat, found their consummation when Bunsen and Kirchhoff settled the main point in question-viz., "that the bright lines of an incandescent gaseous body depend on the chemical constituents of the same." Then at length spectrum analysis became possible. See on this matter Kirchhoff's own historical résumé of the year 1862, reprinted in 'Gesammelte Abhandlungen' (Leipzig, 1882), p. 625, \&c.; also Sir William Thomson's 'Baltimore Lectures,' shorthand notes, 1884, p. 100, and Stokes's translation of Kirchhoff"s first paper in 1860 ('Philos. Magazine,' March 1860). 
greater share of popular attention. ${ }^{1}$ His mental labours have preserved an individual character, shutting them out during his life from common contact, and limiting their fertilising power, like that of an oasis in the desert, to a narrow circle of casual visitors. Minds like Newton and Faraday, full of new life, but modestly content with deepening and strengthening their secluded vigour, refrained from boastful publicity or ostentatious parade, working for all ages rather than for a special school or a passing generation. It is the individualism of the English character, the self-reliant strength of natural genius, which 43. Individualcomes out most strongly in its great examples of scientific character. work. In characters of smaller breadth, in intellects of lesser power, these tendencies show themselves in ways which we cannot always admire or commend: in the emulation for place and position, in the competing for

1 This explains the remarkable richness of English literature in biographies, containing copious collections of correspondence, and the almost total absence of such literature in France, which, on the other side, is rich in memoirs, written by statesmen and authors themselves. As the students of nature have usually little time for autobiography, we possess of the long list of great names in modern French science hardly any personal records such as are so plentiful in English literature. What we miss in many of these elaborate and frequently gossiping narratives is a just appreciation of the position of the subject of the biography in the history of science, literature, and thought, a definition of the exact place and importance which belongs to him and his work. This is what is given in such a masterly and condensed form in the better éloges of
Fontenelle, of Cuvier, of Arago, and other secretaries of the French Academies. In Germany biographical literature is less developed than in this country, and memoirs are almost absent-those of Varnhagen von Ense and of Perthes, among literary men, being remarkable and rare exceptions. Similarly the great correspondence carried on by Goethe through nearly sixty years is a unique monument of his genius and his influence, comparable only to that of Voltaire during the last century. R. Haym in his biographies of Hegel, Wm. von Humboldt, and Herder, which combine the biographical with the historical and critical elements, has done a great work, and these books are invaluable contributions to the history of thought. Justi's 'Winckelmann' is of equal importance ; but Dilthey's 'Schleiermacher' is unfortunately unfinished. 
honours and championships-in all the noble and ignoble forms of racing, where much energy, which might more usefully have been merged in co-operative action, is sacrificed for the sake of individual distinction. But where the height of genius forbids emulation, where the towering intellect has distanced all records, this individualism has produced single specimens of the greatest work, examples of the highest moral worth. It is not in the courses of scientific work alone that we shall have occasion to mark the peculiarity of British, especially of English, thought; but it is interesting to note how even in this sphere, which more than any other seems to bear an international and cosmopolitan character, the genius of the nation strongly asserts itself, baffling every effort to control it or to lead it into more conventional chan44. nels. The last fifty years have done much to destroy the peculiarly national customs, the idiosyncrasies of the different peoples. English institutions have been copied in France, and German customs introduced into England; it has recently been stated that the older type of scientific amateur which existed in this country is dying out, being rendered impossible by the more complicated machinery of science, the manifold conditions on which progress depends. It seems to me doubtful whether this view is correct. Surely the advance of the highest kind of thought will always depend upon the unfettered development of the individual mind, regardless of established habits, of existing forms of expression, or of adopted systems; just as the diffusion and wholesale application of single discoveries will depend on a ready and efficient machinery and organisation; whilst their influence on gen- 
eral thought and literature will depend on the cultivation of a perfect form, of an expressive and elegant style. The French alone in the beginning of the century could boast of the last; the Germans have most successfully developed the second; whilst England, the country of greatest individual freedom, has been the land most favourable to the growth of genius as well as eccentricity, and has thus produced a disproportionate number of new ideas and departures. Nor is it to be desired that the reliance of genius on itself should be in any way curtailed, as it is impossible to foretell whence the new light will come which is to illuminate future ages. This individualism of the English mind presents other accompanying features, and these are of great interest to the historian of thought. They manifest themselves in the province of science as much as in other provinces. We will now study them more closely; in the sequel we shall meet with them in other departments also.

Hitherto our observations on English science have nearly all referred to only one side of modern scientific work,the side on which lie the experimental, measuring, and calculating sciences; those sciences which abroad are termed "exact"; in which mathemathical notions and methods, be it of measurement or of calculation, obtain. But these sciences cover only one side of reality. We noticed how in France, during the great scientific epoch, the other side of nature, that which exhibited and was filled by the phenomena of life, was simultaneously explored with equal originality and equal success. As Laplace was the great representative of the one, so Cuvier was the great representative of the other. We have also seen how in 
Germany this latter department of research was specially cultivated, how all the mathematical, experimental, and philosophical sciences combined to organise the one great 45. science of physiology or biology, with its central and British con. tributions to crowning problem-the problem of consciousness. We also noted how this science worked a great reform in the whole domain of medical theory and practice. Let us now return to the question, What has Great Britain done during the first half of this century in this great department of scientific thought? Single great names, like those of Harvey, ${ }^{1}$ marked in former centuries discoveries in the natural sciences equal to those of Newton in the mathematical; the name of Ray ${ }^{2}$ is still preserved in the

1 William Harvey (1578-1657), a native of Kent, received his medical education in Italy, especially in Padua, under Fabricius of Acquapendente. The discovery of the circulation of the blood belongs to the year 1616 , and is almost contemporary with Napier's invention of logarithms. This discovery is contained in the manuscript of Harvey's lectures preserved in the British Museum, but the publication did not take place till 1628 ('Exercitatio anatomica de motu corporis et sanguinis in animalibus,' published at Frankfort). Although Harvey was drawn into long controversies by his publication of this work, he had the satisfaction of seeing his discovery generally recognised. Descartes abroad took Harvey's part in his letter to Beverwijck in 1637, and in his 'Discours de la Méthode,' published in the same year; and it is noteworthy that - as has been the case with many subsequent English discoveries-the first great acknowledgment came from the Continent, notably Holland. The acceptance in France by the faculties of Paris and
Montpellier was less rapid, and in England it is well known that Lord Bacon took no notice either of Harvey's discovery or of Napier's invention. See James Spedding's preface to the "De interpretatione Nature Procemium" in works of Lord Bacon, vol. iii. p. 507, \&c.; also Harvey's own opinion on Bacon, ibid., p. 515. Hobbes, on the other hand, "was eager to accept Harvey's revolutionary discovery " (Croom Robertson, 'Hobbes,' p. 123), and refers to Harvey in the dedication of the 'De Corpore' (1655) as "the only man I know that, conquering envy, hath established a new doctrine in his lifetime" (ibid., p. 187 n.) On Harvey's other works, notably on the work 'De Generatione,' see, inter' alia, Huxley, 'Science and Culture,' 1888, p. 333, \&c.

2 John Ray, or Rajus, as he is called abroad (1628-1705), a native of Essex, was a Cambridge man; he, however, gave up his fellowship in 1662, feeling himself unable to subscribe to the Act of Uniformity of 1661 . He was one of the first great classifiers of plants; he col- 


\section{Society called after him: in more recent times Hutton formed a school in geology which was opposed to that of Werner, emanating from Germany. ${ }^{1}$ Hunter, the anato-}

lected a vast amount of information, beginning with the neighbourhood of Cambridge and extending it in travels over Great Britain and the Continent with Willoughby. The 'Historia Plantarum'-describing 18,625 species of plants-appeared from 1685 to 1704 in 3 vols. The first volume contains a chapter on the anatomy and physiology of plants, which was much extolled by Cuvier and recommended for republication. The "Ray Society," started in 1844 "for the publication of works on Natural History," brought out among many other excellent and celebrated works (such as Darwin's 'Monograph of the Family Cirripedia'), ITemorials (1844) and Correspondence (1848) of John Ray : it also translated that eccentric specimen of the "Naturphilosophie" Oken's 'Elements of Physio-philosophy,' 1847. A contemporary of John Ray was Nehemiah Grew (1628-1711), one of the first to make extensive use of the microscope (invented in Holland between 1590 and 1600) for the examination of the anatomy and physiology of plants. After Oldenburg he was Secretary of the Royal Society together with Hooke. The Society printed his 'Anatomy of Plants.' About the same time it seems to have exhausted its funds in printing Willoughby's 'Historia Piscium,' so that it was unable to carry out its design of defraying the cost of printing the 'Principia.' This was generously done by Halley. See Weld, 'History of the Royal Society,' vol. i. p. $309, \& c$.

1 Beneath the strife of the Wer. nerians and Huttonians, or the Neptunists and Plutonists as they were termed, the real merits of Robert Jameson (1774-1854) and James Hutton (1726-97) have sometimes been overlooked. Both were ardent naturalists who spent their lives in observation and study of nature. They made Edinburgh for some time the centre of geology in this country. Jameson was fifty years Professor of Natural History, founded the first school of Natural History in this country (see Cossar Ewart's address, quoted by Sir A. Grant, 'Story of the University of Edinburgh,' vol. ii. p. 444), trained a number of eminent naturalists, among whom are Edward Forbes and Grant (N.B.-The name of Darwin must be added with caution, see his 'Autobiography,' vol. i. p. 44, \&c.), founded the Edinburgh Museum of Natural History, which includes the Huttonian collections, and founded the Wernerian and Plinian Societies of Natural History. James Hutton, though not a teacher like Jameson, exerted a great influence through John Playfair, who popularised his views in his "Illustrations of the Huttonian Theory of the Earth' (1802). It is termed by Geikie a "classical contribution to geological literature." Though the opposition of Hutton's theoretical views to those of Werner gave him a great reputation as a theorist, it is claimed for him that he first among geologists disclaimed the intention of investigating the origin of things, and thus put an end to the cosmogonies of the eighteenth century. Such had been promulgated in all the three countries by the most illustrious philosophers and natural. ists, by Burnet, Buffon, and Leibniz. On Hutton's great merits see es. pecially Huxley, "Essay on Geolo- 
mist, acquired a world-wide reputation in the latter part of the eighteenth century.

Many other students of nature could be added to this list. Perhaps none has acquired greater popular celebrity

46. than Jenner. ${ }^{1}$ This he acquired through his extraordinary Jenner. discovery, by which he grappled successfully with one of the most prevalent and distressing epidemics from which 47. former generations had to suffer. The study of animated English love of nature. nature, the observation of the sky and the heavens, have always been favourite occupations of Englishmen. The love of travels abroad and of the country at home has favoured a close intercourse with nature. A fickle and humid climate invited the superior skill of the agriculturist and the gardener, and rewarded them with heavier crops and more luxuriant verdure. ${ }^{2}$ The chill of the long winter

gical Reform" (1869. Reprinted in 'Lay Sermons and Addresses,' No. 11). $\mathrm{He}$ is there considered as the first representative of "Uniformitarianism" against the older "Catastroplism." Uniformitarianism has been followed by "Evolu. tionism."

1 Edward Jemuer (1749.1823), one of the greatest benefactors of mankind, spent twenty years on the farms of Gloucestershire, following the advice of his friend and master John Hunter, "Don't think, but try," before he undertook the first inoculation of cowpox on the 14th of May 1796. About the end of the century the process of raccination, which dispelled the older process of inoculation-introduced into England by Lady Mary W. Montagu in 1721 - had become generally known in Europe. The governments of the Revolution in France and the Academy of Sciences had at the end of the century occupied themselves a good deal with the cure of smallpox, both Voltaire and d'Alembert having taken great interest in the subject.

2 The yield of an acre in wheat is in England about 30 bushels or one ton of grain; next comes Belgium, then Germany, then France : the average yield in the United States of America is barely one-half of that in England. The yield of an acre in Scotland exceeds slightly that in England. In Scotland farming is carried on with much skill and enterprise, and, in spite of the severe climate, gardening is probably further developed there than in any other country. It appears that the first voluntary organisation for the improvement of agriculture was the "Society of Improvers in the Knowledge of Agriculture in Scotland" formed in 1723, of which the Earl of Stair was one of the leaders. Though it counted 300 members, it was shortlived: its 'Select Transactions' were published by Maxwell in 1743 . 
stimulated active exercise and outdoor sport; the abundant rains, which fed the many rivulets with a constant supply of fresh water, suggested the cultivation of that pastime of which Isaac Walton had left a classical description, long before Rousseau in France made the love of nature a fashionable sentiment. Lord Bacon pointed to the study of natural phenomena as the only source of knowledge. Evelyn wrote a treatise on forest-trees, and the old-fashioned English flower-garden is immortalised in Bacon's 'Essays,' in the "Winter's Tale," in Cowper's "Task," and in the works of many other poets. Through the literature of the eighteenth century there runs a vein of increasing love and knowledge of natural objects and natural scenery, beginning in Thomson and Gray, widening and deepening in Erasmus Darwin and Cowper, and attaining full vigour and originality in Burns and Wordsworth, as also in the school of English landscape-painting. William and Caroline Herschel com-

Next came the Bath and West of England Society, 1777; the Highland Society, 1784; and the National Board of Agriculture, 1793. The 'Farmer's Magazine' was started in 1800. About the same time that Lawes and Gilbert in England and Liebig in Germany gave such an impetus to scientific farming through their experiments and publications, "Mr John Finnie at Swanston, near Edinburgh, having suggested (1842) to some of his neighbours the desirableness of obtaining the aid of chemistry to guide farmers in many departments of their business, the hint was promptly acted upon, and these Mid-Lothian tenant-farmers had the merit of originating an Agricultural Chemistry Association (the first of its kind), by which funds were raised, and an eminent chemist engaged" ('Ency. Brit.,' article "Agriculture," vol. i. p. 305). There is probably no country where farming is such a favourite pursuit of gentlemen of leisure and wealth as Great Britain, or where the intelligence of higher society and of the universities is so liberally transferred to the benefit of the country, of its population, its crops and its livestock. Among many examples of the past and present I mention as an outcome of this spirit the little volume by Sir Thomas Dyke Acland, 'On the Chemistry of Farming' (London: Simpkin \& Co., $1891)$, and his liberal patronage of agriculture in the west of England. 
menced the long line of amateur star-gazers of this country; Luke Howard's study of clouds drew from the kindred spirit which lived in the great Goethe a loving memorial; ${ }^{1}$ and John Dalton was induced by the mists and fogs of his native lake country to join in the foundation of the modern science of meteorology.

48.

Union of individualism and naturalism in England.

We now discover the reason why the strong individualism of the English character, which prompted new departures and inspired new ideas in science, as it produced adventures and novel enterprise in life and arts, has not more frequently led to discouraging failures in the latter, or to eccentricity and dreaminess in the former; why it has, on the whole, alike in practical work and in scientific study, been rewarded by signal success. The rare genius, gifted with the power of original thought, who found no academy ready to call him, no schools where he could be trained, no university eager to nurse and develop his

1 Luke Howard (1772.1864), a member of the Society of Friends, was one of the many lovers of nature and amateur naturalists of this country in whom new scienceslike that of meteorology-are nursed during their unpretentious infancy. He himself gave a simple narrative of his life and doings to the great Goethe, who, attracted by his attempted classification of clouds (about 1802, published in his 'Climate of London'), had addressed some lines to him, accompanying them by a statement in verse of Howard's description of the stratus, cumulus, cirrus, and nimbus :-

\footnotetext{
"Er aber, Howard, giebt mit reinem Sinn

Uns neuer Lehre herrlichsten Gewinn:

Was sich nicht halten, nicht erreichen lässt,

Er fasst es an, er hält zuerst es fest;
}

Bestimmt das Unbestimmte, schränkt es eill,

Benennt es treffend !-Sey die Ehre Dein ! Wie Streife steigt, sich ballt, zerflattert, fällt,

Erinnre dankbar Deiner sich die Welt."

Goethe subsequently tried to get some information about Howard's way of life, "so that I might see how such a mind is formed, what opportunities, what circumstances, have led him into ways of looking at Nature naturally, have taught him how to devote himself to her, so as to find her laws and to prescribe these again to her in a natural human manner.' In his autobiographical narrative (reprinted in the last volume of Goethe's Works) Howard refers to the meteoric phenomena of 1783 , mentioned also in Cow. per's Letters (13th June 1788), and White's 'History of Selborne.' 
talent, did not retire into the depths of his own consciousness, or surround himself with the artificial atmosphere of erudition. The result of such a process can be abundantly traced in other countries and other literatures. In England the isolation from society and the solitariness of genius threw him into the arms of Nature, and she has in many instances, in science, in poetry, and in art, rewarded and refreshed him by a novel inspiration-she has lifted her veil to his loving eye and revealed to him one of her secrets. The individualism of English science has been tempered by its naturalism. A type of this peculiar form of the naturalist was Gilbert White, the natural historian of Selborne. ${ }^{1}$

${ }^{1}$ A long list might be given of these retired nature-loving souls, among whom Charles Darwin will always rank as the greatest and most conspicuous. I give here a few names in addition to those mentioned in the text.

John Gough of Kendal (1757. 1825) might, according to John Dalton (see !his Life by Henry, pp. 9 and 10), "be deemed a prodigy in scientific attainments. . . . Deprived of sight in infancy by the smallpox, . . . possessing great powers of mind, he bent them chiefly to the study of the physical and mechanical sciences. It was he who first set the example of keeping a meteorological journal at Kendal; .. he knew by the touch, taste, aud smell almost every plant within twenty miles; he could reason with astonishing perspicuity on the construction of the eye, the nature of light and colours, and of optic glasses," \&c., Sc. For about eight years Dalton and he were intimately acquainted.
George Edwards (1694-17\%3) of ${ }^{\circ}$ Stratford, Essex, was the author of the 'History of Birds,' which he published between 1743 and 1764 in six volumes. He had journeyed through France and other countries, and yave engravings of six hundred subjects not before delineated by naturalists.

Still more remarkable was Thomas Edward (1814-86), the shoemaker of Banff, who, having been turned out of three schools for his zoolo. gical propensities, without friends, without a single book on natural history, not knowing the names of the creatures he found, gained a knowledge unique in its freshness and accuracy. At the University of Aberdeen, where he exhibited his collections, he was told by the professors that he came "several certuries too soon," as they had then no chair of Natural History. His life has been written by Smiles, 1876.

Edward Forbes (1815 - 54) of Douglas, Isle of Man, a born lover 
Not long after Ray and Linnæus had attempted the artificial and logical classification of living beings, and about the same time that Buffon in France infused into the literature of his country a somewhat pretentious love of

49.

White of Selborne.

nature, Gilbert White, in a simpler and more healthy style, betook himself to describe the aspect that nature presented when viewed from the quiet home of an English country parson. He may be said to have represented that other

of nature, "led an unusually full life, occupied in promoting science and arousing enthusiasm and awakening intelligence in others. To almost every department of biology he rendered much service, especially by connecting various branches together and illustrating one by the other. Though his published works have been few, his ideas have been as the grain of mustard-seed in the parable" ("Dictionary of National Biography'). After holding various badly paid offices in London and elsewhere, he succeeded Robert Jameson as Professor of Natural History at Edinburgh (see 'Memoir of E. Forbes,' by G. Wilson and A. Geikie, 1861).

Hugh Miller (1802-56), the selftaught stonemason of Cromarty, combined the soul of an artist with that of a naturalist. His writings occupy a place by themselves in English literature. "The principal scene of his own investigations was the Cromarty district, where he ransacked every wrinkle of the hillside, and traced every stratum sawn through by the watercourse, and where on the beach at ebh, in indurated clay of bluish tint and great tenacity, belonging to the old Red Sandstone formation, he discovered and dug out nodules which, when laid open by a skilful blow of the hammer, displayed organisms that had never been seen by the human eye." In September 1840 there appeared in the 'Witness' a series of articles entitled "The Old Red Sandstone." They formed the nucleus of a book of this title which established the reputation of Miller as an original geologist, as a practical thinker and fascinating writer. 'My Schools and Schoolmasters' is a masterpiece of English language. "In an age prodigal of genius, yet abounding also in extravagance, glare, and bombast, the self-educated stonemason wrote with the calmness and moderation of Addison." "The fossil remains seem in his glowing pages to live and flourish, to fly, swim, or gambol, or to shoot up in regetative profusion and splendour, as in the primal dawn of creation " (Carruthers, quoted by Peter Bayne in "The I,ife and Letters of Hugh Miller,' 2 vols., 1871.)

David Robertson, the naturalist of Cumbrae in the Firth of Clyde (born in 1806), was a farm-labourer till he was twenty-four, then took to the study of medicine, and had afterwards for many years a china and hardware shop in Jail Square, Glasgow. He gained sufficient independence to be able to retire in 1860 to Great Cumbrae, where he devoted the rest of his life to a study of nature. Especially in "the marine section, by his own unaided efforts, he opened up in a remarkable degree the zoology of the Firth of Clyde. 
side of natural science, which does not try to comprehend nature through the artificial arrangement or classification of a museum, but in those connections, among her own animate and inanimate objects, which constitute reality, and are the characteristics of life and development. It was the real, not the artificial, Jardin des Plantes, where he and his successors tried to study natural objects and the habits of living beings. ${ }^{1}$ Another re-

Many animals, till tlien accounted rare, are now known to exist as common objects, while the annals of science have received many important additions of animals altogether new to natural history records - discoveries which have caused the Firth of Clyde, and more particularly the Cumbrae Islands, to become one of the best explored and most widely known districts of Britain" (Gray, Secretary of the Glasgow Natural History Society, quoted by Thomas R. R. Stebbing in his 'Naturalist of Cumbrae,' London, 1891.)

William Pearson (1767-1847) of Borderside, Crosthwaite, near Kendal, was a self-educated yeoman, who after many years spent in a bank at Manchester retired to a small patrimonial estate on the southern border of Westmorland. He possessed a choice collection of books, representing fully the English poets of all ages, and in translation the best German authors. "Of the habits of birds and other native creatures around him he was a watchful observer, and he described them in purest English with a charm that suggested no disadvantageous comparison with White of Selborne" (see Groves, "Life of Hamilton,' rol. iii. p. 15). He was a friend of Wordsworth.

To this list, which could be indefinitely extended, I might add another, beginning with Thomas

VOL. I.
Bewick (1753-1828), the reviver of wood-engraving in England, who lent his art and life to the delineation of nature. 'British Birds' (1797-1804) is a standard work on the borderland of art and science, in which many other British artists have, in humbler or more extensive fields, laboured with so much faithfulness and success.

1 The 'Complete Angler' and the 'Natural History of Selborne' are types of a class of literature peculiar to this country. In these classical productions we are introduced into the nursery of English thought, poetry-nay, of science itself. These, as the nation draws ultimately its wealth from the produce and culture of the land, on their part receive valuable ideas from a study of nature. The purity and originality of English art and poetry have their home in the same region. Gilbert White (1720-93) was born and lived in the little Hampshire village of Selborne. He was one of five brothers, all of whom, in various positions and vocations of life, followed the study of nature in its minute and local aspects, combining with it an antiquarian taste. He may not only be classed with the naturalists, but belongs also to that class of writers, peculiar also to England, who devote their time to the compilation of local records, of county histories, and to the preservation of the relics and memorials 
action against the theorising methods which had come over from the Continent led to the formation of the Geological Society in the year 1807. At that time the war of the Wernerians and Huttonians, or, as they were also called, the Neptunists and Plutonists, was rag50. ing in the northern metropolis. The Geological Society cal Society. of London was established with a view to "multiply and record observations, and patiently to await the result at some future period-that is, its founders resolved to apply themselves to descriptive geology, thinking the time not come for that theoretical geology which had then long fired the controversial ardour of Neptunists and Plutonists." 1 Fifty years after the formation of this society

of country life in bygone centuries. The series of letters written between the years 1765 and 1787 containing "the observations of forty years," and published, 1789, with the title 'The Natural History and Antiquities of Selborne,' had the object "of laying before the public his idea of parochial history, which, he thinks, ought to consist of natural productions and occurrences as well as antiquities." To him "nature is so full that that district produces the greatest variety which is the most examined." $\mathrm{He}$ early insists on the necessity of monographs in natural history; suggests the usefulness of a "full history of noxious insects"; gives in a series of letters a faithful and minute description of the swallow tribe as they are found in his country; traverses the Downs of Surrey with a loving eye a hundred years before they became celebrated through the greater Darwin; makes valuable observations about "earthworms," suggesting a monograph on them; suggests, in an age which was governed by the systematising mania, that "the botanist should study plants philosophically, should investigate the laws of vegetation, should promote their cultivation, and graft the gardener, the planter, and the husbandman on the phytologist," as "system should be subservient to, not the main object of, pursuit."

I "The one point the catastrophists and the uniformitarians agreed upon when this society was founded was to ignore it [viz., geological speculation]. And you will find, if you look back into our records, that our revered fathers in geology plumed themselves a good deal upon the practical sense and wisdom of this proceeding. As a temporary measure I do not presume to challenge its wisdom; but in all organised bodies temporary changes are apt to produce permanent effects; and as time has slipped by, altering all the conditions which may have made such mortification of the scientific flesh desirable, I think the effect of the stream of cold water which has steadily flowed over geological specu. 
the author from whom I quote, Dr Whewell, in the third edition of his 'History of the Inductive Sciences,' could still say that "their task was not yet finished, their mission not yet accomplished-that they had still much to do in the way of collecting facts; and in entering upon the exact estimation of causes, they have only just thrown open the door of a vast labyrinth which it may employ many generations to traverse, but which they must needs explore before they can penetrate to the Oracular Chamber of Truth." 1 One of the many individuals in this country who "had long pursued his own thoughts without aid and Smith. without sympathy" 2 was William Smith. "No literary

Iation within these walls has been of doubtful beneficence" (Huxley on "Geological Reform," Address to the Geological Society, 1869; reprinted in 'Lay Sermons,' \&c., 1891, p. 207.)

1 See Whewell, 'History of the Inductive Sciences,' 3 d ed., vol. iii. pp. 428, 518. Lyell, 'Principles of Geology,' $3 d$ ed., vol. i. p. 102, \&c.

2 Whewell, loc. cit., vol. iii. p. 427. William Smith (1769-1839), a native of Oxfordshire, has been called the Father of English Geology. He was-like so many other naturalists of this country - an amateur in his scientific studies, which were conducted on the occasions of his elaborate surveys of Oxfordshire, Warwickshire, and Somersetshire in connection with the engineering of several canals. He initiated in England the science called on the Continent "Stratigraphy," observed the successive layers in the geological structure of the country, and in 1799 prepared a tabular view of the order of the strata and their organic remains in the neighbourhood of Bath. For many years after this he was occupied in preparing his Geological Map of England and Wales, which appeared on the five miles to the inch scale in 1815 in fifteen sheets. He was popularly known as "Stratum Smith," but remained almost unknown abroad, as he himself also seems to have taken little notice of Continental geology or prevailing theories. Though he began earlier than $\mathrm{Cu}$ vier and Brongniart, they anticipated him by publishing in 1811 their mineralogical description of the Paris Basin, thus becoming the founders of the science of palæontology (see Peschel, 'Geschichte der Erdkunde,' Miinchen, 1877, p. 714 , \&c.) Of the Geological Map Lyell says ('Principles of Geology,' vol. i. p. 101) that it "remains a lasting monument of original talent and extraordinary perseverance; for he had explored the whole country on foot without the guidance of previous observers or the aid of fellow-labourers, and had succeeded in throwing into natural divisions the whole complicated series of British rocks." 
cultivation of his youth awoke in him the speculative love of symmetry and system; but a singular clearness and precision of the classifying power, which he possessed as a native talent, was exercised and developed by exactly those geological facts among which his philosophical task lay. Some of the advances which he made had been entered upon by others who preceded him; but of all this he was ignorant, and perhaps went on more steadily and eagerly to work out his own ideas from the persuasion that they were entirely his own." In what he did and published, beginning with the year 1790, "we see great vividness of thought and activity of mind unfolding itself exactly in proportion to the facts with which it had to deal." 1

About the same time that geological studies received a great impetus in this country from two distinct centresthe philosophical teaching in the Scotch metropolis, and the more empirical labours of the Geological Society-a signal discovery in another line marked a great step in 52. anatomy and physiology. This was Charles Bell's disCharles Bell. covery, in the year 1807, of the difference between sensory and motor nerves, "doubtless the most important accession to physiological knowledge since the time of Harvey." 2

1 Whewell, loc. cit., p. 423.

2 This statement, taken from Dr Henry's 'Report of the British Association,' vol. vi., and repeated by Whewell (loc. cit., vol. iii. p. 352), probably requires a correction, since Du Bois-Reymond and others have placed in their true historical position the great merits of Descartes, who by the discovery of the principle of "reflex action" "did for the physiology of motion and sensation that which Harvey had done for the circulation of the blood, and opened up that road to the mechanical theory of these processes which has been followed by all his successors" (Huxley in his address to the British Association at Belfast, 1874 ; reprinted in 'Science and Culture, \&c.,' p. 200, \&c.) The first enunciation of the principle of reflex action had been variously ascribed to Joh. Miuller, Prochaska, Willis, till Du Bois-Reymond in his most interesting 'Gedächtnissrede 


\section{Bell's career was a unique one. He had early severed} his connection with the great medical schools of Edinburgh, where his brother taught. He lectured and practised privately in London, where he gained a considerable reputation; but in his case also it was on the Continent that his greatness was more generally recognised. As in Dalton's case, his countrymen were slow to do him justice. ${ }^{1}$ In France he had so great a name that a celebrated

auf Joh. Müller' (Berlin Acad., 1859) showed how the merit of enunciating it is due to Descartes, whose tract on 'Les Passions de l'Âme' was published in 1649 . Both Du Bois-Reymond and Huxley give full extracts from the writings of Descartes. There seems, however, to be some doubt to what extent Descartes substantiated his mechanical view of the action of the nervous system by actual experiments. Richet in his 'Physiologie des Muscles et des Nerfs' (Paris, 1882, p. 505, \&c.) refers to this, and while giving Descartes his due, also says that practically from the time of Galen to Charles Bell no marked progress had been made in the knowledge of the nervous system, and that this belongs almost entirely to the nineteenth century (pp.502, 507, 514). Fiuxley, who takes a much higher view of the merits of Descartes, says he was not unly a speculator, but also an observer and dissector (loc. cit., p. 201), and actually places him at the head of modern physiology (p. 334, \&c.)

1 Charles Bell (1774-1842) was born at Edinburgh. His elder brother, John Bell (1763-1820), who was a lecturer of great repute in the extra-mural School of Surgery at Edinburgh, first drew his attention to the medical profession. It was only late in life, and after he had gained his European renown, that he was appointed to the Chair of Surgery at the University of Edinburgh, which had been created in 1831, and it does not appear that he was at all sufficiently appreciated in this position : he used to say, "I seem to walk in a city of tombs," being unknown in the city of his birth (see Sir A. Grant, 'University of Edinburgh,' vol. ii. p. 453). Whilst Charles Bell established the difference of sensory and motor nerves, and dispelled "the confusion which prevailed up to that time in the minds of anatomists and physiologists regarding the functions of the various nerves," the merit of proving by strict experiment the correctness of Bell's theorem belongs to Johannes Müller (1831), who showed it in the frog, and to Magendie and Longet, who succeeded in exhibiting it in warmblooded animals. Up to the date of Muiller's experimental proof nobody regarded "Bell's doctrine as more than an ingenious and indeed plausible, but nevertheless not sufficiently demonstrated, idea " (see Du Bois-Reymond, 'Reden,' vol. ii. p. 176 , \&c.; also Henle's description of the demonstration given by Muiller in Paris on the 13th September 1831 to Humboldt, Dutrochet, Valenciennes, and Laurillart, in 'Jacob Henle,' by Merkel, 1891, p. 83). 
anatomical professor, when Bell visited his lecture-room, dismissed his class with the words, "C'est assez, messieurs, vous avez vu Charles Bell."

In Germany one of the great achievements of Johannes Müller, through which he acquired European celebrity, was his actual experimental proof of Bell's thesis, with which he had occupied himself for many years.

Instances might be indefinitely multiplied, showing the individual greatness, but also the isolation, of English men of science and their discoveries; how the latter emanated so frequently from the depths of original genius in intimate communion with nature; how they as frequently lacked those social advantages, that organisation for development, which the great schools and establishments of the Continent all through the century have possessed in so eminent a degree. Not only in the study of nature has this individual character of British research shown itself, though it is here most conspicuous. In the exploration of foreign lands and the monuments of bygone civilisations-in the historical branches of research, we meet with similar pioneer work. Who does not recall the names of Dr Young and of Layard? I will mention only one instance of this kind, where individual ability joined to fortuitous circumstances laid the foundation of a new branch of research on the borderland of natural and political history, the geography of ancient and modern Greece-the exploration of the land which produced the most remarkable, and perhaps the most intense, culture which the world has yet seen. Note what Ernst Curtius ${ }^{1}$

1 See his essay in the 'Preussische $\mid$ Wetteifer der Nationen in der Jahrbücher,' vol. 38, on M. W. Wiederentdeckung der Länder des Leake, and his discourse, "Der Alterthums" (1880), both reprint- 
says, - the man to whom we are most indebted for the systematic historical and artistic study of this remarkable country; whose mind has better than any other succeeded in representing to itself the natural and ideal features of that country and that bygone race, and who has drawn in his writings a series of pictures, reproducing that past glory in unequalled perfection. In tracing the beginnings of the modern science of archæology or historical geography, he assigns to England and Englishmen a foremost place as pioneers. "In England there was no mediæval tradition which suggested expeditions to the East, nor did there exist any external occasion or public interest, but it was a free and purely human attraction which led Britons to the classical soil, and private means have made all the sacrifices that were required in order to satisfy a craving of the soul. ${ }^{1}$. . . England became the

ed in that valuable collection, 'Alterthum und Gegenwart,' 3 vols., Berlin, 1882 and 1889 . In the rediscovery of the countries of ancient civilisation, Italians made the beginning with Cyriacus of Ancona (from 1412 to 1442). Then follow the French-Jacob Spon of Lyons, a German by birth, being among the earliest (1675). The generation that succeeded the age of Scaliger produced the first maps of Greece (Paulmier). Then follows England, where the name of Arundel has acquired a doubtful celebrity through that wholesale acquisition of ancient relics which Mr (afterwards Sir William) Petty and John Evelyn carried on in his name in Greece and Asia Minor. It is interesting to note here the position that Germany holds in the growing science of archeology, of which Winckelmann may be considered the founder. "The Germans possessed no adrantages and resources by which they could take part in the contest of nations over the rediscovery of the countries of ancient history. . . . Whilst in Italy it was national feeling, in France political relations with the East, in England the love of collecting and travelling common among the aristocracy, which established the connection of the Old World with the New, in Germany it was the workroom of the professor" (Curtius, loc. cit., vol. ii. p. 229).

${ }^{1}$ E. Curtius, loc. cit., vol. ii.p. 226. "In the year 1742 Stuart and Revett wandered among the ruins of Rome, and recognised that in its relics they beheld only later and degenerate forms of ancient art. Six years later they set sail for Greece. It was, after Cyriacus of Ancona and Jacob Spon of Lyons, the third journey of exploration; but it was the first in scientific importance" (p. 227). 
treasury of the wonders of the East, and whilst the Continent was closed to her, her travellers flocked to Hellas, registering with marvellous patience, watch in hand, on the back of the slowly marching mule, piece by piece, the remains of antiquity. . . The political mission, headed by Martin William Leake, was as such quite unsuccessful; for science, it was of priceless value: from the moment that Leake trod on classic soil the reminiscences of Homer and Herodotus were kindled, and he saw clearly his lifework before him. Under the powerful impressions produced by the great table-land of Asia Minor with the solitary snow-peak Argaios, deeply moved by the deserted places, marching over Grecian inscriptions, over sarcophagi and temple ruins, he felt the irresistible charm of the attempt to explore and to understand these homes of ancient culture. ${ }^{1}$... The scientific result was a lasting gain for the civilised world, and the travels which he made from 1805 to 1807 mark an epoch in our knowledge of Grecian antiquity." 2

But the labours of the pioneer in science, life, or art, which form so conspicuous an element of this country's mental work during the first two-thirds of the century, must be supplemented and carried further by a great army of patient and trained explorers. Original ideas must be cast into an appropriate and elegant form; new discoveries must be extended and criticised by strict methods of research; erudition and philosophy are required to guarantee completeness and depth. In the large domain of the historical sciences these labours of

1 E. Curtius, loc, cit., p. $30 \%$.

2 Ibid., p. 312. 
the school and the study are even more important than in the exploration of nature, and thus it is not surprising that in these especially the bulk of the work, though frequently begun by Englishmen, has been carried on by the great schools and academies of the Continent. In the regions of exact science, with which we are at present more immediately concerned, there will always be a much greater inducement for original minds to forsake the beaten track, the recognised method or system.

The genius gifted with a larger field of vision and a keener glance will always feel the longing to return to Nature herself, and the practical man will be allured by the prospects of application of science in the arts and industries. Both will find their reward; nor is it likely that the works of Faraday and Darwin should be the last illustrious examples of great and far-reaching ideas sprung from the living intercourse of original genius and nature without the support of any school; or that the practical success of the Atlantic cable will be the last fruit of the rare combination of highest mathematical genius with industrial and commercial enterprise. The historian of thought is forced to admit that such rare combinations are most likely to spring up amongst a people who have always opposed the rule of systems and methods, of schools and academies; who have nursed and cherished an intimate communion with nature; and for whom practical interests and adventures have always preserved an irresistible attraction.

Living in an age when the foundation in England and in Germany of institutions similar to the Académie Fran- 
çaise has been seriously discussed, ${ }^{1}$ when the British Association has been copied abroad, ${ }^{2}$ and when scientific men of eminence are joined in conference as to the advisability of founding a professorial university in London, in imitation of the great University of Berlin, it seems appropriate to recall the various ways and means by which, mainly in this century, the exact spirit of research, the mathematical method of investigating nature and reality, has been established and diffused.

55.

Work of the three nations compared.

France was the country in which the modern scientific inethods of measurement, calculation, and classification were first practised on a large scale, reduced to a system, and employed for the investigation of the whole of nature. The Academy of Sciences, together with the High Schools of Science, the Natural History collections, and Medical Institutions, all in close connection, furnished an organisation of the highest intelligences of the nation, by which

1 See Matthew Arnold's essay on 'The Literary Influence of Academies,' and Du Bois-Reymond, 'Ueber eine Kaiserliche Akademie der deutschen Sprache,' 1874, reprinted in 'Reden, \&c.,' Leipzig, 1886 , vol. i. p. 141, \&c. On the other side see Huxley in 'Critiques and Addresses,' ed. of 1890, p. 113, \&c.

2 The British Association, itself established somewhat on the model of the German "NaturforscherVersammlung," founded by Oken and Humboldt (see supra, p. 238) in the year 1831, has become the model of the younger 'Association française pour l'Avancement des Sciences,' founded in 1872 under the presidency of Claude Bernard. It held its first public meeting at Bordeaux in 1874 . In the opening addresses of the president, M. de Quatrefages, and the secretary, M. Cornu, the elder sister in England is referred to. A characteristic passage in M. Quatrefages' address as regards the results achieved by the British Association is the following: "Grâce à elle une partie de la population a été transformée. Les fils de ces chasseurs de renards, qui, pour se délasser de leurs rudes passetemps, ne connaissaient que des joies également violentes et matérielles, sont aujourd'hui des botanistes, des géologues, des pliysiciens, des archéologues" ('Comptes Rendus,' Ière session, p. 40). Following the resolutions carried in 1885 , the French Association amalgamated in 1886 with the older "Association scientifique de France," founded by Leverrier in 1864 . See 'Compte Rendu de la 16me Ses. sion,' vol. i. p. 1, \&c. 
a systematic exploration of the heavens and the earth, the inanimate and the living world, could be undertaken. At the same time, the methods of measurement and calculation were submitted to closer study; new sciences were created by the application of these methods; and problems were attacked for the first time, with which, at the end of the century, the scientific world is still occupied. It was in France also that the discoveries of the laboratory were first applied so as to contribute to the revolution of arts and industries. In all its different expressions-in the production of works of classical perfection in substance and in form, in its application to the problems of life and society, and in its influence on general literature-we find the scientific spirit, as we know it, fully established in France in the beginning of the century. About three decades later we find this spirit domiciled in Germany, the study of the exact sciences having been gradually accepted at the German universities as an integral part of the university cycle. It there met the philosophical and classical spirit, which had organised the German university system and the teaching of the higher schools, and had revolutionised historical, especially philological, studies. What might have been wanting at times in French science, historical completeness and philosophical criticism, was added in Germany. Germany has in the course of this century not only become the country where the most faithful and exhaustive record is kept of the scientific labours of the whole world, but it has also become the country where mainly those problems have been attacked which lie on the borderland of natural science and philosophy, the problems of 
life and consciousness. Modern physiology, especially psychophysics, is claimed as essentially a German science.

Meanwhile England, where the introduction of the scientific spirit as an established canon of systematic and methodical research was later than in other countries, has all through this century, as before, continued to do pioneer work in many isolated branches of science: individual, as opposed to corporate effort, has here been rewarded by a succession of brilliant discoveries, which have revolutionised practical life or opened out new views into the hidden recesses of nature. For the want of organisations of research and teaching, such as other countries possessed, these ideas of English thinkers have frequently lain dormant or been elaborated by foreign talent; but this want of a recognised system, and of a standard course of study, has forced original minds into a closer communion with nature and with life, whence they have frequently returned to the laboratory with quite novel revelations. The largest number of works perfect in form and substance, classical for all time, belongs probably to France; the greatest bulk of scientific work probably to Germany; but of the new ideas which during this century have fructified science, the larger share belongs probably to England. Such seems to be the impartial verdict of history. During the second half of the century a process of equalisation has gone on which has taken away something of the characteristic peculiarities of earlier times. The great problems of science and life are now everywhere attacked by similar methods. Scientific teaching proceeds on similar lines, and ideas and discoveries are cosmopolitan property. So much more 
interesting must it be for those who have been born members of this international republic of learning to trace the way in which this confederation has grown up, what have been the different national contributions to its formation, and how the spirit of exact science, once domiciled only in Paris, has gradually spread into all countries, and leavened the thought and literature of the world. 


\section{CHAPTER IV.}

THE ASTRONOMICAL VIEW OF NATURE.

1. The scientifie spirit in the first and second half of the century.
So far I have only treated of the scientific spirit, or of the method of exact research, in a general way; showing how it was firmly established and developed in France, how it spread into Germany, and received there larger and more systematic application, and how in this country it gradually and almost imperceptibly grew out of the older experimental philosophy. This growth, as we have seen, took place partly under the influence of foreign science, but still more through the individual and unaided labours of a small number of native intellects of the very highest order, to each of whom was for a time allotted the enunciation of some specially fruitful idea. The period referred to in this survey was mainly the first half of our century; in it were most clearly marked the characteristic differences between the three great civilisations of France, Germany, and England. A step further in time would lead into the midst of our own periodinto the age which has largely reaped the benefits of those earlier labours, both in theory and in practice, fully realising in many directions the predictions and even the ideals 
of the pioneers of science. One of these benefits, and perhaps that which to an external beholder marks the greatest difference between the first and the second half of the century, is the greatly increased intercourse which now exists as compared with the earlier years of our century. This intercourse has reacted on the domain of thought, and produced that exchange of ideas which promotes more rapid progress. It hardly belongs to the national. history of thought to analyse ${ }^{1}$ the different steps by which the great change has been brought about. Still, a very superficial glance will suffice to show how the work of bringing about an international exchange of ideas has been very characteristically divided among the three nations in which we are specially interested. It was not in the interest of thought, of science, or of literature, but rather in that of commerce and of industry, that the modern facilities of intercourse and exchange were invented and introduced. ${ }^{2}$ We shall therefore expect to

1 The principal dates of the introduction of steam - engines and telegraphs for facilitating communication are as follows:-

1802. The tug Charlotte Dundas, built by Symington, was tried on the Forth and Clyde Canal.

1812. Henry Bell built the Comet with side paddle-wheels. It ran on the Clyde as a passenger steamer.

1829. George Stephenson's Rocket was tried on the Stockton and Darlington Railroad, which had been begun in 1821. In the year 1829 the Liverpool and Manchester Railway was inaugurated.

1838. The first steamboats, Sirius and Great Western, crossed the Atlantic.

1833. A comprehensive system of railways was planned by the French and Belgian Governments.
1835. The first German railway was opened between Nürenberg and Fürth. The first electric telegraphs for public use were almost simultaneously constructed in England, Germany, and the United Statesthe first successful line being prob. ably that constructed by Wheatstone and Cooke between 1836 and 1840. The first Atlantic cable was begun in 1857, and after repeated failures, which were in the main corrected by the scientific investigations of William Thomson (Lord Kelvin), telegraphic communication with America was permanently established in 1866.

2 This remark applies fully to the railway system, but scarcely to the development of the electric telegraph, which was first actually used for scientific purposes by Gauss and 


\section{find them originate mainly in that country in which} those larger spheres of practical work had grown unchecked and flourished-in Great Britain and its extensive dependencies. To Germany, on the other side, with its fully developed system of learning, we are indebted mainly for the complete recording, registering, and analysing of the scientific labours of the whole world. To France

Weber at Göttingen in the year 1833. The documents referring to this interesting application have recently been published in $H$. Weber's biographical notice of Wilhelm Weber, Breslau, 1893, p. 25, \&c. We read there that soon after 1830 Gauss had been occupied with reducing his magnetical measurements to an absolute scale, having laid his celebrated paper, "Intensitas vis magneticæ ad mensuram absolutam revocata," before the Göttingen Society in December of 1832. He had induced Weber to take up similar investigations at the Physical Institute, which was situated about a mile distant from Gauss's Observatory. This distance was found to be an inconvenience, and in order to overcome it, the first longer telegraphic line in which galvanic currents were used, and which had two wires, was carried overhead between the two buildings, and the instruments and signalling arrangements perfected in the years 1833 to 1836. Both Gauss and Weber were well aware of the importance of their invention for practical purposes. The former wrote to Olbers on the 20th November 1833: "I do not know whether I have already written to you regarding a magnificent arrangement which we have made here. It is a galvanic chain between the Observatory and the Physical Institute, carried by wires in the air over the houses, up the Johannis tower and down again. The whole length will be about
8000 feet. . . I hare devised a simple arrangement by which I can instantly reverse the direction of the current, which I call a commutator. . . We have already used this contrivance for telegraphic experiments, which succeed very well with whole words and short sentences. . . . I am convinced that by using sufficiently strong wires one might telegraph instantaneously in this manner from Göttingen to Hanover or from Hanover to Bremen" (see Schering's address on the occasion of Gauss's centenary, Göttingen, 1877, p. 15, \&c.) To Schumacher, 6th August 1835, Gauss wrote as follows: "With a budget of 150 thalers [£22, 10s.] annually for Observatury and Magnetic Institute together, really extensive trials cannot of course be made. But could thousands of thalers be bestowed thereon, I think that, for instance, electromagnetic telegraphy might be carried to a perfection and to dimensions at which imagination almost starts back." Gauss estimates that fifteen millions sterling of copper wire would suffice to reach the antipodes, and he says significantly, "I do not think it impossible to invent a mechanism by which a despatch could be played off almost as mechanically as a musical-box plays off a tune when it is once fixed on a roller" (see "Briefwechsel zwischen Gauss und Schumacher,' ed. Peters, vol. ii. p. $411, \& c$. 
we owe the first beginnings of a general and international system of units and measurements, which, like the common Latin tongue in former centuries, or like the universal languages of algebra or of music, enables us to express the results of scientific research in formulæ intelligible everywhere and at all times, without laborious translations and time-absorbing reductions.

The effect of these international labours has been to destroy the clearly marked differences of national thought. Disappearance of national At least in the domain of science the peculiarities of the differences. French, the German, and the English schools are rapidly disappearing. The characteristics of national thought still exist; but in order to find them in the present age we should have to study the deeper philosophical reasonings, the general literature and the artistic efforts of the three nations. These aspects of the thought of our century belong to later portions of this work. I hope there to take up many of the threads which I here break off, as for the present purpose they cannot be profitably continued. To separate the scientific work of the second half of the century according to countries and nations would lead to unnecessary repetition. The second half of the century sees everywhere in the domain of science the dying out of national restrictions-in every country the introduction of foreign methods and foreign models, foreign institutions and foreign apparatus. The establishment of an observatory or a laboratory in our age lays under contribution almost every civilised country in the world, and the most international of sciences-that of electricityfixes its units by the names of discoverers of many countries. 
I therefore look upon the spirit of exact research as thoroughly domiciled in the leading countries of Europe during the second half of the century, and intend in the sequel to explain more precisely the different views, the

Special scientific ideas.
5. Philosophy of science. leading ideas, under which this research is everywhere conducted. These leading ideas have themselves been more clearly brought out and recognised during this period.

The narrow spirit of the Baconian philosophy which reigned in England, the vagueness of the philosophy of nature which reigned in Germany, during the earlier decades of the century, have disappeared in favour of the more comprehensive and the stricter methods taught by Lavoisier, by Monge, by Laplace, and by Cuvier in France. New ideas of extensive bearing have been added, and in the light of these the powers and the limits of science have been more correctly recognised.

To some of my readers well-known names will occur which might serve as guides to fix these leading ideas, under the influence of which the march of science has proceeded: Sir John Herschel, Auguste Cornte, John Stuart Mill, and Whewell ${ }^{1}$ have indeed done much to

1 Of these writings the earliest is Sir John Herschel's "Preliminary Discourse on the Study of Natural Philosophy," which appeared in Lardner's 'Cabinet Cyclopedia' in 1831. The writings of William Whewell on the 'History' and 'Philosophy of the Inductive Sciences' were begun about the same time. They were planned to serve three distinct ubjects - to give, 1st, a philosophical history of astronomy, mechanics, physics, chemistry, and botany; $2 d$, an analysis of the nature of induction and the rules of its exercise ; and $3 d$, to answer the question of applying inductive processes to other than material sciences - as philology, art, politics, and morals (see ' William Whewell,' by I. Todhunter, vol. i. p. 90). 'The 'History' appeared in 1837 in three volumes, a second edition in 1847 , a third in 1857 ; the 'Philosophy' appeared in 1840 in two volumes, a second edition in 1847 . In the course of its execution the original plan was not strictly adhered to-the scope of the History was enlarged considerably, and the 
familiarise the unscientific public with the progress of science and its canons of thought. And it would thus appear natural to resort to their teaching and their explanations. But this is not the road I propose to follow. Whewell's 'History of the Inductive Sciences,' being the first attempt to compass a large subject, will, like Montucla's earlier 'History of Mathematics,' always remain a standard work. It was, however, written at a time when the tendency of modern scientific thought was

Philosophy was broken up into different parts. Herschel stands mainly on the ground of Bacon's philosophy, whereas Whewell starts with the remark that "Bacon only divined how sciences might be constructed," but that "we can trace in their history how their construction has taken place" ; that "though Bacon's general maxims still guide and animate philosophical inquirers, yet that his views, in their detail, have all turned out inapplicable." He accordingly aims at a "New Organ of Bacon, renovated according to our advanced intellectual position and office" (Preface to $2 \mathrm{~d}$ ed. of the 'Philosophy,' 1847). In the exposition of his views Whewell was greatly influenced by Kant's philosophy. He thus searches for the fundamental ideas which underlie all scientific reasoning; for "besides facts, ideas are an indispensable source of our knowledge." The historical portions of Whewell's works have met with great appreciation in England and Germany even from those who, like Herschel (see the review in the 'Quarterly,' June 1841) and Mill (see 'Autobiography,' p. 208), could not agree with his philosophy. The latter has been eclipsed by the bolder speculations of Auguste Comte, whose 'Philosophie positive' appeared in six volumes between the years 1830 and 1842 in France. Still more than Whewell did Comte emphasise the necessity of learning from the exact sciences how to treat economical and social problems in a methodical manner. Instead of the minute and frequently hesitating elaborations of Whewell, we find in Comte the bold generalisation of the three stages of knowledge-the theological, metaphysical, and positive,which forms the groundwork of "Positivism." Of more permanent value than Whewell's and Comte's philosophies are the investigations of J. Stuart Mill, who in his 'System of Logic, Ratiocinative and Inductive' (1st ed., 1843), has laid the foundation for all subsequent treatises on this subject, and whose thorough-going empiricism is being more and more adopted by scientific thinkers. Like Whewell and Comte, to whom he acknowledges his obligations ('Autobiog.,' pp. 165, 209, \&c.), his ultimate object was to solve the question "how far the methods by which so many of the laws of the physical world have been numbered among truths irrevocably acquired and universally assented to, can be made instrumental to the formation of a similar body of received doctrine in moral and political science" (Preface to 1st ed.) 
not as clear as it has become since, and the work has also been superseded by more detailed labours, especially of German historians.' The 'Philosophy of the Inductive Sciences,' by the same author, was written with the object of doing something towards determining the nature and conditions of human knowledge, and had thus a philosophical rather than a historical object in view. The same can be said of Mill's 'Logic,' of Comte's 'Philosophie positive,' and of more recent works-such as Jevons's 'Principles of Science.' They form an important section of the philosophical literature of our century, and on future occasions I shall frequently have to refer to their teaching. At present I am not about to investigate the eternal principles of correct reasoning, and the particular methods adopted, consciously or unconsciously, by scientific writers of all times. What I desire to do is, to enumerate and analyse briefly the changing ideas, the general views, under the guidance of which scientific work has progressed in the course of this century. No doubt the same object was before

1 Besides the works on the history of the special sciences contained in the Munich Collection, 'Geschichte der Wissenschaften in Deutschland,' which in many instances is not limited to German science and learning, there is the unique 'Geschichte der Chemie,' by Hermann Kopp (Braunschweig, 4 vols., 1843-47), the 'Geschichte der Physik,' by Rosenberger (Braunschweig, 3 vols., 1882-90), and Häser's 'Geschichte der Medicin' (Wien, 1875-82, 3d ed.) In addition to the numerous works of German specialists, I must mention as of the first importance and value the histories by the late Isaac Todhunter of the "Theory of Attraction and Figure of the Earth' (2 vols., 1873), the 'Calculus of Variations,' (1861), the 'Theory of Probability,' (1865), and the "Theory of Elasticity' (continued by $\mathbf{K}$. Pearson, 2 vols. in 3 parts, 1886-93). They supply the want of a good history of modern mathematics, which does not exist. Lastly, the "Deutsche Mathematiker-Vereinigung" have published in their Jahrbuch valuable histories of special branches of mathematics-notably the "Theory of Invariants' by Franz Mayer, and the 'Modern Theory of Functions' by Brill and Noether. 
the mind of Whewell when, after writing his historical work, he attempted in the philosophical sequel Whewell's to abstract the general ideas which have led scientific osophy.' research; but it is instructive for our present purpose to note how, writing about the middle of the century, he hardly brought out any of those principles which in the course of its second half have turned out to be fruitful, and have almost become watchwords of popular science. In the year 1857, the date of the publication of the latest editions of Whewell's works, nothing was popularly known of energy, its conservation and dissipation,-nothing of the variation of species, and the evolution of organic forms, - nothing of the mechanical theory of heat or of that of gases - of absolute measurements and absolute temperature; even the cellular theory seems to have been popular only in Germany. And yet all the problems denoted by these now popular terms were then occupying, or had for many years occupied, the leading thinkers of that period. But we find no mention of them in Whewell's works. ${ }^{1}$ So

1 The dates of the birth of these leading ideas of the second half of our century are approximately as follows :-

Absolute measurements were started by Gauss about 1830, and the scheme published in 1833 in his memoir, "Intensitas vis magne. tice terrestris ad mensuram absolutam revocata.' They were extended to electrical phenomena by Weber in his 'Electrodynamische Maasbestim. mungen,' 1846. The alosolute scale of temperature was introduced by William Thomson in 1848.

The cellular theory was propounded by Schleiden in 1838 , and extended to animal structures by Schwann in 1839; the term "protoplasm" was introduced by Mohl in 1846.

The mechanical theory of heat dates from Mayer's and Joule's determinations of the equivaleut of heat in 1842 and 1843 .

The doctrine of the conservation of energy dates from Helmholtz's memoir, 'Ueber die Erhaltung der Kraft,' in 1847 ; that of dissipation of energy from William Thomson's paper "On a Universal Tendency in Nature to the Dissipation of Mechanical Energy," 1852; it was prepared by Watt's and Poncelet's 
little was the foremost champion of inductive thought able to discern the tendencies of his age: a warning to those who attempt to recognise the aims of contemporary thought. ${ }^{1}$

It is not, then, to the philosophical writers that I shall apply in order to trace the leading directions of scientific

definitions of liorse-power and work (1826), which Whewell does not mention.

The mechanical theory of gasesnot to mention the older speculations of Daniel Bernoulli - dates from Arogadro's and Ampère's hypothesis, published in 1811, "that all gaseous bodies, under the same physical conditions, contain the same number of units," from Herapath (1821) and Joule (1851).

On Whewell's position with regard to the question of the origin and variation of species, then already ventilated by Lyell, see 'History of Induct. Sci.,' vol. iii. p. 489, \&c. (3d ed.), and Huxley's remarks in the 'Life of Charles Darwin,' vol. ii. p. 192, \&c. Wallace's essay 'On the Isaw which has regulated the Introduction of New Species' was published in 1858 along with Darwin's preliminary statement of his views.

We might form a whole catalogue of scientific terms, some of them by no means of recent origin, which are wanting in Whewell's books, but which now govern scientific progress: such are energy, work, action and efficiency, absolute measurement, to mention only physical terms. The general ideas upon which he himself lays some stress, such as those of polarity and symmetry, appear on the other hand to be vague generalisations, which have frequently led people astray.

1 "It is a remarkable evidence of the greatness of the progress which has been effected in our time, that even the second edition of the 'History of the Inductive Sciences,' which was published in 1846 , contains no allusion to the publication in 1843 of the first of the series of experiments by which the mechanical equivalent of heat was correctly ascertained. Such a failure on the part of a contemporary, of great acquirements and remark. able intellectual powers, to read the signs of the times, is a lesson and a waruing worthy of being deeply pondered by any one who attempts to prognosticate the course of scientific progress" ("Huxley in Ward's 'Reign of Queen Victoria,' vol. ii. p. 355). The same writer has pointed out how Auguste Comte was still more uufortunate in his opinions on contemporary science. "What struck me was his want of apprehension of the great features of science; his strange mistakes as to the merits of his scientific contemporaries ; and his ludicrously erroneous notions about the part which some of the scientific doctrines current in his time were destined to play in the future" ("Scientific Aspects of Positivism," "Lay Sermons,' 1891, p. 130). He then goes on to show how Comte treated the undulatory theory with contempt, extolled Gall, depreciated Cuvier, and spoke of the "abuse of microscopic investigations" (ibid., p. 134). 
thought in our century: their position towards this thought is indeed instructive, but it is frequently unsafe.

Philosophical reasoning either precedes or succeeds the labours of the scientific thinker; it rarely accom- and science. panies them. In the history of earlier times, during the first centuries of the modern period, we find some of the foremost philosophers, such as Descartes, Bacon, Leibniz, occupied in attempting to lay down the correct lines on which science should proceed, or to find general ideas which could serve as supreme principles of scientific truth. It is a rare thing to find that they have succeeded in either of these attempts. In more modern times, ever since Locke started on a different track, it has been, especially in this country, the endeavour of philosophers to abstract out of the existing volumes of scientific research the leading ideas which have proved so helpful, and to explain their origin, their bearing, and their value. Perhaps they have been more successful than their predecessors: it has, however, frequently happened to them, that whilst they were elaborately analysing some process of reasoning, or some prevailing scientific principle, science has meanwhile adopted some entirely different line, and presented an entirely unexpected development.

In this respect they resemble that school of historical politicians which in the middle of our century in Germany ${ }^{1}$ attempted to read the signs of the times, and to

1 This is the school represented by the historians Dahlmann and Gervinus. A good account, with a somewhat severe criticism of the aims of this school, will be found in Karl Hillebrand, 'Zeiten, Völker und Menschen,' vol. ii. pp. 205-290. "The State and Literature had grown in Germany alongside of each other without coming into contact, the former active, reticent, modest, the latter declaiming, noisy, pretentious. It appeared as if all our life had become intellect. ual; Gervinus himself thought so and blamed us. In reality it was 
prescribe the lines on which the desired unification of the nation could be secured. Events took their own course, and the great statesman who was the central figure of the new era of European history may be excused the scorn with which he has sometimes treated these theoretical politicians.

Leading scientific ideas most. ly very ancient.

The leading ideas which I select as marking the progress of scientific research in our century have, with few exceptions, hardly been discoveries or inventions of this age. Some of them are very old. The ideas of attraction, which in the hands of Newton and Laplace have led to such remarkable results, are of great age, and were familiar to the philosophers of Greece and Rome; the same can be said of the atomic theory, which in the hands of Dalton became such a powerful instrument. The principles of energy and its conservation can be traced back to the writings of Newton and Leibniz, and even to earlier thinkers. The same may be said of the modern ideas on heat, of the molecular theory of gases, and even of Lord Kelvin's vortices; whilst the views which through Darwin have revolutionised the natural sciences have been traced in the suggestions of much ear-

not so. When the professors turned their backs on science in order to turn to politics, they imagined politics were now only beginning: with the wonted pride of learning they saw in the administrative class only labourers and clerks ; for to them parliaments and freedom of the press were identical with politics. The mouthpiece of Germany was in the universities, as that of France was at the bar; they only heard each other: was it therefore unnatural if they thought the German professors composed the German nation, as the French lawyers formed the French nation? And indeed public opinion in Germany was that of the professors. ... The learned newspaper writers imagined the spirit of the age spake in them; no wonder that they overestimated the importance of this spirit and of this so-called public opinion " (ibid., p. 254). See also Treitschke's 'Deutsche Geschichte,' vol. v. p. 408, \&c. 
lier writers. Elaborate claims to priority have thus been set up for persons to whom it is said the credit of modern discoveries should be given. I do not intend to contribute to this controversial literature, except by a general remark, which will explain how it has come to pass that ideas and principles now recognised as useful instruments of thought and research have only recently attained this importance, while they have frequently been the property of many ages of philosophical thought, and familiar even to the writers of antiquity. It is the scientific method, the exact statement, which was wanting, and which raises the vague guesses of the philosophical or the dreams of the poetic mind to the rank of definite canons of thought, capable of precise expression, of mathematical analysis, and of exact verification. Obscure notions of the attractive and repulsive forces of nature have floated before the minds of philosophers since the time of Empedocles, but they did not become useful to science till Galileo and Newton took the first step to measure the intensity of those forces. Lucretius's poem introduces to us the early speculations on the atomic constitution of matter, but the hypotheses of his school only led to real knowledge of the things of nature when Dalton, following Lavoisier and Richter, reduced this idea to definite numbers; still more so when, through the law of Avogadro and Ampère, and the calculations of Joule, Clausius, and Thomson, the velocities, the number, and sizes of atoms became calculable and measurable quantities. Descartes, and after him Malebranche, filled space with vortices which were to explain the constitution of matter and the movements of its parts; but the notion was abandoned and ridiculed till Helmholtz 
and Thomson approached the subject with mathematical analysis and calculated the properties of vortex motion.

Heraclitus proclaimed, six hundred years before the Christian era, the theory that everything moves or flows; but not till this century was the attempt made to work out the definite hypothesis of Daniel Bernoulli, and to explain the properties of bodies, apparently at restthe pressure of gases, or the phenomena of elasticityby assuming a hidden motion of the imperceptible portions of matter. The same fate of lying dormant for ages at9. taches to the suggestive ideas of many thinkers. In every case the awakening touch has been the mathematical spirit, the attempt to count, to measure, or to calculate. What to the poet or the seer may appear to be the very death of all his poetry and all his visions-the cold touch of the calculating mind,- this has proved to be the spell by which knowledge has been born, by which new sciences have been created, and hundreds of definite problems put before the minds and into the hands of diligent students. It is the geometrical figure, the dry algebraical formula, which transforms the vague reasoning of the philosopher into a tangible and manageable conception; which represents, though it does not fully describe, which corresponds to, though it does not explain, the things and processes of nature: this clothes the fruitful, but otherwise indefinite, ideas in such a form that the strict logical methods of thought can be applied, that the human mind can in its inner chamber evolve a train of reasoning the result of which corresponds to the phenomena of the outer world. By such processes did Gauss and Leverrier succeed in tracing the lines in the heavens on which invisible 
stars were speeding through the universe; without them these objects of nature would probably never have been seen, and if seen, they would not have been recognised. Similar, and still more intricate, reasonings permitted Mendeléeff ${ }^{1}$ to arrange in geometrical order the several elements or simple substances out of which matter is compounded, and to point to the vacant places on the chart, some of which have since been filled up by new discoveries. Thus it has also been shown that the ranges of temperature cannot be extended indefinitely in both directions-viz, those of heat and cold-but that the latter possesses a zero point, representing the complete absence of motion. ${ }^{2}$

1 The periodic arrangement of the elements, according to which, with increasing atomic or combining numbers, the same properties - such as density, fusibility, optical and electric qualities, and formation of oxides, \&c.-recur in periods which are at least approximately fixed, so that they can be represented by curves, dates from the year 1869 , when D. Mendeléeff and Lothar Meyer published almost simultaneously their classification of the elements. Newlands seems to have indicated some of these facts as early as 1864. Mendeléeff predicted the properties of a missing element, found to be those of scandium, which Nilson discovered ten years later. The same applies to the two other elements which were subsequently discovered by Lecocq de Boisbaudran (1878, gallium) and Winkler (1886, germanium), and in 1894 the newly discovered element argon was found to fill a vacant place in the plan.

2 The zero point of temperature was originally a purely mathematical quantity suggested by the for- mula which gives the expansion of air in the air thermometer as dependent on the temperature. The ideal, not realisable, temperature at which, according to the formula, the volume of air would be nothing, was fixed by calculation at $459^{\circ} 13$ Fahr. or $272^{\circ} \cdot 85$ Centigrade. The real physical, not merely mathematical, meaning of the absolute scale of temperature with its zero point was only revealed when, through Carnot and Thomson, it was established that every degree of temperature has an assign. able value for doing work, and when a scale of thermometry was sug. gested by Thomson (1848) in which every one degree had the same dynamical value, $100^{\circ}$ in it corresponding to the $100^{\circ}$ Centigrade in the air thermometer. It was then found that the two scalesthat of the air thermometer and that measuring the dynamical value of temperature-agreed almust exactly. 'The number $273^{\circ}$ Cent. thus acquired a physical meaning (see Clerk Maxwell, 'Heat,' 8th ed., pp. 49, 159, and 215). Another 
By drawing curves on paper which correspond to the thermal properties of various substances, the conditions have been defined beforehand under which gaseous bodies like oxygen, hydrogen, nitrogen, or common atmospheric air can be reduced to liquid and solid bodies, upsetting the notions of the last generation, which looked upon these substances as permanent gases. ${ }^{1}$ If the mathematical formula has killed, or failed to grasp, the true life of nature, that which to the poet and the philosopher will always be the feature of supremest interest, it has on the other side given birth to that new life of ideas which in our reasoning minds serve as the images of things

example of a purely mathematical quantity which, suggested originally by a formula, acquired later a physical meaning, is that of the potential function, used first by Lagrange as a simplification in calculating the forces of a disturbing planet, and termed by Laplace "à cause de son utilité, une véritable découverte" ("Méc. cél.,' v. livre xv. chap. i.) This function, which has the property that by a simple differentiation the component of the force in any direction is found, acquired a physical meaning as the quantity, the change of which measures the work required to move a unit of matter from one point to another (see Thomson and Tait, 'Natural Philosophy,' vol. i. 2, p. 29). Other examples of purely mathematical quantities which reveal physical properties are Hamilton's "characteristic function" (see Tait, "Mechanics," 'Ency. Brit.,' 9th ed., p. 749), Rankine's "Thermodynamic function," called by Clausius "Entropy" (see Maxwell, 'Heat,' pp. 162, 189) : it measures the unavailable energy of a system.

1 Thomas Andrews (1813-85) took up the experiments begun by Cag-
niard-Latour in 1822, and explained how it comes about that a gas remains incondensable however great the pressure may be, provided the temperature exceeds what he termed the "critical temperature," which is different for different gases. He accompanied his statements, which were first published in the $3 \mathrm{~d}$ edition of Miller's Chemical Physics, by curves representing the behaviour of atmospheric air and of carbonic acid, the latter being a condensable gas, and he suggested in 1872 that the so-called permanent gases had a critical point far below the lowest known temperatures, and that this was the reason why their liquefaction had not yet been achieved. Two physicists, Cailletet and Pictet, took up these suggestions; after various trials they succeeded independently in 1877 in liquefying several of the permanent gases, notably oxygen and nitrogen. These have been followed by all the other permanent gases, including atmospheric air, of which large quantities can now be prepared in a liquefied form. 
natural, and allow us to make them subservient to our purposes.

Whoever grasps the significance of the change which the exact or mathematical treatment of knowledge has worked in our life and thought, will readily place that name at the entrance of a history of modern thought, which is identified with a few simple mathematical formulæ, by which ever since his time the progress of science has been guided. Though belonging to an earlier period, the full meaning of Newton's work has only been recognised in the course of our century. In fact the Newtonian philosophy can be said to have governed at least one entire section of the scientific research of the first half of this period: only in the second half of the period have we succeeded in defining more clearly the direction in which Newton's views require to be extended or modified. Newton's greatest achievement was to combine the purely mechanical laws which Galileo and Huygens had established with the purely physical relations which Kepler-following Copernicus and Tycho-had discovered in the planetary motions, and to abstract in so doing the general formula of universal attraction or gravitation. Newton looked upon the motion of the moon round the earth, or the planets round the sun, as examples on a large scale of the motion of falling bodies-studied by Galileo-on the surface of the earth. Delayed in the publication of this simple rule of planetary motion through the absence of correct measurements, and through the necessity of inventing a new calculus by which the mathematical results of the formula could be ascertained, Newton did not publish his 'Principia' till 1687. The 
11. Newton's "Principia.

work, however, was conceived in the highest philosophic spirit, inasmuch as the enunciation of the so-called law of gravitation required the clear expression of the general laws of motion. In the first and second parts, of the work the discoveries of Galileo and Huygens were absorbed, generalised, and restated in such terms as have up to our age been considered sufficient to form the basis for all purely mechanical reasoning. ${ }^{1}$ In the latter part the new rule, corresponding to Kepler's empirical laws, is represented as the key to a system of the universe. The great outlines of this system are boldly drawn, and the working out of it is left as the great bequest of Newton to his successors. At the end of the eighteenth century,

1 The most recent historian of the subject is Prof. Ernst Mach of Prague, whose 'Mechanik in ihrer Entwickelung, historisch - kritisch dargestellt,' 2d ed., 1889, I cannot praise too highly. It has been translated into English by $\mathrm{M}^{6} \mathrm{Cor}$ mack (Chicago and London, 1893). Referring to Newton, he says: "Newton has with regard to our subject two great merits. Firstly, he has greatly enlarged the horizon of mechanical physics through the discovery of universal gravitation. Further, he has also completed the enunciation of the principles of mechanics as we now accept them. After him an essentially new principle has not been established. What after him has been done in mechanics refers to the deductive, formal, and mathematical development of mechanics on the ground of Newton's principles" (p. 174). "Newton's principles are sufficient without the introduction of any new principle to clear up every mechanical problem which may present itself, be it one of statics or of dynamics. If difficulties present themselves, they are always only mathematical, formal, not fundamental " (p. 239). "All important mathematical expressions of modern mechanics were already found and used in the age of Galileo and Newton. The special names . . have sometimes been fixed much later. Still later came the adoption of uniform measures, and this process is even yet incomplete" (p. 252). In this country it is one of the great merits of Thomson and Tait's 'Natural Philosophy' that they "restored" the teaching of mechanics and placed it on the original foundations afforded by Newton's laws of motion, in his own words, as "every attempt that has been made to supersede them has ended in utter failure" (Preface), and, though they "are only temporarily the best," there does not exist, "as yet, anything nearly as good" (Tait in article "Mechanics," 'Ency. Brit.,' 9th ed., p. 749). 
after many able mathematicians and observers had generally investigated the numberless problems contained in the 'Principia,' Laplace published his 'Exposition du Système du Monde,' followed in the course of the first quarter of this century by the 'Mécanique céleste' $;{ }^{1}$ and at the close of the present century the most learned astronomer of the age could say that the 'Principia' still formed the sole foundation of all investigations in that domain. ${ }^{2}$

It is interesting to see how in a simple formula the mathematician is able to condense an almost immeasur- the gran forable volume of thought, bringing the theory and the observations of past ages to a focus from which new lines of thought diverge in many directions. Every mathe-

1 The 'Exposition du Système du Monde' appearcd, 1796, in 2 vols. 8vo: the first and second volume of the 'Mécanique céleste,' 1799 , 4to ; the third, 1802 ; the fourth, 1805; the last, 1825 . Before publishing this work, which has been termed a second edition of the 'Principia,' Laplace had limself during thirty years assisted in dispelling the last doubts as to the sufficiency of the doctrine of universal gravitation to explain all cosmical phenomena; and he had especially brought the investigations of Clairault, Euler, D'Alcmbert, Lambert, and Lagrange to a final result by publishing in successive memoirs between 1773 and 1786 the doctrine of " the stability of the system of the universe," based upon the invariability of the major axes and the pcriods of revolution of the planetary orbits. $\mathrm{He}$ and his predecessors also extended the solution of the problem "to find the orbit of two bodies, acting under the law of mutual gravitation," which was given by Newton in such a way that the action of one or more third (disturbing) bodies could be taken into account, dealing thus with the case of nature, which had in the first instance presented itself in treating of the complex motion of the moon. Laplace himself, who in nuinberless passages of his works recurs to the discoveries of Newton, announced the object of the 'Mécanique céleste' to be the treatment of astronomy "as a great problem of mechanics, from which it was important to banish as much as possible all empiricism," and to perfect it so as "to borrow from observation only the most indispensable data " ('Méc. cél.,' vol. i., introd.)

2 The late Professor Rudolf Wolf of Zürich, whose 'Handbuch der Astronomie, ihrer Geschichte und Litteratur,' 2 vols., $1890-93$, as well as his earlier 'Geschichte der As. tronomie,' Mïnchen, 1877, I warmly recommend. 


\section{matical formula which expresses the existing relations} of natural things acts in a similar way, but probably few, if any, subsequent discoveries have given scientific minds so much fruitful work to do as the gravitation formula. An analysis of it will serve us as a guide through a very large portion of the scientific work of our period; it will serve also as an example of the great service which the mathematical mode of dealing with conceptions renders to the progress of science and of thought.

The so-called law of gravitation states that every two portions of matter, placed at a distance from each other, exert on each other an attractive force, ${ }^{1}$ which depends on the masses of each, and on their distance from each other. The attractive force varies in the direct proportion of the mass of each, and in the inverse duplicate ratio of the distance. Three distinct lines of

1 The gravitation formula gives no indication of the actual or absolute amount of the force in question; it only establishes a relation. It was fully three-quarters of a century after the publication of the 'Principia' that experiments were suggested in order to determine the actual magnitude of the force of gravitation-i.e., the constant $c$ in the formula $f=c \frac{m . m^{\prime}}{r^{2}}$. Michell in 1768 devised an apparatus, employed later (1797) by Carendish, and Maskelyne made measurements towards the end of the last century. More and more accurate determinations were made all through the present icentury, and latterly by Prof. Boys. Few persons have an idea of the extreme feebleness of the force, which nevertheless, through the magnitude of the earth, acquires in our daily experience such formidable proportions. As it is desirable, in accordance with one of the principal scientific tendencies of our age, to place the knowledge of absolute physical quantities in the place of merely relative numbers, I mention here that the force with which two units of matter (i.e., 2 grammes) placed at unit distance (i.e., 1 centimetre) apart attract each other is such that they would approach each other with a velocity of nearly 7 hundred millionths of a centimetre in the first second of time. As a pound is a more familiar quantity, we may also say that two masses, each containing 415,000 tons of matter, and situ. ated at a distance of one statute mile apart, will attract each other with the force of $1 \mathrm{lb}$. (see Sir R. S. Ball, 'Ency. Brit.,' 9th ed., art. "Gravitation"). See also Sir R. S. Ball, "The Story of the Hearens,' p. 106, and Prof. Boys in 'Nature,' vol. 50, p. 330, \&c. 
scientific research are involved and opened out by this statement.

First, There is the purely theoretical task of defining from it. clearly what is meant by the different words which are used, and which in the formula are expressed in algebraic symbols. What is the definition of force, what of mass, what of distance? The 'Principia' give Newton's definitions. ${ }^{1}$

Second, The definitions must be given in such a way that they express definite measurable quantities; and in order to verify and apply the formula, methods must be devised for measuring these quantities as they occur in nature, and these measurements must be actually carried out. $^{2}$

It will be readily admitted that the definition of force as measured by change of motion, and the definition of mass as the quantity of matter, are definitions involving some difficulty. As to distance, it may be thought that this is a purely mathematical, not a physical quantity. So it would be if physical bodies were mathematical points, such as the planets in a first approximation may be considered to be. But in comparing the attraction of the earth upon a body at its surface with that on the moon, the dimensions of the earth could not be neglected, and the problem presented itself how the quantities of mass and distance, in the case of the earth and the body on its surface, had to be defined. It appears from a statement by Prof. Glaisher (see Rouse Ball, 'History of Mathematics,' p. 297, \&c.) that the publication of the 'Principia,' containing the gravitation formula, was delayed, because Newton found it difficult to prove that in a sphere the different parts

with their different distances from any point need not be considered separately, but that a quantity equal to the whole mass situated at the centre of the sphere may be substituted. Laplace showed a century later that this property of the sphere exists only for one decreasing function of the distanceviz., that of the inverse duplicate ratio. It exists likewise for that function which increases in propor. tion to the distance, but for none other (see 'Principia,' 1st ed., pp. 198, 200 ; 'Mécanique céleste,' 1st ed., vol. i. p. 143). Hitherto the delay in publishing the 'Principia' was (see Brewster, 'Life of Newton,' vol. i. p. 290) always attributed to the erroneous figure of the moon's distance from the earth, with which Newton had been reckoning, and which did not satisfy the gravitation formula.

${ }_{2} \mathrm{Up}$ to the beginning of this century the merit of carrying out accurate measurements of astronomical constants is about equally divided between France and Eng.

VOL. I. 


\section{Third, the formula is a mathematical expression, and, as} such, can be subjected to purely mathematical analysis: this analysis may refer to purely algebraical processes of

land; the former country haring supplied the means and organised many expeditions (under Richer, Picard, Cassini, La Condamine, Maupertuis, and others), the latter having invented and furnislied the greater portion of the delicate instruments, through Newton, Gregory, Ramsden, Dollond, Harrison, and others. The latter was a matter of personal, the former one of organised, talent. England did not take any great part in the repeated measurements of the arc of the meridian till, towards the end of the eighteenth century (1785-87), the French astronomer Cassini de Thury presented to the Royal Society a memorial on the uncertainty in the difference of longitude of Greenwich and Paris, and proposed that the English and French mathematicians in concert should determine, by geodetic operations, the distance measured along an arc of parallel. This was assented to, and the late Astronomer Royal (G. B. Airy) claims that it " may be said that in this as in other grand experiments, though we began later than our Continental neighbours, we conducted our operations with a degree of accuracy of which, till that time, no one liad dared to form an idea." Since the beginning of this century Germany has, through the accurate ineasurements of Gauss and Bessel, and througl the famous establishments of Fraunhofer, Steinheil, Repsold, and others, taken a leading position both in theory and practice of measuring. So far as graritational astronomy is concerned, the United States of America seem at the end of this century to eclipse all previous performances. But if we owe to
English genius the invention of logarithms, the sextant, the reflecting and the achromatic telescope, the theodolite, and the chronometer, we owe to France the idea of an absolute system of measurements and the first approximation to it in the metrical system, which England has been tardy to adopt. A really absolute unit of measurement, as the ten-millionth part of the earth quadrant was intended to be-one which would be recoverable, if every actually existing pattern was destroyed-does not yet indeed exist; but the Government of the Revolution laid the foundation in 1790 of our present international decimal centigrade system. It does not appear that the idea of extending this system to all other forces and quantities in nature was then contemplated. A valuable contribution towards this desirable object was made by Fourier, who in his celebrated 'Théorie de la Chaleur' (1822, p. 152, \&c.) laid down the doctrine of the "dimensions" of physical quantities which had to be measured and compared with each other. The first who reduced the measurement of otlier than purely mechanical phenomena to the standard of mechanical forces was Gauss (1832). In his investigations referring to the intensity of magnetic force at different points of the earth, he found it necessary to abandon the unit of weight, the gramme, and to adopt the unit of mass, inasmuch as the weight of the unit of mass varied at different points of the globe. He introduced the name "absolute" to signify that this standard is independent of local or relative influences (see 
calculation, or to geometrical figures. These geometrical figures represent on paper, and on a small scale, the curves or orbits of bodies in space and time, and can be interpreted as such. Then, as in nature two bodies or portions of matter are never single gravitating points occurring alone, but are surrounded by the totality of existing things, the formula which reduces the action of gravitation to that of pairs of things, and to the elements of matter, requires to be extended to more than two-in fact to an infinity of elements. The infinitesimal calculus teaches us how to deal with such a progression from finite numbers and quantities to infinite numbers; or from relations which refer to infinitesimal elements to finite measurable quantities. We find very soon that our powers of calculation reach only a small way, and cover only a small extent of the ground which observation opens to our eyes. We are thus forced to deal with the element of error which creeps into our calculations; to be satisfied with error. approximations $;^{1}$ and instead of certainty, probability is

Gauss, Werke, vol. v. pp. 85, 293, \&c.) Of Weber's electrodynamic measurements I shall speak later on. Absolute measurements were used by William Thomson (Lord Kelvin) as early as 1851, and owing mainly to his influence the present system was gradually established in the course of the following twenty years (see William Thomson, 'Popular Lectures and Addresses,' vol. i. p. $83, \& c$.$) Fourier's theory of dimen-$ sions was first brought prominently before the scientific and teaching world by Clerk Maxwell in his treatise on 'Electricity and Magnetism' (1st ed., vol. i. p. 2). There also we meet for the first time with the use of astronomical magnitudes and relations by which the usual three units, time, mass, and distance, can be reduced to two. This is also lucidly explained by Lord Kelvin (loc. cit.) It has been followed up in detail in two interesting papers by W. Winter in Exner's 'Repertorium der Physik' (vol. 21, p. 775 , and vol. 24, p. 471 ).

1 The history of astronomical calculations since the time of Newton, when the theoretical basis was once for all laid, is a history of gradual approximations. Mathematically a conic section is sufficiently defined if the position of the focus (the sun in our planetary system) and three positions of the moving star are known by observation. But it was a long time before even tolerably complete methods of observation
14. Element of

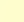




\section{the best we can attain to in our results. ${ }^{1}$ An entirely new branch of investigation springs up-viz., the theory of error, the doctrine of probability, and the investigation}

and calculation were invented to deal practically with the problem. Up to 1781 , when the new planet Uranus was discovered by Herschel, the interest centred mainly in the determination of the orbits of comets, which were assumed to be parabolic. Halley was the first to calculate these by means of tentative methods given by Newton in the 'Principia.' After 1781 the necessity arose of determining closed orbits, and a first attempt was made to do so by assuming circular orbits (neglecting the ellipticity) and neglecting the inclination of the plane of the orbit to that of the earth. But in the first year of this century neither the parabolic nor the circular figure of the orbits seemed to answer in the case of the new planet Ceres, nor could the inclination of the orbit be neglected. It required all the skill of Gauss to tackle the entire, unabbreviated problem, and this was done in his fundamental work "Theoria motus corporum coclestium.' As the 'Principia' form the foundation of all physical, so does the "Theoria motus' of all calculating astronomy. A similar fundamental work which should take the next important step, solving generally the problem of the motion of a body which is attracted from more than one fixed or movable centre (the problem of three bodies), would mark the next great era in calculating astronomy. Hitherto this problem has only been treated under the assumption that the third attracting body disturbs the real orbit which has been calculated. The necessity of solving the problem of three bodies has made itself felt in the theory of the moon and other satellites, which stand under the influence of the main planet as well as the sun, and where therefore the ellipsis of Kepler cannot even be taken as a first approximation. And here again the necessity of taking into account the volume and the figures of the attracting bodies still further complicates the problem. On them depend the precession of the equinoxes and the irregularity of the precession known under the name of nutation.

${ }^{1}$ According to Wolf ("Handbuch der Astronomie,' vol. i. p. 128 sqq.) the merit of having first considered the best methods of dealing with errors of observation belongs to Picard (1670) and Roger Cotes ("Aestimatio errorum in mixta mathesi,' 1722). The former seems to have first used the apparently so obvious rule of taking the arithmetical mean of a number of observations, the latter introduced the notion of attributing to each observation its value or weight. Cotes accordingly found that the centre of gravity of a number of weighted points distributed over a plane coincided with the position of greatest probability. Gauss suspected that Tobias Mayer had already employed modern methods in his calculation of long series of observations, and he himself used what is termed after Legendre the "method of least squares" as early as 1795. It was not published till 1806 by Legendre, in his memoir 'Nouvelles méthodes pour la détermination des orbites des eomètes.' Gauss published his methods in 1809 in the celebrated 'Theoria motus corporum cœlestium.' 'This method of finding the most probable result when a larger number of equations is given than unknown quantities 
of the degree of approximation which we can attain to. And this does not only refer to the methods of calculation which we adopt,--is not only a consequence of the limits of our mathematical powers ; this element of error attaches likewise to our actual observations, to the imperfection of our senses and of our instruments. The many sources of mistake and inaccuracy which surround us may either combine to produce an absolutely useless result, or may be adroitly adjusted so as very largely to destroy each other. ${ }^{1}$ The arrangement of instruments of observation and calculation, so as to minimise our errors, is a special branch of science. Before the time of Newton few minds

is the same as that of finding the centre of gravity of a number of weighted points. This centre has the property that the sum of the squares of its distances from these points is a minimum. After the method had been introduced, Laplace and Gauss independently tried to prove it by a variety of considerations. These have not always been accepted as conclusive, though it is remarkable that very different ways of attacking the problem all lead to the same result, and that the rule is confirmed by actual trials on a large scale. It has been shown that the methor of least squares in the case of a series of observations of one and the same quantity is equal to taking the arithmetical mean,-a process which recommends itself to common-sense, though it is not easy to prove it mathematically to be the best. On the whole, the calculus of probabilities and the so-called law of error are attempts to put into figures and mathematical formulæ a few common-sense notions, and it is interesting to see to what complicated processes of reasoning a combination of these simple notions may lead. The literature of the subject, belonging almost entirely to this century, is very large, Laplace and Gauss heading the list. Encke has summarised the scattered discussions of Gauss and Bessel in his memoir on the subject, reprinted in Taylor's 'Scientific Memoirs' and in the 2d vol. of Encke's 'Abhandlungen,' Berlin, 1888. De Morgan, Airy, and Jevons ('Principles of Science,' vol. i.) in England have done much to popularise the subject, and Bertrand ('Calcul des Probabilités,' 1888) has very fully discussed the principles of the whole matter and shown up the weak points. The application of the calculus to statistics will occupy us in a future chapter.

1 Not only has every instrument its constant errors, but even every observer himself has what is called a personal equation-i.e., he is subject to constant errors of observation, dependent on the peculiarity of his sense organs, or his temperament, \&c. This was hardly recognised at the beginning of this century, when Maskelyne, the Astronomer Royal, dismissed an assistant whose observations showed a constant difference from his own. 
were occupied with the many researches indicated here. But as the contents of the 'Principia' became familiar and intelligible to men of science, a large army of workers, collected from all sides, had within the first century after its publication accumulated a great mass of 15. research. It is the glory of the old French Academy of Laplace and Newton. Sciences, in spite of the opposition to Newton that ruled there for some time, to have in all earnest taken up his great bequest, and to have made such a summary possible as was given by Laplace in the two works above referred to. To Laplace belongs also almost exclusively the merit of having recognised the importance which attaches in all human science to the existence of error, and of having founded the theory of probability. The element of error cannot be eliminated from our observations and our reasonings: the only true scientific method is to measure and study it.

The gravitation formula of Newton not only brought precision and definiteness into scientific work in the three directions mentioned above-it not only produced strict definitions of the fundamental notions of dynamics, promoted accurate measurements of physical quantities, and inaugurated a new literature in pure mathematics; but it had, as all other great generalisations have had since, a very far-reaching influence on scientific thought in other ways. There always have been, and always will be, several distinct interests which induce men to study nature. Some are driven to it by curiosity, or a pure love of nature. To those who belong to this class the end of the study of nature is to describe and to portray the objects which surround us, to see and know them 
better. It would seem as if to such minds the scientific formula, the so-called law of nature, must be distasteful, and probably useless. Nevertheless the scientific view, of which the mathematical formula is an extreme expression, has reacted, though not always beneficially, upon the labours of those who confine themselves to observation and description; it has given to their efforts general interest and encouragement, indicated new directions, and frequently opened new fields. Thus the new formula of Copernicus and Galileo gave a great impetus to stargazing, which was greatly increased by the almost contemporary invention of the telescope. The new theory required the rotation of the planets, and led to minute observations of their phases, and to the discovery of the satellites of Jupiter and the ring of Saturn. Variable stars were incidentally discovered by Tycho, and the long-neglected comets received greater attention. Bernoulli attempted, and Halley actually carried out, the calculation of the return of a comet. Still later-in fact, not before the end of the eighteenth or the beginning of the present century-came the turn for reliable observation of meteors and auroras; for as late as 1790 the 'Décade philosophique,' as well as the Paris Academy and many learned persons, ridiculed the authentic reports of the fall of meteors, and Chladni's classical dissertation on the stone of Pallas. ${ }^{1}$ It seems as if the purest love of

1 When in the year 1790 the municipality of Juillac in Gascogny submitted a report, signed by more than 300 eyewitnesses, to the Paris Academy, on a fall of stones which had there taken place, one of the editors of the 'Décade philosophique' remarked that it would be better to deny such incredible things than to enter into any explanations. Bertholon could not help pitying a community which had such a foolish maire, and remarked in the "Journal des Sciences utiles': "How sad it is to find a whole municipality attesting formally by protocol popu- 
17. nature, the greatest devotion of the observer and the Insuffici-
encservere collector, lead only a little way in finding out the hidden
observation

paths of natural things or the behaviour of natural objects; and however grateful we must be to those pioneers of knowledge who with unrewarded patience amass the material for later theorists, it is to the classification of a Linnæus, to the arrangements of a Cuvier, to the theories of a Darwin, to the measurements of a Bradley and a Herschel, most of all to the formulæ of a Newton or a Gauss, followed by the calculations of their pupils, that we are indebted for a real grasp, for a comprehensive knowledge, of great masses of natural phenomena. Next to the pure love of nature, the desire to apply natural knowledge, and to make it useful for practical purposes, has rendered in return great services to science. The Royal Society and the Royal Institution had both from their infancy a large admixture of the practical spirit. These were founded, more even than the academies abroad, to a great extent upon the desire to make knowledge useful.

- The Govermments of England and of France promoted

lar fables which are only to be pitied! What can I add to such a protocol? The philosophical reader will himself suggest what to say when he reads this authentic proof of an evidently wrong fact, of a phenomenon which is physically impos. sible" (Wolf, "Geschichte der Astronomie,' 1877, p. 697 sq.) Chladni published his essay on the large mass of iron found by the traveller Pallas in Siberia in the year 1794, and, in spite of adverse criticisms, followed it up by a catalogue and an atlas of meteoric stones, suggesting that they were of cosmic origin. Fortunately, a remarkable fall of stones, accompanied by meteoric phenomena, took place in 1803 not far from Paris, at l'Aigle in the department de l'Orne, and Biot was commissioned by the Academy to proceed to the district and examine the case. In the 'Relation,' \&c., which he read before the Institute, he established the fact that a meteor exploded in the district, and that at the same time a fall of many thousand stones, weighing about 20 tons, took place (Biot, 'Mélanges scientifiques et littéraires,' vol. i. p. 15 sqq.) 
the study of the "mechanics of the heavens" by offering large prizes for scientific and practical means of determining the longitude at sea. The lunar theory, which has occupied the attention of the greatest mathematicians since Newton- of Euler, Clairaut, and Tobias Mayer in the last century; of Burckhardt, Plana, and Hansen, of Delaunay and Adams, in the present century-was an outcome of this. It still engages the attention of scientific minds, involving as it does all the most delicate astronomical calculations, whilst for practical nautical purposes the moon has ceased to be the great timekeeper, and has since 1763 been replaced by the wonderful chronometers of Harrison and his successors. A similar stimulus both to abstract scientific research and to the perfection of the practical instruments of measurement was given in this century by the development of submarine telegraphy: in this case both sides of the problem, the scientific and the practical, were attacked, and carried to a high degree of perfection by one and the same mind ${ }^{1}$ -

1 William Thomson's (Lord Kelvin's) investigations and inventions, which made submarine telegraphy at long distances commercially practicable, refer mainly to the overcoming of the "embarrassment" occasioned by the property (discovered by Werner Siemens, 1849, and investigated by Faraday, 1854) which submerged cables possess of "retaining a quantity of electricity in charge along the whole surface." In 1854 Thomson made a full theoretical examination of this phenomenon, showed how it depended on the length, the electric resistance, and the electrostatic capacity of the line, and gave a mathematical formula, with practical examples of the retardation of the signals and the gradual increase of the strength of the electric current at the receiving end of long submarine cables ("On the Theory of the Electric Telegraph" and other papers, reprinted in the $2 \mathrm{~d}$ vol. of 'Math. and Phys. Papers,' 1884). The importance of constructing delicate instruments for registering feeble signals, and of a method for reducing the time of single signals, became evident through these theoretical investigations. The mirror galvanometer was first used in 1858 on the first Atlantic cable, and afterwards on the successful cables of 1865 and 1866. It was followed by the spark-recorder, which led to the syphon-recorder (1867-70), which 
an almost unique instance of the combination of abstract reasoning and practical inventiveness. An almost equally important problem, having both scientific and practical interest, arising out of the Newtonian gravitation formula, is the problem of tides. Here also the first suggestions towards a theory were given in the 'Principia,' whereas the first attempt at a solution is contained in Laplace's great work. A closer approximation was reached by Sir W. Thomson in his extensive theoretical and practical use of Fourier's mathematics.

I shall have frequent opportunity to refer to the beneficial and fructifying influence which practical problems have exerted on scientific thought; ${ }^{1}$ in fact, in spite of

has since been in use in submarine telegraphy. The best account of these discoveries and inventions is to be found in Lord Kelvin's own papers, a good summary being given in his short article in Nichol's ' $\mathrm{Cy}$ clopedia,' reprinted as No. 82 , vol. ii. p. 138.

1 How much science owes to the practical interests of navigation can be seen by a glance at the subjects contained in the third rolume of Lord Kelvin's 'Popular Lectures and Addresses.' The Tides, DeepSea Sounding, Cable-Laying, and Terrestrial Magnetism all furnish important practical as well as highly abstract theoretical problems, the solution of which demands new instruments and new metlods of calculation. The phenomena of tides and those of terrestrial magnetism are intimately connected with two of the most refined mathematical theories which this century has developed. The former was first attacked by the socalled equilibrium theory - the problem being to find the figure of equilibrium of a rotating ellipsoid covered with water under the influence of various attracting forces. Laplace, followed by Airy and Thomson, showed how it is much more a question of dynamics than of statics, and that it resolves itself into the analysis and subsequent synthesis of a number of periodic movements, dependent upon the several periodic changes of the rotation of the earth and the revo. lutions of the moon round the earth and the sun. A general method of dealing mathematically with the superposition of several periodic changes had been invented by Fourier in the early part of this century, and it was this which, especially in the hands of Lord Kelvin and his brother-the late Prof. James Thomson-led to the harmonic analysis of tide motion and the subsequent invention of tide-predicting apparatus (see the above volume, p. 177 sqq.) The observation of the magnetism of the earth is connected with great improvements in the theory and construction of the mariner's compass, suggested and carried out by 
the great opposite influence which science has gained in the course of this century over practical life, I am still doubtful whether scientific thought has, at the end of our century, as yet balanced the debt which it owes to practical inventors. It is instructive, for instance, to consider how much, in the hands of Rumford, of Sadi Carnot, of Hirn, and of Rankine, science has learnt from the steam-engine, and to reflect whether from all the theoretical insight gained any really radical improvement of the steam-engine-still one of the most imperfect machines-has resulted. ${ }^{1}$

Lord Kelvin; and it has in an. other direction led to remarkable scientific results in the hands of Gauss, who between the years 1830 and 1840 brought the theory almost to perfection. Here again the physical phenomenon required for its treatment a special mathematical analysis, which Gauss greatly furthered in his 'Allgemeine Lehrsätze in Beziehung auf die im verkehrten Verhältnisse des Quadrats der Entfernung wirkenden Anziehungs - und AbstossungsKräfte' (1840). This is a mathematical investigation of the Newtonian gravitation formula. Gauss followed out the theories of Laplace and Lagrange simultaneously with Green, whose now celebrated memoir on the subject remained long unknown (see supra,pp.231,247). The mathematical theory showed that in a sphere containing a certain amount of attracting (magnetic) matter an ideal distribution on the surface of the sphere can be found which takes the place of the real but unknown distribution in the interior, and that if through observation the necessary data are supplied, the magnetic condition of any point on the surface can be foretold with great approximation. As an ex- ample, Gauss foretold from the imperfect data at his command the position of the south magnetic pole. In 1840 Capt. Sir James Ross approached it sufficiently to show the correctness of the calculation. The theoretical investigations in connection with magnetic attraction and with tidal movements have remodelled the methods of observation of the phenomena themselves, the older methods having proved to be in many ways insufficient. A full account of Gauss's labours here referred to will be found in E. Schering, 'C. F. Gauss und die Erforschung des Erdmagnetismus,' Göttingen, 1887.

1 I refer in this matter to two addresses delivered recently - one by Prof. Unwin ('Electrician,' vol. 35 , pp. 50 and 79 ) on "The Development of the Experimental Study of Heat-Engines "; the other by Prof. Lodge on "The Second Law of Thermodynamics", ('Electrician,' vol. 35, p. 80 sqq.) From a perusal of these papers one gains the impression that science has been more successful in teaching us why the steam-engine is so wasteful a machine than in showing how it can be greatly improved. It is interesting to hear that "al- 
19. Focalising effect of mathemati. cal formulæ.

The mathematical formula is the point through which all the light gained by science passes in order to be of use to practice; it is also the point in which all knowledge gained by practice, experiment, and observation must be concentrated before it can be scientifically grasped. The more distinct and marked the point, the more concentrated will be the light coming from it, the more unmistakable the insight conveyed. All scientific thought, from the simple gravitation formula of Newton, through the more complicated formulæ of physics and of chemistry, the vaguer so-called laws of organic and animated nature, down to the uncertain statements of psychology and the data of our social and historical knowledge, alike partakes of this characteristic, that it is an attempt to gather up the scattered rays of light, the diffused knowledge, in a focus, from whence it can be again spread out and analysed, according to the abstract processes of the thinking inind. But only where this can be done with mathematical precision and accuracy is the image sharp and well defined, and the deductions clear and unmistakable. As we descend from the mechanical, through the physical, chemical, and biological, to the mental, moral, and social sciences, the process of focalisation becomes less and less perfect, - the sharp point, the

most all the present difference between the best steam-engine and the worst is some 5 or 6 per cent" (Lodge). Prof. Unwin sums up by saying: "Since 1845 purely scientific men, scientific experimenters, and practical engineers have all been engaged in the study of the steam - engine. I do not believe that any one of the three can claim all the credit for the im- provement of the steam-engine to the exclusion of either of the others. . . Representing perhaps rather the scientific than the practical interest, I do not think that the mathematical and physical researches of which I have tried to give an account have had no influence on the practical business of the engineer." 
focus, is replaced by a larger or a smaller circle, the contours of the image become less and less distinct, and with the possible light which we gain there is mingled much darkness, the source of many mistakes and errors. But the tendency of all scientific thought is towards clearer and clearer definition; it lies in the direction of a more and more extensive use of mathematical measurements, of mathematical formulæ.

There is probably no science which has come so perfectly under the control of this kind of mathematical expression as has astronony since the time of Newton or of Laplace, and we may add there exists probably no mathematical formula which has stood the test of application to existing phenomena so long and so thoroughly as the gravitation formula of Newton. It possesses two unique properties which no other formula possesses-so far as we can now see-it is universal ${ }^{1}$ and it is accurate. ${ }^{2}$ These

1 The law of gravitation can be called the first and most general physical law or statement of universal application. The laws of motion may be called mechanical or dynamical statements. Both the law of gravitation and the laws of motion describe facts, and have been found by experience; but the laws of motion contain no physical constant-i.e., no quantity which requires to be fixed and measured by observation, and the absolute value of which has for us at present no ulterior meaning. The law of gravitation has one physical constant, the universal gravitation constant (see p. 320). As it measures what we call matter, it need not be determined, and its actual determination, which has been accurately made only in recent times, has not in any direction advanced our general physical knowledge. For all practical purposes of physics the unit of mass is a weight, just as for all commercial purposes gold is the standard of value. The astronomical view permits us to go a step further and express the mass of a pound of matter in units of time and space, and the political economist may seek for a real standard of value-for instance, an article of food like wheat. Other fundamental physical laws or general statements involve other physical constants, as we shall see later on.

2 The accuracy of the so-called laws of naturc, or, more correctly, of the expressions which science gives to the laws of nature, is a very important question. Little is said on this point in the ordinary text-books. It is only in very 
two properties of the gravitation formula have been brought out by a long line of investigations, carried on with the view of substantiating or of refuting the formula. They mark the development of whole sciences, the foundation of quite novel branches of research. I propose briefly to follow up these developments.

20.

Matter and force mathe- what matter and force are, or in defining them for the matically defined. purposes of practical life. But it took thousands of years to find a definition of these quantities which could serve as the basis of exact measurement, and permit calculations of results into which both factors entered in varying

recent publications that attention is sufficiently drawn to the fact that very few mathematical formulæ in physics or chemistry are more than approximations. The law of gravitation is one of the few mathematical expressions which, besides being universal, have stood the most rigorous tests as to accuracy. A most interesting attempt to prove the inaccuracy of Newton's law was made, but speedily abandoned, by Clairaut, one of the earliest Newtonians in the old Academy of Sciences. Clairaut began about 1743 to study the lunar theory in the light of Newton's system, which Madrin before him had already despaired of reconciling with the facts of observation. When he himself, on calculating the annual motion of the moon's apogee (or farthest point in its orbit round the earth), found only half the value which observation furnished, he was tempted in his communication to the Academy of November 1747 to suggest that the Newtonian formula might require a correction for great distances. This suggestion was followed, as Lalande tells us, by a veritable scandal in the learned world. Buffon, for purely metaphysical reasons, objected to this infringement of the simplicity of the laws of the universe. The opponents of Newton's system had a short triumph, which however was speedily reversed when Clairaut, putting a greater precision into his calculations by taking inequalities into account which he had previously neglected, explained to the Academy in May 1749 that he had succeeded in reconciling the movement of the moon's apogee with the law of attraction according to the inverse square of the distance. From that time the Newtonian theory, to which only shortly before mathematicians like Euler had been won over, reigned supreme. See Lalande in the 4 th volume of Montucla's 'Histoire des Mathématiques,' p. 67, \&c. Euler's merits in solving many problems in physical astronomy were so great that the Academy procured permission from Louis XV. to receive him as a surnuméraire, the eight places granted to external members being all occupied. 
quantities and in varying combinations. That a smaller quantity of matter in motion could produce the same action as a larger which was moving slowly, or even apparently at rest, and acted only by what is termed its dead-weight, was a well-known phenomenon; but it was only within the half-century which preceded the publication of the 'Principia' that, through the labours of Galileo and of Huygens, mathematical definitions and simple formulæ were laid down, and generally accepted, which gave the means of accurately measuring and calculating the phenomena of moving bodies and the combination of forces. These labours resulted in a definition of matter which, translated into the language of our day, says that matter is that which moves and is capable of resisting any change of motion. Motion is a measurable quantity. For its measurement we require the measurement of space and time, and the well-known relation of both -viz., velocity.

The above formula therefore says that matter is measured by the resistance it offers to change of motion or of velocity. And correspondingly force is that which is capable of producing change of motion, or velocity in matter, and it is measured by the amount of change it produces. Given a definite, though unknown, force, portions of matter-i.e., masses-can be compared by the resistance they offer to the change of their motion; the smaller the change the larger the mass or quantity of matter. Given a definite, though unknown, quantity of matter, forces can be measured by the different changes they produce in the motion-i.e., the velocity-of this quantity; they are greater or smaller in the proportion 
of the change of velocity which they produce. One of the great difficulties which stood in the way of the fixing of these very simple mathematical relations and definitions was the fact that all matter with which we can experiment is under the influence of a constant but unknown force, that which makes it fall if not supported. It was only by freeing themselves from the effect of this constant force, or by balancing it, that philosophers gradually arrived at the conception and definition of mass, or quantity of matter, as something independent Weight and mass. of its weight. It was reserved for Newton to show and define the exact relation which weight bears to the other properties of matter defined and measured by his predecessors. By doing so he added a new definition, a new means of measuring the quantity of matter or its mass, showing at the same time to what extent the popular measure of matter-i.e., its weight-could be accurately used for scientific purposes. Again, to express it in the language of our day, Newton showed that matter is not only that which offers resistance to change of motion, but also that which causes change of motion in other portions of matter: it is not only the object on which force spends itself, it is the seat of this force, and the degree in which it can change motion in other portions of matter is proportional to the degree in which it resists the change of its own motion - in other words, the gravity or weight of matter is proportional to its mass or inertia, and is not dependent on any other difference, whether of size or of quality. This second universal property of matter, which brought out more clearly the reciprocity of all mechanical, and subsequently of all 
physical actions, is, however, dependent on the mutual distances of the particles of matter, and can therefore be altered, but can as little as the existence of matter itself be removed. This view of Newton's explained or described clearly ${ }^{1}$ the phenomena of moving and falling

1 The distinction between an explanation and a description of the facts of nature has been slowly developed in the course of modern thought. Probably Leibniz was the first to insist on it, and to maintain in the abstract that all description of nature would be mechanical, but that the explanation or interpretation of nature must be spiritual. But the first practical instance of this important distinction is really to be found in Newton's philosophy. In many passages of the 'Principia,' and especially in the 'Optics,' the double view of the problems of philosophy is clearly indicated. The principles of science since the time of Newton are general facts, established by experience and put into mathematical language, admitting of constant verification by observation and by the deductions of the calculus. These principles are not the ultimate causes, but only a concise description of some of the phenomena of nature. These principles Newton calls mathematicalreferring to measurable quantities -and distinguishes them from the philosophical principles ('Princ.,' 1st. ed., p. 401). Especially as regards gravitation, Newton explains many times that he uses this term not as an explanation, but only as a mathematical description of the force with which bodies approach each other, whatever the cause of this phenomenon may be, which he leaves others (called with some irony metaphysicians) to determine ('Optics,' query 31). That
Newton, besides giving the precise mathematical principles of all future dynamical science, indulged also in further speculations, which he put into the form of queries and advanced with hesitation and merely tentatively, gave his opponents ample opportunity to attack the doubtful and uncertain statements in his philosophy. Instead of studying and understanding the mathematical truths of the "Principia,' they attacked the doctrines which were fragmentarily put forward in the queries to the "Optics' or added in the general scholium at the end of the second edition of the 'Principia.' Roger Cotes in his preface to the second edition of the 'Principia,' and Clarke in his correspondence with Leibniz, pointed out the difference between Newton's descriptive and calculating and the older or metaphysical philosophy. They were, however, more interested in disproving the atheistical consequences of which Newton's philosophy had been accused than in clearly insisting on the fundamental difference between mathematical and metaphysical principles-i.e., between the exact and the philosophical views of nature. And in Bentley's Boyle lectures, delivered in 1692 and 1693 , the principles of Newton's philosophy were specially brought forward to refute atheism, an undertaking which Newton himself supported in his contemporary correspondence with Bentley, published half a century later, in 1756 . 


\section{masses, not only at a point on the surface of our earth, where the force of gravity can be considered to be con- stant, but all through the universe, where it varies with the distances of the moving masses.}

22. Gravitation not an ultimate property of matter.

The Newtonian formula of gravitation was not at once accepted by philosophers as a correct statement of the facts of nature. ${ }^{1}$ It appeared to limit the existence of

1 The philosophy of Descartes, which then reigned on the Continent, seemed in many ways to hinder the acceptance of Newton's doctrines. Descartes had taken a great step in advance in philosophical teaching ; he had placed mathematics at the head of his doctrine; he had opposed the older metaphysical methods, and he had, through his application of algebra to geometry, made great progress towards a mechanical description of phe. nomena. But he had not separated the description from the interpretation of nature. Philosophy and science remained united, the mathematical formulæ were only a new kind of metaphysics, incapable without observation of making any real advance in the knowledge of nature. The facts of geometry which are required for an application of analysis are the well-known axioms of Euclid. An application of analysis to dynamics requires a knowledge of the laws or fundamental proper. ties of motion. These were not correctly and completely known to Descartes; Newton placed them at the head of his mathematical philosophy of nature. A further application to physical phenomena required a knowledge of some general physical fact: such was supplied by Newton in the gravitation formula. The laws of motion and gravitation once admitted as facts, there was plenty to do for mathematics. Not so with Descartes. In his pliiloso- phy the basis of facts was too narrow and indefinite, and had to be supplemented by metaphysical suppositions and deductions. The field for mathematical reasoning not being sufficiently prepared and wide enough, Descartes had speedily got back again into metaphysical reasoning. In fact the doctrines of Newton, in which mathematical and philosophical deductions had for the first time been successfully separated, encountered on the Continent the doctrines of Descartes, in which mathematical and philosophical deductions were hopelessly mixed up. On one point especially the two views seemed to clash. Descartes had by metaphysical considerations tried to define what matter is. Newton had postponed the answer to this question, but had defined mathematically two properties of matter - viz., inertia and gravitation. Descartes' metaphysical considerations had led to the conception that matter and extension were identical, that space therefore could not be empty. Newton, occupying limself not with matter in the abstract, but only with moving observable matter, had established the general law of gravitation, leaving it undecided whether the apparent vacuum existing between visible bodiés was really empty or full. For the deductions from the law of gravitation it might in the first instance be considered empty. Thus on this question about space 
matter to certain changing places in an empty space, and to attach the forces of nature likewise to this distribution of matter. This was hardly the intention of the author himself, who saw in the so-called law of gravitation not a final explanation, but only a description of the phenomena of nature-notably of the larger phenomena. That behind the mathematical formula there may be conditions which are capable of further analysis, - that the larger or molar phenomena of moving bodies are made up of their smaller or molecular movements, was well known to Newton. For before he approached the great laws of the universe he had been occupied with investigations which led him into the minutest phenomena, those of light and colour. To him, indeed, are owing some of the observations and methods by which subsequently the greatest and the smallest measurements of natural objects have been carried out. But in exact science the deeper philosophical meanings disappear where the strict mathematical deductions point to definite conceptions, mark certain fixed paths of research, and promise definite results. The eighteenth century gradually settled down to a wholesale adoption of the gravitation theory-looked upon space as empty, upon matter as subject to a definite though changing distribution in space, and upon the forces of nature as attached to certain moving centres, between which only a mathematical, but no intelligible physical, connection

-whether it was empty or fullthe two doctrines came into conflict. That Newton's position was not a final, but only a provisional one, was overlooked; he was accused of introducing again the occult quali- ties of the scholastic philosophy, and a great fight was started against his views in the Academy of Sciences, where Descartes' philosophy reigned supreme. 


\section{could be traced. ${ }^{1}$ What to some contemporaries of Newton, and even to Newton himself, seemed an absurdity-that action could take place at a distance ${ }^{2}$-became through}

1 Voltaire, who did not dive very deep into the teachings of Newton, gives a graphic description of the different opinions then current in English and French learned circles. In his 'Lettres sur les Anglais,' written about the time of the death of Newton, after having discoursed on Quakerism, the Church and Gorernment, on raccination, Bacon and Locke, he devotes four chapters to the philosophy of Newton, which he contrasts with that of Descartes. "Un Français qui arrive à Londres trouve les choses bien changées en philosophie, comme dans tout le reste. Il a laissé le monde plein, il le trouve vide. À Paris on voit l'univers composé de tourbillons de matière subtile, à Londres on ne voit rien de cela. Chez nous c'est la pression de la lune qui cause le flux de la mer; chez les Anglais c'est la mer qui gravite vers la lune. . . Chez vos Cartésiens tout se fait par une impulsion qu'on ne comprend guère; chez M. Newton c'est par une attraction dont on ne connait pas mieux la cause. . . . Descartes assure encore que l'étendue seule fait la matière, Newton y ajoute la solidité" (lettre xiv.)

2 "You sometimes speak of gravity as essential and inherent to matter. Pray, do not ascribe that notion to me ; for the cause of gravity is what I do not pretend to know " (Newton's 2d letter to Bentley, 17th January 1692-93). "It is inconceivable that inanimate brute matter should, without the mediation of something else, which is not material, operate upon and affect other matter without mutual contact, as it must be, if gravitation, in the sense of Epicurus, be essential and inherent in it. And this is one reason why I desired you would not ascribe innate gravity to me. That gravity should be innate, inherent, and essential to matter, so that one body may act upon another at a distance through a vacuum, without the mediation of anything else, by and through which their action and force may be conveyed from one to another, is to me so great an absurdity that I believe no man, who has in philosophical matters a competent faculty of thinking, can ever fall into it. Gravity must be caused by an agent acting constantly according to certain laws; but whether this agent be material or immaterial, I have left to the consideration of my readers" ( 3 d letter to Bentley, 5th February 1692-93). And in the fifth answer to Leibniz (published after Leibniz's death) Clarke says: "That the sun attracts the earth ... - that is, that the earth and sun gravitate towards each other, or tend towards each other, with a force which is in a direct proportion of their masses, . . . and in an inverse duplicate proportion of their distances, and that the space betwixt them is void-that is, has nothing in it which sensibly resists the motion of bodies passing transversely through: all this is nothing but a phenomenon or actual matter of fact, found by experience. That this phenomenon is not produced sans moyen - that is, without some cause capable of producing such an effect-is undoubtedly true. Philosophers therefore may search after and discover that cause, if they can; be it mechanical or not mechanical. . . . The phenomenon itself, the attraction, gravitation, or tendency of bodies towards each other, and the laws or proportions 
a century of confirming thought, observation, and calculation an adopted axiom, and the accepted formula of all physical explanations. For a time, indeed, the exact formula of gravitation seemed liable to some correction, but gradually the apparent anomalies disappeared, and even in our century none of the many attempts to modify the gravitation formula, to look upon it as merely an approximation, or to go behind it and find some more general relation from which it could be deduced, have been generally useful or acceptable. ${ }^{1}$ It still stands there as the only universally accepted mathematical expression which corresponds to a general physical property of natural objects.

Two different lines of thought combined to give the formula of Newton a still wider importance than its author primarily intended, or than it has been found possible to maintain in the course of further inquiry. The first was the ancient philosophical idea of attraction, which, without being mathematically defined and practically useful, had nevertheless, from the dawn of Greek speculation

of that tendency, are now sufficiently known by observations and experiments. If this or any other learned author can by the laws of mechanism explain these phenomena, he will not only not be contradicted, but will, moreover, have the abundant thanks of the learned world. But in the meantime, to compare gravitation, which is a phenomenon or actual matter of fact, with Epicurus' declination of atoms seems to be a very extraordinary method of reasoning" (\$§ 118-124, Leibniz's 'Philosophische Schriften,' by Gerhardt, Berlin, 1890, vol. vii. p. $439 s q$.)

$i$ A very complete account of these different attempts will be found in the writings of C. Isenkrahe, 'Das Räthsel von der Schwerkraft,' Braunschweig, 1879 ; "Euler's Theorie von der Ursache der Gravitation," in 'Zeitschrift fiir Mathematik und Physik,'vol. xxvi.; 'Ueber die Fernkraft,' Leipzig, 1889 ; “Ueber die Zurïckführung der Schwere auf Absorption," in 'Abhandlungen zur Geschichte der Mathematik,' vol. vi., Leipzig, Teubner, 1892. See also as bearing on this subject, Paul du Bois-Reymond, 'Ueber die Grundlagen der Erkenntniss in den exacten Wissenschaften,' Tübingen, 1890. : 
and all through ancient and mediæval philosophy, figured as one of the occult causes or forces which regulate the

23. Attraction and repulsion. behaviour of living and dead matter. That the force of attraction alone would result in an accumulation of all matter in one body was of course recognised, and a second arbitrary and occult force-that of repulsion-was introduced as a counteracting or balancing agent.

In Newton's system of the universe the balancing force was found to be that of an inherent initial motion which matter, in consequence of its mass or inertia, maintained in addition to the motion due to gravitation. If motion and inertia were able to account for the apparent repulsion of bodies at a distance, it might be that they could also account for their apparent attraction. This idea, though expressed about the time when the Newtonian gravitation formula was established, did not meet with serious attention till far on in our century other lines of thought led to similar views. ${ }^{1}$ The phenomena of attrac-

1 Newton himself seems to have looked for a mechanical explanation of gravitation. Long before the publication of the 'Principia' he laid before the Royal Society a paper containing "a hypothesis explaining the properties of light" by the assumption of an "ætherial medium, much of the same constitution with air, but far rarer, subtiler, and more strongly elastic" (Letter to Oldenburg, January 25, 1675- 76 , given in Brewster's 'Memoirs of Sir I. Newton,' vol. i. p. 390 sqq.), which might explain magnetic and electric phenomena, as well as those of gravitation, and especially light. And in a letter to Robert Boyle, of 28th February 1678-79 (Brewster, vol. i. p. 409), he reverts to this subject. Having, however, in the course of the next decade found it more useful to work out the mathematical conclusions to be drawn from the phenomenon of gravitation, which was a fact and not a hypothesis, he abandoned the metaphysical part of the subject, the question how gravitation was to be explained, "finding" (as Maclaurin says in his account of Newton's discoveries) "that he was not able, from experiment and observation, to give a satisfactory account of this medium and the manner of its operation in producing the chief phenomena of nature." And in his letter to Boyle, as well as in a later one to Halley (20th June 1886, Brewster, vol. i. p. 439), he carefully distinguishes between the results of the 'Principia' and 


\section{tion and repulsion at a distance rather received additional} weight and importance when, following Newton's cosmical measurements, Cavendish and Coulomb, towards the end

the mere framing of hypotheses and conjectures, for which he professes to have little fancy, though "the heads of some great virtuosos rull much upon hypotheses"; and he describes his earlier speculations as "guesses which I did not rely on." In fact, the elaboration of the theorems contained in the 'Principia' marks the transition from the metaphysical to the exact or scientific treatment of natural phenomena. Before Newton showed the far-reaching consequences, the unexpected grasp of a simple mathematical formula in combining facts apparently disconnected, no one could have suspected that such would be possible, and it is not to be wondered at that when once philosophers realised the power of such formulæ, an opposite movement set in through which mathematical processes were extolled at the expense of experiment and observation on the one side, and of philosophical reasoning on the other. Newton himself never fell into this error. He knew well the importance of observation, and he retained to the end of his life a great interest in the philosophical or metaphysical problems which lay beyond or behind the mathematical statement; he carefully distinguished between the vis gravitatis and the causa gravitatis. Two other great thinkers, second only to Newton himself, took up a similar position to the law of gravitation. Whilst firmly believing in it, they considered it to be not an ultimate law of nature, a causa occulta, but believed that it must be possible to derive it from some mechanical properties of matter. The one was older than Newton. It was Huy- gens (1629-95) who through his analysis of centrifugal forces (1673) had done so much to pave the way for Newton's own work. In 1690, after having paid a visit to England in order to become more intimately acquainted with Newton's work, he published at Leyden his 'Discours sur la Cause de la Pesanteur,' a treatise which was little noticed at the time, and in which he is supposed to have revived the vortices of Descartes. Those who have carefully examined it (Fritsch, 'Theorie der Newton'schen Gravitation,' \&c., Königsberg, 1874 ; and Isenkrahe, 'Das Räthsel von der Schwerkraft,' p. 87, \&c.), find that Huygens reverted to his conception of a material fluid, an etler, such as he had suggested for the explanation of optical phenomena, "which surrounds the earth up to very great distances, which consists of the minutest particles, which fly about in the most different ways in all directions with tearing velocity "an anticipation surely of Lesage's "ultramundane corpuscles." The other great thinker who, whilst firmly believing in Newton's law, sought for a mechanical explanation of it, was Leonhard Euler (1707-83). In his ether theory, to which he reverts frequently, he made an attempt to explain the various physical agencies, among them gravitation (1743, in his 'Dissertatio de Magnete,' which received in 1744 the prize offered by the Paris Academy), by the pressure of the ether. He admits the difficulty of the problem, but insists upon the necessity of finding a mechanical cause for gravitation. See Isenkrahe in 'Zeitschrift für Mathematik und Physik,' vol. xxvi.; but 
24. of the last century, subjected the less universal terrestrial Electrical and magnetic action. phenomena of magnetic and electric action to exact measurements, finding that a formula corresponding to the gravitation formula described them with surprising accuracy, with this remarkable difference, that here not only attractive but also repulsive forces, following the same mathematical relations as to mass and distance, came into play. To these confirmatory discoveries must be added the measurement of the intensity of radiations which proceed from centres, such as those of light and heat, made by various philosophers during the latter half of the last century. Newton, and his great successor Laplace more than a century after him, both favoured the emission or emanation hypothesis of light, and it was thus natural to fasten upon the analogy which existed between the intensity in which radiation, gravitation, and electric and magnetic action change with the distance 25. from their respective centres. All these agencies came emanations. thus under the general conception of forces emanating from fixed centres, and spreading through space, in the proportion of the superficial area of the spheres described around their centres with increasing radii-i.e., decreasing or becoming diluted in the ratio of the squares of these radii or distances. These analogies were indeed recognised to be very imperfect, inasmuch as light and radiant heat occupy a measurable time to spread from their centres, whereas the time occupied by the force of gravitation is

especially Miething, 'L. Euler's Lehre vom Aether,' Berlin, 1894. In the course of this century the mechanical theory of gravitation, including the attempts of Lesage, Euler, Huygens, and Newton him- self, has again received attention through Faraday's, Maxwell's, and Hertz's electric theories, and Wm. Thomson (Lord Kelvin) has especially studied the ideas of Lesage. Of this more later on. 


\section{either exceedingly small or this force is propagated} instantaneously through the greatest cosmical distances which come under our notice. Then, again, light and radiated heat spend themselves as they meet with reflecting or absorbing bodies, whereas gravitation does not seem to be affected by intervening or screening bodies. ${ }^{1}$

1 It is now known that this screening effect exists likewise in magnetic and electric action. In the formula which expresses the action at a distance of magnetic, electrical, and ponderable masses, viz., $f=\mu \frac{m . m^{\prime}}{r^{2}}$, the older viewprevious to Faraday's researchesconsidered $m$ and $m^{\prime}$ the masses (ponderable or imponderable), and the distance $r$ to be variable, $\mu$ a constant, corresponding to the gravitation constant. As stated above, the gravitation constant is, so far as we know, a real constant-i.e., it is not affected by the nature of the medium which fills the space intervening between $m$ and $m^{\prime}$, the attractive masses. Faraday doubted this ; but leaving gravitation-"as a relation by some higher quality" -aside, he directed his efforts to the testing of the validity of this view as regards electric and magnetic action. He found that $\mu$ is not a real constant, but dependent on the nature of the medium and the objects which intervene between the magnetic and electric masses. These researches, which are probably the first step in the direction of gaining by observation some notion of the mechanical manner in which action at a distance is brought about, begin with the year 1837 (see 11th series of 'Experimental Researches in Electricity,' No. 1252). The result was that the "specific electric induction for different bodies" was established, contrary to the ideas of
Poisson and others ('Exper. Res.,' No. 1167), and the word "dielectric " invented to denote the "action of the contiguous particles of the insulating medium" (No. 1168). From this point he was led a step farther, to " expect that all polar forces act in the same general manner "-viz., by contiguous particles. Faraday, however, is careful to remark that by contiguous particles he means those "which are next to each other, not that there is no space between them" (No. 1665).

In 1838 Faraday was still doubtful whether magnetic action was similar in this respect to statical electric action; but he thought it probable that it was "communicated by the action of the intervening particles" (No. 1729), and in pursuing this line of thought, in spite of many unsuccessful trials, he at last saw his ideas realised, discovered the magnetisation of light, and invented the term "diamagnetic" to describe "a body through which lines of magnetic force are passing, and which does not by their action assume the usual magnetic state" (1845, 'Exper. Res.' No. 2149). At the end of the 19th series of researches he says: "In former papers (1838) I proposed a theory of electrical induction founded on the action of contiguous particles, . . . and I then ventured to suggest that probably . . magnetic action was also conveyed onward in a similar man. ner. At that time I could discover 
Nevertheless, the fact that gravity, radiation, and electric and magnetic action appear as central emanations, decreasing with the square of the distance,-two properties which lend themselves to mathematical and geometrical representation,- - seemed to pave the way for further generalisations. All forces in nature were put down as central forces, either attractive or repulsive, and if not following the Newtonian formula, still dependent on the distance according to some mathematical expression. For nearly a century theoretical physics were occupied in working out the mathematical formulæ expressive of these ideas, and Laplace himself promoted these attempts by the weight of his great authority. We do not possess the final views on this point with which the great mathematician intended to complete the last edition of his 'Exposition du Système du Monde'; but some of the later chapters of 26. this work, treating of gravitation and molecular attraction,

Yrolecular action. show us clearly in which direction he looked for progress in theoretical physics. ${ }^{1}$

no peculiar condition of the intervening or diamagnetic matter; but now that we are able to distinguish such an action;... now that diamagnetics are shown not to be indifferent bodies, I feel still more confidence in . . . asking whether it may not be by the action of the contiguous or next succeeding particles that the magnetic force is carried onward," \&c. (No. 2443). Faraday also made repeated experiments with the view of determining how the force of gravitation is communicater, believing as little as Newton did in an actio in distans, and he was wont to quote Newton's words on this matter, referring also to Euler's ether theory (No. $3305)$.
${ }^{1}$ In the fifth edition of the ' Exposition du Système du Monde' Laplace had suppressed these chapters, and had announced his intention "to unite the principal results of the application of analysis to phenomena depending on a molecular action differing from universal attraction" into a special treatise which should form a sequel to the 'Exposition,' \&c. This project was never carried out (see "avertissement au sixième édition de 'l'Exposition'"). The success which attended Laplace's attempts to explain double refraction and aberra. tion of light (following Newton's suggestions in the 'Principia' and 'Optics') as well as capillary phenomena (following Haukesbee) left no 


\section{The great prominence given by Laplace to the gravita-} tional explanation of all natural phenomena, the fact that all the observable movements of the universe, the shape and size of the moving masses, and the orbits they describe, as well as many phenomena observable on the surface of our globe, such as the aberration and refraction of light, the phenomena of the tides, of atmospheric pressure, and some of the more important molecular properties of matter, could be perfectly or approximately described, calculated, and predicted by gravitation or analogous attractions, gave to what we may call-following a hint of Clerk Maxwell's-the astronomical method ${ }^{1}$ of con-

doubt in his mind that such phenomena "are owing to attractive and repulsive forces between molecule and molecule" ("Expos.,' 6me. éd., p. 328). He saw in molecular attraction the cause of the solidity of bodies, of chemical affinities, and of the properties of chemical saturation, which Berthollet had developed about that time ('Expos.,'p. 360); he thinks it likely that the law of molecular attraction is the same for all bodies, and he finally dwells on the question whether the attraction of gravity and molecular attraction could be united under one common law or expression (p. 363), and throws out the idea that thus the phenomena of physics and astronomy might be brought under one general law, adding, however, significantly, "Mais l'impossibilité de connaître les figures des molécules et leurs distances mutuelles, rend ces explications vagues et inutiles à l'avancement des sciences."

1 " Cavendish, Coulomb, and Poisson, the founders of the exact sciences of electricity and magnetism, paid no regard to those old notions of 'magnetic effluvia' and 'electric atmospheres' which had been put forth in the previous century, but turned their undivided attention to the determination of the law of force, according to which electrified and magnetised bodies attract or repel each other. In this way the true laws of these actions were discovered, and this was done by men who never doubted that the action took place at a distance, without the intervention of any medium, and who would have regarded the discovery of such a medium as complicating rather than as explaining the undoubted phenomena of attraction. . . . Ampère, by a combination of mathematical skill with experimental ingenuity, first proved that two electric currents act on one another, and then analysed this action into the resultant of a system of push-and-pull forces between the elementary parts of these currents. ... Whereas the general course of scientific method then consisted in the application of the ideas of mathematics and astronomy to eacl tion in turn, Faraday seems to have had no opportunity of acquiring a technical knowledge of 
27.

The astronomical

view.

Cosmical, molar, and molecular phenomena.

sidering nature a great impetus. As we have seen, it was entirely an outcome of Newton's great discovery.

It is sometimes useful to distinguish between cosmical, molar, and molecular phenomena; it is, however, well to note that this distinction is a popular or practical, not a scientific one. The question, in low far pure magnitude affects the appearance and relations of the parts or elements of which the universe is composed, is indeed of great scientific interest, but it has not yet received a definite answer. In the meantime we can use the term cosmical for such magnitudes of space, "mass, or time as far transcend our own powers of direct measurement by the foot-rule, the balance, and the timepiece, and still more, our powers of direct action: those dimensions compared with which our own homes and actions absolutely disappear. We will call molar those masses which we can handle directly, those dimensions in which we build our own homes and pass our own lives. And we will call molecular those sizes and masses which on the other side are so small that the utmost powers of the microscope and the dividing machine fail to make them directly visible, still less tangible or manageable for our active powers. The lines which limit these three regions are indeed neither fixed nor fixable; the middle region, which

mathematics, and his knowledge of astronomy was mainly derived from books. . . Thus Faraday was debarred from following the course of thought which had led to the achievements of the French philosophers, and was obliged to explain the phenomena to himself by means of a symbolism which he could understand, instead of adopting what had hitherto been the only tongue of the learned" (Clerk Maxwell, "Action at a Distance," "Proceedings of the Royal Institution,' vol. vii. Reprinted in 'Scientific Papers,' Cambridge, 1890, vol. ii. p. 317 sq. Cf. also vol. i. p. 156). Du BoisReymond uses the term "astronomical knowledge" in a somewhat wider sense in his discourse "Ueber die Grenzen des Naturerkennens" ('Reden,' vol. i. p. 120). 
we may call our own home, seems to be extending through improved means of seeing and handling; still every one has a vague notion, and science has supported this notion, that there are certain limits, marking the immeasurably large and the immeasurably small, which we cannot transcend. Now it is a question of great scientific interest to what extent mere enlargement, such as the microscope makes familiar to us, would essentially alter the behaviour and appearance of things natural. Would the planetary or stellar systems, reduced in size many million times, present an aspect similar to the view we here enjoy of the inanimate matter on the surface of our earth, and would the molecular structure of microscopic objects, many times enlarged, differ essentially from that aspect? Our present knowledge would lead us to say they would essentially differ. Certain phenomena or modes of motion seem, so far as we know, essentially characteristic of the molecular, others of the molar, others again of the cosmical world. ${ }^{1}$

1 Laplace has made a significant remark on this point. See 'Exposition du Système du Monde,' 6 éd., p. 319 sq.: "La loi de la pesanteur réciproque au carré des distances . . . est cellc de toutes les émanations qui partent d'un centre, telle que la lumière; il paraît même que toutes les forces dont l'action se fait apercevoir à des distances sensibles, suivent cette loi : on a reconnu depuis peu, que les attractions et les répulsions électriques et magnétiques décroissent en raison du carré des distances, en sorte que toutes ces forces ne s'affaiblissent en se propageant, que parcequ'elles s'étendent comme la lumière; leurs quantités étant les mêmes sur les diverses surfaces sphériques que l'on peut imaginer autour de leurs foyers. Une propriété remarquable de cette loi de la nature est que si les dimensions de tous les corps de cet univers, leurs distances mutuelles et leurs vitesses, venaient à augmenter ou à diminuer proportionellement; ils décriraient des courbes entièrement semblables à cclles, qu'ils décrivent, et leurs apparences seraient exactement les mêmes ; car les forces, qui les animent, étant le résultat d'attractions proportionelles aux masses divisées par le carré des distances, elles augmenteraient ou diminueraient proportionellement aux dimensions du nouvel univers. On voit en même temps, que cette propriété ne peut appartenir qu'à la loi de la nature. Ainsi, les apparences des mouvements de l'uni- 
28.

Special interest attachéd to molar dimensions.

And we cannot but be struck by the fact that only those dimensions which we call molar appear to be the abode of living and conscious beings. The cosmical world has, so far as we know, no inhabitant which can behold it in the same way as man beholds this planet, and the same obtains so far as we are acquainted with the molecular world. So far as our knowledge goes and is likely ever to reach, a special importance or dignity will therefore always belong to molar dimensions and masses. The process by which we try to picture to ourselves in tracings and models, constructed in molar dimensions, the behaviour and appearance of cosmical as well as molecular masses will always recommend itself, not only as the most practical, but likewise as the most interesting and plausible, for only by this procedure do these unreachable worlds become amenable to direct observation and to the processes of experiment in the physical laboratory. It seems prima facie that the wealth of phenomena and the variety of different kinds of motion decrease as we ascend into the cosmical, or as we descend into the molecular world, giving way in the former to essentially uniform, though to many times multiplied modes of motion, and disappearing in

vers sont indépendantes de ses dimensions absolues, comme elles le sont, du mouvement absolu, qu'il peut avoir dans l'espace; et nous ne pouvons observer et connaître que des rapports." This is easily seen. For if in the formula $f=\frac{m . m^{\prime}}{r^{n}}$, the dimensions be all multiplied by $K$, we get the new formula $F=K^{6-n} \times \frac{m \cdot m^{\prime}}{r^{n}}$, and the acceleration of a body moving round a centre like the sun would be $\frac{F}{K^{3} m^{\prime}}=K^{3-n} \times \frac{m}{r^{n}}$, which is only $K$ times the acceleration $\frac{m}{r^{n}}$, if $n=2$. In another passage Laplace repeats the above statement in slightly different words: "L'univers réduit successivement jusqu'au plus petit espace imaginable, offrirait toujours les mêmes apparences à ses observateurs" (p. 440). That this would not apply to molecular attractions or repulsions is evident. 
the latter in stable and self-repeating averages. Possessed therefore, as we seem to be, of the greatest wealth and variety of observations and notions, we may-perhaps erroneously - conclude that we can grasp the simpler cosmical and molecular movements and phenomena by starting from molar, physical, or mechanical models. ${ }^{1}$

1 English naturalists have always excelled in this line of investigation, whereas foreign scientific literature has been rich in purely mathematical deductions from formula which contained no construirbarc Vorstellung. And it is interesting to note that both lines of thought go back to Newton. Whereas Newton himself believed in the possibility of a mechanical explanation or representation of the gravitation formula, the second edition of the "Principia' by Cotes can be looked upon as sanctioning the view that gravitation is an ultimate quality which must be accepted as such; and as it was the second edition through which Newton's ideas became largely known on the Continent, it is not surprising that he was there accused of reintroducing the qualitatcs occultce of the older metaphysics, which Descartes and others had successfully banished. Clerk Maxwell says ("Action at a Distance," 'Scient. Pap.,' vol. ii. p. 316): "The doctrine of direct action at a distance cannot claim for its author the discoverer of universal gravitation. It was first asserted by Roger Cotes in his preface to the 'Principia,' which le edited during Newton's life. According to Cotes it is by experience that we learn that all bodies gravitate. We do not learn in any other way that they are extended, movable, or solid. Gravitation, therefore, has as much right to be considered an essential property of matter as extension, mobility, or impenetra- bility. And when the Newtonian philosophy gained ground in Europe, it was the opinion of Cotes rather than that of Newton that became most prevalent." In fact, philosophers could be divided into two classes - those who took the fact of gravity or the wider idea of a universal attraction as a beginning, and drew from this beginning all the possible mathematical and experimental consequences which they could think of ; and those who, whilst admitting this process as a lcgitimate one, thought it necessary to go behind the assumed beginning and find a still more hidden mechanial reason for this admitted property. To the latter. class belonged Newton himself, Huygens, Euler, and in modern times notably Faraday and his followers; to the former class belonged Daniel Bernoulli, who wrote to Euler, 4th February 1744, refer. ring to the ether theory of the latter: "Mloreover, I believe both that the ether is gravis versus solem and the air versus terram, and I cannot conceal from you that on these points I am a perfect Newtonian, and I am surprised that you adhere so long to the principiis Car. tesianis ; there is possibly some feeling in the matter. If God has been able to create an animam whose nature is unknown to us, $\mathrm{He}$ has also been able to impress an attractionem universalem materia, though such is attractio supra captum, whereas the principia Cartesiuna involve always something contra captum" (see 
29.

Geometrical axioms.

I may, in passing, mention here that in the course of our century certain views have been put forward in pure mathematics, or rather in geometry, which make it conceivable, if not probable, that our ideas of space might not apply to immeasurably small or to immeasurably large dimensions. ${ }^{1}$ Should the future progress of thought

Miething, 'L. Euler's Lehre vom Aether,' p. 30). In quite recent times a similar position has again been taken up by Paul du BoisReymond in his essay "Ueber die Unbegreiflichkeit der Fernkraft," in the "Naturwissenschaftliche Rundschau' (vol. iii. No. 14), and in his posthumous work, 'Ueber die Grundlagen der Erkenntniss in den exacten Wissenschaften' (Tübingen, 1890), in which he adds action at a distance as a third "ignorabimus" or unknowable problem to the two given in his brother Emil's address, "Ueber die Grenzen des Naturerkennens" (1872, reprinted in 'Reden,' vol. i. p. 105). On the Continent, about thirty years ago, the fruitlessness of pursuing this problem seemed generally admitted. Helmholtz in 1847 speaks of the initial assumption "that all actions in nature are to be reduced to attracting and repelling forces, whose intensity depends merely on the distance of points mutually acting on each other" (actio in distans), and Du Bois-Reymond repeats this in 1871 in his address. But it is significant that Helmholtz, who (through his memoir on vortex motion in 1858) gave such an impetus to the mechanical explanations of molecular forces, modified his views on this point (see his address on Magnus, 1871, 'Vorträge und Reden,' vol. ii.) ; accordingly in the reprint of his memoir of 1847 he has accompanied it with some significant remarks on the necessity of that initial assumption (1881, 'Wissen- schaftliche Abhandlungen,' rol. i. p. 68).

1 Riemann was probably the first to give expression to this line of thought. His memoir on this subject, "On the Hypotheses which lie at the Foundation of Geometry," has the date 1854. It was read before the Philosophical Faculty of Göttingen in the presence and at the request of Gauss, on whom it made a profound impression (see the biographical notice on Riemann by Dedekind, attached to Riemann's 'Gesammelte Werke,' Leipzig, 1876). The memoir was not published till after Riemann's death in 1867. In England the late Prof. Clifford introduced the subject to the Cam. bridge Philosophical Society in 1870: "The axioms of plane geometry are true within the limits of experiment on the surface of a sheet of paper, and yet we know that the sheet is really covered with a number of small ridges and furrows, upon which these axioms are not true. Similarly although the axioms of solid geometry are true within the limits of experiment for finite portions of our space, yet we have no reason to conclude that they are true for very small portions; and if any help can be got thereby for the explanation of physical phenomena, we may have reason to conclude that they are not true for very small portions of space" (see Clifford's 'Mathematical Papers,' p. 21. Compare also his lectures on "The Philosophy of the Pure Sciences" in 'Lectures and Essays,' vol. i. p. 295 sqq.) 
or observation bring forward any indications that the idea is not only a theoretical possibility, but an actual reality, then the mode of thought now so successfully used-viz., that of transferring phenomena belonging to molar dimensions, and exemplified in the physical laboratory, into cosmic or molecular space by a process of enlarging or of reducing — would become inapplicable. Mathematics indeed would not fail, but our ordinary geometry and the physical model and mechanism would fail: we should probably still be able to calculate, though not to represent, those phenomena of immeasurable dimensions.

As it is, the first great example of calculating and predicting the phenomena of an unreachable world was Newton's successful attempt to explain the movements of the moon, and other cosmical bodies, by using the phenomena of falling bodies on the surface of the earth described by Galileo and Huygens; and he was rewarded by the discovery of a universal law of attraction, which Difficulty of measuring would probably never have been discovered by experigravitation ments carried on within molar dimensions, the mass of the earth being so immeasurably greater than that of any molar masses under our control. It quite escapes our observation that in the action and reaction of the falling stone the immensity of the earth's mass is compensated by the vanishing distance through which the earth moves when attracted by the stone. Thus the astronomical view came to the rescue of physical or molar experiments, helped to explain them, and indicated the manner in which cosmical forces could be measured even on the surface of the earth. The pendulum experi- 
ments of Richer, Halley, and many others, the measurements of the arc of the meridian, and Cavendish's and Maskelyne's experiments, were some of the direct results of the discovery.

It was natural that, having explained the cosmical, and subsequently many terrestrial phenomena, successfully by the formula of attraction, Newton himself, and still more Laplace and his school, should have attempted the explanation of molecular phenomena by similar methods.

31.

Astronomical view of molecular phenomena.

The astronomical view spread into molar and molecular physics. Newton himself made use of the notion of molecular attraction ${ }^{1}$ - i.e., of attraction existing only at

1 In the fourteenth section of the first book of the 'Principia' Newton is however careful to speak always of "attractio vel impulsus," leaving it open to the reader to form his own opinion whether it is an action at a distance or a "vis a tergo," a push. He says also that the particles of light approaching solid bodies with a definite relocity are bent, "quasi attracti in eadem (i.e., corpora)." And in the twenty - third query to the first Latin edition of the 'Opticks' (1706) he says: "May not the small particles of bodies have certain virtues, powers, or forces by which they act at some distance, not only on the rays of light, reflecting, refracting, or inflecting them, but also on each other, producing various natural phenomena? For it is sufficiently known that bodies mutually act on each other through the attraction of gravity and through magnetic and electric virtue. And these examples show what is the order and reason of nature, so that it becomes very probable that there may be other attractive forces. For nature is very similar and agreeing to her- self. Through what efficient cause these attractions are brought about I do not inquire here. What I here call attraction may well be produced by an impulse or in some other way unknown to us. I take this word attraction here in this way, that it be understood merely to mean some universal force with which bodies try to approach each other, whatever cause this force may have to be attributed to. For from the phenomena of nature it behoves us first to be taught which bodies attract each other, and what are the laws and properties of this attraction, before we inquire by what efficient cause this attraction is brought about. The attraction of gravity and of the magnetic and electric virtue extend to sufficiently large distances, so that they fall under the notice of the vulgar senses; but it may be that there are others which are contained in such narrow limits that they have so far escaped all observation." And he goes on to speak of the deliquescence of some salts and of chemical combinations of finely powdered substances. And further on in the same query, after 


\section{very small distances-to explain the refraction and in- flection of light passing from empty space, or from the}

referring to attractive forces acting only at small distances, he proceeds: "And as in algebra, when the positive quantities disappear and cease, negative quantities begin; so in mechanics, where attraction stops, there a repelling force must come in. But that such a force exists, seems to follow from the reflection and inflection of the rays of light. For the rays are repelled by bodies in both these cases, without the immediate contact of the reflecting or inflecting body. And if all this is so, then the whole of nature will be very simple and similar to herself ; performing all the great motions of the heavenly bodies by the attraction of gravity, which exists between all those bodies, and almost all the smaller motions of their particles through some other attracting and repelling force, which exists mutually between those particles" ('Optice,' MDCCVI., p. 341). The suggestions of Newtion regarding forces of molecular dimensious were taken up by other contemporary writers and experimentalists, and the 'Philosophical Transactions' during the early years of the last century contain several memoirs touching on this subject, notably by John Keill (1708), who refers to Newton's 'Opticks,' and enlarges, as does also John Friend ('Lectiones Chymice'), on the usefulness of the idea of molecular attraction in explaining chemical and physiological phenomena. In the later editions of the 'Opticks,' evidently in consequence of the elaborate experiments of Hauksbee, Newton enters more fully into the question of molecular, especially capillary, action; and his last query, No. 31, is quoted by Laplace in his 'Théorie de l'Action capillaire,' which forms the supplement to the tenth book of the 'Mécanique céleste.' I may here mention that as some confusion exists in the different editions of the 'Optics' regarding the numbering of the "Queries," it is best to refer to Horsley's Collected Edition of the Works of Newton, where the latest English edition is reprinted, and all the variations and additions noted from the first (English) edition through the subsequent ones. The first edition breaks off with query 16 ; the first Latin one with query 23 , and this was in later editions numbered 31 , a number of new queries being inserted, Nos. 18 to 24 , referring to the "probability of a medium more subtle than air" and the "mechanical efficient of gravity." This was added "to show" (Newton's words in preface dated 16th July 1717) "that I do not take gravity for an essential property of bodies, ... choosing to propose it by way of a question, because I am not yet satisfied about it by way of experiments." We may note that this was written a few years after the second edition of the 'Principia' was published by Cotes, whose preface did a good deal to occasion the misunderstanding regarding Newton's views on gravitation as a primary quality of matter. From his correspondence with Cotes, edited by Eddleston (1850), we know that Newton in composing the "Scholium generale," which is added to the second and later editions of the 'Principia,' had intended to say " much more about the attraction of the small particles of bodies," but that on second thoughts he abandoned this intention (p. 147). 
atmosphere, into or in the neighbourhood of solid bodies. He conceived light to be a material substance, consisting of minute particles, propelled in straight lines from the luminous centres. These small particles, when arriving at or near the surface of transparent bodies, came under the influence of an attraction from the substance of such bodies, and Newton succeeded in showing that for rays of light which fall on transparent surfaces at an angle, the path of the ray in the body would be deflected according to the rule experimentally determined by Snell, and published by Descartes. This application of the idea of attraction, or action at a distance, to very small or molecular dimensions, required a modification of the gravitation formula. The first who took an important step farther in this direction was Francis Hauksbee. Between the years 1709 and 1713 he made a series of experiments on what is called capillary action. His experiments were discussed by Newton in the later editions of the 'Opticks,' and followed by those of Dr Jurin in 1718. Hauksbee, Newton, Jurin, and subsequent writers, like Clairaut, all attributed these and similar phenomena to molecular attractions, and Laplace showed that for the mathematical treatment of the subject a knowledge of the exact law (corresponding to the Newtonian law of molar attraction) was unnecessary, but that it was necessary and sufficient to assume the existence of an attraction of the molecules of bodies, which decreases very rapidly as their distances increase, "so as to become insensible at the smallest distances perceptible by our senses." 1 The phenomena of atmos-

1 See 'Mécanique céleste,' vol. iv. (1805), Supplement, p. 67. See also p. 2 : "J'ai cherché, il y a long. temps, à déterminer les lois d'attraction qui représentent ces phénomènes: de nouvelles recherches 
pheric refraction as well as those of cohesion and adhesion of bodies-i.e., the attraction of particles of the same or of different matter under what is commonly called contact or at distances which we call in science molecular-were thus submitted to calculation, and the results brought largely into harmony with experience. ${ }^{1}$ The problem presented itself and occupied natural philosophers all through the last century, whether a more general law of action at a distance could be found which comprised the phenomena of molecular as well as of molar attraction.

The most celebrated attempt in this direction is that of the Jesuit Roger Boscovich, who in 1758 published an elaborate treatise on this subject. ${ }^{2}$

33. Boscovich's extension of the Newtonian formula. m'ont enfin conduit à faire voir qu'ils sont tous représentés par les mêmes lois qui satisfont aux phénomènes de la réfraction, c'est-à-dire par les lois dans lesquelles l'attraction n'est sensible qu'à des distances insensibles; et il en résulte une théorie complète de l'action capillaire."

1 The terms insensible and imperceptible, which are commonly used in these discussions, must be taken with caution. It is now known that, though not directly perceptible or sensible, the distance through which molecular action takes place is measurable. Plateau in Belgium (1843 and following years) and Quincke in Germany (1868) made experiments on independent lines, and came to very similar results. The distance of molecular action appears to be about the twenty thousandth part of a millimetre. See Clerk Maxwell's article on Capillary Action in the 9 th edition of the 'Ency. Brit.,' reprinted in 'Scientific Papers,' vol. ii. ; also Violle's ' Cours de Physique,' German edition, vol. i. p. 591, \&c., and p. 639.
2 Roger Joseph Boscovich, of the Society of Jesus (1711-87), took up the ideas thrown out by Newton in the last query to the 'Opticks,' and published in 1758 at Vienna an elaborate treatise with the title 'Theoria Philosophia Naturalis redacta ad unicam legem virium in Natura existentium.' A second edition was published at Venice in 1763. His speculations begin with the year 1745, when he hit upon his general view that all forces in nature can be reduced to the action of indivisible and inextended atoms, endowed with inertia and with a mutual force which at vanishing distances is repulsive, which at insensible distances alternates according to some mathematical formula between repulsion and attraction, and, finally, at sensible distances becomes identical with Newton's force of gravitation. The general form of the curve which exhibits this action at a distance is given, and the algebraical formula discussed, in the Supplement. But it was, of course, impossible to define the law any further. The 


\section{Though many of the views contained in this treatise} were really the same as those embraced by a large school
of Continental mathematicians till far into this century,

whole treatise is really more of a philosophical than a mathematical or experimental investigation. A large portion is taken up in defending his view against possible objections, and in showing how it agrees with or differs from the philosophies of Leibniz and Newton. Whilst this treatise represents in general a view largely held by Continental plilosophers of nature, it does not contain any new mathematical methods such as the 'Prin. cipia' contained before and Laplace's 'Mécanique céleste' later, nor does it contribute any experiments such as those works likewise contained and suggested to others. In fact, it is more a metaphysical than an exact treatise, and as such has exerted no lasting beneficial influence on the progress of science. "The eighteenth century made a school of science for itself, in which for the not unnatural dogma of the earlier schoolmen, 'matter cannot act where it is not,' was substituted the most fantastic of paradoxes, contact docs not exist. Boscovich's theory was the consummation of the eighteenth - century school of physical science. This strange idea took deep root, and from it grew up a barren tree, exhausting the soil and overshadowing the whole field of molecular investigation, on which so much unavailing labour was spent by the great mathematicians of the early part of our nineteenth century. If Boscovich's theory no longer cumbers the ground, it is because one true philosopher required more light for tracing lines of electric force" (Sir William Thomson's Lecture before the Royal Institution, May 1860. Reprinted in 'Papers on
Electrostatics and Magnetism,'2d ed., 1884, p. 224). Nevertheless it is extraordinary to note that Boscovich's theory was more popular among British than among Continental physicists. In France the book seems to have been little appreciated, although Boscovich was well known through his optical and astronomical researches (see Montucla's ' Histoire des Mathématiques,' vol. iii. p. 490, vol. iv. p. 188); and his differences with D'Alembert were notorious. But Frencl science was then occupied less with metaphysical theories than with mathematical analysis and experimental research. In Germany the book remained unknown, probably because Euler's authority favoured an opposite theory. In this country, however, the theory is often referred to from the time of Priestley ("History of Optics,") to Faraday ("On the $\mathrm{Na}$ ture of Matter," 'Phil. Mag.,' 1844, vol. 24), and more recently Thomson (Lord Kelvin). The last has probably more than any other living writer of similar eminence referred to Boscovich, whose theory he considers suggestive, and we are indebted to him for the first serious attempt to establish by actual cal. culation the real capabilities of the Boscovich atoms in explaining the properties of chemical molecules, their stability and degree of saturation (see the Report of the British Association at Liverpool, 1896). In Scotland Boscovich's theory was fully discussed in a posthumous article on "Corpuscular Forces" by John Robison, Professor of Natural Philosophy at Edinburgh, and published by Brewster in the 1st volume of Robison's 'System of Mechanical Philosophy' (Edinburgh, 


\section{the book was almost completely forgotten on the Con-} tinent. ${ }^{1}$ No real progress has indeed been made in the explanation of physical phenomena by the application of

1822). His 'Elements of Mechanical Philosophy' (Edinb., 1804) betray, according to Dugald Stewart, "a strong and avowed leaning to the theory of Boscovich" (Works by Hamilton, vol. v. p. 107). The theory probably found favour, among other reasons, because it seemed to give support to the prevalent corpuscular theory of light, which Euler opposed, as he did simple action at a distance. In the Scotcl school of philosophy, of which Dugald Stewart was the most popular exponent, Boscovich was well known. Stewart refers to him frequently (Works by Hamilton, vol. ii. pp. $50,107,110,343$; vol. iii. p. 233 ; vol. v. p. 93 sqq.; vol. vii. p. $173 s q q$.$) He quotes Priest-$ ley, Robison, and James Hutton as followers of Boscovich, whilst his own adherence is certainly very qualified, and he makes a very pertinent remark in his Introduction to the 'Elements of the Philo. sophy of the Human Mind' (1792): "I cannot help taking this opportunity of remarking that if physical inquirers should think of again employing themselves in speculations about the nature of matter, instead of attempting to ascertain its sensible properties and laws (and of late there seems to be such a tendency among some of the followers of Boscovich), they will soon involve themselves in an inextricable labyrinth, and the first principles of physics will be rendered as mysterious and chimerical as the pneumatology of the schoolmen" (vol. ii. p. 50). Boscovich seems to have been fond of tracing mathematical curves to represent all kinds of processes, such as the intellectual advancement of the age, and he shows graphically that this was declining (Dugald Stewart's quotation in his 'Dissertation,' Works, vol. i. p. 499).

1 When Fechner published the first edition of his 'Atomenlehre' (1st ed., Ieipzig, 1855; 2d ed.,1864), he does not seem to have known of Boscovich's treatise (see p. 229 of the $2 d$ edition), and it was similarly unknown to the Dutch meteorologist Buys Ballot, whose curves of the attracting and repelling forces of matter agree almost exactly with those of Boscovich (see 'Fortschritte der Physik,' 1849, p. 1 sqq.; also Rosenberger's 'Geschichte der Physik,' vol. iii. p. 536 sqq.) In French scientific literature the treatise of Boscovich is mostly ignored-the 'Grande Encyclopédie' does not eren give its title. In fact, French science does not consider itself beholden to the celebrated Jesuit for what I call the astronomical view of matter. See St Venant in 'Comptes Rendus,' vol. 82, p. 1223: "Plusieurs auteurs, soit anglais, soit allemands, dans ses œuvres qui sont du reste d'une haute portée, . . . se sont pris à condamner vivement, sous le nom de theorie de Boscovich, non pas son idée capitale de réduction des atomes ì des centres d'action de forces, mais la loi même, la loi physique générale des actions fonctions des distances mutuelles des particules qui les exercent réciproquement les unes sur les autres. Et ils attribuent ainsi au célèbre religieux l'erreur grave où sont tombés, suirant eux, Navier, Poisson et nos autres savants, créateurs, il $\mathrm{y}$ a un demi siècle, de la mécanique moléculaire ou interne. Or cette loi blâmée, cette loi qui a été mise en ouvre aussi par Laplace, \&c., et 
Boscovich's or similar formulæ, though the idea of action at a distance between the minute particles of matter underlies the theories by which Poisson, Navier, Cauchy, Lamé, and others calculated the effect of elastic forces in solid bodies, or the phenomena of light passing through transparent and crystalline substances. A different school of physicists, starting from ideas of a different kind, with which we shall become acquainted hereafter, have shown that specific notions as to the molecular structure of bodies are not required in order to deal with the phenomena referred to. Nevertheless, the idea of action at a distance governing the movements of immeasurably sniall, as it seemingly does those of immeasurably large masses in nature, received a great support by the development of two other branches of science, which belong essentially to the history of the present century.

34. Coulomb's measure. ments.

The sciences of electricity and magnetism can be said to have originated with Coulomb's accurate measurements with the torsion-balance. With this instrument he measured the attracting and repelling forces of bodies, electrified or magnetised, by comparing them with the mechanical forces required to twist a metallic wire. In this way he fixed what have ever since his time been termed the units of electricity or magnetism, reducing these quantities to the same system of measurement with which we measure the masses or inertia of 35. Gauss and Weber. fied and greatly perfected by Gauss and Weber - the

prise par Coriolis et Poncelet pour base de la mécanique physique, n'est autre que celle de Newton luimême, comme on le voit non seule- ment dans son grand et principal ouvrage, mais dans le scholie général de sa non moins immortelle "Optique." " 
former applying them to the measurement of the magnetic forces of the earth, the latter to that of the forces exerted by currents of electricity - i.e., by electricity which is not at rest but in motion. As I have already stated, the measurements of Coulomb confirmed the prevalent notion that action at a distance, varying inversely as the square of the distance, and directly in the proportion of the quantities of the acting substance, was a universal formula or law of nature. ${ }^{1}$ The idea

1 Coulomb's exact measurements of the attraction and repulsion at a distance of electrified bodies and of magnets were published during the years 1784 to 1789 in seven memoirs presented to the Paris Academy of Sciences. They are conveniently collected together with some other memoirs of Coulomb, Poisson, and others on kindred subjects in the first volume of the 'Collection de Mémoires relatifs à la Physique,' published in 1884 by the Société française de Physique. Coulomb made use of the torsion-balance and the proof-plane, the actions of which he carefully examined. He confirmed the law, which had been vaguely or approximately expressed by various writers before him, that electrified bodies act on each other with a force which is proportional to the inverse square of their distances. This he did by direct measurements of the repulsion of small electrified bodies in the torsion-balance (1785, 1st Mémoire). $\mathrm{He}$ then extended lis measurements by an indirect method to the action of electrified bodies of larger size and to magnets (2d Mémoire). He also defined what is meant by quantity and density of electricity and magnetism, and showed how these could be measured and how the action of electrified bodies and magnets depended on the more or less of these quantities. Coulomb's researches contain experiments of great delicacy. Although the laws which bear his name appear so simple when written down, the phenomena they represent are most complicated, as in the case of electricity the effect of electrical influence, called by Faraday induction, and in the case of magnetism the presence of the earth's magnetism, and the fact that we have never to do with one kind of magnetism but always with two states, destroys all chance of exhibiting experimentally the simple case represented by the mathematical formula. It was therefore necessary to consider this formula as being merely a convenient description of the elementary action of supposed isolated quantities of electricity and magnetism, and by a process of summation to deduce mathematically the actual effects for such cases of interaction as are actually observable in the laboratory. It was especially the phenomena of the distribution of electricity on the surface of electrified bodies of simple shape and the distribution of magnetic forces in the neighbourhood of magnets which had to be calculatcd and measured. In physical astronomy a similar course of reasoning and observation combined had verified 


\section{of mass, which in the Newtonian formula meant merely} the quantity of matter, had indeed to be enlarged, and to the attracting forces had to be added those of repulsion; still, though physically the phenomena were entirely different, the mathematical expression which ruled the two electric and the two magnetic quantities, usually termed fluids, looked very much like the Newtonian gravitation formula: it betrayed philosophers into thinking they possessed an explanation where really they had only a measurement and a description. ${ }^{1}$

Newton's elementary law of gravitation, Laplace as it were summing up the eridence in his great work. What Laplace did for Newton was done by Poisson for Coulomb's elementary law of electric and magnetic action, and on a still larger scale by Gauss, who worked out the mathematical theory and applied it to the case of the magnetic distribution on the earth's surface. In England, already before Coulomb's researches were published, Carendish had, likewise by a combination of experiment and calculation, established the elementary formulie and properties of electrical phenomena. See note to the following page.

1 The exact measurements of Coulomb and the mathematical analysis of Poisson and Gauss superseded the raguer discussions on the nature of electricity and magnetism which were very frequent before that period, just as the mathematical principles of Newton and Laplace drove into the background the discussion on the nature and cause of gravity. Coulomb himself does not profess to settle the controversy carried on between the two schools of which Dufay and Franklin can be considered as the principal representa- tives-riz., whether there existed two electric fluids or only one. Coulomb judged the rival views simply as to their usefulness in describing and measuring phenomena: "Comme ces deux explications n'ont qu'un degré de probabilité plus ou moins grand je préviens, pour mettre la théorie . . . à l'abri de toute dispute systématique, que dans la supposition des deux fluides électriques je n'ai d'autre intention que de présenter avec le moins d'éléments possibles, les résultats du calcul et de l'expérience, et non d'indiquer les véritables causes de l'électricité" ('Collection de Mémoires,' vol. i. p. 252). He had previously, in 1777 , rejected the theory of vortices to explain magnetic phenomena: "Il semble qu'il résulte de l'expérience que ce ne sont point des tourbillons qui produisent les différents phénom. ènes aimantains, et que, pour les expliquer, il faut nécessairement recourir à des forces attractives et répulsives de la nature de celles, dont on est obligé de se servir pour expliquer la pesanteur des corps et la physique céleste" (vol. i. p. 8). And in 1789 he is still more cautious: "Pour éviter toute discussion, j'avertis .. que toute hypothèse d'attraction et de répul- 
The extension and confirmation which the Newtonian attraction formula had thus gained in the minds of many seemed to be entirely upset by a series of discoveries in which electrical, and subsequently magnetic, phenomena played an important part. These were, the discovery of galvanic electricity by Galvani in 1791 and by Volta in 1800; of the physiological and chemical effects of this form of electricity, especially by Davy (1806); of the magnetic effect of moving electricity by Oersted in 1820 ; of the connection of heat and electricity by Seebeck in 1822; of induction by Faraday in 1831 - i.e., of the action of electric currents and magnets in generating other electric currents or magnetic effects in bodies which are moving in their neighbourhood; and, finally, of diamagnetism by Faraday in 1845 .

Many of the celebrated men with whose names the modern discoveries in electricity are identified, and amongst 36. Davy and them notably Davy and Faraday, were not brought up in the mathematical school of the Continent, ${ }^{1}$ in which

sion suivant une loi quelconque ne doit être regardée que comme une formule qui exprime un résultat d'expérience" (vol. i. p. 297).

1 'To these must be added the name of Cavendish (1731-1810), whose electrical researches, in which he anticipated many of Coulomb's results, proceeded on entirely different lines from those of the Continental school. He proved -in or before 1773 - from the fact that a small globe situated in the hollow of a large elcctrified globe and communicating with it showed no signs of electricity, that electric attraction and repulsion must be inversely as the square of the dis. tance. In his published and post- humous papers (edited by Maxwell in 1879 under the title of 'The Electrical Researches of the Hon. Henry Cavendish') he anticipated, as Maxwell has shown, many later investigations of British and Continental writers. He had a clear notion of electrical capacity, of potential and of electrical resistance, he anticipated Ohm's lawi.e., the proportionality between the electro-motive force and the current in the same conductor. He studied the properties of dielectrics, and "not only anticipated Faraday's discovery of the specific inductive capacity of different substances, but measured its numerical value in sereral substances" 
the astronomical view of phenomena had been established and strengthened mainly by a development of the Newtonian philosophy. They belonged to another school, which approached that great field of research from the purely experimental side,-mainly, so far as Davy was concerned, from the side of chemistry, which, dealing with the qualitative, not merely the quantitative, properties of matter, was at that period almost entirely thrown

(Maxwell's Introduction to the 'Researches,' p. xlix sqq.) Cavendish's electrical work seems to have remained unnoticed abroad. $\mathrm{Cu}$ vier, who fully appreciates him as a pioneer in modern chemistry, does not refer to his electrical researches, and in Continental works his name is hardly mentioned in connection with electrical science. He however clearly belongs to the same lineage as Davy and Faraday, whose breadth of experimental observation somewhat prevented them from fully assimilating the results of Coulomb and his school, which moved in narrower but more precise lines. If Cavendish was unknown abroad as an electrician, Coulomb was little known in England. Whewell, who did more than any other to make known the researches of the mathematical school (see his article in the 'Encyclopædia Metropolitana,' 1826, and his British Association Report, 1835), could state in the first edition of his 'History of the Inductive Sciences' (1837) that "the reception of the Coulombian theory has hitherto not been so general as might have been reasonably expected from its very beautiful accordance with the facts which it contemplates" ( $3 \mathrm{~d}$ ed., vol. iii. p. 28). He then refers to the experiments of Snow Harris. These experiments, as well as those of
Faraday, carried on about the same time, dealt largely with the properties of dielectrics and of what we now call the electric field, a subject almost entirely neglected by the mathematical school of that period. It was not till 1845 that William Thomson (Lord Kelvin) cleared up the whole subject in a memoir, "On the Mathematical Theory of Electricity in Equilibrium" (see 'Reprint of Papers,' \&c., p. 15). He there refers to the fact that "many have believed Coulomb's theory to be overturned by the investigations" of Snow Harris and Faraday, and he therefore proposes to show that "all the experiments which they have made having direct reference to the distribution of electricity in equilibrium are in full accordance with the laws of Coulomb, and must therefore be considered as confirming the theory" ( $p, 18$ ). He thus brought together the two independent lines of research and thought, the mathematical and the experimental, represented by the school of Gauss and Weber abroad, and by Faraday in England, and suggested tlose further researches of which Maxwell's 'Treatise on Electricity and Magnetism' is the great exponent. See the preface to this work, p. xi, \&c., 1873 ; also Maxwell's 'Scientific Papers,' vol. ij. pp. $258,302,304$. 


\section{upon experimental research. ${ }^{1}$ Chemistry had only just entered the list of the exact sciences, by the use of the balance, largely owing to Lavoisier and his followers.}

1 Although Faraday's 'Experimental Rescarches in Electricity' (1831-52) contain mostly what chemists would call "qualitative" investigations and only few exact "quantitative" measurements forming in this respect a very remarkable contrast to Weber's 'Electrodynamische Maasbestimmungen ' (1846-78)-it is important to remark that one of the methods for exact measurement of the electric current-viz., by the chemical decomposition of compounds - was established by Faraday in 1833 and 1834. He showed that whenever decomposition took place the quantities decomposed were in proportion to the amount of electricity flowing through the circuit and in proportion to the chemical equivalents. Owing to the want of a clear definition of quantity and intensity of current, Berzelius opposed this view of Faraday's as illogical, confounding the quantity of substance decomposed with the force required to set it free. Clearer definitions and accumulated experience have confirmed Faraday's law, which is now looked upon as one of the best established general facts of chemical and electrical science. Somewhat earlier than Faraday, Georg Simon Ohm established (1827, 'Die galvanische Kette, mathematisch bearbeitet ') the proportionality of the quantity of electricity passing through a circuit with the electromotive force in the same conductor, introduced the notion of electrical resistance, and showed how this varies as the length and inversely as the thickness of the same conductor, and is different in different con. ductors. The accuracy of Ohm's law, though elaborately tested by Fechner and confirmed by Pouillet, was frequently doubted; in France it met with tardy recognition, and in England some of the most important researches-such as those of Faraday-were carried on without reference to it. In the first edition of Whewell's History it is not mentioned. When the second edition was published (1847), Ohm had received the Copley Medal of the Royal Society (1841), and Wheatstone had besides in the year 1843 drawn attention to the clear definitions which $\mathrm{Ohm}$ had introduced. The opinion has been expressed that Ohm found his law by theoretical considerations based on analogy with the flow of heat in conductors, and that he subsequently proved it experimentally. The publication of Ohm's collected papers by Lommel ('Gesammelte Abhandlungen,' Leipzig, 1892), however, disproves this opinion; as his experimental measurements had during 1825 and 1826 -not without some initial mistakes-led him to the well-known expression of the relations of the different quantities (see Lommel's Introduction, p. vii). Whereas in Germany it was a purely scientific interest-that, namely, of subjecting physical phenomena to mathematical calculation-which induced Ohm, Gauss, and Weberto devise instruments and methods for exact measurement, it was in England mainly the practical requirements of telegraphy which created the desire for clear definitions and exact methods. With these requirements in view Wheatstone invented his instruments and drew attention to the definitions of $\mathrm{Ohm}$. See his Bakerian Lecture for 
Yet the great variety, more than the exact measurement of phenomena, attracted the attention of natural philosophers in this new field. And when through Davy, Berzelius, and Faraday in different ways the importance of electric action in chemical processes became established, it was natural that from this school an entirely different view of electrical and magnetic phenomena should emanate: we may term it—in opposition to the astronomical-the physical view of phenomena. This view, which, as the astronomical view had done, found later on its expression in a mathematical formula, will occupy our attention in a subsequent chapter. It has in the course of the second half of the century very largely expelled the other and rival view from the domain of molar and molecular physics. But the astronomical view, with its largely developed mathematical apparatus, was not easily defeated: it was

${ }_{3}^{37 .}$ àr quite able to grapple with even such complicated processes Ampère and Weber develop the astronomical view.

as the discoveries of Oersted and Faraday had revealed. In the opinion of many Continental thinkers it won its greatest laurels when, under the treatment of Ampère in France and of Neumann and Weber in Germany, the perplexing interactions of magnets, diamagnets, and

1843 ('Philos. Transactions,' 1843, p. $303, \& c$.$) : "An energetic source$ of light, of heat, of chemical action, and of mechanical power, we only require to know the conditions under which its various effects may be most economically and energetically manifested to enable us to determine whether the high expectations formed in many quarters of some of these applications are founded on reasonable hope or on fallacious conjecture." Forty years later Lord Kelvin, in his address
"On the Electrical Units of Measurement" (1883; see "Popular Lectures and Addresses,' vol. i. p. 76 ), could still speak of the comparatively recent date at which "anything that could be called electric measurement had come to be regularly practised in most of the scientific laboratories of the world," whereas such measurements had then been for many years "familiar to the electricians of the submarine cable factories and testing stations." 
electric circuits-the phenomena of electro-magnetism, diamagnetism, and induction - were all resolved into elementary processes of attraction and repulsion, and summed up in a formula which looked like an extension of the Newtonian gravitation formula, revealing the mysterious influence of molecular forces.

"Oersted had found that an electric current acts on a magnetic pole, but that it neither attracts it nor repels it, but causes it to move round the current. He expressed this by saying that the electric conflict acts in a revolving manner. The most obvious deduction from this new fact was, that the action of the current on the magnet is not a push-and-pull force, but a rotary force, and accordingly many minds began to speculate on vortices and streams of ether, whirling round the current. But Ampère, by a combination of mathematical skill and experimental ingenuity, first proved that two electric currents act on one another, and then analysed this action into the resultant of a system of push-and-pull forces between the elementary parts of these currents." 1

Weber in Germany took up the work where Ampère had left it. ${ }^{2}$ One of his objects was to combine the

1 Clerk Maxwell "On Action at a Distance" ('Scientific Papers,' vol. ii. p. 317 ).

2 Weber's interest was twofold. The primary object was to put accurate quantitative data in the place of merely qualitative descriptions or mere estimates of phenomena. He had then already published together with his brothers (see supra, p. 196, note 3) two works in which in a similar way exact research has taken the place of inexact description. The first was his experimental investigation of wave-motion ('Die Wellenlehre auf Experimente gegrüdet,' 1825), the other the still more delicate attempt to treat a physiological phenomenon, the mechanism of the organs of locomotion, on exact mechanical principles (1836). This rare gift of exactness, invaluable at all times, but almost unique at that time in Germany, where philosophical vagueness was only too common, attracted the notice of Gauss, who brought Weber to Göttingen in 1830 after 
different electric phenomena-those of electricity in the state of rest, called statical effects; those of electric currents on each other, the dynamical results; and those of electric conductors in a state of motion, the phenomena of induction - in one general and fundamental formula or law. He had before him Coulomb's electrostatic formula, Ampère's electro-dynamic formula, and a more general one established by Franz Neumann, which described and embraced not only the phenomena discovered by Oersted, but also those of moving conductors discovered by Faraday. It is not necessary here to enter into the details of the investigations, experimental and mathematical, by the aid of which Weber succeeded in establishing his very remarkable and seemingly allembracing formula. Two remarks, however, present themselves, bearing upon the history of thought and the value of precise mathematical expressions. The first is, that as the gravitation formula necessitated a series of the most careful definitions and measurements of physical

38. quantities, and the invention of accurate instruments and Weber's fun. damental measuremethods of measurement, so the first and probably the most valuable performances of Weber were his ingenious apparatus, and the careful measurements by which he

the death of Tobias Mayer. Gauss introduced Weber to his own exact measurements of terrestrial magnetism, and from hence Weber's own line of thought led through the phenomena of magneto-induction (discovered by Faraday in 1831) and terrestrial magneto-induction (1832) to electro-dynamics, the science which Ampère had created in the years 1820 to 1823 . In 1846 Weber speaks in the introduction to the 'Electro-dynamische Maas- bestimmungen' of the endeavour to determine natural phenomena according to number and measure, expressing surprise that this has not yet been done ;in electrodynamics, and then proceeds to describe lis "electro-dynamometer," an instrument used by him for many years. With this instrument he then, further, proceeds to confirm Ampère's formula for the action at a distance of the elements of electric currents. 
fixed the elementary conceptions and quantities with which he operated. All his researches were comprised under the very significant title "electro-dynamical measurements." As such they remain a great monument of ingenuity and unparalleled accuracy. ${ }^{1}$ The second

1 Gauss had, some years before Weber commenced his electrical researches, introduced the idea of an absolute measure of other than mechanical forces-i.e., following up the definition of force in the Newtonian laws of motion, that it is the cause which brings about a change of motion, he suggested that every physical force can be measured by the velocity it imparts to a movable body of measurable mass, the quantity of mass being in the same locality measured by its weight; and he applied this to the measurement of magnetic forces. In applying the same idea to the measurement of electric currents, Weber came at once upon the circumstance that the forces exerted by an electric current can be measured in two ways-viz., by the action they have upon magnets or by that which they have on other electric currents. Now by a familiar conception, electricians look upon a current of electricity as measurable by the quantity of electricity which flows through a section of the circuit in a given unit of time, this quantity of electricity being measurable in the same way as Coulomb measured the action at a distance of charged bodies. Should it then be possible to carry out this latter measurement of an electric current, a comparison between the electro-magnetic and the known electro-static units of electricity would become possible. Faraday had already, in 1833 and 1834 , made estimates of the numerical relation of the quantity of electricity in a current, measured

VOL. I. by its chemical or electro-magnetic effects, and of the same quantity if produced by an electrical machine. These estimates were more than twenty years later, in 1856 , reduced to accurate measurements by Weber and Kohlrausch. Through these measurements, which confirmed the enormous numbers which are revealed when we compare electricity at rest and electricity in motion, Weber finished the series of accurate measurements, reduced to an absolute or mechanical standard, which had been begun by Gauss in 1833. It was soon recognised of what practical importance these data must be to electricians. Accordingly the British Association at their meeting at Mancliester in 1861 appointed a committee, on the sug. gestion and under the presidency of Sir William Thomson, called the "British Association Committee of Electrical Standards." "This committee worked for nearly ten years through the whole field of electromagnetic and electro-static measurement, until in its final report, presented to the Exeter meeting in August 1869, it fairly launched the absolute system for general use" (Thomson, "Popular Lectures and Addresses,' vol. i. p. 84). In recognition of Weber's great merit in first introducing this system into electrical science and practice, the name "Weber" had been selected by Latimer Clark for the unit of current. In the final fixing of the units in Paris in 1881 other units than those previously in use were adopted, and to avoid confusion the names were somewhat differently 
point I wish to urge is, how in those days the Newtonian formula was taken as the great model of a law of nature, and how the researches of Coulomb, Poisson, Ampère, and Weber stand in logical connection with the theory of gravitation. Let us see what Weber himself says on this subject:1 "After the general laws of motion had fur-

chosen. This explains the fact, deplored by Weber's friends and admirers, that his name has dropt out of the list of terms now adopted throughout the civilised world. (See Wiedemann, 'Die Electricität,' Braunschweig, 1885, vol. iv. p. 906, \&c.) Recently Prof. Lodge has suggested the introduction of the names of Weber and Gauss to denote some of the derived units in the electrical measurements. See Brit. Assuc. Report, 1895, p. 197 n.

1 Weber's theoretical conception of the nature of electric action at a distance is mixed up with his exact measurements of electrical quantities, though these can be stated without making use of his theoretical conceptions. It is the nature of the absolute system of measurement that it establishes numerical relations based upon a small number of original units (space, time, and mass, or space and time alone, see note to p. 323 above) which are universally intelligible. Whatever, therefore, the theoretical views may be which led the investigation, in the end these are eliminated in the system of original (primary) and derived (secondary) units. But Weber's theory commands attention for its own sake as the furthest stage to which the gravitational view of phenomena, provisionally introduced by Newton, has been pushed. It has been extolled and condemned, according to the favour with which the purely mathematical treatment of phenomena has been received.
In the school of Laplace this purely mathematical treatment quite obscured all other views which did not minister to it. Thus Laplace remained to the end an adherent of the emission or corpuscular theory of light, and opposed the ideas of Young and Fresnel, who developed the dynamical view. In order to make the cosmical view of nature useful for the explanation of molecular phenomena, two distinct and definite conceptions, contained in the gravitation formula, had to be modified and enlarged. The conception of matter, which in physical astronomy is limited to gravitational matter, had to be extended so as to bring into calculation what was then called imponderable matter, sucl as light, heat, and electricity. And the law of gravitation, which defines the purely attractive property of ponderable matter, had to be modified so as to embrace also the repulsive action observable in a certain class of phenomena. Coulomb had shown that ponderable matter charged witl electricity followed the same formula for attraction and repulsion as gravitating bodies did: he simply adopted the twofluid theory of electric matter. Poisson developed the mathematics of fluids, actuated by repelling forces depending on the inverse square of the distance. Oersted showed the action of electric currents on magriets; and Ampère showed that magnets can in their action be supplanted by electric currents. Laplace very early satisfied himself that 
nished a foundation, there remained in physics mainly the investigation of the laws of interaction of bodies; for without interaction bodies would for ever remain in that state of rest or motion in which they happened to be.

these actions of ponderable matter, in which electricity was flowing, could be reduced to an action at a distance proportional to the inverse square of the elements of the electric circuits. When Faraday showed that a current of electricity under certain conditions induced in conductors in its neighbourhood other currents, this was explained by saying that the electric fluid exerted not only pondero-motoric but also electro-motoric action at a distance. Not only did electrified matter act on other electrified matter, but electricity as a fluid acted on electricity itself. Weber adopted, for the purpose of putting these apparent actions into mathematical language, and for finding an elementary law of the ultimate particles of electric matter out of which by summation the observable data might be calculated, the hypothesis of Fechner, according to which in an electric current the two electric fluids were moving with equal velocity in opposite directions. It then became evident -looking at the phenomena discovered by Oersted, Ampère, and Faraday - that the electro-static formula of Coulomb required to be supplemented by an additional term, if the mutual action was to be determined not only for the case of equilibrium and rest, but also for that of relative motion. The additional term, depending on this relative motion, had to be found. (See 'Electrodynamische Maasbestimmungen,' vol. i. p. 102). From this starting-point, and with this definite problem in view, Weber undertook a series of most valuable measurements. No doubt can exist as to the lasting importance of these measurements. Any theoretical conception which produces in its application such results must hold a prominent place in the history of scientific thought. And the very fact that, unlike Boscovich and other purely metaphysical theorists, Weber undertook to fix by experiment the actual constants or numerical quantities which his abstract formula contained, led to much enlargement of actual knowledge. I will mention only one of the most interesting points in his elaborate researches. I stated above that it took a whole century after the discovery of the law of gravitation before tlie gravitation constant was approximately fixed, but that for the progress of physical astronomy this was of little importance, gravity being a universal property of matter. Still such a constant exists, because we possess another definition of matter - viz., inertia or mass. The constant in Coulomb's law cannot be determined in a similar manner, as the property of attraction or repulsion defines for us ultimately the numerical quantity of electricity. We have-so far - no other ultimate absolute measure of electricity. But in Weber's law it was the quantities of electrical matter which acted on each other not only according to their distances, but also according to their relative motion or their velocities. A second constant thus entered into his formula, and this constant established a relation between electricity at rest and electricity in motion. This constant was a velocity, and, if determinable, it revealed a constant of nature in 
All changes of these states, and all phenomena dependent thereon, are therefore consequences of these interactions. But bodies exert such mutual actions when in contact as well as from a distance, and it was evident that a beginning had to be made with the latter in order to gain a clue for the investigation of the former; this being especially needful whenever the spatial relations of bodies escape observation, as is the case with bodies which are in contact. And so it has really happened, inasmuch as a beginning was made by examining the mutual action of cosmic bodies-i.e., with the phenomena of gravitation. To this first field of research-viz., the phenomena of gravitation-there was then added the investigation of electric and magnetic interactions, as next to gravitation these are the only actions which take place from one body to another at measurable distances, - these actions being themselves measurable. Now for a long time Newton's doctrine of gravitation furnished the leading idea for nearly all theories of electricity and magnetism, till a new clue was gained through Oersted's and Ampère's discoveries

the form of a velocity. It had for Weber a theoretical as well as a practical meaning, for it enabled him to effect a connection between the electro-magnetic and the electro-static or absolute system of measurements. When he succeeded in measuring this quantity, it was found that the figure for the constant, which meant a velocity, was practically the same as that for the velocity of the propagation of light. Weber himself does not seem to have attached any physical meaning to this coincidence: later he and Kirchoff remarked that under cer- tain conditions an electrical wavemotion might take place in an electrical conductor, and that the velocity of the propagation of this would coincide with that of light (see Kirchoff in 'Annalen der Physik und Chemie,' 1857 ; and Weber, 'Electrodyn. Maasbest.,' 1864). It was reserved for Clerk Maxwell to point to the real physical interpretation of Weber's constant. Of this I shall speak in a later chapter (see Maxwell's memoir ' On Physical Lines of Force,' 1862, reprinted in 'Scientific Papers,' vol. i.) 
regarding the equivalence of closed electrical currents with magnets. This led, first, to the reduction of all magnetic effects to the action of electrical currents; and, secondly, to the enunciation of a fundamental law of the interaction of two elements of electricity in motion. A third leading idea was that of reducing the interaction of all bodies to that of the mutual action of pairs of bodies. This idea could in general be considered as well established and confirmed by experience on a large scale." 1

This leads me to another and a final remark on the view of natural phenomena, first introduced by Newton's gravitation formula, which has been so successful in the calculation of all the movements of cosmic bodies, and which in the eyes of such a great authority as Laplace contained the clue to an explanation also of molar and molecular phenomena. ${ }^{2}$ This view calculates

1 'Electrodynamische Maasbestimmungen,' 1878 , p. 645 .

2 Although Weber followed the lines so deeply impressed upon the whole of Continental thought by the labours of Laplace and his school, it does not seem that he held the same exalted opinion of the value of any mathematical formula as did Laplace. Though he looked upon his electro-dynamic law as well established by experiment and valuable in guiding further research, he was fully impressed with the fact that all such formula are merely provisional. Thus he says in the first part of his researches, written in the year 1846: "It seems to follow that the immediate interaction of two electrical particles does not depend upon these alone, but also upon the presence of third bodies. ... It is conceivable that the forces comprised in the discovered fundamental law may be partly the forces which two electrical particles exert indirectly on each other, and which therefore depend on the intervening medium.... The general law for the determination of the acting forces might perhaps be yet more simply expressed by taking the intervening medium into account, than has been possible without it in the fundamental law now established. The exploration of the intervening medium, which might afford an insight into many other matters, can alone give an answer to this question. ....A hope now exists that it will be possible, in several new ways, to gain some information as to the neutral electric fluid which pervades everything. Perhaps in
39. Necessity of developing the infinitesimal methods. 
the actions of large masses and complicated systems of bodies by a process of summation from the interaction of units placed in the simplest relation-that of two and two, pushing or pulling each other in a straight line. Now, in consequence of the great distances at which we are placed from the heavenly bodies, these appear to us as mere points, and the observation of their movements, their orbits, and their periods enabled astronomers like Kepler, and mathematicians like Newton, to gain by mere observation and subsequent calculation an idea of the elementary rule which masses, considered to be concentrated in points, follow in their motion in a connected system. The next step was to see how these elementary actions would add up in cases where the dimensions of the moving bodies were not vanishingly small in comparison with their distances. The infinitesimal methods, invented in the age of Newton, and developed by him and others into a special calculus, came to the aid of mathematicians, and enabled them to calculate from elementary data the motions and phenomena of extended bodies and systems of bodies. These could afterwards be actually measured, thereby confirming the elementary formulæ and assumptions which had formed the basis of those calculations. As already remarked, this process

other bodies, which are not conductors, there exist, not currents, but only vibrations, which may in future be observed by the methods indicated above. Further, I need only point to Faraday's recent discovery of the influence of electric currents on the vibrations of light, which makes it probable that the all-pervading neutral electric medium itself constitutes the all-pervad- ing ether which contains and propagates luminous vibrations, or at least that the two are so intimately connected that the observation of luminous vibrations may afford some information regarding the properties of the neutral electric medium." $\mathrm{He}$ then refers to Amperre's own suggestion in this direction. ('Electrodynamische Maasbestimmungen,' Part 1., p. 169.) 
of confirmation occupied a long period, during which it became more and more satisfactory and complete. In fact, so great has the coincidence of calculation with observation turned out to be, in all problems of physical astronomy, that no astronomer at the end of this century doubts that the gravitation formula alone will suffice to explain all anomalies which still exist in great number The Newton. ian formula the basis of physical in the movements of cosmic bodies-such, for instance, as the moon.

Moreover, in the whole wide range of physical and chemical, not to speak of other natural phenomena, there is probably no instance of a simple mathematical relation having been applied to so large a field of facts, found so trustworthy a guide, and been so unfailingly verified.

And yet the very extent of this field must not blind us to the fact that for the explanation of molecular ${ }^{1}$

1 This is indeed not to be wondered at when we consider that in all molecular and molar phenomena such a variety of elements and forces come into play that it is impossible to isolate any special quantities as we do when from the cosmic point of view we lose sight of everything except mass, time, and distancei.e., the elementary factors of our system of measurement. In the phenomena of electricity, for instance, it is merely by a process of mental abstraction, which has no counterpart in the observable phenomena, that we speak of electrical masses, be they one or two; of fluids; of elements of currents, which in nature cannot exist alone; of velocities of a something which as yet cannot be clearly defined. Any mathematical formula can under such conditions be merely ten- tative, and the preciseness of it must not hide from us the fact that it is based upon hypothetical relations and artificial definitions. This was, for the gain of scientific thought, very clearly brought out in the theoretical discussions which followed upon Helmholtz's critical examination of Weber's and kindred formulæ, and is well expressed by Carl Neumann: "Electrical matter" - if such there be- "never exists alone, but only in combination with ponderable matter." Any law like that of Weber can therefore be merely a "particular," not a "fundamental" or "universal" law, for it refers merely to a small portion of the properties, forces, and relations of electric and ponderable matter, leaving others-as, for instance, those between electricity and heat, electricity and light, 
phenomena, or even for such processes as happen continually under our eyes and our hands, this universal law of gravitation has practically done nothing. The action of gravitation alone between masses which we can manipulate directly is so weak that it takes the very finest instruments to detect it at all, and at molecular distances it is so immeasurably small that it is hardly conceivable how it can explain the existence of those enormous forces with which we here have to deal. ${ }^{1}$ If

\&c. - more or less in the dark (see 'Matlematische Annalen,' vol. xi. p. 323). From a philosophical point of view these discussions, in which many other eminent leaders of scientific thought took part, are of great interest and importance, as they bear upon the value of mathematical formulæ in physical research, upon the definition of laws of nature, the extent of their applicability, the correct lines of future research, the use of analogies in the formation of physical theories, \&c. I therefore refer here to the literature of the subject: Tait, 'Sketcl of Thermodynamics' (1868, pp. 57, 76); Thomson and Tait, 'Natural Philosophy' (1st ed., p. 311); Carl Neumann, 'Die Principien der Electrodynamik' (Tübingen, 1868) ; Helmholtz in various memoirs from 1872 onwards, all collected in "Wissenschaftliche Abhandlungen' (vol. i. pp. 545, 636, 774 , \&c.), and in 'Vorträge und Reden' (vol. ii. Faraday Lecture); Carl Neumann, 'Mathematische Annalen' (vol. xi. p. 318). See also Riecke on 'Wilhelm Weber' (Göttingen, 1892), and Clerk Maxwell, 'Electricity and Magnetism,' (vol. ii. last chapter); 'Elementary Treatise on Electricity' (p. 51).

1 An interesting speculation as to whether the Newtonian formula of gravitation is capable of explaining cohesion and capillary attraction will be found in Thomson's (Lord Kelvin's) paper to the Royal Society of Edinburgh (1862), and in his lecture before the Royal Institution (1866) on Capillary Attraction, both reprinted in the first volume of 'Popular Lectures and Addresses.' He there shows that if we combine Newton's law with the assumption of an ultimate heterogeneousness of matter, -as is demanded in the socalled atomic theory used in chem. istry, - the mass of ultimate portions of matter at vanishing distances, or what is called in contact, may give rise to molecular forces of attraction of any magnitude ; since the Newtonian attraction depends on two data - the distance and the density (or mass) of attracting particles. He concludes by saying that "it is satisfactory to find that, so far as cohesion is concerned, no other force than that of gravitation need be assumed " (p. 63). It does not seem that this view, which was also held by Sir John Herschel, is generally adopted by physicists (see Todhunter and Pearson, 'History of the Theory of Elasticity,' vol. i. p. 418, \&c. ; vol. ii. art. 1650). Another interesting speculation arose out of the discussion over Weber's law. One of the objections started by Helmholtz against Weber's law was that, under certain conditions, 
for the purpose of discovering the forces which exist in the universe between cosmic bodies we had been confined to experiments in the laboratory, as we are in all other departments of physics and chemistry, it is very doubtful whether this universal law of gravitation would ever have been discovered. And yet it stands there as The Newtonian formula unique as to almost the only formula universally applicable to all acy. matter throughout the visible and tangible universe.

In the foregoing pages I have sometimes spoken of this great discovery of Newton, on which is based the astronomical view of nature, as a formula, sometimes as a law. A formula is merely the expression in definite terms of certain relations of measurable quantities. By a law we are apt to understand something more-viz., the statement of some fundamental, all-pervading property of the things of nature, which, so far as we are concerned, is final. ${ }^{1}$ Whether the human mind is at all

this expression would give an infinite value for the force between electrical particles in motion. Weber replied that the same argument could be used against the gravitation formula, and hinted at the possibility that a correction might have to be added to the Newtonian formula to make it applicable to molecular distances ("Electrodyn. Maasb.,'1871, p. 60). This idea was taken up by several Continental mathematicians (see Isenkrahe, 'Das Räthsel von der Schwerkraft,' p. 33, \&c. ; Paul du BoisReymond, 'Ueber die Grundlagen der Erkenntniss,' p. 50 ; Tisserand, 'Comptes Rendus,'September 1872).

1 Helmholtz says, referring to Weber's so-called law: "If we are to consider Weber's law as an elementary law, as an expression of the ultimate cause of the phe- nomena to which it refers, and not merely as an approximately correct expression of facts within narrow limits, then we must demand that, if applied to objects of the largest imaginable dimensions, it should give results which are physically possible" (1873, "Wissenschaftliche Abhandlungen,' vol. i. p. 658). This sentence raises a philosophical question as to the demands which we can legitimately expect to be satisfied by any so-called law of nature expressible in the symbols of human thought, be these words or algebraic signs. I venture to think that nowadays, and largely in consequence of discussions similar to those carried on over Weber's law, physicists do not any longer expect to find laws of that general and fundamental character which the words given above describe. 
capable of finding out the ultimate properties of things, is a question which has been answered in opposite

42.

Is the Newtonian formula an ultimate law? ways. But whatever the answer may be to this philosophical question, the further and more modest question can be raised, Does the gravitation formula express one of those universal facts which we have to accept as final, beyond or behind which we cannot penetrate? Opposite answers have been given to this question. But it stands very much in the same position in which Laplace left it when he said: ${ }^{1}$ "The extreme difficulty of the problem referring to the system of the universe obliges us to have recourse to approximations, which leave room for the fear that the neglected quantities may have a sensible influence on the results. As soon as mathematicians by observation became aware of this influence they returned to their analysis: by rectifying the same they have always found the cause of the observed anomalies; they have determined the laws of these, and frequently they have outrun observation by discovering irregularities which had not yet been observed. The lunar theory, the theory of Saturn, of Jupiter and his satellites, offer many examples of this 43. kind. ${ }^{2}$ Thus we may say that nature herself has helped Laplace's
opinion. in perfecting the astronomical theories founded upon the

1 'Exposition du Système du Monde,'6th ed., p. 318.

2 Tisserand, in discussing the difficulties which still beset the lunar theory, and after referring to the "prix Damoiseau" offered by the Academy of Sciences for an essay on this subject, says ('Bulletin astronomique,' 1891, vol. viii. p. 501): "La théorie de la lune se trouve arrêtée par la difficulté que nous venons de développer; déjà a l'époque de Clairaut la gravitation universelle paraissait impuissante à expliquer le mouvement du périgée ; elle triomphera encore du nouvel obstacle qui se présente aujourd'hui, mais il reste ì faire une belle découverte." 
principle of universal gravitation. This is, in my opinion, one of the greatest proofs of the truth of this admirable principle. As to this principle, is it a primordial law of nature? Is it only a general effect of an unknown cause? Here the ignorance in which we are as to the ultimate properties of matter stops us, and removes all hope that we shall ever be able to answer these questions in a satisfactory manner."

In the meantime, as I have tried to show, the clue afforded by this principle has led physicists by strict analysis, by observation, by cleverly arranged experiments as well as by guesses drawn from analogy, to the discovery of many unknown phenomena, to the fixing in mathematical language of interesting relations, and in general to a large extension of the field of natural knowledge. No wonder that a principle which has done, and is still doing, such valuable service in physical astronomy should have done much to establish the astronomical view of nature. ${ }^{1}$ As one of the latest representatives of physical science abroad has said, "The present generation

1 This view was concisely put by Poisson at a time when the corpuscular theory of the imponderables -light, heat, and electricity - still reigned supreme in the Continental school: "Toutes les parties de la matière sont soumises ì deux sortes d'actions mutuelles. L'une est attractive, indépendante de la nature des corps, proportionelle au produit des masses, et en raison inverse du carré des distances: elle s'étend indéfiniment dans l'espace, et produit le pesanteur universelle et tous les phénomènes d'équilibre et du mouvement qui sont du ressort de la mécanique céleste. L'autre est attractive et répulsive; elle dépend de la nature des particules et de leur quantité de chaleur; son intensité décroit très rapidement quand la distance augmente, et devient insensible, dès que la distance a acquis une, grandeur sensible" ("Journal de l'École polytechnique,' cahier $\mathrm{xx}$, p. 4, 1831). See also Clerk Maxwell, 'On the Equilibrium of Elastic Solids' (1850, reprinted in 'Scientific Papers,' vol. i. p. 30), where a similar assumption is stated as the basis of the mathematical theories of Navier, Poisson, Lamé, and Clapeyron. 
is still more or less accustomed to think in the manner of Newton's view of nature, in which the supposition of forces acting at a distance appears as the most simple view: we feel it difficult to step out of this circle of ideas." 1 Nevertheless, the country itself which produced

${ }^{1}$ Kundt, 'Die neuere Entwick. lung der Electricitätslehre ' (Berlin, 1891 , p. 35). This habit is probably more marked on the Continent than in England. In this country the later developments of Laplace's astronomical view of nature have remained unknown except to a few scientific specialists. Through Faraday's influence, and in consequence of the backwardness which the English school of science exhibited early in the century in assimilating Continental ideas (see p. 232, note), theoretical views on electricity as well as on other forms of energy were formed and taught more in conformity with experimental observation. I am not aware that Weber's theory was expounded in any English text-book or handbook before Maxwell referred to it as the view to which Faraday and he himself were opposed. In fact, the astronomical view of molecular physics is almost entirely of foreign growth. In England "action at a distance" is now stigmatised as a pernicious heresy (Tait, 'Properties of Matter,'2d ed., 1890, Introduction) or as unthinkable (O. Lodge, 'Modern Views of Electricity,' 1892, p. 386, \&c.) Abroad weighty authorities have pronounced against the astronomical view of nature as final or even helpful in the present stage of physical and chemical science. Helmholtz, who was trained in it, gradually emancipated himself, probably under the influence of physiological studies; so did Kirchoff, who in his lectures on Electricity (edited by Planck, 1891) hardly mentions Weber's law, though he had previously, in 1857, based an elaborate and valuable investigation upon it ("Ueber die Bewegung der Electricität in Drähten,' 'Gesammelte Abhandlungen,' p. 131, \&c.) Still more marked is the aversion to the attitude or habit of thought which belongs to the astronomical view of nature on the part of those who approached physical problems from the side of chemistry. Hittorf (quoted by Lehmann, 'Molecularphysik,' vol. ii. p. 456) explains the opposition of Berzelius to Faraday's electrolytic law and to his other results from the fact that they stood in direct opposition to that view "which at the end of the last century had been introduced into chemistry through the success of Newton's law in astronomy, and under the influence of Laplace on Lavoisier and Berthollet," and sees the importance of his own laborious researches in the demonstration "that the mysterious potential energy cannot in the case of uncombined chemical substances be explained by the work of attractive forces," and "that a confession of ignorance in such matters is more conducive to progress than the assertion that every process in nature is essentially a phenomenon of attraction in the Newtonian sense." Of Ostwald's endeavours to liberate theoretical views in chemistry from the tyranny of the older hypotheses I shall have frequent occasion to speak. His discourse 'Die Energie und ihre Wandlungen' (Leipzig, 1888) contains an expression of opinion similar to those quoted here. 
THE ASTRONOMICAL VIEW OF NATURE. 381

the author of this the astronomical view of nature has also been the birthplace of a different manner of regarding physical phenomena. It will be the object of a future ${ }_{\text {nature. }}^{\text {view of }}$ chapter to trace the origin and growth of what I propose to call the physical view of nature. We shall then learn how the germs of this different view can be traced even in the writings of Newton. But before I take up this subject I must deal with another and independent way of regarding nature which very largely supplemented the astronomical view. If the Newtonian gravitation formula is the basis and principle of physical astronomy - of our knowledge of cosmic phenomena-the view I am now going to explain has been equally useful in building up another most important science of modern times-the science of chemistry. 


\section{CHAPTER V.}

THE ATOMIC VIEW OF NATURE.

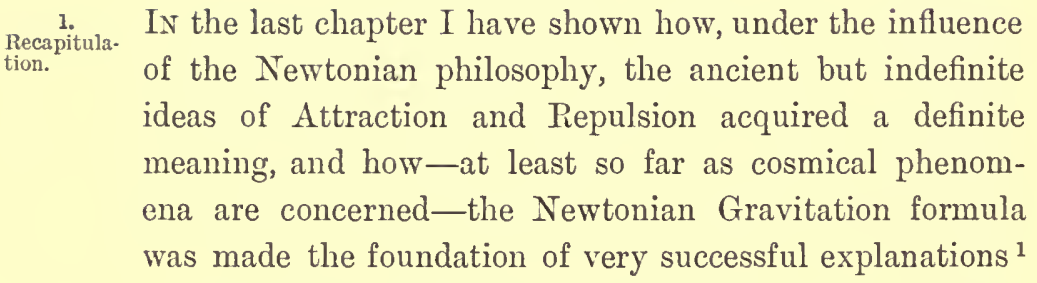

1 I use the word explanation in conformity with the popularly accepted meaning of the term. It is, however, well to remark here that, in the course of our century and greatly owing to the influence of the exact scientific spirit, a change is being gradually introduced into language, which will assist in conveying more correct views as to the objects of science. In England the metaphysical interest has been so long banished from scientific literature, the part also which experiment and observation have played has been so great, that misunderstandings as to the real objects of science have been less frequent than abroad, especially in Germany, where the metaplyysical or philosophical interest still largely pervadcs scientific literature, though metaphysics themsclves may be on the decline. There the definition of the science of mechanics (now more usually termed dynamics in this country), given by Kirchoff' in his "Vorlesun. gen über mathematische Physik' (vol. i. p. 1), has marked quite an epoch in the philosophy of the exact sciences. This definition is as follows: "Nechanics is the science of motion; we can assign as its object: to describe completely and in the simplest manner the motions which occur in nature." Inasmuch as a large school of natural philosophers consider that it is the object of all exact sciences to give a mechanical explanation of natural plienomena, it would follow that the object of all science is to reduce the phenomena of nature to forms of motion, and to describe these completely and in the simplest manner. We may feel some reluctance in assenting at once to this definition. Still an analysis of 
of nature. Towards the end of the last century, and all through the present one, this view of things natural, which I have called the Astronomical view, has exerted a great fascination over scientific minds: especially in the mathematical schools of France and the Continent it has been a leading idea in scientific thought. It has been extended into molar and molecular physics, and has in these led to some very extraordinary and ingenious theories. In England, this astronomical view of Nature has, in the course of the present century, been received

what has been done since Newton in real science will probably convince us that the definition is safe and sufficient. It means the analysis of phenomena as to their appearance in space and their sequence in time. Both can, in consequence of the small number of elementary relations on which arithmetic, geometry, and dynamics are built up, be reduced to - or described in - a small number of elementary terms or conceptions, the alphabet of all science. To show how in every instance the terms of this alphabet are to be put together, in order to correspond to any phenomenon, is all the explanation we can give. Objections have been raised to Kirchoff"s definition by Du Bois-Reymond ("Göthe und kein Ende" in 'Reden,' vol. i. p. 434), inasmuch as it does not define the difference between the rescriptive (historical) and the exact (mathematical) sciences of nature; but the difference is really maintained if we demand a complete description. Natural history only affords an incomplete description. The only complete description is that afforded by a mathematical formula in which the constants are supplied by observation. This permits us to calculate those features or phases of phenomena which are hidden from our observation in space or in time. All objection to the view which identifies physics with mechanics, seems implied in Mach's remarks contained in the last chapter of his very thoughtful book 'Die Mechanik in ihrer Entwickelung' (Leipzig, 1889). According to his view, the aim of exact science is not necessarily to give mechanical explanations or descriptions of phenomena, inasmuch as temperature, electric potential, \&c., are just as simple elements of natural phenomena as mass and motion. It seems, nevertheless, that exact measurements are only possible in the data of time and space. Assum. ing that a complete and simple description - admitting of calculation-is the aim of all exact science, it is evident how much and how little we may expect from science. We shall not expect to find the ultimate and final causes, and science will not teach us to understand nature and life. The search after ultimate causes may perhaps be given up as hopeless; that after the meaning and significance of the things of life will never be abandoned : it is the philosophical or religious problem. 
with less favour, although it was entirely owing to Newton's gravitation formula that it ever obtained its great influence, the labour of Continental men of science being very largely spent in two directions : first, in drawing the purely mathematical consequences of Newton's formula-in this they have met with increasing success, unparalleled by that in any other domain of science; and secondly, in extending the principle of Newton, by experiment and analogy, into other departments. In some of these, very remarkable results have been achieved; but nevertheless at the end of the century no extension or analogue of the Newtonian gravitation formula has been generally accepted, and it still stands there as almost the only firmly established mathematical relation, expressive of a property of all matter, to which the progress of more than two centuries has added nothing, from which it has taken nothing away. The value, however, of all those partial attempts in another direction has been enormous; for with the aim of applying, extending, or modifying a rigorous mathematical formula, those philosophers have carried out a series of the most exact observations and measurements of physical quantities, very greatly extended our knowledge of natural phenomena and their mutual relations, and founded that general system of physical measurement which is now universally adopted. The names of Gauss and Weber stand out prominently as leaders in this work. I shall have to come back to this point later on, after I have shown that other views of nature besides the astronomical have also led up to it, and placed it in similar prominence. 
About a century after the publication of the 'Principia,' which, by propounding the gravitation formula, raised the ancient and indefinite notion of Attraction to the rank of a useful and rigorously defined expression, another favourite theory of the ancient philosophers ${ }^{1}$ was similarly elevated to the rank of a leading and useful scientific idea.

Although no mathematical relation equal in value and definiteness to the gravitation formula marks the intro2. Atomic duction of the Atomic theory in Chemistry, it nevertheless owes its success to similar qualities-viz., to the fact that it led natural philosophers to make definite measurements, and placed exact research in the place of vague reasoning.

The atomic theory, usually associated with the name of Dalton, is, however, not nearly as much the historic property of that great man as gravitation is that of Newton, for whereas the latter gave the fullest generalisation that can so far be safely made, the atomic

1 Ancient philosophers have fur. nished us with three distinct abstractions which have survived, and which, put into definite mathemati. cal language, have led exact research in physics and chemistry in modern times - the theory of Attraction and Repulsion, the Atomic Theory, and the Kinetic Theory, or the notion that everything is motion. Of these three theories the second was most developed in antiquity; Lucretius's great poem on the nature of things being really a treatise on the subject, in which the atomic view is placed in the centre, the two other ideas being likewise largely utilised. The historians of ancient philosophy trace these abstract or leading ideas back to the earlier Greek thinkers. Thus Heraclitus of Ephesus is credited with having first taught that everything is in motion. Empedocles of Agrigentum made use of the notions of Attraction and Repulsion, poetically represented as Love and Hatred, to explain the action of his elements ; and Democritus of Abdera is universally considered to be the true founder of the atomistic theory, which was adopted and developed in the School of Epicurus, and very fully explained by the Roman poet. A very good analysis will be found in Lange's 'History of Materialism, (English translation by Thomas, 3 vols.), in which also the historical connection with modern thought, especially through Bacon, Gassendi, and Hobbes, is clearly brought out.

VOL. I. 
theory has been gradually defined and variously modified in the course of this century, and is still in a somewhat unstable condition. We are also bound to attach the greatest importance to the preliminary step taken by Lavoisier, who is even more justly called the father of modern chemistry than Kepler is called the father of modern astronomy.

3.

Lavoisier.

The exact claims of Lavoisier to this important place in the history of chemistry have been variously stated: ${ }^{1}$

1 Continental writers are pretty unanimous in dating modern chemistry from the time of Lavoisier (1743-1794). In this country there has been less unanimity, the names of Black, of Cavendish, of Priestley, even of Robert Boyle, having occasionally been put forward. The fact that Lavoisier did not sufficiently acknowledge his indebtedness to some of his English contemporaries has given occasion in some quarters to depreciation of his merits. It cannot be upheld that he was the first formally to express the doctrine of the indestructibility or conservation of matter, as this idea underlay many experimental researches before his time; nor that he was the first to refer to the balance as the ultimate test of chemical facts. The assertion that he first introduced the idea of two different kinds of matter, ponderable and imponderable, is also questionable, and still more so his claim to having discorered oxygen, the composition of water and of atmospheric air, the combustibility of the diamond, and other special facts. His fame rests upon a much broader basis, and has been most clearly investigated and settled by Hermann Kopp in his 'Entwickelung der Chemie in der neueren Zeit' (München, 1873).
In this excellent work the author somewhat modifies the view he took in his earlier ' Geschichte der Chemie' (Braunschweig, 1843, especially vol. i. p. 274 , \&c.), and sums up Lavoisier's merit in the following words (p. 145): "His contem. poraries could dispose of the same inherited and much new material, but not one of them understood how to build up out of this material and his own independent researches a chemical system, the reception of which should form the starting point for all future improvement of this science. Lavoisier has the whole merit of having achieved this. He added to his own recognition of the correct riews the work of procuring recognition for them from others. He imparted his own matured views to those who represented chemistry at the end of the last century. .... We must measure his greatness not merely by his own insight but also by the resistance which he had to overcome in other chemists who clung to the older theory. These achievements are great enough not to require the exaggeration with which they have occasionally been announced, and not to be touched by attempts on the other side to minimise them." 
there is however no difference of opinion on this point, that since his time, and greatly through his labours, the quantitative method has been established as the ultimate test of chemical facts; the principle of this method being the rule that in all changes of combination and reaction, the total weight of the various ingredients-be they elementary bodies or compounds-remains unchanged. The science of chemistry was thus established upon an exact, a mathematical basis. By means of this method Lavoisier, utilising and analysing the results gained by himself and others before him, notably those of Priestley, Cavendish, and Black, succeeded in destroying the older theory of combustion, the so-called phlogistic theory. ${ }^{1}$ From a

1 This result was announced in 1777 to the Paris Academy, and the demonstration completed in a memoir of 1783 . "He closes this latter memoir with the expression, that his object had been to bring forward new proofs of his theory of combustion of 1777 , and to prove that Stahl's phlogiston was something purely imaginary, - - that without it facts could be more easily and more simply explained than with it; he did not expect that his views would be at once accepted, . . . time would have to confirm or to reject the opinions he had developed, but already he recognised with satisfaction that unprejudiced students of the science, unbiassed mathematicians and physicists, believed no longer in phlogiston as Stahl viewed it, and that they considered the whole doctrine more as a hindrance than as a helpful scaffolding in erecting the edifice of science " (Kopp, 'Entwickelung,' p. 202). This and the further remark of Kopp that it was the mathematicians who took up Laจoisier's views (see supra, p. 115, note 2) are significant signs of the introduction of the mathematical, the measuring, spirit in to chemistry. Few ideas which once exerted so great and lasting an influence on science as that of phlogiston, have so entirely disappeared from our text-books, and it is interesting to note that those whose researches were guided by it were not so far from grasping a valuable truth as has been supposed. This theory, elaborated by Stahl, a contemporary of Newton and Leibniz (1660-1734), was the first attempt to co-ordinate a great mass of observations, to bring the phenomena of chemical change under one common principle. Phlogiston was the substance the migration of which gave rise to chemical change, and as the most obvious changes were exhibited in the processes of combustion, "Phlogiston" or "Brennstoff" was the name which suggested itself as most suitable for this principle. Not the weight of the substances was made the criterion of chemical change, but the readiness to enter into chemical 
scientific point of view, the principal defect in this theory was, that its explanations could not be subjected to any strict and exact numerical verification. Whenever an element enters into our operations which has either no weight or a negative weight, and thus evades exact determination and control, explanations and observations become vague and uncertain.

In the time of Lavoisier, and pre-eminently through his exertions, this vague and unmeasurable principle phlogiston was eliminated from the laboratory and the textbooks: quantities took the place of indefinable qualities, and numerical determinations increased in frequency and

4. Phlogistic theory. accuracy. The vague phlogistic theory, which contained a germ of truth, but one which at that time could not be put into definite terms, had helped to gather up many valuable facts and observations: these were collected and restated in a new and precise language. It has been said that every science must pass through three periods of development. The first is that of presentiment, or of faith; the second is that of sophistry; and the third is that of sober research. Liebig states the case somewhat

reaction ; and the mobility or inertness of chemical substances was to be measured by the presence or absence of a definite something. A hundred and fifty years after Stahl, science had so far advanced, that besides the change of weight or mass, the change of the power of entering into chemical com. bination could also be measured, and the term "potential energy" was introduced to describe many of those properties and processes which Stahl had fastened upon, when he, as the pioneer, undertook to co- ordinate chemical phenomena. If Stahl considered phlogiston to be a substance, though he did not inquire into its mass or ponderable property, the question might be put again, whether "energy" is not to be considered after all as a sub. stance. Cf. Tait, 'Properties of Matter' (2d ed., introduction, especially p. 5 sqq.); 'Recent Advances of Science,' introduction; also Clerk Maxwell, 'Electricity and Magnetism,' (last chapter); Ostwald, 'Chemische Energie' (Leipzig, 1893, p. 41). 
more correctly when he says: "To investigate the essence of a natural phenomenon, three conditions are necessary: We must first study and know the phenomenon itself, from all sides; we must then determine in what relation it stands to other natural phenomena; and lastly, when we have ascertained all these relations, we have to solve the problem of measuring these relations and the laws of mutual dependence - that is, of expressing them in numbers. In the first period of chemistry, all the powers of men's minds were devoted to acquiring a knowledge of the properties of bodies; it was necessary to discover, observe, and ascertain their peculiarities. This is the alchemistical period. The second period embraces the determination of the mutual relations or connections of these properties; this is the period of phlogistic chemistry. In the third period, in which we now are, we ascertain by weight and measure and express in numbers the degree in which the properties of bodies are mutually dependent. The inductive sciences begin with the substance itself, then come just ideas, and lastly, mathematics are called in, and, with the aid of numbers, complete the work." 1

As Galileo, Huygens, and Newton, by a series of brilliant investigations and theories, such as those of the pendulum, the fall of bodies, finally of universal gravitation, established the usefulness of the mathematical treatment of physical phenomena, so Lavoisier and his school proved the correctness and usefulness of their views by the new theory of combustion, as consisting in the combination of combustion. a special body or element called oxygen with other bodies

1 'Familiar Letters on Chemistry,' translated by Blyth, 4th ed., London, 1859 , p. 60 . 
or elements. A very large field of research-all on the lines pointed out by the new school-was opened out. But the age for a further application of mathematical reasoning came much more slowly in chemistry than in physical science.

The latter had at least one great department, in which a small number of factors, all admitting of mathematical accuracy-those of distance, mass, and motion-sufficed to explain the phenomena, at least if viewed from a great distance. This science is the physics of the heavens, the science of cosmic phenomena. On this earth-in physical and still more in chemical phenomena-the matter stood very differently. Here we have not to deal with a few measurable quantities only. A large number of elements or factors, of which only very few can be accurately measured, combine to make up what we called in the last chapter molar and molecular phenomena. In the study of inanimate nature, astronomy - the mechanics of the heavens-deals with the simplest relations; chemistrythe science of the changes which bodies undergo when being combined or separated-deals with the most complicated side of reality. Physics occupy an intermediate position, and thus we can also trace in the history of physical research the twofold influence of the astronomical method of inquiry on one side, and the chemical on the other.

But the general rule, that in chemical changes the weight of all the constituents put together never changes, was not the only numerical relation which came to the aid of students of nature, when they, at the end of the last century, betook themselves to exact measurements and 
determinations. That rule is indeed the foundation of all work in the laboratory, the principle which decides the degree of accuracy attained in every analysis, and which not infrequently is the only method of determining the presence of some undiscovered constituent. ${ }^{1}$ Not long

1 The revolution in chemistry at the end of the last century manifests itself in nothing more than in the various distinct problems, corresponding to different courses of scientific thought and different interests, which have guided chemical research since that time. The first definite object was the search after the real elements, the attempt to decompose the existing substances of nature into their ultimate constituents. This interesting occupation somewhat puslied into the background the theoretical investigations regarding the forms of the combinations of the various elements into compounds, still more the study of chemical affiuity. A second definite object was the development of the theory of combustion which Lavoisier propounded, and the confirmation or refutation of the idea according to which oxygen occupied almost as important a position in chemical reactions as phlogiston had done before. A third definite object was the development of analytical chemistry, the systematic and methodical use of the balance. So far as the first branch of this pursuit was concerned, Lavoisier's catalogue of the elements was still very incomplete; it contained thirty-three members, including light and heat, and twenty-three of the substances which now figure in the list of the seventy elements enumerated in the text-books; the alkalies and earths were still considered to be simple bodies. A great addition to our knowledge in this department came through Dary's decomposition of soda and potash. And after his proof of the elementary nature of chlorine the oxygen theory of Lavoisier had also to be greatly modified. "Through a series of most important investigations, he rose in the beginning of this century to such eminence, that he was then considered to be the first representative of chemical science. With great experimental ability he combined a singular freedom from all the theoretical doctrines which were recognised in his age" (Kopp, "Entwickelung der Chemie,' p. 451). In this he resembled Dalton and Faraday and other natural philosophers in this country, on whom theoretical notions formed in the Continental schools had little or no influence. Qualitative analysis was less indebted to Lavoisier than other branches of the science were. In fact, it was more at home in Sweden and Germany, where the interests of mineralogy and metallurgy promoted it. Bergmann and Scheele in Sweden, Klaproth in Berlin, were the forerunners of Berzelius and of the Berlin school of analysts. In this country Black and especially Cavendish had carried out some important quantitative determinations, the accuracy of which seems very far behind modern standards (see Kopp, 'Geschichte der Chemie,' vol. ii. p. $70, \& c ., 1844)$. It was the introduction of the notion of chemical equivalence, a term used already by Carendish, which furnished the ultimate test for accuracy and revolutionised quantitative analysis. 
6. before the age of Lavoisier, another general conception Rule of fixed
proportions. had been introduced into chemical research; this was the rule of definite proportions-i.e., the fact that substances, whether simple or compound, combine only in definite proportions of their weight, and that the numbers marking these proportions are characteristic of every definite chemical substance. It took some time, nearly a century, before this idea, which arose through the examination of neutral salts and the determination of the quantities of acids and alkalies which were wanted to effect mutual saturation, became clear; before the rule of definite proportions was generally established, becoming a guide for chemical analysis. It is interesting to note how the vaguer terms of chemical affinity and elective attraction, of chemical action, of adhesion and elasticity-mostly borrowed from other departments of science where they had definite meanings-gradually disappeared, when by the aid of the chemical balance each simple substance and each definite compound began to be characterised, and labelled with a fixed number. Nevertheless, even at the beginning of this century, eminent chemists were still so much engaged in discussing the rival claims of the old phlogistic, and the modern theory of combustion, of Berthollet's chemical equilibrium, of the so-called dynamical and the electro-chemical views of phenomena, that the first methodical attempt actually to fix these numbers-i.e., to give a table of chemical equivalents-remained unnoticed. ${ }^{1}$

1 The history of chemistry early in this century furnishes a good example of the sway which theoretical riews exercised over the minds of investigators. Berthollet, who began by critically examining Bergmann's doctrine of chemical affinities, was evidently much influenced by the mathematical theory of attraction, and by the mechanical laws of equilibrium, which formed so prominent a subject of investigation in the 
The merit of having made this attempt belongs to one who approached chemistry entirely from the mathematical side, who wrote the first chemical book with a title pointing directly to measurements, but who perhaps spoilt his work by giving way to the fascination which regular numerical and geometrical arrangements have again and again exercised over philosophical inquirers. Jeremias Benjamin Richter - a name possessed of no popular brity-published in 1792 to 1794 , in three parts, his "Stœchiometry," or "the art of measuring chemical elements." 1 From his data, Fischer calculated in 1802 the

writings of Laplace and his school. Chemical affinity was to be coordinated with what he called astronomical attraction; both were to be ultimately the same physical property; they acted differently, because in the case of gravitation the dimensions were so large, that the form, distances, and peculiar properties of the molecules had no influence. It was an attempt to introduce the astronomical view of matter into molecular physics, and to base chemistry upon this view. Berthollet adhered to the corpuscular theory of heat against Rumford, who had just propounded his opinion that heat is not a constituent part of bodies ; and he maintained that chemical affinity was a function of the mass of bodies as was astronomical attraction. The germ of truth in Berthollet's views, which were approved by Laplace, but cast into oblivion under the influence of Proust and Richter's theory of fixed proportions, has in recent times been shown by Lothar Meyer ('Modern Theories of Chemistry,' Introduction), and by Ostwald ('Allgemeine Chemie,' vol. ii. p. 557, 1st ed., also 'Die Energie und ihre Wandlungen,' Leipzig,
1888, p. 20 ). If the astronomical view of molecular phenomena prevented Berthollet from accepting Proust's doctrine of fixed proportions and definite combinations, Richter injured his own reputation by adhering to the nomenclature of the phlogiston theory after it had been discarded by French chemists, and in Germany after Klaproth's determinations in 1792. The oxygen theory of combustion of Lavoisier got such a firm hold on the minds of Continental chemists that the labours of those who, like Cavendish in England and Richter in Germany, put forward important discoveries in the language and on the principles of the older theory, were temporarily forgotten. See Kopp, 'Entwickelung der Chemie,' p. 271, \&c.

'Stœchiometry comes from the Greek $\tau \grave{\alpha} \sigma \tau o \iota \chi \in \hat{i} a$, the constituent parts, and $\mu \in \tau \rho \in \hat{i} \nu$, to measure. All Richter's works are connected with the application of mathematics to chemistry; his inaugural dissertation, which appeared in 1789 , having the title 'de usu matheseos in chymia' (Kopp, 'Geschichte der Chemie,' vol. ii. p. 350). " 'Richter était préoccupé de l'idée d'appliquer les mathématiques à la chimie, et en 
first table of chemical equivalents, taking sulphuric acid as the standard with the figure 1000 .

The conviction that chemical substances combine according to fixed and simple proportions gained ground on the Continent, chiefly during the discussion in which Proust finally disproved and defeated Berthollet's theory 8. of chemical affinity; but it is to Dalton that the doctrine of fixed and multiple proportions is indebted for a consistent exposition. Dalton based it upon a mental representation which ever since has been the soul of all chemical reasoning.

When Newton, from the measurable data of the movements of cosmic bodies, deduced the celebrated gravitation formula, he had to descend to molar-nay, even to molecular-dimensions, and to express it as a relation referring to the very elements of matter, before he could apply it in a useful manner: he had to express it as a formula which had reference to the smallest portions of matter. In the same way, the measurements made by

particulier de découvrir des relations numériques entre les quantités des corps qui se combinent. Ses efforts, dans cette direction, n'ont pas été également heureux; car, s'il a reconnu et énoncé le premier la loi de proportionalité entre les quantités de bases qui s'unissent au même poids d'acide et entre les quantités d'acides qui s'unissent au même poids de base, fait important et exact, il a cherché à démontrer, d'un autre côté, que ces quantités fermaient des séries numériques dont les termes augmentent suivant des relations simples, ce qui est erroné. .. Ces erreurs n'ont pas échappé, sans doute, a l'attention des contemporains de Richter et ont contribué à discréditer ses travaux.
. . Mais nous n'avons pas à insister sur ce dernier point. Relevons, dans l'œuvre de Richter, les idées justes et les découvertes fondamen. tales qui recommandent d'autant plus son nom à l'attention reconnaissante de la postérité qu'il est demeuré méconnu et presque ignoré de son temps" (Wurtz, "La Théorie atomique,' $7^{\mathrm{me}}$ ed., 1893 , p. 9, \&c.) "L'opposition même, qu'il professait pour les doctrines du réformateur [Lavoisier] semble avoir contribué à discréditer les travaux de Richter: son heure n'était pas renue; l'intérêt était ailleurs, et en Allemagne, comme en France et en Angleterre, les esprits étaient entrainés par le courant des idées nouvelles" (ibid., p. 13). 
many chemists previous to Dalton had to be interpreted as referring not only to such quantities as the balance could determine, but to the very smallest immeasurable particles of which chemical substances consist. For this purpose Dalton adopted what was known as the atomic view of matter. The conception of matter as made up of independent particles, which for our means and methods prove not only indestructible but likewise indivisible, was revived as the ancient theory of attraction had been. Combined with the Newtonian view that weight is a universal property of all matter, it made the two fundamental rules of chemical action intelligible, the two facts - first, that the total weight of substances remains always the same, be they combined in ever so many different ways; and secondly, that all substances, be they in large or in small quantities, combine with each other, or separate from each other, in definite and fixed proportions. This view could not be consistently maintained, except it was referred to the smallest particles into which matter is practically divisible: the figures expressing the combining numbers were viewed by Dalton as representing the relative weights of the actual atoms or elements of matter. That the ultimate particles of matter have definite weights is the reason why substances combine in fixed proportions, and why the combining weight of the compound is the sum of the combining weights of the constituents.

As the gravitation formula had given rise to a surprising activity in physical astronomy, to a long series of exact measurements, and to theoretical deductions of a purely mathematical kind, so the atomic theory of Dalton 
in the early years of the century fixed the task of chemists for a long time ahead.

To begin with, an enormous amount of work had to be done in determining the actual proportions in which 9. elementary substances combine. A very large share of this work belongs to Berzelius, who by a great number of very accurate determinations confirmed inductively the correctness of Dalton's theory. And still more important than the confirmation of the theory was the great harvest of actual knowledge of the things and processes of nature which was collaterally gathered, whilst chemists were trying to prove or to refute existing opinions.

Indeed, whilst the atomic theory of Dalton was the first step towards a systematic and comprehensive study of chemical phenomena-i.e., of the qualitative varieties under which matter presents itself to us on the surface of this globe-the extension which was gained in the domain of actual facts was much greater than the simplification which the theory had attempted to give. The number of elements or simple bodies, which in Lavoisier's time hardly exceeded thirty, increased before the year 1830 to more than double: the number of new compounds, unknown before, has probably never been counted. Compared with this growth of actual knowledge of facts, the development of the theory was slow and uncertain. The view of nature from the atomic point of view marks indeed a great contrast to that from the astronomical point of view. We now live about as long after the reform of chemistry through Lavoisier and Dalton as compared. Laplace lived after the reform of physical astronomy 
through Newton. But who could compare the state of chemistry at the present day with that of astronomy in the age of Laplace? There, every step had tended to show that the one Newtonian formula sufficed to comprehend all cosmic phenomena; here, the simplification introduced by Dalton has had to give way to a series of modifications which have rendered the atomic theory one of the most complicated machineries ever introduced into science. Let us review in brief the fate of Dalton's hypothesis during the century which followed. Quite in the early years of the atomic theory, Wollaston prophetically foretold that if once an accurate knowledge were prophecy. gained of the relative weights of elementary atoms, philosophers would not rest satisfied with the determination of mere numbers, but would have to gain a geometrical conception of how the elementary particles were placed in space. Van't Hoff's 'La Chimie dans l'Espace'-published at Rotterdam in 1875-was the first practical realisation of this prophecy. Many stages had to be gone through before this latest phase of the atomic view was attained. Had it been the case that every elementary substance combines with any other substance only in one fixed numerical proportion, no necessity would have existed to look upon the atomic numbers as anything else than equivalents. But it was found that though the combining numbers were fixed they were not always the same; it was found that if a substance combined in two or more proportions with any other, the larger proportions were always exact multiples of the smallest proportion. And this-the rule or law of multiple proportions-was 
12.

Rule of multiple proportions.

exactly what gave to Dalton's view its great plausibility, ${ }^{1}$ for if the elementary atom of each substance had a definite weight, it might be that not one atom only combined with one other, but that one combined with two, or two with three, and so on. Indeed it was soon found that this was

1 The different factors of thought which combined to give the atomic theory that definiteness and usefulness which it attained through and since Dalton lay ready-made before him ; but no one had seen so clearly as he did how to combine them. Proust had taught how to distinguish between chemical compounds and mixtures. When he prepared carbonate of copper artificially, he found that it had the same composition as the mineral which he found in nature. Richter had shown that definite proportions describe the quantities in which acids and bases exist in neutral salts. Fischer had attached to his translation of Berthollet's work the first table of equivalent quantities of bases and acids which combine to neutralise each other. Richter, and after him Gay-Lussac, had also found that the quantities of different metals which dissolve in the same quantity of acid to form saturated solutions combine alsc with the same weights of oxygen to form oxides. Richter, and after him Proust, had found that certain metals, like iron and mercury, form more than one fixed compound with oxygen, but without perceiving that the different quantities of oxygen in these fixed compounds stand in simple proportions to each other. So far as the theoretical side is concerned, the idea that bodies are formed of distinct particles - the notion of the ultimate heterogeneousness or discontinuity of matter-was not only familiar to the ancients, but was adopted by many physicists before Dalton; though the chemical specialists who prepared the way for Dalton do not seem to have made use of this idea. Boerhaare, and before him Boyle, had spoken of atoms and of the massulce or particles. Theories were not wanting that these ultimate particles differed in size and form, nor the opposite view, that the particles which combined had the same weight. The latter was the view of Higgins, in the exposition of which $(1790)$ he entangled himself in contradictions, losing his chance of being one of the founders of the atomic theory. As Wurtz and Kopp and others who have carefully inrestigated the rival claims have said: This honour of founding the atomic theory belongs undividedly to Dalton. It seems important to notice that his experiments with mixtures of gases, which must have begun about 1790, impressed upon him the idea that different gases could exist independently of each other in the same space, suggesting the conception that neither of them filled the whole space, but that they consisted of discontinuous particles. He himself refers to these first investigations as containing the germ of his later opinions. It must, however, be borne in mind that Dalton was only imperfectly acquainted with the writings of contemporary - especially Continental - writers, and that he had a wholesome distrust for statements of facts which he had not verified or observed himself. All this is rery clearly stated in Kopp's 'Entwickelung der Chemie,' p. 285, \&c. 
actually the case. The lowest number according to which any substance entered into combination with any other was called the atomic weight or equivalent.

There was, so far, no necessity to look upon atomic weights as anything else than numbers fixing a proportion. The unit could be selected arbitrarily. It was not long before that element, hydrogen, which entered into compounds in the relatively smallest weight was taken as an arbitrary unit, and all other elements and compounds were tabulated according to the relative amount of their weights required to form compounds with hydrogen or with any other element-e.g., oxygen-the equivalent of which with hydrogen was known. ${ }^{1}$

${ }^{1}$ For many years after the enunciation of the atomic theory great uncertainty and much difference of opinion existed on this and other points. The man who did most to elaborate the edifice of which Dalton had laid the foundations, who filled in the outlines and invented the language of chemistry, was Berzelius. He proceeded inductively and gathered materials from all sides; to him are also owing the greatest number of accurate analyses, especially of inorganic substances. When he began his labours he was favourably dis. posed towards Dalton's hypothesis ; he clearly saw its capabilities, but also that it was based only upon a liappy suggestion, that it was introduced more by deductive than by inductive reasoning, and that it needed to be exhaustively tested and verified. After ten years, during which he published in Gilbert's 'Annalen ' and in Thomson's 'Annals of Philosophy' many series of investigations, he was able in 1818 to publish, in his 'Essay on Chemical Proportions and on the Chemical Effects of
Electricity' (French translation, 1819 ; German translation, 1820), the first systematic and complete exposition of the atomic theory. The beginning of a really exact treatment of chemistry has been dated by $H$. Rose, the greatest analy tical chemist of the century, from this year 1818-the year in which Dalton's hypothesis was proved and generally accepted. Others have dated the beginning from 1808, when Dalton published his theory; others again from 1776 , when Lavoisier destroyed the older phlogiston theory and appealed to the balance; others again from Black's discovery of latent heat in 1760. In an international history of thought it is not of much interest to decide whose claims to be the founder of modern chemistry as a science are best established. Every one of these dates marks an epoch in the advance of an important and independent branch of research. Black took an important step in the foundation of physical chemistry through his introduction of the conception of the quantity
13. Equivalents. 
A great door was now opened, not only for actual observation and research, but also for speculation-i.e., for abstract thought. Some substances, if they entered into combination with hydrogen, required more than one unit of hydrogen, and it might therefore be that the proportion of the combining weight of hydrogen with any substance did not correctly give the atomic weight of the latter, but merely a multiple or sub-multiple of it. Thus, assuming oxygen combined with hydrogen in the proportion of 8 parts of the former to 1 part of the latter, the possibility was that the proportion might more correctly be written 16 to 2 than 8 to 1 . Then, again, were the equivalent or atomic weights necessarily whole numbers? Were combinations all binary, such as acids and alkalies forming salts? and were more complex compounds resolvable into binary compounds of simpler binary compounds? Further, assuming the proportions fixing the combining weights to be known, how did the volume of bodies combine? - was there a rule of volumes as there was of weights? and lastly, what was the reason or cause which made substances change their combinations, forming new ones, what did chemical affinity consist in, what did it depend on, how could it be defined and measured?

Considering that we have to do with a large number of independent, apparently unchangeable, elements, entering into many thousands of differing compounds, the task of

of heat. Lavoisier led the way in the development of the purely arithmetical department of chemistry, in the exclusive study of which physical chemistry was greatly neglected. Dalton suggested a formula which lent itself admirably to the representation of these purely arithmetical relations, and Berzelius elaborated this and invented a practical nomenclature. Black and Dalton threw out novel ideas; Lavoisier and Berzelius elaborated great systems and created great schools which numbered many converts and industrious workers. 
the chemist was enormous, offering a large, almost limitless, field of research and speculation. Let us see under what leading ideas this knowledge has been arranged.

In the gradual development and clearer definition of these conceptions a general rule of thought seems to have unconsciously guided philosophers probably more than in any other departinent of knowledge. It is the rule of simplicity. ${ }^{1}$ How the human mind should have 14.
"Simplex arrived at the old formula of "simplex sigillum veri" is difficult to understand on any other ground than that of convenience and expediency. The prevailing impression, indeed, which the world of phenomena makes on the mind of an unbiassed observer must be the very reverse of simplicity or unity of law and purpose. That, nevertheless, the knowledge of some simple relations in time, number, and space would enable the human intellect to acquire a considerable insight into the course of events and the order of Nature's processes must have come to philosophers

\begin{abstract}
1 The progress of chemical theory is the history of the attempt to find simple relations of number and form, representing the countless combinations of elementary substances; and of the growing conviction that nearly every simplification must, in course of time, be abandoned. No formula remains unchallenged except the doctrine of fixed and fixed multiple proportions, and that only if we confine ourselves to solid compounds; but the proportions themselves are not accurately known, though no phenomenon exists which disproves the assumption that they are invariable. The original conception of the atom as a round hard body had to be abandoned for the more complicated
\end{abstract}

notion of a molecule, an assemblage of atoms ; the conception of elementary bodies had to be amplified by that of compound elements or radicles; the idea that the atomic weights were multiples of a lowest number had to be abandoned; the binary theory of the combination of bodies was replaced by the theory of radicles, of nuclei, of types; the simple nature of the elementary particles had to give way to a complicated atomicity, from which there had to be again distinguished the valency or capacity of saturation of the elementary constituents. It is a progress from simpler to more and more complex methods of representation.

VOL. I. 
as a kind of revelation, and it is not surprising that it came late in the course of civilisation. ${ }^{1}$

Nothing can have tended more in this direction than the success of the Newtonian gravitation formula, and of the simple laws of motion, which, at the time of the birth of modern chemistry, stood firmly established as the key to all problems of physical astronomy. No wonder that men were on the look-out for correspondingly simpleperhaps analogous-relations in the world of molecular phenomena. One of the earliest suggestions, which came forward soon after Dalton's atomic view had helped to establish the prevailing rule of fixed and of multiple proportions in the chemical combinations and reactions of matter, was the idea that, as to each element belonged a definite combining number, all these numbers must be the multiple of the lowest among them, the equivalent or atomic weight of hydrogen. This is Prout's celebrated hypothesis. hypothesis, which had some ardent admirers, and which has been repeatedly abandoned and revived in the course of this century. ${ }^{2}$ It is hardly possible to maintain it any longer, since the accurate and elaborate measurements of

${ }^{1}$ Except indeed the Pythagorean notions are regarded as an anticipation of it.

2 The hypothesis of Prout, published anonymously in 1815, and warmly defended by Thomson, has been again and again rerived. From the beginning it was put forward together with the suggestion that the different elementary substances might after all turn out to be all derived from one and the same primary form of matter, and that the atoms of this might in the atoms of our present elements merely be aggregated in different numbers and figures, held together by forces, which by the means and processes at our command could not be broken up. This primary substance might then be either liydrogen, the lightest in weight of known substances, or some other substance of which hydrogen itself was an atomic multiple. Abroad, Prout's hypothesis was disproved by Berzelius's accurate determinations, in England by Turner's, and about 1830 it fell into oblivion. It was again revived in 1840 by Dumas, who, as well as his followers, Laurent and Gerhardt, faroured the idea that the explanation of the different properties of chemical compounds, notably organic compounds, was to be found in the arrangement 
Stas, who began with a belief in the hypothesis, led to the result " that the simplicity supposed by Prout's hypothesis to exist in the ratios of weights which come into play in chemical processes has experimentally not been found; it does not exist in reality." 1

of the elementary atoms, in the structure rather than in the material difference of the elements themselves. The development of this view in the modern chemistry of "types" and "structures" will always go hand in hand with an avowed or tacit belief in the existence of an ultimate uniformity of substance, out of which by a diversity of configuration of atoms the infinite variety of compounds is produced. The accurate measurements of Stas had again about the year 1860 disproved the hypothesis of Prout. It has, however, again turned up in recent scientific literature. The theories of evolution, pliysical and philosophical, the discoveries of the spectroscope regarding the small number of elements contained in the photosphere of the sun, the periodic laws of Lothar Meyer and Mendeléeff and the stereometric theory of the carboncompounds, of which I shall speak later on, all point to the conclusion that our so-called elements are composite bodies, and favour a view, similar to that of Prout, that possibly a single kind of matter may form the only substance of which atoms, molecules, elcments, and compounds are made up. Professor Crookes in his address to the chemical section of the British Association in 1886 revived interest in the subject. After quoting a variety of authorities, he sums up: "From these passages, which might easily be multiplied, it plainly appears that the notionnot necessarily of the decomposibility, but at any rate of the complexibility of our supposed elements -is, so to speak, in the air of science, waiting to take a further and more definite development. It is important to keep before men's minds the idea of the genesis of the elements; this gives some form to our conceptions, and accustoms the mind to look for some physical production of atoms." Further on he coins the word "protyle" (from $\pi \rho \omega \dot{\tau} \eta$ and $\delta \tilde{\lambda} \eta$ ) to denote the original kind of matter, and thus reminds us that, though speculations of this nature are not infrequent in English philosophy since Roger Bacon, the English language has no word to denote what the Germans call "Urstoff," the Romans "prima materia," the Grecks $\tau \dot{\partial} \sigma \tau o$ ' $\chi \in \hat{\imath} \circ \nu$ or simply $\forall \lambda \eta$. The line of thought which again and again leads philosophers to speculate on this " prima materia" and upon a hypothesis similar to that of Prout is interesting and noteworthy, though it must be acknowledged that, so far, no real scientific benefit has been derived from it, and that it rather tends to upset the only firm foundation of modern chemistry, the fixity of the equivalent proportions as we now use and know them. Mendeléef himself, in his excellent Fara. day lecture on the periodic law (Journal of the Chemical Society, 1889, p. $634, \& \mathrm{c}$.) distinctly refuses to recognise any connection between the periodic law and the idea of an unique matter.

I Stas, quoted by Ostwald, 'Lehrbuch der Allgemeinen Chemie,' vol. i. 2 d ed., Leipzig, 1891, p. 129. The revival of the hypothesis of Prout about the middle of the century was owing to the discovery by Dumas and Stas of the fact that Berzelius's figure, $12 \cdot 20$, for the 
Prout's simple but incorrect assumption belongs to the age which witnessed the decomposition of many compounds into their two constituents by Davy's successful use of the galvanic battery, at the poles of which the two elements of substances made their separate appearance. Substances which had always been considered as elemental and permanent, such as many oxides and earths, came to be ranged among the list of binary compounds. This lent plausibility to the idea that even the supposed elements themselves might ultimately prove to be aggregates-differing in number and figure-of the elementary particles of one and the same primary substance. Though with Prout's hypothesis this view has been repeatedly held and refuted, another theory-recommended likewise by its simplicity - had its origin in the discoveries of Davy, and the further development of them by Berzelius. This is the so-called electro-chemical or binary theory of chemical compounds. The dual combination of one elementary substance with another, and again of two dual compounds with each other, and so on, even to the most complicated compounds, was to be the simple type of chemical combination. This view, so

atomic weight of carbon, taking oxygen as 16, was incorrect. An account of the long series of determinations of this important constant will be found in the same work, p. 82 , \&c. I believe that in the first edition of this work will also be found the first consistent attempt to introduce into chemical data an estimate of the degree of accuracy or the amount of error which attaches to our knowledge of the constants of nature and the so- called laws of phenomena. This consideration, so familiar to astronomers, was, I believe, quite orerlooked in many of the best handbooks during the earlier half of our century, and it is even yet hardly touched upon in the ordinary textbooks. The result is an entirely erroneous impression produced on the popular mind as to the degree of certainty which belongs to scientific statements. 


\section{simple and plausible, governed research for a long period, but has finally been abandoned as insufficient. ${ }^{1}$}

Another blow was dealt at the simple theory by which

16. Discovery of isomerism.
1 The electro-chemical theory of Davy and Berzelius was, after about fifteen years of development, during which period the use of the significant terms electro-positive and electro-negative was not consistent, finally enunciated by Berzelius in 1818 in his ' Essay on the theory of Chemical Proportions and on the Chemical Action of Electricity.' From that time it reigned almost supreme for twenty years, when both physical and chemical discoveries began to show its insufficiency. A very concise account of it is given in Kopp's 'Entwickelung der Chemie,' and in E. von Meyer's 'History of Chemistry,' translated by M'Gowan (Macmillan \& Co., 1891). Berzelius clung to it to the last, and at the present moment there exists a widespread opinion that the future will see a revival and modified acceptance of the Davy - Berzelius theory. In relation to this Helmholtz's celebrated Faraday lecture of the year 1881 should be read (see the reprint in Helmholtz's 'Vorträge und Reden,' vol. ii.) The peculiarity of the electro-chemical theory was that it was an atomic theory as well as a theory of chemical affinity. When it was abandoned, the two distinct interests, that of developing the atomic view, so as to give a correct description of the constitution of chemical compounds and reactions, and that of giving an explanation of chemical affinity, fell for a time asunder. The former interest preponderated, owing mainly to two reasons, the one theoretical, the other practical. The theoretical reason was the need of a different method of systematically arranging the chaos of new organic compounds with which chemistry became crowded about the year 1840 . Berzelius had created the nornenclature and notation of chemistry ; but this proved insufficient to describe and grasp the processes and products of the many carbon compounds. The practical reason which cast into the background the study of chemical affinity and its nature was the growing demands of manufacturing chemistry. This was during a long period occupied mainly with the analysis and synthesis of new products, or with new and simpler methods for producing well-known compounds. The study of reactions and of the products of bodies was practically of more interest than that of the forces which governed them. The question of the cost of producing chemical products was for a long time a secondary one. Towards the end of our century both theoretical and practical considerations forced upon chemists the necessity of making themselves acquainted with the different forms of energy which are at our command in chemical as well as in mechanical operations, and this has led to a renewal of the study of chemical and mechanical energy, and of the nature and laws of chemical affinity. Economy in practical chemistry can be divided into two branches: the economy of materials and the economy of energy. The great developments in the course of this century have consisted largely in utilising byproducts and in avoiding waste of substance. We are now only approaching the second problem : how to put the energy which is at our command to the best use. 
Berzelius united Dalton's and Davy's researches into a comprehensive system of chemistry. The identity or difference of chemical substances seemed in the early part of the century to be fixed by the constituent elements and their quantitative proportions determined by a qualitative and quantitative analysis. This simple view had to be abandoned when Wöhler in 1823, Liebig in 1824, and Faraday in 1825 found that entirely different qualities, indicating a different constitution, could belong to bodies having the same elements in the same numerical proportions. ${ }^{1}$ The composition of a compound had to be distinguished from its constitution, the elementary from the constituent analysis and formula. It took forty years before the great variety of views which were brought forward with the purpose of explaining how composition and constitution of the same aggregate of elements might

1 This phenomenon is termed "Isomerism," from the Greek word

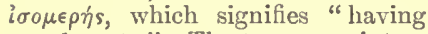
equal parts." The term was introduced by Berzelius in 1830, after he had satisfied himself that compounds existed, differing widely in their properties, which contain the same constituent elements in the same proportions, and which combine with other bodies in the same proportions to form neutral salts. This he found to be the case with " racemic" and "tartaric" acid. Up to that time he had hesitated in accepting the growing evidence that equal constituents in equal proportions did not constitute identity of compounds. Wöhler in 1823 and Liebig in 1824 had found the same numerical composition for "cyanate" and "fulminate" of silver. In 1825 Faraday found two hydrocarbons which contained the same proportions of carbon and hydrogen, but showed totally different properties, such as unequal density in the gaseous state. Two oxides of tin, having the same composition, were also known, and two modifications of "phosphoric acid." The explanation of these anomalies caused Berzelius much difficulty. $\mathrm{He}$ resorts to the notion of a difference of grouping of the constituent atoms. "The isomerism of compounds," he says, "in itself presupposes that the positions of the atoms in them must be different" (see E. von Meyer, "History of Chemistry,' p. 238). A. Rau in his 'Theorien der modernen Chemie' (3 parts, Braunschweig, 1877-84) gives in the appendix to the third part a detailed history of isomerism. He denies that Berzelius refers to the different position of atoms in order to explain isomerism; he attributes this suggestion to Dumas in 1833. 
differ, could be approximately brought into line and order. This period was filled by the development of the chemistry of organic compounds. The chemical substances which make up the framework and numerous tissues chemistry. of all living beings, the juices and products of vegetable, the food and the excreta of animal organisms, consist mostly of a few elementary bodies, combined according to numbers which are highly complex and unintelligible. Most of these compounds, if removed from the organism which contained them, proved to be subject to rapid decomposition. An increasing number of stable compounds, however, were in course of time prepared from these residues, and these formed especially the subject of organic analysis. Already Lavoisier had indicated how some system might be brought into the apparent complexity of these organic bodies; and this view was adopted by Berzelius and incorporated in his dual or binary system. ${ }^{1}$

1 Kopp's account of the development of Berzelius's views on organic compounds is most interesting and instructive. As late as 1814 he could not reconcile the composition of organic acids, such as oxalic acid, with the atomic theory; but renewed efforts and improved methods of analysis taught him in the following years how to apply the atomic formulæ to the description of such compounds. " $\mathrm{He}$ was the first to show the only right road to inform ourselves regarding the constitution of these bodies, the method, namely, of analysing their combinations with inorganic substances of known atomic weight. ... He had also a great share in establishing the view that the ratios of combination in organic compounds are analogous to those of inorganic substances, and that theories of the former must begin by comparing them with the latter" ('Geschichte der Chemie,' vol. i. p. 398 ; cf. also ' Die Entwickelung der Chemie,' p. 532, \&c.) To Berzelius is thus due more than to any other man the breaking down of the barrier which had before his time divided the chemistry of organic from that of inorganic substances, For a considerable time Berzelius did not look upon organic compounds as binary-in fact, in 1814 he assumed that the difference between organic and inorganic compounds lay in this, that the latter were all binary, whereas the former were ternary or quaternary. The French chemists, under the influence of Lavoisier's oxygen theory, favoured the binary view, and this was much strengthened by GayLussac's researches on cyanogen (in 
It was supposed that the simple and well-known elements of these bodies might have the property of forming primarily combinations which were more firmly knit together than others, that these primary combinations might then as it were take the place of elements and act like them, forming with others of similar constitution, or with the simple elements themselves, more complex compounds. In these higher compounds they might behave like elementary bodies, entering into and being expelled from them in their own proper combinations without being broken up into the ultimate elementary constituents. One of the functions of the living organism was by the action of the vital forces to produce these primary compounds or complex atoms. It was thus thought that as inorganic bodies were made up of constituents which were elements, so organic bodies were made up of constituents which were themselves partly compounds. A new term had to be coined for those constituents which might comprise both elementary bodies and these primary compounds which behaved like elements in organic substances. This was the term "Radicle." A radicle might be an element or a compound. ${ }^{1}$ For a long time it was thought that these

1815), a compound of. carbon and nitrogen, which was shown to behave like an element. Ampère in the following year showed how the salts of ammonia could be brought into line with the salts of other alkalies by considering them to contain a compound element (consisting of nitrogen and hydrogen) in place of a simple element. In his celebrated essay of 1818 Berzelius defines organic acids as binary compounds of oxygen with com- pound elements or radicles (Kopp, 'Geschichte der Chemie,' vol. iv. p. 269).

1 The term " radicle," to desig. nate the principal constituent of a compound, was used as far back as 1787 in the discussions through which the French chemists reformed the nomenclature of chemistry (Kopp, 'Geschichte,' \&c., vol. iv. p. 266). It acquired a more definite meaning about the year 1835 , when Liebig, in common with Ber- 
complex radicles, as distinguished from the elements, were produced mainly-if not exclusively-in the organism of the plant or of the animal. Liebig himself, who favoured this view, and who first brought organic chem18. Liebig's deistry in its application to agriculture and physiology finition of organic under the notice of a large circle of readers, introduced this branch of the subject with the designation of the chemistry of compound radicles, inorganic or mineral chemistry being termed the chemistry of simple radicles. The radicles were, according to Liebig, the true elements of organic chemistry. The binary system of Berzelius received another attack led by the celebrated French chemists Laurent and Gerhardt, with whom Dumas temporarily allied himself. It was about the year 1840 that the idea of "substitution" entered the list of formulæ by which chemical philosophers attempted to systematise Substitu. 19. and simplify the ever-growing number of definite compounds, supplied mainly by organic analysis. ${ }^{1}$ It was

zelius and with Dumas, established what is now called the older radicletheory of organic compounds. As Kopp has shown ('Entwickelung der Chemie, p. 576, \&c.), it remained undecided at that time whether these organic radicles had actual existence, or whether they were merely a convenient symbolism,whether they could be isolated, like cyanogen, or whether they existed only in combinations, - whether they were fixed and unchangeable, or whether they could themselves be converted one into another,whether the same compound could be referred-for convenience sake - to more than one constituent radicle. "By most chemists the definition of organic chemistry given by Liebig ('Organic Chemistry,' 1843) was adopted, that it was the chemistry of compound radicles; . . . that these radicles really existed in the compounds as definite constituents; and if it was then said that these radicles were mostly hypothetical, this was understood as meaning that some of them were known in the free state, others not" (p. 581).

${ }^{1}$ Even before that time the views of many eminent chemists had been greatly influenced by the discoveries and experiments of two great natural philosophers of this country who kept themselves free from the theoretical considerations which had led Berzelius in the elaboration of his electro-chemical and binary system. These were the researches of Davy regarding the so-called hydro- 
found that one or more atoms in an organic compound, notably of hydrogen, might be replaced by an equal number of atoms of other elements, and that such products of substitution retained similar qualities, and could be mutually converted into each other, the type of the compound remaining the same. The process of substitution led to the conception of "Types," which remained the same whilst the individual compounds varied according to the different elements which were introduced.

gen acids of chlorine, bromine, and iodine, and the investigations of Graham into the salts of phosphoric acid and its different modifications. Davy, though together with Berzelius the founder of the electrochemical theory, had found it necessary to modify the oxygen theory of Lavoisier-viz., that oxygen was necessarily the acid-forming element: he, and after him Dulong in France, had explained the socalled oxygen acids like sulphuric acid as hydrogen compounds of certain compound radicles $\left(\mathrm{SO}_{4}\right)$ exactly as liydrochloric acid is a hydrogen acid of the simple radicle chlorine. Graham's discorery of three modifications of phosphoric acid, and of the different power of saturation of these three modifica. tions, led to long discussions as to what is really meant by a neutral salt. Liebig in the year 1838, in an important memoir gathering together the conclusions which these facts, not easily reconciled with Berzelius's system, had led him to, emphasised there the twofold pos. sibility of regarding metallic salts either with Berzelius as binary combinations of oxides with anhydrous acids, or else as products of substitution of hydrogen compounds, hydrogen being replaced by metals. The choice might then depend on considerations of convenience: the one view might be more suitable for inorganic-notably metallic-compounds, the other for organic compounds. The liydrogen theory was thus introduced alongside of the oxygen theory; substi. tution was introduced alongside of simple combination. Though in this stage the radicle theory was already threatened, it was still possible to uphold the binary theory, though it was not necessary. Chlorine could act in the same way as oxygen, being an electro-negative element. But when, in pursuing the line of investigation opened out, it was found that chlorine, the electro-negative clement, could take the place of hydrogen in organic compounds without changing their chemical character, the binary theory, based upon polar (electrical) contrasts, became insufficient as a means of explanation or even of classification. Dumas was the first to indicate this (1834), though he attempted to save the electrochemical or polar theory by stating that the two electrically opposite constituents of an organic compound might contain the same elements in the opposite electrical positions (Kopp, 'Entwickelung der Chemie,' pp. 564, 595, \&c.) 


\section{Whilst the "Radicle" theory of Berzelius and Liebig} sought to simplify the study of chemical compounds by reducing them to a definite number of complex atoms, the "Type" theory of Laurent and Gerhardt sought to attain the same object by establishing a small number of simple theory. formulæ, corresponding to well-known simple substances, under which the vast number of organic compounds could be grouped. ${ }^{1}$ The conception of a "type" exhibiting

1 The type theory was slowly and lesitatingly developed. Dumas, whose researches about 1835 prepared the way, did not himself draw the immediate consequences; this was done by Laurent, "who maintained that the structure and chemical character of organic compounds are not materially altered by the entrance of chlorine and the separation of lydrogen" (E. v. Meyer, 'History of Chemistry;' p. 261). Laurent then elaborated his theory of "Nuclei." They remind one of Berzelius's and Liebig's radicles. The nuclei were the groundwork of organic compounds; they were not unalterable as the radicles had been considered to be. Dumas, who at first repudiated Laurent's ideas, was later on, through his own experimental discoveries, led to adopt similar views. The "radicle," as the permanent constituent in organic compounds-corresponding to the elements in inorganic chemistry -liad given way to the changeable nucleus, which only preserved its form; the unchangeable principle was found in the form, the structure or type, instead of in the substance of the simple or composite constituents. This led to an extensive study of the forms of chemical compounds-as expressed by their formulæ, and apart from the study of the properties of the original constituents. Types were invented, frequently in a somewhat arbitrary manner. "The ultimate result was that an empty scheme of formulation carried the day over what was really good in this doctrine" (ibid., p. 264). "The unitary conception was to step into the place of the dualistic. . . . Every chemical compound forms a complete whole, and cannot therefore consist of two parts. The chemical character is dependent primarily upon the arrangement and number of the atoms, and in a lesser degree upon their chemical nature" (p. 265). This is the beginning of the second great step which was taken in the elaboration of the atomic view of matter and nature. The atomic view first became a scientific instrument, when arithmetical relations of a definite and unalterable kind were suggested and proved to exist; it became a yet more useful instrument, when to the arithmetical there were added geometrical conceptions. Position, arrangement, and structure are conceptions which involve ideas of distance and space. It is true that for a long time these terms were used merely symbolically; the ultimate consequences of such conceptions can however not be avoided. The history of chemical theory in the second half of the nineteenth cen. tury is a proof of this. 
certain stable qualities with a multitude of changing varieties was a notion familiar to other branches of natural history. The idea of substituting one element for another gave the death-blow to the theory of Berzelius, which assumed that elements paired with each other, according to some polar contrast. It was found, for instance, that the element chlorine, which stood on one side of the scale-the electro-negative-could take the place of the opposite electro-positive element hydrogen.

In the course of time the conception of types was much changed, and became more and more complicated; it had however the effect of finally destroying the binary view of chemical composition, and restoring in its place the older unitary conception.

All these attempts to simplify the study of chemical compounds, by reducing them to simple or complex elements, or to pairs of simpler combinations, or by ranging them according to types, were useful in many ways in extending the knowledge of bodies, in indicating new methods of inquiry, and in suggesting instructive experiments: ${ }^{1}$ none of them were universally accepted in the

${ }^{1}$ About that time - so far as chemistry proper, i.e., the study of compounds and of reactions was concerned-there existed two main currents of thought, the most illus. trious and influential representatives of which were Kekule (1829. 96, first professor at Ghent, then since 1865 at Bonn), and Kolbe (1818-1884, first professor at Marburg, then since 1865 at Leipsic). As teachers and centres of academic influence, though in different, frequently opposite directions, these two eminent men continued the work started in Germany by
Liebig, Wöhler, and Bunsen. To them as a third can be added the name of A. W. von Hofmann (18181892), who, through his twenty years' residence in London, did much to introduce a knowledge of German chemistry and German teaching methods in England, and who from 1865 established the modern Berlin school of chemistry. It would be impossible to enter here into details as to how-mainly through the influence of these three men-the work begun by Liebig and Wöhler was extended, and how especially also the great derelopment of chemical 


\section{middle of the century. ${ }^{1}$ It thus happened that a variety ${ }^{21 .}$ of circumstances combined to bring into prominence, and Uncertainty in chemical subsequently into general acceptance, the modern view of the middle of the cen-}

industry in Germany was brought about; a creation almost as characteristic of German intellect, and probably more lastingly beneficial, than the political changes which mark the same period in history. More important for a history of Thought is it to note how Kolbe attached himself to the school of Wöhler and Berzelius, and tried to preserve the continuity of thought in developing the fruitful ideas contained in the writings of the latter. "He united the conclusions from his own researches with the declining theory of Berzelius; he endued the latter with new life by throwing aside whatever of it was dead, and replacing this by vigorous principles. From his own and other investigations he came to the conclusion that the unalterability of radicles, as taught by Berzelius, could no longer be main tained, since the facts of substitution had to be taken into account." $\mathrm{He}$ especially developed Berzelius's idea of paired compounds. (See E. v. Meyer's 'History of Chemistry,' p. 295.) Kolbe's joint work with Frankland was of the greatest importance to science. The influence of Kolbe was also largely of a polemical nature, inasmuch as he and some others, notably F. Mohr (whose name will have to be mentioned in a later chapter), protested energetically against the formal character of much of the writings and work produced by the French school which opposed the views of Berzelius. This school, of which Dumas, Laurent, and Gerhardt were the founders, and which exerted a very marked and beneficial influence through the teaching and the finished literary productions of
Wurtz (1817-84), was closely allied with the school of Kekule in Germany, who indeed began by logically developing Gerhardt's ideas, being afterwards led to special views and methods of his own, through which he became the real founder of the so-called structural formulæ, and of the doctrine of the linking of atoms. I must here especially record my indebtedness to the admirable historical essays of Wurtz ('Théorie atomique,' $7^{\text {me }}$ ed., 1893, and his 'History of Chemical 'Theory,' transl. by Watts). For clearness and elegance of style, they are quite as marked as are Kopp's historical work for breadth, impartiality, and philosophical insight.

1 The adherents of the theory of substitution and types, sometimes called the "modern," also the "French," school, urged against the followers of Berzelius, which adhered to the "electro-chemical" or "radicle" view, that since an electro-positive element could be replaced by a contrary one, there was no sense in upholding the polar difference. They pointed out that organic substances were not electrolytic, and they criticised the artificial invention and multiplication of new radicles which had no real existence, as arbitrary. On the other side, the followers of Berzelius objected to the entire ignoring by the new school of the really existing electro-chemical differences, and reproved them for having destroyed the connection between organic and inorganic chemistry, and for having introduced a purely formal systematisation according to merely external differences. They rightly upheld 
the "atomicity" or "valency" of chemical substancesbe they elements or compounds. This most recent development of chemical systematisation originated in England, ${ }^{1}$ whereas the "radicle" theory belonged more to the

the view that an understanding of chemical reactions must ultimately depend upon a study of the nature and degree of chemical affinity, and maintained that so far the connection of chemical with electrolytic phenomena afforded the only clue to the comprehension of the nature of chemical affinity. The atomic theory had now absorbed all interest, to the detriment of a physical theory of chemical affinity such as Berthollet had attempted. It was held that by ignoring the electro-chemical differences, the " modern" school lost the only remaining chance of explaining, and not classifying merely, chemical phenomena. A good exposition of the latter argument will be found in A. Rau, 'Die Theorien der modernen Chemie.'

1 The number is small of the English names which about the middle of this century figured prominently in the discussions by which, in the German and French annals of science, correcter views on the constitution of chemical compounds were gradually elaborated. Kane's work was overlooked, but Williamson, Odling, and Frankland have had a very marked influence; and, as in so many other sciences, pioneer work in modern chemistry was done in this country, notably by Frankland. Liebig, after his visit to England in 1837, wrote to Wöhler: "I have traversed England, Ireland, and Scotland in all directions, have seen much that is astonishing, but have learnt little : whence is scientific knowledge to come in England, as the teachers are so inferior? Among older men, Thomson is still the best; among younger men,
Graham : modest and unassuming, he makes the most beautiful discoveries. Nevertheless, a splendid nation," \&c., \&c. ('Liebig's und Wöhler's Briefwechsel,' vol. i. p. 113.) From what I stated above (chapter iii. p. 296, \&c.), we are, however, quite prepared to find that the idea which more than any other has brought some order and system into modern chemical theory, and which has united the diverging currents of the foreign schools, has come from England. Frankland more than any other must be looked upon as the originator of the modern theory of the atomicity or valency of chemical elements and compounds. The history of this conception can be well studied in the collection of scientific papers which he published with valuable introductions in 1877 ('Experimental Researches in Pure, Applied, and Physical Chemistry,' London, van Voorst). His researches commenced in those years when great confusion existed in organic chemistry, "when the wildest theories of the constitution of organic compounds created but little surprise ; the assertion, for instance, that an atom of carbon was united with four atoms of hydrogen and two of chlorine would scarcely have been considered intrinsically improbable, and certainly not impossible" (loc. cit., p. 26). The idea existed that bodies could enter in to combination with other bodies, notably organic radicles, and could still retain in such combination their original affinities unimpaired; a new term, that of "conjugate," "copulated," or "paired" compounds, had been invented and adopted by Berzelius. 
German, and the "type" theory to the French, school of chemists. But the idea of the "atomicity" and "valency" or saturating capacity of the element of any substance was not possible without the clear notion of the "molecule" as distinct from the "atom." This idea had lain dormant in the now celebrated but long forgotten law of Avogadro, which was established in the year 1811, almost immediately after the appearance of Dalton's atomic theory.

The atomic theory may be regarded in two distinct ways, and it is instructive from the point of view of the of the $\begin{gathered}\text { Twe } \\ \text { atomic }\end{gathered}$ history of thought to see how these two different aspects theory. of the theory have gradually presented themselves. The older and vague atomic theory professed to be a theory of the constitution of bodies, and to afford the basis for an explanation of physical phenomena; in order to do this, forces of attraction and repulsion between the particles of

It appears that this theory was largely based upon a compound prepared by Bunsen, and called "cacodyl." This compound was one of the few organic radicles which contained a metal-arsenic. Frankland, partly alone, partly in union with Kolbe, entered upon a series of researches which had two distinct objects. Both these objects were foreign to that school which had given up the radicle theory, and which, by looking upon organic compounds as essentially different from inorganic compounds, had lost that important clue-the connection of the two branches of clemistry. These objects were the isolation of the so-called radicles or compound elements and the preparation of other " organo-metallic" bodies. The latter research led to new insight into the nature of chemical combinations. "I had not proceeded far," says Frankland, "in the investigation of the organometallic compounds before the facts brought to light began to impress upon me the existence of a fixity in the maximum combining value or capacity of saturation in the metallic elements which had not before been suspected. . . . It was evident that the atoms of zinc, tin, arsenic, antimony, \&c., had only room, so to speak, for the attachment of a fixed and definite number of the atoms of other elements, or, as I should now express it, of the bonds of other elements. This hypothesis, which was communicated to the Royal Society on May 10,1852 , constitutes the basis of what has since been called the doctrine of atomicity or equivalence of elements; and it was, so far as I am aware, the first announcement of that doctrine" (ibid., p. 145). 
matter had to be assumed, and elaborate calculations as to the integral or resultant effect of these elementary forces had to be instituted, or at least formulated. An interesting and typical case of these attempts was the theory of Boscovich, referred to in the last chapter. ${ }^{1}$ In looking back on the history of science, it can now be safely stated that, ingenious as those theories were, they led to no results in the direction of the calculation of the molar and molecular properties of bodies, or if they did, they yielded none which could not be gained by the opposite view which regarded matter as continuous. The atomic theory, however, did good service from another point of view, when through Richter, Dalton, Proust, and Berzelius the fact that bodies combine only in definite proportions of weight, or their simple multiples, became firmly established. The authors of this discovery were driven to the atomic view

1 See also Berthollet, 'Statique chimique,' 1803, vol. i. : "Les puissances qui produisent les phénomc̀nes chimiques sont toutes dérivées de l'attraction mutuelle des molécules des corps, à laquelle on a donné le nom d'affinité, pour la distinguer de l'attraction astronomique. Il est probable que l'une et l'autre ne sont qu'une même propriété" (p. 1). "Il y a des sciences qui peuvent parvenir à un certain degré de perfection sans le secours d'aucune théorie, et seulement par le moyen d'un ordre arbitraire qu'on établit entre les observations des faits naturels, dont elles s'occupent principalement; mais il n'en est pas le même en chimie, où les observations doivent naître presque toujours de l'expérience même et où les faits résultent de la réunion factice des circonstances qui doivent les produire. Pour tenter les expériences, il faut avoir un but, être guider par une hypothèse . . . ainsi les suppositions plus ou moins illusoires et même des chimères qui sont aujourd'hui ridicules, mais qui ont engagé aux tentatives les plus laborieuses, ont été nécessaires, au berceau de la chimie. Par leur moyen les faits se sont multipliés, un grand nombre de propriétés a été constaté, et plusieurs arts se sont perfectionnés" (p. 4). "Si les propriétés chimiques des différentes substances sont dues à leur affinité et à leurs dispositions particulières, celles des combinaisons qu'elles forment dépendent de la saturation respective, des changements de constitution qui sont dus à l'action réciproque, du degré de la force qui maintient la combinaison ; ainsi les propriétés des substances simples sont non seulement la cause des combinaisons, mais encore celle de leurs propres affections" (vol. ii. p. 552). 
of matter as the most convenient method of expressing the formulæ of chemical compounds. Ever since that time the atomic view has served as a kind of symbolism by A conveni. which different chemical elements could be characterised, ent sym their compounds described, and the actual weights practically calculated. And here we must note the reserve with which some of the greatest representatives of chemical science expressed themselves up to the middle of the century regarding the actual physical existence of those elementary particles with which they operated so freely in their formulæ, and which they even represented by balls and coloured dises in their demonstrations.

\section{Wollaston, one of the first who accepted Dalton's ${ }^{1}$ views}

1 Dalton does not seem to have been troubled by any philosophical doubts or by the anticipation of the mathematical difficulties which would stand in the way of a consistent development of the atomic view. He was led to formulate and employ his atomic theory by pondering over the most convenient man. ner in which certain chemical facts - the facts of definite and multiple proportions - and certain physical discoveries-the separate existence of aqueous vapour from the other constituents of the air - could be represented, and he adopted the view suggested by Newton in his 'Queries," "that matter was formed in solid, massy, hard, impenetrable, movable particles" (see Sir H. Roscoe, 'John Dalton,' Century Series, p. 128, \&c.) Wollaston and Davy were much more cautious: the former foresaw the complicated and far-reaching mathematical problems which were involved in the atomic view, the latter thought the generalisation premature. His labours had been largely in the direction of showing that bodies which had been looked upon as elementary were compound, and he "doubts whether we have yet obtained elements" (ibid., p. 155). Even as late as 1826, in his award to Dalton of the Royal Medal, he speaks of his "Development of the Chemical Theory of Definite Proportions, usually called the Atomic Theory," he emphasises its practical usefulness, "making the statics of chemistry depend upon simple questions in subtraction or multi. plication, and enabling the student to deduce an immense number of facts from a few well authenticated, accurate, experimental results." $\mathrm{He}$ refers to Wollaston's table of equivalents, which "separates the practical part of the doctrine from the atomical or hypothetical part." It has, in fact, been maintained that the hesitancy which Wollaston dis. played on this subject deprived him of his well-deserved share of the glory which the introduction of the atomic view of matter has shed upon Dalton and Berzelius. (See Peacock, 'Life of Dr Young,' p. 469.)

VOL. I. 
as to fixed and multiple proportions, expressed himself with great reserve as to the value of the atomic hypothesis, and when drawing up a table of atomic weights, he preferred to call them equivalents - a term used already by Cavendish-as implying no other meaning than that they fix the proportions in which bodies combine into, or separate out of, compounds. Davy was hesitating and reluctant to admit any hypothesis as to the ultimate constitution of matter. Liebig ${ }^{1}$ and Faraday, ${ }^{2}$ at a somewhat

1 "In endeavouring to derelop the theory which at present prevails respecting the cause of the unchangeableness of chemical proportions, let it not be forgotten that its truth or falsehood has nothing whatever to do with the natural law itself. The latter is the expression of universal experience; it remains true, invariably and immutably, however our notions respecting its cause may from time to time vary and change." Thus wrote Liebig ("Familiar Letters on Chemistry,' 1844) at a time when great confusion existed as to the real atomic or smallest combining weights which should be assigned to the chemical elements ; when in consequence many chemists preferred to discard the word "atomic weight" altogether, and to revert to the term equivalent (see Kopp, 'Entwickelung der Chemie,' p. 718 , \&c.) Dumas in 1840 declared that the term atomic weight did not deserve the confidence with which chemists made use of it: if he could he would banish the word atom from chemistry, convinced as he was that science should not transgress the limit of that which could be known by experience. Liebig, in 1839, about the time when his important memoirs on the constitution of organic bases and acids appeared in his 'Annals,' em- phasised likewise the fact that equivalents never change; but he doubted whether chemists would ever agree as to the relative atomic weights, and he hoped tlie time was not far distant when they would all return again to equivalents (ibid., p. 438). In France an infuential school, headed by the eminent M. Berthelot, up to the present day limits itself to the use of equivalents. See Berthelot, 'La Synthèse chimique,' $7^{\text {me }}$ éd., p. $164 \mathrm{n}$.

2 The objections which Faraday urged against the notion of atom and atomic weight seem to come from a different quarter. In 1834 , when explaining his researches on electro-chemical action, he says ('Exper. Res.,' No. 869): "If we adopt the atomic theory or phraseology, then the atoms of bodies which are equivalents to each other in their ordinary chemical action have equal quantities of electricity naturally associated with them. But I must confess I am jealous of the term atom; for though it is very easy to talk of atoms, it is very difficult to form a clear idea of their nature, especially when compound bodies are under consideration." Ten years later, in his 'Speculation touching Conduction and the Nature of Matter' (see 'Exper. Res.,' vol. ii. p. 285), 
later date, appeared similarly averse to admit the physical existence of atoms in the older sense, and warned chemists against the introduction of unnecessary and unproven hypotheses. Even Gerhardt, as late as 1856, opposed the idea that chemical formulæ could express the actual constitution of substances: they were merely a convenient symbolism, a kind of alphabet, by which reactions between different elements or compounds could be conveniently described, and the proportional weights of the constituents or the products could be ascertained. ${ }^{1}$ Accordingly, it was also maintained that formulæ could be written in very different ways, expressive of the different processes and reactions which had in special cases to be considered. ${ }^{2}$

Although, therefore, chemical research was governed all through the century by the atomic view of matter, it does

he says : "The word atom, which can never be used without involving much that is purely hypothetical, is often intended to be used to express a simple fact. . . . There can be no doubt that the words definite proportions, equivalents, primes, \&c., which did and do express fully all the facts of what is usually called the atomic theory in chemistry, were dismissed because they were not expressive enough, and did not say all that was in the mind of him who used the word atom in their stead; they did not express the hypothesis as well as the fact." He then enlarges on the necessity of the atomic view, and expresses his preference for the form which Boscovich had giren to it over "the more usual notion," as according to the latter "matter consists of atoms and intervening space," whilst with the former "matter is everywhere present, and there is no intervening space unoccupied by it" (ibid., pp. 290, 291). It is evidently the objection to action at a distance, uncommunicated action, which is implied in the ordinary atomic view of matter, that makes Faraday jealous of the term atom. This objection was quite foreign to the chemists abroad who in the middle of the century elaborated the atomic view of matter and nature; it belongs to a different direction of thought, which will occupy us in a later chapter.

1 In his "Traité de Chimie organique,' which he brought out as a continuation of the French edition of Berzelius's 'Treatise of Inorganic Chemistry' in the years 1853 to 1856. See Kopp, 'Entwickelung der Chemie,' pp. 747, $796,800,809,819,834$.

2 Even the combining weight or equivalent of an element, that datum upon which-since Richter and Dalton-the whole system of chemistry has been built up, was 
not appear that philosophers considered the existence and usefulness of chemical formulæ as a proof of the physical existence of atoms, or of smallest indivisible particles of matter, in the older sense of the theory. Hand in hand with this purely formal and experimental treatment of

24. Neglect of the study of affinity. chemical phenomena went the almost absolute neglect with which questions referring to chemical affinity were treated. The word was little more than a name for an unknown something.

How it came to pass that substances had more or less affinity for each other, what was meant by a chemical compound, symbolically expressed by writing two or more letters, near or above each other, in a square or in a circle, united by parentheses or brackets, did not seem to trouble chemical philosophers at all. To compare the problem of chemistry with that of astronomy, the former for a great part of our century resembled that phase of astronomical knowledge, in which stellar maps and catalogues, plans of orbits and orreries, were considered sufficient, giving a picture of a certain constellation of the heavenly bodies, but no idea of how these configurations were maintained and altered. In fact, chemistry was for a long time a science purely of numbers, to which was attached a natural history of the substances to which these numbers belonged. The geometrical arrangement of the formulæ was usually looked upon as only symbolical : of the dynamical changes which take place in time, and imply the knowledge of

considered to be represented by more than one number in instances where the same metal had several basic or acid oxides, as in the case of nitrogen and phosphorus (ibid., p. 805). Laurent in 'Comptes
Rendus,'1844, vol. xix. p. 1099, says : "Le même corps simple se présente tantôt avec certaines propriétés, tantôt avec d'autres, il entre dans les corps composés, tantôt avec un certain poids, taintôt avec un autre." 
forces or movements, few took any notice whatever. In spite of the enormous accumulation of well-arranged knowledge, and the marvellous practical achievements of chemistry, the foremost historian of that science could, as late as 1873, write as follows: "No theory has as yet been formed in chemistry which, starting from a definite chemical Kopp on principle, attempts to deduce the results of experience as ${ }^{1873 .}$ necessary consequences. The doctrines which have been termed in chemistry theoretical are still only such as permit us to bring connection into the results which practical chemistry has gained in special directions; or to form a picture how we might think of them as mutually related." 1

1 Kopp, 'Entwickelung der Chemie,' 1873, p. 844. A generation earlier Dumas had written ('Comptes Rendus,' vol. x., 1840, pp. $171,176,178)$ : "Dans les vues de l'électrochimie la nature de leurs particules élémentaires doit déterminer les propriétés fondamentales des corps, tandis que dans la théorie des substitutions, c'est de la situation de ces particules, que les propriétés dérivent surtout. ... La théorie des types ... explique ce que la loi des substitutions se contente de préciser. Elle envisage les corps organiques comme étant formés des particules, qui peuvent être déplacées et remplacées, sans que le corps soit détruit, pour ainsi dire. . . Voila donc en présence deux systèmes: l'un qui attribue le rôle principal à la nature des éléments, l'autre qui la réserve pour le nombre et l'arrangement des équivalents. Poussé à l'extrême chacun d'eux ... se trouverait conduire à l'absurde." In 1861 Kekulé, in his 'Lehrbuch der organischen Chemie' (vol. i. p. 95), declares that, "besides the laws of fixed and multiple proportions of weight (and in gaseous bodies also of volume), chemistry had as yet discovered no exact laws, . . . and all so-called theoretical conceptions were merely points of view which possessed probability or convenience." And Wurtz ('La Théorie atomique,' 1863) speaks of the atomic hypothesis in terms which might lead one to think we were on the eve of an entirely different conception of the phenomena of nature: "Nous reteindrons l'hypothèse aussi longtemps qu'elle permettra d'interpréter fidèlement les faits; de les grouper, de les relier entre eux et d'en prévoir de nouveaux, aussi longtemps, en un mot, qu'elle se montrera féconde" (p. 2). "Les considérations sur la valeur de com. binaison des éléments survivraient à l'hypothèse des atomes si celle-ci venait à être remplacée un jour par une hypothèse plus générale. Mais ce jour n'est pas arrivé ; c'est vainement qu'on chercherait à discréditer la première aussi longtemps qu'elle se montrera féconde. Et sa fécondité, sa puissance éclatent dans les progrès incessants de la science. C'est elle qui vivifie les découvertes les plus récentes, comme elle a été depuis Dalton son immortel auteur, 
This statement implies that even as late as the end of the third quarter of the century, foremost thinkers hesitated to attach a more than provisional importance to chemical symbolism and the various elaborations of the atomic theory, as chemical text-books then exhibited them. Similar merely provisional theories have existed in other branches of science. The theory of the two fluids in electricity did good service for a long time in enabling philosophers to define their ideas, to describe, calculate, and predict phenomena. In optics, the so-called corpuscular theory of light is still used with advantage as a convenient means of summarising the laws of reflection and refraction; similarly, in treatises on the conduction of heat, the old caloric theory still holds a place alongside of the 26. more modern dynamical views. It may be questioned The periodic whether the celebrated periodic law of Newlands, Lothar Meyer, and Mendeléeff, which has brought some order into the atomic and other numbers referring to the different elements, and has even made it possible to predict the existence of unknown elements with definite properties, stands really in a firmer position than the once well-known but now forgotten law of Bode, ${ }^{1}$ according to

l'instrument le plus parfait pour les conceptions élevées de la théorie et le guide le plus sûr pour les recherches expérimentales" (p. 241). And quite mournfully does Kopp report at the close of his historical survey of the development of chemistry ('Entwickelung,'\&c.,p. 829) how that science about 1860 again "turned into the course which it had tried so often, and had so often abandoned as hopeless, endeavouring to gain a knowledge how the elementary atoms are arranged in the smallest particles of their compounds."
1 According to the relation, first observed by Christian Wolf and Daniel Titius, that the distances of the planets from the sun obey approximately the formula $0.4+0.3$ $\times 2^{n}$, where $n$ for Venus, Earth, Mars, \&c., assumes the values 0, 1, 2, \&c., the planet corresponding to $n=3$ was missing. When, on the discovery of Uranus in 1781 , it was found that this planet's distance also agrees approximately with the formula, Bode and von Zach drew attention to this fact, and suggested a systematic search for the missing 


\section{which the gap in the series which gives the distances of the planets from the sun indicated the existence of a}

planet, " $\mathrm{a}$ chercher une aiguille dans une botte de foin." About the same time that this search was contemplated Piazzi found the first - of the small planets, which-like the other subsequently discovered asteroids-corresponds very nearly with the expected position in the system. The periodic system of the elements, according to which the physical and chemical properties of all the elements show a periodic dependence upon the atomic weights, was first systematically stated by Newlands (in 1864) and by Lothar Meyer and Mendeléeff on the Continent. The latest edition of Meyer's treatise on "Modern Theories of Chemistry," of which only the first part, with the title 'Die Atome und ihre Eigenschaften " has been published (posthumously by the author's brother, Breslau, 1896), gives a good idea of how from small beginnings these statistics of the atomic theory of matter have grown into a great accumulation of interesting facts, upon which a system of inorganic chemistry can now be based which compares with the system of organic chemistry founded upon the types of Gerhardt in their original or in some modified form, and upon the "homologous" series of hydrocarbon compounds. As the typical arrangement of organic compounds, or rather of carbon compounds (for many real organic compounds are not easily classed by these methods), led to the suggestion of the existence of many compounds which were not known at the time, and have since been prepared, so the periodic arrangement enabled Mendeléeff to predict the properties of missing numbers of the periodic series. And although this mapping out of the elements according to their atomic weights does not indicate how and where the missing numbers are to be found, as is the case with the law of Titius and Bode, and still more so with the homologous series of carbon compounds, still it is interesting to be able to state that in several instances-notably on the discovery of the new elements, gallium (by Lecoq de Boisbaudran in 1878), scandiuin (by Nilson in 1880), and germanium (by Winkler in 1886)-the properties of these substances confirmed to a very great extent the predictions of Mendeléeff. And when in 1894 Lord Rayleigh and Professor Ramsay announced their discovery of a new element in atmospheric air, which, from its inertness, was called argon, interesting suggestions as to its properties were drawn from speculations regarding its probable position in the periodic curve (see Lothar Meyer, loc. cit., p. 165). It is true that these numerical regularities, which for some minds possess a great fascination, are, so far, purely statistical. It is possible to arrive by interpolation or extrapolation at valuable suggestions in statistics, in meteorology, and in mining operations; but so long as the actual cause or intrinsic connection is not known, which explains the necessity of these regularities, they are apt to be misleading, and have to be used with great caution. Still, the fact alone that they bring some order into a bewildering mass of figures and data makes them almost indispensable. For similar reasons many chemists adopted Gerhardt's types and homologous series as affording a ready method of classification, though not a rational explanation of phenomena. 
planet between Mars and Jupiter, anticipating the discovery of the Asteroids, which have accordingly been regarded as the fragments of the missing planet.

27. Difference between chemical and physical reasoning.

It thus appears that purely "chemical reasoning," as it has been called, has proved insufficient to establish the atomic view of nature on the same firm basis as has supported the mechanical or astronomical view ever since the age of Galileo and Newton. ${ }^{1}$ In the second half of the century, the atomic view of matter has however been put forward from a different side, and independent researches have, in combination with the older chemical theories, introduced so much definiteness into this line of thought that "the Newtonian theory of gravitation is

1 "Many diagrams and models of compound molecules have been constructed. These are the records of the efforts of chemists to imagine configurations of material systems by the geometrical relations of which chemical phenomena may be illustrated or explained. No chemist, however, professes to see in these diagrams anything more than symbolic representations of the various degrees of closeness with which the different components of the molecule are bound together. In astronomy, on the other hand, the configurations and motions of the heavenly bodies are on such a scale that we can ascer. tain them by direct observation; ... the doctrine of universal gravitation not only explains the observed motions of our system, but enables us to calculate the motions of the system in which the astronomical elements may have any values whatever" (Clerk Maxwell, "On the Dynamical Evidence of the Molecular Constitution of Bodies," June 1875, "Scientific Papers,' vol. ii. p. 418). "The chemists ascertain by experiment the ratios of the masses of the different substances in a compound. From these they deduce the chemical equivalents of the different substances, that of a particular substance being taken as unity. The only evidence made use of is that furnished by chemical combination. It is also assumed, in order to account for the facts of combination, that the reason why substances combine in definite ratios is, that the molecules of the substances are in the ratio of their chemical equivalents, and that what we call combination is an action which takes place by a union of a mole. cule of one substance to a molecule of the other. This kind of reasoning, when presented in a proper form, and sustained by proper evidence, has a high degree of cogency. But it is purely chemical reasoning; it is not dynamical reasoning. It is founded on chemical experience, not on the laws of motion" (Id. article "Atom," 'Ency. Brit.,' 1875; ibid., vol. ii. p. 456). 
not surer to us now than is the atomic or molecular theory in chemistry and physics-so far, at all events, as its assertion of heterogeneousness in the minute structure of matter, apparently homogeneous to our senses, and to our most delicate direct instrumental tests." 1

This side of the atomic view of matter has been developed by the study of the properties of bodies in the gaseous state, and, in its modern form, goes back to the experiments of Gay Lussac, which were almost simultaneous with those of Dalton. ${ }^{2}$ It is interesting to note how little the latter recognised the importance of these researches, when he rejected the so-called law of volumes, according to which gases, under the same pressure, and at equal temperatures, enter into, or separate out of, chemical combination in definite and very simple proportions of their volume. As, according to the law of definite proportions, bodies (including gases) combine only

1 Lord Kelvin on "Capillary Attraction," 1886. See 'Popular Lectures and Addresses,' vol. i. p. 4.

2 The first results referring to the combining volumes of oxygen and hydrogen gas in forming water were given by Gay Lussac and Humboldt in a joint memoir. Their experiments were carricd on in 1805. Gay Lussac continued the experiments alone, extended them to gaseous compounds, and published his results in 1809 in the second volume of the 'Mémoires d'Arcueil.' This was one year after the publication of Dalton's 'New System of Chemical Philosophy,' and two years after Thomas Thomson had published a sketch of the atomic theory in his text-book on Chemistry. The law of equal expansion of all gases with temperature was published by Dalton in 1801; the law of pressures-that the volume of a gas, at the same temperature, is inversely as the pressure-was published by Boyle in 1662. It goes on the Continent under the name of Mariotte, who first made it generally known about twelve years later (see on this the fourth appendix to the $2 d$ edition of Tait's 'Properties of Matter,' 1890). The law of temperatures was published in 1802 by Gay Lussac in the 'Annales de Chimie et de Physique' (vol. xliii., p. 137), where he remarks that Charles, Professor of Physics at the "Conservatoire," had fifteen years earlier noted the property indicated by this law. Both these so-called laws of gases are only accurate within certain not very wide limits of temperature and pressure.
28. The kinetic theory of gases. 
according to definite proportions of their weight, it follows that in the gaseous state these combining weights of bodies have either equal volumes or such as stand in very simple proportions. Now the amount of matter (measured by weight) in the same volume is called the density of a gas. It therefore follows, by putting Dalton's and Gay Lussac's discoveries together, that the combining weights of gases are either directly proportional to their densities or to a simple multiple thereof. Some years after this discovery in 1809, Gay Lussac extended his statement so as not only to embrace elementary gases, such as hydrogen, oxygen, and nitrogen, but also compounds, such as ammonia, carbonic acid, hydrochloric acid, and showed how, if they enter into chemical combination, they likewise do so in the simple proportions of one volume of one, to one or two volumes of the other.

Whilst chemists such as Gay Lussac, Berzelius, and others ${ }^{1}$ recognised in the facts discovered by the first a

1 Dalton was the only person who doubted the correctness of Gay Lussac's figures, although both Thomson and Berzelius pointed out to him the great support they afforded to the atomic theory. Berzelius also saw the usefulness of the law of volumes in fixing the smallest combining or atomic numbers in cases where the reference to weight alone left the matter undecided. Thus he correctly inferred that the formula of water should be $\mathrm{H}_{2} \mathrm{O}$, as we write it to-day, because two volumes of hydrogen combined with one of oxygen. But it was unfortunate that, through his want of appreciation of Avogadro's further expositions, he was unable to reconcile more completely the appeal to volume with that to weight, and that in consequence great uncertainty reigned for a long time in these matters. This induced L. Gmelin to disregard the volumetric relations in his system of equivalents, to the great detriment of those who in the middle of the century were brought up with very vague and unsatisfactory explanations on this subject-different numbers being used in books on organic and inorganic chemistry. A great confusion existed at that time, Gerhardt showing good reasons, based upon his observations of the substitution of hydrogen in organic compounds and the system of classification which he introduced, why several of Gmelin's figures should be doubled; but the matter was not cleared up till Cannizzaro 
method for determining the combining weights of elements or their simple multiples, they did not draw the natural consequences as to the physical constitution of bodies in the gaseous state which followed from these and other facts which had been known before. It had been known since the time of Boyle and Mariotte that equal volumes of different gases under equal pressure change their volumes equally if the pressure is varied equally, and it was also known through Gay Lussac himself that equal volumes of different gases under equal pressure change their volumes equally with equal rise of temperature. The like behaviour of equal volumes of different gases towards pres- Avogadro's sure, temperature, and chemical combination suggested to Avogadro, and almost simultaneously to Ampère, the very simple assumption that this is owing to the fact that equal volumes of different gases contain an equal number of smallest independent particles of matter. This is Avogadro's celebrated hypothesis. It was the first step in the direct physical verification of the atomic view of matter, and if maintained by further experience, it was destined to be one of the most important proofs of this view. But this assumption or hypothesis had to be reconciled with facts. It was, for instance, observed that a given quantity of hydrochloric acid gas occupied the same

showed the real meaning and importance of Avogadro's hypothesis. A good exposition of the difference of opinions which were held at that time will be found in A. Wurtz, 'La Théorie atomique,' p. 55, \&c. See also Prof. Bedson's 'Memorial Lecture' on Lothar Meyer (1896), in the 'Journal of the Chemical Society,' p. 519, \&c., and especi- ally the graphic description by $\mathrm{L}$. Meyer himself of the meeting held in September 1860 at Carlsruhe for the purpose of ventilating these important theoretical questions (L. Meyer's translation of Cannizzaro's "Sunto di un corso di filosofia chimica,' in Ostwald's 'Classiker der exacten Wissenschaften,' No. 30, Appendix, p. 58). 
volume as did each of the equivalent quantities, hydrogen and chlorine, out of which it was compounded, and it appeared that accordingly double the number of atoms were condensed into the same volume. To explain this, and yet maintain his original hypothesis, Avogadro was forced into the conception of compound atoms or particles -i.e., into the assumption that the smallest independent particles need not be the elementary atoms of hydrogen and chlorine themselves, but might be made up of two or more of such atoms, chemically connected in such a way that the expansion of the gas under increasing temperature or decreasing pressure did not affect this complex of elementary particles. ${ }^{1}$ Such a compound

1 Arogadro published his memoir in the 'Journal de Physique' in 1811, and Ampère expounded similar views three years later in the form of a letter to Berthollet in the 'Annales de Chimie.' Neither the celebrity of Ampère nor the exhaustive explanations of Avogadro, who was then an unknown author, prevented this hypothesis, which is now looked upon as a cornerstone of the atomic view, from falling into oblivion. Whewell does not mention it. Even Kopp, whose labours for many years covered a field little cultivated by most other chemists, that of physical chemistry, makes no mention of Avogadro's and Ampère's hypothesis in his great work on the History of Chemistry, published between the years 1843 and 1847 . In his later work ('Die Entwickelung der Chemie,' 1873) he enters elaborately in to the causes which made chemical philosophers overlook so valuable a suggestion (p. $353, \&$ c.) Like Whewell's History, Poggendorf's Dictionary (1863) was silent about Avogadro. The distinc- tion between molecules and atoms seemed to complicate matters; besides, the new hypothesis was not launched in conjunction with any new experimental discoveries, as had been the case with Dalton's, Davy's, and Gay Lussac's theories. The first who again drew attention to the subject was Dumas, who in 1826 began his investigations regarding the specific weight of vapours-i.e., of bodies in a gaseous state. He there drew attention to the necessity of distinguishing between chemical and physical particles, but he does not yet consistently use the terms atom and molecule to denote the former and the latter. In the meantime, lowever, a very important step had been taken in the development of the atomic view. In 1819 Dulong and Petit published their experimental researches concerning the specific heat of a large number of elementary bodies-i.e., the measured'quantities of heat (compared with a standard substance) which were required to raise a number of metals by one degree in tempera- 
atom or complex was termed a molecule, and it was assumed that molecules, or smallest individual particles of chemical substances, might be made up of one or more atoms of the same or of different substances. Avogadro was able in this way to explain how a certain number of molecules of hydrogen-each made up of two atomscombine with an equal number of molecules of chlorine; these being likewise composed of two atoms of chlorine, in order to form an equal number of molecules of hydrochloric acid, each of these consisting of two atoms-viz., one of chlorine and one of hydrogen. This view, which Ampère likewise adopted, did not recommend itself to Neglect of chemists for many years; not indeed till about the year 1840 several eminent chemists-notably Laurent-were independently led to consider chemical compounds as formed by what is termed substitution instead of simple combination. ${ }^{1}$ For, according to Avogadro's view, the for-

ture. They then found that these quantities stood very nearly in inverse proportions to the atomic or combining numbers. They at the same time pointed out the uncertainty which - in consequence of the law of fixed multiple proportions - existed regarding the smallest figure which was to determine the combining weights; they chose those numbers which brought out clearly the physical regularity and coincidence which they had discovered; and they expressed their result in the rule that the atoms of all elementary bodies have the same capacity for heat. Whereas Berzelius ignored the theoretical discussions of Avogadro and Ampère, he liailed the experimental data of Dulong and Petit as most useful in helping to fix correctly the real equivalent numbers, a task to which, as the fundamental requisite of all chemistry, he devoted so much time and labour. It must, however, be noted that the law of Dulong and Petit, now universally accepted as a fundamental fact in the atomic theory, is, as little as the laws of Boyle, Charles, and Gay Lussac, rigidly correct : it obtains within certain limits. The experiments of Dulong and Petit were extended to compounds by F. Neumann in 1831. The connection of the specific heat or thermal capacity of compounds and that of their constituents was fully investigated by Regnault. A statement of the difficulties and anomalies which still exist will be found in L. Meyer's 'Die Atome und ihre Eigenschaften' (p. $73, \& c$.

1 A very important influence in contributing to the gradual recog. 
mation of the molecule of hydrochloric acid depended upon an exchange of places of the atomic constituents in the molecules of the elementary substances, an atom of chlorine being substituted for an atom of hydrogen in the hydrogen molecule, and vice ver'sa in the chlorine molecule.

About the middle of this century the conviction was thus firmly established in the minds of chemical philosophers that the simple symbolism by which Dalton and Berzelius expressed chemical combinations and processes was insufficient for the purpose of systematically arranging the

nition of the difference between atom and molecule belongs also to Gerhardt, who emphasised a fact known already to Berzelius-viz., that hydrogen according to his notation appeared to combine with other bodies always in paired atoms. This fact remained unnoticed if the atomic number of hydrogen was put at 1 , oxygen at 8 , as was done by English chemists and reintroduced by Gmelin. Berzelius did not attach a fundamental importance to this fact. Blomstrand ("Die Chemie der Jetztzeit,' 1869, p. 30) has shown that this originated in his clinging to Lavoisier's oxygen theory. Oxygen was made the centre and measure of everything in chemistry, also of the equivalence of substances: Berzelius thus started from a unit which was too large, and with which the smaller value of hydrogen could not be measured. Gerhardt fully recognised the importance of this fact; showed in many examples that the. combining or atomic weight of hydrogen had been fixed too high; and proposed to halve most of the organic formula. In this way he proposed to bring harmony into the theory of combining volumes and the atomic theory. He partially succeeded in doing so, although in the case of inorganic elements he went too far. This important step, which has been extolled by some, and depreciated by other historians of chemistry, is lucidly expounded by Rau in his 'Theorien der modernen Chemie' (vol. ii. p. 107, \&c.) Wurtz ('Théorie atomique,' p. 64) consider's Gerhardt's influence as a reform, and alludes to it as bringing again into view the hypothesis of Arogadro : "Voilà le thème d'Avogadro et d'Ampère, qui revient à l'horizon, comme une étoile dirigeante, après une longue éclipse. Et pourtant on ne peut pas dire qu'elle ait été pour Gerhardt, à cette époque du moins, un guide exclusif. Les considérations mâ̂tresses qu'il a inroquées sont plutôt d'ordre purement chimique. Elles étaient justes, et il s'est trouvé qu'elles concordaient avec une idée également juste et qui était tombée dans l'oubli. La distinction entre deux espèces de petites particules, molécules et atomes, qu'Avogadro et Ampcre araient introduite inutilement dans la science, que $\mathbf{M}$. Dumas avait essayé de faire revivre dans sa Philosophie chimique, cette distinction était peut-être faite dans l'esprit de Gerhardt, mais elle n'apparaissait pas encore dans son langage." 
growing volume of chemical knowledge; that the conception of the atom must be extended and more closely deDevelop. ment of the atomic view. fined; that the proportions of weight were inadequate for the purpose of distinguishing and identifying the many organic compounds; and especially that the relations of volume and the arrangements of particles of matter in space must be taken notice of, if the atomic view of matter was to be made further serviceable for scientific purposes. That purely geometrical relations, such as can be grasped only by our space conceptions, are of importance in the chemical composition of substances, was very evident, for instance, in some of the optical properties of crystallised organic substances. The discoveries of Pasteur, published in 1850 , mark in this respect an epoch in science. ${ }^{1} \mathrm{He}$ showed that there exist chemical substances which are different, but only as a right-hand glove differs from a left-hand one, a right-handed screw from a left-handed,

1 A special line of "physical" or "mechanical" reasoning which bears upon the atomic view of matter began with Biot's discovery in 1815 that certain fluids-notably organic - have the property of rotating the plane of polarisation of light which passes through them. Later on he extended this observation to the vapours formed by such fluids. Faraday found in 1846 that substances which are optically "inactive" become active in the manner described under the influence of powerful electro-magnets. An explanation of the phenomenon by Fresnel, which was based upon crystalline structure, would - for liquids and vapours - have to be applied to the structure of the molecule itself. Pasteur found in 1850 that there exist two modifications of tartaric acid, which differ in this only, that one of them turns the plane of polarisation to the right, the other to the left, and that a mixture of both in the proper proportions is inactive. As far back as 1860, in his 'Lecons de Chimie,' he put the question, "whether the atoms in tartaric acid are arranged like the turns of a righthanded screw, or situated in the corners of an irregular tetrahedron, or have they any other asymmetrical grouping ?... There can be no doubt that the atoms have an unsymmetrical arrangement after the fashion of mirrored images which cannot be made to fall into each other" (quoted by Van't Hoff, 'Die Lagerung der Atome im Raume,' German translation, 2d. ed., p. 9). 
the image in a mirror from the original. Was it possible to suppress any longer the conviction that the smallest particles of matter, in forming chemical compounds, do so not only in definite proportions of weight, but also in definite geometrical distances and positions?

About the middle of the century the atomic view of matter had thus received considerable modifications. Originally suggested only to explain, describe, or symbolise the fact that different substances combine in fixed, and especially in fixed multiple proportions, it had to be modified by a recognition of the fact that in gases at least a distinction exists between particles which are closely knit together-as it were, geometrically inseparable-and such as can move away from each other. The latter explain the increase of volume under increasing temperature or decreasing pressure. Geometrical distance came in as the means of distinguishing the molecule from the atom. And lastly, about 1.850, the phenomena of rightand left-handedness, ${ }^{1}$ discovered by Pasteur, suggested the

33. Atom and molecule. idea of geometrical position as well as of distance. The atom had become a molecule, with a definite geometrical arrangement.

It took, however, a full generation before, in the second half of the century, these different suggestions for a modification of the atomic view became clear, before philosophers took seriously the opinion that molecules and atoms existed in reality, and were not merely a convenient symbolism, as many great chemists during the first half of the century were inclined to think. This change in the habit of chemical thought has no doubt been greatly

1 Called by Lord Kelvin "chirality." 
brought about by the development of the so-called kinetic theory of gases in the second half of the century. This is a physical, not a chemical, theory.

The kinetic theory of gases, invented for the purpose of explaining the pressure which all bodies in the gaseous state exert on the walls of the containing vessels, will always be identified with the two names of Clausius in Germany and Clerk Maxwell in England. ${ }^{1}$ But if we

1 Before the atomic view of matter had, in the course of the last fifty years, closely and definitely allied itself with the kinetic view, it had been allied with the astronomical view of matter. In the last century and the earlier decades of the present century we frequently find the behaviour of a complex of molecules or atoms compared with that of a planetary system; but in addition to the forces of attraction, those of repulsion had to be resorted to in order to explain the expansiveness of gases. Heat was then considered to be a material substance, the particles of which repelled each other. Dalton favoured this view in the introduction to his 'New System of Chemical Philosophy'; so did Berthollet and most of the French physicists who were brought up in the school of Newton and Laplace. Lasswitz, in his 'Geschichte der Atomistik' (2 vols., Hamburg, 1890), has traced the 'Decline of Kinetic Atomism ' in the seventeenth century under the influence of the 'Corpuscular Philosophy.' The kinetic view of matter was allied with the Cartesian physical philosophy, which was dispelled by Newtonianism in France and by Kant's philosophy in Germany. In consequence, when in Germany A. Krönig published his 'Grundzüge einer Theorie der Gase' in 1856, philosophers who had been speculating in the direction of a Newtonian atomism (see Fechner's 'Atomenlehre,' 1855; Redtenbacher's 'Dynamiden System,' 1857 ; and other publications quoted by Rosenberger, 'Geschichte der Physik,' vol. iii. p. $536, \& c$.) were much taken by surprise. It had the immediate result of inducing R. Clausius, who.had been occupied with similar researches since 1850 , to publish his celebrated memoir, "Ueber die Art der Bewegung welche wir Wärme nennen' (Poggendorf's 'Annalen,' vol. c., 1857). These two publications first called general attention to the subject. Joule's paper, which appeared in the 'Memoirs of the Lit. and Phil. Soc. of Manchester,' had remained unnoticed, but was reprinted by him, at the request of Clausius, in the 'Philosophical Magazine' (4th ser. vol. xiv.) in 1857. Subsequently, the researches of Paul du Bois-Reymond and others unearthed a whole list of authors who, in more or less definite ways, had resorted to the hypothesis of a rectilinear translatory motion of the molecules in order to explain the phenomena of pressure and other properties of gases. Among these, Daniel Bernoulli (in his 'Hydrodynamica,' 1738) seems to have expressed the clearest views, and he is usually now named as the father of the hypothesis. The fullest statement of the historical data will be found in the posthumous second edition of

VOL. I. 
agree to date the real birth, not the incubation, of any scientific idea from the moment when it was set forth in definite figures, and with mathematical precision permitting of a precise verification by actual test, the modern theory of gases was born in Manchester in the school

34. Joule's calculations. of Dalton, when Joule in 1857 actually calculated the velocity with which a particle of hydrogen at ordinary atmospheric pressure and temperature must be moving, assuming that this atmospheric pressure is equilibrated by the rectilinear motion and impact of the supposed particles of the gas on each other and the walls of the containing vessel. This meant taking the atomic view of matter in real earnest, not merely symbolically, as chemists had done. Joule gave up the older and vague ideas of a rotatory or a vibratory motion of the particles of a gas which had been floating about since the time of Hooke ${ }^{1}$ in various theories, and adopted the suggestion of Daniel Bernoulli, known to him through Herapath, that all particles of gaseous matter are in a natural state of rectilinear motion, which is changed only by the encounter with other particles or by the walls of the containing vessel on which they impinge, and from which they rebound. ${ }^{2}$

Clausius, 'Die mechanische Wärmetheorie' (Braunschweig, 1889-91, p. 2, \&c.) See also O. E. Mayer, 'Die kinetische Theorie der Gase' (2d ed., Breslau, 1895, part i. p. 11).

1 See Tait, 'Properties of Matter, $2 \mathrm{~d}$ ed., p. 289, also J. P. Joule's Memoir on 'Heat and the Constitution of Elastic Fluids,' 1848, reprinted in 'Scientific Papers,' vol. i. p. 290 , \&c.

2 The real proof that the kinetic, in contradistinction to what we may call the Newtonian, view of the motion of the molecules of a gas is the correct one, and that Newtonian (attracting and repelling) forces play only a subordinate, if any, part in the observable phenomena of gaseous bodies, is based upon Joule and Thomson's experiments made in 1853. It belongs to quite a different line of reasoning, neither chemical nor mechanical, but going upon the principle introduced into scientific thought about the middle of the century, that heat and work are convertible terms and equivalent quantities. Now, it was generally assumed, before Joule and Thomson 
This idea of the rectilinear motion of the particles of matter in a free, i.e. a gaseous, state (the first attempt to explain the physical properties of matter by giving a numerical value to a molecular, not molar, quantity) was not regarded by chemists, for it was indeed of little use in explaining chemical combinations and reactions. It, however, very soon received an important addition under the flirstmemoir. treatment of Clausius. ${ }^{1}$

The kinetic theory of gases had not been propounded for the purpose of explaining chemical phenomena; it had grown out of repeated attempts to explain the nature of heat, and the fact, established about ten years earlier by Mayer and Joule, that heat can be transformed into the mechanical energy of molar motion. The idea suggested itself that if heat can disappear and be replaced by the measurable motion of molar (measurably large) masses, and vice versa, heat itself may be merely the energy of the directly immeasurable movements of molecular (immeasurably small) masses; and as every body

made their careful experiments, that if gaseous bodies were allowed to expand, without doing work, no cliange of temperature took place-i.e., that heat neither appeared nor disappeared. This would mean that no work of either repelling or attracting forces was done. Joule and Thomson showed that there was indeed a very slight cooling, indicating that a small amount of heat or energy was used up in doing work against attracting forces - the forces of cohesion. Had repelling forces existed, their work would have shown itself in a rise of temperature. This line of reasoning will occupy us in a subsequent cliapter (see O. E. Meyer, 'Theorie der Gase,' vol. i. p. 7, \&c., also
Joule's 'Scientific Papers,' vol. ii. p. 216, \&c.)

1 How little chemical and physical reasoning went hand in hand before the middle of the century is seen from the fact that only after Clausius had published his first paper (see note, p. 433), in which he came to the conclusion that the molecules or smallest physical particles of simple (elementary) substances consist of several atoms, was his attention drawn to the fact that some French chemists, notably Dumas, Laurent, and Gerhardt, had already, by different arguments, arrived at the conclusion that the molecules of simple (elementary) gases consist of several atoms (see Clausius, loc. cit., p. 22, \&c.) 
in the gaseous state shows the mechanical energy which we call pressure or expansiveness, the attempt was made to explain the phenomena of expansion, pressure, and temperature of gases by a purely mechanical hypothesis. This answered remarkably well. On the assumption that the particles of a perfect gas possess a rectilinear motion, the experimental formulæ of Boyle and Mariotte, of Dalton, and of Gay Lussac, could be theoretically deduced. It also became evident that under this conception the forgotten statement of Avogadro must be correct, according to which equal volumes of different gases, under equal pressures and at equal temperatures, contain an equal number of freely moving particles.

And when Clausius showed further that in perfect gases only a portion of the quantities of energy which are measured as motion or as heat can be explained by the assumed rectilinear motion of the particles of gases, and that an internal motion of the particles themselves must be assumed, the new ideas became still more exactly defined; they included the conception familiar to chemists of compound atoms or molecules. The smallest individual particles of matter in the free state were themselves not simple bodies, but systems of still smaller particles; they were molecules composed of atoms; the symbols of chemists became descriptive of real physical conditions; the vague notions of radicles, types, or compound atoms began to acquire geometrical and mechanical definiteness.

Thus the atomic theory, known to the ancients, revived by Dalton in the early years of the century, and employed by chemical philosophers for half a century as a 
convenient symbolism, had, about the year 1860, been accepted by physicists, and used not merely as a convenient symbolism, but as a physical reality.

Joule had actually calculated the velocity of a particle The atomic theory accepted as a physical theory about 1860 . of hydrogen gas. The atomic view of nature was now taken in real earnest. To establish it still further, there were required definite numerical data ${ }^{1}$ as to the size of the smallest particles (henceforth sometimes called atoms, sometimes more correctly molecules) and their number, and also clearer views as to the composition of the molecules out of their elements, the chemical atoms.

The interest which attaches to this latest development of the atomic theory is very great: it has brought about a union of the researches of chemists and physicists, and has made chemistry a province of natural philosophy. ${ }^{2}$ No one has done more than the late Professor Clerk Max-

1 Numerical data regarding the size and number of smallest physical particles contained in a given volume of matter have been supplied by various methods or various "lines of reasoning." The best summary will be found in Lord Kelvin's lecture, "On the Size of Atoms" (1883: reprinted in 'Popular Lectures and Addresses,' vol. i. p. $147 s q q$.$) The four lines of$ reasoning are founded on the undulatory theory of light, on the phenomena of contact electricity, on capillary attraction, and on the kinetic theory of gases. They "agree in showing that the molecules of ordinary matter must be something like the one ten-millionth, or from the one ten-millionth to the one hundred-millionth of a centimetre in diameter."

2 "We can distinguish two kinds of motion, atomic motion and molecular motion. . . To this dis- tinction corresponds the division of natural philosophy into physics and chemistry, not rigidly, yet in so far as chemistry is mainly occupied with the equilibrium of the atoms, physics with the mechanics of the molecules. Chemical equilibrium, unchanged condition of the molecules; exists if the affinity which holds together the atoms equilibrates the forces which tend to loosen the composition of the molecule: these forces consist in the motion of the atoms. ... As accordingly in a chemically stable compound the atomic motions remain in lasting dynamical equilibrium with the chemical forces, ... . there remains for the examination of the purely physical phenomena in the first instance only the molecular movements" (O. E. Meyer, 'Die kinetische Theorie der Gase,' vol. i. p. 6). 


\section{well to develop the novel conceptions which here force} themselves upon us. Especially are we indebted to him for the idea-marking an epoch in the history of scientific thought-of the difference between historical knowledge

38.

Clerk Maxwell. The statistical view of nature. of natural phenomena and a merely statistical summary of average results. ${ }^{1}$ If the atomic view of nature has to be adopted seriously, as the development of the kinetic

1 See Clerk Maxwell's memoir, 'Illustrations of the Dynamical Theory of Gases' (1859: reprinted in 'Scientific Papers,' vol. i. p. 377). Clausius had in his second paper, "On the average mean path of a particle" (Poggendorf's 'Annalen,' 1858), given an expression for this quantity as depending on the average distance of two particles and on the average diameter of the sphere of action of a particle. As these quantities are all only mean or average quantities, he had been obliged to resort to a method which was then novel in physical science, the method of averages and the calculus of probability, which is its mathematical expression. He had calculated the probability of a certain motion of a particle. Maxwell, who had in 1856 been engaged in writing his Adams prize essay "On the stability of the motion of Saturn's rings," had there considered the possibility of these rings being composed of a cloud of scattered particles moving with all possible velocities towards each other and round some attracting centre: he was thus familiar with physical problems in which the given data could be only average quantities. He now undertook to develop systematically the methods necessary for treating such problems, of which we have only statistical knowledge, and he there developed his famous law which gives the distribution of different velocities in a crowd of particles moving at random and in their collisions obeying the condition of the conservation of energy. This investigation marks an epoch in mathematical physics and in the history of the atomic view of nature. Like all theorems connected with the theory of probability, it has provoked a large literature, the foundations of the proof and the different steps in the logic of the deductions having been examined and criticised in the most searching manner. The expression given by Maxwell has stood all these criticisms, - " he has demonstrated the possibility of calculating in a strict manner the averages which before him had only been estimated, but which were required for a further development of the theory of gases." See O. E. Meyer, 'Die kinetische Theorie der Gase,'2d. ed., vol. i. p. 45, \&c., where also a complete account is given of the various steps by which the doubts which attached to Maxwell's theories and his proofs were at length removed, and the "variety of traps and pit-falls" avoided "which are met with even in the elements of the subject" (see Tait, "On the Foundations of the Kinetic Theory of Gases," "Trans. of the Royal Soc. of Edinburgh,' 1886, vol, xxxiii. part 1, p. 66). In a later cliapter of this history $I$ intend to trace the development of the statistical view of nature, and shall then have occasion to revert to this subject. 
theory of gases suggests, we begin to realise the enormous numbers of individual elements of matter with which we have to do in any physical or chemical operation or experiment. The step which enabled mathematicians to calculate molar and cosmical phenomena by looking upon them as made up of an immeasurably, nay infinitely, large number of elementary parts, be these of space or time, was taken by Newton and Leibniz: its result was the invention, development, and application of the infinitesimal calculus. Our fundamental notions applied only to integrals, to a summation of these differential properties. It was the problem of the new calculus to deduce from the simple differential properties, expressed in what is called the differential equation, the results of finite observable quantities. This was done by a process of summation or integration. In this process the elements were, however, all considered to be equal. This was an assumption which, for the purposes of simplicity, might be safely made in a first approximation. When, however, the kinetic theory of gases took seriously into account the motion, velocity, number, and size of the constituent particles of matter contained in any finite measurable volume, or portion of matter, two distinct views presented themselves: the one which looks only at the total or average result and aspect of the phenomena, the other which looks at the actual behaviour and properties of the component parts, be these ever so numerous or ever so small. These latter could no longer be regarded as differentials which lose their independent existence in the process of summation: they had individual properties, which were not lost in the aggregate. It is evident that chemists had been 
studying those properties of matter that are preserved distinct in ever so large a number of individuals which are characteristically and specifically alike: while physicists had been mainly studying the properties of distance, motion, velocity, and size, which, if added together, merge themselves into a common sum, integral or average. It does not follow that, even so far as these latter properties are concerned, the numberless individual particles of matter behave alike; their sizes, velocities, and movements may be very different: indeed it is evident that, in a large crowd of moving particles, they must be widely different.

39. Doctrine of averages.

In assigning numbers to these data, it was therefore clear that only average or mean values could be meant, and that our actual physical knowledge of the individual elements resembles that statistical information which we possess, for instance, regarding the mortality, average age, and general properties and ways of the members of a great population. It is statistical knowledge, it is not individual, historical, or biographical knowledge, that we possess.

The individual behaviour of the single molecules, their sizes, their velocities, the length of their paths, their vibrations, rotations, and internal motions, remain unknown. What can be known is only the average magnitudes of these quantities, and possibly the extreme limits within which these individual magnitudes vary. The great differences exhibited by larger portions of different kinds of matter-i.e., the chemical differences or qualities-were reduced to the actual composition and qualities of the molecules and atoms themselves. Chemists and physi- 
cists were now alike compelled to venture on some more definite hypothesis, descriptive of the great variety of constitution which the molecules of chemically distinct substances exhibit. These molecules show in their combining numbers, and in their physical properties, great fixity, excluding apparently all gradual transitions. The manner in which they enter into, and again separate out of, combinations and compounds, always regaining and showing their original characteristics, forced more and more upon natural philosophers the conviction that compounds were merely geometrical arrangements of individually independent atoms, and that these atoms must possess geometrically different forms and figures, enabling them, without loss of their individuality, to enter into varying configurations.

The conception of the molecule as a system of atoms, geometrically arranged, had gradually grown from vague suggestions in the minds of physicists as well as chemists -i.e., of students of the quantitative as well as of those of the qualitative properties of substances. To the former it was especially the forms of crystals, to the latter the different degrees of saturation of chemical substances, that suggested a geometrical arrangement of atoms as the constitution of the smallest particles or molecules of different substances.

Ever since the study of the regular forms of minerals or of artificially prepared crystals was reduced to an graphy. exact science by the labours of Haiiy, at the end of the last century, ${ }^{1}$ the forms of these regular shapes have been valued by investigators, for two distinct rea-

1 See above, chapter i. p. 116. 
sons. They seemed to afford a practical means of recognising and obtaining in the laboratory substances in their qualitative or chemical purity, if they were elements, or in identical chemical combinations, if they were compounds. And secondly, these regular, recurring forms, which, in many cases, exhibited characteristic and geometrically fixed arrangements of plane surfaces, appeared the only means by which we could gain an insight into the grouping and the shape of the ultimate particles, out of which, according to the atomic view, molar substances were constituted. If the particles of any substance, when set free to follow their most natural movements by solution, by fusion, or by volatilisation, meet again during the process of solidification in definite, always recurring forms, the conclusion seems obvious that the individual and ultimate particles possess marked peculiarities in the different directions of space. And it is almost inconceivable that these peculiarities should consist in anything else than in distinct primitive forms, arranged in varying, but geometrically definable, meshes of a network. Accordingly, different systems have been elaborated ever since the age of Haiiy, which have the object of easily classifying, recognising, and measuring crystalline structures, or, more ambitiously, of discovering the number of simple forms and arrangements of networks of which our spatial conceptions admit. It is satisfactory to be able to state that investigations of the latter kind, carried on from seemingly different beginnings, have resulted in the recognition of a certain limited number of forms of symmetry. This symmetry is referred to points, called 
centres, or to lines, called axes, or to planes of symmetry. ${ }^{1}$ French and German investigators have deduced in different ways the different possible forms of symmetry, and have shown that in all thirty-two different forms of symmetry or groups are geometrically possible. These thirty-two fundamental groups of crystals can be gathered up into six classes or types, according to the different systems of crystallographic axes or the number of planes of symmetry belonging to them. ${ }^{2}$

1 The question may be raised, to what extent crystallography is obliged to assume a molecular structure of matter, or what support does the atomic view receive from it? On this point see Ostwald's 'Allgemeine Chemie,' vol. i. p. $855, \&$ c. The geometrical forms of crystals cau either be derived from elementary polyhedra, as Haüy attempted to do by his "molécules intégrantes" and his theory of decrescences, space being in this system considered as continuously filled; or the elementary particles may be considered to consist of meshes of points geometrically arranged in the corners of a primitive figure in three dimensions; or elementary spheres or ellipsoids may be supposed to be piled on each other like cannon-balls. The twolatter systems assume vacant spaces; the first view refers the crystalline shape to some primitive crystal, and, therefore, does not explain it. It has accordingly been said that "the structure of crystals is one of the principal supports of the molecular theory. In assuming continuous matter without at least points which are geometrically or kinematically distinct, the anisotropic structure of crystals is quite unthinkable" (Lehmann, "Molecularphysik,' vol. ii. p. 376). This view does not agree with what Ostwald says ('Allgemeine Chemie,' vol. i. p. 868 ) ; he considers that the structure of crystals affords no proof for the molecular constitution of matter, as the data of elasticity by no means necessarily require a molecular arrangement, but formally can be ascribed as easily to continuous matter. "Nevertheless the molecular view has the advantage of greater evidence, and leads to the same results with much greater simplicity, and hence more convincingly." It seems, however, that if chemical facts and physical theory force upon us the atomic view, crystallographic phenomena force us to complete it by some conception of geometrical arrangements.

2 This purely geometrical treatment was introduced by Bravais in his 'Études crystallographiques' (1851), the much earlier work of Hessel ('Krystallometrie,' 1831) having been forgotten. It was further developed by L. Sohnke ('Entwickelung der Theorie der Krystallstructur,' 1879), and completed by Curie (1884) and Minnigerode (1886). A concise summary will be found in Liebisch, 'Physikalische Krystallographie,' Leipzig, 1891, pp. 3 to 50 ; also Groth, 'Physikalische Krystallographie,' Leipzig, 1895, p. 324, \&c. 
42.

Analogy between crystallographic and atomic laws.

An analogy has been pointed out ${ }^{1}$ between the atomic theory in chemistry, by which Dalton explained the fixed simple and multiple proportions of the combining weights of various substances, and the molecular theory of crystalline structures, by which the fundamental forms of crystals are defined and the accessory forms derived from them. It has been found that if once a crystal has been defined by a fundamental plane referred to three axes at fixed angles, all other planes or faces can be defined by simple multiples of the numbers which belong to the fundamental plane, and which are called the parameters of the crystal. This fundamental rule or law of crystallisation, termed by Haiiy the law of derivation, stands thus in the same relation to the corpuscular theory of the structure of bodies as the law of fixed multiple proportions stands to the original atomic view of matter, and it is thought that it may in the future lead to important results. ${ }^{2}$

43. Isomorphism.

Another very remarkable discovery had been made by Mitscherlich in 1823. ${ }^{3}$ This is the property which various compounds possess of crystallising in the same forms, although they contain different elements-such elements being, however, joined together by similar formulæ. The elements are, as it were, interchangeable. This phe-

1 See Ostwald, 'Allgemeine Chemie,' vol. i. p. 870.

2 A question arises in this connection as to the accuracy of the crystallographic law of the fixity of the angles. In respect of this Ostwald says: "On examining the validity of the fundamental laws of crystallography, it becomes evident that they are only approximate, or perhaps more correctly, that there exist numerous circumstances which permit them to show themselves only in a somewhat disturbed manner" (loc. cit., vol. i. p. 890). This I understand to mean that, if disturbing circumstances could be removed, the law of the fixity of angles and the simple multiples of the indices would obtain with the same accuracy as do the combining numbers and their multiples in chemical combinations.

${ }^{3}$ See supra, chap. ii. p. 191 and note. 
nomenon has been called isomorphism. The discovery has been of great practical value, as well as theoretical interest. If the definite and invariable form of existence which the crystal exhibits is considered as a proof of the purity of a chemical substance, and if in the same crystal one elementary substance can be replaced by one or several other substances, then this substitution must take place in definite proportions of weight, in the equivalent proportions. Thus the production of such isomorphous crystals affords a method of determining the relative atomic weights or equivalents. As such it was hailed by Berzelius; the more so, as in no case did the equivalents thus obtained contradict the numbers he had found by other methods. ${ }^{1}$ Theoretically, the property of isomorphism acquired a still greater interest when Mitscher-

${ }^{1}$ In the early days of the atomic theory as developed by Berzelius, great uncertainty existed as to the numbers which were to be chosen for the atomic weights of the elements. This was owing to the property of fixed multiple ratios-it remaining undecided which was the smallest submultiple of a given combining ratio in which any special element could enter into combination. Otlier methods were then used to assist in deciding this point. The law of volumes, and later the properties of isomorphism, were therefore hailed by Berzelius as welcome aids in fixing the atomic numbers. Both these methods are still used, though the latter is not always decisive. The most important method according to the present state of our knowledge is the determination of the vapour density, where such can be got, and that of the specific heat in tlee solid state. It is mainly owing to Cannizzaro (1858) that the apparent contradictions, which were supposed to exist in the numbers arrived at by various methods, were explained by reverting to Avogadro's forgotten hypothesis. The periodic law or arrangement of the elements into classes showing similar physical properties is likewise of use. A complete, lucid, and exhaustive statement of the most recent position of our knowledge of the true atomic weights of the elements will be found in Lothar Meyer's posthumous tract, 'Die Atome und ihre Eigenschaften,' Breslau, 1896. In this valuable book, as also in Ostwald's 'Allgemeine Chemie,' vol. i., will also be found an account of the degree of accuracy which attaches to our present knowledge of the atomic and combining numbers, which form the solid foundation of all quantitative chemistry and all practical applica. tions. 
lich discovered another crystalline property of certain chemically pure substances. He found that some substances can crystallise in more than one distinct and definite form. The alums and vitriols are typical of isomorphism. As typical of the second property, which was termed by him dimorphism or polymorphism, we have the well-known mineral calc-spar, which is dimorphous with aragonite, both having the same chemical constitution and properties. A typical example of dimorphism is the mineral rutile, which is chemically the same substance as the mineral anatase, both being chemically pure titanic oxide. Among the elements, pure sulphur crystallises in two different forms. The property of dimorphism seemed at first to contradict the inference which Mitscherlich had drawn from his first discovery-viz., that the crystalline shape is expressive of the number and chemical connection of the smallest particles or atoms; but the further discovery, that if of two isomorphous bodies one is dimorphous, the other is likewise so, gave again a great support to the geometrical conception of atomic complexes-i.e., to the idea that chemical individuality is ultimately to be explained not only by the number, but also by the mutual fixed position and shape, of the atoms. And yet it seemed a long way, and is a long way still, from the external, visible, and well-marked shape of a crystal, with its peculiar and well-defined geometrical, elastic, optical, and thermal properties, to the primitive molecule, made up of still more simple atoms, in the form, number, and arrangement of which we are again and again tempted to see the nature of chemical or qualitative individuality. To obtain a clear view in this way would be to work our way from 
outside inward-a method which has rarely led to definite results in scientific research.

A department of chemical science called structural chemistry - which has quite recently developed into stereo-chemistry-has during the last fifty years of the century been working by the opposite method. Even those organic chemists who ridiculed the notion that a chemical formula, which on the surface of the paper on which it is written cannot help making use of geometrical position and proximities, is in any way a picture of the arrangements of atoms in real space, were nevertheless forced to avail themselves of this symbolism. About the middle of the century, especially through the researches of Frankland, followed by those of Couper and Kekulé, the phenomenon of multiple proportions was explained by introducing the notion of saturation. An element which can combine with one or more atoms of the same or of different elements or definite chemical compounds was looked upon as having a chemical affinity which might be wholly or only partially satisfied. The different compounds arising out of such combinations would then represent different degrees of saturation of the first element; and it was evident that elements as well as compounds could be arranged according to the degrees of saturation of which they were capable. A compound containing elements which possessed a greater capacity for saturation than the combination afforded were called unsaturated. The term valency was introduced to denote the degrees of saturation of elements and compounds, which were therefore mono-, di-, or poly-valent, according to the compounds existing in fixed simple or 
fixed multiple proportions. In a table of the valencies or saturating capacities of elements and compounds, the element hydrogen forms the unit and point of reference, as it does in the scale of the atomic or combining weights, and very remarkable relations and analogies have been established between the periodic law of Mendeléeff and the valency of the different elements. Nevertheless it must be remarked that the valency of an element or compound does not, according to our present knowledge, show such absolute fixity as the equivalents or combining weights do, or as the angles of crystallisation of chemically pure substances do. ${ }^{1}$

The introduction of the conception of valency has had an enormous influence on the development of the science of chemistry, and this in a twofold direction. Its practical use was demonstrated by Kekulé, when he placed the idea of the tetravalency, or fourfold saturating capacity, of carbon in the front of his treatise of organic chemistry, ${ }^{2}$ and by so doing gave a great impetus to organic research. One of the first symbols used to denote

1 Not only are many of the elements, such as oxygen and phos. phorus, classed differently by different chemists according as their valency or saturating capacity is put at a higher or lower multiple, but compounds which are universally considered to be saturated compounds, such as neutral salts and water, form chemical combinations according to their combining numbers, which are quite definite and stable: such are the hydrated crystallised salts and the double salts. These compounds are called " molecular compounds." Various explanations have been attempted, but the fact remains that
" no characteristic distinction has been found, either in physical or chemical behaviour, between the ordinary compounds and the molecular compounds; and therefore, strictly speaking, from the phenomena exhibited, at present no other conclusion can be drawn except that chemical compounds do undoubtedly exist which cannot be included in the structure scheme which is based on the doctrine of a constant valency" (see Nernst, 'Theoretical Chemistry,' transl. by Palmer, London, 1895, p. 246).

2 A. Kekulé (1829-1896), 'Lehrbuch der organischen Chemie,' Ist ed., Erlangen, 1859, and later. 
the valency of an element was to attach to it as many lines as it possessed capacities of saturation. The capacities of saturation or valencies thus appeared very early as points of saturation, and the saturation itself as a linkage. These geometrical artifices or expressions were, for a long time, used merely as symbols, and to the present day many eminent chemists refuse to attach to them any real meaning: formulæ of this kind were called formulæ of structure, not of constitution. One of the most remarkable instances of the exact use of linkages to explain the difference of a series of organic compounds, all closely connected with each other, is the theory of the so-called aromatic compounds, derived from benzene, which linkage. we owe to Kekulé. It has stood the criticism of more than a quarter of a century, and has led to the most wonderful practical knowledge of a large number of old and new compounds.

It is not astonishing if, in the face of these remarkable strides which geometrical symbols have led to, an attempt has been made to form an actual conception of the geometrical figure and grouping of the atoms of which chemical molecules and compounds are made up.

Space relations are the only ones in which the difference of symmetry and asymmetry can be at all conceived by us; and when chemical compounds were discovered which show no other difference than that one of them turns the plane of polarisation of a ray of light passing through it to the right, the other to the left side, the time seemed ripe to seek an explanation of this in a purely stereometrical difference of form or grouping. vOL. I. 
In 1874 two chemists, Le Bel and Van't Hoff, suggested independently a picture of the tetravalent carbon atom, which would explain how it could enter with its four points or capacities of saturation into two compounds having the same saturating substances, but arranged in ways which were not geometrically superposable, but only symmetrical, like a right- and left-hand glove, or the 48. images in a mirror. The suggestion amounts to this, tetrahedron. that the carbon atom has the shape of a tetrahedron, the four corners representing the four valencies or capacities of saturation. ${ }^{1}$

The carbon tetrahedron is the last step which has been taken in the development of the atomic view of matter and of nature. No book on organic chemistry can now well avoid introducing this and other similar ways of representing chemical relations. On the further specialisation of this conception will probably depend to a large extent the future of our chemical theory-i.e., of our attempts to grasp the qualitative nature of different substances. It is clear that we are far on the way to realising Wollaston's prophecy of the year 1808-viz., "that the

1 This speculation was at first looked upon with very great doubt. Only few chemists of note took it up; others, such as Kolbe, who led a consistent opposition to the ideas and developments of structural chemistry, treated it with ridicule. Van't Hoff, ten years after the publication of the first edition of his pamphlet, 'La Chimie dans l'Espace' (Rotterdam, 1875) reviewed the position in his 'Dix Années dans l'Histoire d'une Théorie' (translated by Marsh, Oxford, 1891), and, after reproducing the two opposite reviews, with which the original theory was met by Wislicenus and Kolbe, was able to state "that the theory in question now forms part of elementary chemical teaching, and is to be found enunciated in the most widely used text-books" (translation, p. 19). Further applica. tions of the theory, especially to the compounds of nitrogen, will be found in the $2 d$ edition of the German translation 'Die Lagerung der Atome im Raume' (Braunschweig, 1894). 
atomic theory could not rest contented with a knowledge of the relative weights of elementary atoms, but would have to be completed by a geometrical conception of the arrangement of the elementary particles in all the three dimensions of solid extension." 1

But though a further development of the atomic view, not only "pondere" but also " mensura," may be expected in the near future, the progress of chemistry, which has benefited so much by this view of nature, will not depend exclusively upon this line of thought, nor perhaps Defects and insufficiency to so large an extent as it has done during the greater of the part of the century. We have seen how the atomic theory of Dalton rose to the position of being more than a convenient symbolism, and how it became a physical theory of matter and of nature mainly by the support which it received from a different line of reasoning.

The development of this line of reasoning led to the employment of the statistical method, a view quite foreign to other branches of physical science.

The kinetic theory of gases itself had been elaborated in connection with still another line of reasoning, with the endeavour to get a clearer and more comprehensive view of the nature of the different forces which the astronomical as well as the atomic views had merely accepted as given quantities without further examination. We are thus necessarily led on to trace the history of

1 See Wollaston's memoir, "On Super-acid and Sub-acid Salts," read before the Royal Society, Jan. 28, 1808 ('Phil. 'Trans.', 1808, p. 96, \&c.), where he even suggests the examination of the stability of aggregates of particles in different configurations, mentioning the tetrahedron, since become celebrated through Pasteur and Van't Hoff. 
these other views of nature, which up to the middle of the century had grown up independently.

The next chapter will accordingly deal with the kinetic view of nature.

At the time when the atomic theory was firmly established and defined, the great founders of chemical science were well aware that the investigation and measurement of chemical forces, of what was termed affinity, was just as important a problem as the fixing of the combining weights and the formulæ of chemical compounds.

Accordingly we find men like Bergman, Berthollet, Davy, Berzelius, and Faraday all propounding or suggesting theories of chemical affinity, some of which, like the electro-chemical theory, remained long in use. The difficulty, however, which was experienced in defining, and still more in measuring, chemical affinity, and the absence of a general system for the computation and calculation of all physical quantities, retarded the progress of this line of research compared with the study of the weights or proportions of mass which existed in chemical processes, and which were more easily ascertained by means of the balance, and made intelligible by the atomic theory.

The tendency of chemical reasoning during the first half of the century lay therefore in the direction of a onesided development of the knowledge of matter, its definite constituents and infinite compounds, rather than in a study of that equally important but more subtle quantity, now called energy, which appears or disappears, but is never created or destroyed in physical or chemical processes.

A clear recognition of this fundamental doctrine-nay, 
even a name for the thing implied—did not exist before the middle of the century. How both were gradually introduced will be shown in another of the following chapters.

The atomic view or theory which gave such good help in classifying and in studying the characteristic feature of all chemical processes-the fact that they take place according to definite proportions of weight-had also the effect of promoting a somewhat one-sided habit of thought in the domain of chemical science itself.

The search for the elements, the fixing of their combining weights and properties, absorbed a great deal of time, labour, and ability.

The practical demands of the arts stimulated the pre- ${ }_{\text {Practical }}^{51}$ paration of metals, of acids, and of alkalies, all of which influences. possessed useful properties in their isolated, as distinguished from their natural, condition. This gave a stimulus in practice to the invention of processes of disintegration, and in reasoning to processes of analysis. The synthesis or putting together was expected to take place easily, if once the elements or constituent parts were got. In mineral chemistry and metallurgy this is indeed very frequently the case. It was soon found that it is not so in organic chemistry, and that when in organic chenistry a synthesis is effected, the product is frequently unlike that original natural substance from the analysis or disintegration of which the constituents or elements were procured.

It soon became evident that synthesis does not mean merely addition. A certain order had to be observed in the way of putting together, and this led to the introduction of structural, further of geometrical, formulæ. Even then, however, it was found that if a synthesis succeeded, 
it did not always produce a natural, but frequently a purely artificial, compound. The practical effect of this discovery has been remarkable, not to say astonishing. New industries have been founded, and a branch of science has been created called "organic chemistry," but more correctly the "chemistry of carbon compounds," which was undreamt of in the beginning of the century. 52. At that time "organic chemistry" meant that branch of

Change in definition of organic chemistry. the science which dealt with the compounds which were found in the structures of the vegetable and animal kingdoms, and which were peculiar to them. ${ }^{1}$ This meaning of the term "organic chemistry" has disappeared; but the branch of science which deals specially with the substances contained in living matter has not disappeared. Only the development of chemistry on the lines pre-eminently prescribed by the atomic view of nature has diverted the attention of many investigators and philosophers from the original problems of organic chemistry-the study, the analysis, and the reproduction or synthesis of such compounds as are immediately connected with living matter.

To the extent that these problems which have not lain

I The merit of having upheld the twofold aspect of organic chemistry and of having urged the necessity of two distinct ways of analysing organic substances, belongs in this century pre-eminently to Chevreul. Not only are his 'Recherches sur les Corps gras d'Origine animale,' carried on from 1813 to 1823 , a model work of great theoretical and practical value; but he has in various writings, notably in his historical memoirs ('Journal des Savants,'
$1852-60$ ), insisted on the necessity of studying what he terms, after Fourcroy, "les principes immédiats, qui constituent les végétaux et les animaux." This study is based upon quite a different method from that usually called " analyse élémentaire." Cherreul's great work has been continued and developed by M. Berthelot in his celebrated book, 'Chimie organique fondée sur la Synthèse,' 1860, two vols. 
specially on the lines marked out by the atomic view of nature have, in the course of time, reasserted themselves, the atomic view itself has been regarded with less favour by students who have made these problems their especial study. In fact, one meets not infrequently with an inclination to disparage the atomic theory, to point out that it is merely a hypothesis, and that as such it should only assist, but not govern, scientific research. ${ }^{1}$

In the domain of specially chemical reasoning we meet with severe criticisms of the one-sided and formal development to which the atomic view has led, of the playing with symbols and of their empty formalism; notably structural chemistry and stereo-chemistry have not escaped severe ridicule. ${ }^{2}$ Whilst it is not very evident how the school from which these criticisms proceed can in the long-run escape those logical consequences which are embodied in stereo-chemistry, other criticisms claim our attention

1 See Berthelot, 'La Synthèse chimique,' 7 me éd., 1891, p. 167. "Le principal reproche, que l'on puisse adresser à la théorie atomique, comme à toutes les conceptions analogues, c'est qu'elles conduisent à opérer sur ces rapports numériques des éléments et non sur les corps eux mêmes, en rapportant toutes les réactions à une unité type, nécessairement imaginaire. Bref elles enlèvent aux phénomènes tout caractère réel, et substituent à leur exposition véritable une suite de considérations symboliques, auxquelles l'esprit se complait, parce qu'il s'y exerce avec plus de facilité que sur les réalités proprement dites ... les symboles de la chimie présentant à cet égard d'étranges séductions par la facilité algébrique de leurs combinaisons et par les tendances
53. Criticisms of the atomic view. de l'esprit humain, naturellement porté à substituer à la conception directe des choses . . . la vue plus simple... de leurs signes représentatifs."

2 The late eminent Professor Hermann Kolbe of Leipsic, whose labours both alone and jointly with Frankland have done so much to break down the formalism of the older type theory, was especially conspicuous by his virulent attacks on the representatives of 'Modern Chemistry.' The controversy is elaborately and lucidly treated in A. Rau, 'Die Theor'en der modernen Chemie' (Braunschweig, 1877-84, 3 parts), which contains very valuable historical references. I am afraid it is greatly owing to this party spirit that Kolbe's own greatness is hardly sufficiently known in this country. 
because they follow from distinctly defined and independent lines of reasoning. The three criticisms can be summed up in three distinct arguments, all three demanding our special and exhanstive study. These three arguments may be summarised as follows:-

First. The atomic view is a hypothesis resting upon the fact that substances combine in fixed and fixed multiple proportions, and upon the further observation that bodies both in the solid and liquid state show different properties in different directions of space. But as to the nature of the differences of the elements the atomic view gives no information; it simply asserts these differences, assumes them as physical constants, and tries to describe them by number and measurement.

The atomic view is therefore at best only a provisional basis, a convenient resting-place, ${ }^{1}$ similar to that which Newton found in physical astronomy, and on which has been established the astronomical view of nature.

Sccond. The atomic view in its present development gives us no insight into the nature of those forces on which depend the formation or destruction of chemical compounds. It neglects the study of chemical affinity. This must be conducted on different lines of observation and reasoning. ${ }^{2}$

${ }^{1}$ As these and other points referred to here will be taken up and fully treated in future chapters of this work, I abstain from giving exhaustive references, limiting $\mathrm{my}$ self to such writings as will give the reader a general idea of the various attempts which have been made to go beyond or behind the Atomic View of Nature or to supplement it by other views.
Very suggestive in the first instance is Lord Kelvin's address to the mathematical and physical section of the British Association in $\mathbf{1 8 8 4}$, reprinted in the first volume of his 'Popular Lectures and Addresses,' p. 218 , \&c., "Steps towards a Kinetic Theory of Matter."

2 In respect of this the Introduction to the first edition of Lothar Meyer's 'Modern Theories in Chem. 
Third. The atomic view, as developed in chemical formulæ, has unduly favoured and promoted the analytical tendency of research and thought, limiting synthesis to such compounds as can be artificially prepared, but neglecting that kind of synthesis by which compounds are formed in nature, and especially in living organisms. ${ }^{1}$

As representative of these three lines of argument, leading beyond or outside of the atomic view of nature, I mention the three names of Lord Kelvin in England, coupled with the kinetic-specially the vortex-theory of matter; of Professor Ostwald in Germany, coupled with the modern doctrines of chemical affinity; and of $\mathrm{M}$. Berthelot in France, as especially identified with the development of modern synthetical methods in chemistry. In the next chapter I shall take up the line of thought embodied in the first of these developments-the kinetic view of nature. In order to understand the history of this view, we shall have to go back to opinions held

istry,' written in 1862 and reprinted in the subsequent editions and also in the English translation by Bedsonand Williams (London, 1888), gives a very lucid summary of the historical developments. The publication of Meyer's book, by the controversies it produced, did a great deal to give "theoretical " or "physical" chemistry a distinct and independent position. Separate chairs and laboratories for physical chemistry have since been inaug. urated, first at Leipsic and subsequently at other German universities. See Ostwald's article on "Physikalische Chemie," in Lexis, 'Die deutschen Universitäten,' vol. ii. p. 50, \&c. Professor Ostwald is also the editor, since 1857 , of the first periodical devoted to physical chemistry. To his great work, entitled 'Allgemeine Chemie,' which, since its first appearance in 1884, has done so much for "general" as distinguished from "systematic" chemistry, and to his numerous suggestive addresses, I shall frequently have occasion to refer.

${ }^{1}$ See the works of M. Berthelot, quoted above, pp. 454, 455 ; also an address by Prof. Meldola before the chemical section of the British Association in $\mathbf{1 8 9 5}$.

VOL. I. 
already in antiquity; just as I showed that the astronomical and atomic views of nature grew out of vaguer theories of older times, and that they owe their revival and scientific usefulness to the fact that they have received in recent days the precise treatment of exact measurement and mathematical reasoning.

END OF THE FIRST VOLLME. 


\section{PHILOSOPHICAL WORKS.}

HISTORICAL PHILOSOPHY IN FRANCE AND FRENCH BELGIUM AND SWIIZERLAND. By ROBERT FLINT, Corresponding Member of the Institute of France, Hon. Member of the Royal Society of Palermo, Professor in the University of Edinburgh, \&c. 8vo, 21s.

A STUdY OF ETHICAL PR]NCIPLES. By James Seth, M.A., Professor of Philosophy in Brown University, U.S.A. Second Edition. Post 8 vo, 10s. 6d. net.

SCOTTISH PHILOSOPHY. A CoMpaRison of the Scottish and German answers to HUme. Balfour Philosophical Lectures, University of Edinburgh. By ANDREW SETH, M.A., Professor of Logic, Rhetoric, and Metaphysics in the University of Edinburgh. Second Edition. Crown 8vo, $5 \mathrm{~s}$.

HEGELIANISM AND PERSONALITY. Balfour Philosophical Lectures. Second Series. By the SAME AUthor. Second Edition. Crown 8vo, 5s.

SCHOPENHAUER'S SYSTEM IN ITS PHILOSOPHICAL SIGNIFICANCE. (The Shaw Fellowship Lectures, 1893.) By WILLIAM CALDWELL, M.A., D.Sc., Professor of Moral and Social Philosophy, Northwestern University; U.S.A.; formerly Assistant to the Professor of Logic and Metaphysics, Edin.; and Examiner in Philosophy in the University of St Andrews. Demy 8vo, 10s. 6d. net.

ASPECTS OF PESSIMISM. By R. M. Wenley, M.A., D.Sc., D.Phil., Professor of Philosophy in the University of Michigan, U.S.A. Crown 8vo, 6s.

JOHN STUART Mill. A Study of his Philosophy. By Charles DOUGLAS, M.A., D.Sc., Lecturer in Moral Philosophy, and Assistant to the Professor of Moral Philosophy, in the University of Edinburgh. Crown 8vo, 4s. 6d. net.

THE ELEMENTS OF ETHICS. By James H. Hrslop, Ph.D., Instructor in Ethics, Columbia College, New York; Author of 'The Elements of Logic.' Post 8 vo, 7s. 6d. net.

THE ETHICS OF NATURALISM. Being the Shaw Fellowship Lectures, 1884. By W. R. SORLEY, M.A., Professor of Moral Philosophy in the University of Aberdeen. Crown 8vo, $6 \mathrm{~s}$.

KNOWING AND BEING. Essays in Philosophy. First Series. By JOHN VEITCH, LL.D., Professor of Logic and Rhetoric in the University of Glasgow ; Author of 'Institutes of Logic,' \&c. Crown 8vo, 5 s.

DUALISM AND MONISM, AND OTHER ESSAYS. ESSAYS IN Philosophy. Second Series. By the SAME AUTHOR. With an Introduction by R. M. Wenlex. Crown 8vo, 4s. 6d, net.

THE METHOD, MEDITATIONS, AND PRINCIPLES OF PHILOSOPHY OF DESCARTES. Translated from the original French and Latin. With a new Introductory Essay, Historical and Critical, on the Cartesian Philosophy. By Professor VEITCH. Tenth Edition, 6s.6d.

WILLIAM BLACKWOOD \& SONS, EDINBURGH AND LONDON. 


\section{PHILOSOPHICAL CLASSICS FOR ENGLISH READERS.}

Edited by Professor KNIGHT, St Andrews.

In Crown Octavo Volumes, with Portraits. Each price 3s. 6d.

Descartes. By Professor J. P. Mahaffy, Dublin.

BUTLER. By the Rev. W. Lucas Collins, M.A.

Berkeley. By Professor A. Campbell Fraser, Edinburgh.

FICHTE. By Professor Adamson, M.A., Glasgow.

KANT. By Professor Wallace, Merton College, Oxford.

HAMILTON. By Professor Veitch, Glasgow.

HEGEL. By Edward CaIrd, D.C.L., LL.D., Master of Balliol.

"Professor Caird's monograph on Hegel is a most satisfactory piece of work...... Life and philosophy are interwoven in a most skilful and interesting fashion in the first half of the book; while in the second half the principles and outlines of the Hegelian philosophy are stated with a breadth and perspicuity that place in clear relief the relations of this way of thinking to all the main problems of modern life."-Scotsman.

\section{LEIBNIZ. By JoHn Theodore Merz.}

"The position of Leibniz is fairly gauged-his famous views and monads on pre-established harmony, on the principle of sufficient reason, and his theological optimism, can be learned by readers with accuracy and considerable fulness and clearness in these pages."-Scotsman.

VICO. By Professor Flint, D.D., Edinburgh.

"Professor Flint has presented the pith of Vico's writings with great clearness and tact. ...... He has indeed done his work in such a masterly manner that Vico can no longer be said to be practically unknown in England."-British Quarterly Review.

\section{HOBBES. By Professor Croom Robertson, London.}

"A model of what work of the kind should be, exact and learned, yet never dull; sympathetic, yet perfectly dispassionate -in a word, a thoroughly appreciative survey of the life and work of one of the most fertile and comprehensive of English thinkers."-London Quarterly Review.

HUME. By the EdiTor.

"It would not be easy to speak of this little volume in too ligh terms. It is at once genuinely popular and genuinely philosophical....... The more carefully this admirable study is considered, the more highly it will be valued." - Spectator.

SPINOZA. By the Very Rev. Principal CaIrd.

"A masterly piece of exposition, and, as such, will be welcomed by all students of philosophy.......A metaphysical disquisition, extremely able, and very valuable."-Globe.

BACON. Part I.-The Life. Part II. - Philosophy. By Professor NichoL, Glasgow.

"As a manual for the university student, or for the general reader, we know of no volume on Bacon's philosophy so highly to be commended as this one."-London Quarterly Review.

LOCKE. By Professor A. Campbell Fraser, Edinburgh.

"The account of the philosophy of the 'Essay' is the most comprehensive and best considered to which either student or common reader can now turn."-Mind.

WILLIAM BLACKWOOD \& SONS, EDINBURGH AND LONDON. 
k.229

inablew

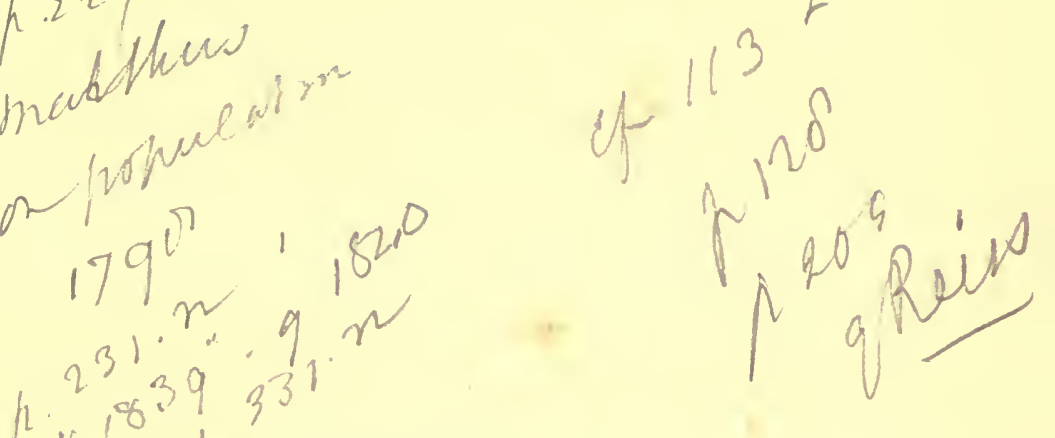

hatalogue

of

Messrs Blackwood \& Sons'

Publications

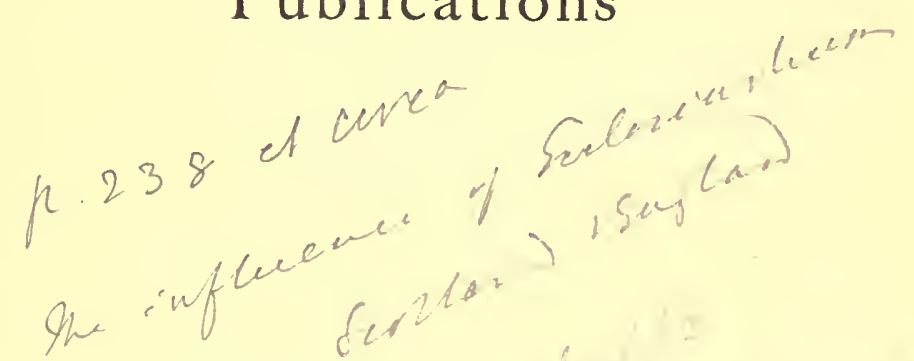

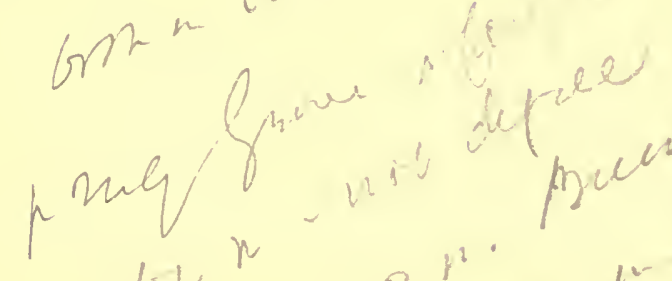

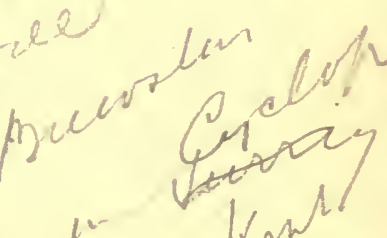




\title{
PHILOSOPHICAL GLASSICS FOR ENGLISH READERS.
}

\author{
Edited BX WILLIAM KNIGHT, LL.D.,
}

Professor of Moral Philosophy in the University of St Andrews.

In crown 8vo Volumes, with Portraits, price 3s. 6d.

Contents of the Series.

Descartes, by Professor Mahaffy, Dublin.-Butler, by Rev. W. Lucas Collins, M.A.-Berkeley, by Professor Campbell Fraser.-Fichte, by Professor Adamson, Glasgow. - Kaxt, by Professor Wallace, Oxford.-Hamiton, by Professor Veitch, Glasgow.-HEGEL, by the Master of Balliol. -Leibxiz, by J. Theodore Merz. - Vico,

by Professor Flint, Edinburgh.-НоввEs, by Professor Croom Robertson.-HסME, by the Editor. - SPINoza, by the Very Rev. Principal Caird, Glasgow.-Bacon: Part I. The Life, by Professor Nichol.Bacon: Part II. Philosophy, by the same Author.-Locke, by Professor Campbell Fraser.

\section{FOREIGN CLASSICS FOR ENGLISH READERS.}

\section{Edited by Mrs OLIPHANT.}

In crown $8 \mathrm{vo}, 2 \mathrm{~s}$. $6 \mathrm{~d}$.

Contents of the Series.

Daste, by the Editor. - Voltaire, by | Editor. - Corneille avd Racine, by General Sir E. B. Hamley, K.C.B. Henry M. Trollope.- Madase DE -Pascal, by Principal Tulloch. - Pet- Sévigné, by Miss Thackeray.-LA FoNRarch, by Henry Reeve, C.B.-Goethe, taine, and other French Fabulists, by A. Hayward, Q.C.-Molière, by the by Rev. W. Lucas Collins, M.A.-Schil. Editor and F. Tarver, M.A.-Montaigne, LER, by James Sime, M.A., Author of by Rev. W. L. Collins, M.A.-RabelaIs, 'Lessing, his Life and Writings.'-Tasso, by Sir Walter Besant. - CALDERoN, by by E. J. Hasell. - Roussead, by Henry E. J. Hasell.- SAixt Simox, by Clifton Grey Graham.-AlFred DE MUSsET, by W. Collins, M.A.-Cervantes, by the C. F. Oliphant.

\section{ANCIENT CLASSICS FOR ENGLISH READERS.}

\section{Edited by the Rev. W. LUCAS COLLINS, M.A.}

Complete in 28 Vols. crown 8vo, cloth, price 2s. 6d. each. And may also be had in 14 Volumes, strongly and neatly bound, with calf or vellum back, $£ 3,10$ s.

\section{Contents of the Series.}

HoMER: THE ILIAD, by the Editor,Herodotus, by George C. Swayne, M.A.XexophoN, by Sir Alexander Grant, Bart., LL.D. - Euripides, by W. B. Donne.Aristophaxes, by the Editor.-Plato, by Clifton W. Collins, M.A.-Lucias, by the Editor. - EschyLUs, by the Right Rev. the Bishop of Colombo. - Sophocles, by Clifton W. Collins, M.A. - Hesiod AND Theogris, by the Rev. J. Davies, M.A.GreEk ANTHology, by Lord Neaves. VIRGIL, by the Editor.-HoRACE, by Sir Theodore Martin, K.C.B. - JuvenaL, by Edward Walford, M.A. - Plautus AND
Terexce, by the Editor.-The CoysexTARIES OF CASAR, by Anthony Trollope. -TAcitus, by W. B. Donne.-Cicero, by the Editor. - Pliny's Letrens, by the Rev. Alfred Church, M.A., and the Rev. W. J. Brodribb, M.A. - LIVY, by the Editor-Ovid, by the Rev. A. Church, M.A. - Catullus, Tibullus, and Propertius, by the Rev. Jas. Davies, M.A. - Demosthenes, by the Rev. W. J. Brodribb, M.A.-ARIstotle, by Sir Alexander Grant, Bart., LL.D.-THUCYDIDEs, by the Editor. - Lucretius, by W. H. Mallock, M.A.-Pindar, by the Rev. F. D. Morice, M.A.

Saturday Review.- "It is difficult to estimate too highly the value of such a series as this in giving 'English readers' an insight, exact as far as it goes, into those olden times which are so remote, and yet to many of us so close." 


\section{A T A L O G U E}

\section{OF \\ MESSRS BLACKWOOD \& SONS' \\ $P U B L I C A T I O N S$.}

ALISON.

History of Europe. By Sir Archibald Alison, Bart., D.C.L.

1. From the Commencement of the French Revolution to the Battle of Waterloo.

Library Edition, 14 vols., with Portraits. Demy 8vo, £10, 10s.

ANother Edition, in 20 vols. crown 8 vo, $£ 6$.

People's Edition, 13 vols. crown 8vo, £2, $11 \mathrm{~s}$.

2. Continuation to the Accession of Louis Napoleon.

LibRARY EdITION, 8 vols. 8vo, £6, 7s. 6d.

PEople's Edition, 8 vols. crown 8vo, 34s.

Epitome of Alison's History of Europe. Thirtieth Thousand, 7s. 6d.

Atlas to Alison's History of Europe. By A. Keith Johnston.

Library EDition, demy 4to, £3, 3s.

PEople's Edition, 31s. 6d.

Life of John Duke of Marlborough. With some Account of his Contemporaries, and of the War of the Succession. Third Edition. 2 vols. 8vo. Portraits and Maps, 30 s.

Essays: Historical, Political, and Miscellaneous. 3 vols. demy $8 \mathrm{vo}, 45 \mathrm{~s}$.

ACROSS FRANCE IN A CARAVAN : Being some Account OF A JOURNEY FROM BORDEAUX TO GENOA IN THE "ESCARGOT," taken in the Winter 1859-90. By the Author of 'A Day of my Life at Eton.' With fifty Illustrations by John Wallace, after Sketches by the Author, and a Map. Cheap Edition, demy $8 v 0,7 s .6 d$.

ACTA SANCTORUM HIBERNIÆ⿸; Ex Codice Salmanticensi. Nunc primum integre edita opera CAROLI DE SMEDT et JOSEPHI DE BACKER, e Soc. Jesu, Hagiographorum Bollandianorum; Auctore et Sumptus Largiente Joanne Patricio Marchione Bothae. In One handsome 4 to Volume, bound in half roxburghe, $£ 2,2 \mathrm{~s}$.; in paper cover, $31 \mathrm{~s}$. $6 \mathrm{~d}$.

ADOLPHUS. Some Memories of Paris. By F. AdolpHus. Crown 8vo, 6s.

AIKMAN.

Manures and the Principles of Manuring. By C. M. Arkuar, D.Sc., F.R.S.E., \&c., Professor of Chemistry, Glasgow Veterinary College;
Examiner in Chemistry, University of Glasgow, \&c. Crown 8vo, 6s. 6d.

Farmyard Manure: Its Nature, Composition, and Treatment. Crown 8vo, 1s. 6d.

AIRD. Poetical Works of Thomas Aird. Fifth Edition, with Memoir of the Author by the Rev. JARDINE WALLACE, and Portrait. Crown 8vo, 7s. $6 \mathrm{~d}$. 
ALLARDYCE.

The City of Sunshine. By Alexander Allardyce, Author of 'Earlscourt,' \&c. New Edition. Crown 8vo, 6s.

Balmoral : A Romance of the Queen's Country. New Edition. Crown 8vo, $6 \mathrm{~s}$.

Memoir of the Honourable George Keith Elphinstone, K.B., Viscount Keith of Stonehaven, Marischal, Admiral of the Red. 8vo, with Portrait, Illustrations, and Maps, 21s.

ALMOND. Sermons by a Lay Head-master. By HeLY HбтcHINson ALMOND, M.A. Oxon., Head-Master of Loretto School. Crown 8vo, $5 \mathrm{~s}$.

ANCIENT CLASSICS FOR ENGLISH READERS. Edited by Rev. W. Lucas Collins, M.A. Price 2s. 6d. each. For List of Vols., see p. 2.

ANDERSON. Daniel in the Critics' Den. A Reply to Dean Farrar's 'Book of Daniel.' By RoBert ANDERson, Lu.D., Barrister-at-Law, Assistant Commissioner of Police of the Metropolis; Author of 'The Coming Prince,' 'Human Destiny,' \&c. Post 8vo, 4s. 6d.

AYTOUN.

Lays of the Scottish Cavaliers, and other Poems. By W. Edmondstoune Aytoun, D.C.L., Professor of Rhetoric and Belles-Lettres in the University of Edinburgh. New Edition. Fcap. 8vo, 3s. 6d.

Axother Edition. Feap. 8vo, 7s. 6d.

CHEAP Edition. 1s. Cloth, 1s. 3d.

An Illustrated Edition of the Lays of the Scottish Cavaliers. From designs by Sir NoEL Paton. Cheaper Edition. Small 4to, 10s. 6d.

Bothwell : a Poem. Third Edition. Fcap., 7s. 6d.

Poems and Ballads of Goethe. Translated by Professor Aytoun and Sir Theodore Martin, K.C.B. Third Edition. Fcap., 6s.

The Ballads of Scotland. Edited by Professor Aytoun. Fourth Edition. 2 vols. fcap. 8 vo, $12 \mathrm{~s}$.

Memoir of William E. Aytoun, D.C.L. By Sir Theodore Martin, K.C.B. With Portrait. Post 8vo, 12s.

$\mathrm{BACH}$.

On Musical Education and Vocal Culture. By Albert B. BACH. Fourth Edition. 8vo, 7s. 6 d.

The Principles of Singing. A Practical Guide for Vocalists and Teachers. With Course of Vocal Exercises. Second Edition. With Portrait of the Author. Crown 8vo, 6s.

The Art Ballad: Loewe and Schubert. With Musical Illustrations. With a Portrait of Loewe. Third Edition. Small 4to, 5s.

BEDFORD \& COLLINS. Annals of the Free Foresters, from 1856 to the Present Day. By W. K. R. BEDFoRD, W. E. W. ColLiNs, and other Contributors. With 55 Portraits and 59 other Illustrations. Demy 8vo, 21s. net.

BELLAIRS. Gossips with Girls and Maidens, Betrothed and Free. By Lady Bellairs. New Edition. Crown 8vo, 3s. 6d. Cloth, extra gilt edges, $5 \mathrm{~s}$.

BELLESHEIM. History of the Catholic Church of Scotland. From the Introduction of Christianity to the Present Day. By AlpHoNs BeL. Lesherm, D.D., Canon of Aix-la-Chapelle. Translated, with Notes and Additions, by D. Oswald Hunter Blair, O.S.B., Monk of Fort Augustus. Cheap Edition. Complete in 4 vols. demy 8vo, with Maps. Price 21s. net.

BENTINCK. Racing Life of Lord George Cavendish Bentinck, M.P., and other Reminiscences. By JoHN KENT, Private Trainer to the Goodwood Stable. Edited by the Hon. Francis Lawley. With Twenty-three full. page Plates, and Facsimile Letter. Third Edition. Demy 8vo, 25s. 
BESANT. The Revolt of Man. By Sir Walter Besant. Tenth Edition. Crown 8vo, 3s. 6d.

BEVERIDGE.

Culross and Tulliallan; or, Perthshire on Forth. Its History and Antiquities. With Elucidations of Scottish Life and Character from the Burgh and Kirk-Session Records of that District. By DAVID BEverIDGe. 2 vols. 8 vo, with Illustrations, $42 \mathrm{~s}$.

Between the Ochils and the Forth; or, From Stirling Bridge to Aberdour. Crown 8vo, 6s.

BICKERDYKE. A Banished Beauty. By JoHN Bickerdyke, Author of 'Days in Thule, with Rod, Gun, and Camera,' 'The Book of the AllRound Angler,' 'Curiosities of Ale and Beer,' \&c. With Illustrations. Crown $8 \mathrm{vo}, 6 \mathrm{~s}$.

BIRCH.

Examples of Stables, Hunting-Boxes, Kennels, Racing Establishments, \&c. By JoHN BIRCH, Architect, Author of 'Country Architecture,' \&c. With 30 Plates. Royal 8vo, 7s.

Examples of Labourers' Cottages, \&c. With Plans for Improving the Dwellings of the Poor in Large Towns. With 34 Plates. Royal 8vo, $7 \mathrm{~s}$.

Picturesque Lodges. A Series of Designs for Gate Lodges, Park Entrances, Keepers', Gardeners', Bailiffs', Grooms', Upper and Under Servants' Lodges, and other Rural Residences. With 16 Plates. 4to, 12s. $6 \mathrm{~d}$.

BLACK. Heligoland and the Islands of the North Sea. By WilliaM George Black. Crown 8vo, 4s.

BLACKIE.

Lays and Legends of Ancient Greece. By JoHs Stuart BLACKIE, Emeritus Professor of Greek in the University of Edinburgh. Second Edition. Fcap. 8vo, 5s.

The Wisdom of Goethe. Fcap. 8vo. Cloth, extra gilt, 6s.

Scottish Song: Its Wealth, Wisdom, and Social Significance. Crown 8vo. With Music. 7s. 6d.

A Song of Heroes. Crown 8vo, 6s.

John Stuart Blackie: A Biography. By Anna M. Stoddart. With 3 Plates. Third Edition. 2 vols. demy 8vo, $21 \mathrm{s.}$

Popular EDition. With Portrait. Crown 8vo, 6s.

BLACKMORE. The Maid of Sker. By R. D. Blackmore, Author of 'Lorna Doone,' \&c. New Edition. Crown 8vo, 6s. Cheaper Edi. tion. Crown $8 \mathrm{vo}, 3 \mathrm{~s} .6 \mathrm{~d}$.

\section{BLACKWOOD.}

Blackwood's Magazine, from Commencement in 1817 to August 1896. Nos. 1 to 970 , forming 159 Volumes.

Index to Blackwood's Magazine. Vols. 1 to $50.8 \mathrm{vo}, 15 \mathrm{~s}$.

Tales from Blackwood. First Series. Price One Shilling each, in Paper Cover. Sold separately at all Railway Bookstalls.

They may also be had bound in 12 vols., cloth, 18s. Half calf, richly gilt, $30 \mathrm{~s}$. Or the 12 vols. in 6 , roxburghe, 21 s. Half red morocco, $28 \mathrm{~s}$.

Tales from Blackwood. Second Series. Complete in Twenty. four Shilling Parts. Handsomely bound in 12 vols., cloth, 30 s. In leather back, roxburghe style, $37 \mathrm{~s}$. $6 \mathrm{~d}$. Half calf, gilt, $52 \mathrm{~s}$. $6 \mathrm{~d}$. Half morocco, $55 \mathrm{~s}$.

Tales from Blackwood. Third Series. Complete in Twelve Shilling Parts. Handsomely bound in 6 vols., cloth, $15 \mathrm{~s}$.; and in 12 vols., cloth, 18s. The 6 vols. in roxburghe, $21 \mathrm{~s}$. Half calf, $25 \mathrm{~s}$. Half morocco, $28 \mathrm{~s}$.

Travel, Adventure, and Sport. From 'Blackwood's Magazine.' Uniform with 'Tales from Blackwood.' In Twelve Parts, each price 1s. Handsomely bound in 6 vols., cloth, 15s. And in half calf, $25 \mathrm{~s}$. 


\section{BLACKWOOD.}

New Educational Series. See separate Catalogue.

New Uniform Series of Novels (Copyright).

Crown 8vo, cloth. Price 3s. 6d. each. Now ready:-

The MaId of Sker. By R. D. Blackmore.

WeNderholme. By P. G. Hamerton.

The Story of MARgrédel. By D. Storrar Meldrum.

Miss Maruoribanks. By Mrs Oliphant.

The Perpetual Curate, and The Rector. By the Same.

SAlem Chapel, and The Doctor's Family. By the Same.

A Sensitive Plant. By E. D. Gerard.

LADY LEE's WIDOWHOOD. By General Sir E. B. Hamley.

Katie Stew ARt, and other Stories. By Mrs Oliphant.

VAlentine AND His Brother. By the Same.

Sons AND Daughters. By the Same.

Marmorne. By P. G. Hamerton.

Reata. By E. D. Gerard.

Begaar my Neighbour. By the Same.

The Waters of Hercules. By the Same.

Fair to See. By L. W. M. Lockhart.

Mine is Thine. By the Same.

Doubles ANd Quits. By the Same.

Altiora Peto. By Laurence Oliphant.

Piccadilly. By the Same. With Illustra. tions.

The Revolt of MaN. By Walter Besant.

LADY BABY. By D. Gerard.

The Blacksmith of Voe. By Paul Cushing.

The Dilemma. By the Author of "The Battle of Dorking.'

My Trivial Life and Misfortune. By A Plain Woman.

Others in preparation.

Standard Novels. Uniform in size and binding. Each complete in one Volume.

FLORIN SERIES, Illustrated Boards. Bound in Cloth, 2s. 6d.

Tom Cringle's Loa. By Michael Scott.

The Cruise of the Midae. By the Same.

Cyril Thornton. By Captain Hamilton.

Annals of the Parish. By John Galt.

The Provost, \&c. By the Same.

Sir ANDrew Wylie. By the Same.

The EntaIL. By the Same.

Miss Molly. By Beatrice May Butt.

Reginald Dalton. By J. G. Lockhart.
PeN Owex. By Dean Hook.

ADAM BLAIR. By J. G. Lockhart.

LADY LEE's WIDOWHOOD. By General Sir E. B. Hamley.

Salem Chapel. By Mrs Oliphant.

The Perpetual Curate. By the Same.

Miss Marjoribanks. By the Same.

Jонк: A Love Story. By the Same.

SHILLING SERIES, nlustrated Cover. Bound in Cloth, 1s. 6d.

The Rector, and The Doctor's Family. Sir Frizzle Pompkin, Nights at Mess, By Mrs Oliphant. The Life of Maxis Wauch. By D. M. The Subaltern.
Moir.

Peninsular Scenes and Sketches. By Yalerius: A Roman Story. By J. G. F. Hardman. Lockhart.

BON GAULTIER'S BOOK OF BALLADS. Fifteenth Edition. With Illustrations by Doyle, Leech, and Crowquill. Fcap. 8vo, 5s.

BRADDON. Thirty Years of Shikar. By Sir Edward Braddon, K.C.M.G. With Illustrations by G. D. Giles, and Map of Oudh Forest Tracts and Nepal Terai. Demy 8 vo, $18 \mathrm{~s}$.

BROUGHAM. Memoirs of the Life and Times of Henry Lord Brougham. Written by HimselF. 3 vols. $8 \mathrm{vo}, £ 2,8 \mathrm{~s}$. The Volumes are sold separately, price $16 \mathrm{~s}$. each.

BROWN. The Forester: A Practical Treatise on the Planting and Tending of Forest-trees and the General Management of Woodlands. By James Brown, LL.D. Sixth Edition, Enlarged, Edited by JoHN NisBet, D. CEc., Author of 'British Forest Trees,' \&c. In 2 vols. royal 8vo, with 350 Illustra. tions, 42s. net.

BROWN. Stray Sport. By J. Moray Brows, Author of "Shikar Sketches,' 'Powder, Spur, and Spear,' 'The Days when we went Hog-Hunting.' 2 vols. post $8 \mathrm{vo}$, with Fifty Illustrations, $21 \mathrm{~s}$.

BROWN. A Manual of Botany, Anatomical and Physiological. For the Use of Students. By Roberr Brows, M.A., Ph.D. Crown 8vo, with numerous Illustrations, 12s. 6d. 
BRUCE.

In Clover and Heather. Poems by Wallace Bruce. New and Enlarged Edition. Crown 8vo, 3s. 6d.

$A$ limited number of Copies of the First Edition, on large hand-made paper, $12 \mathrm{~s} .6 \mathrm{~d}$.

Here's a Hand. Addresses and Poems. Crown 8vo, 5s. Large Paper Edition, limited to 100 copies, price $21 s$.

BUCHAN. Introductory Text-Book of Meteorology. By AlexANDER BUCHAN, LL.D., F.R.S.E., Secretary of the Scottish Meteorological Society, \&c. New Edition. Crown 8vo, with Coloured Charts and Engravings.

BURBIDGE.

In preparation.

Domestic Floriculture, Window Gardening, and Floral Decorations. Being Practical Directions for the Propagation, Culture, and Arrangement of Plants and Flowers as Domestic Ornaments. By F. W. BurbidGe. Second Edition. Crown 8vo, with numerous Illustrations, 7s. 6d.

Cultivated Plants: Their Propagation and Improvement. Including Natural and Artificial Hybridisation, Raising from Seed, Cuttings, and Layers, Grafting and Budding, as applied to the Families and Genera in Cultivation. Crown 8 vo, with numerous Illustrations, 12s. 6d.

BURGESS. The Viking Path: A Tale of the White Christ. By J. J. HALDANE Burgess, Author of 'Rasmie's Büddie,' 'Shetland Sketches,' \&c. Crown 8vo, 6s.

BURKE. The Flowering of the Almond Tree, and other Poems. By Christian Burke. Pott 4 to, 5 s.

BURROWS.

Commentaries on the History of England, from the Earliest Times to 1865. By Montagu Burrows, Chichele Professor of Modern History in the University of Oxford; Captain R.N.; F.S.A., \&c. ; "Officier de l'Instruction Publique," France. Crown 8vo, 7s. 6d.

The History of the Foreign Policy of Great Britain. Demy $8 \mathrm{ro}, 12 \mathrm{~s}$.

BURTON.

The History of Scotland: From Agricola's Invasion to the Extinction of the last Jacobite Insurrection. By JoHN HILL BURTON, D.C.L., Historiographer-Royal for Scotland. New and Enlarged Edition, 8 vols., and Index. Crown 8vo, £3, 3s.

History of the British Empire during the Reign of Queen Anne. In 3 vols. $8 \mathrm{vo}$. $36 \mathrm{~s}$.

The Scot Abroad. Third Edition. Crown 8vo, 10s. 6d.

The Book-Hunter. New Edition. With Portrait. Crown $8 \mathrm{vo}, 7 \mathrm{~s} .6 \mathrm{~d}$.

BUTCHER. The Fortunes of Armenosa. A Historical Romance of Memphis and Old Cairo. By the Very Rev. Dean Butcher, D.D., F.S.A., Chaplain at Cairo. Crown 8 ro, $6 \mathrm{~s}$.

BUTE. The Altus of St Columba. With a Prose Paraphrase BUTT. and Notes. In paper cover, 2s. 6d.

Theatricals : An Interlude. By Beatrice May Bбtт. Crown $8 \mathrm{ro}, 6 \mathrm{~s}$.

Miss Molly. Cheap Edition, 2s.

Eugenie. Crown 8vo, 6s. 6d.

Elizabeth, and other Sketches. Crown 8vo, 6s.

Delicia. New Edition. Crown 8vo, 2s. 6d.

CAIRD. Sermons. By JoHN CAIRD, D.D., Principal of the University of Glasgow. Seventeenth Thousand. Fcap. 8vo, 5s. 
CALDWELL. Schopenhauer's System in its Philosophical Significance (the Shaw Fellowship Lectures, 1893). By WILLIAM CALDWELL, M.A., D.Sc., Professor of Moral and Social Philosophy, Northwestern University, U.S.A. ; formerly Assistant to the Professor of Logic and Metaphysics, Edin., and Examiner in Philosophy in the University of St Andrews. Demy 8vo, 10s. 6d. net.

CALLWELL. The Effect of Maritime Command on Land Campaigns since Waterloo. By Major C. E. CALLWELL, R.A. With Plans. Post 8ro, 6s. net.

CAMPBELL. Sermons Preached before the Queen at Balmoral. By the Rev. A. A. Campreld, Minister of Crathie. Published by Command of Her Majesty. Crown 8vo, 4s. $6 \mathrm{~d}$.

CAMPBELL. Records of Argyll. Legends, Traditions, and Recollections of Argyllshire Highlanders, collected chiefly from the Gaelic. With Notes on the Antiquity of the Dress, Clan Colours, or Tartans of the Highlanders. By Lord ARCHIBALD CAMPBELL. Illustrated with Nineteen full-page Etchings. 4 to, printed on hand-made paper, $£ 3$, 3s.

CAMPBELL. Critical Studies in St Luke's Gospel : Its Demonology and Ebionitism. By CoLIN CAMPBELL, D.D., Minister of the Parish of Dun. dee, formerly Scholar and Fellow of Glasgow University. Author of the 'Three First Gospels in Greek, arranged in parallel columns.' Post 8vo, 78. 6d.

CANTON. A Lost Epic, and other Poems. By William CaNTON. Crown 8vo, $5 \mathrm{~s}$.

CARSTAIRS.

Human Nature in Rural India. By R. Carstairs. Crown $8 \mathrm{vo}, 6 \mathrm{~s}$.

British Work in India. Crown 8vo, 6s.

CAUVIN. A Treasury of the English and German Languages. Compiled from the best Authors and Lexicographers in both Languages. By JosepH CAUviN, LL.D. and Ph.D., of the University of Göttingen, \&c. Crown 8 vo, 7s. $6 \mathrm{~d}$.

CHARTERIS. Canonicity ; or, Early Testimonies to the Existence and Use of the Books of the New Testament. Based on Kirchhoffer's 'Quellensammlung.' Edited by A. H. CharTERIs, D.D., Professor of Biblical Criticism in the University of Edinburgh.

CHENNELLS. Recollections of an Egyptian Princess. By her English Governess (Miss E. ChEnwelds). Being a Record of Five Years' Residence at the Court of Ismael Pasha, Khedive. Second Edition. With Three Portraits. Post $8 \mathrm{vo}, 7 \mathrm{~s} .6 \mathrm{~d}$.

CHesNeY. The Dilemma. By General Sir George Chesney, K.C.B., M.P., Author of 'The Battle of Dorking,' \&c. New Edition. Crown 8 vo, $3 \mathrm{~s} .6 \mathrm{~d}$.

CHRISTISON. Life of Sir Robert Christison, Bart., M.D., D.C.L. Oxon., Professor of Medical Jurisprudence in the University of Edinburgh. Edited by his Soss. In 2 vols. 8 vo. Vol. I.-Autobiography. 16s. Vol. II.-Memoirs. 16s.

CHURCH. Chapters in an Adventurous Life. Sir Richard Church in Italy and Greece. By E. M. ChURCH. With Photograrure Portrait. Demy 8vo, 10s. 6d.

CHURCH SERVICE SOCIETY.

A Book of Common Order: being Forms of Worship issued by the Church Service Society. Scventh Edition, carefully revised. In 1 vol. crown $8 \mathrm{vo}$, cloth, $3 \mathrm{~s}$. 6d. ; French moroceo, $5 \mathrm{~s}$. Also in 2 vols. crown $8 \mathrm{vo}$, cloth, 4s. ; French morocco, 6s. 6 d.

Daily Offices for Morning and Evening Prayer throughout the Week. Crown 8vo, 3s. 6d.

Order of Divine Service for Children. Issued by the Church Service Society. With Scottish Hymnal. Cloth, 3d. 
CLOUSTON. Popular Tales and Fictions: their Migrations and Transformations. By W. A. Cloustow, Editor of 'Arabian Poetry for Eng. lish Readers,' \&c. 2 vols. post $8 \mathrm{vo}$, roxburghe binding, $25 \mathrm{~s}$.

COCHRAN. A Handy Text-Book of Military Law. Compiled chiefly to assist Officers preparing for Examination; also for all Officers of the Regular and Auxiliary Forces. Comprising also a Synopsis of part of the Army Act. By Major F. CochraN, Hampshire Regiment Garrison Instructor, North British District. Crown $8 v 0,7 \mathrm{~s} .6 \mathrm{~d}$.

COLQUHOUN. The Moor and the Loch. Containing Minute Instructions in all Highland Sports, with Wanderings over Crag and Corrie, Flood and Fell. By JонN CoLquног,. Cheap Edition. With Illustrations. Demy 8vo, 10s. 6d.

COLVILE. Round the Black Man's' Garden. By Lady Z. CoLvILE, F.R.G.S. With 2 Maps and 50 Mlustrations from Drawings by the Author and from Photographs. Demy 8vo, 16s.

CONDER. The Bible and the East. By Lieut.-Col. C. R. Conder, R.E., LL.D., D.C.L., M.R.A.S., Author of 'Tent Work in Palestine,' \&c. With Illustrations and a Map. Crown 8vo, $5 \mathrm{~s}$.

CONSTITUTION AND LAW OF THE CHURCH OF SCOTLAND. With an Introductory Note by the late Principal Tullnch. New Edition, Revised and Enlarged. Crown 8vo, 3s. 6d.

COTTERILL. Suggested Reforms in Public Schools. By C. C. Cotterill, M.A. Crown 8vo, 3s. 6d.

COUNTY HISTORIES OF SCOTLAND. In demy 8vo volunes of about $350 \mathrm{pp}$. each. With 2 Maps. Price $7 \mathrm{~s}$. $6 \mathrm{~d}$. net.

Fife and Kinross. By Æxeas J. G. Mackay, LL.D., Sheriff of these Counties.

Dumfries and Galloway. By Sir Herbert Maxwell, Bart., M.P.

CRANSTOUN.

The Elegies of Albius Tibullus. Translated into English Verse, with Life of the Poet, and Illustrative Notes. By JAmes Craxstous, LL.D., Author of a Translation of 'Catullus.' Crown 8vo, 6s. 6d.

The Elegies of Sextus Propertius. Translated into English Verse, with Life of the Poet, and Illustrative Notes. Crown 8vo, 7s. 6d.

CRAWFORD. Saracinesca. By F. Marion Crawford, Author of 'Mr Isaacs,' \&c., \&c. Eighth Edition. Crown 8vo, 6s.

CRAWFORD.

The Doctrine of Holy Scripture respecting the Atonement. By the late Thomas J. Crawford, D.D., Professor of Divinity in the University of Edinburgh. Fifth Edition. 8vo, 12s.

The Fatherhood of God, Considered in its General and Special Aspects. Third Edition, Revised and Enlarged. 8vo, 9s.

The Preaching of the Cross, and other Sermons. 8vo, 7s. $6 \mathrm{~d}$.

The Mysteries of Christianity. Crown 8vo, 7s. 6d.

CROSS. Impressions of Dante, and of the New World ; with a Few Words on Bimetallism. By J.'W. Cross, Editor of 'George Eliot's Life, as related in her Letters and Journals.' Post 8 vo, 6 s.

CUMBERLAND. Sport on the Pamirs and Turkistan Steppes. By Major C. S. Cumberlakd. With Map and Frontispiece. Demy 8vo, 10s. 6d.

CURSE OF INTELLECT. Third Edition. Fcap. 8vo, 2s. 6d. net.

CUSHING. The Blacksmith of Voe. By Paul Cushing, Author of 'The Bull i' th' Thorn,' 'Cut with his own Diamond.' Cheap Edition. Crown 8 ro, 3s. 6 d. 
DAVIES.

Norfolk Broads and Rivers; or, The Waterways, Lagoons, and Decoys of East Anglia. By G. Christopher Davies. Inlustrated with Seven full-page Plates. New and Cheaper Edition. Crown 8vo, 6s.

Our Home in Aveyron. Sketches of Peasant Life in Aveyron and the Lot. By G. Christopher Davies and Mrs Broughall. Mlustrated with full-page Illustrations. 8vo, 15s. Cheap Edition, 7s. 6d.

DE LA WARR. An Eastern Cruise in the 'Edeline.' By the Countess DE LA WARR. In Illustrated Cover. 2s.

DESCARTES. The Method, Meditations, and Principles of Philosophy of Descartes. Translated from the Original French and Latin. With a New Introductory Essay, Historical and Critical, on the Cartesian Philosophy. By Professor Veitch, LL.D., Glasgow University. Tenth Edition. 6s. 6d.

DOGS, OUR DOMESTICATED : Their Treatment in reference to Food, Diseases, Habits, Punishment, Accomplishments. By 'Magenta.' Crown 8vo, 2s. 6d.

DOUGLAS.

The Ethics of John Stuart Mill. By Charles Dodglas, M.A., D.Sc., Lecturer in Moral Philosophy, and Assistant to the Professor of Moral Philosophy in the University of Edinburgh. Crown 8vo, is. 6d. net.

John Stuart Mill : A Study of his Philosophy. Crown 8vo, 4s. 6 d. net.

DOUGLaS. Chinese Stories. By Robert K. Dodglas. With numerous Illustrations by Parkinson, Forestier, and others. New and Cheaper Edition. Small demy 8vo, 5s.

DOUGLAS. Iras: A Mystery. By Theo. Douglas, Author of 'A Bride Elect.' Crown 8vo, 3s. 6d.

DU CANE. The Odyssey of Homer, Books I.-XII. Translated into English Verse. By Sir CharLes DU CANE, K.C.M.G. 8vo, 10s. 6d.

DUDGEON. History of the Edinburgh or Queen's Regiment Light Infantry Militia, now 3rd Battalion The Royal Scots; with an Account of the Origin and Progress of the Militia, and a Brief Sketch of the Old Royal Scots. By Major R. C. DUdGEoN, Adjutant 3rd Battalion the Royal Scots. Post 8vo, with Illustrations, 10s. $6 \mathrm{~d}$.

DUNSMORE. Manual of the Law of Scotland as to the Relations between Agricultural Tenants and the Landlords, Servants, Merchants, and Bowers. By W. Dunsmore. 8vo, 7s. $6 \mathrm{~d}$.

\section{ELIOT.}

George Eliot's Life, Related in Her Letters and Journals. Arranged and Edited by her husband, J. W. Cross. With Portrait and other Illustrations. Third Edition. 3 vols. post $8 \mathrm{vo}, 42 \mathrm{~s}$.

George Eliot's Life. With Portrait and other Illustrations. New Edition, in one volume. Crown 8vo, 7s. $6 \mathrm{~d}$.

Works of George Eliot (Standard Edition). 21 volumes, crown 8vo. In buckram cloth, gilt top, 2s. 6d. per vol.; or in roxburghe binding, 3s. $6 \mathrm{~d}$. per vol.

Adam Bede. 2 vols.-The Mill on the Floss. 2 vols.-Felix Holt, the Radical. 2 vols. - Romola. 2 vols. - Scenes of Clerical Life. 2 vols. Middlemarch. 3 vols.-Daniel Deronda. 3 vols.-Silas Marner. 1 vol. -Jubal. 1 vol.-The Spaxish GIPSy. 1 vol.-Essays. 1 vol.-TheophrasTUS Such. 1 vol.

Life and Works of George Eliot (Cabinet Edition). 24 volumes, crown $8 v 0$, price $£ 6$. Also to be had handsomely bound in half and full calf. The Volumes are sold separately, bound in cloth, price $5 \mathrm{~s}$. each. 
ELIOT.

Novels by George Eliot. Cheap Edition.

Adam Bede. Illustrated. 3s. 6d., cloth.-The Mill on the Floss. Illus. trated. 3s. 6d., cloth.-Scenes of Clerical Life. Illustrated. 3s., cloth.Silas Marner: the Weaver of Raveloe. Illustrated. 2s. 6d., cloth.-Felix Holt, the Radical. Illustrated. 3s. 6d., cloth.-Romola. With Vignette. 3s. 6 d., eloth.

Middlemarch. Crown 8vo, 7s. 6d.

Daniel Deronda. Crown 8vo, 7s. 6d.

Essays. New Edition. Crown 8vo, 5s.

Impressions of Theophrastus Such. New Edition. Crown 8 vo, $5 \mathrm{~s}$.

The Spanish Gypsy. New Edition. Crown 8vo, 5s. The Legend of Jubal, and other Poems, Old and New.

Wise, Witty, and Tender Sayings, in Prose and Verse. Selected from the Works of GEORGE ELIOT. New Edition. Frap. 8vo, 3s. 6d.

ENGLISH CHURCH AND THE ROMISH SCHISM. Crown 8vo, 2s. 6d.

ESSAYS ON SOCIAL SUBJECTS. Originally published in the 'Saturday Review.' New Edition. First and Second Series. 2 vols. crown $8 \mathrm{vo}, 6 \mathrm{~s}$, each.

FAITHS OF THE WORLD, The. A Concise History of the Great Religious Systems of the World. By various Authors. Crown 8vo, $5 \mathrm{~s}$.

FALKNER. The Lost Stradivarius. By J. Meade Falkner. Second Edition. Crown 8vo, 6s.

FERGUSON. Sir Samuel Ferguson in the Ireland of his Day. By LADY FERgusos, Author of 'The Irish before the Conquest,' 'Life of William Reeves, D.D., Lord Bishop of Down, Connor, and Drumore,' \&c.., \&c. With Two Portraits. 2 vols. post 8 vo, $21 \mathrm{~s}$.

FERRIER.

Philosophical Works of the late James F. Ferrier, B.A. Oxon., Professor of Moral Philosophy and Political Economy, St Andrews. New Edition. Edited by Sir ALEXANDER GRANT, Bart., D.C.L., and Professor LUSHINGTON. 3 vols. crown 8 Vo, $34 \mathrm{~s}$. $6 \mathrm{~d}$.

Institutes of Metaphysic. Third Edition. 10s. 6d.

Lectures on the Early Greek Philosophy. 4th Edition. 10s. 6d.

Philosophical Remains, including the Lectures on Early FLINT. Greek Philosophy. New Edition. 2 vols. 24s.

Historical Philosophy in France and French Belgium and Switzerland. By ROBERT FLINT, Corresponding Member of the Institute of France, Hon. Member of the Royal Society of Palermo, Professor in the University of Edinburgh, \&c. 8vo, $21 \mathrm{~s}$.

Agnosticism. Being the Croall Lecture for 1887-88.

Their the press. Revised. Crown 8vo, 7s. 6d

Anti-Theistic Theories. Being the Baird Lecture for 1877. Fifth Edition. Crown 8vo, 10s. 6d.

FOREIGN CLASSICS FOR ENGLISH READERS. Edited by Mrs Oliphaxt. Price 2s. 6d. For List of Volumes, see page 2.

FOSTER. The Fallen City, and other Poems. By Will Foster. Crown 8vo, 6s. 
FRANCILLON. Gods and Heroes; or, The Kingdom of Jupiter. By R. E. Fraxcillon. With 8 Illustrations. Crown 8vo, 58.

FRANCIS. Among the Untrodden Ways. By M. E. Fraxcis (Mrs Francis Blundell), Author of 'In a North Country Village,' 'A Daughter of the Soil,' 'Frieze and Fustian,' \&c. Crown 8vo, 3s. 6d.

FRASER.

Philosophy of Theism. Being the Gifford Lectures delivered before the University of Edinburgh in 1894-95. First Series. By ALExArdER Campbell Fraser, D.C.L. Oxford; Emeritus Professor of Logic and Metaphysics in the University of Edinburgh. Post 8vo, 7s. 6d. net.

Philosophy of Theism. Being the Gifford Lectures delivered before the University of Edimburgh in 1895-96. Second Series. Post 8vo, is. 6d. net.

FRASER. St Mary's of Old Montrose : A History of the Parish of Maryton. By the Rev. Williay Ruxtox Fraser, M.A., F.S.A. Scot., Emeritus Minister of Maryton; Author of 'History of the Parish and Burgh of Laurencekirk.' Crown Svo, 3s. 6d.

FULLARTON.

Merlin: A Dramatic Poem. By Ralph Macleod Fullarrox. Crown 8vo, 5 s.

Tanhäuser. Crown 8 vo, 6s.

Lallan Sangs and German Lyrics. Crown 8vo, $5 \mathrm{~s}$.

GALT.

Novels by JoHx GALT. With General Introduction and Prefatory Notes by S. R. CrockETT. The Text Revised and Edited by D. Storrar Meldrey, Author of 'The Story of Margrédel.' With Photogravure Illustrations from Drawings by John Wallace. Feap. 8vo, 3s, net each vol.

Arvals of the Parish, and The Ayrshire Legaters. 2 vols.-Sir ANdrew Wylie. 2 vols.-The Entall; or, The Lairds of Grippy. 2 vols.-The Provost, and THE LAST OF THE LAIRDS. 2 vols.

See also Staxdard Novels, p. 6.

GENERAL ASSEMBLY OF THE CHURCH OF SCOTLAND.

Scottish Hymnal, With Appendix Incorporated. Published for use in Churches by Authority of the General Assembly. 1. Large type, cloth, red edges, 2s. 6d.; French morocco, 4s. 2. Bourgeois type, limp cloth, Is.; French morocco, 2s. 3. Nonpareil type, cloth, red edges, 6d.; French morocco, 1s. 4d. 4. Paper covers, 3d. 5. Sunday-School Edition, paper covers, Id., cloth, 2d. No. 1, bound with the Psalms and Paraphrases, French morocco, 8s. No. 2, bound with the Psalms and Paraphrases, cloth, 2s.; French morocco, 3s.

Prayers for Social and Family Worship. Prepared by a Special Committee of the General Assembly of the Church of Scotland. Entirely New Edition, Revised and Enlarged. Fcap. 8vo, red edges, 2s.

Prayers for Family Worship. A Selection of Four Weeks' Prayers. New Edition. Authorised by the General Assenibly of the Church of Scotland. Fcap. 8vo, red edges, 1s. 6d.

One Hundred Prayers. Prepared by the Committee on Aids to Devotion. $16 \mathrm{mo}$, cloth limp, $6 \mathrm{~d}$.

Morning and Evening Prayers for Affixing to Bibles. Prepared by the Committee on Aids to Devotion. Id. for 6, or 1s, per 100 .

GERARD.

Reata: What's in a Name. By E. D. Gerard. Cheap Edition. Crown 8vo, 3s. 6d.

Beggar my Neighbour. Cheap Edition. Crown 8vo, 3s. 6d.

The Waters of Hercules. Cheap Edition. Crown 8vo, 3s. 6d. A Sensitive Plant. Crown 8vo, 3s. 6d. 
GERARD.

A Foreigner. An Anglo-German Study. By E. Gerard. Crown 8vo, 6s.

The Land beyond the Forest. Facts, Figures, and Fancies from Transylvania. With Maps and Illustrations. 2 vols. post 8vo, 25s.

Bis : Some Tales Retold. Crown 8vo, 6s.

A Secret Mission. 2 vols. crown 8vo, 17s. GERARD.

The Wrong Man. By Dorothea Gerard. Second Edition. Crown 8vo, 6s.

Lady Baby. Cheap Edition. Crown 8vo, 3s. 6d.

Recha. Second Edition. Crown 8vo, 6s.

The Rich Miss Riddell. Second Edition. Crown 8vo, 6s.

GERARD. Stonyhurst Latin Grammar. By Rev. JoHs Gerard. GILL. Second Edition. Feap. 8vo, 3s.

Free Trade: an Inquiry into the Nature of its Operation. By Richard Gill. Crown 8vo, 7s. 6d.

Free Trade under Protection. Crown 8vo, 7s. 6d. GORDON CUMMING.

At Home in Fiji. By C. F. Gordon Comming. Fourth Edition, post 8vo. With Illustrations and Map. 7s. 6d.

A Lady's Cruise in a French Man-of-War. New and Cheaper Edition. 8vo. With Illustrations and Map. 12s, 6d.

Fire-Fountains. The Kingdom of Hawaii: Its Volcanoes, and the History of its Missions. With Map and Illustrations. 2 vols. 8vo, 25s.

Wanderings in China. New and Cheaper Edition. 8vo, with Illnstrations, 10s.

Granite Crags: The Yō-semité Region of California. Illus. trated with 8 Engravings. New and Cheaper Edition. 8vo, 8s. 6d.

GRAHAM. Manual of the Elections (Scot.) (Corrupt and Illegal Practices) Act, 1890. With Analysis, Relative Act of Sederunt, Appendix con. taining the Corrupt Practices Acts of 1883 and 1885, and Copious Index. By J. GRAND. EDWARD GRAHAMr, Advocate. 8ro, 4s. 6d.

A Domestic Experiment. By SARAH Grand, Author of 'The Heavenly Twins,' 'Ideala: A Study from Life.' Crown 8vo, 6s.

Singularly Deluded. Crown 8vo, 6s.

GRANT. Bush-Life in Queensland. By A. C. Gravt. New Edition. Crown 8vo, $6 \mathrm{~s}$.

GRANT. Life of Sir Hope Grant. With Selections from his Correspondence. Edited by HENRY KNoLLYs, Colonel (H.P.) Royal Artillery, his former A.D.C., Editor of 'Incidents in the Sepoy War;' Author of 'Sketches of Life in Japan,' \&c. With Portraits of Sir Hope Grant and other Illus. GRIER. trations. Maps and Plans. 2 vols. demy 8 vo, 21s.

In Furthest Ind. The Narrative of Mr EDward Carlyor of Ellswether, in the County of Northampton, and late of the Honourable East India Company's Service, Gentleman. Wrote by his own hand in the year of grace 1697 . Edited, with a few Explanatory Notes, by SYDNEY C. GrIER. Post 8vo, 6s.

His Excellency's English Governess. Crown 8vo, 6s.

An Uncrowned King: A Romance of High Politics. Crown Sro, $6 \mathrm{~s}$.

GUTHRIE-SMITH. Crispus: A Drama. By H. GuthrieSurite. Fcap. 4to, 5s. 
HAGGARD. Under Crescent and Star. By Lieut.-Col. ANDREw HAGgard, D.S.O., Author of 'Dodo and I,' 'Tempest Torn,' \&c. With a Portrait. Second Edition. Crown 8vo, 6s.

HALDANE. Subtropical Cultivations and Climates. A Handy Book for Planters, Colonists, and Settlers. By R. C. HALdarz. Post 8vo, 9s.

HAMERTON.

Wenderholme: A Story of Lancashire and Yorkshire Life. By P. G. Hamerton, Author of 'A Painter's Camp.' New Edition. Crown 8 vo, 3s. $6 \mathrm{~d}$.

Marmorne. New Edition. Crown 8vo, 3s. 6d.

\section{HAMILTON.}

Lectures on Metaphysics. By Sir William HamiltoN, Bart., Professor of Logic and Metaphysics in the University of Edinburgh. Edited by the Rev. H. L. MANser, B.D., LL.D., Dean of St Paul's; and JoHN VEITCH, M.A., LL.D., Professor of Logic and Rhetoric, Glasgow. Seventh Edition. 2 vols. 8 vo, $24 \mathrm{~s}$.

Lectures on Logic. Edited by the SAmE. Third Edition, Revised. 2 vols., 24 s.

Discussions on Philosophy and Literature, Education and University Reform. Third Edition. 8vo, 21s.

Memoir of Sir William Hamilton, Bart., Professor of Logic and Metaphysics in the Uuiversity of Edinburgh. By Professor VEITch, of the University of Glasgow. 8vo, with Portrait, 18s.

Sir William Hamilton: The Man and his Philosophy. Two Lectures delivered before the Edinburgh Philosophical Institution, January and February I883. By Professor Vertch. Crown 8vo, 2s.

HAMLEY.

The Operations of War Explained and Illustrated. By General Sir Edward Broce Hamley, K.C.B., K.C.M.G. Fifth Edition, Revised throughout. 4to, with numerous Illustrations, 30s.

National Defence; Articles and Speeches. Post 8vo, 6s.

Shakespeare's Funeral, and other Papers. Post 8vo, 7s. 6d.

Thomas Carlyle: An Essay. Second Edition. Crown 8vo, $2 \mathrm{~s} .6 \mathrm{~d}$.

On Outposts. Second Edition. 8vo, 2s.

Wellington's Career; A Military and Political Summary. Crown 8vo, 2s.

Lady Lee's Widowhood. New Edition. Crown 8vo, 3s. 6d. Cheaper Edition, 2s. 6 d.

Our Poor Relations. A Philozoic Essay. With Illustrations, chiefly by Ernest Griset. Crown 8vo, cloth gilt, 3s. 6d.

The Life of General Sir Edward Bruce Hamley, K.C.B. K.C.M.G. By Alexander Inves Shasd. With two Photogravure Portraits and other Illustrations. Cheaper Edition. With a Statement by Mr EDwARD Hamley. 2 vols. demy 8vo, 10s. 6 d.

HARE. Down the Village Street: Scenes in a West Country Hamlet. By Christopher Hare. Second Edition. Crown 8vo, 6s.

HARRADEN. In Varying Moods : Short Stories. By Beatrice Harradex, Author of 'Ships that Pass in the Night.' Twelfth Edition. Crown 8 vo, 3s. 6d.

HARRIS.

From Batum to Baghdad, via Tiflis, Tabriz, and Persian Kurdistan. By Walter B. Harris, F.R.G.S., Author of 'The Land of an African Sultan; Travels in Morocco,' \&c. With numerous Illustrations and 2 Maps. Demy Svo, 12s. 
HARRIS.

Tafilet. The Narrative of a Journey of Exploration to the Atlas Mountains and the Oases of the North-West Sahara. With Illustrations by Maurice Romberg from Sketches and Photographs by the Author, and Two Maps. Demy 8 vo, $12 \mathrm{~s}$.

A Journey through the Yemen, and some General Remarks upon that Country. With 3 Maps and numerous Illustrations by Forestier and Wallace from Sketches and Photographs taken by the Author. Demy 8vo, 168.

Danovitch, and other Stories. Crown 8vo, 6s.

HAWKER. The Prose Works of Rev. R. S. HAwkER, Vicar of Morwenstow. Including 'Footprints of Former Men in Far Cornwall.' Re-edited, with Sketches never before published. With a Frontispiece. Crown 8vo, 3s.6d.

HAY. The Works of the Right Rev. Dr George Hay, Bishop of Edinburgh. Edited under the Supervision of the Right Rev. Bishop STraiv. With Memoir and Portrait of the Author. 5 vols. crown 8vo, bound in extra cloth, £1, 1s. The following Volumes may be had separately-viz. :

The Devout Christian Instructed in the Law of Christ from the Written Word. 2 vols., 8s. - The Pious Christian Instructed in the Nature and Practice HEATLEY. of the Principal Exercises of Piety. 1 vol., 3 s.

The Horse-Owner's Safeguard. A Handy Medical Guide for every Man who owns a Horse. By G. S. HEATLEX, M.R.C.V.S. Crown 8vo, 58 .

The Stock-Owner's Guide. A Handy Medical Treatise for every Man who owns an $0 x$ or a Cow. Crown $8 v 0,4 \mathrm{~s} .6 \mathrm{~d}$.

HEDDERWICK. Lays of Middle Age; and other Poems. By JAMES HEDDERWick, LL.D., Author of 'Backward Glances.' Price 3s. 6d.

HEMANS.

The Poetical Works of Mrs Hemans. Copyright Editions. Royal 8vo, 5s. The Same with Engravings, cloth, gilt edges, 7s. 6d.

Select Poems of Mrs Hemans. Fcap., cloth, gilt edges, $3 \mathrm{~s}$.

HERKLESS. Cardinal Beaton: Priest and Politician. By JoHs Herkiess, Professor of Church History, St Andrews. With a Portrait. Post 8vo, 7s. 6d.

HEWISON. The Isle of Bute in the Olden Time. With Illustrations, Maps, and Plans. By JAmes King Hewison, M.A., F.S.A. (Scot.) Minister of Rothesay. Vol. I., Celtic Saints and Heroes. Crown 4to, 15s. net. Vol. II., The Royal Stewards and the Brandanes. Crown 4to, 15s. net.

HIBBEN. Inductive Logic. By John Grier HibBen, Ph.D., Assistant Professor of Logic in Princeton University, U.S.A. Crown Svo, 3s. 6 d. net.

HOME PRAYERS. By Ministers of the Church of Scotland and Members of the Church Service Society. Second Edition. Fcap. 8vo, 3s.

HORNBY. Admiral of the Fleet Sir Geoffrey Phipps Hornby, G.C.B. A Biography, By Mrs Fred. EgertoN. With Three Portraits. Demy $8 \mathrm{ro}, 16 \mathrm{~s}$.

HUTCHINSON. Hints on the Game of Golf. By Horace G. HutchINSON. Ninth Edition, Enlarged. Fcap. 8vo. cloth, 1s.

HYSLOP. The Elements of Ethics. By Jayes H. Hyslop, Ph.D., Instructor in Ethics, Columbia College, New York, Author of "The Elements of Logic.' Post 8vo, 7s. 6d. net.

\section{IDDESLEIGH.}

Lectures and Essays. By the late EARL of IDDESLEIGH, G.C.B., D.C.L., \&c. Svo, $16 \mathrm{~s}$.

Life, Letters, and Diaries of Sir Stafford Northcote, First Earl of Iddesleigh. By ANDREw LANG. With Three Portraits and a View of Pynes. Third Edition. 2 vols. post Svo, 31s. 6d.

PopUlar Edrtiox. With Portrait and View of Pynes. Post 8vo, 7s. 6d. 
IGNOTUS. The Supremacy and Sufficiency of Jesus Christ, as set forth in the Epistle to the Hebrews. By Ig vorus. Crown 8ro, 3s. 6d.

INDEX GEOGRAPHICUS: Being a List, alphabetically arranged, of the Principal Places on the Globe, with the Conntries and Sabdivisions of the Countries in which they are sitnated, and their Latitudes and Longitudes. Imperial Svo, pp. 676, $21 \mathrm{s.}$

JEAN JAMBON. Our Trip to Blunderland ; or, Grand Excursion to Blundertown and Back. By JEAx JAMBOx. With Sixty Ilustrations designed by Charles Dotle, engraved by Dalziel. Fourth Thousand. Cloth, gilt edges, 6s. 6d. Cheap Edition, cloth, 3s. 6d. Boards, 2s. 6d.

JEBB. A Strange Career. The Life and Adventures of JoHN GLADWYN JEBB. By his Widow. With an Introduction by H. RIDER HAGgaRD, and an Electrogravure Portrait of Mr Jebb. Third Edition. Demy 8vo, 10s.6d.

Cheap Editios. With Illustrations by John Wallace. Crown 8vo, 3s. 6d.

Some Unconventional People. By Mrs GLadwy JebB, Author of 'Life and Adventures of J. G. Jebb.' With Illustrations. Crown sro, 3s. 6d.

JENNINGS. Mr Gladstone: A Study. By Loois J. Jensisgs, M.P., Author of 'Republican Government in the United States,' "The Croker Memoirs,' \&c. Popalar Edition. Crown Svo, 1s.

JERNINGHAM.

Reminiscences of an Attaché. By Hobert E. H. Jerningham. Second Edition. Crown 8 vo, $5 \mathrm{~s}$.

Diane de Breteuille. A Love Story. Crown 8vo, 2s. 6d.

JOHNSTON.

The Chemistry of Common Life. By Professor J. F. W. Johxstox. New Edition, Revised. By Arthur Herbert Church, M.A. Oxon.; Author of 'Food: its Sources, Constituents, and Uses,' \&c. With Mraps and 102 Engravings. Crown $8 v 0,7 s .6 \mathrm{~d}$.

Elements of Agricultural Chemistry. An entirely New Edition from the Edition by Sir Charles A. Camerow, M.D., F.R.C.S.I., \&c. Revised and brought down to date by C. M. AIKMax, M.A., B.Sc., F.R.S.E., Professor of Chemistry, Glasgow Veterinary College. 17th Edition. Crown 8vo, 6s. $6 \mathrm{~d}$.

Catechism of Agricultural Chemistry. An entirely New Edition from the Edition by Sir Charles A. CaMerox. Revised and Enlarged by C. M. AIksas, M.A., \&c. 95th Thousand. With numerous Illustrations. Crown 8vo, is.

JOHNSTON. Agricultural Holdings (Scotland) Acts, 1883 and 1889 ; and the Ground Game Act, 1880. With Notes, and Summary of Procedure, \&c. By Christopher N. Johiston, M.A., Advocate. Demy 8vo, 5 s.

JOKAI. Timar's Two Worlds. By Madrus JokaI. Authorised Translation by Mrs Hegax Kexsard. Cheap Edition. Crown 8vo, 6s.

KEBBEL. The Old and the New : English Country Life. By T. E. KEBBEL, M..A., Author of 'The Agricultural Labourers,' 'Essays in History and Politics,' 'Life of Lord Beaconsfield.' Crown $8 \mathrm{vo}, 5 \mathrm{~s}$.

KERR. St Andrews in 1645-46. By D. R. KerR. Crown sro, 2 s. $6 \mathrm{~d}$.

KINGLAKE.

History of the Invasion of the Crimea. By A. W. KingLake. New Edition, Abridged by Lt.-Colonel Sir George S. Clarke, K.C.Mr.G., R.E. Witl Maps and Plans.

History of the Invasion of the Crimea. By A. W. KINGLAKE. Cabinet Edition, Revised. With an Index to the Complete Work. Illustrated with Maps and Plans. Complete in 9 vols., crown $8 \mathrm{vo}$, at $6 \mathrm{~s}$. each. 
KINGLAKE.

History of the Invasion of the Crimea. Demy 8vo. Vol. VI. Winter Troubles, With a Map, 16s. Vols. VII. and VIII. From the Morrow of Inkerman to the Death of Lord Raglan. With an Index to the Whole Work. With Maps and Plans. 28s.

Eothen. A New Edition, uniform with the Cabinet Edition of the 'History of the Invasion of the Crimea.' $6 \mathrm{~s}$.

CheAPer Edition. With Portrait and Biographical Sketch of the Author. Crown 8vo, 3s. 6d.

KIRBY. In Haunts of Wild Game: A Hunter-Naturalist's Wanderings from Kahlamba to Libombo. By Frederick VAdGHAN KIRBY, F.Z.S. (Maqaqamba). With numerous Illustrations by Charles Whymper, and a Map. Large demy 8 vo, $25 \mathrm{~s}$.

KLEIN. Among the Gods. Scenes of India, with Legends by the Way. By Augusta KLniv. With 22 Full-page Illustrations. Demy 8vo, 15s.

KNEIPP. My Water-Cure. As Tested through more than Thirty Years and Described for the Healing of Diseases and the Preservation of Health. By'Sebastian KNeipP, Parish Priest of Wörishofen (Bavaria). With a Portrait and other Illustrations. Authorised English Translation from the Thirtieth German Edition, by A. de F. Cheap Edition. With an Appendix, con. taining the Latest Developments of Pfarrer Kneipp's System, and a Preface by E. Gerard. Crown 8vo, 3s, 6d.

KNOLLYS. The Elements of Field-Artillery. Designed for the Use of Infantry and Cavalry Officers. By HENRY KNollys, Colonel Royal Artillery; Author of 'From Sedan to Saarbrück,' Editor of 'Incidents in the Sepoy War,' \&c. With Engravings. Crown 8vo, 7s. 6d.

LANG. Life, Letters, and Diaries of Sir Stafford Northcote, First Earl of Iddesleigh. By ANDrew LANG. With Three Portraits and a View of Pynes. Third Edition. 2 vols. post $8 \mathrm{vo}, 31 \mathrm{~s} .6 \mathrm{~d}$.

Popular Edition. With Portrait and View of Pynes. Post 8vo, 7s. 6d.

LEES. A Handbook of the Sheriff and Justice of Peace Small Debt Courts. With Notes, References, and Forms. By J. M. LEes, Advocate, Sheriff of Stirling, Dumbarton, and Clackmannan. $8 \mathrm{vo}, 7 \mathrm{~s} .6 \mathrm{~d}$.

LINDSAY.

Recent Advances in Theistic Philosophy of Religion. By Rev. JAnes Lindsay, M.A., B.D., B.Sc., F.R.S.E., F.G.S., Minister of the Parish of St Andrew's, Kilnnarnock. Deiny svo, 9s.

The Progressiveness of Modern Christian Thought. Crown 8 vo, 6 s.

Essays, Literary and Philosophical. Crown 8vo, 3s. 6d.

LOCKHART.

Doubles and Quits. By Ladrence W. M. Lockhart. New Edition. Crown 8vo, 3s. 6d.

Fair to See. New Edition. Crown 8vo, 3s. 6d.

Mine is Thine. New Edition. Crown 8vo, 3s. 6d.

LOCKHART.

The Church of Scotland in the Thirteenth Century. The Life and Times of David de Bernham of St Andrews (Bishop), A.D. 1239 to 1253. With List of Churches dedicated by him, and Dates. By William Locknart, A.M., D.D., F.S.A. Scot., Minister of Colinton Parish. 2d Edition. 8vo, 6s.

Dies Tristes : Sermons for Seasons of Sorrow. Crown 8vo, 6s. LORIMER.

The Institutes of Law : A Treatise of the Principles of Jurisprudence as determined by Nature. By the late JAMEs Loriser, Professor of Public Law and of the Law of Nature and Nations in the University of Edin. burgh. New Edition, Revised and much Enlarged. 8vo, 18s.

The Institutes of the Law of Nations. A Treatise of the Jural Relation of Separate Political Communities. In 2 vols. 8vo. Volume I., price 16s. Volume II., price $20 \mathrm{~s}$. 
LUGARD. The Rise of our East African Empire : Early Efforts in Uganda and Nyasaland. By F. D. Lugard, Captain Norfolk Regiment. With 130 Illustrations from Drawings and Photographs under the personal superintendence of the Author, and 14 specially prepared Maps. In 2 vols. large demy $8 \mathrm{vo}, 42 \mathrm{~s}$.

\section{M'CHESNEY.}

Miriam Cromwell, Royalist: A Romance of the Great Rebellion. By Dora Greenwell M'Chesney. Crown Svo, 6 s.

Kathleen Clare: Her Book, 1637-41. Edited by Dora GrewsWELL M'ChesNey. With Frontispiece, and five full-page Illustrations by James A. Shearman. Crown $8 v 0,6 \mathrm{~s}$.

M'COMBIE. Cattle and Cattle-Breeders. By Wilitam M'Combie, Tillyfour. New Edition, Enlarged, with Memoir of the Author by JAsES MacdoNald, F.R.S.E., Secretary Highland and Agricultural Society of Scotland. M'CRIE. Crown 8vo, 3s. 6d.

Works of the Rev. Thomas M'Crie, D.D. Uniform Edition. 4 vols. crown $8 v 0,24 \mathrm{~s}$.

Life of John Knox. Crown 8vo, 6s. Another Edition, 3s. 6d.

Life of Andrew Melville. Crown 8vo, 6s.

History of the Progress and Suppression of the Reformation in Italy in the Sixteenth Century. Crown $8 v 0,4 \mathrm{~s}$.

History of the Progress and Suppression of the Reformation in Spain in the Sixteenth Century. Crown 8 vo, 3s. 6 d.

M'CRIE. The Public Worship of Presbyterian Scotland. Historically treated. With copious Notes, Appendices, and Index. The Fourteenth Series of the Cunningham Lectures. By the Rev. Charles G. M'CRIE, D.D. Demy 8vo, 10s. 6d.

MACDONALD. A Manual of the Criminal Law (Scotland) Procedure Act, 1887. By Norman Doran Macdonald. Revised by the Lord JUSTICE-ClERK. Svo, 10s. $6 \mathrm{~d}$.

MACDONALD AND SINCLAIR. History of Polled Aberdeen and Angus Cattle. Giving an Account of the Origin, Improvement, and Charac. teristics of the Breed. By James Macdonald and JAmes Sinclair. Illustrated with numerous Animal Portraits. Post 8vo, 12s. 6d.

MACDOUGALL AND DODDS. A Manual of the Local Government (Scotland) Act, 1894. With Introduction, Explanatory Notes, and Copious Index. By J. PATTEN MACDovgall, Legal Secretary to the Lord Adrocate, and J. M. Dopds. Tenth Thousand, Revised. Crown 8 vo, 2s. 6 d. net.

MACINTYRE. Hindu-Koh : Wanderings and Wild Sports on and beyond the Himalayas. By Major-General Donald Macistyre, V.C., late Prince of Wales' Own Goorkhas, F.R.G.S. Dedicated to H.R.H. The Prince of Wales. New and Cheaper Edition, Revised, with numerous Illustrations. Post 8vo, 3s. 6d.

MACKAY.

A Manual of Modern Geography; Mathematical, Physical, and Political. By the Rev. Alexander MACKay, LL.D., F.R.G.S. 11th Thousand, Revised to the present time. Crown 8vo, pp. 688, 7s. 6d.

Elements of Modern Geography. 55th. Thousand, Revised to the present time. Crown 8 vo, pp. $300,3 \mathrm{~s}$.

The Intermediate Geography. Intended as an Intermediate Book between the Author's 'Outlines of Geography' and 'Elements of Geography.' Eighteenth Edition, Revised. Fcap. 8 vo, pp. 238, 2s.

Outlines of Modern Geography. 191st Thousand, Revised to the present time. Fcap. 8vo, pp. 128, 1s.

Elements of Physiography. New Edition. Rewritten and Enlarged. With numerous Illustrations. Crown Svo. [In the press. 
MACKENZIE. Studies in Roman Law. With Comparative Views of the Laws of France, England, and Scotland. By Lord MACKENziE, one of the Judges of the Court of Session in Scotland. Sixth Edition, Edited by JoHn KirkPatrick, M.A., LL.B., Advocate, Professor of History in the University of Edinburgh. 8vo, 12s.

MACPHERSON. Glimpses of Church and Social Life in the Highlands in Olden Times. By Alexander Macpherson, F.S.A. Scot. With 6 Photogravure Portrảits and other full-page Illustrations. Small 4to, 25s.

M'PHERSON. Golf and Golfers. Past and Present. By J. Gordon M'Prerson, Ph.D., F.R.S.E. With an Introduction by the Right Hon. A. J. Balfour, and a Portrait of the Author. Fcap. 8vo, 1s. 6d.

MACRAE. A Handbook of Deer-Stalking. By Alexander MACRAE, late Forester to Lord Henry Bentinck. With Introduction by Horatio Ross, Esq. Fcap. 8vo, with 2 Photographs from Life. 3s. 6d.

MAIN. Three Hundred English Sonnets. Chosen and Edited by David M. MaIN. New Edition. Feap. 8vo, 3s. 6d.

MAIR. A Digest of Laws and Decisions, Ecclesiastical and Civil, relating to the Constitution, Practice, and Affairs of the Church of Scotland. With Notes and Forms of Procedure. By the Rev. Willias MaIR, D.D., Minister of the Parish of Earlston. New Edition, Revised. Crown 8vo, 9s. net.

MARCHMONT AND THE HUMES OF POLWARTH. By One of their Descendants. With numerous Portraits and other Illustrations. Crown 4to, 21s. net.

MARSHMAN. History of India. From the Earliest Period to the present time. By JoHn Clark Marshmas, C.S.I. Third and Cheaper Edition. Post 8vo, with Map, 6s.

MARTIN.

The Aneid of Virgil. Books I.-VI. Translated by Sir Theodore Martin, K.C.B. Post 8 vo, 6s.

Goethe's Faust. Part I. Translated into English Verse. Second Edition, crown 8vo, 6s. Ninth Edition, feap. 8vo, 3s. 6d.

Goethe's Faust. Part II. Translated into English Verse. Second Edition, Revised. Fcap. 8vo, 6s.

The Works of Horace. Translated into English Verse, with Life and Notes. 2 vols. New Edition. Crown 8vo, 21s.

Poems and Ballads of Heinrich Heine. Done into English Verse. Third Edition. Small crown 8vo, $5 \mathrm{~s}$.

The Song of the Bell, and other Translations from Schiller, Goethe, Uhland, and Others. Crown 8vo, 7s. $6 \mathrm{~d}$.

Madonna Pia: A Tragedy; and Three Other Dramas. Crown 8vo, 7s. 6d.

Catullus. With Life and Notes. Second Edition, Revised and Corrected. Post 8vo, 7s. $6 \mathrm{~d}$.

The 'Vita Nuova' of Dante. Translated, with an Introduction and Notes. Third Edition. Small crown $8 v 0,5 \mathrm{~s}$.

Aladdin: A Dramatic Poem. By Adam Oenlenschlakger. Fcap. 8vo, 5 s.

Correggio: A Tragedy. By Oenlenschlateger. With Notes. Fcap. 8vo, 3s.

MARTIN. On some of Shakespeare's Female Characters. By Helena Faucit, Lady M.ARtix. Dedicated by permission to Her Most Gracious Majesty the Queen. Fifth Edition. With a Portrait by Lehmann. Demy 8vo, 7s. 6d.

MARWICK. Observations on the Law and Practice in regard to Municipal Elections and the Conduct of the Business of Town Councils and Commissioners of Police in Scotland. By Sir James D. Marwick; LL.D., Town-Clerk of Glasgow. Royal 8vo, 30s. 


\section{MATHESON.}

Can the Old Faith Live with the New? or, The Problem of Evolution and Revelation. By the Rev. GeorGe Mathesor, D.D. Third Edition. Crown 8vo, 7s. 6d.

The Psalmist and the Scientist ; or, Modern Value of the Religious Sentiment. Third Edition. Crown $8 \mathrm{vo}, 5 \mathrm{~s}$.

Spiritual Development of St Paul. Third Edition. Cr. 8 vo, $5 \mathrm{~s}$.

The Distinctive Messages of the Old Religions. Second Editíon. Crown $8 \mathrm{vo}, 5 \mathrm{~s}$.

Sacred Songs. New and Cheaper Edition. Crown 8vo, 2s. 6d. MAURICE. The Balance of Military Power in Europe. An Examination of the War Resources of Great Britain and the Continental States. By Colonel Madrice, R.A., Professor of Military Art and History at the Royal Staff College. Crown 8vo, with a Map, 6s.

MAXWELL.

A Duke of Britain. A Romance of the Fourth Century. By Sir Herbert MaXwelt, Bart., M.P., F.S.A., \&c., Anthor of 'Passages in the Life of Sir Lucian Elphin.' Fourth Edition. Crown 8vo, 6s.

Life and Times of the Rt. Hon. William Henry Smith, M.P. With Portraits and numerons Mlustrations by Herbert Railton, G. L. Seymour, and Others. 2 vols. demy 8 ro, $25 \mathrm{~s}$.

Popular EDIrion. With \& Portrait and other Illnstrations. Crown 8vo, 3s. 6d.

Scottish Land-Names: Their Origin and Meaning. Being the Rhind Lectures in Archrology for 1893. Post 8vo, 6s.

Meridiana: Noontide Essays. Post 8vo, 7s. 6d.

Post Meridiana: Afternoon Essays. Post 8vo, 6s.

Dumfries and Galloway. Being one of the Volumes of the County Histories of Scotland. With Two Maps. Demy 8 ro, is. 6d. net.

MELDRUM.

The Story of Margrédel : Being a Fireside History of a Fifeshire Family. By D. Storrar. MeldrUdr. Cheap Edition. Crown 8vo, 3s. 6d.

Grey Mantle and Gold Fringe. Crown 8vo, 6s.

MERZ. A History of European Thought in the Nineteenth Century. By JoHs Theodore MERz. Vol. I., post 8 ro.

[Immediately.

MICHEL. A Critical Inquiry into the Scottish Language. With the view of Illustrating the Rise and Progress of Civilisation in Scotland. By FrANCISQUE-MICHEL, F.S.A. Lond. and Scot., Correspondant de l'Institut de France, \&c. 4to, printed on hand-made paper, and bonnd in roxburghe, $66 \mathrm{~s}$.

MICHIE.

The Larch: Being a Practical Treatise on its Culture and General Management. By Caristopher Y. Michis, Forester, Cullen House. Crown 8vo, with Illustrations. New and Cheaper Edition, Enlarged, 5s.

The Practice of Forestry. Crown 8vo, with Illustrations. 6s.

MIDDLETON. The Story of Alastair Bhan Comyn; or, The Tragedy of Dunphail. A Tale of Tradition and Romance. By the Lady MIDDLETos. Sqnare 8vo, 10s. Cheaper Edition, $5 \mathrm{~s}$.

MILLER. The Story of Mr H-, the Herbalist. By HugH MILLER, F.R.S.E., late H.M. Geological Surrey, Author of 'Landscape Geology.' MINTO. With a Photogravure Frontispiece. Crown Svo, 2s. 6d.

A Manual of English Prose Literature, Biographical and Critical: designed mainly to show Characteristics of Style. By W. MrsTo, M.A., Hon. LL.D. of St Andrews; Professor of Logic in the University of Aberdeen. Third Edition, Revised. Crown 8vo, 7s. 6d.

Characteristics of English Poets, from Chaucer to Shirley. New Edition, Revised. Crown 8vo, 7s. 6d.

Plain Principles of Prose Composition. Crown 8vo, 1s. 6d. 
MINTO.

The Literature of the Georgian Era. Edited, with a Biographical Introduction, by Professor Knight, St Andrews. Post 8vo, 6s.

MOIR. Life of Mansie Wauch, Tailor in Dalkeith. By D. M. MoIr. With CrUikshask's Illustrations. Cheaper Edition. Crown 8vo, 2s. 6d. Another Edition, without Illustrations, fcap. 8ro, 1s. 6d.

MOLE. For the Sake of a Slandered Woman. By Marion Mole. Fcap. 8vo, 2s. 6d. net.

MOMERIE.

Defects of Modern Christianity, and other Sermons. By AlFred Williams Momerie, M.A., D.Sc., LL.D. Fifth Edition. Crown $8 \mathrm{vo}, 5 \mathrm{~s}$.

The Basis of Religion. Being an Examination of Natural Religion. Third Edition. Crown 8vo, 2s. 6d.

The Origin of Evil, and other Sermons. Eighth Edition, Enlarged. Crown 8vo, 5 s.

Personality. The Beginning and End of Metaphysics, and a Necessary Assumption in all Positive Philosophy. Fifth Edition, Revised. Crown 8vo, 3s.

Agnosticism. Fourth Edition, Revised. Crown 8vo, 5s.

Preaching and Hearing; and other Sermons. Fourth Edition, Enlarged. Crown 8vo, 5s.

Belief in God. Third Edition. Crown 8vo, 3s. Inspiration; and other Sermons. Second Edition, Enlarged.

Church and Creed. Third Edition. Crown 8vo, 4s. 6d.

The Future of Religion, and other Essays. Second Edition. Crown 8vo, 3s. 6d.

MONCREIFF.

The Provost-Marshal. A Romance of the Middle Shires. By the Hon. Frederick Movcreiff. Crown Svo, 6 s.

The X Jewel. A Romance of the Days of James VI. Crown 8vo, 6s.

MONTAGUE. Military Topography. Illustrated by Practical Examples of a Practical Subject. By Major-General W. E. Montague, C.B., P.S.C., late Garrison Instructor Intelligence Department, Author of 'Campaign' ing in 'South Africa.' With Forty-one Diagrams. Crown $8 v 0,5 \mathrm{~s}$.

MONTALEMBERT. Memoir of Count de Montalembert. A Chapter of Recent French History. By Mrs OLiphant, Author of the 'Life of Ed ward Irving,' \&c. 2 vols. crown 8 vo, £1, 4 s.

MORISON.

Doorside Ditties. By Jeanie Morison. With a Frontispiece. Crown 8vo, 3s. 6d.

Eolus. A Romance in Lyrics. Crown 8vo, 3s.

There as Here. Crown 8vo, 3s. ${ }^{*}{ }^{*}$ A limited impression on hand-made paper, bound in vellum, 7s. $6 d$.

Selections from Poems. Crown 8vo, 4s. 6d.

Sordello. An Outline Analysis of $\mathrm{Mr}$ Browning's Poem. Crown 8vo, $3 \mathrm{~s}$.

Of "Fifine at the Fair," "Christmas Eve and Easter Day," and other of Mr Browning's Poems. Crown 8vo, 3s.

The Purpose of the Ages. Crown 8vo, 9s.

Gordon : An Our-day Idyll. Crown 8vo, 3s.

Saint Isadora, and other Poems. Crown 8vo, 1s. 6d.

Snatches of Song. Paper, 1s. 6d. ; cloth, 3s.

Pontius Pilate. Paper, 1s. 6d. ; cloth, 3s. 
MORISON.

Mill o' Forres. Crown 8vo, 1 s.

Ane Booke of Ballades. Fcap. 4to, 1s.

MOZLEY. Essays from 'Blackwood.' By the late ANNe MozLeY, Author of 'Essays on Social Subjects'; Editor of 'The Letters and Correspondence of Cardinal Newman,' 'Letters of the Rev. J. B. Mozley,' \&c. With a Memoir by her Sister, Fanny Mozley. Post 8vo, 7s. 6d.

MUNRO. The Lost Pibroch, and other Sheiling Stories. By Neil Munro. Crown 8vo, 6s.

MUNRO. Rambles and Studies in Bosnia-Herzegovina and Dalmatia. With an Account of the Proceedings of the Congress of Archæologists and Anthropologists held at Sarajevo in 1894. By RoBERT MUNRo, M.A., M.D., F.R.S.E., Author of 'The Iake-Dwellings of Europc,' \&c. With numerous Illustrations. Demy 8vo, 12s. 6d. net.

MUNRO. On Valuation of Property. By William Munro, M.A., Her Majesty's Assessor of Railways and Canals for Scotland. Second Edition, Revised and Enlarged. 8vo, 3s. 6 d.

MURDOCH. Manual of the Law of Insolvency and Bankruptcy : Comprehending a Summary of the Law of Insolvency, Notour Bankruptcy, Composition-Contracts, Trust-Deeds, Cessios, and Sequestrations; and the Winding-up of Joint-Stock Companies in Scotland; with Annotations on the various Insolvency and Bankruptey Statutes; and with Forms of Procedure applicable to these Subjects. By James Murdoch, Member of the Faculty of Procurators in Glasgow. Fifth Edition, Revised and Enlarged. 8vo, 12s, net.

MY TRIVIAL LIFE AND MISFORTUNE: A Gossip with no Plot in Particular. By A Plain Woman. Cheap Edition. Crown 8vo, 3s. 6d. By the Same Author.

POOR NELLIE. Cheap Edition. Crown 8vo, 3s. 6d.

MY WEATHER-WISE COMPANION. Presented by B. T. Fcap. Svo, Is. net.

NAPIER. The Construction of the Wonderful Canon of Logarithms. By JoHN NAPIER of Merchiston. Translated, with Notes, and a Catalogue of Napier's Works, by WilliaM RaE MacdoNald. Small 4to, I5s. A few large-paper copies on Whatman paper, 30s.

NEAVES. Songs and Verses, Social and Scientific. By An Old Contributor to 'Mraga.' By the Hon. Lord NEAvEs. Fifth Edition. Fcap. $8 \mathrm{vo}, 4 \mathrm{~s}$.

NICHOLSON.

A Manual of Zoology, for the Use of Students. With a General Introduction on the Principles of Zoology. By HeNRY ALLEYxE NICHoLSON, M.D., D.SC., F.L.S., F.G.S., Regius Professor of Natural History in the University of Aberdeen. Seventh Edition, Rewritten and Enlarged. Post 8 vo, pp. 956, with 555 Engravings on Wood, 18s.

Text-Book of Zoology, for Junior Students. Fifth Edition, Rewritten and Enlarged. Crown 8vo, with 358 Engravings on Wood, 10s. 6d.

Introductory Text-Book of Zoology, for the Use of Junior Classes. Sixth Edition, Revised and Enlarged, with 166 Engravings, 3s.

Outlines of Natural History, for Beginners: being Descriptions of a Progressive Series of Zoological Types. Third Edition, with Engravings, 1s. 6d.

A Manual of Palæontology, for the Use of Students. With a General Introduction on the Principles of Palæontology. By Professor H. Alleyse Nicholson and Richard LYDEkKER, B.A. Third Edition, entirely Rewritten and greatly Enlarged. 2 vols. 8 vo, $£ 3,3$ s.

The Ancient Life-History of the Earth. An Outline of the Principles and Leading Facts of Palæontological Science. Crown 8vo, with 276 Engravings, 10s. 6d. 
NICHOLSON.

On the "Tabulate Corals" of the Palæozoic Period, with Critical Descriptions of Illustrative Species. Illustrated with 15 Lithographed Plates and numerous Engravings. Super-royal 8vo, 21s.

Synopsis of the Classification of the Animal Kingdom. 8vo, with 106 Illustrations, 6s.

On the Structure and Affinities of the Genus Monticulipora and its Sub-Genera, with Critical Descriptions of Illustrative Species. Illustrated with numerous Engravings on Wood and Lithographed Plates. Super-royal 8vo, 18s.

NICHOLSON.

Thoth. A Romance. By Joseph ShIEld Nicholson, M.A., D.Sc., Professor of Commercial and Political Economy and Mercantile Law in the University of Edinburgh. Third Edition. Crown 8vo, 4s. 6d.

A Dreamer of Dreams. A Modern Romance. Second Edition. Crown 8vo, 6s.

NICOLSON AND MURE. A Handbook to the Local Government (Scotland) Act, 1889. With Introduction, Explanatory Notes, and Index. By J. Badenach Nicolson, Advocate, Counsel to the Scotch Education Department, and W. J. MurE, Advocate, Legal Secretary to the Lord Advocate for Scotland. Ninth Reprint. $8 v 0,5 \mathrm{~s}$.

OLIPHANT.

Masollam: A Problem of the Period. A Novel. By Ladrexce OLIPHANT. 3 vols. post 8 vo, 25s. $6 \mathrm{~d}$.

Scientific Religion; or, Higher Possibilities of Life and Practice through the Operation of Natural Forces. Second Edition. 8vo, 16s.

Altiora Peto. Cheap Edition. Crown 8vo, boards, 2s. 6d. ; cloth, 3s. 6d. Illustrated Edition. Crown 8vo, cloth, 6s.

Piccadilly. With Illustrations by Richard Doyle. New Edition, 3s. 6d. Cheap Edition, boards, 2s. 6d.

Traits and Travesties; Social and Political. Post 8vo, 10s. 6d. Episodes in a Life of Adventure; or, Moss from a Rolling Stone. Cheaper Edition. Post 8vo, 3s. 6d.

Haifa: Life in Modern Palestine. Second Edition. 8vo, 7s. 6d. The Land of Gilead. With Excursions in the Lebanon. With Illustrations and Maps. Demy 8vo, 21s.

Memoir of the Life of Laurence Oliphant, and of Alice Oliphant, his Wife. By Mrs M. O. W. OLIPHANT. Seventh Edition. 2 vols. post $8 v o$, with Portraits. 21 .

Popular Edition. With a New Preface. Post 8vo, with Portraits. 7s. 6d.

OLIPHANT.

Who was Lost and is Found. By Mrs Oliphant. Second Edition. Crown 8vo, 6s.

Miss Marjoribanks. New Edition. Crown 8vo, 3s. 6d.

The Perpetual Curate, and The Rector. New Edition. Crown 8vo, $3 \mathrm{~s} .6 \mathrm{~d}$.

Salem Chapel, and The Doctor's Family. New Edition. Crown 8vo, 3s. 6d.

Katie Stewart, and other Stories. New Edition. Crown 8vo, cloth, 3s. 6d.

Katie Stewart. Illustrated boards, 2s. 6d.

Valentine and his Brother. New Edition. Crown 8vo, 3s. 6d.

Sons and Daughters. Crown 8vo, 3s. $6 \mathrm{~d}$.

Two Stories of the Seen and the Unseen. The Open Door -Old Lady Mary. Paper covers, 1s. 
OLIPHANT. Notes of a Pilgrimage to Jerusalem and the Holy Land. By F. R. OLlphast. Crown 8vo, 3s. 6 d.

OSWALD. By Fell and Fjord; or, Scenes and Studies in Iceland. By E. J. OswaLD. Post 8vo, with Illustrations. 7s. 6d.

PAGE.

Introductory Text-Book of Geology. By David PAGE, LL.D., Professor of Geology in the Durham University of Physical Science, Newcastle. With Engravings and Glossarial Index. New Edition, Revised by Professor LAPWORTH of Mason Science College, Birmingham.

[In preparation.

Advanced Text-Book of Geology, Descriptive and Industrial. With Engravings, and Glossary of Scientific Terms. New Edition. Revised by Professor LAPWORTH. IIn preparation.

Introductory Text-Book of Physical Geography. With SketchMaps and Illustrations. Edited by Professor LapwortH, LL.D., F.G.S., \&c., Mason Science College, Birmingham. Thirteenth Edition, Revised arłd Enlarged. 2s. $6 \mathrm{~d}$.

Advanced Text-Book of Physical Geography. Third Edition. PATON. Revised and Enlarged by Professor LAPWORTH, With Engravings. 5s.

Spindrift. By Sir J. Noel Paton. Fcap., cloth, 5s.

Poems by a Painter. Fcap., cloth, 5s.

PATON. Body and Soul. A Romance in Transcendental Pathology. By Frederick Noel PatoN. Third Edition. Crown 8vo, 1s.

PATRICK. The Apology of Origen in Reply to Celsus. A Chapter in the History of Apologetics. By the Rev. J. PATRICK, D.D. Post 8vo, 7s. $6 \mathrm{~d}$.

PAUL. History of the Royal Company of Archers, the Queen's Body-Guard for Scotland. BY JAMES BALFOUR PAUL, Advocate of the Scottish Bar. Crown 4to, with Portraits and other Illustrations. £2, 2s.

PEILE. Lawn Tennis as a Game of Skill. By Lieut.-Col. S. C. F. PEILE, B.S.C. Revised Edition, with new Scoring Rules. Fcap. Svo, cloth, 1s.

PETTIGREW. The Handy Book of Bees, and their Profitable Management. By A. PetriGrew. Fifth Edition, Enlarged, with Engravings. Crown 8vo, 3s. 6d.

PFLEIDERER. Philosophy and Development of Religion. Being the Edinburgh Gifford Lectures for 1894. By OTTo PFLEIDERER, D.D. Professor of Theology at Berlin University. In 2 vols. post $8 \mathrm{vo}$, 15s. net.

PHILOSOPHICAL CLASSICS FOR ENGLISH READERS. Edited by Willias Kright, LL.D., Professor of Moral Philosophy, University of St Andrews. In crown 8vo volumes, with Portraits, price 3s. 6d.

[For List of Volumes, see page 2.

POLLARD. A Study in Municipal Government: The Corporation of Berlin. By JaMes Pollard, C.A., Chairman of the Edinburgh Public Health Committee, and Secretary of the Edinburgh Chamber of Commerce. Second Edition, Revised. Crown 8vo, 3s. 6d.

POLLOK. The Course of Time: A Poem. By Robert Pollok, A.N. Cottage Edition, 32mo, 8d. The Same, cloth, gilt edges, 1s. $6 \mathrm{~d}$. Another Edition, with Illustrations by Birket Foster and others, fcap., cloth, 3s. 6d., or with edges gilt, 4s.

PORT ROYAL LOGIC. Translated from the French; with Introduction, Notes, and Appendix. By THomas SPENcER BAyNes, LL.D., Professor in the University of St Andrews. Tenth Edition, 12mo, 4s.

POTTS AND DARNELL.

Aditus Faciliores: An Easy Latin Construing Book, with Complete Vocabulary By A. W. PotTs, M.A., LL. D., and the Rev. C. DARsele, M.A., Head-Master of Cargilfield Preparatory School Edinburgh. Tenth Edition, feap. $8 v 0,3 s .6 d$. 
POTTS AND DARNELL.

Aditus Faciliores Graeci. An Easy Greek Construing Book, with Complete Vocabulary. Fifth Edition, Revised. Fcap. 8vo, 3s.

POTTS. School Sermons. By the late Alexander Wm. Potts, LL.D., First Head-Master of Fettes College. With a Memoir and Portrait. Crown 8vo, 7s. 6d.

PRINGLE. The Live Stock of the Farm. By Robert O. Pringle. Third Edition. Revised and Edited by James Macdonald. Crown 8vo, 7s. 6d.

PRYDE. Pleasant Memories of a Busy Life. By David Pryde, M.A., LL. D., Author of 'Highways of Literature,' 'Great Men in European History, 'Biographical Outlines of English Literature,' \&c. With a Mezzotint Portrait. Post 8 vo, 6 s.

PUBLIC GENERAL STATUTES AFFECTING SCOTLAND from 1707 to 1847 , with Chronological Table and Index. 3 vols. large 8 vo, $£ 3,3 \mathrm{~s}$.

PUBLIC GENERAL STATUTES AFFECTING SCOTLAND, COLLECTION OF. Published Annually, with General Index.

RAE. The Syrian Church in India. By George Mrlne Rae, M.A., D.D., Fellow of the University of Madras; late Professor in the Madras Christian College. With 6 full-page Illustrations. Post 8 vo, 10s. $6 \mathrm{~d}$.

RAMSAY. Scotland and Scotsmen in the Eighteenth Century. Edited from the MSS. of JoHN RAMSAx, Esq. of Ochtertyre, by Ar.exander AllaRdyce, Author of 'Memoir of Admiral Lord Keith, K.B.,' \&c. 2 vols. $8 \mathrm{vo}, 31 \mathrm{s.} 6 \mathrm{~d}$.

RANKIN.

A Handbook of the Church of Scotland. By JAMEs Rankin, D.D., Minister of Muthill; Author of 'Character Studies in the Old Testament,' \&c. An entirely New and much Enlarged Edition. Crown 8vo, with 2 Maps, 7s. $6 \mathrm{~d}$.

The First Saints. Post 8vo, 7s. 6d.

The Creed in Scotland. An Exposition of the Apostles Creed. With Extracts from Archbishop Hamilton's Catechism of 1552, John Calvin's Catechism of 1556, and a Catena of Ancient Latin and other Hymns. Post 8vo, 7s. 6d.

The Worthy Communicant. A Guide to the Devout Observance of the Lord's Supper. Limp cloth, 1s. 3d.

The Young Churchman. Lessons on the Creed, the Commandments, the Means of Grace, and the Church. Limp cloth, 1s. 3d.

First Communion Lessons. 25th Edition. Paper Cover, 2d.

RANKINE. A Hero of the Dark Continent. Memoir of Rev. Wm. Affleck Scott, M.A., M.B., C.M., Cluurch of Scotland Missionary at Blantyre, British Central Africa. By W. Hexry Rankine, B.D., Minister at St Boswells. With a Portrait and other Illustrations. Crown 5 vo, $5 \mathrm{~s}$.

RECORDS OF THE TERCENTENARY FESTIVAL OF THE UNIVERSITY OF EDINBURGH. Celebrated in April 1884. Published under the Sanction of the Senatus Academicus. Large 4to, £2, 12s. 6 d.

ROBERTSON. The Early Religion of Israel. As set forth by Biblical Writers and Modern Critical Historians. Being the Baird Lecture for 1888-89. By James RoBertson, D.D., Professor of Oriental Languages in the University of Glasgow. Fourth Edition. Crown 8vo, 10s. 6d.

ROBERTSON.

Orellana, and other Poems. By J. Logie RoBertson, MI.A. Fcap. 8vo. Printed on hand-made paper. 6s.

A History of English Literature. For Secondary Schools. With an Introduction by Professor MAssos, Edinburgh University. Cr. 8vo, 3s. 
ROBERTSON.

English Verse for Junior Classes. In Two Parts. Part I.Chancer to Coleridge. Part II. -Nineteenth Century Poets. Crown 8vo, each 1s. 6 d. net.

ROBERTSON. Our Holiday among the Hills. By JAMES and JANET Logie Robertson. Fcap. 8vo, 3s. 6d.

ROBERTSON. Essays and Sermons. By the late W. Robertsov, B.D., Minister of the Parish of Sprouston. With a Memoir and Portrait. Crown 8vo, 5s. 6d.

RODGER. Aberdeen Doctors at Home and Abroad. The Story of a Medical School. By ELLA Hill BUrton Rodger. Demy 8vo, 10s. 6d.

ROSCOE. Rambles with a Fishing-Rod. By E. S. Roscoe. Crown 8vo, 4s. 6d.

ROSS AND SOMERVILLE. Beggars on Horseback: A Riding Tour in North Wales. By Martis Ross and E. E. Somerville. With Illustra. tions by E. CE. Somervilile. Crown 8vo, 3s. $6 \mathrm{~d}$.

RUTLAND.

Notes of an Trish Tour in 1846. By the Duke of Rotland, G.C.B. (Lord Johs MAnners). New Edition. Crown 8vo, 2s. 6d.

Correspondence between the Right Honble. William Pitt and Charles Duke of Rutland, Lord-Lieutenant of Ireland, 1781-1787. With Introductory Note by JoHN Duke of RUTLAND. 8vo, 7s. $6 \mathrm{~d}$.

RUTLAND.

Gems of German Poetry. Translated by the Duchess of Rutland (Lady John Manners). [New Edition in preparation.

Impressions of Bad-Homburg. Comprising a Short Account of the Women's Associations of Germany under the Red Cross. Crown 8vo, 1s. 6d.

Some Personal Recollections of the Later Years of the Earl of Beaconsfield, K.G. Sixth Edition. 6 d.

Employment of Women in the Public Service. 6d.

Some of the Advantages of Easily Accessible Reading and Recreation Rooms and Free Libraries. With Remarks on Starting and Main. taining them. Second Edition. Crown 8vo, 1s.

A Sequel to Rich Men's Dwellings, and other Occasional Papers. Crown 8vo, 2s. 6d.

Encouraging Experiences of Reading and Recreation Rooms, Aims of Guilds, Nottingham Social Guide, Existing Institutions, \&c., \&c. Crown 8vo, 1 s.

SAINTSBURY. The Flourishing of Romance and the Rise of Allegory (12th and 13th Centuries). By GEorge SaInTsBury, M.A., Professor of Rhetoric and English Literature in Edinburgh University. Being the first volume issued of "Periods of European Literature." Edited by Professor Saintshury. Crown Svo, 3s. 6d.

SALMON. Songs of a Heart's Surrender, and other Verse. By Arthur L. Salmon. Fcap. 8vo, 2s.

SCHEFFEL. The Trumpeter. A Romance of the Rhine. By Joseph Victor voN Scherfel. Translated from the Two Hundredth German Edition by JESSIE BeCK and LouISA LORIMER. With an Introduction by Sir Theodore Martin, K.C.B. Long 8vo, 3s. 6d.

SCHILLER. Wallenstein. A Dramatic Poem. By FrIEdrICH voN Schiller. Translated by C. G. N. Lockhart. Fcap. 8vo, 7s. 6d.

SCOTT. Tom Cringle's Log. By Michael Scott. New Edition. With 19 Full-page Illustrations. Crown 8vo, 3s. 6d.

SCOUGAL. Prisons and their Inmates; or, Scenes from a Silent World. By Francis ScovgaL. Crown 8vo, boards, 2s. 
SELKIRK. Poems. By J. B. Selkirk, Author of 'Ethics and Esthetics of Modern Poetry,' 'Bible Truths with Shakespearian Parallels,' \&c. Crown 8 vo, printed on antique paper, $6 \mathrm{~s}$.

SELLAR'S Manual of the Acts relating to Education in Scotland. By J. EDward Graha 1 , B.A. Oxon., Advocate. Ninth Edition. Demy $8 \mathrm{vo}, 12 \mathrm{~s} .6 \mathrm{~d}$.

SETH.

Scottish Philosophy. A Comparison of the Scottish and German Answers to Hume. Balfour Philosophical Lectures, University of Edinburgh. By ANDREW SETH, LL.D., Professor of Logic and Metaphysics in Edinburgh University. Second Edition. Crown 8vo, 5s.

Hegelianism and Personality. Balfour Philosophical Lectures. Second Series. Second Edition. Crown 8vo, $5 \mathrm{~s}$.

SETH. A Study of Ethical Principles. By James Seth, M.A., Professor of Philosophy in Cornell University, U.S.A. Second Edition, Revised. Post 8vo, 10s, 6d. net.

SHADWELL. The Life of Colin Campbell, Lord Clyde. Illustrated by Extracts from his Diary and Correspondence. By Lieutenant-General Shadwell, C.B. With Portrait, Maps, and Plans. 2 vols. 8 vo, $36 \mathrm{~s}$.

SHAND.

The Life of General Sir Edward Bruce Hamley, K.C.B., K.C.M.G. By Alex. INNes Shand, Author of 'Kilcarra,' 'Against Time,' \&c.. With two Photogravure Portraits and other Illustrations. Cheaper Edition, with a Statement by Mr Edward Hamley. 2 vols. demy 8 vo, 10s. 6d.

Half a Century; or, Changes in Men and Manners. Second Edition. 8vo, 12s, 6d.

Letters from the West of Ireland. Reprinted from the 'Times.' Crown 8vo, $5 \mathrm{~s}$.

SHARPE. Letters from and to Charles Kirkpatrick Sharpe. Edited by Alexander Allardyce, Author of 'Memoir of Admiral Lord Keith, K.B.,' \&c. With a Memoir by the Rev. W. K. R. BEDFord. In 2 vols. 8vo. Illustrated with Etchings and other Engravings. $£ 2,12 \mathrm{~s} .6 \mathrm{~d}$.

SIM. Margaret Sim's Cookery. With an Introduction by L. B. WALFORD, Author of 'Mr Smith: A Part of his Life', \&c. Crown 8vo, 5s.

SIMPSON. The Wild Rabbit in a New Aspect; or, RabbitWarrens that Pay. A book for Landowners, Sportsmen, Land Agents, Farmers, Gamekeepers, and Allotment Holders. A Record of Recent Experiments con. ducted on the Estate of the Right Hon. the Earl of Wharncliffe at Wortley Hall. By J. Snipsox. Second Edition, Enlarged. Small crown 8vo, 5s.

SKELTON.

The Table-Talk of Shirley. By John Skelton, Advocate, C.B., LL.D., Author of 'The Essays of Shirley.' With a Frontispiece. Sixth Edition, Revised and Enlarged. Post 8vo, 7s. 6d.

The Table-Talk of Shirley. Second Series. Summers and Winters at Balmawhapple. With Illustrations. Two Volumes. Post Svo, 10s. net.

Maitland of Lethington; and the Scotland of Mary Stuart. A History. Limited Edition, with Portraits. Demy 8vo, 2 vols., 28s. net.

The Handbook of Public Health. A Complete Edition of the Public Health and other Sanitary Acts relating to Scotland. Annotated, and with the Rules, Instructions, and Decisions of the Board of Supervision brought up to date with relative forms. Second Edition. With Introduction, containing the Administration of the Public Health Act in Counties. 8vo, 8s. 6d.

The Local Government (Scotland) Act in Relation to Public Health. A Handy Guide for County and District Councillors, Medical Officers, Sanitary Inspectors, and Members of Parochial Boards. Second Edition. With a new Preface on appointment of Sanitary Officers. Crown 8vo, 2s. 
SKRINE. Columba: A Drama. By John Hontley Skrine, Warden of Glenalmond ; Author of 'A Memory of Edward Thring.' Fcap. 4to, 6s.

SMITH.

Thorndale ; or, The Conflict of Opinions. By William Smith, Author of 'A Discourse on Ethics,' \&c. New Edition. Crown 8vo, 10s. 6d.

Gravenhurst; or, Thoughts on Good and Evil. Second Edition. With Memoir and Portrait of the Author. Crown 8vo, 8s.

The Story of William and Lucy Smith. Edited by GEorge Merriam. Large post 8vo, 12s. 6d.

SMITH. Memoir of the Families of M'Combie and Thoms, originally $M^{\prime}$ Intosh and $M^{\prime}$ Thomas. Compiled from History and Tradition. By WILLIAM M'CoyBIE SMITH. With Illustrations. 8vo, 7s. 6d.

SMITH. Greek Testament Lessons for Colleges, Schools, and Private Students, consisting chiefly of the Sermon on the Mount and the Parables of our Lord. With Notes and Essays. By the Rev. J. Hunter SMith, M.A., King Edward's School, Birmingham. Crown 8vo, 6s.

SMITH. The Secretary for Scotland. Being a Statement of the Powers and Duties of the new Scottish Office. With a Short Historical Introduction, and numerous references to important Administrative Documents. By W. С. SмIтн, LL.B., Advocate. 8vo, $6 \mathrm{~s}$.

"SON OF THE MARSHES, A."

From Spring to Fall; or, When Life Stirs. By "A Sox of THE Marshes." Cheap Úniform Edition. Crown \&vo, 3s. 6d.

Within an Hour of London Town: Among Wild Birds and their Haunts. Edited by J. A. OwEs. Cheap Uniform Edition. Crown 8vo, 3s. $6 \mathrm{~d}$.

With the Woodlanders and by the Tide. Cheap Uniform Edition. Crown $8 v 0,3 s .6$ d.

On Surrey Hills. Cheap Uniform Edition. Crown 8vo, 3s. 6d.

Annals of a Fishing Village. Cheap Uniform Edition. Crown 8vo, 3s. $6 \mathrm{~d}$.

SORLEY. The Ethics of Naturalism. Being the Shaw Fellowship Lectures, 1884. By W. R. Sorley, M.A., Fellow of Trinity College, Cam. bridge, Professor of Moral Philosophy in the University of Aberdeen. Crown $8 \mathrm{vo}, 6 \mathrm{~s}$.

SPEEDY. Sport in the Highlands and Lowlands of Scotland with Rod and Gun. By ToM SpEeDy. Second Edition, Revised and Enlarged. With Illustrations by Lieut.-General Hope Crealocke, C.B., C.M.G., and others. $8 \mathrm{vo}, 15 \mathrm{~s}$.

SPROTT. The Worship and Offices of the Church of Scotland. By George W. SprotT, D.D., Minister of North Berwick. Crown Svo, 6s.

STATISTICAL ACCOUNT OF SCOTLAND. Complete, with Index. 15 vols. $8 \mathrm{vo}, £ 16,16 \mathrm{~s}$.

STEPHENS.

The Book of the Farm ; detailing the Labours of the Farmer, Farm-Steward, Ploughman, Shepherd, Hedger, Farm-Labourer, Field-Worker, and Cattle-man. Illustrated with numerous Portraits of Animals and Engravings of Implements, and Plans of Farm Buildings. Fourth Edition. Revised, and in great part Rewritten by James MAcDonALD, F.R.S.E., Secretary Highland and Agricultural Society of Scotland. Complete in Six Divisional Volumes, bound in cloth, each 10s. 6d., or handsomely bound, in 3 volumes, with leather back and gilt top, $£ 3,3 \mathrm{~s}$.

Catechism of Practical Agriculture. 22d Thousand. Revised by James MACDoNaLD, F.R.S.E. With numerous Illustrations, Crown 8vo, 1s.

The Book of Farm Implements and Machines. By J. Suight and R. Scotr Burx, Engineers. Edited by HeNry StEphexs. Large 8vo, £2, 2s. 
STEVENSON. British Fungi. (Hymenomycetes.) By Rev. JoHN STEveNson, Author of 'Mycologia Scotica,' Hon. Sec. Cryptogamic Society of Scotland. Vols. I. and II., post 8vo, with Illustrations, price 12s. $6 \mathrm{~d}$. net each.

STEWART. Advice to Purchasers of Horses. Вy ЈонN Stewart, V.S. New Edition. 2s. 6d.

STEWART. Boethius: An Essay. By Hugh Fraser S'Tewart, M.A., Trinity College, Cambridge. Crown 8vo, 7s. $6 \mathrm{~d}$.

STODDART. Angling Songs. By Thomas Tod Stoddart. New Edition, with a Memoir by ANva M. StodDART. Crown 8vo, 7s. 6d.

STODDART.

John Stuart Blackie: A Biography. By Arsa M. Stoddart. With 3 Plates. Third Edition. 2 vols. deiny 8 vo, $21 \mathrm{~s}$.

Popular Edirion, with Portrait. Crown $8 v 0 ; 6 s$.

Sir Philip Sidney : Servant of God. Illustrated by MARgareT L. Hugorss. With a New Portrait of Sir Philip Sidney. Small 4to, with a specially designed Cover. $5 \mathrm{~s}$.

STORMONTH.

Dictionary of the English Language, Pronouncing, Etymological, and Explanatory. By the Rev. JAMES Stormonth. Revised by the Rev. P. H. Phelp. Library Edition. New and Cheaper Edition, with Supplement. Imperial $8 v o$, handsomely bound in half morocco, 18s. net.

Etymological and Pronouncing Dictionary of the English Language. Including a very Copious Selection of Scientific Terms. For use in Schools and Colleges, and as a Book of General Reference. The Pronunciation carefully revised by the Rev. P. H. PHELP, M.A. Cantab. Thirteenth Edition, with Supplement. Crown 8vo, pp. 800. 7s. 6d.

The School Etymological Dictionary and Word-Book. New Edition, Revised.

[In prepuration.

STORY.

Nero; A Historical Play. By W. W. StoRY, Author of 'Roba di Roma.' Fcap. 8vo, 6s.

Vallombrosa. Post 8vo, 5s.

Poems. 2 vols., 7 s. $6 \mathrm{~d}$.

Fiammetta. A Summer Idyl. Crown 8vo, 7s. 6d.

Conversations in a Studio. 2 vols. crown $8 \mathrm{vo}, 12 \mathrm{~s}$. $6 \mathrm{~d}$.

Excursions in Art and Letters. Crown 8vo, 7s. 6d.

A Poet's Portfolio: Later Readings. 18mo, 3s. 6d.

STRACHEY. Talk at a Country House. Fact and Fiction. By Sir Edward STrachey, Bart. With a Portrait of the Author. Crown Svo, 4s. 6 d. net.

STURGIS. Little Comedies, Old and New. By Julian Sturgis. Crown 8vo, 7 s. $6 \mathrm{~d}$.

SUTHERLAND. Handbook of Hardy Herbaceous and Alpine Flowers, for General Garden Decoration. Containing Descriptions of upwards of 1000 Species of Ornamental Hardy Perennial and Alpine Plants; along with Concise and Plain Instructions for their Propagation and Culture. By WILliaM Sutherlaxd, Landscape Gardener; formerly Manager of the Herbaceous Department at Kew. Crown 8vo, 7s, 6d.

TAYLOR. The Story of my Life. By the late Colonel Mradows TAYLoR, Author of 'The Confessions of a Thug,' \&c., \&c. Edited by his Daughter. New and Cheaper Edition, being the Fourth. Crown 8vo, $6 \mathrm{~s}$. 


\section{THOMSON.}

The Diversions of a Prime Minister. By Básil Thomson. With a Map, numerous Illustrations by J. W. Cawston and others, and Reproductions of Rare Plates from Early Voyages of Sixteenth and Seventeenth Cen. turies. Small demy 8 vo, $15 \mathrm{~s}$.

South Sea Yarns. With 10 Full-page Illustrations., Cheaper Edition. Erown 8vo, 3s. 6d.

THOMSON.

Handy Book of the Flower-Garden: Being Practical Directions for the Propagation, Culture, and Arrangement of Plants in FlowerGardens all the year round. With Engraved Plans. By David Thosfsos, Gardener to his Grace the Duke of Buccleuch, K.T., at Drumlanrig. Fourth and Cheaper Edition. Crown $8 v 0,5 \mathrm{~s}$.

The Handy Book of Fruit-Culture under Glass: Being a series of Elaborate Practical Treatises on the Cultivation and Forcing of Pines, Vines, Peaches, Figs, Melons, Strawberries, and Cucumbers. With Engravings of Hothouses, \&c. Second Edition, Revised and Enlarged. Crown 8vo, 7s, 6d.

THOMSON. A Practical Treatise on the Cultivation of the Grape Vine. By Williasr Thossos, Tweed Vineyards. Tenth Edition. 8vo, 5s.

THOMSON. Cookery for the Sick and Convalescent. With Directions for the Preparation of Poultices, Fomentations, \&c. By BARBARA Tномsos. Fcap. 8vo, 1s. 6d.

THORBURN. Asiatic Neighbours. By S. S. Thorburn, Bengal Civil Service, Author of 'Bannú; or, Our Afghan Frontier,' 'David Leslie : A Story of the Afghan Frontier,' 'Musalmans and Money-Lenders in the Panjab.' With Two Maps. Demy 8vo, 10s. 6d. net.

THORNTON. Opposites. A Series of Essays on the Unpopular Sides of Popular Questions. By Lewis THorxtos. 8vo, 12s. 6d.

TRANSACTIONS OF THE HIGHLAND AND AGRICUL. TURAL SOCIETY OF SCOTLAND. Published annually, price $5 \mathrm{~s}$.

TRAVERS.

Mona Maclean, Medical Student. A Novel. By Graham Travers. Eleventh Edition. Crown 8vo, 6s.

Fellow Travellers. Third Edition. Crown 8vo, 6s.

TRYON. Life of Admiral Sir George Tryon. By Rear-Admiral C. C. Pexrose Fitzgerald. With Portrait and numerous Illustrations. Demy Svo, 18s.

\section{TULLOCH.}

Rational Theology and Christian Philosophy in England in the Seventeenth Century. Ву Jонх Tulzосн, D.D., Principal of St Mary's Col. lege in the University of St Andrews, and one of her Majesty's Chaplains in Ordinary in Scutland. Second Edition. 2 vols. 8vo, $16 \mathrm{s.}$

Modern Theories in Philosophy and Religion. 8vo, 15s.

Luther, and other Leaders of the Reformation. Third Edition, Enlarged. Crown 8vo, 3s. 6d.

Memoir of Principal Tulloch, D.D., LL.D. By Mrs Oliphaxt, Author of 'Life of Edward Irving.' Third and Cheaper Edition. 8vo, with Portrait, 7s. 6d.

TWEEDIE. The Arabian Horse: His Country and People. By Major-General W. TweEdie, C.S.I., Bengal Staff Corps; for many years H.B.M.'s Consul-General, Baghdad, and Political Resident for the Government of India in Turkish Arabia. In one vol. royal 4to, with Seven Coloured Plates and other Illustrations, and a Map of the Country. Price £3, 3s, net. 
TYLER. The Whence and the Whither of Man. A Brief History of his Origin and Development through Conformity to Environment. The Morse Lectures of 1895. By JoHs M. Tyler, Professor of Biology, Amherst College, U.S.A. Post $8 v 0,6$ s. net.

\section{VEITCH.}

Memoir of John Veitch, LL.D., Professor of Logic and Rhetoric, University of Glasgow. By MARy R. L. Bryce. Witl Portrait and 3 Photogravure Plates. Demy Svo, 7s. 6d.

Border Essays. By JohN Veitch, LL.D., Professor of Logic and Rhetoric, University of Glasgow. Crown 8 vo, 4s. 6d. net.

The History and Poetry of the Scottish Border : their Main Features and Relations. New and Enlarged Edition. 2 vols. demy 8vo, 16s.

Institutes of Logic. Post $8 \mathrm{vo}, 12 \mathrm{~s}$. $6 \mathrm{~d}$.

The Feeling for Nature in Scottish Poetry. From the Ear-

- liest Times to the Present Day. 2 vols. fcap. $8 v 0$, in roxburghe binding, 15s.

Merlin and other Poems. Fcap. 8vo, 4s. 6d.

Knowing and Being. Essays in Philosophy. First Series. Crown 8vo, 5s.

Dualism and Monism; and other Essays. Essays in Philosophy. Second Series. With an Introduction by R. M. Wenley. Crown Svo, 4s. 6 d. net.

VIRGIL. The Aneid of Virgil. Translated in English Blank Verse by G. K. RICKARDs, M.A., and Lord RAVENswORTH. 2 vols. fcap. 8vo, 10s.

WACE. Christianity and Agnosticism. Reviews of some Recent Attacks on the Christian Faitli. By Henry WACE, D.D., Principal of King's College, London; Preacher of Lincoln's Inn; Chaplain to the Queen. Second Edition. Post 8vo, 10s. 6d. net.

WADDELL. An Old Kirk Chronicle : Being a History of Auldhame, Tyninghame, and Whitekirk, in East Lothian. From Session Records, 1615 to 1850 . By Rev. P. HATELY WADDELL, B.D., Minister of the United Parish. Small Paper Edition, 200 Copies. Price \&l. Large Paper Edition, 50 Copies. Price $£ 1,10$ s.

WALFORD. Four Biographies from 'Blackwood': Jane Taylor, Hannah More, Elizabeth Fry, Mary Somerville. By L. B. WALFond. Crown $8 \mathrm{vo}, 5 \mathrm{~s}$.

WARREN'S (SAMUEL) WORKS :-

Diary of a Late Physician. Cloth, 2s. 6d. ; boards, 2s.

Ten Thousand A-Year. Cloth, 3s. 6d.; boards, 2s. $6 \mathrm{~d}$.

Now and Then. The Lily and the Bee. Intellectual and Moral Development of the Present Age. 4s. 6d.

Essays : Critical, Imaginative, and Juridical. 5s.

WENLEY.

Socrates and Christ: A Study in the Philosophy of Religion. By R. M. WEnLEY, M.A., D.Sc., D.Phil., Professor of Philosophy in the University of Michigan, U.S.A. Crown $8 v 0,6 \mathrm{~s}$.

Aspects of Pessimism. Crown 8vo, 6s.

WHITE.

The Eighteen Christian Centuries. By the Rev. James WhITE. Seventh Edition. Post 8vo, with Index, 6s.

History of France, from the Earliest Times. Sixth Thousand. Post 8vo, with Index, 6 s. 
WHITE.

Archæological Sketches in Scotland-Kintyre and Knapdale. By Colonel T. P. WhiтE, R.E., of the Ordnance Survey. With numerous Illus. trations. 2 vols. folio, £4, 4s. Vol. I., Kintyre, sold separately, $£ 2$, $2 \mathrm{~s}$.

The Ordnance Survey of the United Kingdom. A Popular Account. Crown $8 v 0,5 \mathrm{~s}$.

WILLIAMSON. The Horticultural Handbook and Exhibitor's Guide. A Treatise on Cultivating, Exhibiting, and Judging Plants, Flowers, Fraits, and Vegetables. By W. Wrlliamsox, Gardener. Revised by Malcosm Duss, Gardener to his Grace the Duke of Buccleuch and Queensberry, Dalkeith Park. New and Cheaper Edition, enlarged. Crown 8vo, paper cover, 2s.; cloth, 2s. 6d.

WILLIAMSON. Poems of Nature and Life. By David R. Wiluinsson, Minister of Kirkmaiden. Feap. 8vo, 3s.

WILLS. Behind an Eastern Veil. A Plain Tale of Events occurring in the Experience of a Lady who had a unique opportunity of observ. ing the Inner Life of Ladies of the Upper Class in Persia. By C. J. WILLS, Author of 'In the Land of the Lion and Sun,' 'Persia as it is,' \&c., \&c. Cheaper Edition. Demy 8vo, $5 \mathrm{~s}$.

WILSON.

Works of Professor Wilson. Edited by his Son-in-Law, Professor Ferrier. 12 vols. crown $\$$ vo, $£ 2,8 \mathrm{~s}$.

Christopher in his Sporting-Jacket. 2 vols., 8s.

Isle of Palms, City of the Plague, and other Poems. 4s.

Lights and Shadows of Scottish Life, and other Tales. 4s.

Essays, Critical and Imaginative. 4 vols., 16s.

The Noctes Ambrosianæ. 4 vols., 16s.

Homer and his Translators, and the Greek Drama. Crown 8 vo, $4 \mathrm{~s}$.

\section{WORSLEY.}

Poems and Translations. By Philip Staxhope Worsley, M.A. Edited by EDward Worsuex. Second Edition, Enlarged. Fcap. 8vo, 6s.

Homer's Odyssey. Translated into English Verse in the Spenserian Stanza. By P. S. Worsley. New and Cheaper Edition. Post 8vo, 7s. 6 d. net.

Homer's Iliad. Translated by P. S. Worsley and Prof. Conington. 2 vols. crown $8 v 0,21 s$.

YATE. England and Russia Face to Face in Asia. A Record of Travel with the Afghan Boundary Commission. By Captain A. C. YATE, Bombay Staff Corps. 8vo, with Maps and Illustrations, $21 \mathrm{s.}$

YATE. Northern Afghanistan; or, Letters from the Afghan Boundary Commission. By Major C. E. YATE, C.S.I., C.M.G., Bombay Staff Corps, F.R.G.S. Svo, with Maps, 18s.

YULE. Fortification : For the use of Officers in the Army, and Readers of Military History. By Colonel YULE, Bengal Engineers. Svo, with Numerous Illustrations, 10s. 


$$
2 q \text { - Aefuidime } X
$$

$$
\frac{104}{314}
$$




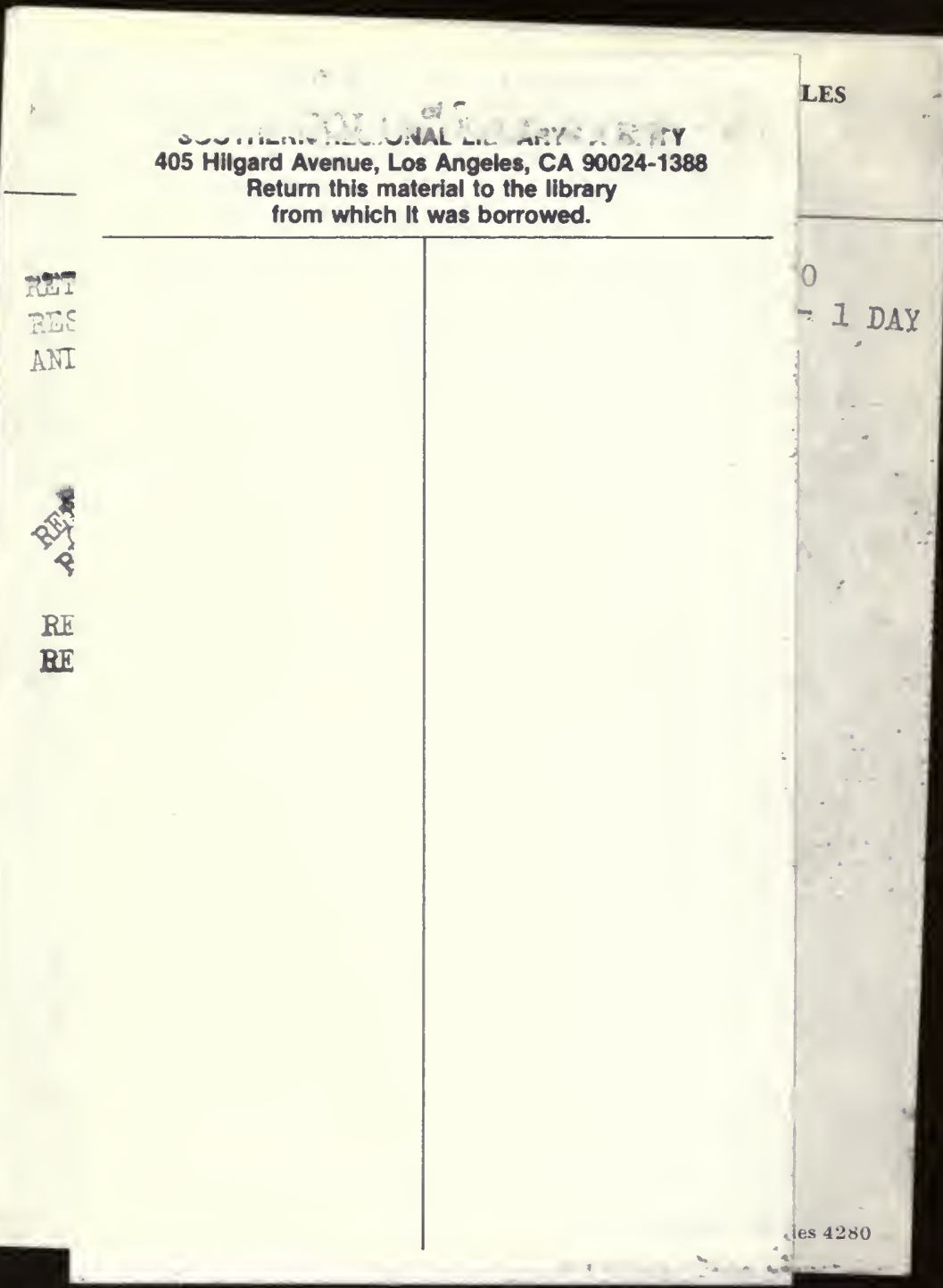




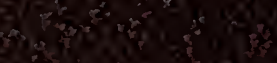

Novers

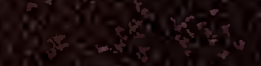

$x^{2}+3-20^{2}=$

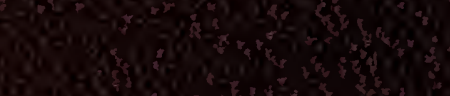

$0,5=5$

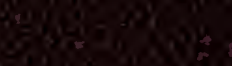

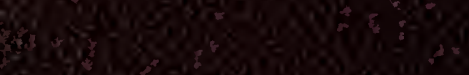

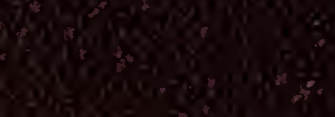

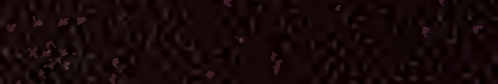

258.

$\frac{10}{2} 8$

की

$\operatorname{lic} 5$

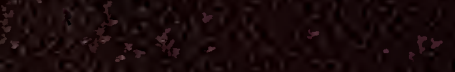

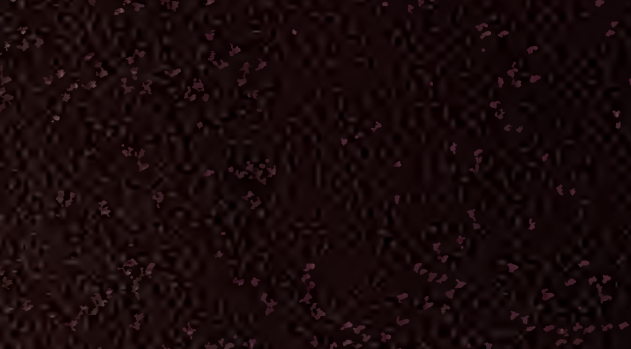

2.t.

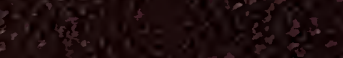

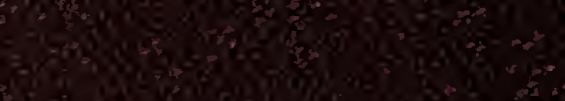

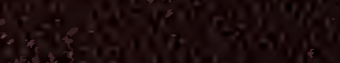

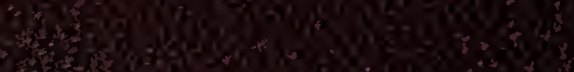

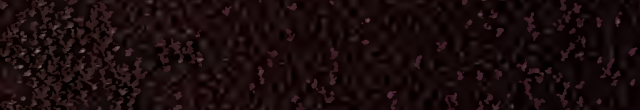

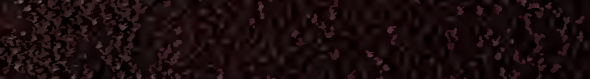

